MARCOS HENRIQUE MARTINS

\title{
CRÍTICA À GEOGRAFIA DA EFETIVIDADE ou \\ Como se Geografar com o Martelo
}




\section{CRÍTICA À GEOGRAFIA DA EFETIVIDADE}

ou

Como se Geografar com o Martelo

Dissertação apresentada à Faculdade de Filosofia, Letras e Ciências Humanas da Universidade de São Paulo para obtenção do Título de Mestre em Ciências.

Linha de Pesquisa: Informação geográfica: tratamento, representação e análise.

Orientador: Professor Doutor Fernando Shinji Kawakubo. 
Autorizo a reprodução e divulgação total ou parcial deste trabalho, por qualquer meio convencional ou eletrônico, para fins de estudo e pesquisa, desde que citada a fonte.

Catalogação na Publicação

Serviço de Biblioteca e Documentação

Faculdade de Filosofia, Letras e Ciências Humanas da Universidade de São Paulo

Martins, Marcos Henrique

M379c

Crítica à Geografia da Efetividade ou Como se Geografar com o Martelo / Marcos Henrique Martins ; orientador Fernando Shinji Kawakubo. - São Paulo, 2020 .

$272 \mathrm{f}$.

Dissertação (Mestrado) - Faculdade de Filosofia, Letras e Ciências Humanas da Universidade de São Paulo. Departamento de Geografia. Área de concentração: Geografia Física.

1. Cidade. 2. Urbano. 3. Hegel. 4. Nietzsche. 5. Marx. I. Kawakubo, Fernando Shinji, orient. II. Título. 
MARTINS, M. H. Crítica à Geografia da Efetividade ou Como se Geografar com o Martelo. 2019. Dissertação (Mestrado) - Faculdade de Filosofia, Letras e Ciências Humanas, Universidade de São Paulo. São Paulo, 2019.

Aprovado em:

Banca Examinadora:

Prof. Dr.: Instituição:

Julgamento: Assinatura:

Prof. Dr.: Instituição:

Julgamento: Assinatura:

Prof. Dr.: Instituição:

Julgamento: Assinatura:

Prof. Dr.: Instituição:

Julgamento: Assinatura:

Prof. Dr.: Instituição:

Julgamento: Assinatura: 
Aos meus Avós Maternos, que com Sangue e Suor lavraram da terra o cerne de minhas contradições.

À minha Mãe, cuja força do amor incondicional me inspirou nestas páginas.

À minha companheira Kaya, saúde em minha doença, sustentáculo de minhas fraquezas, ombro forte, mente sã, coração amigo-amante. 


\section{AGRADECIMENTOS}

Primeiramente, agradeço aos meus avós maternos, Tereza e Agenor, pessoas singelas a quem tanto amo e que me sustentaram em minhas forças e fraquezas por todos esses anos, incondicionalmente.

Agradeço também minha mãe, Gislene, que sozinha enfrentou as efetivas dificuldades de mãe solteira, acordando $4 \mathrm{~h}$ da manhã quase todos os dias para que eu pudesse dormir até mais tarde e sonhar do sonho que hoje transcrevo nestas páginas.

Não tenho palavras para descrever o quão agradecido sou à minha companheira Kaya, que desde 2012 tem me incentivado e me acompanhado mesmo nas horas mais difíceis dos dias mais doentes de nossas vidas.

Não posso deixar de agradecer também ao meu orientador, Fernando Shinji Kawakubo; mas não por obrigação. Agradeço pela sua presença comedida, por suas poucas e preciosas palavras. Agradeço por ter me apoiado em meu desvairado desafio teórico, ainda que com suas reconhecidas limitações. Agradeço por ter compartilhado comigo seus conhecimentos e também por ter me incentivado naquele momento em que quase desisti. Agradeço, enfim, pelo que muitas pessoas chamariam de "orientalismo" em seu comportamento, mas que eu, condizentemente, prefiro denominar de verdadeiro "amiguismo".

Sou profundamente grato aos meus amigos do Basquete de sextas-feiras e de quase todas as quartas-feiras também. Amigos de carne, muitos deles "de quebrada", periféricos, mas jamais tão pobres que não pudessem ser amigos de um qualquer.

E dentre meus amigos mais preciosos, tenho dívida de irmandade com Júlio Witer, meu melhor e mais admirado Amigo. Somos fisiologicamente parecidos? Somos irritadinhos? Pouco importa, porque somos Irmãos. Irmãos do desespero e Irmãos na esperança. Irmãos de muitos momentos preciosos, que sempre levarei comigo, aonde quer que possamos ir.

Depois dos reais agradecimentos, gostaria também de formalizar minhas palavras para dirigir-me à Fundação de Amparo à Pesquisa do Estado de São Paulo (FAPESP) em agradecimento pela bolsa de Mestrado (Processo 2017/15940-0), a qual possibilitou minha completa dedicação na realização dessa pesquisa. Agradeço, ainda que esta não seja mais do que a finalidade da referida Fundação - amparar financeiramente as pesquisas. 
Se quer seguir-me, narro-lhe; não uma aventura, mas experiência, a que me induziram, alternadamente, séries de raciocínios e intuições. Tomou-me tempo, desânimos, esforços. Dela me prezo, sem vangloriar-me. Surpreendome, porém, um tanto à-parte de todos, penetrando conhecimento que os outros ainda ignoram. O senhor, por exemplo, que sabe e estuda, suponho nem tenha ideia do que seja na verdade - um espelho? Demais, decerto, das noções de física, com que se familiarizou, as leis da óptica. Reporto-me ao transcendente. Tudo, aliás, é a ponta de um mistério. Inclusive os fatos. Ou a ausência deles. Duvida? Quando nada acontece, há um milagre que não estamos vendo (ROSA, 2008, p.76) 


\section{RESUMO}

MARTINS, M. H. Crítica à Geografia da Efetividade ou Como se Geografar com o Martelo. 2019. Dissertação (Mestrado) - Faculdade de Filosofia, Letras e Ciências Humanas, Universidade de São Paulo. São Paulo, 2019.

A Geografia é um sentido humano de uma humanidade desumana. Na cidade colonial moderna, o Espírito é material e metafísico, sendo sua cisão e união a moralina causal. A necessidade de Espírito era a necessidade do colonizador, ou seja, o próprio processo de colonização é o engendramento desta necessidade - a necessidade de cidades e de urbanos. E necessidade de muita moralina - substância cuja materialidade é o corpo e cuja alma é a razão: a moralina é a contradição entre o corpo e a alma que instaura a união entre meio material (cidade) e meio universal (urbano). O acontecimento deste processo é a Dimensão Geográfica do Ser, ou seja, a efetividade dos sentidos desta moralina e de tudo o que ela é - cidade-moralina-urbana. Destarte, a fisiologia da pessoa urbana colonial é a fisiologia da moralina citadina. Neste sentido, o processo de impermeabilização do solo também constitui tal físiologia, cientificamente observável em sua dinâmica, como as mudanças que constitui na hidrodinâmica, no microclima e na saúde da população no decorrer dos anos. Ademais, é relevante considerar que as doenças do aparelho circulatório se tornaram a principal tipologia de morte mundial. Entre as causas que explicam a predominância e distribuição espacial dessa tipologia de óbito estão os fatores ambientais, dentre os quais figuram, especialmente, os determinantes climáticos. Neste sentido, a investigação que se apresenta no escopo desta monografia teve como objetivo analisar a relação entre impermeabilização do solo e a ocorrência de óbitos ocasionados por doenças associadas ao aparelho circulatório, com auxílio de imagens de satélite e dados do Instituto Brasileiro de Geografia e Estatística e do Sistema Único de Saúde Brasileiro, no município de São Paulo, Estado de São Paulo - Brasil, em 2015. Os resultados "cientificamente obtidos" sustentam, ao menos, duas considerações fundamentais: 1) os óbitos associados às doenças do sistema circulatório não podem ser satisfatoriamente compreendidos sem que se considere sua localização e distribuição; 2) fatores de ordem ambiental, como a impermeabilização do solo, podem apresentar uma "determinação" sobre a localização e distribuição desta tipologia de óbito, indicando a necessidade de estudos mais aprofundados sobre o assunto. Ademais, a análise da relação entre impermeabilização do solo e a ocorrência de óbitos ocasionados por doenças associadas ao aparelho circulatório possibilitou uma outra abordagem genérica da questão, a qual fora intitulada "Sensualismo Geográfico Dialético", um posicionamento que tem se demonstrado mais questionador que absolutamente conclusivo face à ossatura do proceder científico; ossatura tal que fora considerada como parte e não aparte desta fisiologia colonial moderna.

Palavras-chave: Doenças do Aparelho Circulatório, Fisiologia, Impermeabilização do Solo, Cidade, Urbano, Geografia, Hegel, Nietzsche, Marx. 


\begin{abstract}
MARTINS, M. H. Critique of Effectiveness Geography or How to Geographize with a Hammer. 2019. Dissertação (Mestrado) - Faculdade de Filosofia, Letras e Ciências Humanas, Universidade de São Paulo. São Paulo, 2019.

Geography is a human sense to a unhuman humanity. In the modern colonial city the Spirit is material and metaphysical, and your scission and union are the casual moraline. The Spirit necessity was the colonizer necessity which means the own process of colonization is the engendering of this necessity - the cities and urbans necessity. And the nessity of a lot of moraline - substance whose materiality is the body and the soul is the reason: it is the contradiction between body and soul that stablishes the union of material (city) and universal (urban). The happening of this process is the Geographic Dimension of Being which means the effectiveness of the senses this moraline and all that it is - city-moraline-urban. Thus, the phisiology of an urban colonial person is the phisiology of city moraline. In this meaning, the soil waterproofing process also contitutes this phisiology, scientifically observable in its dynamics as changes that contitutes in hydrodinamic, microclimate and population health over the years. Furthermore, it is relevant to consider circulatory system diseases became the main type of global death. Among the causes explaining predominance and spatial distribution of this type of death are environmental factors which are specially the climatic determinats. Along with, the investigation presented in this monography scope had as purpose analize the relation between soil waterproofing and the death occurence caused by circulatory system diseases using as support satellite images and data from Brazilian Institute of Geography and Statistics (IBGE) and from Brazilian National Health System (SUS) in the county of São Paulo, Estate of São Paulo - Brazil, in 2015. The "scientifically obtained" results sustain at least two fundamental considerations: 1) deaths associated with circulatory system diseases cannot be understood satisfactorily without consider your location and distribution; 2) environmental factors as soil waterproofing can show a "determination" about localization and distribution of this death type, indicating the need of further studies on this subject. Moreover, the analysis of the relation between soil waterproofind and death occurence caused by circulatory system diseases made it possible another generical approach of the question titled "Dialectical Geographic Sensualism", a standing that has been demonstrated more questining than absolutely conclusive in view of scientific procedure that was considered as part and not aside from this colonial modern phisiology.
\end{abstract}

Key words: Circulatory System Disease, Phisiology, Soil Waterproofing, City, Urban, Geography, Hegel, Nietzsche, Marx. 


\section{LISTA DE FIGURAS}

FIGURA 2.1 - CLASSES GERADAS A PARTIR DOS VALORES DOS PIXELS DA IMAGEM DAS ÁREAS INALTERADAS 43

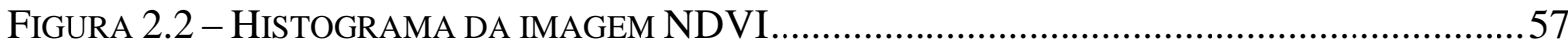

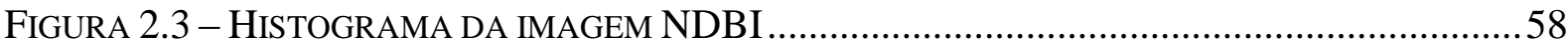

FiguRA 2.4 - RESULTADOS DA ANÁLISE DE AUTOCORRELAÇÃO ESPACIAL PARA O INDICADOR VARIMP 70

FIGURA 2.5 - REGRESSÃO LINEAR COMPARATIVA DA TEMPERATURA RADIANTE DA ÁGUA E DA

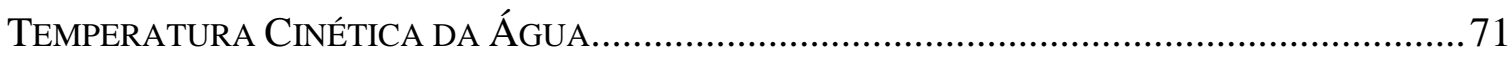

FIGURA 2.6 - RESULTADOS DA ANÁLISE DE AUTOCORRELAÇÃO ESPACIAL................................ 77

FIGURA 2.7 - ESQUEMA ILUSTRATIVO DO INDICADOR VARIMP ............................................ 107

FIGURA 5.1 - PARTITURA DA MÚSICA “PARABÉNS PRA VOCÊ”.............................................2242

FIGURA 5.2 - PARTITURA DO ACORDE DE C (DÓ MAIOR) ........................................................243

Figura 5.3 - PARTITURA do CAMPO HARMÔNICO MAIOR TRIÁdICO DE C (DÓ MAIOR) ..........243

Figura 5.4 - PARTITURA do CAMPo HARMÔNICO de LÁ MENOR NATURAl TRiádico ..........244 


\section{LISTA DE GRÁFICOS}

GRÁFICO 2.1 - REGRESSÃO LINEAR ESTIMATIVA DA IMPERMEABILIZAÇÃO DO SOLO A PARTIR DO NDVI

GRÁFICO 2.2 - ANÁLISE DA MODELAGEM NDVI A PARTIR DAS 500 AMOSTRAS DE CONTROLE. 50

GRÁFICO 2.3 - HISTOGRAMA DOS RESÍDUOS DO MODELO COM USO DO NDVI 51

GRÁFICO 2.4 - BLOXPOT DOS RESÍDUOS DA MODELAGEM COM USO DE NDVI. .52

GRÁFICO 2.5 - EQUAÇÃO ESTIMATIVA DA IMPERMEABILIZAÇÃO DO SOLO A PARTIR DO ÍNDICE DE REFLETÂNCIA AJUSTADO

GRÁFICO 2.6 - ANÁLISE DA MODELAGEM COM ÍNDICE DE REFLETÂNCIA AJUSTADO A PARTIR DAS 500 AMOSTRAS DE CONTROLE. 61

GRÁFICO 2.7 - HistogRAMA DOS RESÍDUOS DO MODELO COM USO DO ÍNDICE DE REFLETÂNCIA AJUSTADO 61

GRÁFICO 2.8 - BLOXPOT DOS RESÍDUOS DA MODELAGEM COM USO DO ÍNDICE DE REFLETÂNCIA AJUSTADO

GRÁFICO 2.9 - RELAÇÃO LINEAR ENTRE OS PERCENTUAIS DE IMPERMEABILIZAÇÃO DO SOLO E A TEMPERATURA APARENTE DE SUPERFÍCIE PARA AS 4000 JANELAS AMOSTRAIS. 73

GRÁFICO 2.10 - TAXA DE MORTALIDADE MSC (POR 100.000 HABITANTES) ACUMULADA ....... 85

GRÁFICO 2.11 - BLOXPOT DA TAXA DE MORTALIDADE MSC. .85

GRÁFICO 2.12 - RELAÇÃO ENTRE O INDICADOR SOCIOECONÔMICO E O INDICADOR DE MORTALIDADE MSC PARA AS ÁREAS DE CLUSTERS DE MORTALIDADE MSC 88

GRÁFICO 2.13 - RELAÇÃO ENTRE O INDICADOR DE RENDA E O INDICADOR DE MORTALIDADE MSC PARA AS ÁREAS DE CLUSTERS DE MORTALIDADE MSC 88

GRÁFICO 2.14 - RELAÇÃO ENTRE O INDICADOR DE ALFABETIZAÇÃO E O INDICADOR DE MORTALIDADE MSC PARA AS ÁREAS DE CLUSTERS DE MORTALIDADE MSC 89

GRÁFICO 2.15 - RELAÇÃO ENTRE O INDICADOR DE RENDA E O INDICADOR DE MORTALIDADE MSC CONSIDERANDO-SE A TOTALIDADE DOS DISTRITOS ADMINISTRATIVOS DO MSP 90

GRÁFICO 2.16 - FREQUÊNCIA DAS CLASSES DE RESÍDUOS DA MODELAGEM MSC 91

GRÁFICO 2.17 - BLOXPOT DOS RESÍDUOS DO MODELO MSC 91

GRÁFICO 2.18 - RELAÇÃO ENTRE OS INDICADORES DE RENDA E DE MORTALIDADE MSC NOS DISTRITOS ARROLADOS NA TABELA 2.8 . 94

GRÁFICO 2.19 - RELAÇÃo ENTRE OS INDICADORES DE MORTALIDADE MSC E DE FRAGILIDADE ETÁRIA PARA OS OITO DISTRITOS ADMINISTRATIVOS DISCRIMINADOS. 95 
GRÁFICO 3.1 - RELAÇÃO ENTRE OS INDICADORES DE RENDA E VARIMP NOS CLUSTERS VARIMP 128

GRÁFICO 3.2 - RELAÇÃO ENTRE OS INDICADORES DE ALFABETIZAÇÃO E VARIMP NOS CLUSTERS VARIMP

GRÁFICO 3.3 - RELAÇÃO ENTRE OS INDICADORES SOCIOECONÔMICO E VARIMP NOS CLUSTERS VARIMP 129

GRÁFICO 3.4 - RELAÇÃO ENTRE A TAS E O INDICADOR VARIMP NOS CLUSTERS VARIMP .. 130 GRÁFICO 3.5 - RELAÇÃO ENTRE RENDA E FRAGILIDADE ETÁRIA NOS DISTRITOS ADMINISTRATIVOS DO MSP 133

GRÁFICO 3.6 - RELAÇÃo ENTRE ALFABETIZAÇÃO E FRAGILIDADE ETÁRIA NOS DISTRITOS ADMINISTRATIVOS DO MSP 134

GRÁFICO 3.7 - RELAÇÃO ENTRE ALFABETIZAÇÃO E RENDA NOS DISTRITOS ADMINISTRATIVOS DO MSP 134

GRÁFICO 3.8 - RELAÇÃO ENTRE OS INDICADORES SOCIOECONÔMICO E DE FRAGILIDADE ETÁRIA NOS DISTRITOS ADMINISTRATIVOS DO MSP 135

GRÁFICO 3.9 - RELAÇÃO ENTRE OS INDICADORES DE FRAGILIDADE ETÁRIA E VARIMP NOS CLUSTERS VARIMP 136

GRÁFICO 3.10 - RELAÇÃO ENTRE OS INDICADORES DE FRAGILIDADE ETÁRIA E DE MORTALIDADE MSC NOS DISTRITOS ADMINISTRATIVOS DO MUNICÍPIO DE SÃO PAULO. 137

GRÁFICO 3.11 - RELAÇÃO ENTRE OS INDICADORES DE FRAGILIDADE ETÁRIA E DE MORTALIDADE MSC NOS CLUSTERS MSC

GRÁFICO 3.12 - RELAÇÃO ENTRE OS INDICADORES VARIMP E DE RENDA NOS DISTRITOS SELECIONADOS.

GRÁFICO 3.13 - RELAÇÃO ENTRE O INDICADOR VARIMP E OS PERCENTUAIS DE IMPERMEABILIZAÇÃO DO SOLO NOS DISTRITOS DISCRIMINADOS 144

GRÁFICO 3.14 - RELAÇÃO ENTRE O INDICADOR VARIMP E OS PERCENTUAIS DE IMPERMEABILIZAÇÃO DO SOLO NOS DISTRITOS ADMINISTRATIVOS DO MSP 145

GRÁFICO 3.15 - RELAÇÃO ENTRE O INDICADOR VARIMP E A TEMPERATURA APARENTE DE SUPERFÍCIE (TAS) NOS DISTRITOS ADMINISTRATIVOS DISCRIMINADOS 146

GRÁFICO 3.16 - RELAÇÃO ENTRE IMPERMEABILIZAÇÃO DO SOLO E TEMPERATURA APARENTE DE SUPERFÍCIE (TAS) NOS DISTRITOS ADMINISTRATIVOS DISCRIMINADOS 146

GRÁFICO 3.17 - RELAÇÃO ENTRE OS INDICADORES DE MORTALIDADE MSC E SOCIOAMBIENTAL NOS DISTRITOS ADMINISTRATIVOS DISCRIMINADOS 
GRÁFICO 3.18 - RELAÇÃO ENTRE OS INDICADORES SOCIOAMBIENTAL E DE MORTALIDADE MSC NOS DISTRITOS ADMINISTRATIVOS DO MSP

GRÁFICO 3.19 - FREQUÊNCIA DAS CLASSES DE RESÍDUOS DA MODELAGEM SOCIOAMBIENTAL 149

GRÁFICO 3.20 - BLOXPOT DOS RESÍDUOS DO MODELO SOCIOAMBIENTAL

GRÁFICO 3.21 - RELAÇÃO ENTRE OS INDICADORES DE RENDA E DE MORTALIDADE MSC PARA OS DISTRITOS SELECIONADOS A PARTIR DA ANÁLISE DOS RESÍDUOS DA MODELAGEM SOCIOAMBIENTAL.

GRÁFICO 3.22 - RELAÇÃO ENTRE OS INDICADORES SOCIOAMBIENTAL E DE MORTALIDADE MSC PARA OS DISTRITOS SELECIONADOS A PARTIR DA ANÁLISE DOS RESÍDUOS DA MODELAGEM SOCIOAMBIENTAL. 


\section{LISTA DE MAPAS}

MAPA 1 - LOCALIZAÇÃO DO MUNICÍPIO DE SÃO PAULO. .25

MAPA 2 - MUNICÍPIO DE SÃO PAULO: USO E OCUPAÇÃO DA TERRA NAS AMOSTRAS DE ÁREAS INALTERADAS ENTRE 2010 E 2015.

MAPA 3 - MUNICÍPIO DE SÃO PAULO: USO E OCUPAÇÃO DA TERRA E IMPERMEABILIZAÇÃO DO SOLO EM UMA JANELA AMOSTRAL

MAPA 4 - MUNICÍPIO DE SÃO PAULO: IMPERMEABILIZAÇÃO DO SOLO E NDVI EM UMA JANELA AMOSTRAL

MAPA 5 - MUNICÍPIO DE SÃO PAULO: COMPORTAMENTO DOS CORPOS D'ÁGUA E DAS ÁREAS IMPERMEÁVEIS ESTIMADAS A PARTIR DO NDVI..

MAPA 6 - MUNICÍPIO DE SÃO PAULO: ÍNDICE DE REFLETÂNCIA AJUSTADO .

MAPA 7 - MUNICÍPIO DE SÃO PAULO: COMPORTAMENTO DOS CORPOS D'ÁGUA E DAS ÁREAS IMPERMEÁVEIS ESTIMADAS A PARTIR DO ÍNDICE DE REFLETÂNCIA AJUSTADO

MAPA 8 - MUNICÍPIO DE SÃO PAULO: ÁREA NÃO INCLUSA NA MODELAGEM DA IMPERMEABILIZAÇÃO DO SOLO.

MAPA 9 - MUNICÍPIO DE SÃO PAULO: ESTIMATIVA DA IMPERMEABILIZAÇÃO DO SOLO ....99

MAPA 10 - MUNICÍPIO DE SÃO PAULO: ESTIMATIVA DA IMPERMEABILIZAÇÃO DO SOLO POR SETOR CENSITÁRIO

MAPA 11 - MUNICÍPIO DE SÃO PAULO: ESTIMATIVA DA IMPERMEABILIZAÇÃO DO SOLO POR DISTRITO ADMINISTRATIVO

MAPA 12 - MUNICÍPIO DE SÃO PAULO: VARIABILIDADE DOS PERCENTUAIS DE

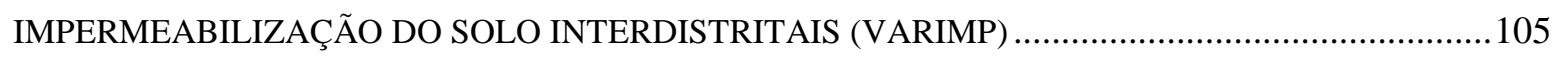

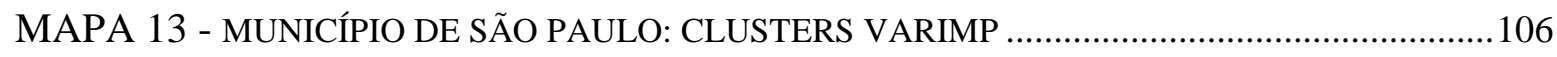

MAPA 14 - MUNICÍPIO DE SÃO PAULO: TEMPERATURA APARENTE DE SUPERFÍCIE............110

MAPA 15 - MUNICÍPIO DE SÃO PAULO: TEMPERATURA APARENTE DE SUPERFÍCIE POR SETOR CENSITÁRIO

MAPA 16 - MUNICÍPIO DE SÃO PAULO: TEMPERATURA APARENTE DE SUPERFÍCIE POR DISTRITO ADMINISTRATIVO

MAPA 17 - MUNICÍPIO DE SÃO PAULO: TAXA DE MORTALIDADE POR DOENÇAS ASSOCIADAS AO APARELHO CIRCULATÓRIO POR DISTRITO ADMINISTRATIVO 116

MAPA 18 - MUNICÍPIO DE SÃO PAULO: INDICADOR DE MORTALIDADE POR DOENÇAS ASSOCIADAS AO APARELHO CIRCULATÓRIO POR DISTRITO ADMINISTRATIVO

MAPA 19 - MUNICÍPIO DE SÃO PAULO: CLUSTERS DO INDICADOR DE MORTALIDADE POR DOENÇAS ASSOCIADAS AO APARELHO CIRCULATÓRIO POR DISTRITO ADMINISTRATIVO.118 MAPA 20 - MUNICÍPIO DE SÃO PAULO: INDICADOR DE RENDA POR SETOR CENSITÁRIO ..120 
MAPA 21 - MUNICÍPIO DE SÃO PAULO: INDICADOR DE RENDA POR DISTRITO ADMINISTRATIVO

MAPA 22 - MUNICÍPIO DE SÃO PAULO: INDICADOR DE ALFABETIZAÇÃO POR SETOR CENSITÁRIO

MAPA 23 - MUNICÍPIO DE SÃO PAULO: INDICADOR DE ALFABETIZAÇÃO POR DISTRITO ADMINISTRATIVO

MAPA 24 - MUNICÍPIO DE SÃO PAULO: INDICADOR SOCIOECONÔMICO POR SETOR CENSITÁRIO

MAPA 25 - MUNICÍPIO DE SÃO PAULO: INDICADOR SOCIOECONÔMICO POR DISTRITO ADMINISTRATIVO

MAPA 26 - MUNICÍPIO DE SÃO PAULO: CLUSTERS DO INDICADOR DE RENDA POR DISTRITO ADMINISTRATIVO

MAPA 27 - MUNICÍPIO DE SÃO PAULO: INDICADOR DE FRAGILIDADE ETÁRIA POR SETOR CENSITÁRIO

MAPA 28 - MUNICÍPIO DE SÃO PAULO: INDICADOR DE FRAGILIDADE ETÁRIA POR DISTRITO ADMINISTRATIVO

MAPA 29 - MUNICÍPIO DE SÃO PAULO: DISTRITOS ADMINISTRATIVOS SELECIONADOS PARA ANÁLISE .140

MAPA 30 - MUNICÍPIO DE SÃO PAULO: INDICADORES DOS DISTRITOS ADMINISTRATIVOS SELECIONADOS PARA ANÁLISE

MAPA 31 - MUNICÍPIO DE SÃO PAULO: DISTRITOS ADMINISTRATIVOS SELECIONADOS A PARTIR DA MODELAGEM SOCIOAMBIENTAL 152

MAPA 32 - MUNICÍPIO DE SÃO PAULO: DISTRITOS ADMINISTRATIVOS SELECIONADOS A PARTIR DA MODELAGEM SOCIOAMBIENTAL, CLUSTERS MSC E INDICADOR SOCIOAMBIENTAL 153 


\section{LISTA DE TABELAS}

TABela 1.1 - Óbitos OCORRIDOS NO BRASIL POR CAUSA (CAP. CID-10) E REGIÃo EM 2015.22

TABEla 1.2 - ÓBITOS ASSOCIAdOS ÀS DOENÇAS DO APARElHO CIRCULATÓRIO POR NÚMERO

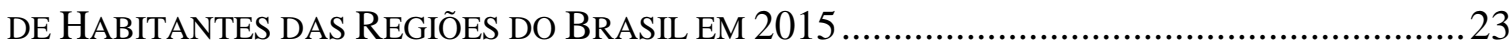

TABEla 1.3 - ÓBITOS OCORRIDOS NO MunicíPIO DE SÃo PAUlo, EM 2015, POR CAUSA Do CID 10

TABela 1.4 - Óbitos Associados Às DoEnças do Aparelho CirculatóRio, POR CAuSA ESPECÍFICA, OCORRIDOS EM SÃO PAULO EM 2015 26

TABElA 1.5 - ÓBITOS AsSOCIADOS ÀS DOENÇAS DO APARELHO CIRCULATÓRIO POR SEXO -

MunicíPIO de SÃo PAULO (2015) 27

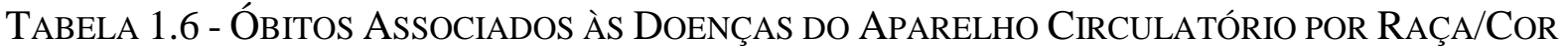
- MunicíPIO de SÃo PAUlo (2015) 27

TABELA 2.1 - MATERIAIS EMPREGADOS NA FASE ESTATÍSTICO-ANALÍTICA DO TRABALHO.........39

TABELA 2.2 - CLASSES DE USO E OCUPAÇÃO DA TERRA …...................................................... 44

TABELA 2.3 - VALORES DE NDVI PARA AS CLASSES DE USO E OCUPAÇÃO DA TERRA................ 55

TABELA 2.4 - VALORES DE NDBI PARA AS CLASSES DE USO E OCUPAÇÃO DA TERRA ................55

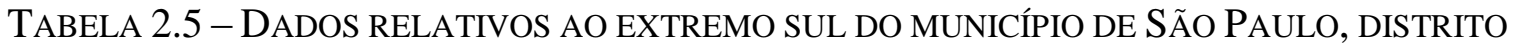
ADMINISTRATIVO DE MARSILAC, REGIÃO EXTERNA À CENA DO LANDSAT-8. 66

TABELA 2.6 - TAXA DE MORTALIDADE MSC (POR 100.000 HABITANTES) SEGUNDO FAIXA ETÁRIA 84

TABELA 2.7 - DISTRITOS SELECIONADOS A PARTIR DOS RESÍDUOS DA MODELAGEM MSC 92

TABELA 2.8 - INDICADORES DE RENDA E DE MORTALIDADE MSC PARA OS OITO DISTRITOS SELECIONADOS A PARTIR DOS RESÍDUOS DA MODELAGEM MSC 93

TABELA 2.9 - IndiCADORES DE MORTALIDADE MSC E DE FRAGILIDAdE ETÁRIA PARA OS OITO DISTRITOS ADMINISTRATIVOS DISCRIMINADOS 94

TABELA 2.10 - INDICADORES ELABORADOS PARA A ANÁLISE DOS OITO DISTRITOS SELECIONADOS. 96

TABELA 2.11 - INDICADOR SOCIOAMBIENTAL DOS OITO DISTRITOS DISCRIMINADOS PARA ANÁLISE

TABELA 3.1 - DADOS RELATIVOS AOS DISTRITOS SELECIONADOS PARA ANÁLISE. 139

TABela A1 - DAdos DAS IMAGENS DOS SATÉLITES LANDSAT-7 E LANDSAT-8 UTILIZADAS NO ESCOPO DO TRABALHO 
TABELA A2 - METADADOS DAS BANDAS DOS SATÉLITES LANDSAT-7 E LANDSAT-8 UTILIZADAS

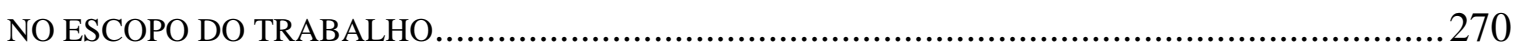




\section{SUMÁRIO}

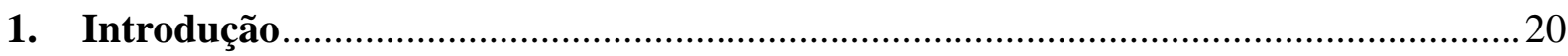

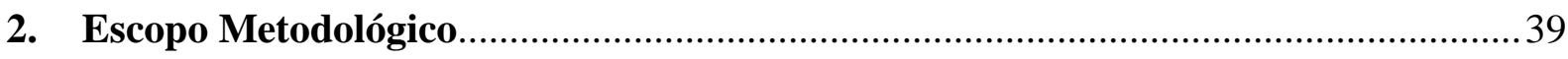

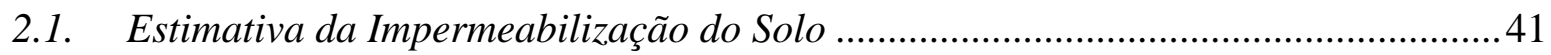

2.1.1. Cálculo da Impermeabilização de Referência a partir das Janelas Amostrais ... 41

2.1.2. Modelagem Estimativa da Impermeabilização do Solo ..................................... 48

2.1.3. Indicador de Variabilidade dos Percentuais de Impermeabilização do Solo

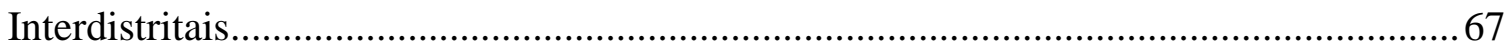

2.2. Mapeamento da Temperatura Aparente de Superfície ............................................. 71

2.3. Mapeamento dos Óbitos Associados às Doenças do Aparelho Circulatório .............73

2.3.1. Cálculo de Taxa de Mortalidade MSC .............................................................. 74

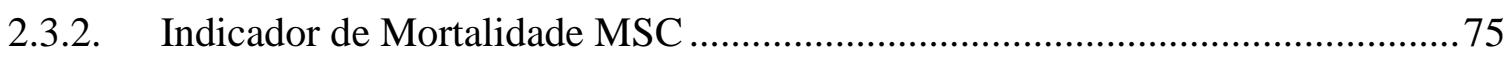

2.3.3. Autocorrelação Espacial e Formação de Clusters ............................................. 76

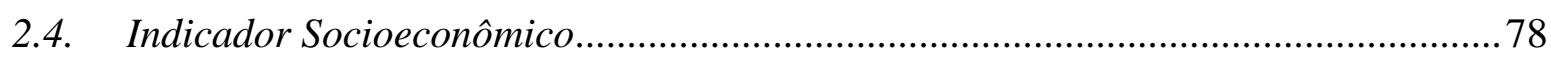

2.4.1. Indicador de Renda Média por Domicílio ...................................................... 79

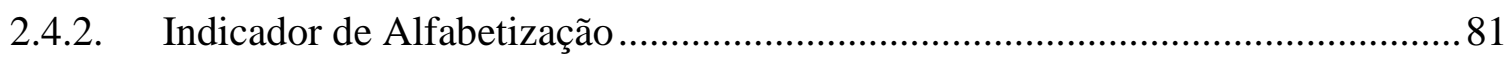

2.4.3. Indicador Socioeconômico e Agregação dos Dados ........................................... 83

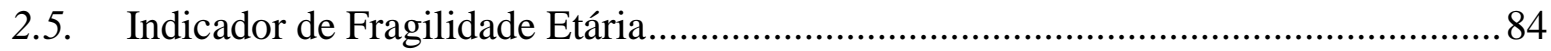

2.6. Seleção dos Distritos Administrativos Adequados para Análise ............................... 87

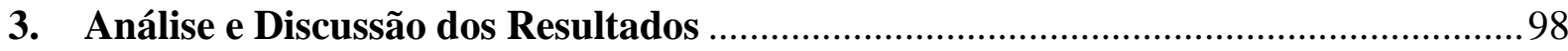

3.1. Impermeabilização do Solo no Município de São Paulo .............................................. 98

3.2. Temperatura Aparente de Superfície no MSP (TAS) ............................................. 108

3.3. Óbitos Associados às Doenças do Aparelho Circulatório no Município de São Paulo 115

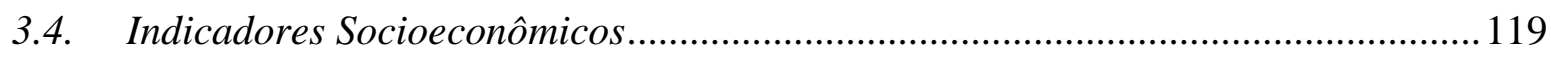

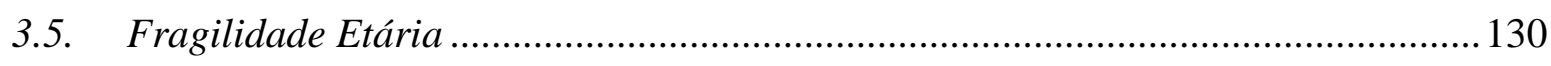

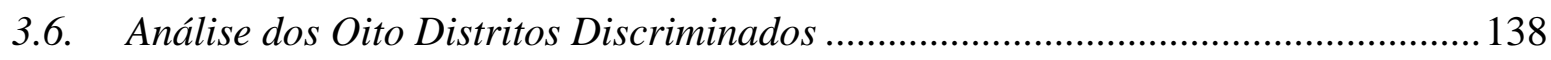

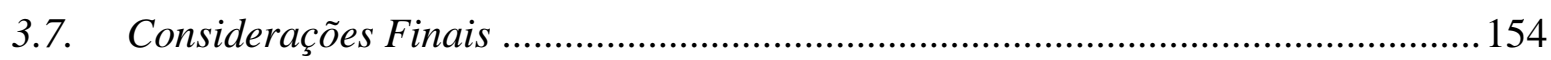

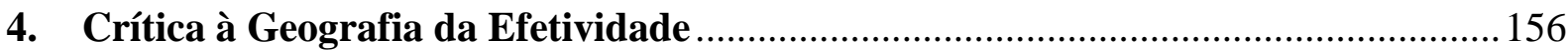

4.1. A Lógica Formal e As Bases Metafísicas da Ciência Moderna ...............................157

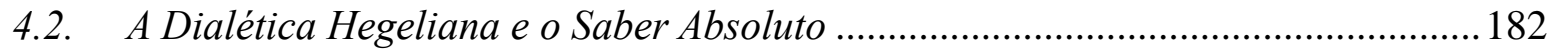

4.3. Crítica da Dialética e da Filosofia Hegelianas em Geral .......................................211

5. Da Cidade Colonial Moderna, de Seus Corpos e de Suas Sombras ........................233

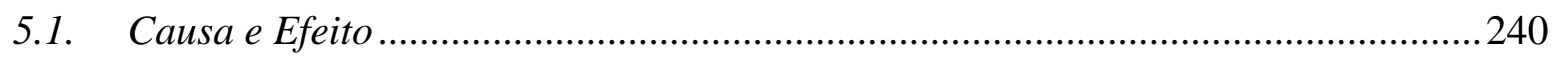


5.2. A Dialética ......

5.3. Sensualismo Geográfico Dialético ... .255

6. Considerações Finais - ou divagações sobre o Martelo Geográfico 259

7. Referências .262

ANEXOS 268 


\title{
1. Introdução
}

\begin{abstract}
"Mais vale aceitar o mito dos deuses, do que ser escravo do destino dos naturalistas: o mito pelo menos nos oferece a esperança do perdão dos deuses através das homenagens que lhes prestamos, ao passo que o destino é uma necessidade inexorável" (EPICURO, 2002, p.49).
\end{abstract}

A Geografia, no âmbito das sociedades nas quais domina o modo de produção capitalista, apresenta-se como "O Fundamento Geográfico do Ser” (MARTINS, 2007). A análise deste "fundamento", engendrado enquanto constituinte do ser, será, portanto, o necessário ponto de partida e, simultaneamente, a finalidade de nossas investigações.

É senso comum dos que se prestam a investigar geograficamente o mundo que tal “investigar" seja o engendrar de uma heterodoxia notável. A despeito desta heterodoxia, há também a impostura de uma ortodoxia científica, que constituiria a unidade destas investigações sob o adjetivo "científico". A ciência geográfica, portanto, a despeito de sua heterodoxia, constituir-se-ia enquanto uma ciência.

A ciência, por sua vez, é a cultura do argumento científico. $\mathrm{O}$ argumento científico, por definição, é o argumento que é capaz de se provar logicamente sustentado. A lógica, por seu turno, é o mantra da validade do argumento, ou seja, é a produção da certeza da validade do argumento enquanto "lógico" nos termos de dadas premissas que constituem, em relação às conclusões deduzidas ou induzidas, uma análise pela atuação do sujeito da razão.

O sujeito da razão é a consciência-de-si humana. Esta consciência, que para a História Natural aparece como Homo sapiens sapiens, ou seja, que aparece como um efeito do autoengendramento da natureza, como cérebro e linguagem na forma de um corpo ereto, é o produzir mesmo desta consciência enquanto Homo sapiens sapiens, enquanto cérebro e linguagem constituídos pelo engendrar da Mater Natura. Neste sentido, na relação entre a consciência-de-si humana e a natureza residiria a produção mesma destes termos da referida relação.

Destarte, não parece completo absurdo ressaltar que o ser humano não é apenas um fenômeno natural, da mesma forma como ele não pode ser compreendido tão somente enquanto um fenômeno social. Sociedade e natureza constituiriam uma totalidade complexa, cuja compreensão é o (re)produzir mesmo da vida humana. Neste sentido, há, entre nós, aqueles que compreendam o ser humano enquanto um complexo bio-ontológico (MARTINS, 2007).

Partindo desta premissa, a qual seja a existência de uma humanidade tal que se particularize na existência bio-ontológica de seus indivíduos, há que se considerar que tais 
indivíduos, do ponto de vista biológico, sejam constituídos por uma ambiência. Esta "ambiência", para nós geógrafos, seria propriamente o "fundamento geográfico do ser" (MARTINS, 2007). Este fundamento, ou melhor, a apropriação deste fundamento enquanto racionalização, ou seja, enquanto argumento lógico, é a instituição do referido complexo bioontológico. Considerando tais asserções primeiras, tomaremos um exemplo que apreciamos legitimamente científico para que se possa abordar os pormenores de uma problemática mais sutil que se esconde por detrás da racionalidade do argumento científico.

Considerando-se o referido "complexo bio-ontológico", a constituição estritamente biológica do ser humano é sistêmica, ou mesmo mecânica: sou um organismo composto de um conjunto de órgãos que operam sistêmica ou mecanicamente, ou ainda, que operam organicamente:

o homem é um todo resultante das combinações de certas matérias dotadas de propriedades particulares, cujo arranjo é chamado de organização e cuja essência é sentir, pensar, agir, em poucas palavras, mover-se de uma maneira que o distingue dos outros seres com os quais ele se compara (HOLBACH, 2010, p.41, grifo no original e grifo nosso).

Em outras palavras, "o homem não passa de um conjunto de peças que se montam todas umas às outras [...]" (LA METTRIE, 1982, p.89). Neste sentido, não é absurda a afirmação de que, dentre os órgãos que compõem a interioridade do corpo humano estão aqueles que constituem o aparelho circulatório. Deste "aparelho" depende todo o funcionamento orgânico do corpo. Ademais, a vida humana não se resume ao fluído sanguíneo, mas não existe sem ele. Tão menos existe sem a complexa rede de veias e artérias que se distribuem pelo corpo humano. Dito isto, a empiria comprovaria que falhas graves na circulação sanguínea levariam ao óbito.

No Brasil, as doenças do aparelho circulatório têm sido a principal causa de morte da população, representando $30,13 \%$ dos óbitos entre as mulheres e $25,74 \%$ entre os homens, segundo dados de 2015 (DATASUS, 2017). Ademais, "as doenças do aparelho circulatório têm tido a maior carga de mortalidade prematura (entre 30 a 69 anos de idade)" (MINISTÉRIO DA SAÚDE, 2015). A tabela 1.1, disponibilizada a seguir, apresenta os óbitos ocorridos no Brasil, em 2015, por causa e região. Nota-se que as doenças do aparelho circulatório representaram $27,66 \%$ das causas de óbito no país em 2015, sendo a principal causa de mortalidade no referido ano. 
Tabela 1.1 - Óbitos Ocorridos no Brasil por Causa (Cap. CID-10) e Região em 2015

\begin{tabular}{|c|c|c|c|c|c|c|c|}
\hline Causa (Cap. CID-10) & $\begin{array}{l}\text { Região } \\
\text { Norte }\end{array}$ & $\begin{array}{l}\text { Região } \\
\text { Nordeste }\end{array}$ & $\begin{array}{l}\text { Região } \\
\text { Sudeste }\end{array}$ & $\begin{array}{l}\text { Região } \\
\text { Sul }\end{array}$ & $\begin{array}{l}\text { Região Centro- } \\
\text { Oeste }\end{array}$ & $\begin{array}{c}\text { Total } \\
\text { Absoluto }\end{array}$ & $\begin{array}{c}\text { Total } \\
\text { Percentual }\end{array}$ \\
\hline I. Algumas doenças infecciosas e parasitárias & 3979 & 14521 & 25386 & 7388 & 3748 & 55022 & 4,35 \\
\hline II. Neoplasias (tumores) & 10573 & 45632 & 99930 & 40163 & 13482 & 209780 & 16,59 \\
\hline III. Doenças do sangue e dos órgãos hematopoéticos e alguns transtornos imunitários & 486 & 1988 & 2860 & 730 & 442 & 6506 & 0,51 \\
\hline IV. Doenças endócrinas nutricionais e metabólicas & 5359 & 25275 & 29782 & 10879 & 4940 & 76235 & 6,03 \\
\hline V. Transtornos mentais e comportamentais & 450 & 3916 & 5575 & 1730 & 887 & 12558 & 0,99 \\
\hline VI. Doenças do sistema nervoso & 1340 & 6980 & 17459 & 6668 & 2274 & 34721 & 2,75 \\
\hline VII. Doenças do olho e anexos & 2 & 6 & 10 & 1 & 2 & 21 & 0,00 \\
\hline VIII. Doenças do ouvido e da apófise mastoide & 13 & 46 & 73 & 10 & 5 & 147 & 0,01 \\
\hline IX. Doenças do aparelho circulatório & 17889 & 92681 & 163509 & 53565 & 21998 & 349642 & 27,66 \\
\hline X. Doenças do aparelho respiratório & 7585 & 34541 & 74601 & 23128 & 9686 & 149541 & 11,83 \\
\hline XI. Doenças do aparelho digestivo & 3434 & 17031 & 29864 & 9411 & 4462 & 64202 & 5,08 \\
\hline XII. Doenças da pele e do tecido subcutâneo & 225 & 1361 & 2712 & 447 & 225 & 4970 & 0,39 \\
\hline XIII. Doenças sistema osteomuscular e tecido conjuntivo & 269 & 1235 & 2679 & 842 & 360 & 5385 & 0,43 \\
\hline XIV. Doenças do aparelho geniturinário & 1713 & 7981 & 20089 & 4595 & 2171 & 36549 & 2,89 \\
\hline XV. Gravidez, parto e puerpério & 217 & 624 & 685 & 215 & 155 & 1896 & 0,15 \\
\hline XVI. Algumas afecções originadas no período perinatal & 2789 & 7318 & 7872 & 2464 & 1719 & 22162 & 1,75 \\
\hline XVII. Malformações congênitas, deformidades e anomalias cromossômicas & 1096 & 3015 & 4411 & 1482 & 985 & 10989 & 0,87 \\
\hline $\begin{array}{l}\text { XVIII. Sintomas, sinais e achados anormais de exames clínicos e de laboratório, não } \\
\text { classificados em outra parte }\end{array}$ & 6188 & 24348 & 32114 & 6593 & 2470 & 71713 & 5,67 \\
\hline XX. Causas externas de morbidade e mortalidade & 14337 & 49214 & 54354 & 20861 & 13370 & 152136 & 12,03 \\
\hline Total Absoluto & 77944 & 337713 & 573965 & 191172 & 83381 & 1264175 & 100,00 \\
\hline Total Percentual & 6,17 & 26,71 & 45,40 & 15,12 & 6,60 & 100,00 & $\mathrm{x}$ \\
\hline
\end{tabular}

Fonte: DATASUS, 2017. 
Observando-se a tabela 1.2, notar-se-á que as regiões sudeste, nordeste e sul do Brasil apresentam o maior número de óbitos associados às doenças do sistema circulatório por mil habitantes, superando as demais regiões do país. De acordo com Albanesi Filho (2004, p.267),

a maior taxa de mortalidade entre as dez maiores frequências em internações por IC [Insuficiência Cardíaca] pertence ao Estado de São Paulo, seguindo-se o Rio de Janeiro. Talvez esta incidência decorra da maior afluência de pacientes de outros Estados, que procuram o eixo São Paulo-Rio para tratamento, ou da maior gravidade dos casos atendidos.

Tabela 1.2 - Óbitos Associados às Doenças do Aparelho Circulatório por Número de Habitantes das Regiões do Brasil em 2015

\begin{tabular}{l|c|r|r|r|r}
\hline \multicolumn{1}{c|}{$\begin{array}{c}\text { Regiões do } \\
\text { Brasil }\end{array}$} & $\begin{array}{c}\text { Número de } \\
\text { Habitantes } \\
(\mathbf{2 0 1 0})\end{array}$ & \multicolumn{1}{c|}{$\begin{array}{c}\text { Habitantes } \\
(\mathbf{\%})\end{array}$} & $\begin{array}{c}\text { Óbitos por Doenças } \\
\text { do Aparelho } \\
\text { Circulatório (2015) }\end{array}$ & Óbitos (\%) & \multicolumn{1}{c}{$\begin{array}{c}\text { Óbitos por } \\
\text { Habitante (\%) }\end{array}$} \\
\hline Região Norte & 15.864 .454 & 8,32 & 17889 & 5,12 & 1,13 \\
\hline Região Nordeste & 53.081 .950 & 27,83 & 92681 & 26,51 & 1,75 \\
\hline Região Sudeste & 80.364 .410 & 42,13 & 163509 & 46,76 & 2,03 \\
\hline Região Sul & 27.386 .891 & 14,36 & 53565 & 15,32 & 1,96 \\
\hline $\begin{array}{l}\text { Região Centro- } \\
\text { Oeste }\end{array}$ & 14.058 .094 & 7,37 & 21998 & 6,29 & 1,56 \\
\hline Brasil & 190.755 .799 & 100 & 349642 & 100,00 & 1,83 \\
\hline
\end{tabular}

Fonte: DATASUS, 2017.

As doenças do aparelho circulatório estão indicadas de forma sistematizada na Classificação Internacional de Doenças (CID - 10), manual utilizado pelo Sistema Único de Saúde brasileiro (SUS) para a padronização do armazenamento de dados relativos à saúde no âmbito do território nacional. De acordo com o Ministério da Saúde (2017),

a CID-10 foi conceituada para padronizar e catalogar as doenças e problemas relacionados à saúde, tendo como referência a Nomenclatura Internacional de Doenças, estabelecida pela Organização Mundial de Saúde. Com base no compromisso assumido pelo Governo Brasileiro, a organização dos arquivos em meio magnético e sua implementação para disseminação eletrônica foi efetuada pelo DATASUS, possibilitando, assim, a implantação em todo o território nacional, nos registros de Morbidade Hospitalar e Ambulatorial, compatibilizando estes registros entre todos os sistemas que lidam com morbidade.

O capítulo IX do CID-10 dispõe sobre a classificação das doenças relativas ao aparelho circulatório, compreendendo as seguintes tipologias de patologias:

I00-I02 Febre reumática aguda

I05-I09 Doenças reumáticas crônicas do coração

I10-I15 Doenças hipertensivas 
I20-I25 Doenças isquêmicas do coração

I26-I28 Doenças cardíaca pulmonar e da circulação pulmonar

I30-I52 Outras formas de doença do coração

I60-I69 Doenças cerebrovasculares

I70-I79 Doenças das artérias, das arteríolas e dos capilares

I80-I89 Doenças das veias, dos vasos linfáticos e dos gânglios linfáticos, não classificadas em outra parte

195-199 Outros transtornos, e os não especificados do aparelho circulatório (MINISTÉRIO DA SAÚDE, 2017).

No município brasileiro de São Paulo, localizado no Estado de São Paulo (mapa 1, a seguir), as doenças do aparelho circulatório também são a principal causa de morte da população, representando aproximadamente 30,63\% dos óbitos em 2015, segundo indicado na tabela 1.3. Ademais, o município registrou 2,3 mortes associadas às referidas doenças a cada mil habitantes naquele ano, totalizando 25.848 mortes (DATASUS, 2017), das quais 9.786 (37,86\% , aproximadamente) foram ocasionadas por doenças isquêmicas do coração e 6.052 (23,41\%, aproximadamente) por doenças cerebrovasculares (DATASUS, 2017), conforme podemos observar na tabela 1.4 a seguir. 


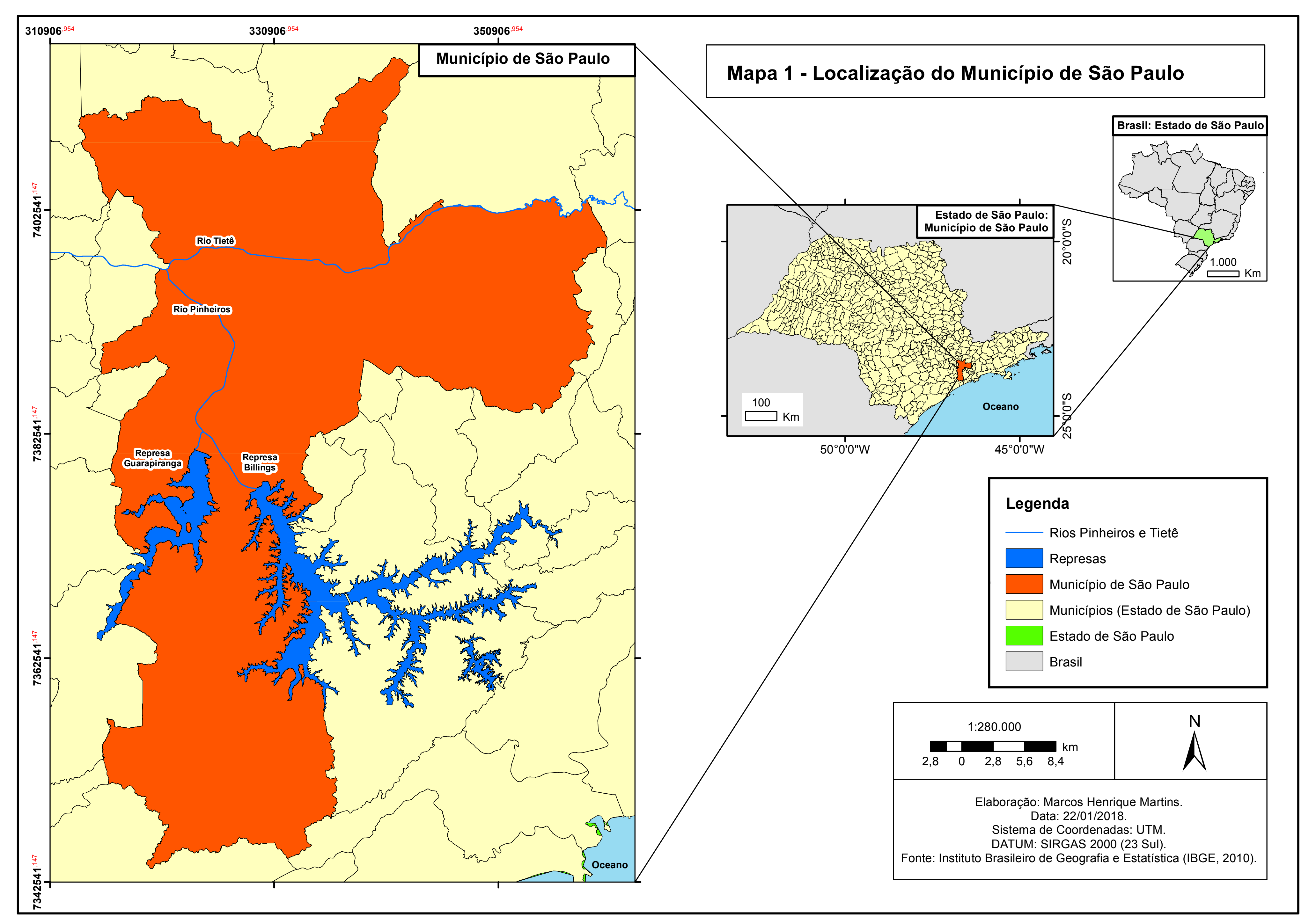


Tabela 1.3 - Óbitos Ocorridos no Município de São Paulo, em 2015, por Causa do CID 10

\begin{tabular}{l|r|r}
\hline \multicolumn{1}{c|}{ Causa (Capítulos da CID10) } & Número de Óbitos & Óbitos (\%) \\
\hline I. Algumas doenças infecciosas e parasitárias & 3170 & 3,76 \\
\hline II. Neoplasias (tumores) & 19407 & 23,00 \\
\hline $\begin{array}{l}\text { III. Doenças do sangue e dos órgãos hematopoiéticos e alguns } \\
\text { transtornos imunitários }\end{array}$ & 281 & 0,33 \\
\hline IV. Doenças endócrinas nutricionais e metabólicas & 3252 & 3,85 \\
\hline V. Transtornos mentais e comportamentais & 1136 & 1,35 \\
\hline VI. Doenças do sistema nervoso & 2983 & 3,53 \\
\hline VII. Doenças do olho e anexos & 2 & 0,00 \\
\hline VIII. Doenças do ouvido e da apófise mastoide & 9 & 0,01 \\
\hline IX. Doenças do aparelho circulatório & 25848 & 30,63 \\
\hline X. Doenças do aparelho respiratório & 11056 & 13,10 \\
\hline XI. Doenças do aparelho digestivo & 4509 & 5,34 \\
\hline XII. Doenças da pele e do tecido subcutâneo & 446 & 0,53 \\
\hline XIII. Doenças sistema osteomuscular e tecido conjuntivo & 404 & 0,48 \\
\hline XIV. Doenças do aparelho geniturinário & 2757 & 3,27 \\
\hline XV. Gravidez, parto e puerpério & 106 & 0,13 \\
\hline XVI. Algumas afecções originadas no período perinatal & 1263 & 1,50 \\
\hline XVII. Malformaçes congênitas, deformidades e anomalias & 1006 & 1,19 \\
\hline cromossômicas & & 677 \\
\hline XVIII. Sintomas, sinais e achados anormais de exames clínicos e de & 6078 & 0,80 \\
\hline laboratório, não classificados em outra parte & 84390 & 7,20 \\
\hline XX. Causas externas de morbidade e mortalidade & & 100,00 \\
\hline
\end{tabular}

Fonte: DATASUS, 2017.

Tabela 1.4 - Óbitos Associados às Doenças do Aparelho Circulatório, por Causa Específica, ocorridos em São Paulo em 2015

\begin{tabular}{l|r|r}
\hline \multicolumn{1}{c|}{ Causas Específicas } & Óbitos Totais & \multicolumn{1}{c}{ Óbitos (\%) } \\
\hline Doenças reumáticas crônicas do coração & 256 & 0,99 \\
\hline Doenças hipertensivas & 2087 & 8,07 \\
\hline Doenças isquêmicas do coração & 9786 & 37,86 \\
\hline Doenças da circulação pulmonar & 1531 & 5,92 \\
\hline Miocardiopatias & 1174 & 4,54 \\
\hline Insuficiência cardíaca & 1309 & 5,06 \\
\hline Doenças cerebrovasculares & 6052 & 23,41 \\
\hline Aneurisma e dissecção da aorta & 1187 & 4,59 \\
\hline Demais causas de morte & 2466 & 9,54 \\
\hline & 25848 & 100 \\
\hline
\end{tabular}

Fonte: DATASUS, 2017.

Ademais, houve uma predominância no número de óbitos associados às doenças do aparelho circulatório na população masculina, bem como nas parcelas branca, preta e amarela 
que habitam o referido município, conforme podemos verificar nas tabelas 1.5 e 1.6, dispostas abaixo.

Tabela 1.5 - Óbitos Associados às Doenças do Aparelho Circulatório por Sexo Município de São Paulo (2015)

\begin{tabular}{|c|c|c|c|c|}
\hline Causas Específicas & Masculino & Feminino & Ignorado & Total \\
\hline Doenças reumáticas crônicas do coração & 79 & 177 & 0 & 256 \\
\hline Doenças hipertensivas & 860 & 1227 & 0 & 2087 \\
\hline Doenças isquêmicas do coração & 5541 & 4244 & 1 & 9786 \\
\hline Doenças da circulação pulmonar & 609 & 922 & 0 & 1531 \\
\hline Miocardiopatias & 743 & 431 & 0 & 1174 \\
\hline Insuficiência cardíaca & 531 & 778 & 0 & 1309 \\
\hline Doenças cerebrovasculares & 2875 & 3177 & 0 & 6052 \\
\hline Aneurisma e dissecção da aorta & 679 & 508 & 0 & 1187 \\
\hline Demais causas de morte & 1099 & 1367 & 0 & 2466 \\
\hline Total de Mortes & 13016 & 12831 & 1 & 25848 \\
\hline População Total (2010) & 5328632 & 5924871 & $\mathrm{x}$ & 11253503 \\
\hline Total Relativo (mortes por mil habitantes - \%o) & 2,44 & 2,17 & $\mathrm{x}$ & 2,30 \\
\hline
\end{tabular}

Fontes: DATASUS, 2017 e IBGE, 2010.

Tabela 1.6 - Óbitos Associados às Doenças do Aparelho Circulatório por Raça/Cor - Município de São Paulo (2015)

\begin{tabular}{|c|c|c|c|c|c|c|c|c|}
\hline Causas Específicas & Branca & Preta & Amarela & Parda & Indígena & $\begin{array}{c}\text { Não } \\
\text { Informado }\end{array}$ & $\begin{array}{l}\text { Total de } \\
\text { Mortes }\end{array}$ & Total (\%) \\
\hline $\begin{array}{l}\text { Doenças reumáticas } \\
\text { crônicas do coração }\end{array}$ & 196 & 14 & 4 & 36 & 0 & 6 & 256 & 0,99 \\
\hline Doenças hipertensivas & 1420 & 208 & 27 & 409 & 0 & 23 & 2087 & 8,07 \\
\hline $\begin{array}{l}\text { Doenças isquêmicas do } \\
\text { coração }\end{array}$ & 7209 & 590 & 224 & 1689 & 1 & 73 & 9786 & 37,86 \\
\hline $\begin{array}{l}\text { Doenças da circulação } \\
\text { pulmonar }\end{array}$ & 1075 & 127 & 21 & 298 & 0 & 10 & 1531 & 5,92 \\
\hline Miocardiopatias & 736 & 115 & 14 & 294 & 1 & 14 & 1174 & 4,54 \\
\hline Insuficiência cardíaca & 957 & 80 & 27 & 221 & 0 & 24 & 1309 & 5,06 \\
\hline $\begin{array}{l}\text { Doenças } \\
\text { cerebrovasculares }\end{array}$ & 3960 & 499 & 182 & 1335 & 4 & 72 & 6052 & 23,41 \\
\hline $\begin{array}{l}\text { Aneurisma e dissecção da } \\
\text { aorta }\end{array}$ & 849 & 80 & 42 & 201 & 0 & 15 & 1187 & 4,59 \\
\hline Demais causas de morte & 1861 & 140 & 49 & 375 & 1 & 40 & 2466 & 9,54 \\
\hline Total de Mortes & 18263 & 1853 & 590 & 4858 & 7 & 277 & 25848 & 100,00 \\
\hline População Total (2010) & 6824668 & 736083 & 246244 & 3433218 & 12977 & 313 & 11253503 & $\mathrm{x}$ \\
\hline $\begin{array}{l}\text { Total Relativo (mortes } \\
\text { por mil habitantes - \%o) }\end{array}$ & 2,68 & 2,52 & 2,40 & 1,41 & 0,54 & $\mathrm{x}$ & 2,30 & $\mathrm{x}$ \\
\hline
\end{tabular}

Fontes: DATASUS, 2017 e IBGE, 2010.

Os dados observados nas tabelas de 1.1 a 1.6 não são representativos apenas da realidade brasileira e/ou não estão estritamente relacionados ao município de São Paulo. As doenças do aparelho circulatório têm se tornado a principal causa de morte mundial (BREITNER, 2014, 
p.1272), especialmente nos países desenvolvidos e em desenvolvimento (SOARES et al, 2012), fato este que tem preocupado a comunidade médica e os especialistas em saúde. Ademais, outros estudos têm apontado que países subdesenvolvidos e em desenvolvimento são afetados por esta tipologia de doença de forma desproporcional e mais severa (LANE et al., 2017). Neste sentido,

\begin{abstract}
o interesse em [sic] compreender quais fatores são necessários para que as doenças do aparelho cardiovascular se manifestem vem do fato de que é necessário traçar um perfil da doença, para que medidas de mitigação e políticas de saúde sejam desenvolvidas. $\mathrm{O}$ conhecimento precoce dos riscos cardiovasculares associados às condições climáticas fundamentam medidas preventivas de educação em saúde, necessárias para a diminuição da morbidade (GALVÃO; LEITE; VIRGENS FILHO; PONTES, 2015, p.94).
\end{abstract}

Pesquisas realizadas nas últimas décadas têm demonstrado que há correlação entre a mortalidade e as variáveis climáticas, especialmente a temperatura, a umidade relativa do ar e a pluviosidade (SOARES et al, 2012). Neste sentido, os estudos que correlacionam variáveis meteorológicas e saúde têm despertado interesse e ganhado relevância, haja vista a "[...] necessidade de melhor compreender os efeitos das alterações ambientais urbanas na saúde da população e as possíveis vulnerabilidades frente às mudanças climáticas globais" (SILVA; RIBEIRO; SANTANA, 2014, p.1). A maior parte desses estudos indicou haver relação entre as variáveis climáticas associadas ao conforto térmico e a saúde humana (SILVA; RIBEIRO; SANTANA, 2014).

Sabe-se que o ser humano está imerso na atmosfera e inevitavelmente estabelece com ela interações complexas e em permanente estado de instabilidade-estabilidade "[...] para manter o balanço das suas funções vitais, ou seja, o equilíbrio entre a produção e a perda de calor. As reações do organismo podem ser compreendidas como uma resposta às mudanças dos estados químico e físico da atmosfera" (SILVA; RIBEIRO; SANTANA, 2014, p.2). Destarte, do ponto de vista da saúde, a relevância da avaliação do ambiente térmico, especialmente em áreas urbanas, está associada à forte relação entre a termorregulação, a regulação circulatória e o ambiente atmosférico, haja vista que "condições estressantes levam à sobrecarga no sistema termorregulador e ao comprometimento da saúde das pessoas, podendo, até mesmo, leva-las à morte" (SILVA; RIBEIRO; SANTANA, 2014, p.1).

Alguns estudos têm apontado para a existência de correlação entre as variáveis climáticas e as principais causas de morte no Brasil, conforme aponta Soares et al. (2012, p.138): 
verificou-se a presença de correlação entre as variáveis meteorológicas e os coeficientes de mortalidade total e por causas de acordo com o CID-10. A mortalidade total não apresentou correlação com as variáveis climáticas. As doenças infecciosas e parasitárias apresentaram correlação positiva significativa com a Umidade Mínima $(\mathrm{r}=0,642)$ e correlação negativa com a Temperatura Mínima $(\mathrm{r}=-0,731)$. As doenças endócrinas, nutricionais e metabólicas apresentaram correlação negativa significativa com a Temperatura Mínima $(r=-0,690)$ e a Temperatura Máxima $(r=-0,676)$. As doenças do aparelho respiratório apresentaram correlação negativa significativa com a Umidade Mínima $(r=-0,669)$.

Em um estudo sobre o município de Ponta Grossa (RS), verificou-se que

ao ser analisada sazonalmente, a taxa de morbidade por doenças do aparelho circulatório apresentou uma tendência de aumento no outono e o maior pico no inverno, ou seja, à medida que a atmosfera apresenta um quadro geral de resfriamento e com o ar mais seco. Conforme observado em outros estudos, o frio provoca uma constrição nos vasos sanguíneos podendo aumentar assim as internações por hipertensão arterial, insuficiência cardíaca, acidente vascular cerebral, trombose e embolia (GALVÃO; LEITE; VIRGENS FILHO; PONTES, 2015, p.99)

Ademais, dois outros fatores fisiológicos se alteram com a temperatura mais baixa:

o primeiro seria a maior ocorrência de inflamações respiratórias que influenciam em patologias do sistema cardiovascular e o segundo seria a maior ativação dos fatores formadores de coágulos, ocasionando assim a maior ocorrência de doenças isquêmicas tais como o infarto (GALVÃO; LEITE; VIRGENS FILHO; PONTES, 2015, p.99)

Por outro lado, o aumento da temperatura exerce também uma influência sobre o aparelho circulatório, podendo desencadear alterações bioquímicas no corpo humano que, associadas a outros fatores, promovem o aumento da mortalidade:

com o aumento da temperatura há uma elevação da eliminação do suor que pode levar a uma redução do volume plasmático e queda da pressão arterial. Além disso, há aumento na viscosidade do sangue, causada pela concentração de hemácias, plaquetas e colesterol. A queda da pressão arterial reduz o fluxo sanguíneo nas arteríolas e as plaquetas, junto com o colesterol, facilitam o aparecimento de trombos. Estes se envolvem em ateromas e pela interrupção do fluxo sanguíneo para os tecidos causam infarto do miocárdio ou acidente vascular cerebral [...] (GALVÃO; LEITE; VIRGENS FILHO; PONTES, 2015, p.103).

Em um estudo sobre a relação entre a variação da temperatura diurna e a ocorrência de doze tipos de mortalidade em 47 cidades do Japão, Lee et al. (2018) indicaram que o risco de mortalidade aumenta quando associado com a variação da temperatura diurna para todas as causas de morte analisadas, especialmente as associadas ao aparelho circulatório, sugerindo que a mortalidade tende a aumentar com o aumento da temperatura. 
Breitner et al. (2014) investigaram a relação entre a variação diária de temperatura do ar e as diferentes causas de morte associadas às doenças cardiovasculares em estudo sobre a região da Bavária, sul da Alemanha. As referidas autoras indicaram que altas e baixas temperaturas aumentam a ocorrência da tipologia de óbito em questão. De acordo com o referido estudo, um aumento de $4,8^{\circ} \mathrm{C}$ (de $20^{\circ} \mathrm{C}$ para $24,8^{\circ} \mathrm{C}$ ) na temperatura média de dois dias consecutivos representaria um aumento de $10 \%$ dos óbitos associados às doenças do aparelho circulatório (BREITNER, 2014, p.1275). Ademais, estudos teriam demonstrado que temperaturas elevadas afetam a taxa de mortalidade mais imediatamente, enquanto as baixas temperaturas têm um efeito mais retardado e duradouro (BREITNER, 2014, p.1275).

Em estudo relativo ao município brasileiro de São Paulo, Ikefuti (2016) concluiu que, entre os anos de 2002 a 2011, tanto as variáveis socioeconômicas quanto as ambientais exerceram influência na mortalidade por algumas doenças do aparelho circulatório.

Neste sentido, não é precipitado indicar que vários estudos têm apontado para a relação existente entre certos eventos climáticos, tal como a chegada de frentes frias e de ondas de calor, e o aumento nos indicadores de morbidade e mortalidade associadas às doenças cardiovasculares em várias populações e localizações geográficas da Terra (LIU et al., 2015). Tomando como referência esta miríade de estudos, ainda que se considerem suas limitações, faz-se necessário indicar o crescente interesse pela relação entre a ocorrência de óbitos associados às doenças do aparelho circulatório e os indicadores climáticos e, consequentemente, ambientais.

Neste ponto, vale ressaltar que é imperativo considerar, no âmbito da medicina, um complexo conjunto de fatores aparentemente mais fortemente correlacionados à ocorrência de doenças cardiovasculares do que os indicadores ambientais, como fatores bioquímicos do corpo humano, culturais e socioeconômicos. Os fatores ambientais podem ser relevantes para a compreensão da distribuição espacial e temporal da morbidade, mas não são suficientes se isolados dos demais determinantes. Neste sentido, é notório observar que

[...] as patologias do sistema cardiovascular são influenciadas tanto pelas temperaturas máximas como também pelas mínimas, uma vez que ficou entendido que a temperatura do ar colabora bidirecionalmente para retirar o sistema cardiovascular de sua homeostasia e com isso provocar a ocorrência de patologias (GALVÃO; LEITE; VIRGENS FILHO; PONTES, 2015, p.105)

Destarte, a temperatura do ar apresenta correlação com a taxa de morbidade por doenças do aparelho circulatório (GALVÃO; LEITE; VIRGENS FILHO; PONTES, 2015). No município de São Paulo, um estudo realizado recentemente evidenciou que tanto as variáveis 
ambientais como socioeconômicas têm influência na mortalidade por algumas doenças do aparelho circulatório (IKEFUTI, 2016). Ademais, o referido estudo indicou que "os fatores socioeconômicos são fortemente associados com a mortalidade" (IKEFUTI; BARROZO, 2015, p.642), evidenciando a “[...] associação entre as áreas mais pobres com áreas de alto risco \{de ocorrência de doenças cardiovasculares\}" (IKEFUTI; BARROZO, 2015, p.649).

De acordo com Ikefuti e Barrozo (2015, p.653), observou-se, para o município de São Paulo, correlação linear significativa entre renda per capita, iluminação pública e arborização em 2010 e o risco relativo de mortalidade por acidente vascular cerebral (AVC) entre 2006 e 2009. Outras duas variáveis consideradas foram o asfaltamento e a presença de calçada, que não apresentaram coeficiente de correlação apreciável. O referido estudo reforçou, portanto, a necessidade de se compreender a relação entre os indicadores socioeconômicos e a distribuição dos óbitos associados às doenças do aparelho circulatório. Entretanto, como será possível verificar nos dois primeiros capítulos que seguem, algumas premissas adotadas pelas referidas pesquisadoras são questionáveis. Segundo o referido estudo, e à guisa de exemplo, “[...] esperase que o aumento da população idosa eleve o número de casos de AVC, apresentando uma epidemia intensa nos anos futuros" (IKEFUTI; BARROZO, 2015, p.642). Entretanto, a concentração da população idosa, conforme demonstraremos adiante, não está necessariamente relacionada a um aumento número de casos de mortes associadas às doenças do aparelho circulatório, haja vista os bairros com maior expectativa de vida serem os com menor concentração de óbitos da tipologia em análise.

Ademais, os dados relativos ao asfaltamento e à presença de calçadas, também considerados por Ikefuti e Barrozo (2015), não são suficientes para uma apreciação adequada da relação entre infraestrutura urbana e a distribuição dos óbitos associados às doenças cardiovasculares. Estas pesquisadoras consideram tais variáveis enquanto "[...] fatores que influenciam na caminhada e na atividade física" (IKEFUTI; BARROZO, 2015, p.649). Entretanto, o asfaltamento e a calçada, em conjunto com outros objetos construtivos que constituem o ambiente urbano-citadino, não são relevantes apenas enquanto um "palco" para atividades físicas, mas compõem o próprio ambiente em que vive a população e que não se distingue deste viver.

Neste sentido, ainda que poucas pesquisas tenham evidenciado como os aspectos do ambiente construído contribuem para o progresso das doenças cardiovasculares na escala intraurbana, Lane et al. (2015), em um estudo sobre a cidade indiana de Chennai, concluíram que indivíduos residentes em áreas com elevada impermeabilização do solo e presença de luzes 
noturnas, bem como com pouca cobertura vegetal, apresentam significativamente maior pressão sistólica, diastólica e de pulso, indicando que uma elevada exposição residencial à impermeabilização do solo e às luzes noturnas provocam um aumento nos biomarcadores associados ao Envelhecimento Vascular Precoce (EVP).

As principais teorias sobre o envelhecimento cardiovascular apontam como suas variáveis explicativas o estresse oxidativo, a produção de radicais livres, as alterações neuroendócrinas e a predisposição genética (MIKAEL et al., 2017). "A confluência desses fatores, atuando principalmente nos miócitos e na camada miointimal das artérias, leva ao aumento na rigidez ventricular e vascular, fenômeno intimamente relacionado ao processo de envelhecimento cardiovascular" (MIKAEL et al., 2017, p.253). O EVA, por sua vez, é um processo de envelhecimento acelerado que envolve modificações bioquímicas, enzimáticas e celulares nas paredes arteriais e que é caracterizado por biomarcadores teciduais de disfunções endoteliais e de endurecimento e espessamento das artérias, com ocorrência de aumento da pressão arterial (LANE et al., 2017, p.1). O referido envelhecimento precoce pode ocorrer devido a inflamações e ao estresse oxidativo, particularmente quando estão presentes outros fatores de risco (LANE et al., 2017, p.1). Destarte, como as áreas urbanas têm se tornado cada vez mais populosas, especialmente a partir do século passado, é relevante compreendermos como as variações nos ambientes que constituem as cidades estão ou não relacionadas às doenças do aparelho circulatório.

Neste sentido, não é prematuro presumir-se que a qualidade do ambiente urbano exerce influência aparentemente "determinante" sobre a qualidade de vida da população. A forma da cidade, suas funções, os materiais que a compõem e que configuram o uso e ocupação de seu território, bem como os "determinantes" históricos, sociais, culturais, políticos e econômicos que engendram o tecido urbano seriam elementos essenciais que interfeririam na saúde da população que habita e produz o ambiente urbano e, que ao produzi-lo, produz a si mesmo enquanto uma população para uma cidade. Destarte, a produção da cidade é a produção do indivíduo urbano enquanto um indivíduo que não se dissocia de seu meio urbano, ou seja, que é um indivíduo cujos membros são membros citadinos, cujos sentidos são sentidos citadinos. Assim, esta "influência aparentemente determinante" que o ambiente urbano exerce sobre a "qualidade de vida da população" não é uma determinidade propriamente dita, mas um engendrar.

Neste sentido, é patente considerar que “[...] a urbanização parece promover um aumento da prevalência de alguns fatores de risco cardiovascular, com maior incidência dessas 
patologias nos aglomerados urbanos" (NASCIMENTO NETO, 2005, p.28). Ademais, de acordo com o referido autor, o ritmo acelerado do crescimento urbano teria constituído uma “[...] falta de recursos e serviços de saúde adequados para os centros urbanos mais pobres, o que dificulta a prevenção e promoção da saúde cardiovascular nessas regiões" (NASCIMENTO NETO, 2005, p.28).

Ainda de acordo com Nascimento Neto (2005, p.28),

[...] constata-se um aumento significativo da prevalência da diabetes quando se comparam as cidades pelo número de habitantes. Uma das causas disso pode ser a migração populacional do campo para as cidades, nas quais verifica-se um extraordinário aumento na propaganda e promoção de produtos nocivos à saúde, principalmente nos países em desenvolvimento, pois esses países são mercados para atrativos veiculados pelas indústrias que comercializam produtos prejudiciais à saúde, como as indústrias de cigarro, de álcool e de alimentos não saudáveis. Nesses países, as regulamentações nacionais e os programas de educação em saúde pública são ineficazes ou, em muitos casos, inexistem. Poderemos confrontar no "Corações do Brasil" as regiões brasileiras sob a ótica da distribuição de renda e o impacto das estratégias de marketing criativas que, em muitos casos, parecem tirar proveito das sociedades carentes. A combinação de privação e a exposição precoce a produtos prejudiciais à saúde figura-se especialmente rentável para empresas que comercializam produtos nocivos. Infelizmente, o sucesso dessas campanhas de marketing é proporcional à devastação que acarreta à saúde, à economia e ao bemestar social dos países e suas populações.

A despeito de necessitarmos considerar o processo de urbanização no âmbito da análise que aqui se apresenta, parece precipitado atribuirmos ao ritmo da urbanização as carências sociais, econômicas e infraestruturais observadas nos países considerados. O "acelerado" crescimento urbano observado no Brasil a partir da década de 1980, que estaria intimamente associado à "migração populacional do campo para as cidades" promovida na referida década, não se desvincula da longa história colonial brasileira. Assim, a relação entre “privação e exposição precoce a produtos prejudiciais à saúde” apresentar-se-ia enquanto um engendrar desta relação na própria produção das cidades brasileiras e não simplesmente enquanto uma causalidade constituída pelo excesso de ritmo que levaria à privação urbana e pela privação urbana que levaria ao excesso mercadológico. Destarte, esta explicação da falta pelo excesso e do excesso pela falta se demonstra demasiado frágil.

Outra consideração relevante de Nascimento Neto (2005, p.29) diz respeito à relação entre envelhecimento da população e o aumento das cardiopatias: "as situações de cardiopatias crônicas estão se tornando mais expressivas no mundo inteiro. Em consequência dos avanços na saúde pública, as populações estão envelhecendo e um número cada vez maior de indivíduos vive décadas com patologias cardiovasculares e seus fatores de risco”. Em relação a esta 
consideração, já apontamos que ela é limitada pela complexidade da questão: “envelhecer" é um processo de engendramento da corporeidade do indivíduo, que não se dissocia de seus sentidos urbanos. Destarte, não seria o envelhecimento da população, mas o engendrar mesmo deste envelhecimento que estaria relacionado com o aumento das mortes associadas às cardiopatias.

Por outro lado, Nascimento Neto (2005), assim como Ikefuti e Barrozo (2015), Ikefuti (2016) e outros pesquisadores, evidenciam a necessidade de se considerar a relação entre as características socioeconômicas dos indivíduos e as mortes associadas às doenças do aparelho circulatório. No âmbito do presente estudo, portanto, tais variáveis foram consideradas conforme indicado no capítulo subsequente. Por outro lado, há uma insuficiência explicativa em torno da relação entre o ambiente urbano e a tipologia de mortalidade analisada no escopo do presente lavrado.

Neste sentido, tendo em vista a relação entre o meio ambiente e a saúde humana e levando em consideração o número considerável de pessoas vivendo em áreas urbanas no Brasil (IBGE, 2010), vale ressaltar que um dos "efeitos" mais marcantes do processo de urbanização é o aumento das superfícies impermeáveis. A impermeabilização do solo implica várias alterações ao ambiente "preexistente", como mudanças na hidrodinâmica e no microclima local, deterioração da qualidade da água, dentre outros. Estas mudanças não são apenas alterações externas aos indivíduos que habitam a cidade, mas constituem os sentidos mesmos desses indivíduos, ou seja, sua própria condição existencial de Ser.

O aumento de superfícies impermeáveis provoca alteração significativa no fluxo de calor latente e sensível, causando ilhas de calor (CHANGNON, 1992). Materiais como asfalto, concreto e amianto, por exemplo, possuem propriedades de absorver grande quantidade de energia solar, que é então liberada na forma de calor. Como consequência, há uma forte relação linear positiva entre aumento de superfície impermeável e aumento da temperatura do ambiente (YUAN; BAUER, 2007).

De acordo com um estudo realizado em três megacidades do sudeste asiático (ESTOQUE et al., 2017) e cujo objetivo foi examinar a relação entre a temperatura aparente de superfície e a abundância e o padrão espacial de áreas impermeabilizadas e de áreas verdes em Bangkok, Jakarta e Manila, há uma considerável correlação positiva entre as médias de temperatura aparente de superfície e a densidade de superfícies impermeáveis, bem como uma correlação negativa apreciável entre as referidas médias e a presença de áreas verdes. 
Ademais, esta alteração física do ambiente também é a alteração física do ser humano para o qual o ambiente é e em relação ao qual este ser é humano. Entretanto, esta "alteração" não se apresentaria enquanto uma causalidade, uma determinidade, mas como o produzir desta "alteração" enquanto o produzir do ser humano sensível a ela e que não se distingue dela.

Uma característica importante das superfícies impermeáveis é que elas não se manifestam de forma pontual no espaço, seja pela extensão que atingem ou pelo grau de influência sobre o meio ambiente que elas podem exercer. Neste sentido, o aumento de temperatura nas áreas mais impermeabilizadas do município de São Paulo pode promover, como consequência, agravamento na saúde da população que se encontra nessas áreas. Este “aumento", entretanto, é a produção deste aumento pela produção da impermeabilização do solo e, consequentemente, é também a produção do agravamento na saúde da população que se encontra nessas áreas, ou seja, é o engendrar da humanidade impotente, doente.

Tendo em vista a relação entre a temperatura do ar e a ocorrência de doenças associadas ao aparelho circulatório, conforme apontado previamente, é razoável conjecturar que é possível haver uma correlação entre a distribuição dos óbitos associados a essas doenças e a impermeabilização do solo. Neste sentido, a hipótese que fomenta a investigação científica proposta é a de que, havendo uma correlação entre temperatura do ar e impermeabilização do solo e entre temperatura do ar e ocorrência de óbitos ocasionados por doenças associadas ao aparelho circulatório, há provavelmente uma relação entre a distribuição desta tipologia de óbito e a impermeabilização do solo.

No intuito de se fomentar as investigações em torno do objetivo desta reflexão, algumas etapas principais compuseram a execução da presente investigação: 1) mapeamento da superfície impermeável e da temperatura aparente de superfície do município de São Paulo; 2) mapeamento dos óbitos ocasionados por doenças associadas ao aparelho circulatório no referido município; 3) elaboração de indicadores socioeconômicos (renda, alfabetização e fragilidade etária) e de um indicador socioambiental - constituído pelo indicador de renda e por um indicador de impermeabilização do solo - para os distritos administrativos de São Paulo e 4) análise (estatística e espacial) detalhada do conjunto de variáveis consideradas previamente, no intuito de se determinar as forças de correlação entre essas variáveis, investigando-se os condicionantes, os processos e as implicações dessas correlações. Tomou-se como aceitável, de acordo com a literatura investigada, o valor $\mathrm{p}$ (significância) máximo de $5 \%$ para a validação das referidas análises estatísticas. Ademais, os valores $\mathrm{p}$ obtidos foram sempre notados de 
acordo com os resultados alcançados, de forma que o apreciador de nosso trabalho possa ter contado direto com os resultados assim como observados por nós.

Os referidos resultados abichados até o presente momento sustentam, ao menos, duas considerações fundamentais: 1) os óbitos associados às doenças do sistema circulatório não podem ser satisfatoriamente compreendidos sem que se considere sua localização e distribuição; 2) fatores de ordem ambiental, como a impermeabilização do solo, apresentam relação com a localização e distribuição desta tipologia de óbito, indicando a necessidade de estudos mais aprofundados sobre o assunto.

Considerando-se os dados relativos à mortalidade ocasionada por doenças associadas ao aparelho circulatório, por faixa etária, sem que se considere sua localização e distribuição, observou-se que há uma relação entre o envelhecimento da população e sua susceptibilidade a esta tipologia de mortalidade. Entretanto, ao se considerar a localização e distribuição dos referidos óbitos, observou-se que o envelhecimento da população está condicionado a fatores de ordem socioeconômica que invertem a relação da fragilidade etária com a referida tipologia de mortalidade. Em outras palavras, envelhecer em locais distintos de uma mesma cidade, ser/estando sujeito, portanto, de/a condicionantes socioeconômicos e ambientais distintos, resulta em efeitos distintos. Destarte, o tempo de morte e de vida se nos apresenta para além, mas não a despeito de, simples indicadores biológicos.

Ademais, a análise da relação entre os óbitos associados às doenças do sistema circulatório e o indicador socioambiental indicou a necessidade de se melhor analisar a relação entre renda e impermeabilização do solo na compreensão da distribuição desta tipologia de mortalidade. Ainda que se considerem as limitações impostas ao pesquisador pela complexidade do estudo, fica evidenciado que a impermeabilização do solo possui relação com a distribuição dos óbitos associados às doenças do aparelho circulatório.

Do ponto de vista estritamente científico, justificar-se-ia, portanto, a relevância desta investigação pelas reflexões que o compõem e pelos dados que fornecerá aos estudos relacionados à saúde humana, à prática médica e ao planejamento urbano. Elegeu-se o município de São Paulo (MSP) como objeto deste estudo devido ao grande número de habitantes deste município (IBGE, 2010), bem como tendo em vista sua importância enquanto centralidade de uma das maiores regiões metropolitanas do mundo e, consequentemente, por apresentar condições de impermeabilização do solo condizentes com o tipo de crescimento do tecido urbano que o município sofreu nas últimas décadas. 
Entretanto, reitera-se que a reflexão engendrada no âmbito deste escrito não apreende como objeto o estritamente definido nos termos da investigação científica proposta, mas toma esta referida investigação como o objeto mesmo de reflexão. Esta reflexão será sustentada, no âmbito das páginas que somam este limitado escrito, por referências explicitas a três grandes filósofos ocidentais da modernidade: Hegel, Marx e Nietzsche.

Neste sentido, a constituição do presente escrito perpassa pela investigação científica proposta, executada no escopo do segundo e terceiro capítulos desta monografia, veleja pelos interstícios de suas fundamentações física e metafísica no capítulo 4 e tem como proposta o aprofundamento da temática da crítica à geografia da efetividade na forma de um proposto Sensualismo Geográfico Dialético no capítulo 5.

O quarto capítulo da presente investigação justifica-se pela sua relevância intestinal. Após a apresentação do escopo metodológico e dos resultados da investigação científica, estruturada em torno de uma hipótese e de um objetivo bem definidos, nos dois primeiros capítulos a seguir, o quarto capítulo apresentará as bases lógicas e metafísicas da argumentação científica proposta, bem como uma crítica à Geografia da efetividade elaborada nos termos da Filosofia em Hegel e Marx e, posteriormente aprofundada com referências à Nietzsche no capítulo cinco.

A principal contribuição deste estudo reside na necessidade de se estabelecer uma compreensão adequada do engendrar da sociedade moderna. Este "engendrar" apresentar-se-ia como o processo de constituição do sujeito objetivo cuja corporeidade é a produção mesma dos sentidos deste sujeito, sentidos estes que não estão absolutamente encarcerados em uma suposta corporeidade em-si, objetiva, consciente-de-si, subjetiva, mas que se constituem enquanto sentidos propriamente geográficos. Estes sentidos, por um lado, apresentam-se enquanto consciência-de-si humana e, por outro, como objetividade imanente. A simultaneidade efetiva destes dois lados, portanto, constituiria uma das reflexões centrais deste texto: a Geografia é um sentido humano de uma humanidade desumana. Destarte, a constituição de uma racionalização em torno da relação entre natureza, sociedade e mortalidade é o processo mesmo de constituição de uma corporeidade doente, fraca, impotente: “[...] jamais duvidei que o estado de nossos órgãos e de nossos sentidos tem muita influência sobre nossa metafísica e sobre nossa moral, e que nossas ideias mais puramente intelectuais, se posso assim exprimir-me, dependem muito de perto da conformação de nosso corpo" (DIDEROT, 1979, p.36)

Neste sentido, seria possível evidenciar que não é um determinado padrão de mortalidade ou de morbidade que caracterizaria uma data sociedade enquanto doente ou afetada 
por uma epidemia, mas a constituição efetiva de uma dada sociedade é a constituição necessária dos sentidos humanos indissociáveis desta sociedade, sentidos objetivos, materialmente constituídos, que comporiam a força e a miséria da humanidade.

Tendo em vista as referidas considerações, o elaborar de uma compreensão cuja finalidade seja mais um evidenciar que um nutrir o argumento determinista e/ou fatalista da qual a ciência lança mão apresenta-se enquanto uma urgência. Neste sentido, a relação entre impermeabilização do solo e a distribuição dos óbitos associados às doenças do aparelho circulatório apresenta-se enquanto uma relação de produção efetiva, na qual os objetos constituintes de uma aparente exterioridade em relação à consciência-de-si em-si e para-si (HEGEL, 2014) são o engendrar material dos sentidos humanos objetivos desta referida consciência-de-si (MARX, 2004). Pensar e Ser, portanto, não constituem substâncias distintas, ainda que apresentem distinções entre si.

A cidade, portanto, é um sentido humano alienado - mas ainda assim um sentido humano. Destarte, a impermeabilização do solo constituiria, portanto, um órgão humano indistinto dos demais órgãos fisiológicos. Esta "fisiologia" geográfica, por sua vez, constituise também enquanto uma moral, cujo princípio será explorado nos capítulos 4 e 5 do presente estudo. Esta moral aparece aos nossos olhos enquanto uma necessária contradição entre a certeza de uma incerteza (material) e a incerteza de uma certeza (racional).

Por fim, a produção das reflexões que aqui se apresentam procurou constituir, no movimento mesmo do presente lavrado, o referido "movimento mesmo", ou seja, a tese final que ofereceremos à apreciação será a evidenciação de uma necessária crítica à efetividade enquanto efetividade crítica no âmbito da qual, em linhas de considerações finais, constituirse-á um "como geografar com o martelo".

"Apenas o mais nobre é perfeitamente duro.

Esta nova tábua, ó irmãos, ponho sobre vós: tornai-vos duros!" (NIETZSCHE, 2017, p.91). 


\section{Escopo Metodológico}

Nesta seção, objetiva-se apresentar as metodologias empregadas para a elaboração de todos os indicadores utilizados no corpus deste trabalho. Neste sentido, nas subseções seguintes será exposto o escopo metodológico para o cálculo de estimativa da impermeabilização do solo e do indicador elaborado para este dado, da temperatura aparente de superfície, dos indicadores sociais e demográficos utilizados, bem como do indicador relacionado à taxa de mortalidade para os óbitos associados às doenças do aparelho circulatório do município de São Paulo (MSP).

$\mathrm{Na}$ tabela 2.1, disponibilizada abaixo, estão dispostos todos os materiais (alfanuméricos, vetoriais e matriciais) empregados na fase de desenvolvimento estatísticoanalítico da obra que segue, bem como um breve descritivo de cada um desses materiais e suas respectivas fontes referenciais.

Tabela 2.1 - Materiais empregados na fase estatístico-analítica do trabalho

\begin{tabular}{|c|c|c|}
\hline Material & Descritivo & Referências \\
\hline $\begin{array}{l}\mathbf{1} \text { - Fotografias } \\
\text { Aéreas } \\
\text { Ortorretificadas }\end{array}$ & $\begin{array}{l}\text { Ortofotos do ano de } 2010 \\
\text { do município de São } \\
\text { Paulo na escala } 1: 10.000 .\end{array}$ & $\begin{array}{l}\text { EMPRESA PAULISTA DE } \\
\text { PLANEJAMENTO METROPOLITANO S.A. } \\
\text { (EMPLASA). Recobrimento } \\
\text { Aerofotogramétrico do Estado de São Paulo. } \\
\text { São Paulo, 2010. Disponível no Laboratório de } \\
\text { Aerofotogeografia e Sensoriamento Remoto } \\
\text { (LASERE) do Departamento de Geografia da } \\
\text { Faculdade de Filosofia, Letras e Ciências } \\
\text { Humanas da Universidade de São Paulo. }\end{array}$ \\
\hline $\begin{array}{l}2 \text { - Cena do } \\
\text { Landsat-7 }\end{array}$ & $\begin{array}{lrr}\text { Imagens do } & \text { sensor } \\
\text { Enhanced } & \text { Thematic } \\
\text { Mapper Plus } & (\mathrm{ETM}+) \text { a } \\
\text { bordo do } & \text { satélite } \\
\text { Landsat-7 de } & \text { 13/06/2010 } \\
\text { (órbita/ponto: } & 219 / 076) \text {. } \\
\end{array}$ & $\begin{array}{l}\text { UNITED STATES GEOLOGICAL SURVEY } \\
\text { (USGS). Earth Explorer. Disponível em: } \\
\text { <https://earthexplorer.usgs.gov/>. Acesso em } \\
24 \text { jan. } 2017 \text {. }\end{array}$ \\
\hline $\begin{array}{l}3 \text { - Cena do } \\
\text { Landsat-8 }\end{array}$ & \begin{tabular}{|lr} 
Imagens dos & sensores \\
Operational rand & Land \\
Imager(OLI) e & Thermal \\
Infrared Sensor & (TIRS) a \\
bordo dor satélite & dor \\
Landsat- 8 de & $23 / 09 / 2015$ \\
(órbita/ponto: & $219 / 076)$. \\
\end{tabular} & $\begin{array}{l}\text { UNITED STATES GEOLOGICAL SURVEY } \\
\text { (USGS). Earth Explorer. Disponível em: } \\
\text { <https://earthexplorer.usgs.gov/>. Acesso em } \\
24 \text { jan. } 2017 \text {. }\end{array}$ \\
\hline $\begin{array}{l}4 \text { - Dados de } \\
\text { Mortalidade }\end{array}$ & \begin{tabular}{|lr}
\multicolumn{2}{l}{ Dados sobre o número de } \\
óbitos associados às \\
doenças do aparelho \\
circulatório & agregados \\
por & distrito \\
administrativo & do \\
\end{tabular} & $\begin{array}{l}\text { PREFEITURA DO MUNICÍPIO DE SÃO } \\
\text { PAULO (PMSP). TabNet: Mortalidade Geral. } \\
\text { São Paulo, 2018. Disponível em } \\
\text { <http://www.prefeitura.sp.gov.br/cidade/secret } \\
\text { arias/saude/tabnet/mortalidade/index.php?p=6 } \\
\text { 529>. Acesso em 24 jan. 2018. } \\
\end{array}$ \\
\hline
\end{tabular}




\begin{tabular}{|c|c|c|}
\hline & $\begin{array}{l}\text { município de São Paulo } \\
\text { para o ano de 2015, } \\
\text { discriminados por faixas } \\
\text { etárias de } 5 \text { anos. }\end{array}$ & \\
\hline $\begin{array}{l}5 \text { - Dados do } \\
\text { Censo de } 2010\end{array}$ & $\begin{array}{l}\text { Conjunto de dados } \\
\text { demográficos do ano de } \\
2010 \text { agregados por setor } \\
\text { censitário para o } \\
\text { município de São Paulo. }\end{array}$ & $\begin{array}{l}\text { INSTITUTO BRASILEIRO DE GEOGRAFIA } \\
\text { E ESTATÍSTICA (IBGE). Características da } \\
\text { População e dos Domicílios: Resultados do } \\
\text { Universo. Rio de Janeiro, 2010. Disponível em: } \\
\text { <https://censo2010.ibge.gov.br/resultados.html } \\
\text { >. Acesso em } 24 \text { jan. 2018. }\end{array}$ \\
\hline $\begin{array}{l}\text { 6 - Bases } \\
\text { Cartográficas }\end{array}$ & $\begin{array}{l}\text { Arquivos vetoriais dos } \\
\text { setores censitários, dos } \\
\text { distritos administrativos } \\
\text { e dos limites do } \\
\text { município de São Paulo. }\end{array}$ & 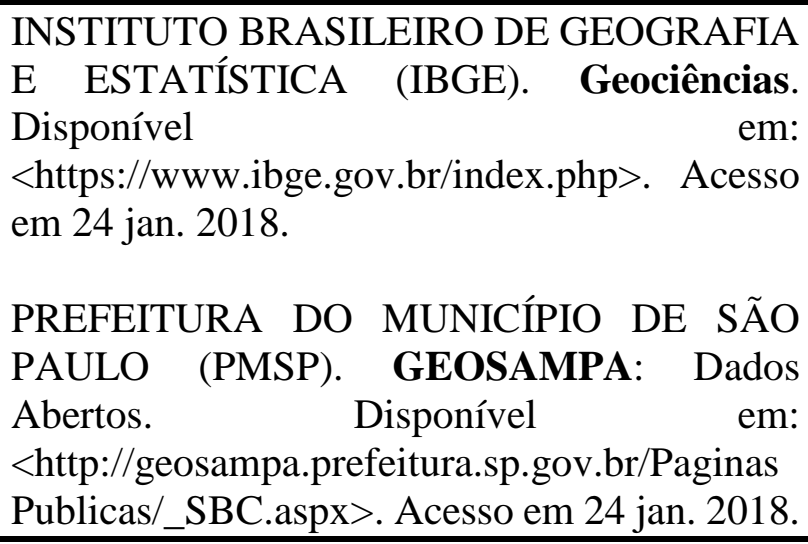 \\
\hline $\begin{array}{l}7 \text { - Software } \\
\text { ArcGIS } 9.0\end{array}$ & $\begin{array}{l}\text { Software utilizado para } \\
\text { processamento e análise } \\
\text { dos dados alfanuméricos, } \\
\text { vetoriais e matriciais } \\
\text { espacializados, bem } \\
\text { como para elaboração do } \\
\text { conjunto de mapas que } \\
\text { serão apresentados no } \\
\text { escopo desta obra. }\end{array}$ & $\begin{array}{l}\text { Disponível no Laboratório de } \\
\text { Aerofotogeografia e Sensoriamento Remoto } \\
\text { (LASERE) do Departamento de Geografia da } \\
\text { Faculdade de Filosofia, Letras e Ciências } \\
\text { Humanas da Universidade de São Paulo. }\end{array}$ \\
\hline $\begin{array}{l}8 \text { - Software } \\
\text { Excel (Pacote } \\
\text { Office 2010) }\end{array}$ & $\begin{array}{l}\text { Software utilizado para } \\
\text { processamento e análise } \\
\text { dos dados alfanuméricos, } \\
\text { bem como para } \\
\text { elaboração do conjunto } \\
\text { de mapas que serão } \\
\text { apresentados no escopo } \\
\text { desta obra. }\end{array}$ & $\begin{array}{l}\text { Disponível no Laboratório de } \\
\text { Aerofotogeografia e Sensoriamento Remoto } \\
\text { (LASERE) do Departamento de Geografia da } \\
\text { Faculdade de Filosofia, Letras e Ciências } \\
\text { Humanas da Universidade de São Paulo. }\end{array}$ \\
\hline $\begin{array}{l}\text { 9- Software } \\
\text { QGIS 2.18.4 }\end{array}$ & $\begin{array}{l}\text { Software utilizado para } \\
\text { processamento e análise } \\
\text { dos dados alfanuméricos, } \\
\text { vetoriais e matriciais } \\
\text { espacializados, bem } \\
\text { como para elaboração do } \\
\text { conjunto de mapas que } \\
\text { serão apresentados no } \\
\text { escopo desta obra. }\end{array}$ & $\begin{array}{l}\text { Disponível para download gratuito no sítio: } \\
\text { <https://qgis.org/en/site/forusers/download.ht } \\
\text { ml>. Acesso em } 02 \text { fev. } 2018 \text {. }\end{array}$ \\
\hline
\end{tabular}

Fonte: Elaboração própria. Data: 02/02/2018. 
Ademais, para melhor definição dos materiais utilizados, no Anexo A desta obra, encontram-se disponíveis tabelas descritivas dos metadados das bandas dos satélites Landsat-7 e Landsat-8 que foram utilizadas no escopo deste trabalho.

Nos subcapítulos e subseções a seguir serão apresentadas as metodologias empregadas para tratamento e análise dos dados arrolados na tabela 2.1.

\subsection{Estimativa da Impermeabilização do Solo}

A estimativa da impermeabilização do solo do município de São Paulo (MSP) consistiu em um cálculo que tomou por referência os valores de brilho dos pixels das imagens geradas pelo sensor OLI do satélite Landsat-8 de 2015 (USGS, 2018). Esses valores foram comparados com valores percentuais de impermeabilização do solo calculados a partir das formas de uso e ocupação da terra que foram vetorizadas tomando-se como referência as ortofotos de 2010 da EMPLASA (EMPLASA, 2010) para 40 janelas amostrais distribuídas aleatoriamente pelo MSP. Tais janelas possuíam dimensões de 10 por 10 pixels das imagens $\mathrm{OLI}^{1}$.

2.1.1. Cálculo da Impermeabilização de Referência a partir das Janelas Amostrais

Inicialmente, para o cálculo estimativo de impermeabilização do solo do município de São Paulo, utilizou-se as imagens OLI, do satélite Landsat-8, e ETM+, do satélite Landsat-7, as quais foram convertidas para valores de refletância espectral no topo da atmosfera, a partir da aplicação da equação 1 , abaixo, tendo em vista a necessidade de melhor caracterizar-se o comportamento espectral dos objetos que compõem a superfície terrestre. Ademais, operou-se também uma correção atmosférica a partir do método Dark Object Subtraction (DOS) para as referidas imagens com auxílio do Semi-Automatic Classification Plugin, disponível para o software QGIS 2.18.4.

$\mathbf{L} \boldsymbol{\lambda}=\mathrm{MlQcal}+\mathrm{Al}$

Onde:

- L $\quad \mathbf{\lambda}$ : refletância espectral no topo da atmosfera.

- Ml: fator multiplicativo de reescalonamento para cada banda (Anexo A).

\footnotetext{
${ }^{1}$ Cada pixel das bandas OLI têm dimensões de 30 metros por 30 metros.
} 
- Qcal: número digital correspondente a cada pixel da imagem.

- Al: fator aditivo de reescalonamento para cada banda (Anexo A).

Devido ao intervalo temporal existente entre as fotografias aéreas, de 2010 (EMPLASA, 2010), e as imagens dos sensores do satélite Landsat-8, de 2015 (USGS, 2018), realizou-se um procedimento metodológico para definição das áreas do Município de São Paulo (MSP) cujas formas de uso e ocupação da terra não se alteraram neste período (YI ZHOU et al, 2014). O referido procedimento consistiu no cálculo das imagens NDVI (Normalized Difference Vegetation Index) (ROUSE et al., 1973) e NDBI (Normalized Difference Built-up Index) para o Landsat-8 a partir das quais foi possível gerar uma imagem com as áreas construídas (BU) da RMSP. Na sequência, repetiu-se o mesmo procedimento para imagens geradas pelo sensor ETM do satélite Landsat-7. Reitera-se que, no Anexo A desta obra, encontram-se disponíveis tabelas descritivas dos metadados das bandas dos satélites Landsat-7 e Landsat-8 que foram utilizadas no escopo deste trabalho. As equações utilizadas para o cálculo dos índices supracitados estão disponíveis a seguir, numeradas de 2 a 4 .

$$
\begin{aligned}
& \text { NDVI }=\frac{\text { Infravermelho Próximo-Vermelho }}{\text { Infravermelho Próximo+Vermelho }} \\
& \text { NDBI }=\frac{\text { Infravermelho Médio-Infravermelho Próximo }}{\text { Infravermelho Médio+infravermelho Próximo }} \\
& \text { BU }=\text { NDBI-NDVI }
\end{aligned}
$$

As imagens finais (BU) obtidas foram então subtraídas (BU Landsat-8 - BU Landsat$7^{2}$ ), indicando as áreas cujas formas de uso e ocupação da terra não se alteraram entre os anos de 2010 e 2015 a partir da distribuição dos pixels em relação à média do índice BU8-BU7 calculado, de forma que os pixels que distavam menos de um desvio padrão da média foram considerados representativos de áreas cujas formas de uso e ocupação do solo não se alteraram no período considerado, conforme a figura 2.1, a seguir. Considerando-se que a média dos valores dos pixels é igual a -0,0691 e o desvio padrão é equivalente a 0,1584, o intervalo entre $-0,2275$ e 0,0893 representa as áreas inalteradas entre 2010 e 2015 do MSP (YI ZHOU et al, 2014). Posteriormente, operou-se uma análise visual cujo intuito fora verificar se realmente não houve nenhuma alteração nas formas de uso e ocupação nas áreas selecionadas. Os pontos insatisfatórios foram excluídos e novos pontos foram gerados para substituí-los.

\footnotetext{
${ }^{2}$ No mapa 2, disposto abaixo, esta imagem será, portanto, determinada "Índice BU8-BU7".
} 
Figura 2.1 - Classes geradas a partir dos valores dos pixels da imagem das áreas inalteradas

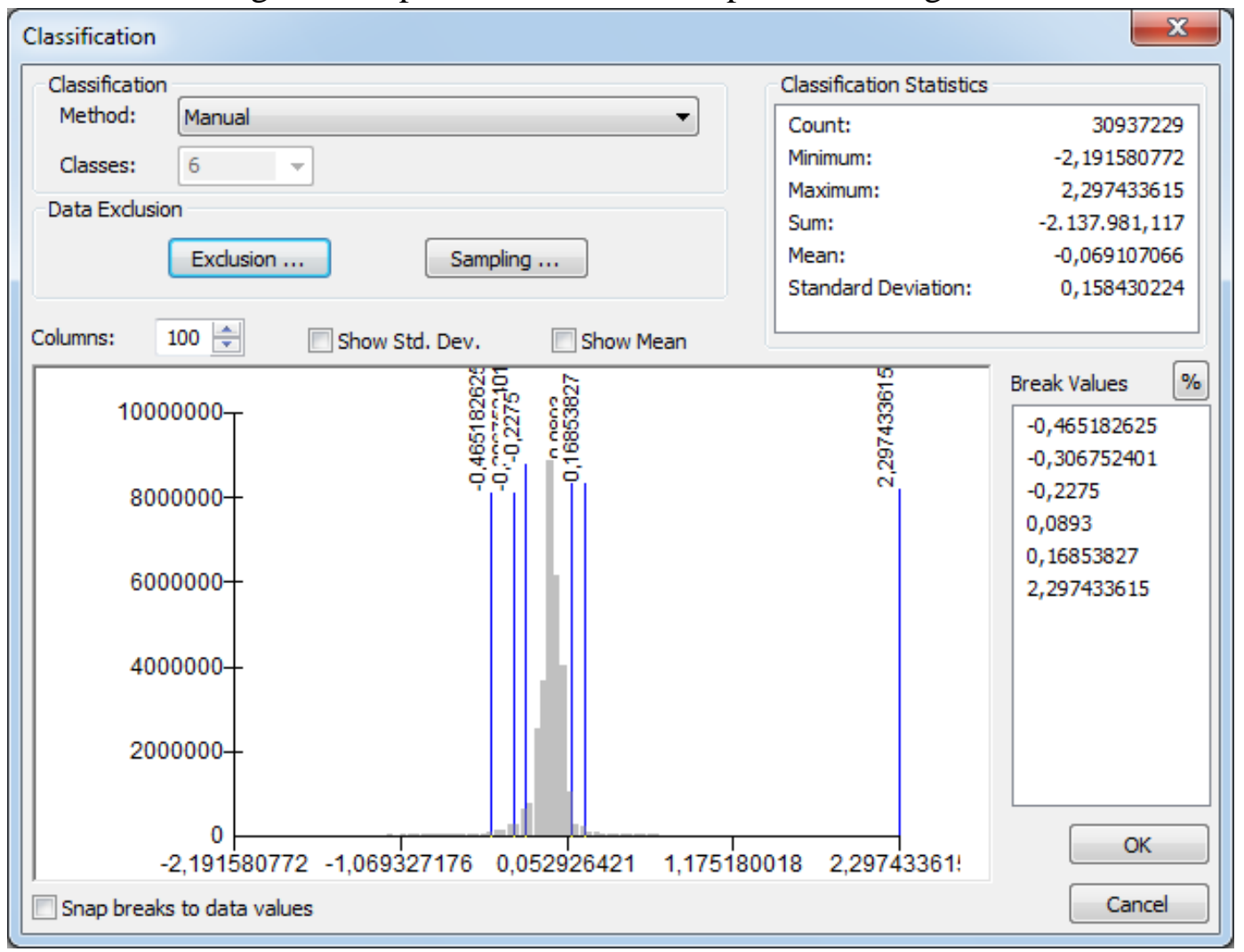

Fonte: ArcGIS 9.0. Elaboração própria. Data: 02/02/2018.

A partir da imagem gerada pelo índice BU8-BU7 foi possível definir aleatoriamente as janelas amostrais para o cálculo da impermeabilização de referência, conforme pode-se observar no mapa 2, disposto a seguir. No referido mapa, as áreas em cinza escuro são as que não sofreram alterações nas formas de uso e ocupação da terra entre 2010 e 2015.

A etapa seguinte consistiu na definição de 40 janelas amostrais distribuídas aleatoriamente pelas áreas inalteradas do MSP determinadas previamente. As aludidas janelas amostrais foram formadas com dimensões de 10 por 10 pixels do sensor OLI (USGS, 2018) e georreferenciadas de acordo com os pixels constituintes das ortofotos (EMPLASA, 2010) e das imagens do referido sensor.

Utilizando-se as informações detalhadas das ortofotos digitais (EMPLASA, 2010), operou-se a vetorização e classificação visual, em tela, das formas de uso e ocupação da terra das referidas janelas (JENSEN, 2009; CERON; DINIZ, 1966; PAINE; KISER, 2003), considerando-se as 12 classes apresentadas na tabela 2.2, abaixo. Ao final da vetorização, tais janelas foram subdivididas em uma malha regular cujos polígonos constituintes possuíam dimensões correspondentes aos pixels das imagens do sensor OLI (polígonos regulares com 30m de lado, ou $900 \mathrm{~m}^{2}$ de área). Assim sendo, foram digitalizadas 4000 amostras de controle, de forma que, para cada polígono constituinte da malha regular, foi possível determinar os 
percentuais de impermeabilização do solo partindo-se das classes de uso e ocupação da terra que caracterizavam esses polígonos.

Tabela 2.2 - Classes de Uso e Ocupação da Terra

\begin{tabular}{l}
$\frac{\text { Classes de Uso e Ocupação da Terra }}{1 \text { - Área Agrícola-Pastoril (Plantações e Pastagens) }}$ \\
\hline 2 - Área Rural (Residencial, Industrial, Serviços) \\
\hline 3 - Área Urbana (Residencial, Industrial, Serviços) \\
\hline 4 - Espelho d'Água \\
\hline 5 - Solo Exposto \\
\hline 6 - Solo Exposto com Vegetação Herbácea- \\
Arbustiva \\
\hline 7 - Vegetação Arbórea/Florestal \\
\hline 8 - Vegetação Herbácea \\
\hline 9 - Vegetação Herbácea-Arbustiva \\
\hline 10 - Via Asfaltada \\
\hline 11 - Via de Terra \\
\hline 12 - Via Férrea \\
Fonte: Elaboração própria. Data: $02 / 02 / 2018$.
\end{tabular}

No mapa 2, é possível visualizar uma das janelas amostrais que foram vetorizadas e seccionadas nas dimensões dos pixels OLI para os fins deste estudo. A janela disposta no referido mapa pode ser visualizada também no mapa 3, disposto abaixo. No terceiro mapa é possível observar uma equiparação entre as formas de uso e ocupação da terra com os percentuais de impermeabilização calculados para a malha regular sobreposta. Ademais, importa notar que, no mapa 2 , há quatro janelas amostrais que foram definidas fora da área determinada pela imagem gerada a partir das equações 2, 3 e 4 acima dispostas, ou seja, estão foras da área de abrangência do índice BU8-BU7³. Como a cena do satélite Landsat-7 não abrange o extremo sul do MSP, adotou-se um procedimento para que se pudesse incluir tal região no pool de amostragem. $\mathrm{O}$ referido procedimento consistiu em considerar o mapeamento das áreas de remanescentes de mata atlântica do município de São Paulo para o ano de 2015 (PMSP, 2016). Destarte, foi possível classificar as formas de uso e ocupação da terra nestas janelas a partir das informações disponíveis no mapeamento realizado no âmbito do Plano Municipal de Mata Atlântica, do qual o autor desta monografia foi partícipe.

Nas páginas seguintes, portanto, é possível observar os mapas 2 e 3, os quais possibilitarão ao leitor a compreensão mais pormenorizada das etapas descritas nos parágrafos

\footnotetext{
${ }^{3}$ BU Landsat-8 - BU Landsat-7: Built-up Area do Landsat 8 menos Built-up Area do Landsat 7.
} 
acima. Na subseção 2.1.2 será apresentada a continuidade da sequência metodológica para a estimativa da impermeabilização do solo. 


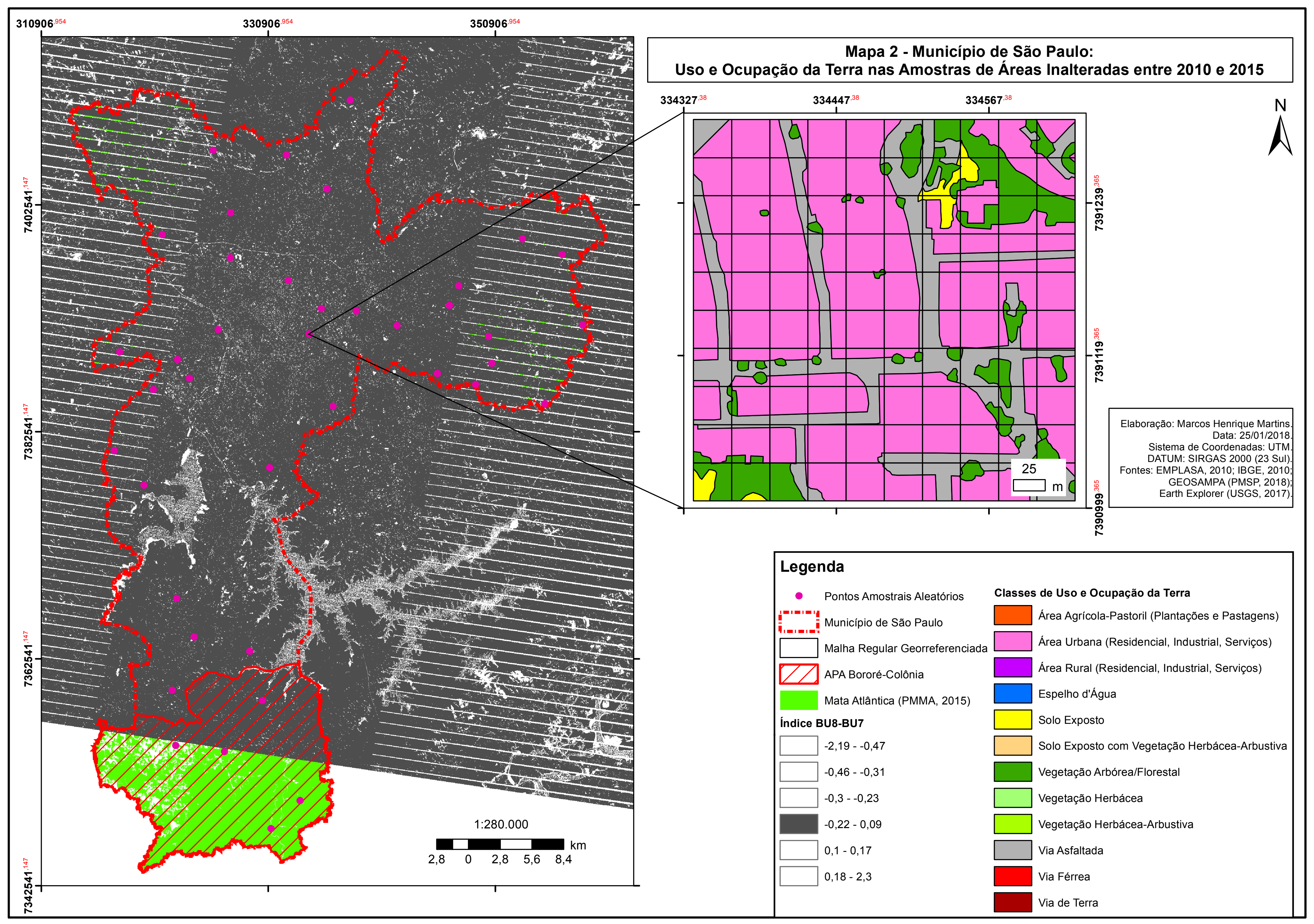




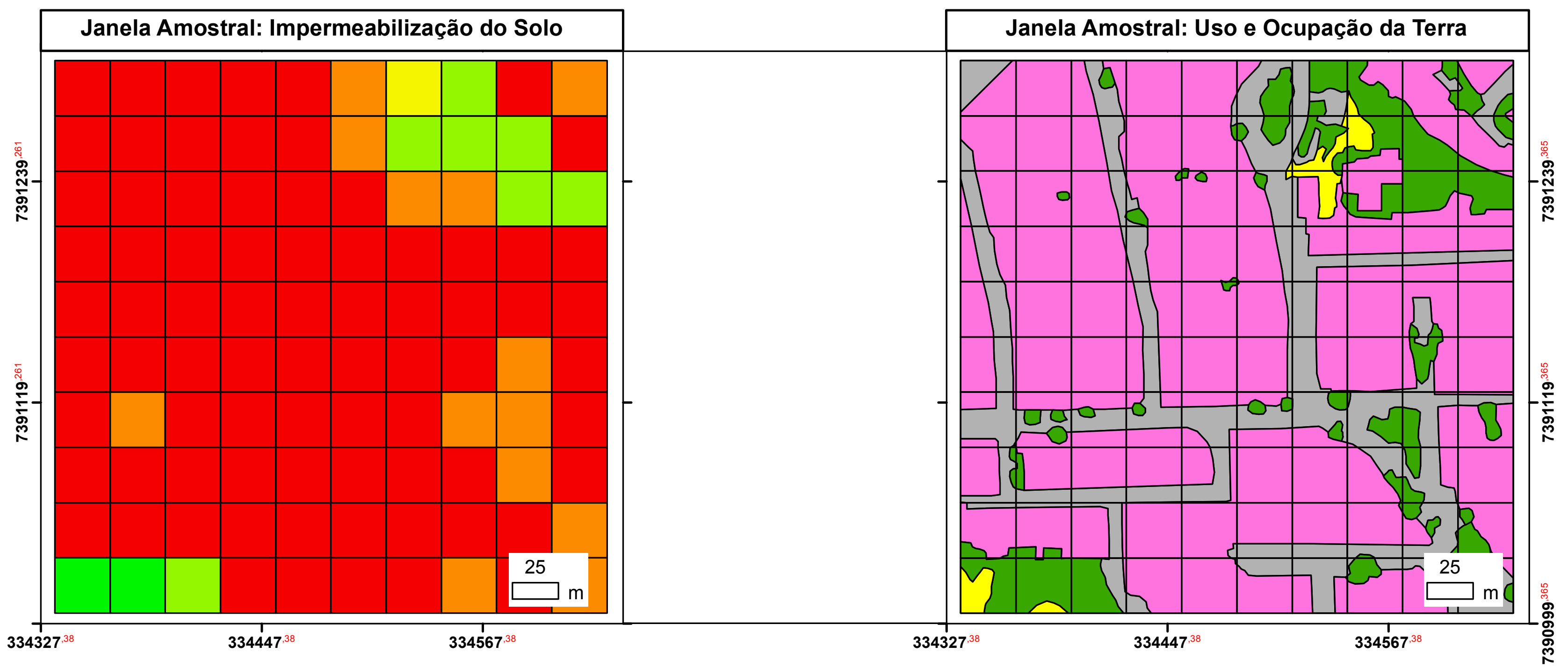

\begin{tabular}{|c|c|c|}
\hline \multicolumn{3}{|l|}{ Legenda } \\
\hline Grade Regular Georreferenciada & Classes de Uso e Ocupação da Terra & Vegetação Arbórea/Florestal \\
\hline Impermeabilização (\%) & Área Agrícola-Pastoril (Plantações e Pastagens) & Vegetação Herbácea \\
\hline $80,01-100,00$ & Área Urbana (Residencial, Industrial, Serviços) & Vegetação Herbácea-Arbustiva \\
\hline $60,01-80,00$ & Área Rural (Residencial, Industrial, Serviços) & Via Asfaltada \\
\hline $40,01-60,00$ & Espelho d'Água & Via Férrea \\
\hline $20,01-40,00$ & Solo Exposto & Via de Terra \\
\hline $0,00-20,00$ & Solo Exposto com Vegetação Herbácea-Arbustiva & \\
\hline
\end{tabular}

Elaboração: Marcos Henrique Martins Data: $26 / 01 / 2018$

Sistema de Coordenadas: UTM

DATUM: SIRGAS 2000 (23 Sul)

Fontes: EMPLASA, 2010; IBGE, 2010

GEOSAMPA (PMSP, 2018); Earth Explorer (USGS, 2017). 


\subsubsection{Modelagem Estimativa da Impermeabilização do Solo}

Tendo em vista a necessidade de se proceder à estimativa da impermeabilização do solo no ano de 2015 para a totalidade do território do MSP, os valores de impermeabilização calculados na subseção 2.1.1 necessitaram ser correlacionados de forma consistente com as imagens do Landsat-8. Neste sentido, a proposta inicial, tomando-se como base a literatura disponível (YUAN; BAUER, 2007; WENG, 2007; SAKUNO et al, 2017) e estudos precedentes realizados por nós (KAWAKUBO et al., 2017; MARTINS et al., 2017), consistia em relacionar por meio de um modelo matemático os valores de impermeabilização gerados a partir das formas de uso e ocupação da terra com os valores de brilho do Normalized Difference Vegetation Index (NDVI) gerados a partir das imagens do Landsat-8.

Neste sentido, operou-se, portanto, uma avaliação cruzada dos dados, ou seja, adotouse as 4000 amostras constituintes da malha regular (subseção 2.1.1), as quais foram consideradas representativas dos percentuais reais de impermeabilização do solo em 2015 e a partir das quais foi possível extrair da imagem NDVI do Landsat-8 (equação 2, subseção 2.1.1) os valores do referido índice para os pixels correspondentes a essas amostras. No mapa 4, disposto abaixo, é possível observar uma das janelas amostrais classificada de acordo com os valores percentuais de impermeabilização do solo estimados a partir das formas de uso e ocupação da terra e a mesma janela com os valores correspondentes do NDVI.

Das 4000 amostras, selecionou-se aleatoriamente 43500 para a elaboração da equação estimativa dos valores de impermeabilização do solo para o MSP. As 500 amostras restantes foram separadas para a avaliação dos resíduos ${ }^{5}$ da modelagem. Os resultados obtidos podem ser observados nos gráficos 2.1 e 2.2 .

\footnotetext{
${ }^{4}$ Esta seleção aleatória não pode ser considerada aleatória de fato, haja vista ter sido computada com auxílio de um computador e não de um gerador de número aleatório. Assim sendo, como o computador utiliza um algoritmo para determinar um suposto número aleatório, este número não pode, por esse motivo, ser considerado aleatório. Entretanto, para os fins deste estudo, considerar-se-á a seleção feita pelo computador como aleatória.

${ }^{5}$ Os resíduos são calculados a partir da subtração dos valores estimados em relação aos reais, ou seja: valores estimados - valores reais.
} 


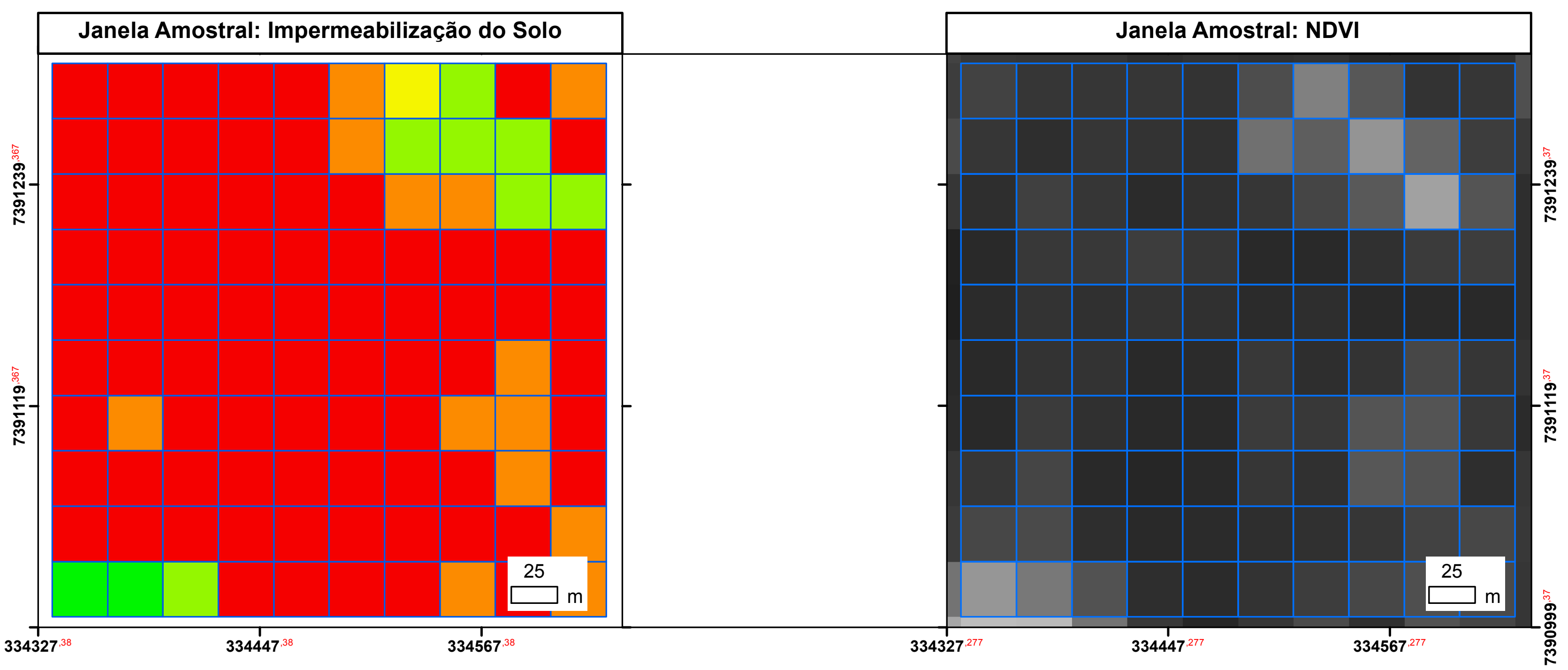

\section{Legenda}

Grade Regular

Georreferenciada

NDVI

Impermeabilização (\%)

$\square 80,01-100,00$

$60,01-80,00$

$40,01-60,00$

$20,01-40,00$

Sistema de Coordenadas: UTM DATUM: SIRGAS 2000 (23 Sul) 
Gráfico 2.1 - Regressão linear estimativa da impermeabilização do solo a partir do NDVI

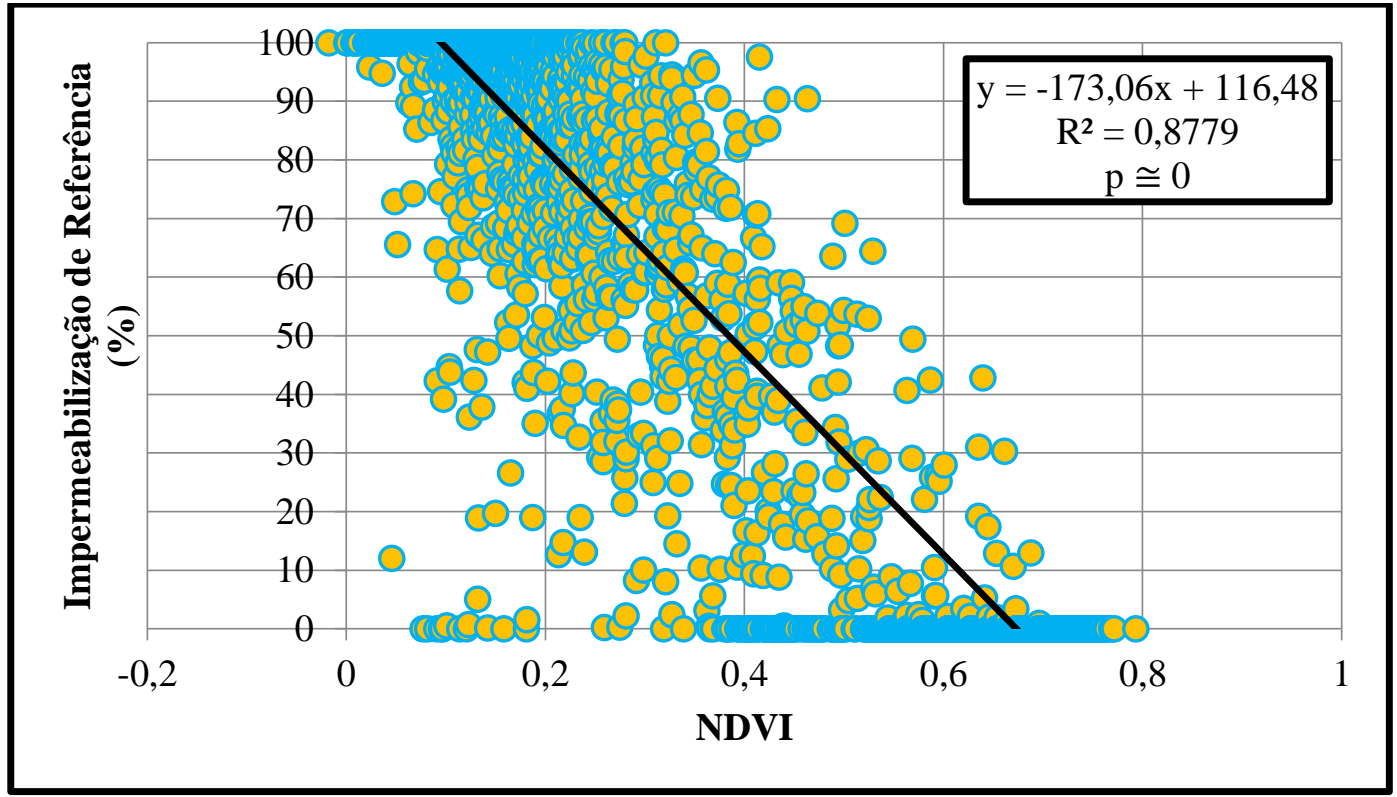

Fonte: Elaboração própria. Data: 02/02/2018.

Gráfico 2.2 - Análise da modelagem NDVI a partir das 500 amostras de controle

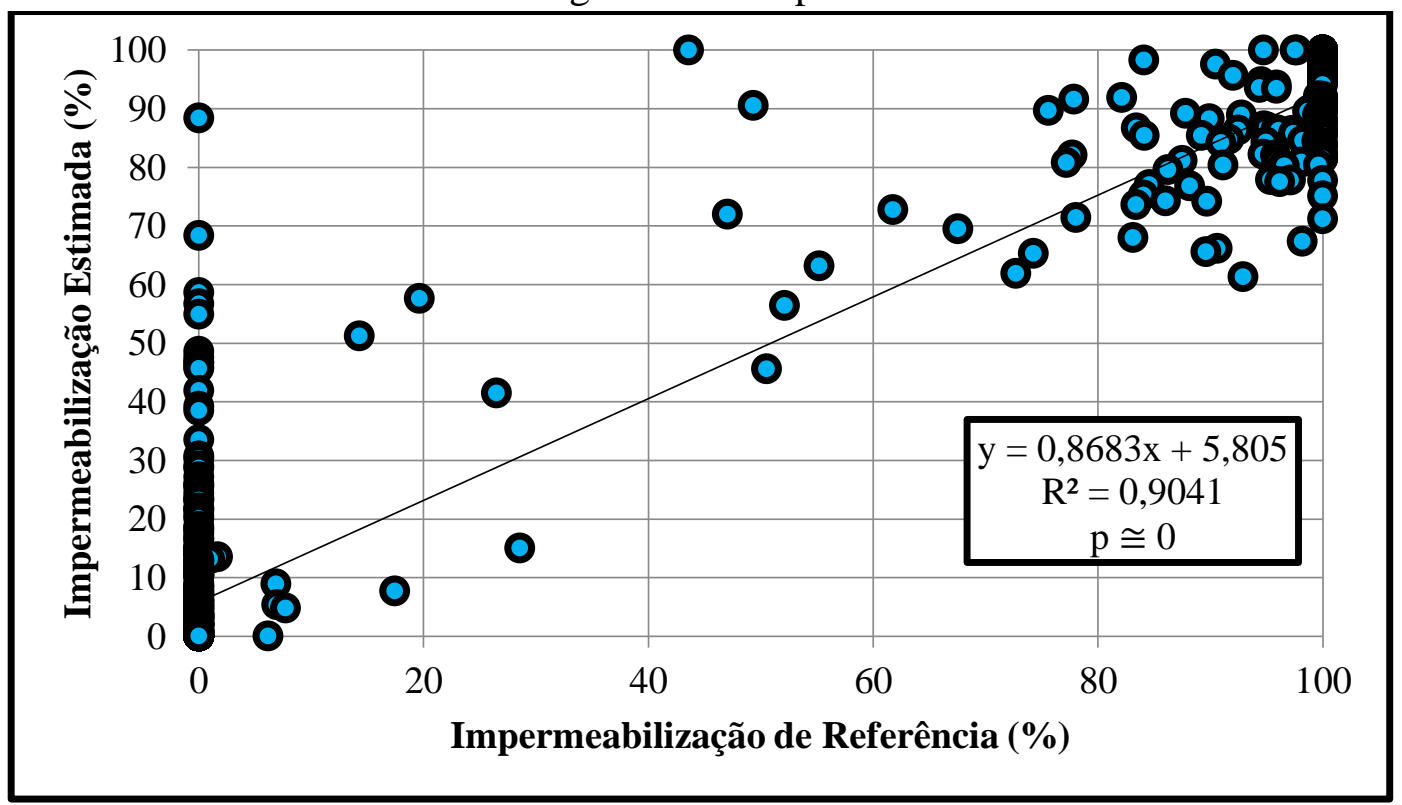

Fonte: Elaboração própria. Data: 02/02/2018.

A análise desses gráficos demonstra que o modelo gerado a partir da imagem NDVI obteve resultados que, em um primeiro momento, poderiam ser considerados satisfatórios. O gráfico 2.1 apresenta forte correlação entre o índice de vegetação e a impermeabilização de referência, com aproximadamente $88 \%$ dos valores representados no eixo das coordenadas 
sendo satisfatoriamente determinados pela equação da reta. A significância estatística (valor-p) tende à zero, indicando que a hipótese nula ${ }^{6}$ pode ser descartada

$\mathrm{Na}$ sequência, o gráfico 2.2 também faz crer que os resultados da modelagem são satisfatórios, pois os valores estimados para as 500 amostras de controle apresentam correlação significativa com os valores de referência. $O$ índice de determinação $R^{2}$ foi elevado, ultrapassando $90 \%$ dos casos, e o valor-p, o qual tende à zero, indica que a hipótese nula pode ser rejeitada.

Ademais, a distribuição dos resíduos revela que o modelo apresenta um bom nível de acurácia, conforme podemos observar no gráfico 2.3.

\section{Gráfico 2.3 - Histograma dos resíduos do modelo com uso do NDVI}

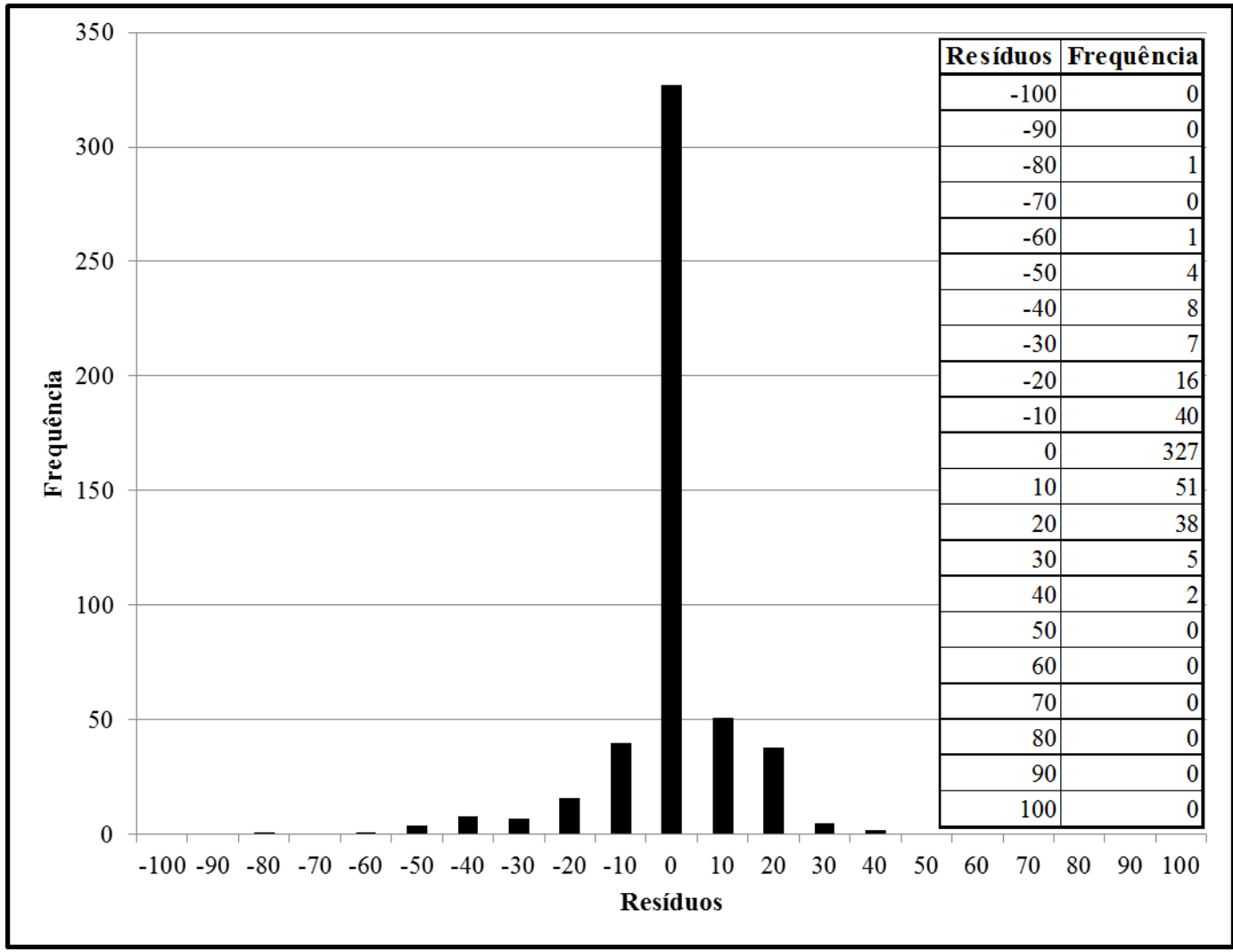

Fonte: Elaboração própria. Data: 02/02/2018.

No gráfico 2.4, abaixo, é possível avaliar descritivamente o comportamento dos resíduos. Observa-se, no quarto gráfico, que a média dos referidos resíduos é, aproximadamente, -2,6, ou seja, próxima de zero, e seu desvio padrão equivale a, aproximadamente, 12,81 . Neste sentido, os gráficos 2.3 e 2.4 apontam que a distribuição dos resíduos indica uma pequena subestimativa das áreas impermeáveis. Esses dados indicam,

\footnotetext{
${ }^{6}$ Denominamos por "hipótese nula" a hipótese contrária à correlação aventada, ou seja, quando consideramos que "a hipótese nula pode ser descartada" indicamos que a correlação indicada pode ser considerada válida.
} 
portanto, que o modelo poderia ser aceito como satisfatório para os objetivos deste estudo. Porém, uma análise mais detalhada da imagem gerada a partir da equação presente no gráfico 2.1 demonstrou que seria preciso adotar medidas para se aperfeiçoar o modelo, haja vista o comportamento apresentado pelos os objetos de superfície na imagem NDVI.

Gráfico 2.4 - Bloxpot dos resíduos da modelagem com uso de NDVI

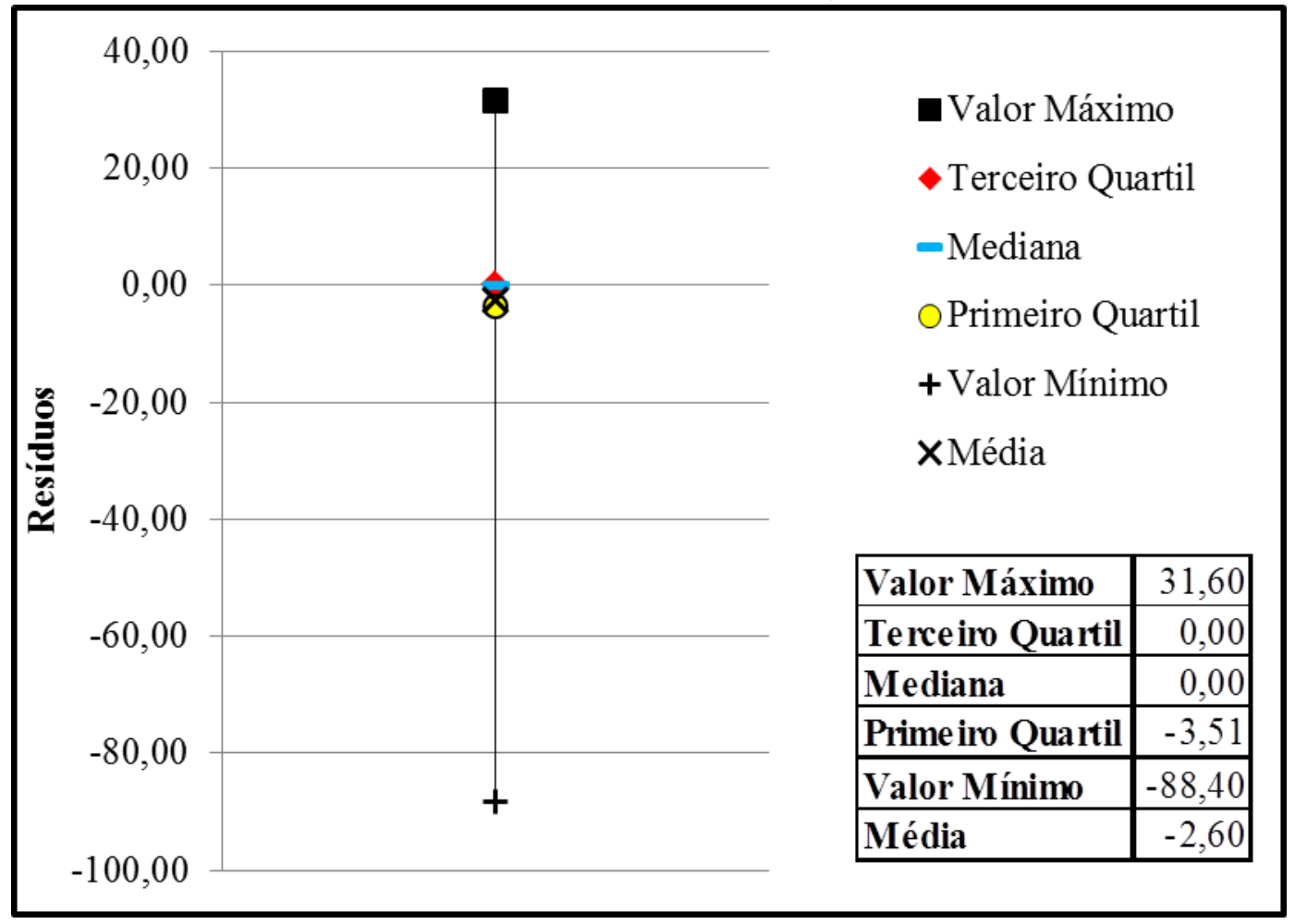

Fonte: Elaboração própria. Data: 02/02/2018.

No mapa 5, disposto abaixo, pode-se notar que o comportamento espectral dos corpos d'água no índice NDVI é similar ao comportamento dos materiais construtivos impermeáveis que recobrem o MSP. Observando-se comparativamente as ortofotos, a imagem NDVI e o modelo de impermeabilização do solo relativos à represa Guarapiranga e entorno, localizada na zona sul do MSP, pode-se notar que o valor de impermeabilização da área urbana do entorno da represa é inferior ao valor de impermeabilização da água que preenche o reservatório. Conclui-se, portanto, que quando se aplica a equação presente no gráfico 2.1, os referidos corpos d'água apresentam percentuais de impermeabilização elevados, fato que é desprovido de sentido lógico. 

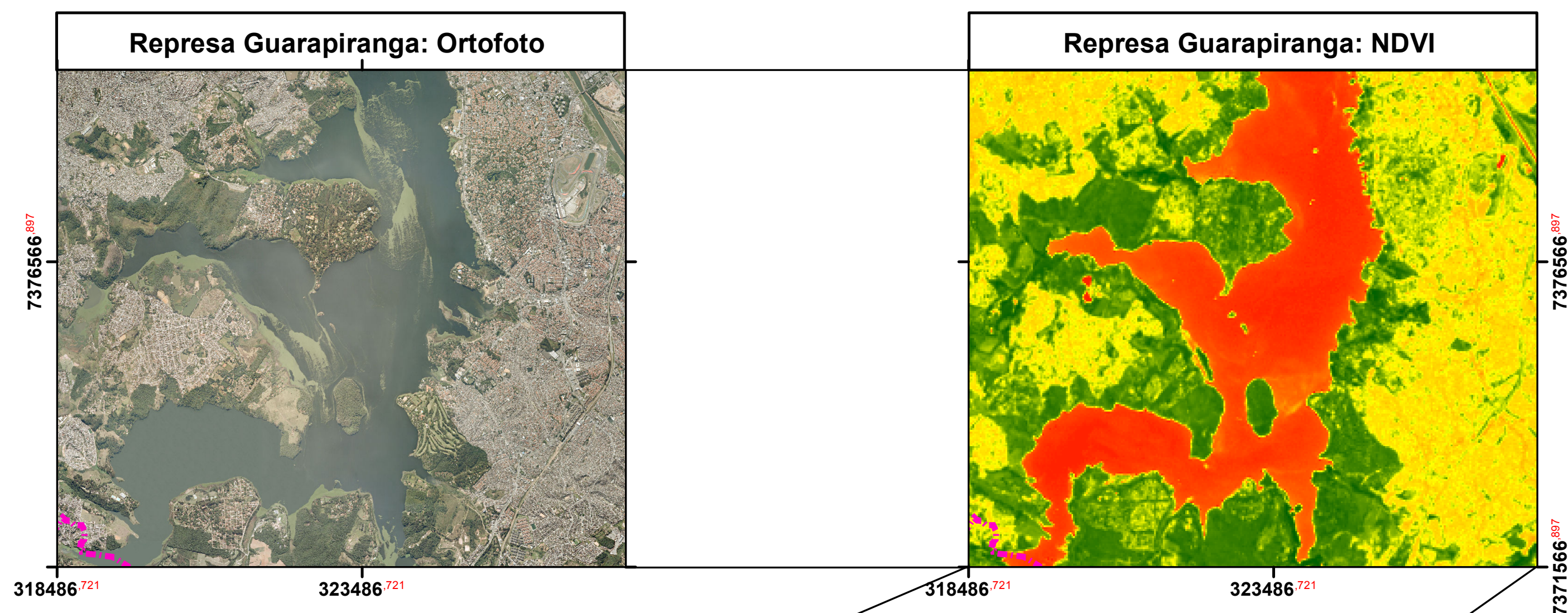

惫

Legenda

Município de São Paulo NDVI
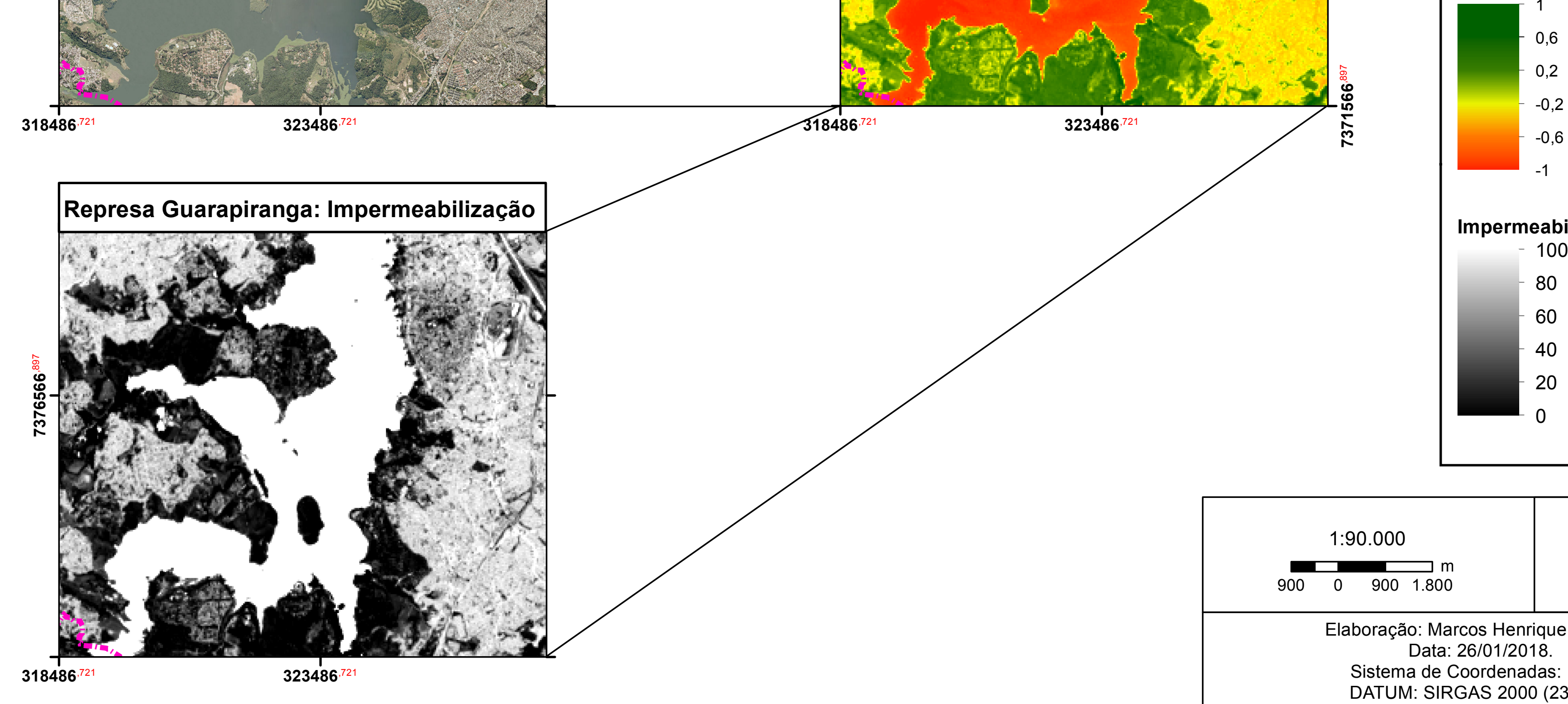

Impermeabilização (\%)

-100
-80

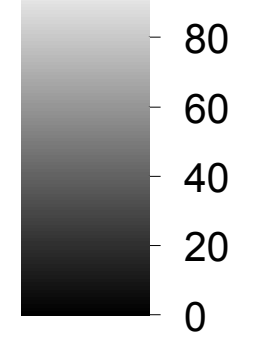

\begin{tabular}{|c|c|}
\hline & $\begin{array}{c}\text { 1:90.000 } \\
900 \quad 0 \quad 9001.800\end{array}$ \\
\hline Elaboração: Marcos Henrique Martins. \\
Data: 26/01/2018. \\
Sistema de Coordenadas: UTM. \\
DATUM: SIRGAS 2000 (23 Sul). \\
Fontes: EMPLASA, 2010; IBGE, 2010; GEOSAMPA (PMSP, 2018); \\
Earth Explorer (USGS, 2017). \\
\hline
\end{tabular}


O erro identificado na modelagem deve-se ao comportamento da equação presente no gráfico 2.1: como o NDVI varia de -1 a 1, sendo os valores mais próximos de 1 representativos das áreas verdes, os valores próximos a 0 representativos das áreas urbanas e os valores próximos a -1 representativos dos corpos d'água, esta equação equivocadamente correlaciona, linear e simplificadamente, os valores de -1 a 1 do NDVI com os valores de $0 \%$ a $100 \%$ da impermeabilização de referência, respectivamente (BORATTO; GOMIDE, 2013; JENSEN, 2009). Ademais, as áreas vetorizadas apresentam poucos exemplares de espelhos d'água, os quais possuem reduzida extensão, produzindo uma interferência na leitura dos pixels compositores desses corpos oriunda do efeito de mistura dos referidos pixels, que geralmente encontravam-se imersos em áreas verdes, haja vista os referidos corpos d'água serem, em geral, pequenos açudes localizados nas áreas rurais.

Neste sentido, ao observar-se a tabela 2.3, disposta abaixo, obtêm-se os valores mínimos, máximos e médios de NDVI calculados para cada classe de uso e ocupação da terra vetorizada. Nota-se, pela leitura da referida tabela, uma aproximação dos valores das áreas verdes e dos espelhos d'água, dificultado o estabelecimento de uma correlação adequada dos valores NDVI com os percentuais de impermeabilização. Além do mais, como os corpos d'água apresentam, em geral, valores negativos na escala NDVI, a descaracterização dos açudes pela presença de vegetação abundante no seu entorno, bem como seu tamanho reduzido relativamente ao tamanho do pixel da imagem NDVI e presença de macrófitas aquáticas, reforçou, na regressão linear, a compreensão de que, quanto mais baixos os valores NDVI, maior o percentual de impermeabilização do solo. 
Tabela 2.3 - Valores de NDVI para as classes de uso e ocupação da terra

\begin{tabular}{l|r|r|r}
\hline \multicolumn{1}{c|}{ Classes de Uso e Ocupação da Terra } & $\begin{array}{c}\text { NDVI } \\
\text { Mínimo }\end{array}$ & $\begin{array}{c}\text { NDVI } \\
\text { Máximo }\end{array}$ & $\begin{array}{c}\text { NDVI } \\
\text { Médio }\end{array}$ \\
\hline Via Férrea & 0,09 & 0,09 & 0,09 \\
\hline Área Urbana (Residencial, Industrial, Serviços) & $-0,02$ & 0,52 & 0,15 \\
\hline Via Asfaltada & 0,00 & 0,57 & 0,17 \\
\hline Solo Exposto & 0,05 & 0,70 & 0,32 \\
\hline Solo Exposto com Vegetação Herbácea-Arbustiva & 0,06 & 0,73 & 0,34 \\
\hline Vegetação Herbácea & 0,10 & 0,73 & 0,45 \\
\hline Vegetação Herbácea-Arbustiva & 0,13 & 0,73 & 0,46 \\
\hline Via de Terra & 0,15 & 0,65 & 0,51 \\
\hline Espelho d'Água & 0,46 & 0,64 & 0,52 \\
\hline Área Agrícola-Pastoril (Plantações e Pastagens) & 0,28 & 0,74 & 0,63 \\
\hline Área Rural (Residencial, Industrial, Serviços) & 0,63 & 0,64 & 0,64 \\
\hline Vegetação Arbórea/Florestal & 0,07 & 0,79 & 0,65 \\
\hline
\end{tabular}
Fonte: Elaboração própria. Data: 02/02/2018.

Assim sendo, foi necessário aplicar experimentalmente um ajuste ao índice de refletância adotado para a estimativa da impermeabilização. Este índice ajustado foi elaborado a partir dos valores dos índices NDVI e NDBI (equações 2 e 3 da subseção 2.1.1) para as imagens do Landsat-8 (USGS, 2018). De modo similar ao NDVI, as imagens NDBI apresentam valores que variam de -1 a 1 , porém, os valores positivos mais próximos a 1 representam os corpos d'água, os valores positivos em torno de zero representam a vegetação e os valores negativos representam a área urbana (ZHA et al., 2003). Na tabela 2.4, abaixo, pode-se observar os valores máximos, mínimos e médios de NDBI calculados para cada classe de uso e ocupação da terra vetorizada. O problema de efeito de mistura, para os açudes, permanece na imagem NDBI, bem como para as áreas rurais impermeáveis, classificadas como “Área Rural (Residencial, Industrial, Serviços)”. Estas áreas rurais apresentam valores positivos, quando deveriam se assemelhar às áreas urbanas.

Tabela 2.4 - Valores de NDBI para as classes de uso e ocupação da terra

\begin{tabular}{l|r|r|r}
\hline \multicolumn{1}{c|}{ Classes de Uso e Ocupação da Terra } & \multicolumn{1}{c|}{$\begin{array}{c}\text { NDBI } \\
\text { Mínimo }\end{array}$} & $\begin{array}{c}\text { NDBI } \\
\text { Máximo }\end{array}$ & \multicolumn{1}{c}{$\begin{array}{c}\text { NDBI } \\
\text { Médio }\end{array}$} \\
\hline Área Urbana (Residencial, Industrial, Serviços) & $-0,27$ & 0,21 & $-0,09$ \\
\hline Via Asfaltada & $-0,20$ & 0,24 & $-0,05$ \\
\hline Via Férrea & $-0,05$ & $-0,05$ & $-0,05$ \\
\hline Solo Exposto & $-0,23$ & 0,36 & 0,03 \\
\hline Solo Exposto com Vegetação Herbácea-Arbustiva & $-0,19$ & 0,35 & 0,05 \\
\hline Vegetação Herbácea & $-0,10$ & 0,36 & 0,08 \\
\hline Vegetação Herbácea-Arbustiva & $-0,11$ & 0,40 & 0,10 \\
\hline
\end{tabular}




\begin{tabular}{l|r|r|r} 
Via de Terra & $-0,06$ & 0,29 & 0,17 \\
\hline Área Agrícola-Pastoril (Plantações e Pastagens) & 0,06 & 0,37 & 0,23 \\
\hline Área Rural (Residencial, Industrial, Serviços) & 0,24 & 0,27 & 0,25 \\
\hline Espelho d'Água & 0,19 & 0,34 & 0,27 \\
\hline Vegetação Arbórea/Florestal & $-0,13$ & 0,42 & 0,30 \\
\hline
\end{tabular}

Fonte: Elaboração própria. Data: 02/02/2018.

Tendo como princípio as particularidades das imagens NDBI e NDVI geradas a partir das bandas OLI a bordo do satélite Landsat-8, foi possível avaliar o comportamento dos objetos de superfície para esses índices de forma comparativa, o que possibilitou a composição de uma nova imagem que solucionasse o problema encontrado no modelo anterior.

Analisando-se o histograma das imagens NDVI e NDBI, presentes respectivamente nas figuras 2.2 e 2.3 , bem como considerando-se o comportamento dos alvos de superfície nessas imagens, como descrito sucintamente nos parágrafos precedentes, discriminou-se a parcela negativa da imagem NDVI, na qual se localizam os corpos d'água, multiplicando-a, em seguida, por -4 , no intuito de se forçar uma caracterização desses corpos que superasse numericamente o comportamento das áreas verdes, haja vista a água ser logicamente o elemento constituinte da superfície da terra menos impermeável. Em seguida, esta nova parcela da imagem NDVI foi somada ao restante da imagem, cujos valores eram equivalentes ou superiores a zero e que, consequentemente, caracterizavam as áreas constituídas por materiais impermeáveis e pelas áreas verdes. Por fim, esta nova imagem foi somada à parcela da imagem NDBI superior a 0,13 , parcela esta que caracteriza a maior extensão das áreas permeáveis do MSP. Esta soma foi realizada no intuito de melhor se distinguir os objetos de superfície permeáveis dos demais objetos. A equação final deste procedimento foi disposta abaixo (equação 5).

Índice de Refletância Ajustado $=($ NDVI $>0)+($ NDVI $<0 *-4)+$ NDBI $>0.13$ 
Figura 2.2 - Histograma da imagem NDVI

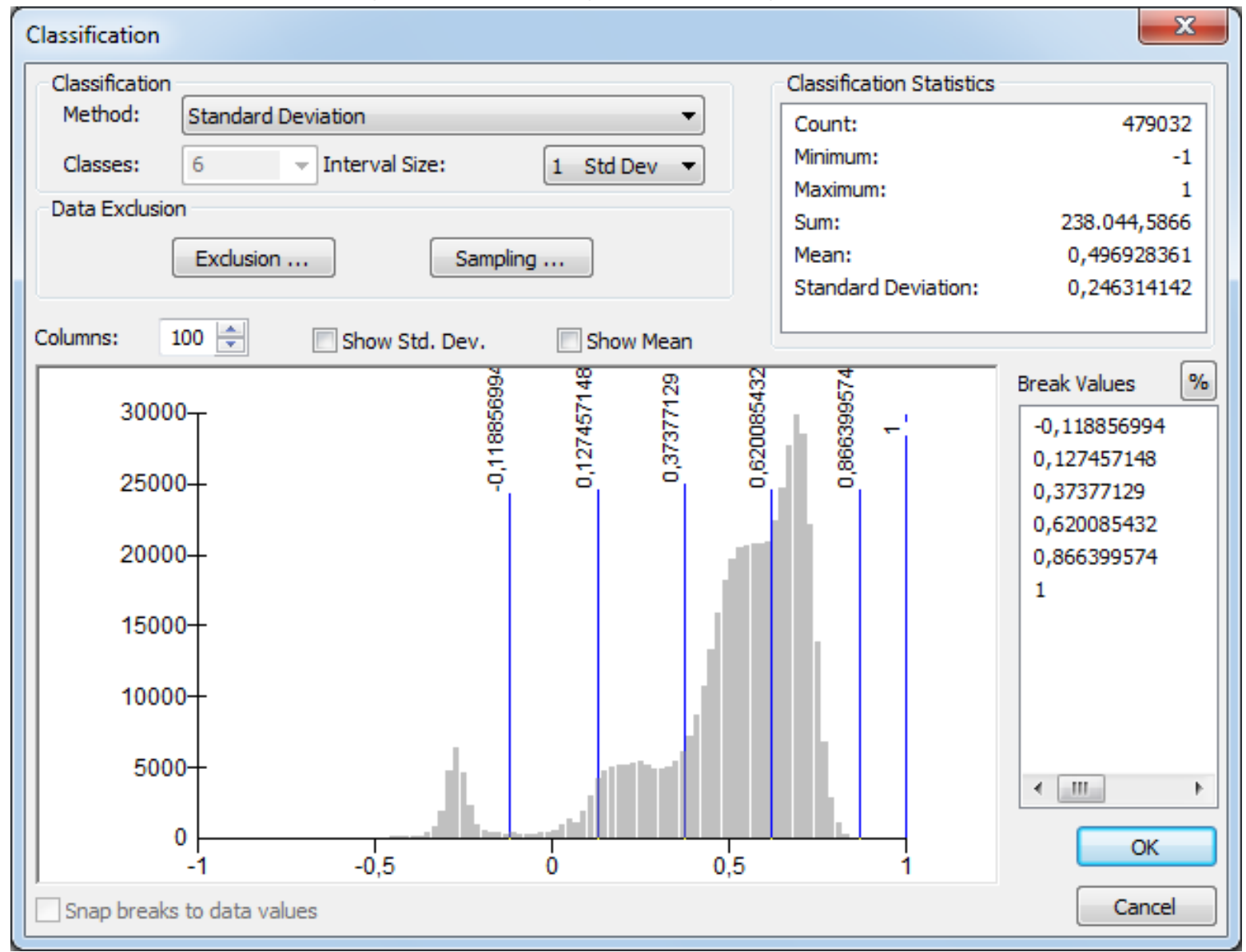

Fonte: ArcGIS 9.0. Elaboração própria. Data: 02/02/2018. 
Figura 2.3 - Histograma da imagem NDBI

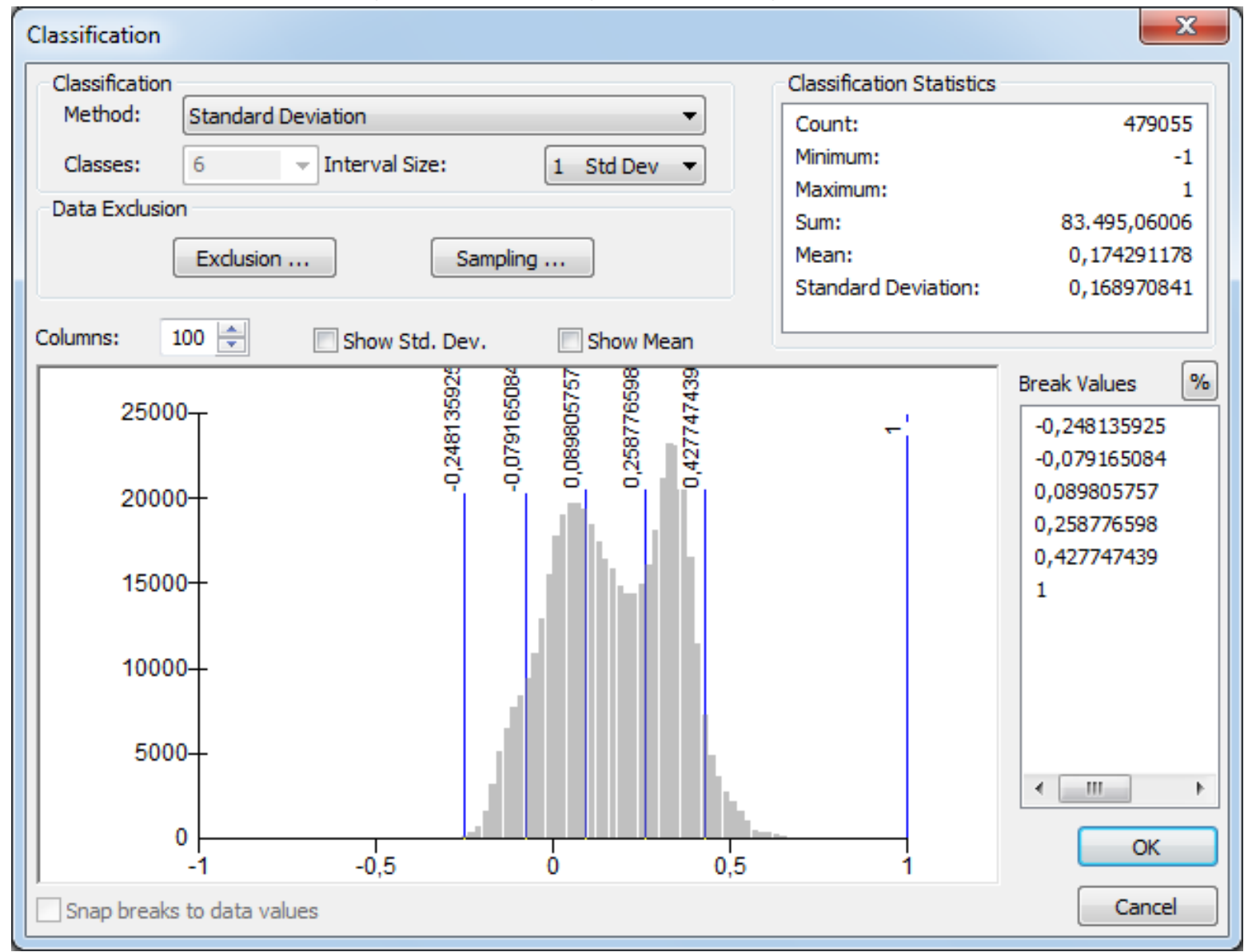

Fonte: ArcGIS 9.0. Elaboração própria. Data: 02/02/2018.

A nova imagem experimentalmente gerada a partir da equação 5, disposta no mapa 6 abaixo, foi submetida aos mesmos procedimentos para a geração e avaliação do modelo estimativo de impermeabilização aos quais a imagem NDVI também fora submetida, conforme descrito nos parágrafos precedentes. Neste sentido, o gráfico 2.5 , disposto na sequência, expõe a equação gerada para estimativa das superfícies impermeáveis a partir do índice de refletância ajustado.

A leitura do mapa 6 indica que houve uma melhor caracterização dos alvos, ainda que o efeito de mistura para áreas muito pequenas tenha permanecido. Entretanto, observa-se que as áreas urbanizadas, as áreas verdes e os corpos d'água agora estão corretamente discriminados, possibilitando uma melhor correlação com os percentuais de impermeabilização do solo. 


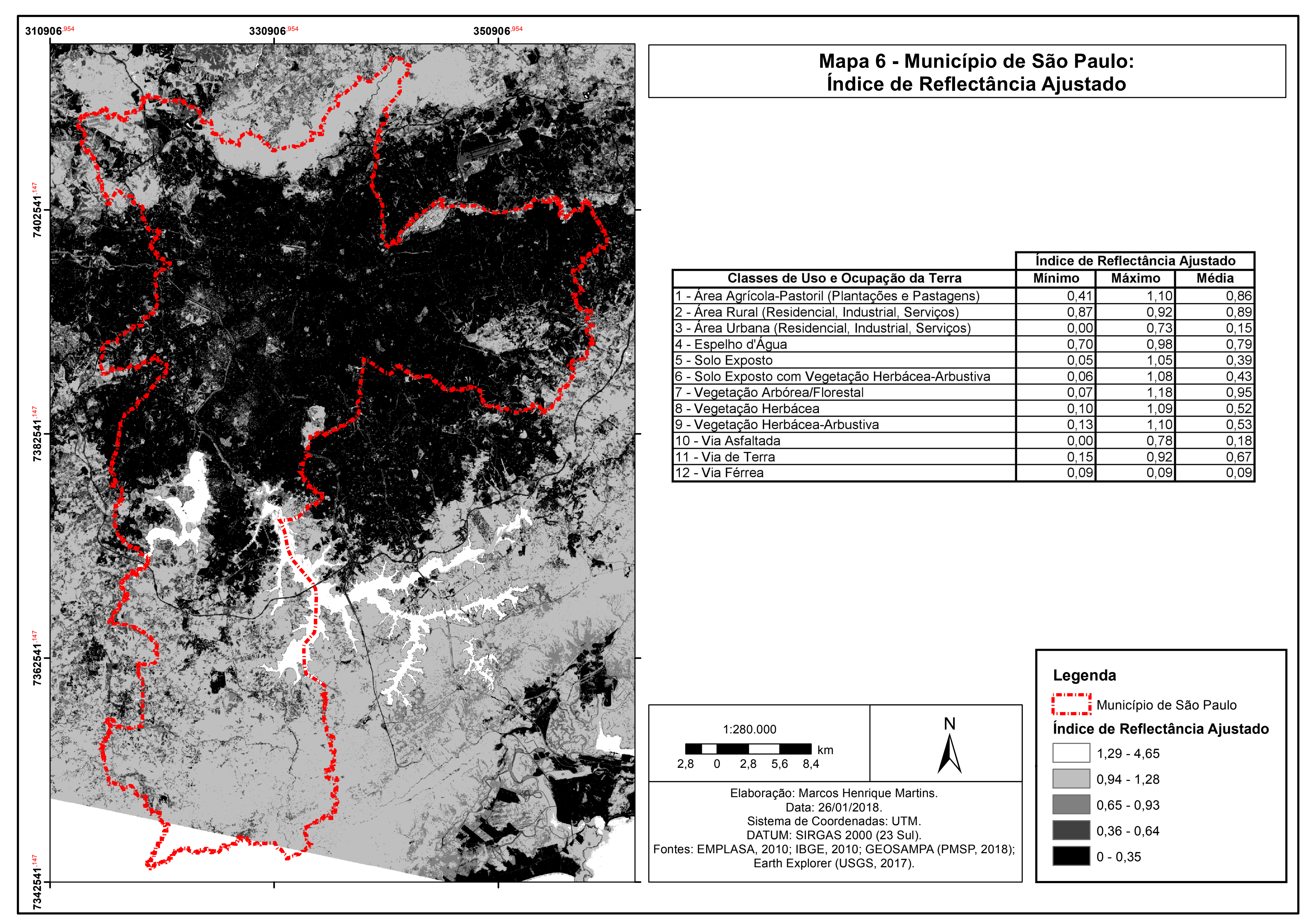


Gráfico 2.5 - Equação estimativa da impermeabilização do solo a partir do índice de refletância ajustado

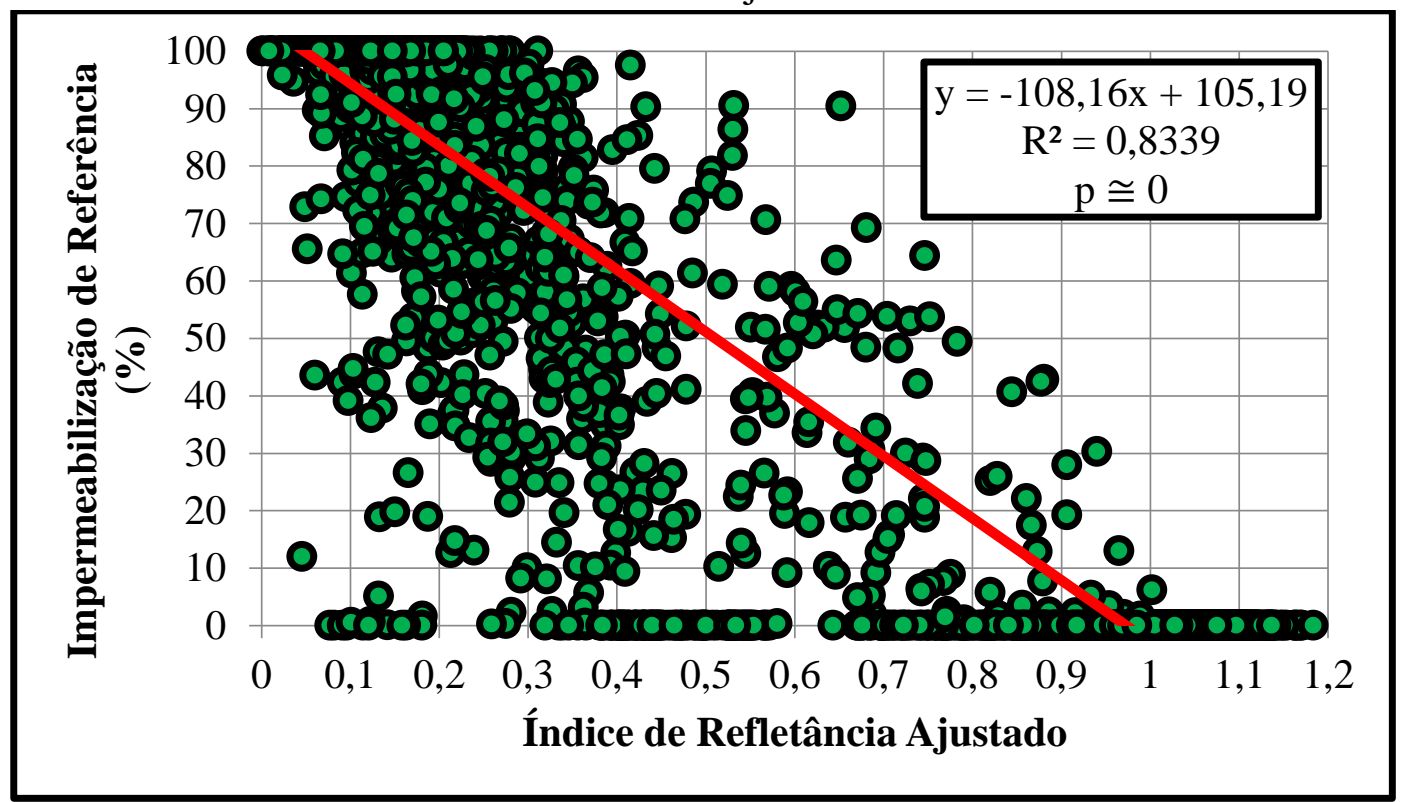

Fonte: Elaboração própria. Data: 02/02/2018.

Nota-se, no gráfico 2.5, que o coeficiente de determinação $\left(\mathrm{R}^{2}\right)$ apresentou valor aproximado de $83 \%$, sendo, portanto, inferior ao observado no gráfico 2.1. Entretanto, não é desarrazoado considerar a relevância deste valor, que ainda é elevado. Ademais, o valor-p nos sugere desconsiderar a hipótese nula, indicando que a aplicação da equação pode gerar resultados interessantes.

A posterior análise das amostras de controle e dos resíduos da modelagem apresentou também resultados que podem ser considerados positivamente, conforme se pode apreciar nos gráficos 2.6, 2.7 e 2.8, dispostos abaixo. 
Gráfico 2.6 - Análise da modelagem com índice de refletância ajustado a partir das 500 amostras de controle

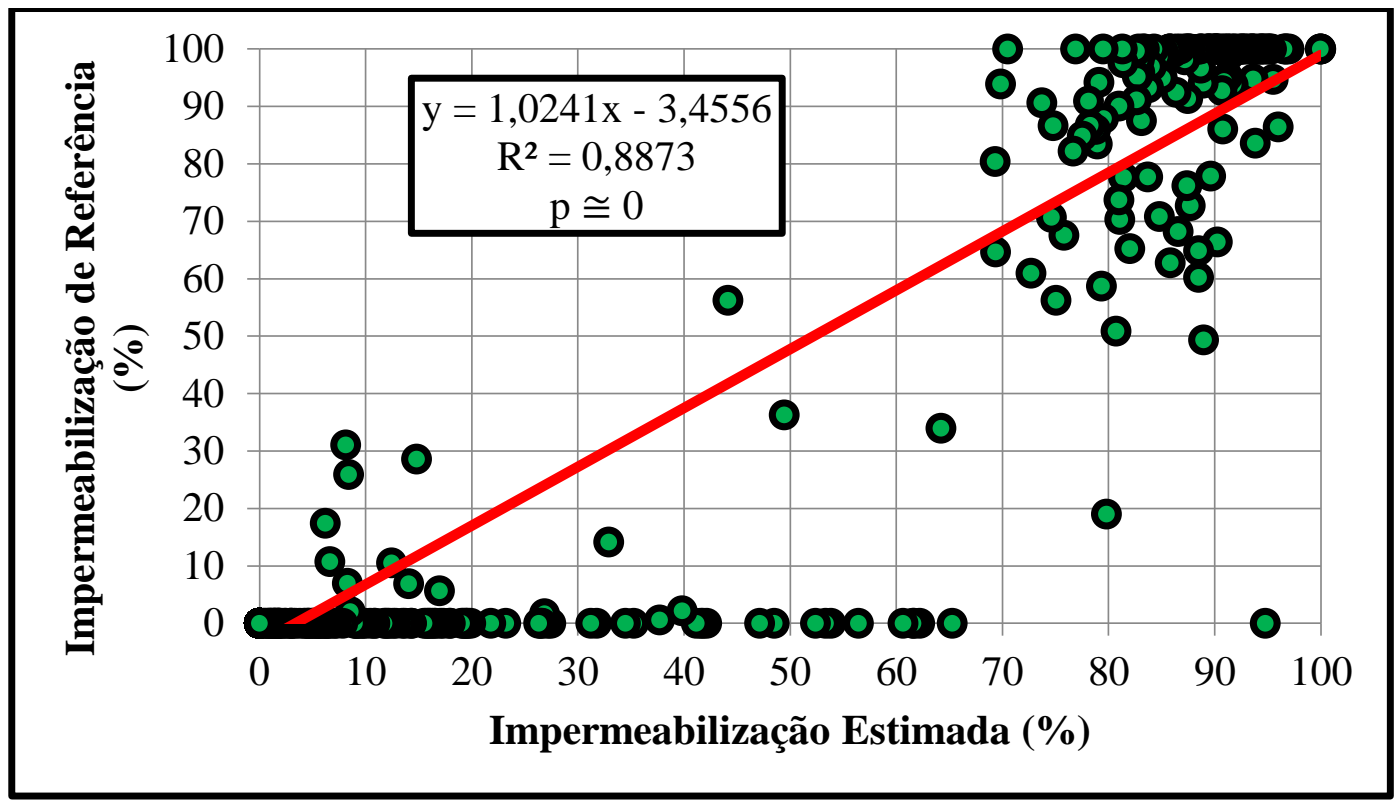

Fonte: Elaboração própria. Data: 02/02/2018.

De acordo com o gráfico 2.6, a correlação dos valores estimados com os valores das amostras de controle apresentou coeficiente de determinação de aproximadamente $89 \%$, valor equiparável aos 90\% do modelo anterior. Ademais, o valor-p, o qual tende à zero, sugere desconsiderar-se a hipótese nula. Além do mais, o gráfico 2.7 indica, a partir da distribuição dos resíduos, que o modelo apresenta boa acurácia.

Gráfico 2.7 - Histograma dos resíduos do modelo com uso do índice de refletância ajustado

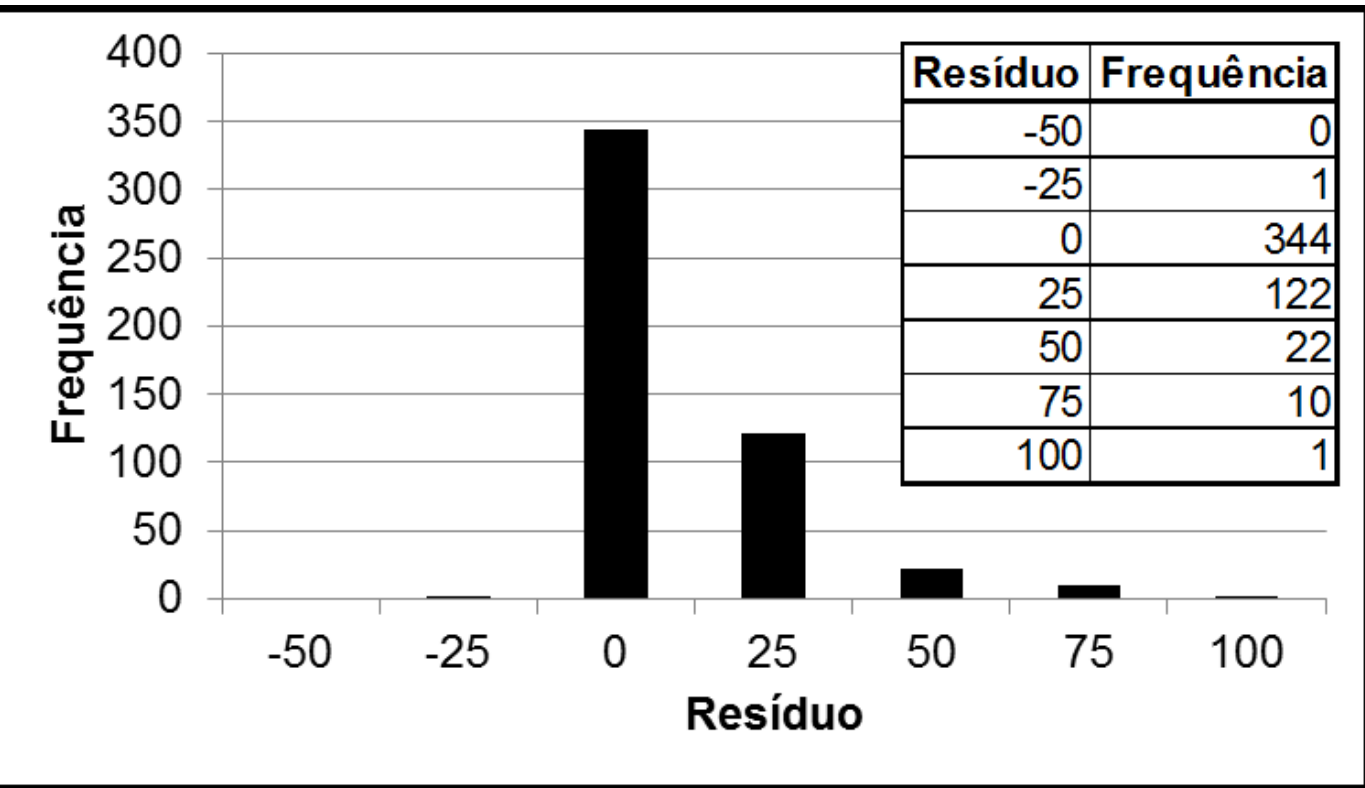

Fonte: Elaboração própria. Data: 02/02/2018. 
Gráfico 2.8 - Bloxpot dos resíduos da modelagem com uso do índice de refletância ajustado

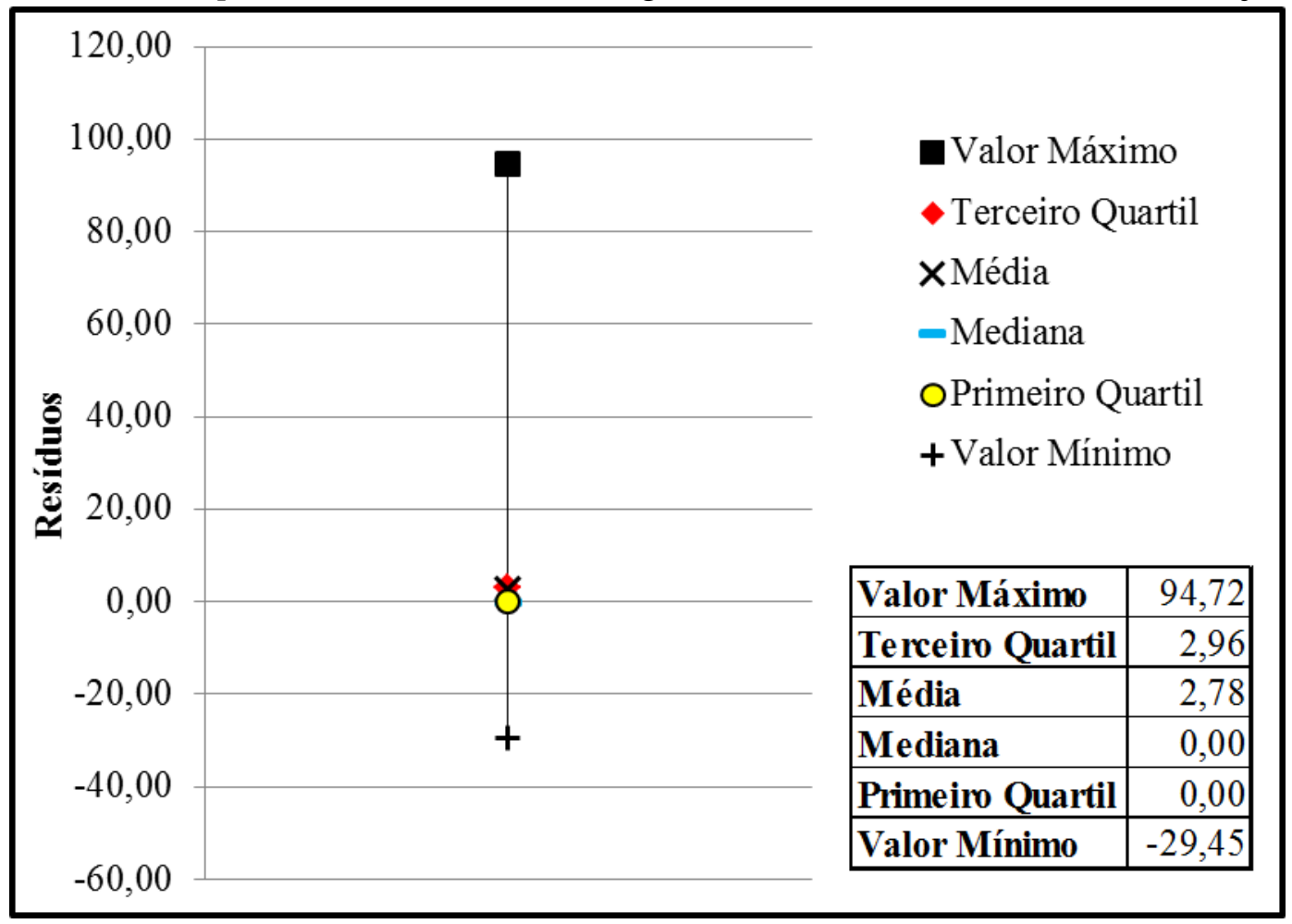

Fonte: Elaboração própria. Data: 02/02/2018.

No gráfico 2.8, é possível avaliar descritivamente o comportamento dos resíduos. Observa-se que a média dos referidos resíduos é 2,78, ou seja, próxima de zero. Comparandose com os resultados do gráfico 2.4, é possível observar uma proporcionalidade nas distâncias entre as médias obtidas em relação ao valor nulo, haja vista a modelagem apresentada anteriormente ter apresentado uma média dos resíduos equivalente a -2,6. Os gráficos 2.7 e 2.8 apontam que a distribuição dos resíduos indica uma pequena superestimativa das áreas impermeáveis. Ademais, o desvio padrão dos resíduos é 13,9, aproximadamente, valor este ligeiramente superior ao observado no gráfico 2.4 (12,81). Esses dados indicam que o novo modelo gerado pode ser aceito como satisfatório para os objetivos deste estudo.

O mapa 7, disposto na sequência, é uma reprodução do mapa 5 na qual a imagem NDVI foi substituída pela imagem gerada a partir do cálculo do índice de refletância ajustado e o modelo de impermeabilização do solo foi substituído pelo novo modelo gerado. Observase que o problema notado previamente foi corrigido, e o novo modelo de impermeabilização produzido pode ser utilizado para os propósitos a que este estudo se destina. 


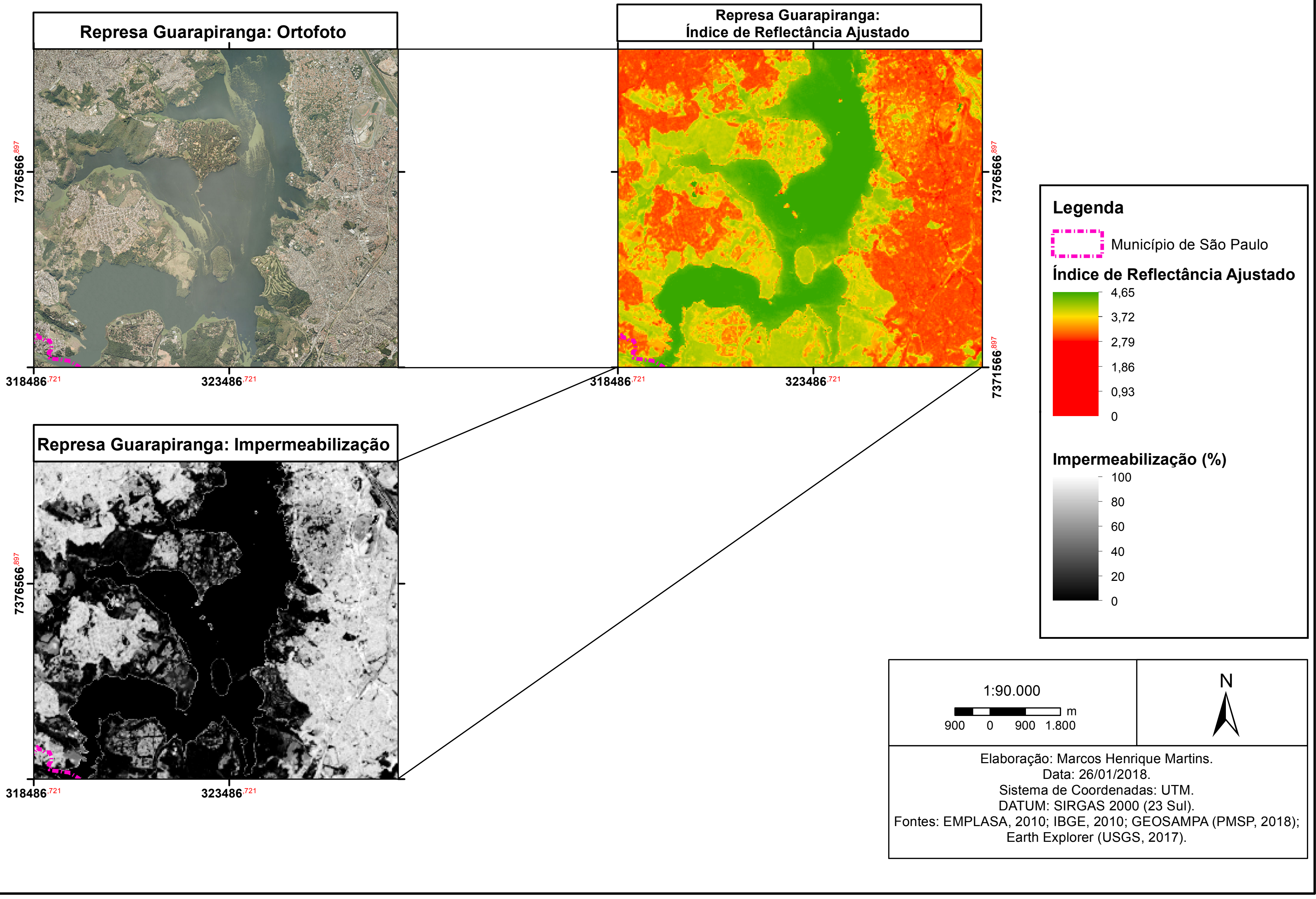


Ademais, é indispensável notar que, para ambos os modelos gerados e discutidos nesta subseção da metodologia, os valores de impermeabilização estimados, em tese, deveriam se restringir ao intervalo de $0 \%$ (superfícies totalmente permeáveis) a 100\% (superfícies totalmente impermeáveis). Entretanto, a aplicação das equações produziu valores que extrapolaram este intervalo, gerando inconsistências lógicas nos modelos. A análise das imagens geradas levou-nos a conclusão de que a solução mais viável para esta inconsistência seria o reescalonamento dos valores negativos e dos superiores a $100 \%$, de forma que os valores negativos foram transformados em $0 \%$ e valores acima de $100 \%$, em $100 \%$.

A despeito dos bons resultados obtidos, é importante considerar que o distrito de Marsilac apresenta dados insuficientes relativos à impermeabilização do solo, haja vista a cena do Landsat-8 utilizada não recobrir o extremo sul do município de São Paulo, área esta que constitui parcela do distrito em questão, como pode ser observado no mapa 8 , a seguir. 


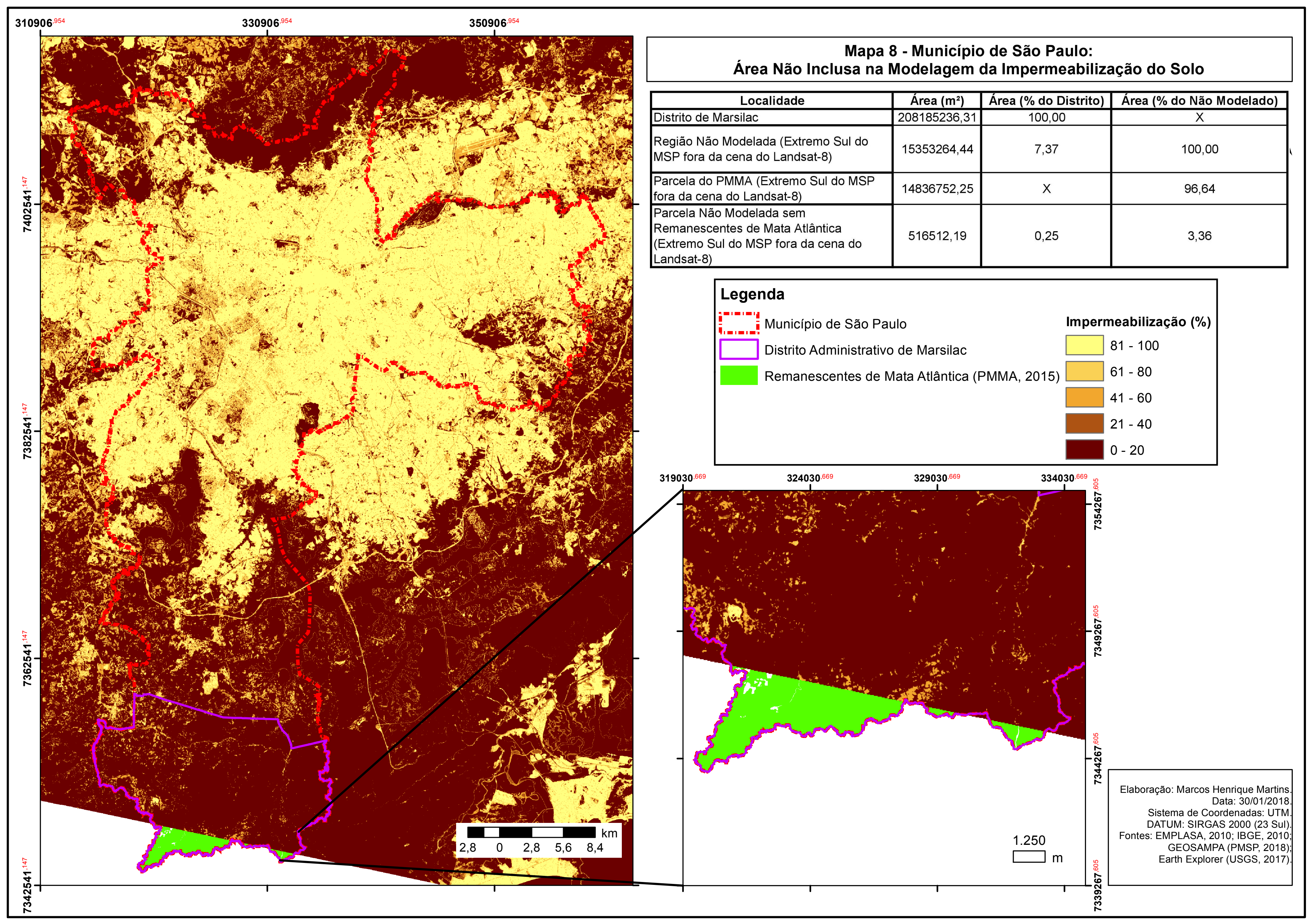


Tendo em vista a insuficiência dos dados relativos à impermeabilização do solo para o distrito de Marsilac, é necessário que se faça validar a informação relativa à impermeabilização do solo nesse distrito.

De acordo com a estimativa realizada para a área recoberta pela cena do Landsat-8, cerca de 4,7\% deste distrito encontra-se impermeabilizado. Tendo em vista a necessidade de se ratificar esta informação, considerou-se os dados relativos ao mapeamento realizado no âmbito do Plano Municipal da Mata Atlântica do Município de São Paulo (PMSP, 2016). Pode-se observar, partindo-se desta referência e analisando-se os dados da tabela 2.5 e o mapa 8 , que a parcela do distrito cujo percentual de impermeabilização não fora estimado está praticamente recoberta com remanescentes de mata atlântica, ou seja, consiste em áreas 100\% permeáveis. Ademais, o restante da área não modelada representa apenas 0,25\% do Distrito de Marsilac, dado que não provoca alterações significativas no percentual estimado de impermeabilização do solo para este distrito. Assim sendo, não é desarrazoado considerar válida a estimativa de impermeabilização do solo para o distrito de Marsilac.

Tabela 2.5 - Dados relativos ao extremo sul do município de São Paulo, distrito administrativo de Marsilac, região externa à cena do Landsat-8.

\begin{tabular}{l|c|c|c}
\hline \multicolumn{1}{c|}{ Localidade } & Área $\left(\mathbf{m}^{2}\right)$ & $\begin{array}{c}\text { Área (\% do Distrito } \\
\text { de Marsilac) }\end{array}$ & $\begin{array}{c}\text { Área (\% do Não } \\
\text { Modelado) }\end{array}$ \\
\hline Distrito de Marsilac & 208185236,31 & 100,00 & X \\
\hline $\begin{array}{l}\text { Região Não Modelada (Extremo Sul do } \\
\text { MSP fora da cena do Landsat-8) }\end{array}$ & 15353264,44 & 7,37 & 100,00 \\
\hline $\begin{array}{l}\text { Parcela do PMMA (Extremo Sul do } \\
\text { MSP fora da cena do Landsat-8) }\end{array}$ & 14836752,25 & $\mathrm{X}$ & 96,64 \\
\hline $\begin{array}{l}\text { Parcela Não Modelada sem } \\
\text { Remanescentes de Mata Atlântica } \\
\text { (Extremo Sul do MSP fora da cena do } \\
\text { Landsat-8) }\end{array}$ & 516512,19 & 0,25 & 3,36 \\
\hline
\end{tabular}

Fonte: Elaboração própria. Data: 02/02/2018.

Por fim, o resultado final da modelagem será apresentado no capítulo 3 desta obra, capítulo que se destina à análise e discussão dos resultados finais das metodologias apresentadas no escopo do presente capítulo 2. 
2.1.3. Indicador de Variabilidade dos Percentuais de Impermeabilização do Solo Interdistritais

A partir da estimativa de impermeabilização do solo do MSP foi possível calcular o número de ocorrências dos pixels que compõem o modelo de impermeabilização para cada distrito administrativo do MSP. A finalidade deste procedimento reside na necessidade de se equiparar os valores de impermeabilização interdistritais, bem como na necessidade de se analisar a relação entre a impermeabilização do solo e os óbitos associados às doenças do aparelho circulatório.

Partindo-se do modelo de impermeabilização, cujos valores dos pixels que o compõem variam entre $0 \%$ e $100 \%$ na escala de precisão de seis casas decimais, operou-se, primeiramente, uma aproximação desses valores para números inteiros, determinando-se 101 classes de impermeabilização no intervalo de $0 \%$ a 100\%. Para cada uma dessas classes, determinou-se o número de ocorrências dos pixels, por distrito administrativo do MSP, com auxílio da ferramenta Patch Analyst, disponível para utilização no software ArcGIS. Em seguida, agrupou-se os valores das referidas ocorrências em 10 faixas de impermeabilização (0\%-10\%; 10\%-20\%; 20\%-30\%; ...; 90\%-100\%), contabilizando-se o total de ocorrências para cada um desses intervalos, por distrito administrativo.

A partir deste procedimento, foi possível quantificar o percentual de contribuição de cada uma das 10 faixas de impermeabilização relativamente ao total de pixels que compõem o universo distrital avaliado aplicando-se a equação 6, disposta a seguir.

PCID $=\frac{100 * \mathrm{NPCID}}{\mathrm{TPCID}}$

Onde:

- PCID: percentual de contribuição de uma determinada faixa de impermeabilização por distrito administrativo do município de São Paulo.

- NPCID: número de pixels de uma determinada faixa de impermeabilização por distrito administrativo do município de São Paulo.

- TPCID: total de pixels de uma determinada faixa de impermeabilização considerandose a totalidade dos distritos administrativos do município de São Paulo.

A partir dos valores percentuais obtidos pela aplicação da equação 6 foi possível estabelecer um indicador normalizado, por faixa de impermeabilização e distrito administrativo, capaz de quantificar a variabilidade da composição interdistrital relativamente às faixas percentuais de impermeabilização do solo, de forma que, quanto mais próximo de $1 \mathrm{o}$ 
indicador apontar, maior a contribuição de uma determinada faixa de impermeabilização, em um determinado distrito, considerando-se a mesma faixa de impermeabilização para a totalidade dos distritos do município de São Paulo. Para o cálculo deste indicador, aplicou-se a equação 7 , a seguir.

IFID $=\frac{(\text { PCIDn }- \text { mPCIDn })}{(\text { MPCIDn }-\mathrm{mPCIDn})}$

Onde:

- IFID: indicador de contribuição de uma determinada faixa percentual de impermeabilização.

- PCIDn: percentual de contribuição de uma determinada faixa de impermeabilização e de um determinado distrito administrativo do município de São Paulo.

- mPCIDn: menor valor percentual de contribuição de uma determinada faixa de impermeabilização considerando-se todos os distritos administrativos do município de São Paulo.

- MPCIDn: maior valor percentual de contribuição de uma determinada faixa de impermeabilização considerando-se todos os distritos administrativos do município de São Paulo.

De posse do conjunto de indicadores elaborados para cada faixa de impermeabilização e distrito administrativo, foi possível computar um indicador geral, partindo-se do cálculo da soma dos dez indicadores computados previamente, por distrito administrativo. Optou-se por efetuar a soma dos indicadores, e não a média, haja vista a necessidade de se obter um indicador geral capaz de indicar o total da variabilidade, por distrito administrativo, das faixas de impermeabilização consideradas. Este dado apresenta relevância analítico-descritiva, haja vista sua capacidade de mensurar a variabilidade nos percentuais de impermeabilização do solo, por distrito administrativo, considerando-se a totalidade do MSP. O referido indicador geral, entretanto, apresenta uma limitação, haja vista os distritos administrativos apresentarem áreas distintas entre si. O distrito da Sé, o menor em extensão territorial dentre os 96 distritos do MSP, possui área cerca de 95 vezes menor que a do distrito de Marsilac, o mais vasto do município em questão. Esta diferença impossibilita estabelecer uma relação lógica plausível entre os valores do indicador geral calculado, pois o número de pixels que compõem cada distrito é distinto entre si. Assim sendo, tendo em vista a necessidade de se solucionar este impasse, optou-se por calcular uma variável que garantisse a proporcionalidade desse indicador geral considerando-se as distintas áreas dos distritos administrativos. Esta variável foi constituída estabelecendo-se uma relação de proporcionalidade entre as áreas de cada distrito 
administrativo e a área do menor distrito, de forma que se obteve, para cada distrito administrativo, uma variável cujo valor corresponde à divisão de sua área pela área do menor distrito.

De posse das variáveis de proporcionalidade das áreas, dividiu-se o indicador geral pela variável, por distrito administrativo, obtendo-se assim o Indicador de Variabilidade dos Percentuais de Impermeabilização do Solo Interdistritais (VARIMP). Este Indicador, constituído pela soma dos indicadores de contribuição das faixas de impermeabilização ponderada pela variação relativa das áreas dos distritos administrativos em relação ao seu menor exemplar em termos de extensão territorial, opera de forma a estabelecer valores no intervalo de 1 a 0 para cada distrito administrativo do MSP, de modo que, quanto maior o valor do indicador em um determinado distrito, mais heterogênea é a composição da impermeabilização do solo nesse distrito e, consequentemente, quanto menor o valor do referido indicador, menor é a variabilidade dos percentuais de impermeabilização.

Ademais, partindo-se do modelo de impermeabilização do solo, foi possível extrair o percentual de impermeabilização por setor censitário e por distrito administrativo do MSP. Estes dados também serão utilizados para análises posteriores.

No intuito de se avaliar a existência ou não de agrupamentos de distritos correlacionados espacialmente segundo o Indicador de Variabilidade dos Percentuais de Impermeabilização do Solo Interdistritais (VARIMP), empregou-se a ferramenta Spatial Autocorrelation (Moran I), do software ArcGIS 9.0 (ESRI, 2018). Esta ferramenta avalia se as feições vetoriais poligonais que compõem uma determinada área apresentam um padrão de agrupamento, de dispersão ou de aleatoriedade segundo um determinado atributo (ESRI, 2018). No âmbito deste estudo, as feições poligonais são o conjunto de distritos administrativos do município de São Paulo, e o atributo considerado é o Índicador VARIMP. A ferramenta calcula o índice de Moran, bem como um z-escore e o valor-p, para que se possa avaliar a significância estatística deste índice. Na figura 2.4, abaixo, pode-se observar o resultado da análise de autocorrelação espacial. 
Figura 2.4 - Resultados da análise de autocorrelação espacial para o Indicador VARIMP

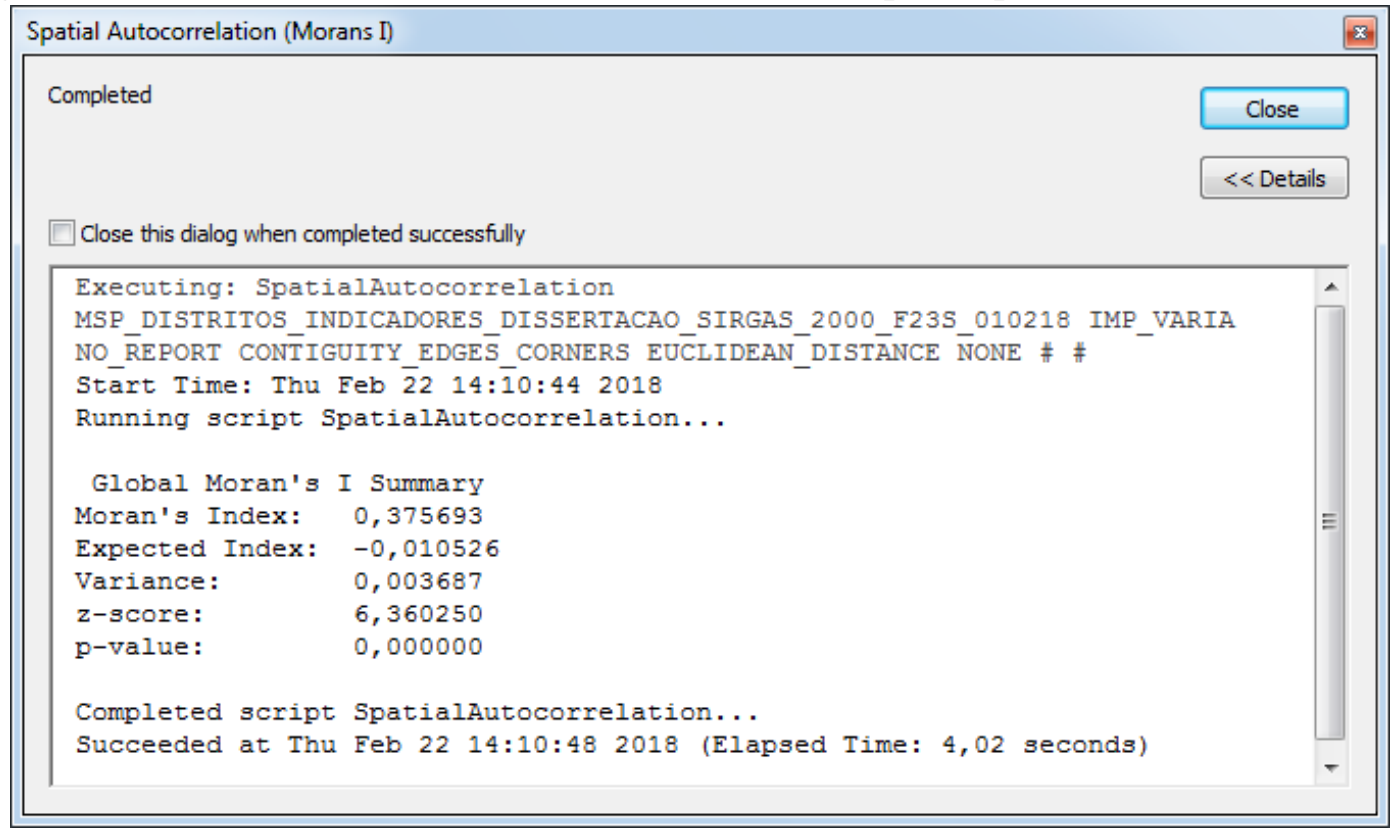

Fonte: ArcGIS 9.0. Data: 22/02/2018.

A análise dos resultados indica que o Índice de Moran foi significativo (cerca de 0,38). O z-score positivo e o valor-p nulo indicam que a hipótese nula pode ser descartada e que há autocorrelação espacial para o Indicador VARIMP nos distritos administrativos analisados.

Assim sendo, na sequência, utilizou-se a ferramenta Cluster and Outlier Analysis (Anselin Local Moran's I) do ArcGIS 9.0 (ESRI, 2018), cuja finalidade é mapear os hot spots, cold spots e os valores atípicos (outliers) de um conjunto de feições poligonais a partir de um atributo determinado. No âmbito deste estudo, as feições poligonais são o conjunto de distritos administrativos do município de São Paulo, e o atributo considerado é o Índice VARIMP.

No subcapítulo 2.7, será apresentada a metodologia para definição da relação entre impermeabilização do solo e os óbitos associados às doenças do aparelho circulatório, partindose do indicador de variabilidade da contribuição distrital para a impermeabilização do solo descrito no decorrer desta subseção, bem como dos valores percentuais, por distrito administrativo, da impermeabilização do solo. No capítulo 3 serão apresentados os resultados dos procedimentos metodológicos adotados neste capítulo, bem como uma análise detalhada desses resultados. 


\subsection{Mapeamento da Temperatura Aparente de Superfície}

No intuito de se correlacionar a temperatura aparente de superfície e os percentuais de impermeabilização do solo do município de São Paulo, efetuou-se o mapeamento da referida temperatura, com auxílio da banda 10, gerada pelo sensor TIRS (Thermal Infrared Sensor) do Landsat- 8 , de 23 de setembro de $2015^{7}$.

De acordo com Jensen (2009), as informações sobre a temperatura superficial podem ser obtidas por sensoriamento remoto, tendo em vista que o calor interno de um alvo é convertido em energia radiante e para a maioria dos alvos existe uma alta correlação positiva entre sua temperatura cinética e o fluxo radiante proveniente dos mesmos, conforme figura 2.5, disposta a seguir.

Figura 2.5 - Regressão linear comparativa da Temperatura Radiante da Água e da Temperatura Cinética da Água

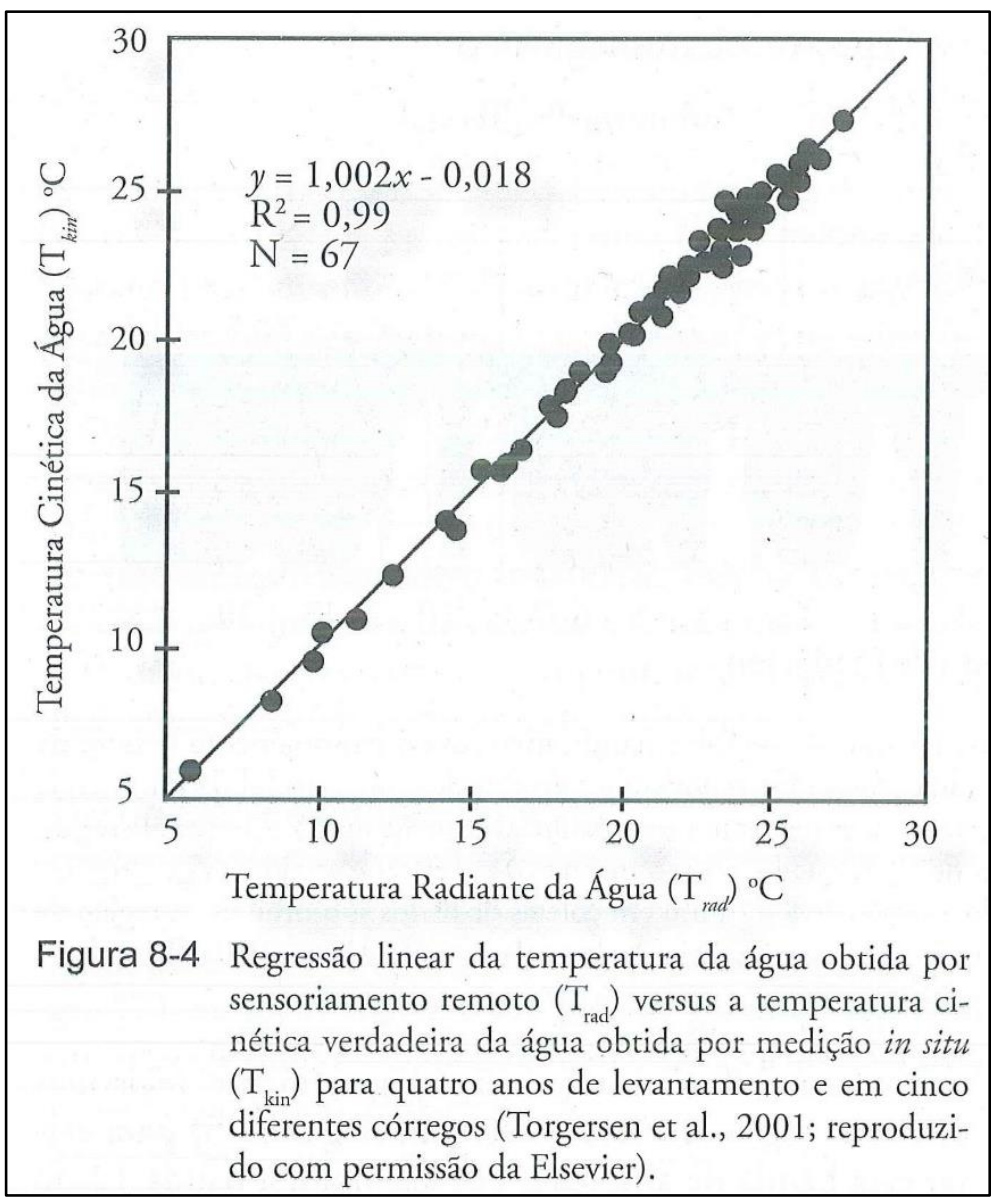

Fonte: Jensen (2009, p.255).

\footnotetext{
${ }^{7}$ Para maiores informações relativas às bandas dos satélites Landsat-7 e Landsat-8 utilizadas no escopo deste estudo, consultar o Anexo A.
} 
Nesse sentido, a temperatura de superfície diz respeito ao fluxo de calor dado em função da energia que chega e sai do alvo, sendo de suma importância para o entendimento das interações entre a superfície terrestre e a atmosfera. A melhor faixa que permite uma maior transmissão da energia emitida da Terra que alcança o sensor na região do infravermelho termal do espectro eletromagnético é o intervalo de 8,0 a 14,0 $\mu \mathrm{m}$ (PIRES; FERREIRA JÚNIOR, 2015). Assim sendo, utilizou-se a banda termal do Landsat-8 para o cálculo da temperatura aparente de superfície (TAS).

Inicialmente, para o cálculo da TAS do município de São Paulo, converteu-se a imagem TIRS, banda 10, do Landsat-8 para valores de radiância no topo da atmosfera (equação 1), tendo em vista a necessidade de melhor caracterizar o comportamento espectral dos objetos que compõem a superfície terrestre. Em seguida, aplicou-se a equação 8, abaixo, no intuito de se obter os valores da TAS, em graus Kelvin, para o MSP.

TASsc $=\frac{\mathrm{K} 2}{\ln \left(\frac{\mathrm{K} 1}{\mathrm{~L} \lambda}+1\right)}$

Onde:

- TASsc: temperatura aparente de superfície sem correção atmosférica (K)

- K1: constante de calibração 1 da banda 10 do Landsat-8

- K2: constante de calibração 2 da banda 10 do Landsat-8

- L $\lambda$ : radiância espectral (Watts / $\left(\mathrm{m} 2 * \operatorname{srad}^{*} \mu \mathrm{m}\right)$ ) da banda 10 do Landsat- 8

As temperaturas resultantes foram convertidas para graus Celsius $\left({ }^{\circ} \mathrm{C}\right)$ aplicando-se a subtração do valor da temperatura do ponto de congelamento da água ao nível do mar, que equivale a $273,15 \mathrm{~K}$.

Ademais, observa-se que, não por acaso, optou-se por não se realizar a conversão dos valores de radiância no topo da atmosfera para valores de radiância com correção atmosférica, haja vista estudos posteriores terem identificado uma melhor correlação entre a TAS e a temperatura do ar quando não se realiza a referida correção (PIRES; FERREIRA JÚNIOR, 2015).

Partindo-se das 4000 janelas amostrais, utilizadas anteriormente para modelagem da impermeabilização do solo, foi possível associar os percentuais de impermeabilização de

\footnotetext{
${ }^{8}$ UNITED STATES GEOLOGICAL SURVEY (USGS). Using the USGS Landsat Level-1 Data Product. Disponível em: <https://landsat.usgs.gov/using-usgs-landsat-8-product>. Acesso em 19 set. 2018.
} 
referência com os valores da temperatura dos alvos de superfície em graus Celsius. Os resultados dessa relação estão expressos no gráfico 2.9 , abaixo.

Gráfico 2.9 - Relação linear entre os percentuais de impermeabilização do solo e a temperatura aparente de superfície para as 4000 janelas amostrais

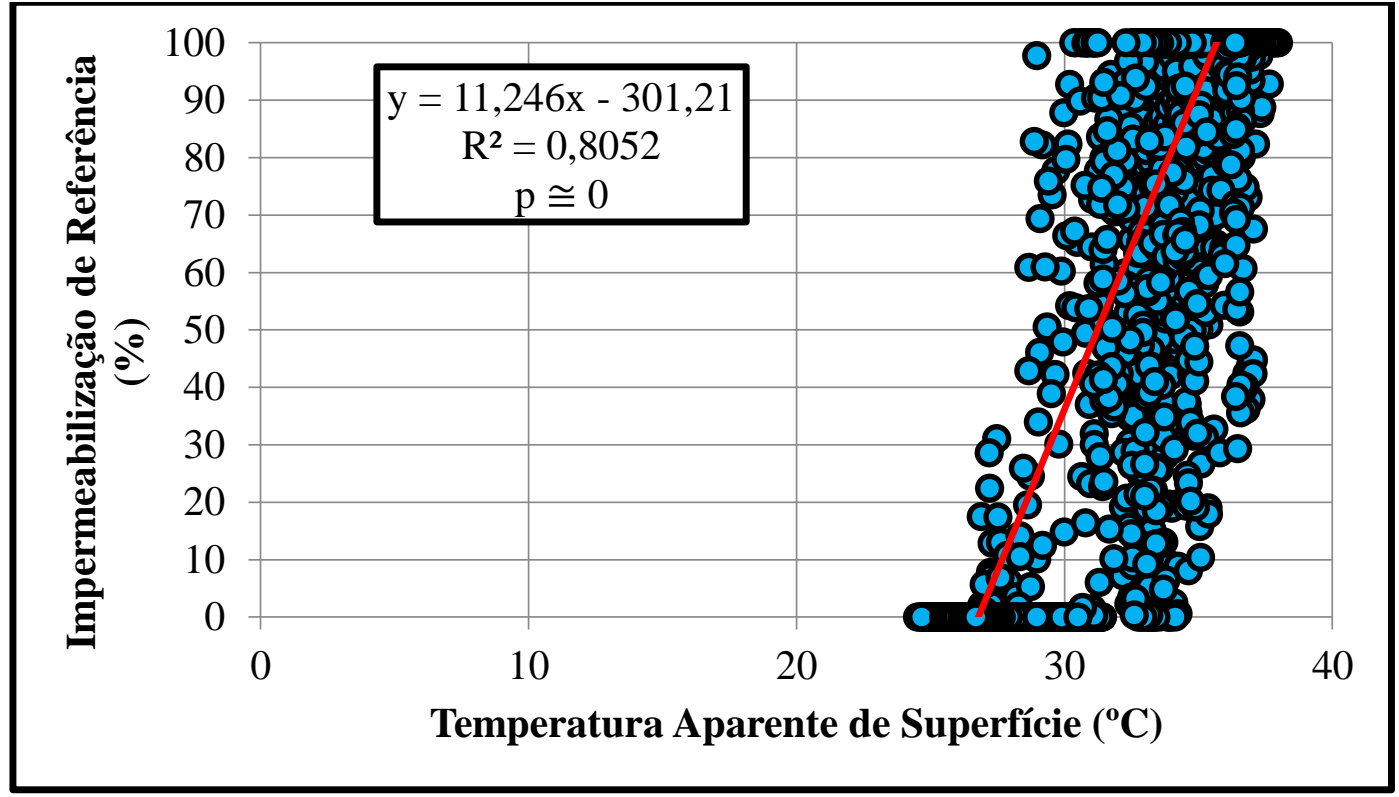

Fonte: Elaboração própria. Data: 02/02/2018

A análise do gráfico 2.9 indica haver considerável correlação entre as variáveis associadas, haja vista o elevado coeficiente de determinação apresentado (aproximadamente 80\%) e o valor-p de significância indicar ser plausível desconsiderar-se a hipótese nula. Assim sendo, conclui-se que os valores percentuais de impermeabilização possuem uma relação positiva com as temperaturas dos alvos de superfície, ou seja, ambientes mais impermeabilizados emitem mais energia térmica do que os menos impermeabilizados.

No capítulo subsequente serão apresentados os resultados relativos ao mapeamento da temperatura aparente de superfície, bem como uma análise detalhada dos mesmos.

\subsection{Mapeamento dos Óbitos Associados às Doenças do Aparelho Circulatório}

Para o mapeamento dos óbitos associados às doenças do aparelho circulatório (MSC $\left.{ }^{9}\right)$ ocorridos no ano de 2015 no MSP, adotou-se os dados agregados por distrito administrativo e discriminados em faixas etárias de 5 anos disponíveis no sítio do portal TabNet da prefeitura do município de São Paulo (PMSP, 2018), conforme citado anteriormente (tabela 2.1).

\footnotetext{
${ }^{9}$ Adotaremos a sigla MSC (Mortes Sistema Circulatório) para nos referirmos aos óbitos associados às doenças do aparelho circulatório.
} 
Entretanto, esses dados são disponibilizados em valores absolutos (número total de óbitos ocorridos por local de residência). Assim sendo, tais valores não podem ser imediatamente considerados para uma análise comparativa deste tipo de mortalidade nos distritos administrativos, haja vista tais distritos apresentarem populações e composições etárias distintas, ou seja, os valores absolutos não possuem relação lógico-matemática imediata, pois não há proporcionalidade demográfica interdistrital. Neste sentido, tendo em vista a necessidade de se efetuar um mapeamento comparativo desta tipologia de mortalidade entre os distritos que compõem o município de São Paulo, primeiramente foi necessário calcular a taxa de mortalidade MSC para estes distritos.

\subsubsection{Cálculo de Taxa de Mortalidade MSC}

Para o cálculo da taxa de mortalidade adotou-se os dados relativos à composição etária da população do censo de 2010 agregados por setor censitário (IBGE, 2010). Tais dados foram organizados em faixas etárias de cinco anos. Em seguida, agregou-se os valores para a escala dos distritos administrativos, somando-se a população, por faixas etárias de cinco anos, dos setores censitários que compõem cada um dos 96 distritos do MSP.

De posse dos dados relativos à composição etária da população e à mortalidade MSC absoluta dos distritos administrativos do MSP, aplicou-se a equação 9, disponível abaixo. Tal equação tem como finalidade operar uma padronização da mortalidade observada em um determinado lugar considerando-se a estrutura etária deste lugar relativamente ao restante do mundo. Destarte, foi necessário utilizar-se os dados disponíveis no manual para padronização populacional por faixa etária da Organização Mundial da Saúde (OMS, 2001).

MSC Padrão $=\frac{\left(\frac{100000^{*} \mathrm{MSC} A B S}{\mathrm{POP} A B S}\right) *\left(\frac{100000^{*} \mathrm{TAB} \text { OMS }}{100}\right)}{100000}$

Onde:

- MSP Padrão: taxa de óbitos associados às doenças do aparelho circulatório, por faixas etárias de cinco anos e distrito administrativo.

- MSC ABS: valor absoluto dos óbitos associados às doenças do aparelho circulatório, por faixas etárias de cinco anos e distrito administrativo.

- POP ABS: população absoluta, por faixas etárias de cinco anos e distrito administrativo.

- TAB OMS: valores padronizados por faixas etárias de cinco anos disponibilizados pela OSM para o cálculo da população padrão. 
A equação 9 foi aplicada, portanto, para cada um dos distritos administrativos do MSP e para cada uma das 16 faixas etárias discriminadas ( 15 faixas de 0 a 74 anos e uma faixa de 75 anos ou mais). Desta forma, obteve-se a taxa de mortalidade MSC para cada um dos distritos, para o ano de 2015, e de acordo com cada uma das faixas etárias consideradas.

Em seguida, elaborou-se um indicador normalizado para as taxas de mortalidade MSC calculadas, conforme será descrito na subseção seguinte.

\subsubsection{Indicador de Mortalidade MSC}

Para o cálculo do indicador de mortalidade MSC, considerou-se a taxa de mortalidade para cada distrito e de acordo com cada faixa etária computada. Cada um dos valores foi convertido em uma escala percentual, conforme apresentado na equação 10. Em seguida, os valores percentuais foram normalizados no intervalo entre 0 e 1 , conforme a equação 11 , de forma que, quanto maior a taxa de mortalidade MSC em um determinado distrito, e para uma determinada faixa etária, maior o valor do indicador (mais próximo de 1). Na sequência, os valores dos indicadores gerados para cada uma das 16 faixas etárias foram agregados a partir do cálculo da média aritmética desses valores, por distrito administrativo. Assim sendo, o conjunto dos 16 indicadores compôs um indicador de mortalidade MSC final.

PTMSCFE $=\frac{100 * \text { TMSCFE }}{\text { STMSCFE }}$

Onde:

- PTMSCFE: percentual da taxa de óbitos associados às doenças do aparelho circulatório de uma determinada faixa etária e de um determinado distrito.

- TMSCFE: taxa de óbitos associados às doenças do aparelho circulatório de uma determinada faixa etária e de um determinado distrito.

- STMSCFE: soma das taxas de óbitos associados às doenças do aparelho circulatório de uma determinada faixa etária para a totalidade dos distritos.

IND TMSCFE $=\frac{(\text { PTMSCFE - mPTMSCFE })}{(\text { MPTMSCFE - mPTMSCFE })}$

Onde: 
- IND TMSCFE: indicador para a taxa de óbitos associados às doenças do aparelho circulatório para uma determinada faixa etária e de um determinado distrito.

- PTMSCFE: percentual da taxa de óbitos associados às doenças do aparelho circulatório de uma determinada faixa etária e de um determinado distrito.

- mPTMSCFE: menor valor percentual da taxa de óbitos associados às doenças do aparelho circulatório de uma determinada faixa etária considerando-se a totalidade dos distritos administrativos.

- MPTMSCFE: maior valor percentual da taxa de óbitos associados às doenças do aparelho circulatório de uma determinada faixa etária considerando-se a totalidade dos distritos administrativos.

Após estes procedimentos, foi possível mapear o indicador de mortalidade MSC para o ano de 2015, por distrito administrativo, para o município de São Paulo. Este resultado será apresentado e analisado no capítulo 3 desta obra.

A posteriori, efetuou-se uma análise para avaliação da autocorrelação espacial do indicador de mortalidade MSC a partir do Índice de Moran. Esta avaliação foi pormenorizada na subseção 2.3.3, a seguir.

\subsubsection{Autocorrelação Espacial e Formação de Clusters}

No intuito de se avaliar a existência ou não de agrupamentos de distritos correlacionados espacialmente segundo o Indicador de Mortalidade MSC, empregou-se a ferramenta Spatial Autocorrelation (Moran I), do software ArcGIS 9.0 (ESRI, 2018). Esta ferramenta avalia se as feições vetoriais poligonais que compõem uma determinada área apresentam um padrão de agrupamento, de dispersão ou de aleatoriedade segundo um determinado atributo (ESRI, 2018). No âmbito deste estudo, as feições poligonais são o conjunto de distritos administrativos do município de São Paulo, e o atributo considerado é o Índice de Mortalidade MSC. A ferramenta calcula o índice de Moran, bem como um z-escore e o valor-p, para que se possa avaliar a significância estatística deste índice. Na figura 2.6, abaixo, pode-se observar o resultado da análise de autocorrelação espacial. 
Figura 2.6 - Resultados da análise de autocorrelação espacial

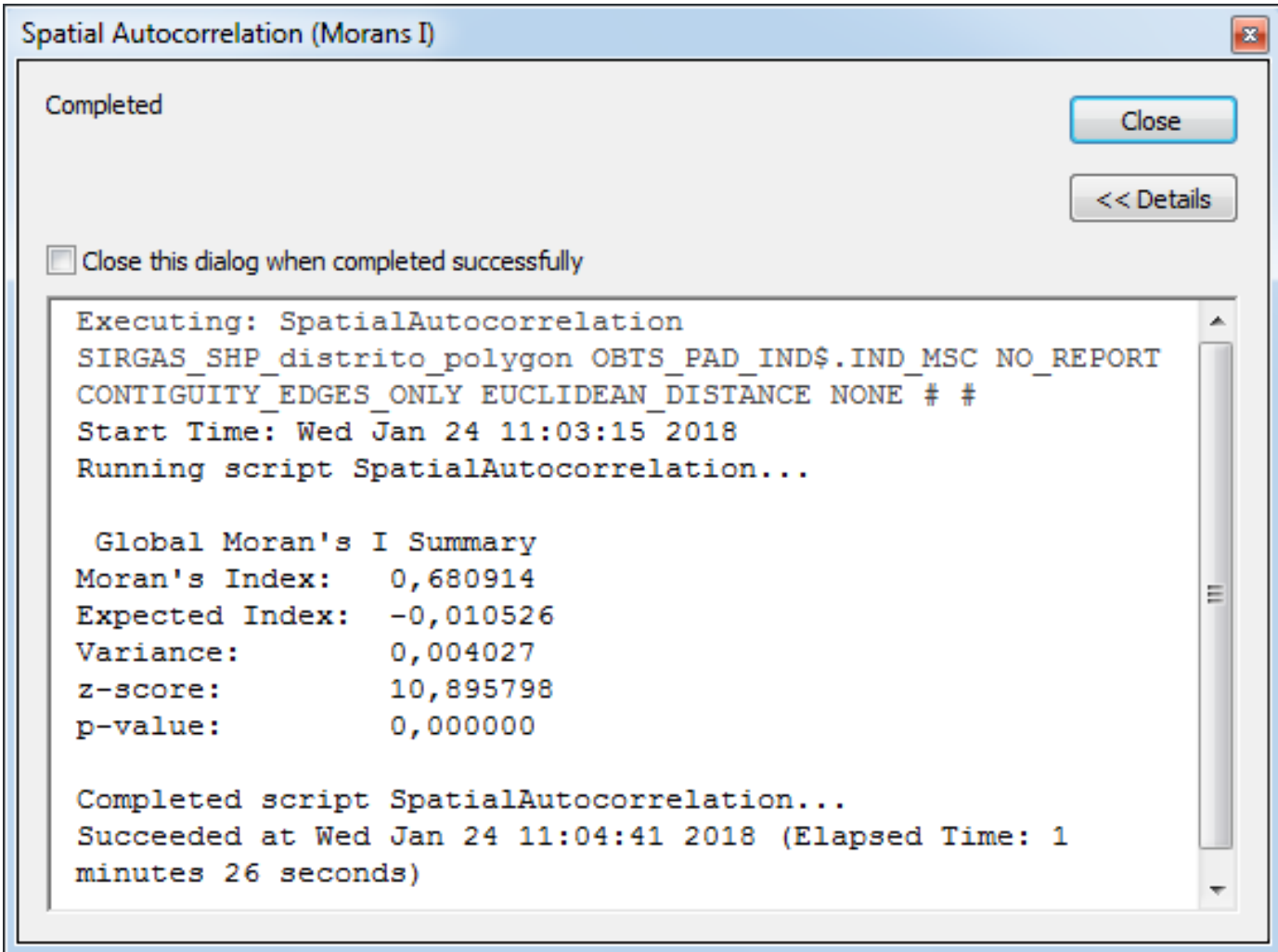

Fonte: ArcGIS 9.0. Data: 03/02/2018.

A análise dos resultados indica que o Índice de Moran foi elevado (cerca de 0,68), aproximando-se do valor máximo, que é 1 . O z-score positivo e o valor-p nulo indicam que a hipótese nula pode ser descartada e que há autocorrelação espacial para o Indicador de Mortalidade MSC nos distritos administrativos analisados.

Assim sendo, na sequência, utilizou-se a ferramenta Cluster and Outlier Analysis (Anselin Local Moran's I) do ArcGIS 9.0 (ESRI, 2018), cuja finalidade é mapear os hot spots, cold spots e os valores atípicos (outliers) de um conjunto de feições poligonais a partir de um atributo determinado. No âmbito deste estudo, as feições poligonais são o conjunto de distritos administrativos do município de São Paulo, e o atributo considerado é o Índice de Mortalidade MSC.

O resultado do mapeamento dos clusters do Indicador de Mortalidade MSC dos distritos administrativos do MSC será apresentado e analisado no capítulo subsequente. Por hora, basta indicar que a análise dos clusters reafirmou os resultados de estudos precedentes sobre a relação entre os óbitos associados às doenças do sistema circulatório e questões de ordem socioeconômica (IKEFUTI, 2016; BRASIL, 2017), indicando-se a necessidade de 
estudos contínuos relativos à associação entre os indicadores de saúde e renda, escolaridade, composição racial da população, gênero, dentre outros.

Tanto em países desenvolvidos como em desenvolvimento, as desigualdades sociais impactam na mortalidade cardiovascular, entre diferentes territórios e grupos populacionais. A influência das condições socioeconômicas na mortalidade cardiovascular tem sido avaliada por meio de abordagens associadas aos estilos de vida dos indivíduos, como fatores de risco, ou por aquelas que incorporam, em suas análises, agregados populacionais e nível socioeconômico das áreas geográficas (FARIAS, 2014, p.58).

Em estudo sobre a mortalidade associada às doenças do aparelho circulatório no município de São Paulo realizado pela autora citada no parágrafo acima, verificou-se que

as áreas de exclusão social concentravam a maioria da população residente no município [de São Paulo], vivendo sob um baixo padrão de autonomia, qualidade de vida, desenvolvimento humano e equidade. $\mathrm{O}$ aumento do risco de morte na medida em que aumentou a exclusão social pode ser explicado pelas abordagens contextuais, representadas pela influência do meio ambiente físico e social, inerente a diversas realidades e épocas (FARIAS, 2014, p.63).

Ademais, vale ressaltar que "a influência do risco relativo de morte por doenças cardiovasculares, aumentado em áreas menos favorecidas, pode resultar de uma combinação de fatores e condições socioambientais e comportamentais que impactam em maiores razões de mortalidade, taxas de prevalência e incidência de tais doenças" (FARIAS, 2014, p.63-64).

Neste sentido, na seção 2.4, a seguir, será apresentada a metodologia utilizada para definição e análise da realidade socioeconômica do município de São Paulo.

\subsection{Indicador Socioeconômico}

Após a execução de uma sequência de experimentações e considerando-se a literatura disponível sobre o assunto, foi possível compor um Indicador Socioeconômico síntese a partir dos dados do censo de 2010 relativos à renda nominal média por domicílio e ao número de pessoas alfabetizadas. Esses dados, disponibilizados de forma agregada por setor censitário, compuseram dois indicadores distintos, os quais foram utilizados para a confecção do Indicador Socioeconômico. 


\subsubsection{Indicador de Renda Média por Domicílio}

Os dados relativos à renda média por domicílio, agregados por setor censitário, foram organizados de acordo com as faixas de renda dispostas na relação a seguir:
a) Sem Renda
b) $\mathrm{De} 1 / 8 \mathrm{SM}^{10}$ a $1 / 2 \mathrm{SM}$
c) $\mathrm{De} 1 / 2 \mathrm{SM}$ a $1 \mathrm{SM}$
d) $\mathrm{De} 1 \mathrm{SM}$ a $2 \mathrm{SM}$
e) De 2 a $3 \mathrm{SM}$
f) De 3 a $5 \mathrm{SM}$
g) De 5 a $10 \mathrm{SM}$
h) Acima de $10 \mathrm{SM}$

Esta relação foi adotada considerando-se as normas estabelecidas para definição de famílias ou indivíduos com baixa renda que são beneficiadas pelos programas sociais do Governo Federal. Tomou-se como referência o Decreto n ${ }^{\circ} 6.135$ de 26 de junho de 2007 (BRASIL, 2007), que dispõe sobre o cadastro único para programas sociais do Governo Federal. De acordo com o artigo 4 do referido Decreto, famílias de baixa renda são aquelas com renda familiar mensal per capita de até meio salário mínimo ou aquelas que possuam renda familiar mensal de até três salários mínimos. Neste sentido, procedeu-se ao escalonamento das faixas de renda a partir deste decreto e considerando-se como baixas as rendas nominais médias de até três salários mínimos.

Para o cálculo do Indicador de Renda, considerou-se os valores absolutos de domicílios agregados para os setores censitários que compõem o MSP, por faixa de renda. Aplicou-se a equação 12 para o cálculo dos percentuais, a partir do número de domicílios, por setor censitário e por faixa de renda. Em seguida, para as faixas de renda de zero a 3 salários mínimos (de a a e), operou-se a equação 13, cuja finalidade é a determinação de parte dos índices de renda que comporão o Indicador de Renda final. Esta equação determina que os setores censitários com valores percentuais elevados de domicílios com baixa renda sejam classificados mais próximos ao valor mínimo do índice normalizado, que varia de 0 a 1 . Em outras palavras, para as faixas de renda de a) a e), quanto maior for o percentual de domicílios, por setor censitário, com renda média considerada baixa, menor é o valor dos índices de renda para cada uma dessas faixas de renda.

${ }^{10}$ SM: Salário(s) Mínimo(s) 
$\mathrm{PFR}=\frac{100 * \mathrm{DFR}}{\mathrm{SDFR}}$

Onde:

- PFR: percentual de domicílios, por faixa de renda e por setor censitário.

- DFR: número de domicílio, por faixa de renda e por setor censitário.

- SDFR: total de domicílios, por faixa de renda, para o universo dos setores censitários que compõem o município de São Paulo.

$\mathrm{IBR}=\frac{(\text { PFRae }- \text { MPFRae })}{(\text { mPFRae }- \text { MPFRae })}$

Onde:

- IBR: índices de baixa renda

- PFRae: percentual de domicílios, por faixa de renda e por setor censitário, das faixas de renda de a) a e).

- MPFRae: maior valor percentual de domicílios, por faixa de renda, para o universo dos setores censitários que compõem o município de São Paulo, das faixas de renda de a) a e).

- mPFRae: menor valor percentual de domicílios, por faixa de renda, para o universo dos setores censitários que compõem o município de São Paulo, das faixas de renda de a) a e).

Em seguida, operou-se a equação 14, para as faixas de renda acima de 3 salários mínimos (f, $\mathbf{g}, \mathbf{e} \mathbf{h}$ ). Como estas faixas não são consideradas como rendas baixas, a equação 14 determina que os setores censitários com valores percentuais elevados de domicílios com essas faixas de renda sejam classificados mais próximos do valor máximo do índice normalizado, que varia de 0 a 1 . Em outras palavras, para as faixas de renda de f) a $\mathbf{g}$ ), quanto maior for o percentual de domicílios, por setor censitário, com renda média não considerada baixa, maior é o valor dos índices de renda para cada uma dessas faixas de renda.

$\operatorname{IRE}=\frac{(\text { PFRfh }- \text { mPFRfh })}{(\text { MPFRfh }- \text { mPFRfh })}$

Onde:

- IRE: índices de renda elevadas.

- PFRfh: percentual de domicílios, por faixa de renda e por setor censitário, das faixas de renda de f) a h).

- mPFRfh: menor valor percentual de domicílios, por faixa de renda, para o universo de setores censitários do MSP, das faixas de renda de f) a h). 
- MPFRfh: maior valor percentual de domicílios, por faixa de renda, para o universo de setores censitários do MSP, das faixas de renda de f) a $\mathbf{h}$ ).

A partir deste conjunto de equações, foi possível elaborar, por fim, o Indicador de Renda para o universo de setores censitários que compõem o MSP. O referido indicador foi gerado a partir de uma média ponderada, conforme a equação 11, abaixo.

$$
\mathbf{I R}=\frac{((5 * I B R a+4 * I B R b+3 * I B R c+2 * I B R d+I B R e) / 15)+((\operatorname{IREf}+\operatorname{IREg}+\operatorname{IREh}) / 3)}{2}
$$

Onde:

- IR: Indicador de Renda

- IBRa: índice de baixa renda para a faixa de renda a).

- IBRb: índice de baixa renda para a faixa de renda b).

- IBRc: índice de baixa renda para a faixa de renda c).

- IBRd: índice de baixa renda para a faixa de renda d).

- IBRe: índice de baixa renda para a faixa de renda e).

- IREf: índice de renda elevada para a faixa de renda f).

- IREg: índice de renda elevada para a faixa de renda g).

- IREh: índice de renda elevada para a faixa de renda $\mathbf{h}$ ).

A partir da equação 15, foi possível classificar de forma normalizada e comparativamente os setores censitários do MSP a partir da composição das rendas médias por domicílio. O Indicador de Renda varia de 0 a 1 , de forma que os setores que apresentam percentuais mais elevados de moradias com baixas rendas foram classificados mais próximos do valor nulo, e os setores que apresentam percentuais mais elevados de moradias com rendas altas, foram classificados mais próximos do valor 1 .

Os resultados dos procedimentos metodológicos adotados nesta subseção serão apresentados e analisados no capítulo 3.

\subsubsection{Indicador de Alfabetização}

Os dados absolutos concernentes ao número de pessoas alfabetizadas, por faixa etária e setor censitário, disponibilizados pelo IBGE para o MSP (IBGE, 2010), foram reorganizados em três faixas etárias: de 5 a 15 anos (estágio de alfabetização obrigatória), de 16 a 65 anos (alfabetização relevante para definição de status econômico e acesso às informações de saúde) e mais de 66 anos (alfabetização desejada). Para cada uma dessas faixas etárias, calculou-se o 
percentual de pessoas alfabetizadas relativamente ao total de habitantes, de acordo com as três faixas etárias definidas, conforme equação 16, disposta abaixo.

PALF $=\frac{100 * \mathrm{NALF}}{\mathrm{PTFE}}$

Onde:

- PALF: percentual de pessoas alfabetizadas, por faixa etária e por setor censitário.

- NALF: número de pessoas alfabetizadas, por faixa etária e por setor censitário.

- PTFE: total de habitantes, por faixa etária e por setor censitário.

Em seguida, os valores percentuais para cada faixa etária foram normalizados para uma escala de 0 a 1, de forma que, quanto mais próximo de 1, maior o índice de alfabetização de um determinado distrito. Neste sentido, aplicou-se a equação 17 , disposta abaixo.

IALFE $=\frac{(\text { PALFE }- \text { mPALFE })}{(\text { MPALFE }- \text { mPALFE })}$

Onde:

- IALFE: índice de alfabetização por faixa etária.

- PALFE: percentual de alfabetizados, por faixa etária e por setor censitário.

- mPALFE: menor valor percentual, por faixa etária, para o universo de setores censitários do MSP.

- MPALFE: maior valor percentual, por faixa etária, para o universo de setores censitários do MSP.

Os índices de alfabetização para cada uma das faixas etárias compuseram, por fim, o Indicador de Alfabetização. Tal composição foi calculada a partir da média ponderada exposta na equação 18, abaixo. Considerou-se que a faixa etária de 5 a 15 anos representa o período de alfabetização obrigatório, porém de relevância menor, do ponto de vista do acesso à saúde pública atualmente, haja vista representar a parcela da população menor de idade, dependente do acesso à saúde e às informações de saúde recebidas pela família. A faixa etária de 16 a 65 anos foi considerada a mais relevante, pois o nível de alfabetização neste período é determinante para o status econômico dos indivíduos e para o acesso à saúde pública. Por fim, para a faixa etária acima de 66 anos representa um recorte histórico de acesso à educação, sendo considerada, portanto, a de menor peso para o cálculo do Indicador de Alfabetização. 
$\mathbf{I A}=\frac{(3 * \mathrm{IALFEa}+5 * \mathrm{IALFEb}+2 * \mathrm{IALFEc})}{10}$

Onde:

- IA: Indicador de Alfabetização.

- IALFEa: índice de alfabetização para a faixa etária de 5 a 15 anos.

- IALFEb: índice de alfabetização para a faixa etária de 16 a 65 anos.

- IALFEc: índice de alfabetização para a faixa etária acima de 66 anos.

Os resultados produzidos a partir da metodologia apresentada nesta subseção serão apresentados e analisados em capítulo subsequente.

\subsubsection{Indicador Socioeconômico e Agregação dos Dados}

O Indicador Socioeconômico foi gerado a partir da média aritmética simples dos indicadores de renda e de alfabetização. No capítulo 3 apresentaremos o mapeamento desses indicadores, bem como uma análise detalhada dos resultados obtidos.

Nesta subseção será apresentada a metodologia para agregação dos indicadores de renda, de alfabetização e socioeconômico na escala dos distritos administrativos do município de São Paulo. Para tanto, utilizou-se a ferramenta Dissolve do ArcGIS 9.0.

Os setores censitários que compõem o MSP são classificados a partir de um identificador individual, o código do setor. Além deste código, para cada setor censitário também é definido um código do distrito ao qual ele pertence. Este código possibilita a utilização da ferramenta Dissolve, a qual é capaz de agrupar os valores dos indicadores em questão a partir do cálculo da média desses valores para o conjunto de setores censitários que compõem um determinado distrito. Além da média, a referida ferramenta é capaz de executar outros cálculos, entre os quais se encontra o desvio padrão dos valores considerados para agregação. Neste sentido, ao agregar-se os valores dos indicadores de renda, de alfabetização e socioeconômico dos setores censitários para a escala dos distritos administrativos, operou-se o cálculo da média dos valores desses indicadores para o conjunto de setores censitários que compõem o universo dos distritos administrativos do MSP.

Posteriormente, os valores médios desses indicadores serão utilizados para a análise da relação entre a impermeabilização do solo e o Indicador de Mortalidade MSC.

No capítulo 2, serão apresentados os resultados das agregações, bem como suas respectivas análises. 


\subsection{Indicador de Fragilidade Etária}

Considerando-se a taxa de mortalidade por doenças associadas ao aparelho circulatório, por faixa etária quinquenal para a totalidade dos distritos administrativos do MSP, foi possível computar a tabela 2.6, disposta a seguir.

Tabela 2.6 - Taxa de mortalidade MSC (por 100.000 habitantes) segundo faixa etária

\begin{tabular}{l|r}
\hline \multicolumn{1}{c|}{ Faixa Etária } & Taxa MSC (por 100000 habitantes) \\
\hline 0 a 4 anos & 33,56 \\
\hline 5 a 9 anos & 4,35 \\
\hline 10 a 14 anos & 8,54 \\
\hline 15 a 19 anos & 61,60 \\
\hline 20 a 24 anos & 92,92 \\
\hline 25 a 29 anos & 88,13 \\
\hline 30 a 34 anos & 144,81 \\
\hline 35 a 39 anos & 243,29 \\
\hline 40 a 44 anos & 386,18 \\
\hline 45 a 49 anos & 560,21 \\
\hline 50 a 54 anos & 965,85 \\
\hline 55 a 59 anos & 1289,31 \\
\hline 60 a 64 anos & 1787,08 \\
\hline 65 a 69 anos & 2181,12 \\
\hline 70 a 74 anos & 2319,59 \\
\hline Acima de 75 anos & 9304,55 \\
\hline
\end{tabular}

Fonte: TabNet (PMSP, 2018). Elaboração própria. Data: 08/02/2018.

Uma análise pormenorizada desta tabela indica um crescimento significativo da taxa de mortalidade MSC com o aumento da faixa etária considerada, conforme podemos observar no gráfico 2.10, a seguir. 
Gráfico 2.10 - Taxa de Mortalidade MSC (por 100.000 habitantes) Acumulada

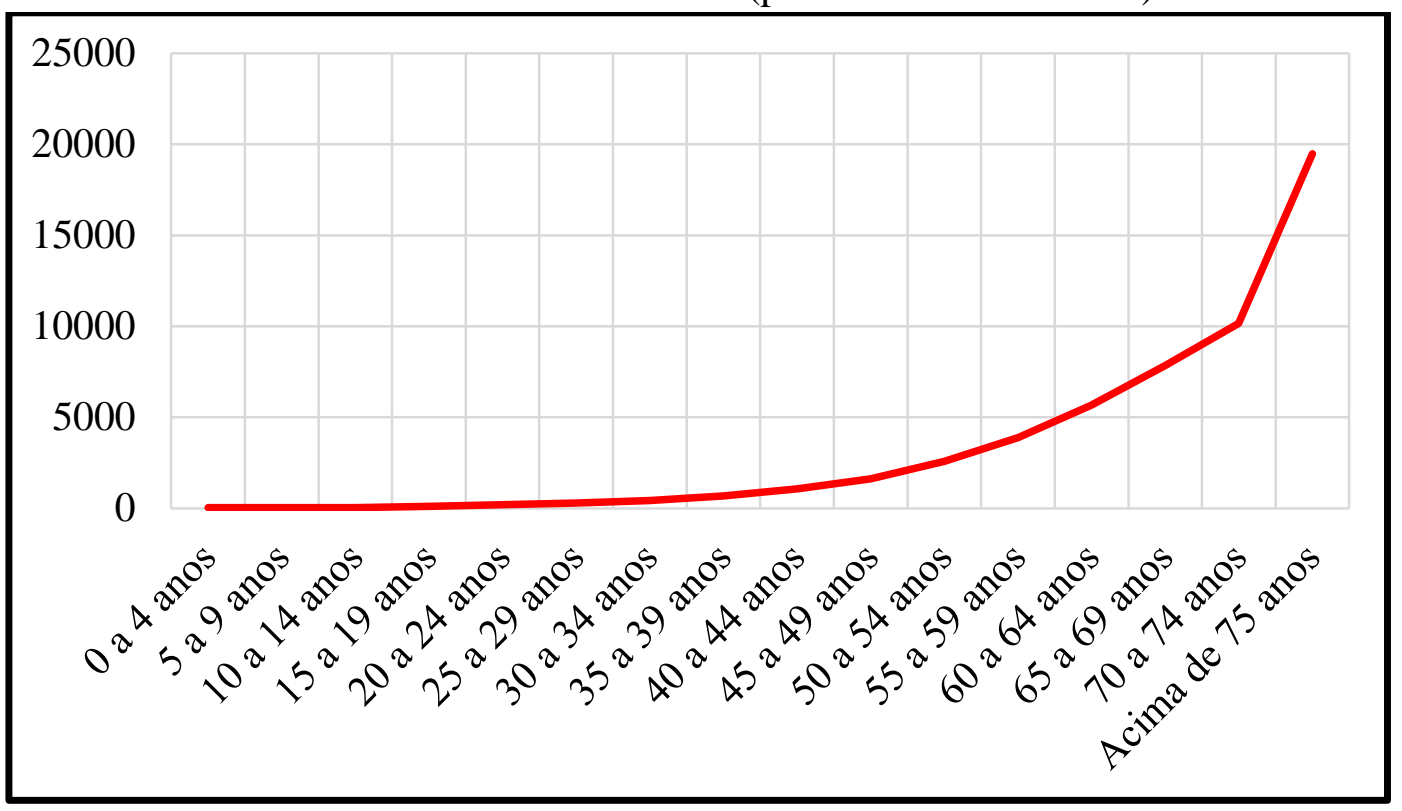

Fonte: TabNet (PMSP, 2018). Elaboração própria. Data: 08/02/2018.

Levando em consideração estes dados, é possível detalhar a distribuição das taxas em um diagrama de caixa, conforme apresentado no gráfico 2.11 , abaixo.

Gráfico 2.11 - Bloxpot da taxa de mortalidade MSC.

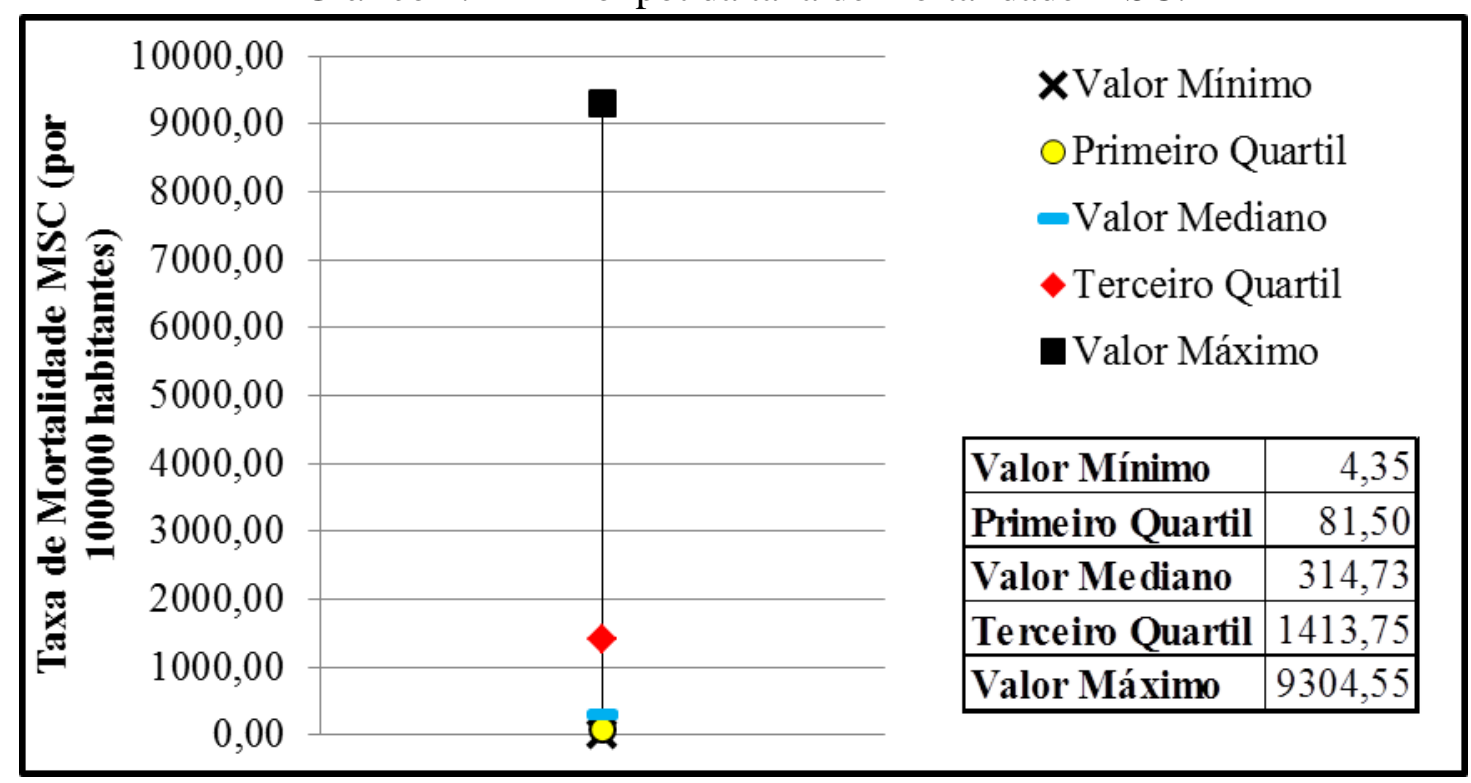

Fonte: Elaboração própria. Data: 03/02/2018.

Observa-se, no gráfico 2.11 acima, que a distância entre o valor máximo e o terceiro quartil, a qual é representativa de $25 \%$ das ocorrências analisadas, concentra consideravelmente altas taxas de mortalidade MSC. Este quartil, cuja taxa MSC mínima é equivalente a 1413,75 
óbitos por 100.000 habitantes, localiza-se entre as faixas etárias de 55 a 64 anos. Esta concentração do número de óbitos MSC nas faixas acima de 55 anos está relacionada à maior susceptibilidade dos idosos às ocorrências das doenças associadas ao sistema circulatório. Neste sentido, faz-se necessário computar um indicador de fragilidade etária que considere estas faixas etárias acima de 55 anos e que possibilite uma análise da relação entre a concentração de pessoas com mais de 55 anos e a ocorrência de óbitos MSC, por distrito administrativo do MSP.

No âmbito desta finalidade, adotou-se os dados relativos à composição etária da população do censo de 2010 agregados por setor censitário (IBGE, 2010). Contabilizou-se o total populacional e o número de habitantes com 55 anos ou mais, por setor censitário. Em seguida, aplicou-se a equação 19, abaixo, no intuito de se calcular o percentual de habitantes com mais de 55 anos, por setor censitário.

$$
\mathbf{P 5 5}=\frac{100 * \mathrm{~N} 55}{\mathrm{TH}}
$$

Onde:

- P55: percentual de habitantes com mais de 55 anos, por setor censitário.

- N55: número de habitantes com mais de 55 anos, por setor censitário.

- TH: total de habitantes, por setor censitário.

Na sequência, com base na equação 20, elaborou-se um indicador de fragilidade etária normalizado capaz de discriminar quantitativamente os setores com maior concentração de habitantes com idades acima de 55 anos. O referido indicador opera da seguinte maneira: quanto mais próximo de 1 , maior a fragilidade etária e, quanto mais próximo de 0 , menor a fragilidade etária, ou seja, menor a concentração de idosos. Em outras palavras, setores censitários com indicadores mais próximos de 1 são mais susceptíveis, do ponto de vista da composição etária, à ocorrência das doenças associadas ao sistema circulatório.

$$
\mathbf{I F E}=\frac{(\mathrm{P} 55-\mathrm{mP55})}{(\mathrm{MP5} 5-\mathrm{mP} 55)}
$$

Onde:

- IFE: indicador de fragilidade etária.

- P55: percentual de habitantes com mais de 55 anos, por setor censitário.

- mP55: menor valor percentual de habitantes com mais de 55 anos, para o universo dos setores censitários que compõem o MSP. 
- MP55: maior valor percentual de habitantes com mais de 55 anos, para o universo dos setores censitários que compõem o MSP.

Por fim, agregou-se os valores do Indicador de Fragilidade Etária, para o nível dos distritos administrativos do MSP, com auxílio da ferramenta Dissolve, do ArcGIS 9.0. Ao se agregar os valores do referido indicador, operou-se o cálculo da média dos valores desse indicador para o conjunto de setores censitários que compõem cada distrito administrativo do MSP.

O indicador em questão nesta subseção, bem como o indicador socioeconômico, serão aplicados para discriminação dos distritos que apresentam forte correlação entre questões socioeconômicas e demográficas e a ocorrência dos óbitos MSC, haja vista a necessidade de se avaliar a relação entre a impermeabilização do solo e a ocorrência desta tipologia de óbitos, evitando-se, para isto, a interferência de outros fatores também determinantes para a taxa de mortalidade MSC. Neste sentido, no próximo subcapítulo será apresentada a metodologia adotada para seleção dos distritos para os quais se realizou a análise da referida relação. No capítulo 3, serão apresentados os resultados obtidos a partir dos procedimentos metodológicos apresentados nesta subseção.

\subsection{Seleção dos Distritos Administrativos Adequados para Análise}

A seleção dos distritos administrativos mais adequados para análise da relação entre impermeabilização do solo e a taxa de mortalidade das doenças associadas ao aparelho circulatório considerou os indicadores socioeconômico e de fragilidade etária no intuito de se verificar quais distritos possuíam maior correlação entre esses indicadores e o indicador de mortalidade MSC. Partindo-se desta correlação, foi possível identificar os distritos nos quais esses indicadores estavam menos associados à tipologia de mortalidade em questão.

A análise dos clusters de mortalidade MSC, que poderá ser melhor apreciada no capítulo 3, indicou uma alta correlação entre os indicadores de renda e socioeconômico e o índice relativo a esta tipologia de mortalidade, conforme podemos observar nos gráficos $2.12 \mathrm{e}$ 2.13, dispostos abaixo. 
Gráfico 2.12 - Relação entre o indicador socioeconômico e o indicador de mortalidade MSC para as áreas de clusters de mortalidade MSC

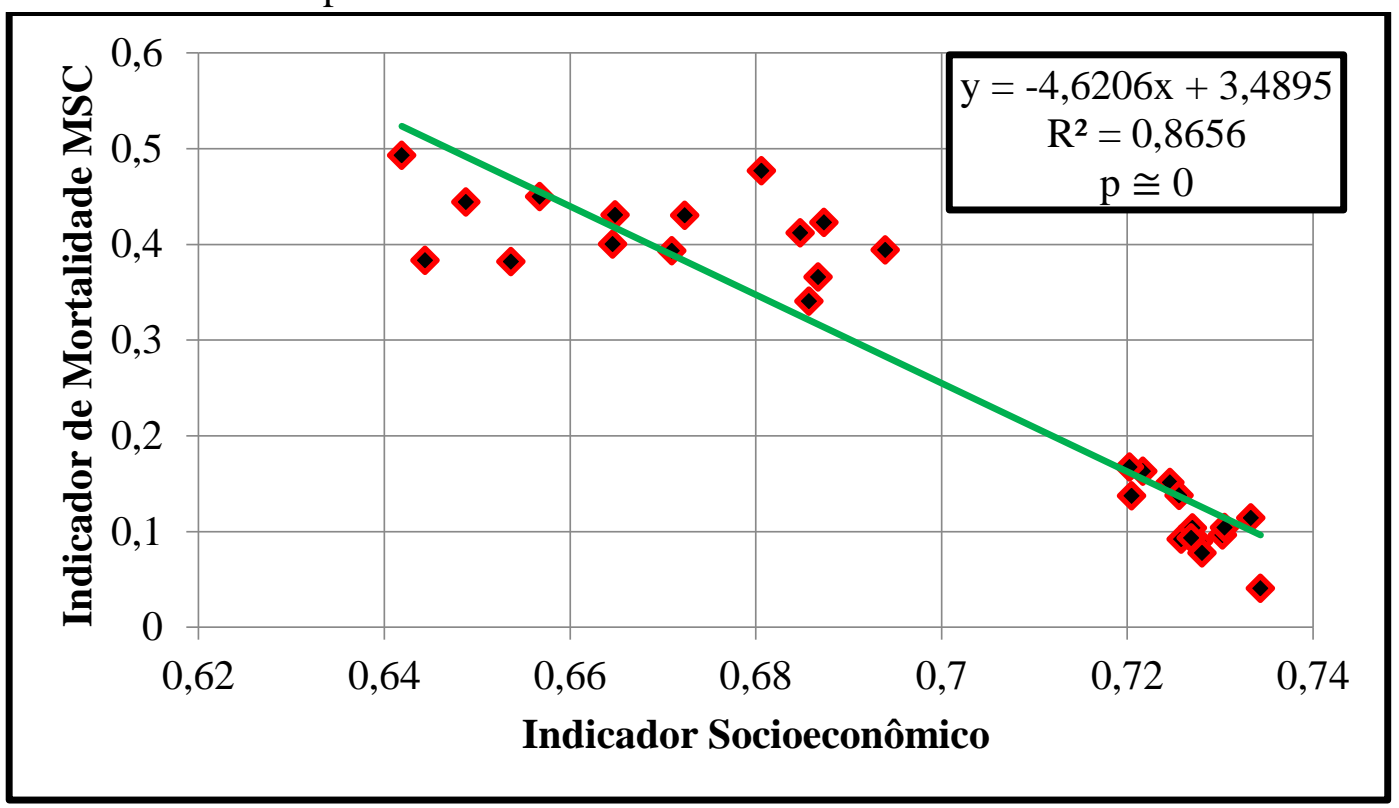

Fonte: Elaboração própria. Data: 04/02/2018.

Gráfico 2.13 - Relação entre o indicador de renda e o indicador de mortalidade MSC para as áreas de clusters de mortalidade MSC

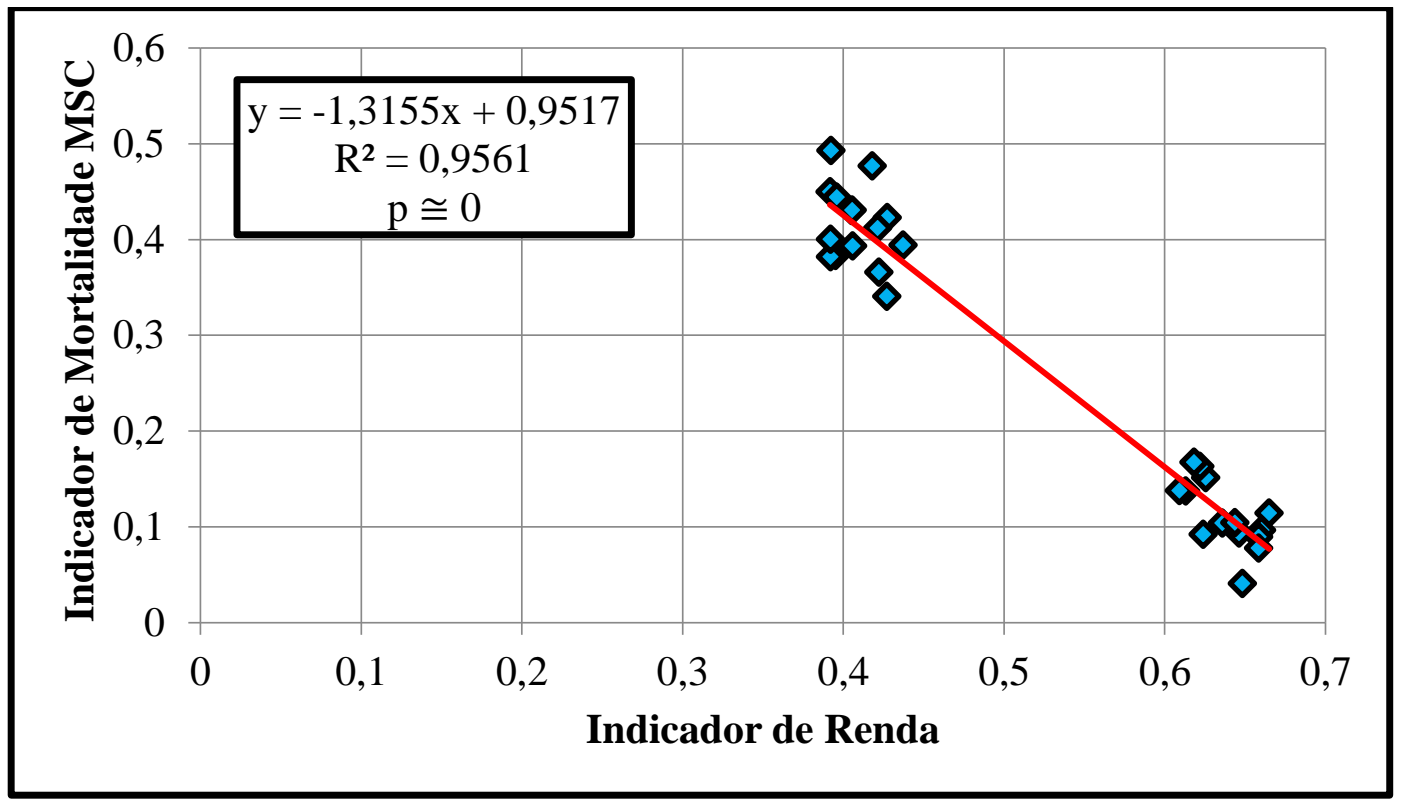

Fonte: Elaboração própria. Data: 04/02/2018.

Observa-se que o coeficiente de determinação entre os indicadores de renda e de mortalidade MSC é superior ao da regressão representativa da correlação entre este indicador de mortalidade e o socioeconômico. Este resultado obtido deve-se à correlação entre o indicador de alfabetização e o referido indicador de mortalidade para as áreas em questão, como se pode observar no gráfico 2.14 . 
Gráfico 2.14 - Relação entre o indicador de alfabetização e o indicador de mortalidade MSC para as áreas de clusters de mortalidade MSC

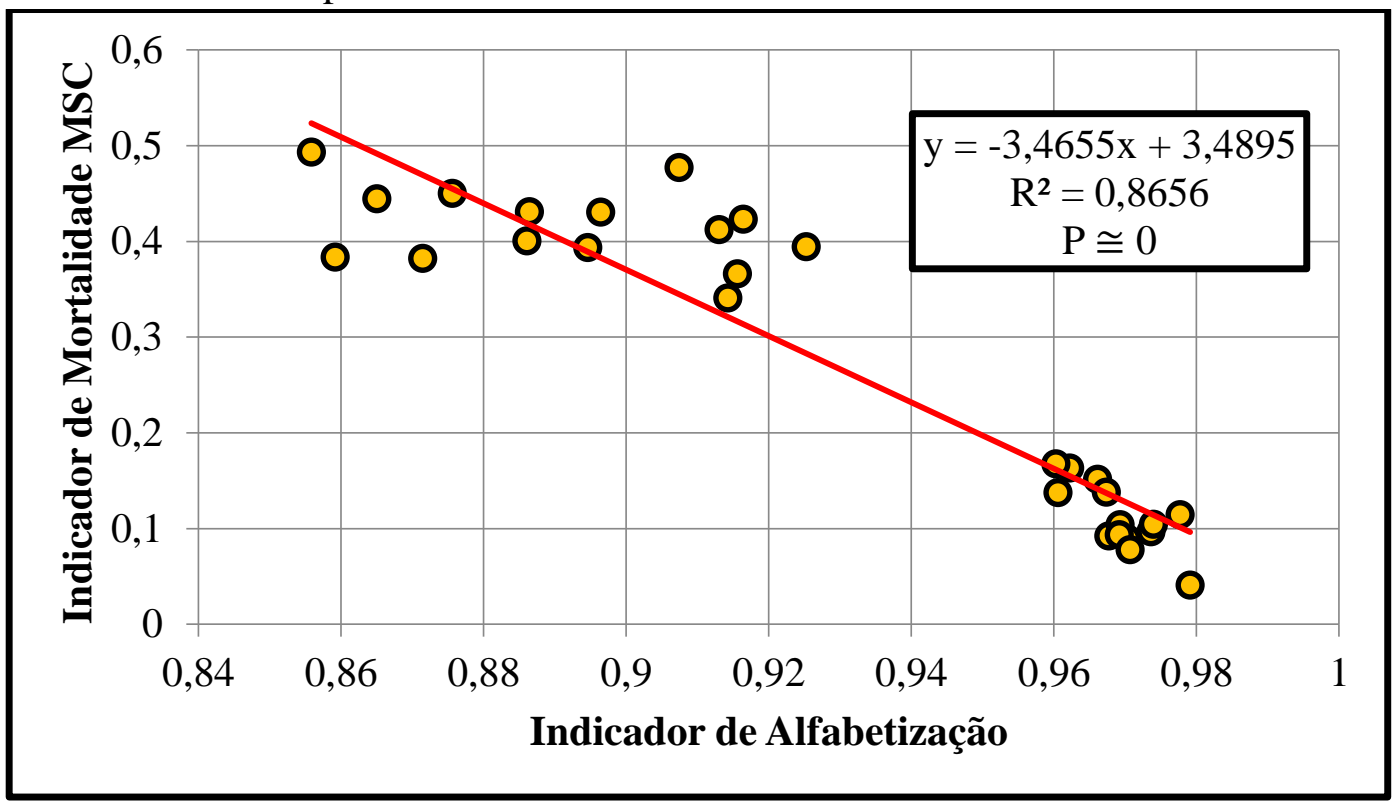

Fonte: Elaboração própria. Data: 04/02/2018.

Nota-se que o coeficiente de determinação da regressão apresentada no gráfico 2.14 é considerável, porém responsável pela menor correlação observada entre o indicador socioeconômico e o indicador de mortalidade MSC relativamente à correlação observada entre este indicador e o de renda. Assim sendo, considerou-se o indicador de renda o mais apto para o prosseguimento do procedimental metodológico.

Partindo-se desta análise, observou-se que a relação entre os indicadores de renda e de mortalidade MSC também é significativa quando se considera a totalidade dos distritos administrativos que compõem o município de São Paulo. Neste sentido, por um lado, observase um alto coeficiente de determinação no gráfico 2.13 (próximo a 96\%) e um valor-p de significância tendendo à nulidade, sugerindo, portanto, desconsiderarmos a hipótese nula. Por outro lado, no gráfico 2.15, disposto abaixo, observa-se também um elevado coeficiente de determinação (aproximadamente $75 \%$ ), porém menor que o do gráfico 2.13 , sugerindo a necessidade de se considerar outros determinantes para a compreensão da distribuição da taxa de mortalidade MSC no município de São Paulo. Ademais, no gráfico 2.15 o valor-p de significância também tende a zero, sugerindo desconsiderarmos a hipótese nula. 
Gráfico 2.15 - Relação entre o indicador de renda e o indicador de mortalidade MSC considerando-se a totalidade dos distritos administrativos do MSP

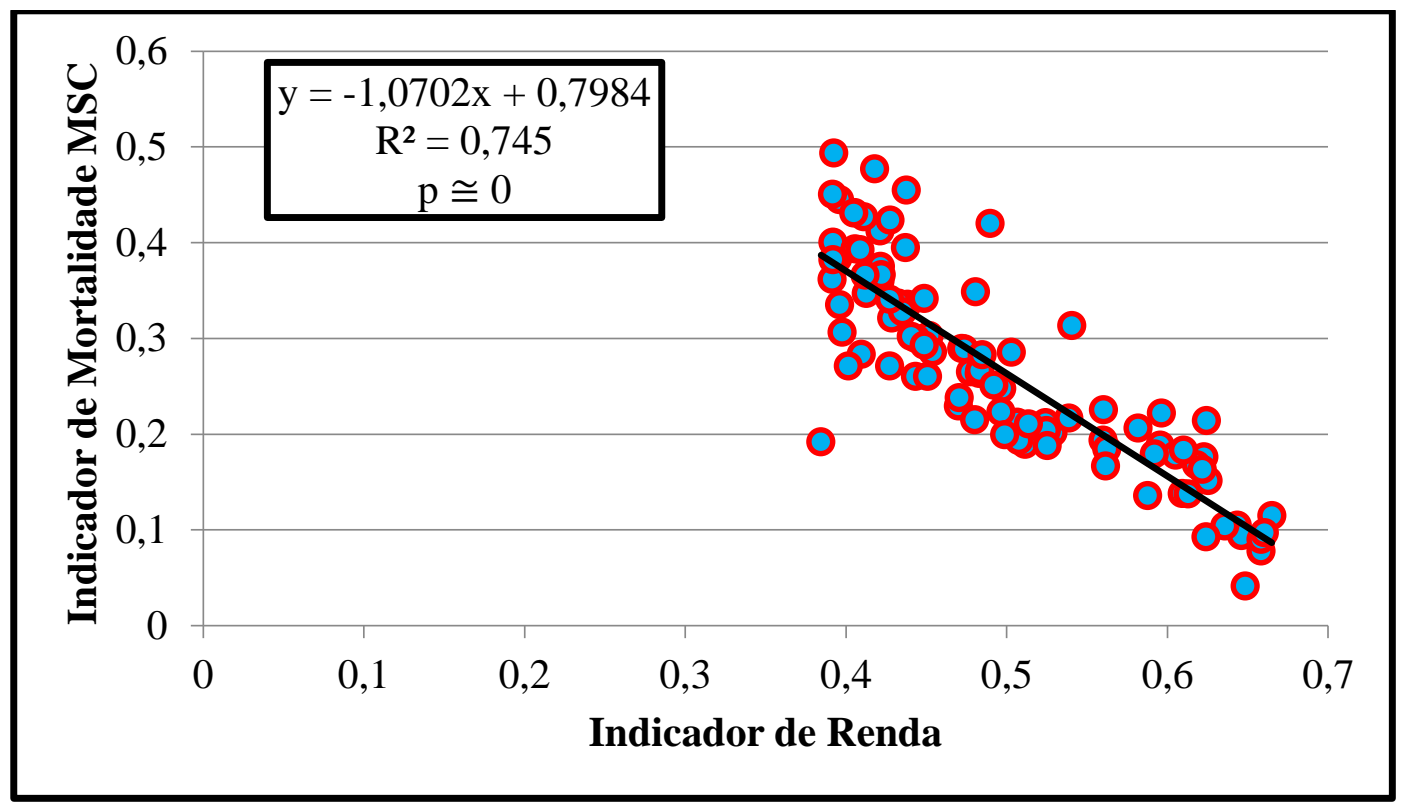

Fonte: Elaboração própria. Data: 04/02/2018.

Partindo-se desses dados, aplicou-se a equação disponível no gráfico 2.15 para que se pudesse estimar, em cada distrito do MSP, sua taxa de mortalidade (y) a partir de seu respectivo indicador de renda $(\mathbf{x})$. A finalidade deste procedimento metodológico não consiste em simplesmente determinar o indicador MSC a partir do indicador de renda, mas de selecionar os distritos que, na modelagem, apresentaram menor correlação com a reta determinada pela equação. Neste sentido, calculou-se, para cada distrito do MSP, os resíduos da modelagem em questão. No gráfico 2.16, disposto abaixo, apresenta-se a distribuição desses resíduos, os quais indicam que o modelo utilizado apresenta uma boa acurácia. 
Gráfico 2.16 - Frequência das classes de resíduos da modelagem MSC

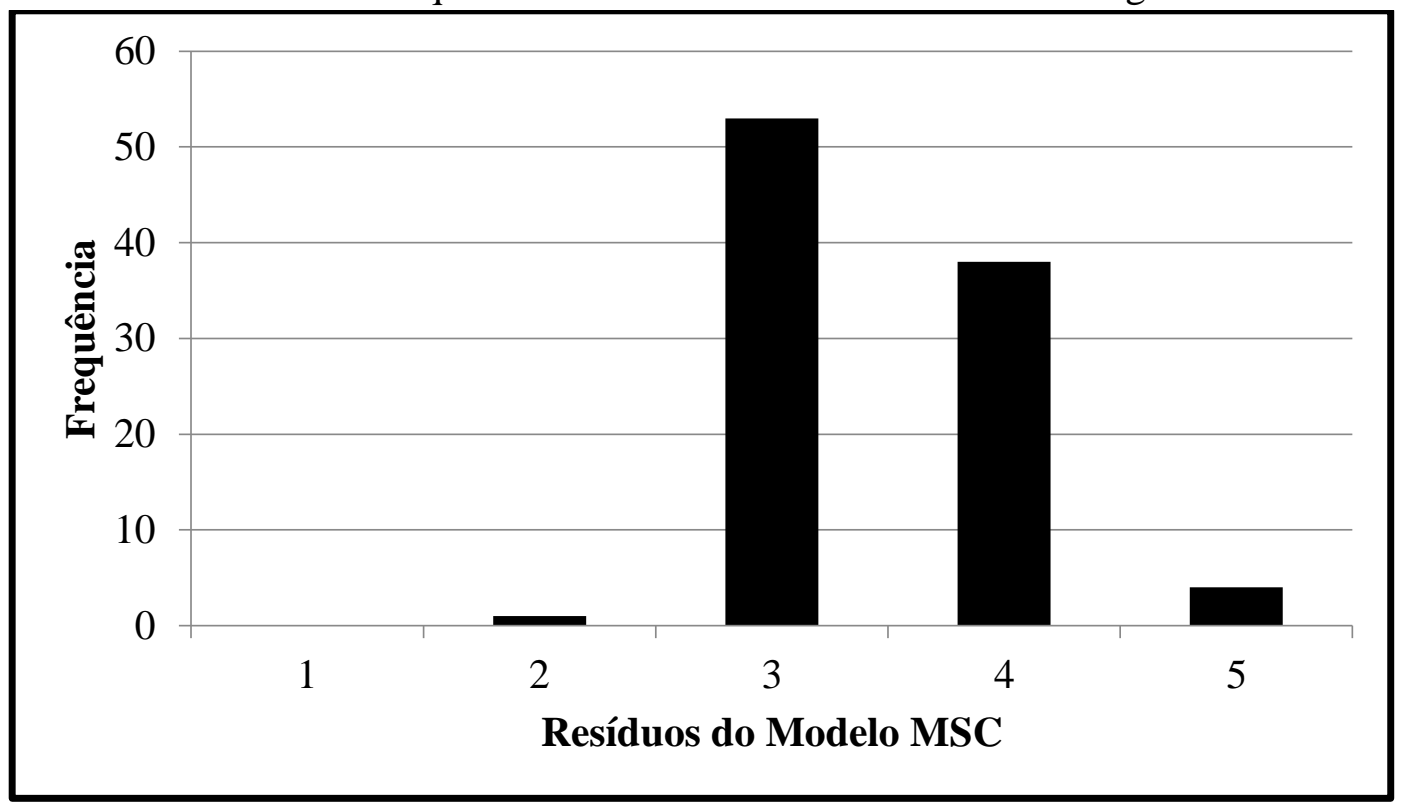

Fonte: Elaboração própria. Data: 04/02/2018.

Ademais, a partir da análise do diagrama de caixa (gráfico 2.17) abaixo, pode-se compreender que a dispersão dos resíduos não distou significativamente da média, que se igualou a zero, indicando que a modelagem apresentou resultados bastante condizentes com a realidade estimada.

Gráfico 2.17 - Bloxpot dos resíduos do modelo MSC

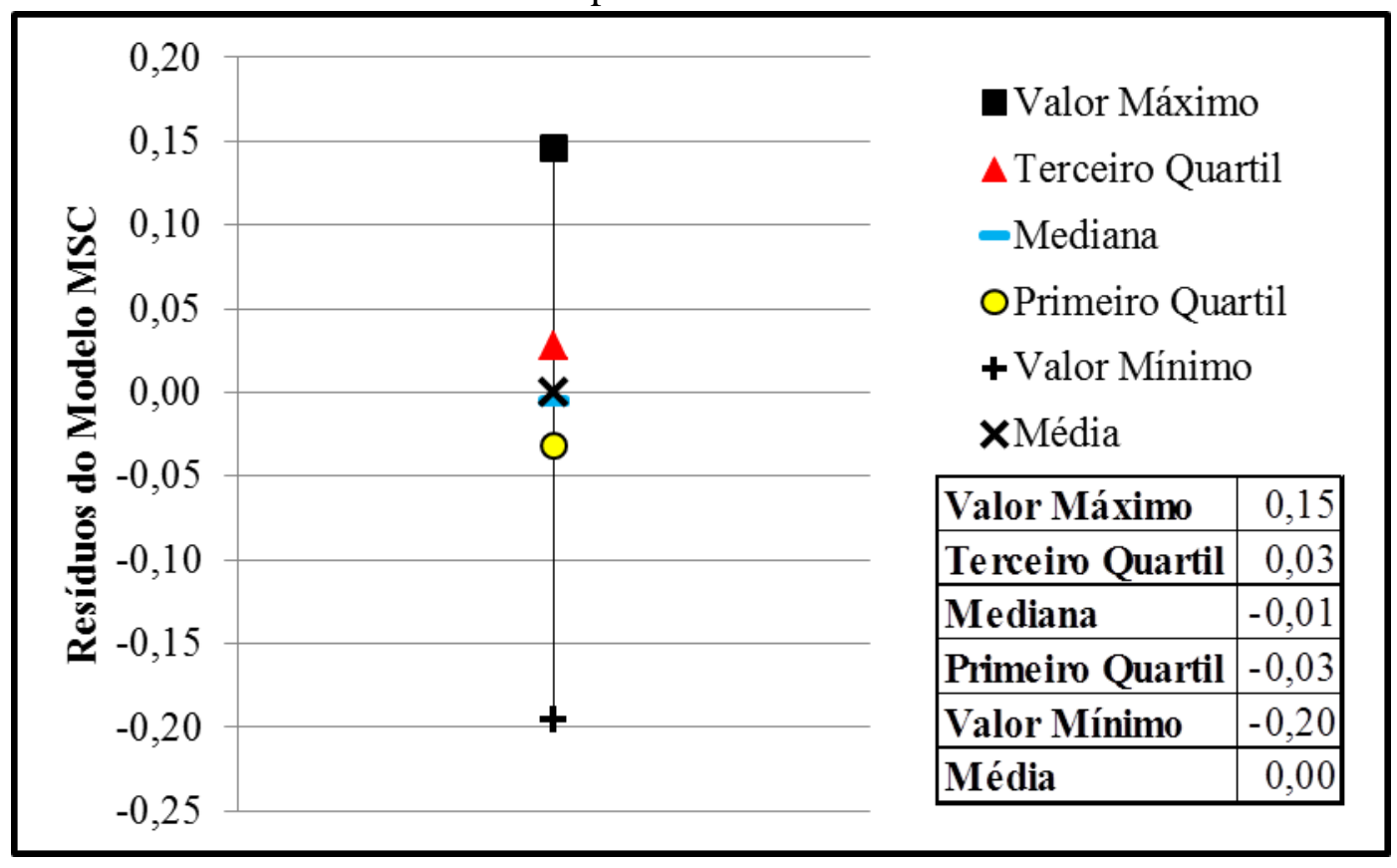

Fonte: Elaboração própria. Data: 04/02/2018. 
Conclui-se, portanto, que o modelo estimativo da mortalidade MSC, ao tomar como variável explicativa o indicador de renda, ratificou a forte correlação entre este indicador e o de mortalidade MSC, o que pode ser observado na análise dos resíduos da referida modelagem. Neste sentido, adotou-se a distribuição desses resíduos para se selecionar os distritos nos quais o indicador de renda apresentou menor eficiência em estimar o indicador de mortalidade MSC. Tendo em vista esta finalidade, considerou-se o desvio padrão dos resíduos, cujo valor é de 0,053, bem como a média, que se equivale a zero. Operou-se, então, a discriminação dos distritos a partir dos valores de seus resíduos, de forma que os distritos cujos valores residuais se encontravam no intervalo entre um desvio padrão e meio abaixo da média e um desvio padrão e meio acima da média foram considerados os que apresentavam melhor correlação entre os indicadores de renda e de mortalidade MSC. O restante dos distritos foi considerado como sendo menos ajustado à reta da modelagem MSC, carecendo, portanto, de outros indicadores explicativos para a compreensão dos valores dos seus respectivos indicadores de mortalidade MSC.

Assim sendo, dos noventa e seis distritos administrativos que compõem o município de São Paulo, nove deles foram discriminados a partir do procedimento descrito no parágrafo anterior, conforme disposto na tabela 2.7 , abaixo.

Tabela 2.7 - Distritos selecionados a partir dos resíduos da modelagem MSC

$\frac{\text { Distrito }}{\frac{1-\text { Belém }}{2-\text { Brás }}}$
$\frac{\frac{3 \text { - Cachoeirinha }}{4-\text { José Bonifácio }}}{5-\text { Marsilac }}$
Fonte: Elaboração própria. Data: $05 / 02 / 2018$.

A despeito dos procedimentos metodológicos dispostos nesta subseção e na subseção 2.1.2, relativa à modelagem estimativa da impermeabilização do solo para o município de São Paulo, considerou-se sensato proceder à exclusão do distrito de Marsilac, haja vista a necessidade de se manter a maior rigorosidade metodológica possível. O referido distrito apresenta uma parcela de seu território fora do modelo de impermeabilização elaborado, indicando-se a necessidade de se proceder à sua exclusão, ainda que, do ponto de vista 
metodológico seja aceitável considerar esta área. Porém, o aceitável é uma opção subjetiva, sugerindo que, para melhor prosseguimento da análise, seja razoável proceder à exclusão do distrito administrativo do conjunto dos nove distritos discriminados para análise.

Destarte, dentre os 96 distritos administrativos que compõem o município de São Paulo, discriminou-se 8 distritos para o prosseguimento dos procedimentos analíticos, sendo que, para estes distritos, a variável explicativa adotada (o indicador de renda) apresenta correlação desconsiderável com o indicador de mortalidade MSC. Na tabela 2.8 estão dispostos os distritos, bem como seus respectivos indicadores de renda e de mortalidade MSC.

Tabela 2.8 - Indicadores de Renda e de Mortalidade MSC para os oito distritos selecionados a partir dos resíduos da modelagem MSC

\begin{tabular}{l|r|r}
\hline \multicolumn{1}{c|}{ Distrito } & Indicador de Renda & Indicador de Mortalidade MSC \\
\hline 1 - Belém & 0,54 & 0,31 \\
\hline 2 - Brás & 0,49 & 0,42 \\
\hline 3 - Cachoeirinha & 0,44 & 0,45 \\
\hline 4 - José Bonifácio & 0,42 & 0,48 \\
\hline 5 - Parelheiros & 0,39 & 0,49 \\
\hline 6 - Parque do Carmo & 0,43 & 0,42 \\
\hline 7 - Perus & 0,40 & 0,27 \\
\hline 8 - Vila Leopoldina & 0,62 & 0,21 \\
\hline
\end{tabular}

Fonte: Elaboração própria. Data: 05/02/2018.

Considerando-se as informações da tabela 2.8, nota-se que, para estes distritos, a relação entre os indicadores de renda e de mortalidade MSC é notavelmente desconsiderável, pois, ainda que esta correlação apresente um coeficiente de determinação aproximadamente equivalente a 47, o valor-p de significância extrapola o limite admissível de 0,05, indicando que não se pode desconsiderar a hipótese nula e que, portanto, para esses distritos, o status socioeconômico não explica eficazmente, do ponto de vista estatístico, a taxa de mortalidade associada às doenças do aparelho circulatório. Esses dados podem ser melhor apreciados no gráfico 2.18, disposto abaixo. 
Gráfico 2.18 - Relação entre os indicadores de renda e de mortalidade MSC nos distritos arrolados na tabela 2.8

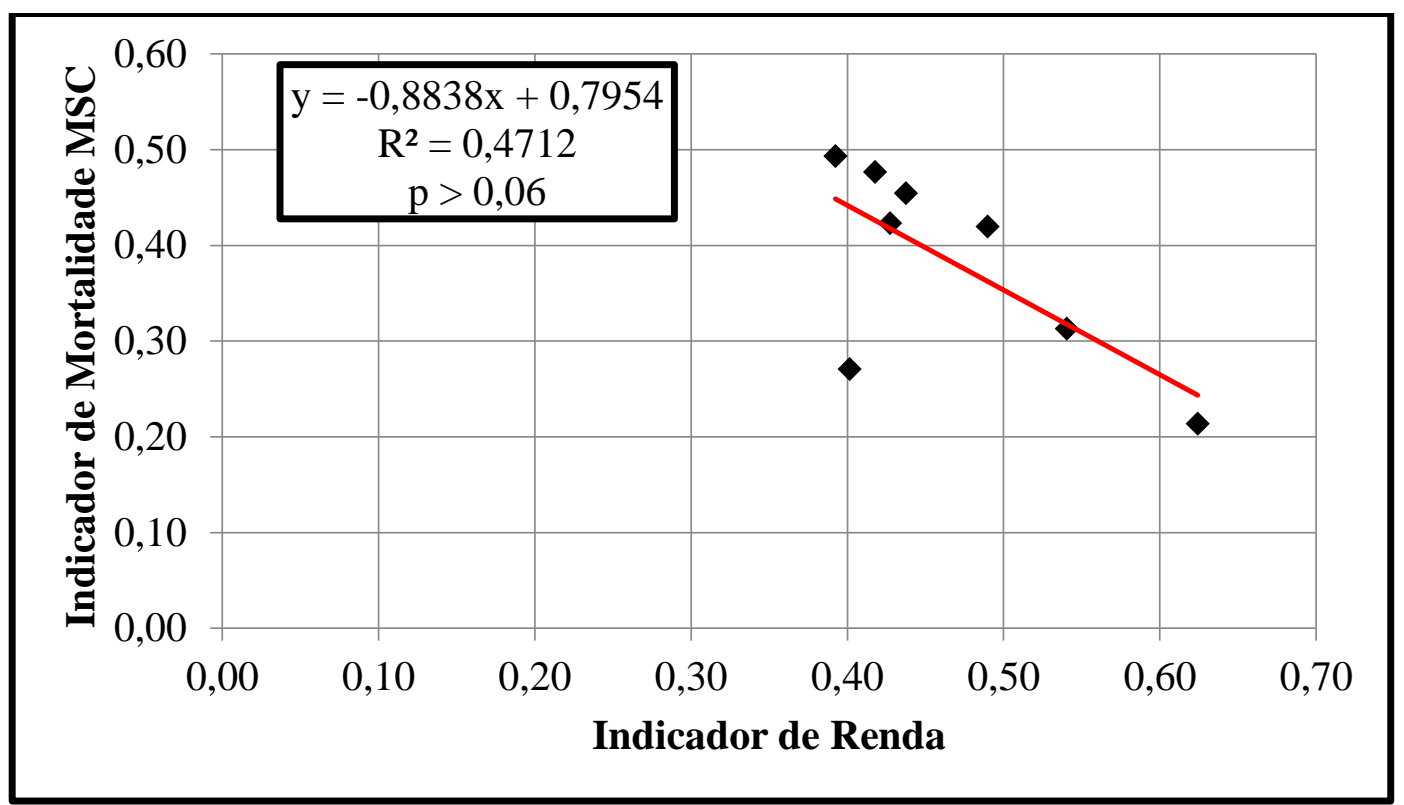

Fonte: Elaboração própria. Data: 05/02/2018.

Ademais, tendo em vista a apreciável relação entre a distribuição dos óbitos MSC e a concentração de indivíduos com mais de 55 anos nos distritos administrativos do MSP, faz-se necessário considerar o indicador de fragilidade etária e sua relação com o indicador de mortalidade MSC para os 8 distritos selecionados. Esta relação está expressa no gráfico 2.19 e toma como base os dados da tabela 2.9 .

Tabela 2.9 - Indicadores de Mortalidade MSC e de Fragilidade Etária para os oito distritos administrativos discriminados

\begin{tabular}{l|r|r}
\hline \multicolumn{1}{c|}{ Distrito } & Indicador de Fragilidade Etária & Indicador de Mortalidade MSC \\
\hline 1 - Belém & 0,22 & 0,31 \\
\hline 2 - Brás & 0,16 & 0,42 \\
\hline 3 - Cachoeirinha & 0,14 & 0,45 \\
\hline 4 - José Bonifácio & 0,15 & 0,48 \\
\hline 5 - Parelheiros & 0,11 & 0,49 \\
\hline 6 - Parque do Carmo & 0,14 & 0,42 \\
\hline 7 - Perus & 0,12 & 0,27 \\
\hline 8 - Vila Leopoldina & 0,19 & 0,21 \\
\hline
\end{tabular}

Fonte: Elaboração própria. Data: 04/02/2018.

Partindo-se das informações da tabela 2.9, pode-se calcular a reta de regressão que correlaciona os indicadores de mortalidade MSC e de fragilidade etária para os distritos selecionados, conforme observa-se no gráfico 2.19 . 
Gráfico 2.19 - Relação entre os indicadores de mortalidade MSC e de fragilidade etária para os oito distritos administrativos discriminados

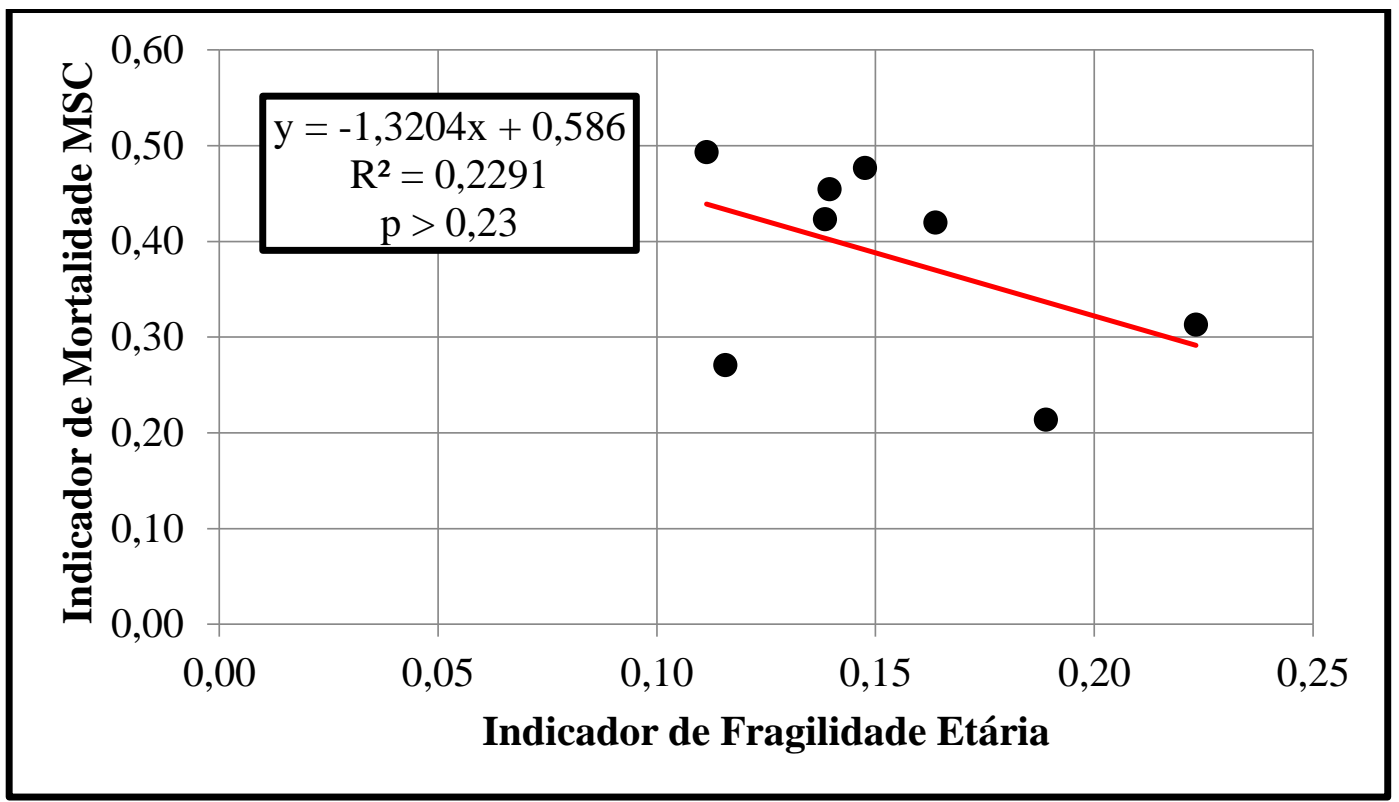

A análise do gráfico 2.19 indica haver uma correlação desconsiderável entre os indicadores considerados, haja vista o coeficiente de determinação ser aproximadamente $23 \%$ e o valor-p de significância ser maior que 0,23, indicando a impossibilidade de desconsiderarmos a hipótese nula. Destarte, os oito distritos discriminados apresentam condições satisfatórias para que se dê prosseguimento à análise da relação entre o indicador de mortalidade MSC e a impermeabilização do solo.

Por fim, vale ressaltar que os resultados dos procedimentos descritos neste subcapítulo serão melhor apresentados e discutidos no capítulo 3 desta obra.

2.7. Relação entre Impermeabilização do Solo e os Óbitos Associados às Doenças do Sistema Circulatório

A análise da relação entre impermeabilização do solo e o indicador de mortalidade MSC foi realizada com auxílio dos dados relativos ao conjunto de indicadores elaborados previamente, para os oito distritos discriminados, conforme tabela 2.10, a seguir. 
Tabela 2.10 - Indicadores elaborados para a análise dos oito distritos selecionados

\begin{tabular}{|c|c|c|c|c|c|c|c|c|c|c|c|c|}
\hline $\begin{array}{c}\text { Código } \\
\text { do } \\
\text { Distrito }\end{array}$ & Nome do Distrito & Área $\left(\mathbf{m}^{2}\right)$ & $\begin{array}{c}\text { Impermeabilização } \\
\text { do Solo }\left(\mathbf{m}^{2}\right)\end{array}$ & $\begin{array}{c}\text { Impermeabilização } \\
\text { do Solo }(\%)\end{array}$ & \begin{tabular}{|c|} 
Indicador de \\
Variabilidade de \\
Impermeabilização \\
do Solo \\
\end{tabular} & TAS $\left({ }^{\circ} \mathbf{c}\right)$ & $\begin{array}{c}\text { Indicador de } \\
\text { Mortalidade } \\
\text { MSC }\end{array}$ & $\begin{array}{c}\text { Clusters de } \\
\text { Mortalidade } \\
\text { MSC }\end{array}$ & $\begin{array}{l}\text { Indicador de } \\
\text { Fragilidade } \\
\text { Etária }\end{array}$ & $\begin{array}{l}\text { Indicador } \\
\text { de Renda }\end{array}$ & $\begin{array}{c}\text { Indicador de } \\
\text { Alfabetização }\end{array}$ & $\begin{array}{c}\text { Indicador } \\
\text { Socioeconômico }\end{array}$ \\
\hline 8 & Belém & 6045899,57 & 5312640,26 & 87,87 & 0,26 & 34,14 & 0,31 & Aleatório & 0,22 & 0,54 & 0,96 & 0,72 \\
\hline 10 & Brás & 3629272,92 & 3441263,78 & 94,82 & 0,23 & 34,66 & 0,42 & Aleatório & 0,16 & 0,49 & 0,95 & 0,71 \\
\hline 13 & Cachoeirinha & 13543301,88 & 6687321,39 & 49,38 & 0,17 & 31,33 & 0,45 & Aleatório & 0,14 & 0,44 & 0,90 & 0,68 \\
\hline 47 & José Bonifácio & \begin{tabular}{|l|}
14547052,71 \\
\end{tabular} & 8010359,62 & 55,07 & 0,25 & 30,41 & 0,48 & Alto-Alto & 0,15 & 0,42 & 0,91 & 0,68 \\
\hline 55 & Parelheiros & 152607454,57 & 23068012,78 & 15,12 & 0,11 & 27,34 & 0,49 & Alto-Alto & 0,11 & 0,39 & 0,86 & 0,64 \\
\hline 57 & Parque do Carmo & 15451447,34 & 6538108,73 & 42,31 & 0,18 & 29,39 & 0,42 & Alto-Alto & 0,14 & 0,43 & 0,92 & 0,69 \\
\hline 61 & Perus & 23663672,40 & 10585104,42 & 44,73 & 0,23 & 29,74 & 0,27 & Aleatório & 0,12 & 0,40 & 0,89 & 0,67 \\
\hline 88 & Vila Leopoldina & 6992380,12 & 5558319,71 & 79,49 & 0,27 & 33,88 & 0,21 & Aleatório & 0,19 & 0,62 & 0,96 & 0,72 \\
\hline
\end{tabular}

Fonte: Elaboração própria Data: 22/02/2018. 
A análise dos dados da tabela 2.10, apresentada de forma detalhada no capítulo 3, levou à elaboração de um indicador composto pela média dos indicadores de renda e de variabilidade da impermeabilização do solo para os distritos selecionados. Este novo indicador, denominado Indicador Socioambiental, apresentou resultados consistentes com o objetivo geral destes procedimentos metodológicos, qual seja analisar a relação entre os óbitos associados às doenças do aparelho circulatório e a impermeabilização do solo do município de São Paulo. O indicador socioambiental para os oito distritos selecionados é apresentado na tabela 2.11, disposta a seguir.

Tabela 2.11 - Indicador Socioambiental dos oito distritos discriminados para análise

\begin{tabular}{r|l|r}
\hline Código do Distrito & Nome do Distrito & Indicador Socioambiental \\
\hline 8 & Belém & 0,40 \\
\hline 10 & Brás & 0,36 \\
\hline 13 & Cachoeirinha & 0,30 \\
\hline 47 & José Bonifácio & 0,33 \\
\hline 55 & Parelheiros & 0,25 \\
\hline 57 & Parque do Carmo & 0,31 \\
\hline 61 & Perus & 0,31 \\
\hline 88 & Vila Leopoldina & 0,45 \\
\hline
\end{tabular}

Fonte: Elaboração própria. Data: 22/02/2018.

Os procedimentos metodológicos descritos no escopo deste capítulo foram fundamentais para elaboração dos mapas, gráficos e tabelas os quais serão apresentados e analisados de forma detalhada no capítulo 3, a seguir. 


\section{Análise e Discussão dos Resultados}

Partindo-se dos procedimentos metodológicos apresentados previamente, este capítulo objetiva expor os resultados obtidos, bem como as respectivas análises relativas a estes resultados. Nos subcapítulos a seguir serão exibidos e analisados os referidos resultados de cada etapa metodológica realizada, de forma que, ao final do capítulo 3, será possível obter, por fim, uma análise da relação entre os óbitos associados às doenças do aparelho circulatório e a impermeabilização do solo no município de São Paulo.

\subsection{Impermeabilização do Solo no Município de São Paulo}

Os procedimentos para estimativa da impermeabilização do solo no Município de São Paulo (MSP) possibilitaram a elaboração do mapa 9, disposto abaixo. No referido mapa é possível visualizar os percentuais de impermeabilização para a quase totalidade do MSP, bem como se apresenta, em nível de exemplo, um recorte correspondente a uma área localizada no entorno da represa Billings. 


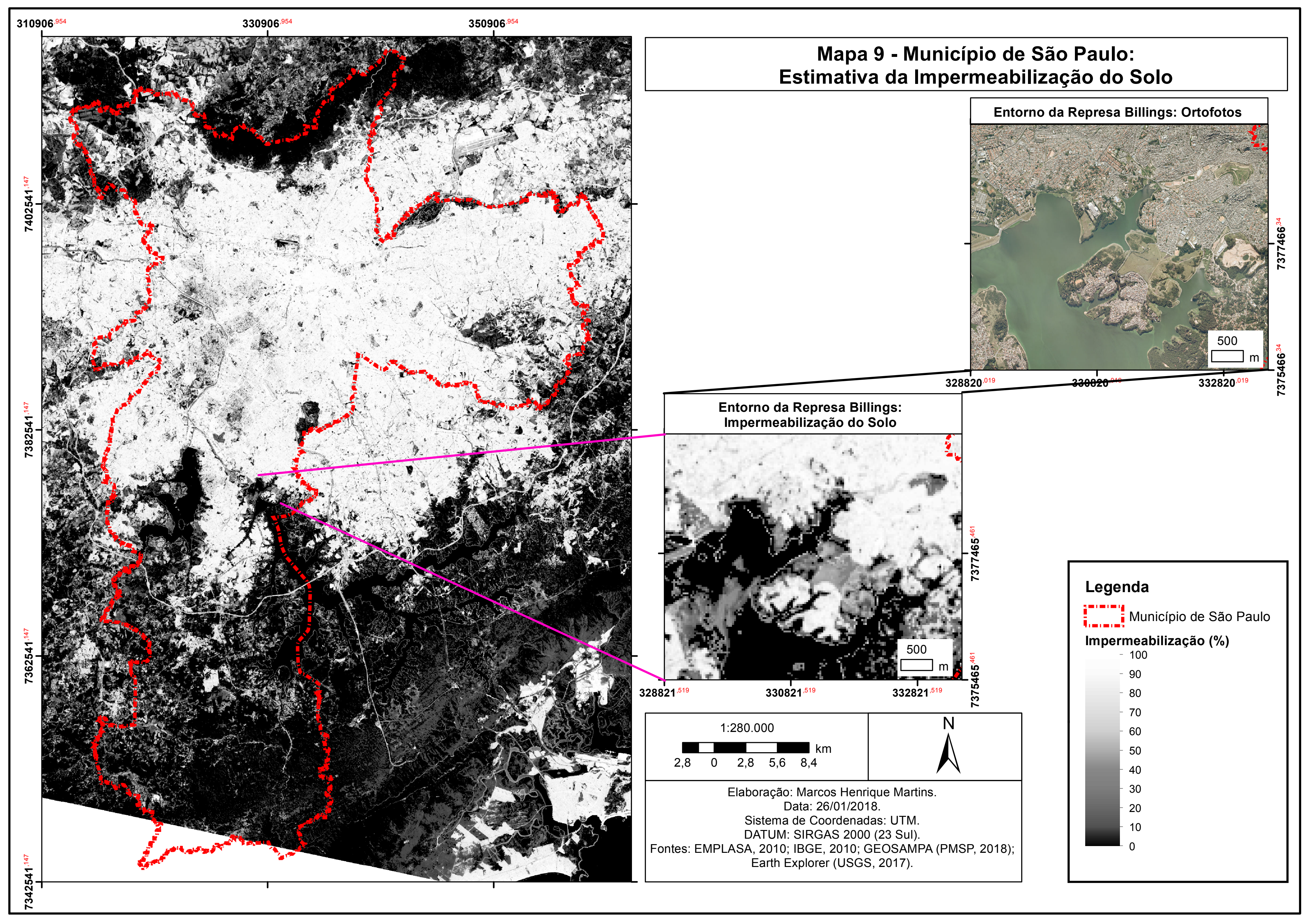


Observa-se, no referido mapa 9, que os objetos de superfície foram corretamente caracterizados, do ponto de vista dos percentuais de impermeabilização, ainda que o modelo apresente limitações, como se observa na área em destaque no mapa. Ao se proceder a análise dos erros de modelagem, nota-se que o principal equívoco encontrado foi considerar classes permeáveis de alto albedo como superfície impermeável. Estas classes (solo exposto preparado para o cultivo, loteamentos, entornos das represas etc.) foram modeladas como apresentando altas porcentagens de impermeabilização do solo (frequentemente acima de 90\%). Os casos mais evidentes deste erro são encontrados nas margens dos grandes reservatórios de água que se encontram no interior do MSP (Guarapiranga e Billings). Em razão do rebaixamento expressivo dos níveis de água dessas represas em decorrência da forte seca que atingiu a região no ano de 2015, observou-se em suas margens extensas faixas contínuas de solo exposto que antes eram cobertos pelas águas. As áreas de pasto seco também apresentaram valores de impermeabilização da ordem de 30 a 40\%, daí a explicação para tonalidades cinza nas áreas rurais. Os erros de modelagem, apesar de, frequentemente, serem interpretados negativamente, são essenciais para que se possa ponderar a validade do modelo, não o invalidando necessariamente. Neste sentido, vale indicar aqui que os referidos erros estão concentrados na franja urbana do município de São Paulo, bem como no perímetro rural, não comprometendo significativamente as análises realizadas no escopo do trabalho. Ademais, os dados apresentados no capítulo 2, no subcapítulo 2.1, relativo à modelagem estimativa da impermeabilização do solo, indicam ser razoável considerar a validade do modelo adotado, ainda que, como qualquer outro modelo, sejam notadas algumas limitações.

No mapa 10, disposto a seguir, é possível visualizar a estimativa de impermeabilização do solo por setor censitário. Nota-se que há uma concentração de áreas impermeabilizadas na faixa leste-oeste do município, principalmente nas regiões centrais, o que se ratifica pela análise do mapa 11. Neste mapa, é possível notar que há uma concentração de distritos administrativos com elevado percentual de impermeabilização do solo ao redor do Rio Tietê, o que não se observa no entorno do Rio Pinheiros. Esta configuração está intimamente associada à história de ocupação do município de São Paulo e os meandros socioeconômicos e políticos desta ocupação:

o sistema de canais, as represas e o moderno sistema viário, com as vias marginais expressas instalados sobre as várzeas, ao longo do Tietê e do Pinheiros, constituem uma massa de força produtiva social essencial para processos urbano-industriais localizados na Região Metropolitana de São Paulo. Configura-se um quadro de implantações bastante diversificadas ao longo dos vinte e cinco quilômetros do canal do Pinheiros, desde a confluência com o Tietê até a Represa Billings, assim como, ao 
longo do canal do Tietê, nos dezenove quilômetros, que distam da confluência do Pinheiros à Penha. São essas implantações elementos materiais de produção e consumo que bem caracterizam o desenvolvimento econômico do País, com suas ambiguidades e contradições (SEABRA, 1987, p.2).

\section{O entorno do rio Tietê tem sido constituído por um processo histórico de ocupação que} remonta aos aldeamentos indígenas do século XVI, tendo sido marcado, no século passado, pelo desenvolvimento de setores industriais e de serviços públicos:

Ao longo do Tietê, a Prefeitura do Município de São Paulo tornou-se proprietária de vastas extensões de terra também por ter executado o projeto de retificação. Eram as áreas dos meandros que foram suprimidos pelas obras de engenharia. Áreas que a administração municipal tem gradativamente destinado a usos públicos, como por exemplo, o Terminal Rodoviário do Tietê, as alças de passagem para permitir acesso às pontes, a construção do prédio da Santa Casa, entre outras. Ao longo de toda várzea, geralmente ocupando os baixos terraços, tem-se na atualidade uma dinâmica indústria imobiliária que produz apartamentos residenciais. Beneficia-se, essa indústria, da existência de grandes terrenos disponíveis, principalmente no reverso de antigos bairros, usufruindo a um só tempo, do contexto ainda que modesto desses mesmos bairros e da circulação viária, de caráter metropolitano, que permite acesso relativamente fácil para qualquer localidade metropolitana (SEABRA, 1987, p. 9-10).

Por outro lado,

na marginal do Pinheiros formou-se uma importante área de escritórios com funções terciárias e quaternárias, domínio de alta tecnologias, desde a ponte da Avenida Euzébio Mattoso, até a ponte da Avenida João Dias e englobando áreas já urbanizadas, que foram completamente transformadas, como a Avenida Luiz Carlos Berrini. O pleno domínio da várzea, que foi território canadense em passado recente é, agora, um espaço produzido com atributos de primeiro mundo, reluzente segundo a estética pósmoderna, nascido "da noite para o dia". São as grandes torres de escritórios, hotéis, casas de espetáculos, shopping centers que integram uma frente de expansão do circuito imobiliário do capital. Respondem às estratégias empresariais bem plantadas ligadas aos fenômenos de internacionalização e financeirização, situadas na confluência dos interesses que movem a máquina do capitalismo em escala global (SEABRA, 1987, p.10).

O processo de impermeabilização do solo no município de São Paulo, portanto, possui determinações políticas e econômicas que, desdobrando-se no decorrer da trama histórica, materializa-se na contemporânea geografia da cidade. 


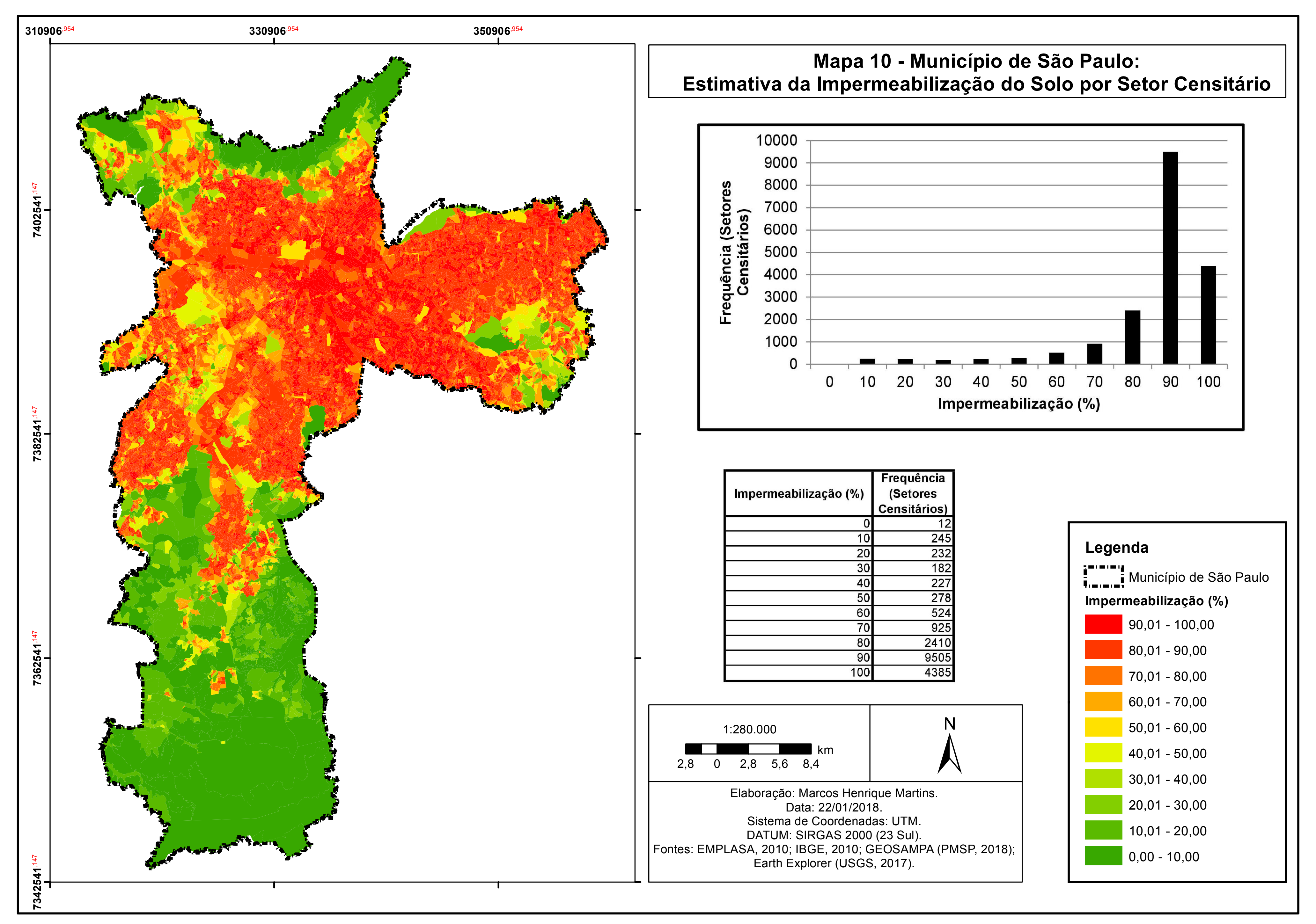




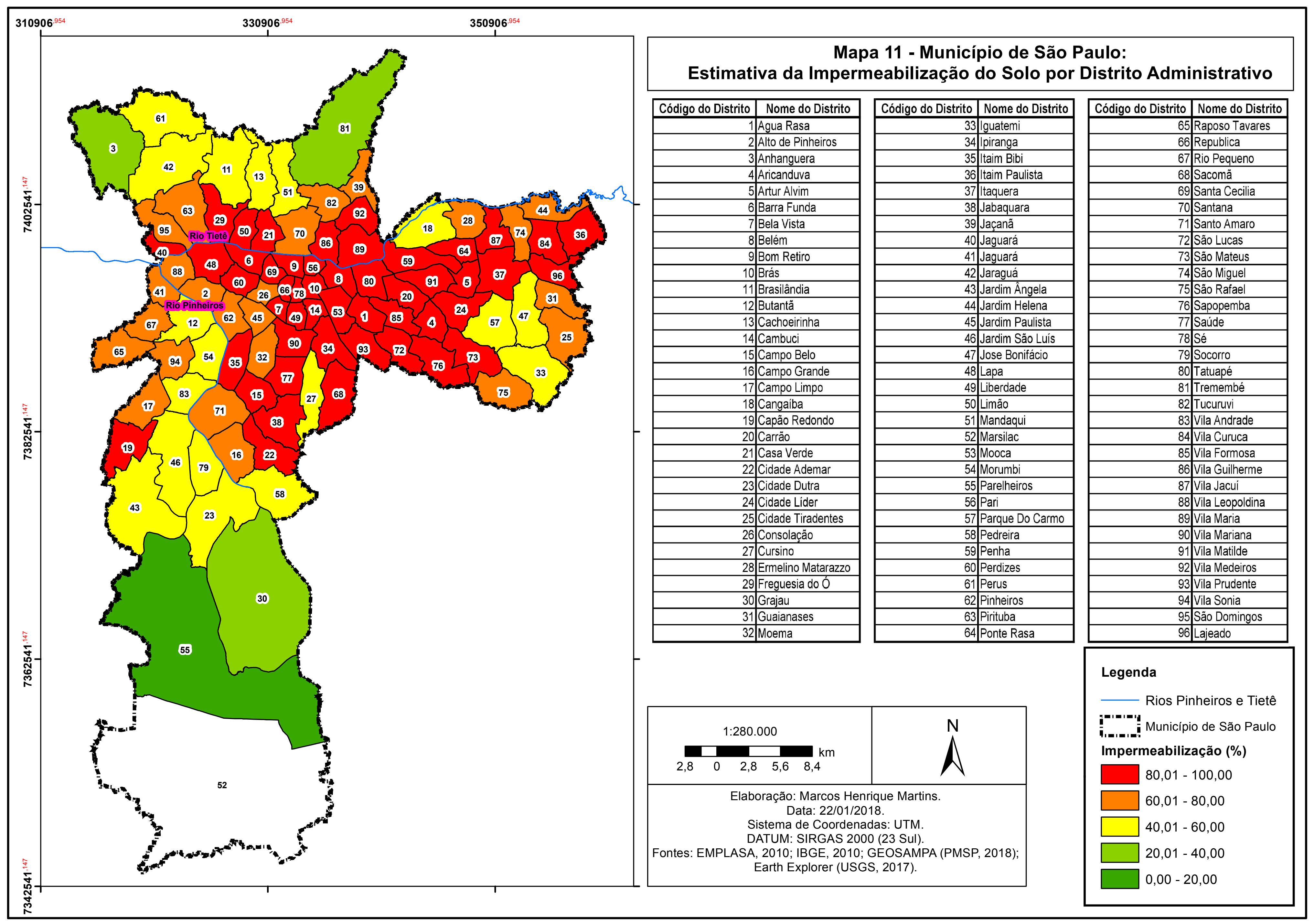


Ademais, a análise da variabilidade dos percentuais de impermeabilização do solo interdistritais indicou a possibilidade de ocorrência de aglomerados de baixa ou alta variabilidade nos percentuais de impermeabilização do solo, conforme observa-se no mapa 12. Assim sendo, o resultado do mapeamento dos clusters do Indicador VARIMP pode ser contemplado no mapa 13, disposto a seguir. 


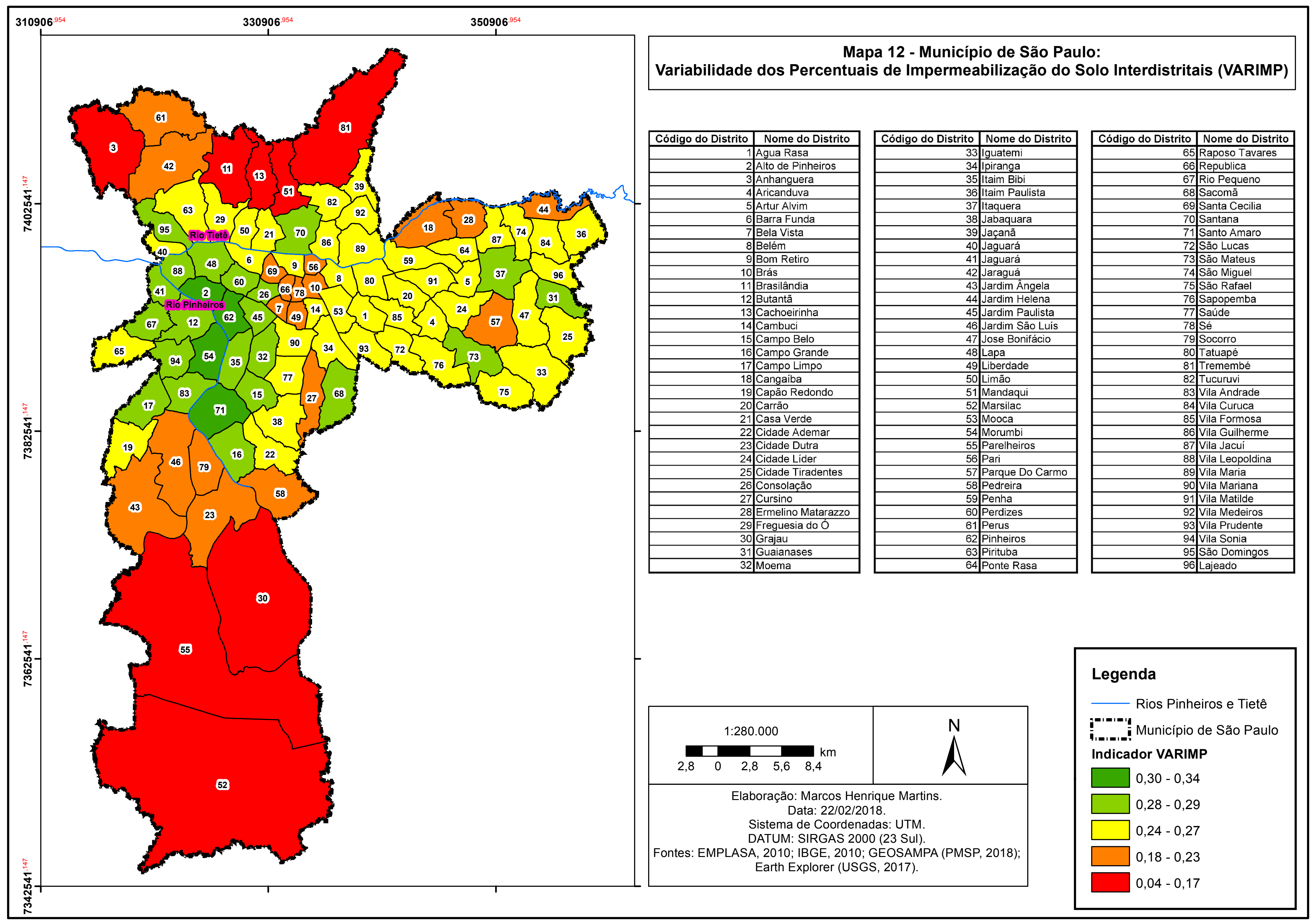




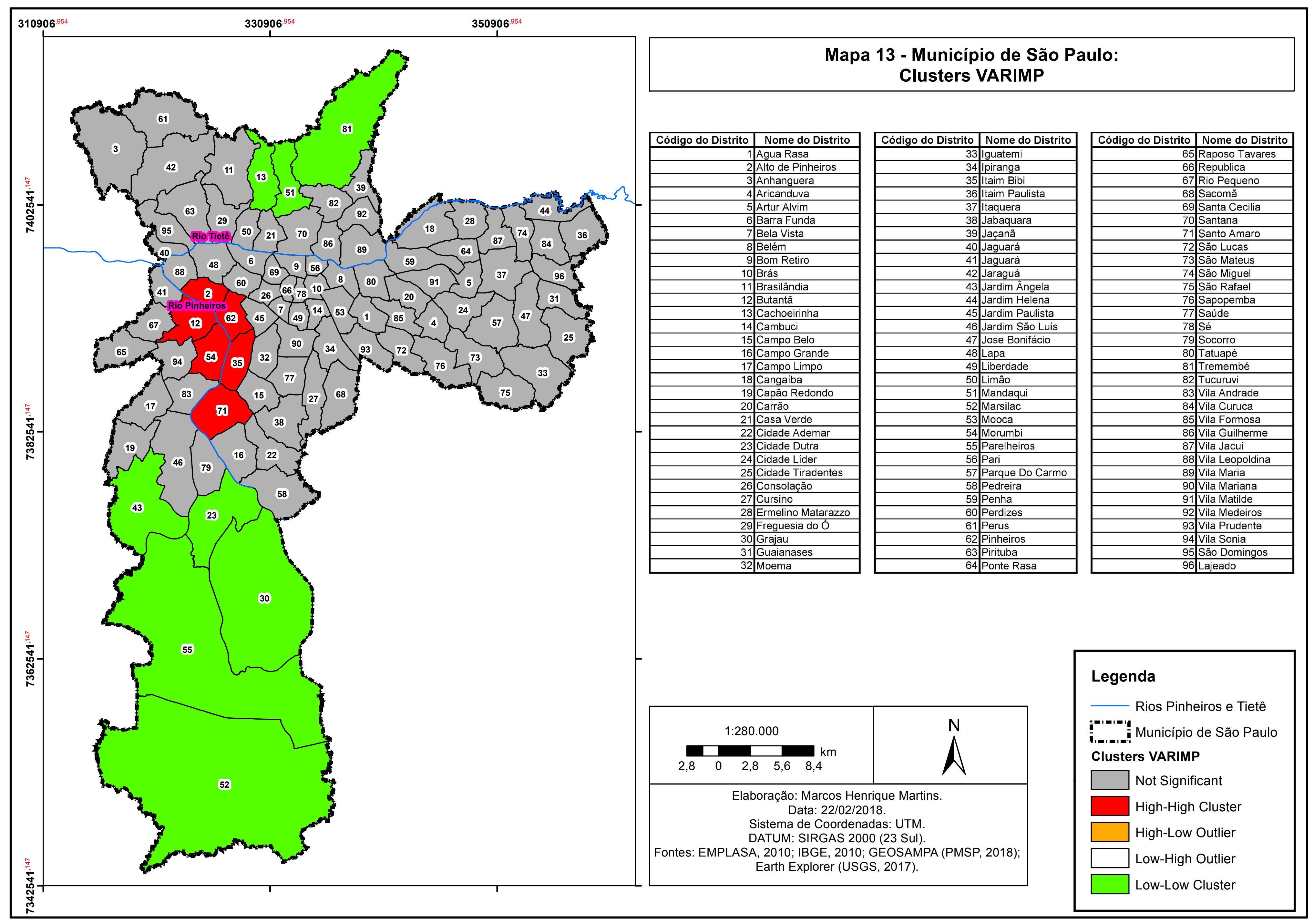


Os mapas 12 e 13 são relevantes por indicar a variabilidade na composição percentual da impermeabilização do solo dos distritos administrativos do MSP. Em outras palavras, o indicador VARIMP classifica os distritos de forma a discriminá-los segundo a variabilidade da contribuição das faixas percentuais de impermeabilização em seu território, considerando-se a totalidade do universo distrital. Distritos muito ou pouco impermeabilizados, que concentram largas faixas impermeabilizadas ou amplas áreas verdes, como a Sé e Marsilac, por exemplo, são classificados mais próximos ao valor mínimo (zero), enquanto os distritos com maior variabilidade na composição percentual de impermeabilização, como Alto de Pinheiros, Butantã, Itaim Bibi, Morumbi, Pinheiros e Santo Amaro, os quais constituem uma ilha de alta variabilidade, são classificados com valores mais elevados, próximos a um.

A figura 2.7, disposta abaixo, representa, de forma simplificada, o funcionamento do indicador VARIMP. Considere-se as letras I, L, N, T e V como faixas percentuais distintas, conforme descrito no subcapítulo 2.1 desta obra. Neste sentido, o valor do referido indicador em a) é inferior ao valor em b), haja vista b) apresentar maior variabilidade na composição dos materiais de superfície, representando um equilíbrio maior na composição da impermeabilização do solo.

Figura 2.7 - Esquema ilustrativo do indicador VARIMP

a) \begin{tabular}{|c|c|c|}
\hline $\mathbf{V}$ & $\mathbf{V}$ & $\mathbf{V}$ \\
\hline $\mathbf{V}$ & $\mathbf{V}$ & $\mathbf{V}$ \\
\hline $\mathbf{V}$ & $\mathbf{V}$ & $\mathbf{V}$ \\
\hline $\mathbf{I}$ & $\mathbf{I}$ & $\mathbf{I}$ \\
\hline $\mathbf{I}$ & $\mathbf{I}$ & $\mathbf{I}$ \\
\hline
\end{tabular}

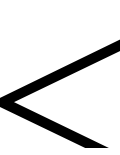

b) \begin{tabular}{|c|c|c|}
\hline $\mathbf{V}$ & $\mathbf{I}$ & $\mathbf{V}$ \\
\hline $\mathbf{T}$ & $\mathbf{N}$ & $\mathbf{T}$ \\
\hline $\mathbf{V}$ & $\mathbf{N}$ & $\mathbf{V}$ \\
\hline $\mathbf{I}$ & $\mathbf{L}$ & $\mathbf{I}$ \\
\hline $\mathbf{V}$ & $\mathbf{I}$ & $\mathbf{V}$ \\
\hline
\end{tabular}

Fonte: Elaboração própria. Data: 24/02/2018.

Destarte, é possível notar, nos mapas 12 e 13, que há uma concentração de áreas menos impermeabilizadas nas regiões sul e norte do MSP, indicando também uma composição menos variável dos percentuais de impermeabilização do solo, ou seja, há, nas referidas áreas, grandes ilhas verdes bordeadas por uma franja urbana em crescente expansão. Ademais, na zona sul, nos distritos de Grajaú e Parelheiros, há a presença das represas Billings e Guarapiranga, as quais certamente apresentam interferência nos processos de impermeabilização do solo. Por outro lado, na região central do MSP, onde se localizam os distritos da Sé e lindeiros, há grandes manchas impermeáveis, ou seja, observa-se uma concentração de áreas cuja impermeabilização do solo ultrapassa os $80 \%$, geralmente alcançando $100 \%$. Essas áreas também foram classificadas mais próximas ao valor nulo na escala VARIMP. 
Prosseguindo-se a análise dos mapas 12 e 13, nota-se ainda, ao redor do Rio Pinheiros, uma aglomeração de distritos com valores VARIMP elevados, a saber: Alto de Pinheiros, Butantã, Itaim Bibi, Morumbi, Pinheiros e Santo Amaro. Esses distritos possuem uma maior variabilidade nas faixas percentuais que compõem sua impermeabilização do solo, ou seja, apresentam áreas muito impermeabilizadas intercaladas com áreas pouco impermeabilizadas, bem como com áreas com valores de impermeabilização médios. Em outras palavras, a variabilidade dos percentuais de impermeabilização do solo nesses distritos é elevada, indicando que há áreas muito distintas que compõe seus territórios, do ponto de vista em análise.

Esta elevada variabilidade nas faixas percentuais de impermeabilização do solo indicam que, nos bairros onde ela ocorre, há uma maior amenidade ambiental. De acordo com RUBIA (2008, p.2),

tanto os problemas como as amenidades ambientas não são distribuídos aleatoriamente entre a população. Por amenidades ambientais podemos considerar a boa qualidade do ar, essencial para evitar problemas respiratórios, assim como a arborização urbana, que desempenha papel importante no ambiente urbano. Como problemas ambientais, podemos citar as inundações recorrentes, que levam prejuízos à população carente, além dos riscos de contágio de doenças como a leptospirose. Além disso, os escorregamentos que deixam milhares de desabrigados podem ser mencionados. Na medida em que alguns grupos sociais mais vulneráveis são submetidos a uma carga muito maior das consequências ambientais de atividades econômicas, temos o que conceituamos como desigualdade ambiental. Quanto mais desigual é essa carga, maior é a desigualdade ambiental (MORATO, 2008, p.2).

Destarte, verifica-se que os distritos administrativos que apresentam maior VARIMP são aqueles que também possuem melhores indicadores de renda e de alfabetização, bem como temperaturas aparentes de superfície mais amenas. Por outro lado, os distritos com valores VARIMP menores encontram-se agrupados nos extremos norte e sul do MSP, regiões caracterizadas por concentrarem parcela significativa da população de baixa renda do município. As observações realizadas no âmbito desta referência podem ser ratificadas nos subcapítulos seguintes.

\subsection{Temperatura Aparente de Superfície no MSP (TAS)}

A Temperatura Aparente de Superfície do MSP, calculada a partir dos procedimentos metodológicos descritos no subcapítulo 2.2, possui íntima relação com a impermeabilização do solo, conforme podemos observar no mapa 14. Nota-se, no referido mapa, que as áreas impermeáveis apresentam maior fluxo radiante de calor que as áreas menos impermeabilizadas. 
Analisando-se mais pormenorizadamente as áreas ao redor da represa Billings, em nível de exemplo, pode-se notar como a temperatura aparente de superfície é maior nas áreas impermeabilizadas ao redor da represa relativamente à do próprio reservatório e/ou das áreas verdes lindeiras. 


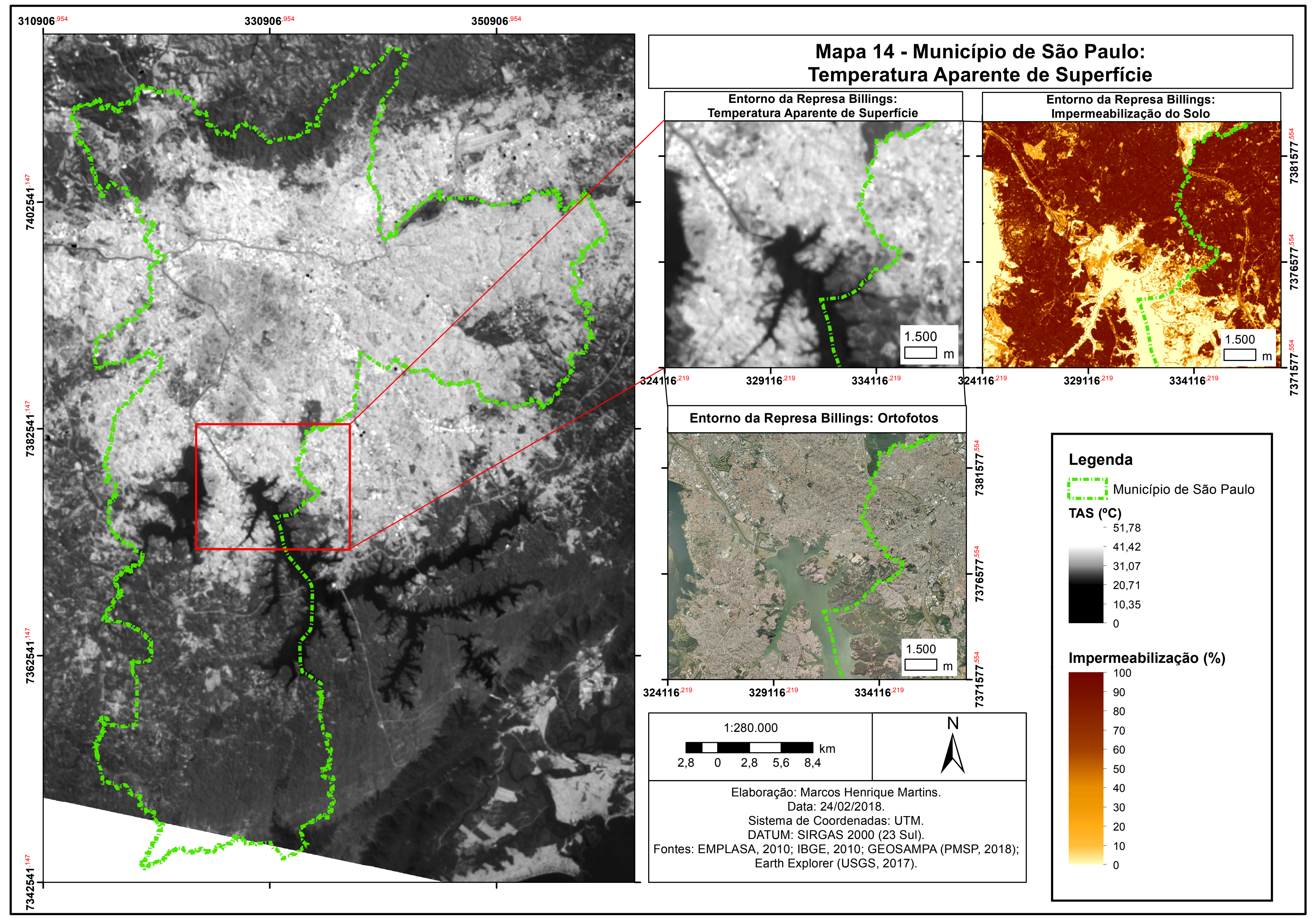


O mapa 15 apresenta a TAS média dos setores Censitários que compõem o MSP. Notase, mais claramente neste mapa, que os extremos sul e norte do município, bem como uma porção da zona leste apresentam temperaturas mais amenas. As áreas com menor fluxo radiante são compostas principalmente por extensas faixas de vegetação, bem como pelos reservatórios Billings e Guarapiranga. Ademais, pode-se observar que os distritos ao redor do Rio Tietê apresentam um maior fluxo radiante que os distritos localizados ao redor do Rio Pinheiros. No mapa em questão é possível ainda avaliar a correlação entre os percentuais de impermeabilização do solo e a temperatura aparente de superfície, por setor censitário, no gráfico anexo ao referido mapa. 


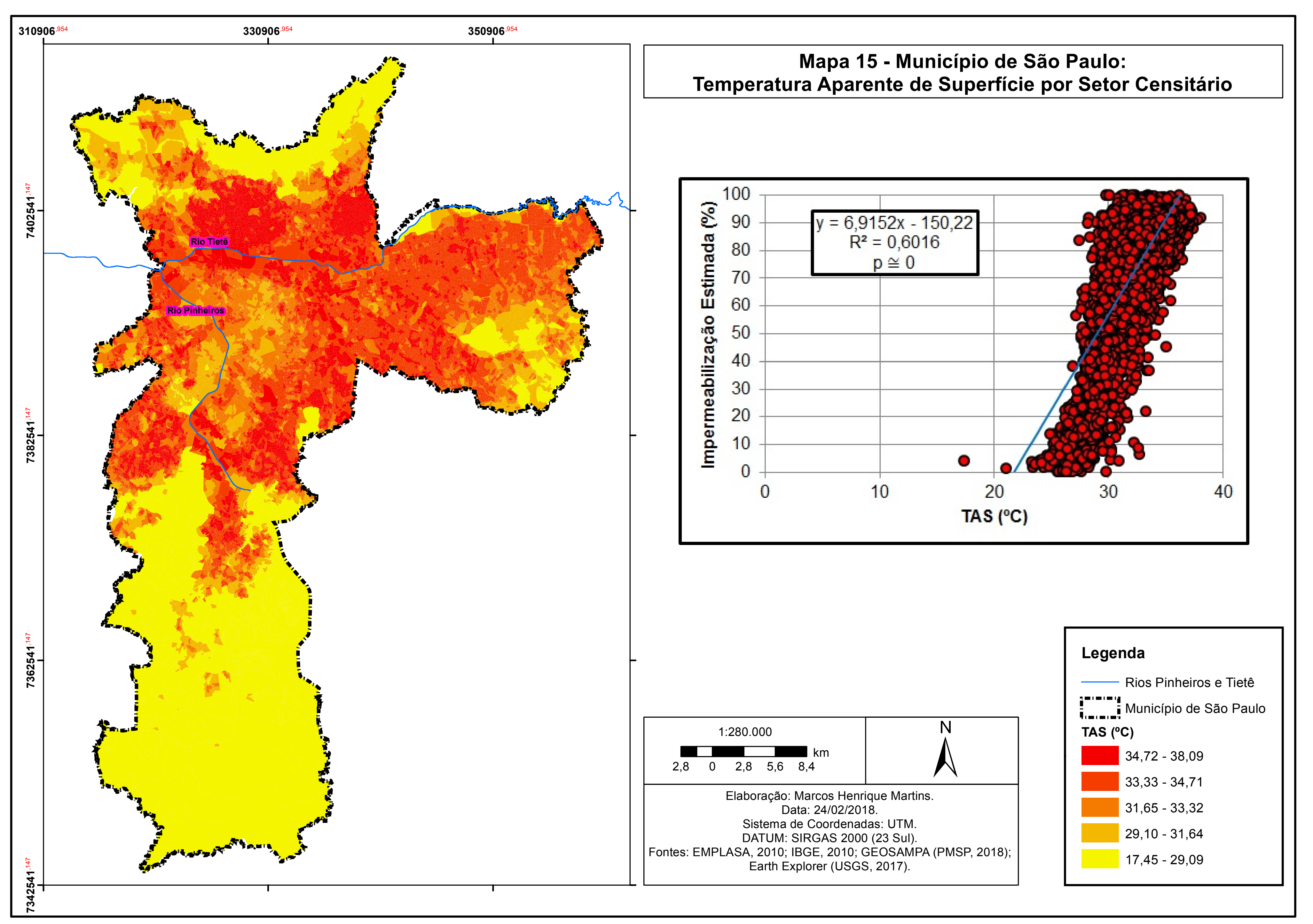


No mapa 16, o qual apresenta a TAS média dos distritos administrativos do MSP, é possível observar mais claramente as distinções interdistritais no que se refere ao atributo em questão, ainda que se considere as generalizações oriundas do aumento da escala de apresentação dos dados. O referido mapa também apresenta, de forma sobreposta à TAS, os cluster de variabilidade dos percentuais de impermeabilização do solo interdistritais (VARIMP). Os agrupamentos com valores VARIMP mais baixos estão localizados nos extremos sul e norte do município, áreas que apresentam uma TAS mais amena, enquanto os hot-spots estão localizados na região entorno do Rio Pinheiros, cujas temperaturas encontramse próximas à média municipal $\left(33,43^{\circ} \mathrm{C}\right)$. Neste sentido, vale considerar que os referidos distritos compositores do agrupamento high-high representam localidades cujos moradores usufruem de condições socioeconômicas acima da média do MSP, conforme apreciaremos em subcapítulo referente à temática. 


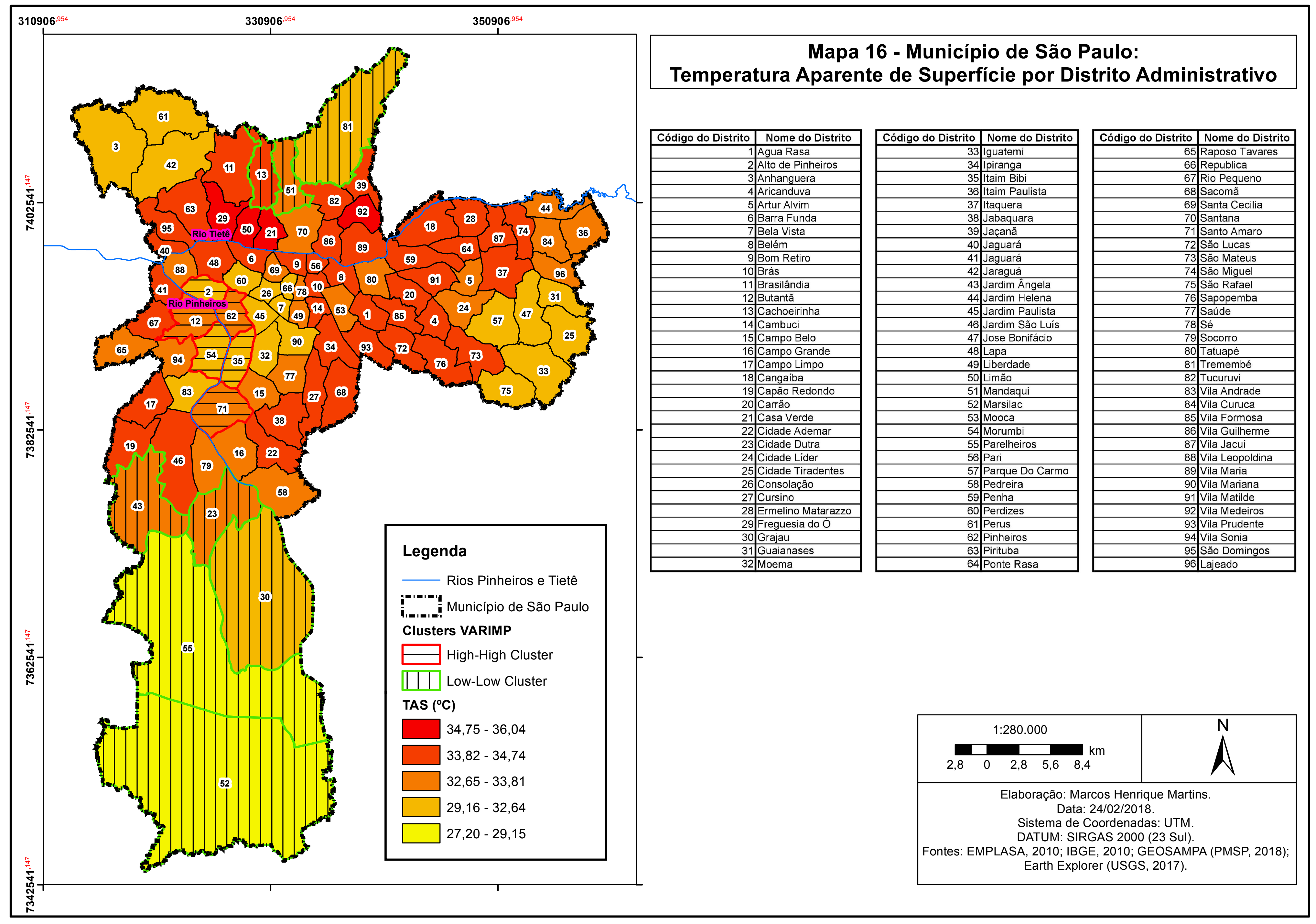




\section{3. Óbitos Associados às Doenças do Aparelho Circulatório no Município de São Paulo}

No mapa 17, pode-se observar a taxa de Óbitos por Doenças Associadas ao Aparelho Circulatório (MSC), por distrito administrativo do MSP. Calculou-se a taxa geral de mortalidade a partir da soma das taxas discriminadas por faixas etárias, conforme indicado no subcapítulo 2.3, devido à necessidade de se avaliar, de forma geral, sem discriminação de sexo ou idade, a distribuição da mortalidade MSC no município de São Paulo.

Nota-se, no mapa 17, que há, aparentemente, uma concentração de óbitos MSC nas áreas periféricas do município. No mapa 18, o qual apresenta o indicador de mortalidade MSC, cuja finalidade é possibilitar um comparativo interdistrital, pode-se ratificar a concentração desta tipologia de óbitos nas áreas periféricas do MSP.

Os clusters de mortalidade MSC, apresentados no mapa 19, ratificam o padrão de distribuição crescente da taxa de mortalidade no sentido das extremidades do MSP. Observa-se uma concentração do número de óbitos nas zonas norte, sul e leste, considerando-se a totalidade do município de São Paulo. Por outro lado, os distritos administrativos localizados ao redor do distrito de Pinheiros, localizados às margens do Rio Pinheiros, apresentam as menores taxas de mortalidade MSC, constituindo um cold-spot municipal. 


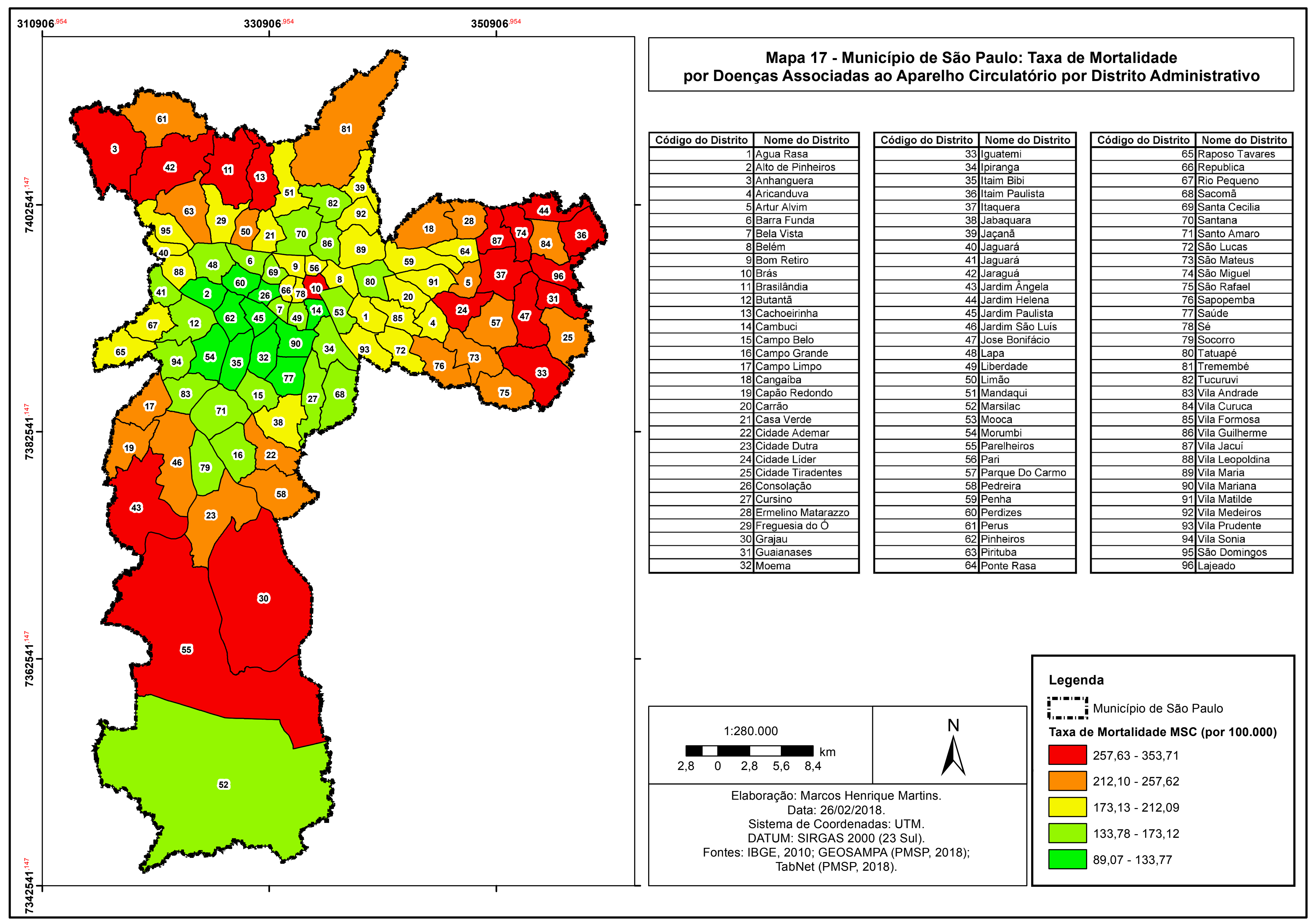




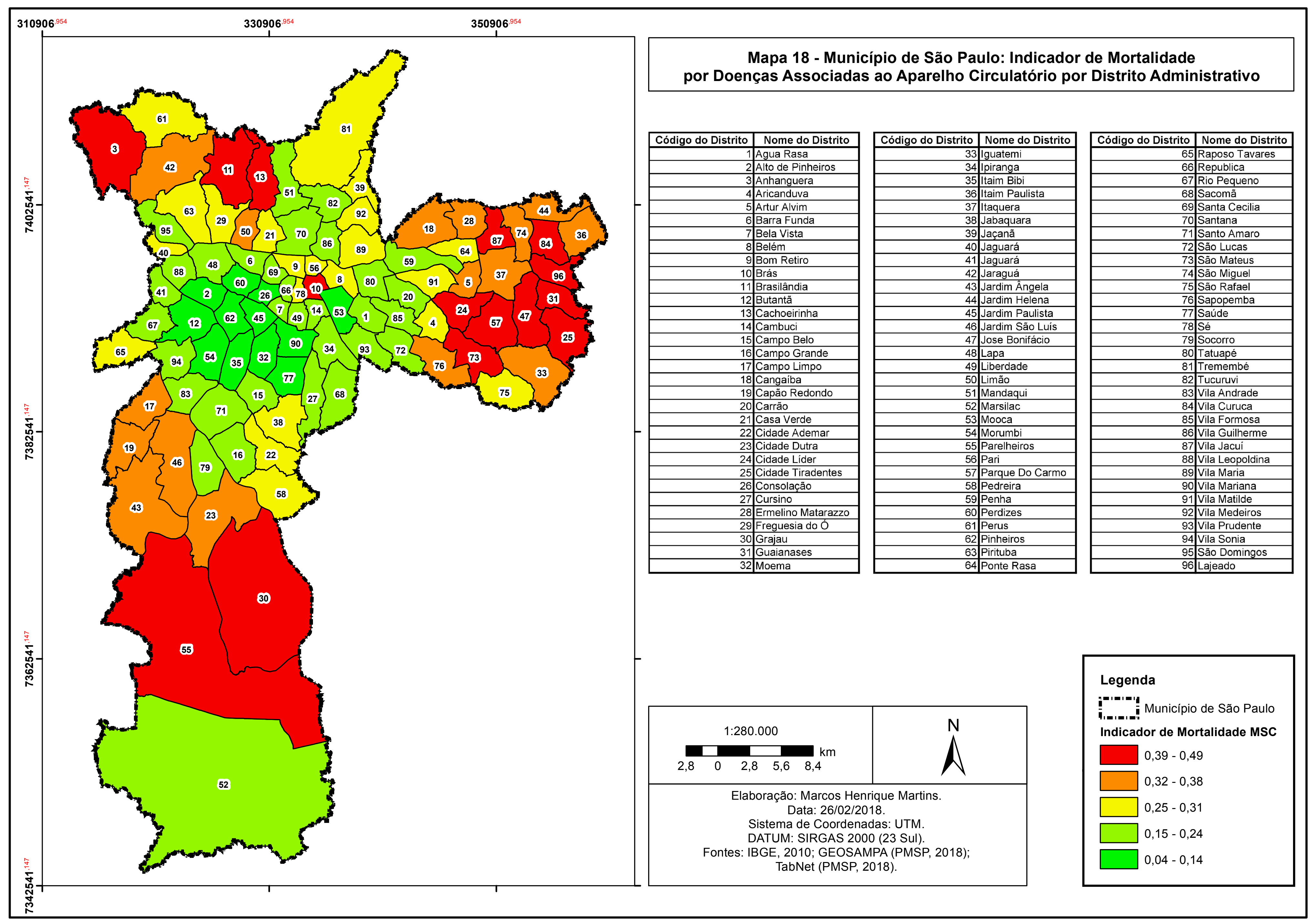




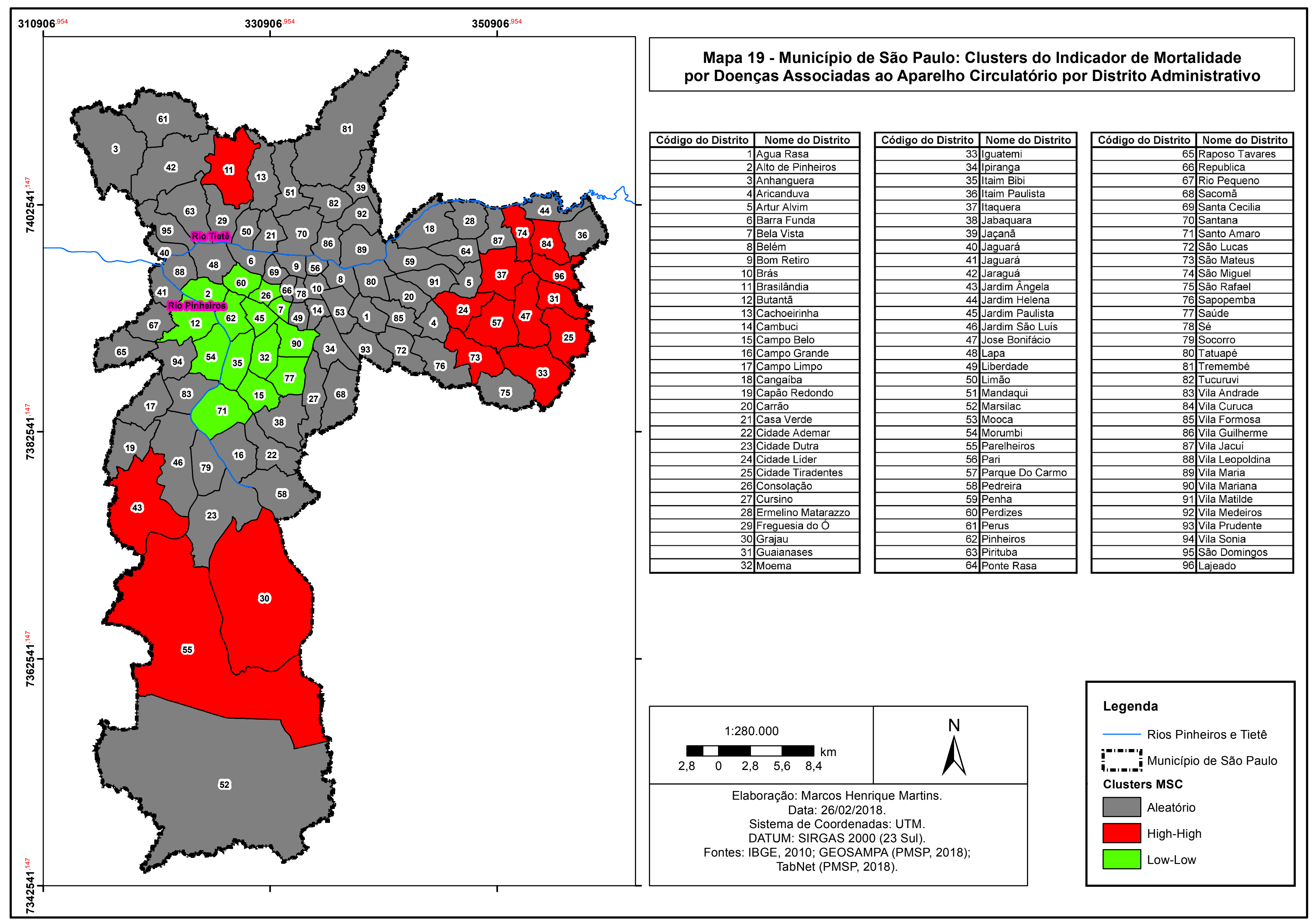


A distribuição da mortalidade MSC observada no ano de 2015 para o município de São Paulo é ratificada por outros estudos que trataram da temática a partir de uma perspectiva temporal (BRASIL, 2017; FARIAS, 2014; IKEFUTI, 2016). A distribuição dos óbitos MSC no município de São Paulo, no ano de 2015, comporta-se, portanto, de acordo com a tendência observada nos anos precedentes. Tal tendência aparenta sofrer uma influência determinante de condições socioeconômicas características dos distritos administrativos em análise. Nota-se, curiosamente, que o perfil de mortalidade observado no entorno do curso do Rio Pinheiros é representativo desta tendência, a saber: quanto maior a distância da confluência dos dois principais rios do MSP, maior a taxa de mortalidade MSC dos distritos administrativos.

Destarte, é necessário que se apresente os dados socioeconômicos relativos aos distritos em análise, haja vista a necessidade de se avaliar a concentração da mortalidade MSC nos distritos mais periféricos do município de São Paulo.

\subsection{Indicadores Socioeconômicos}

Os indicadores socioeconômicos apresentam significativa relevância para o escopo deste estudo, conforme já apontado no capítulo 2, devido à considerável correlação observada entre a distribuição da mortalidade MSC e o status socioeconômico característico dos distritos analisados.

Neste sentido, a sequência de mapas a seguir apresenta os indicadores elaborados para a renda e alfabetização, bem como o indicador socioeconômico síntese, composto pela média dos dois indicadores anteriores. Os mapas 20 e 21 apresentam o indicador para renda nominal média, por domicílio, para a escala dos setores censitários e dos distritos administrativos que compõem o MSP, respectivamente. Os mapas 22 e 23 apresentam o indicador de alfabetização para os setores censitários e distritos administrativos, respectivamente. Os mapas 24, 25 e 26 apresentam, por fim, o indicador socioeconômico respectivamente para os setores censitários e distritos administrativos. 


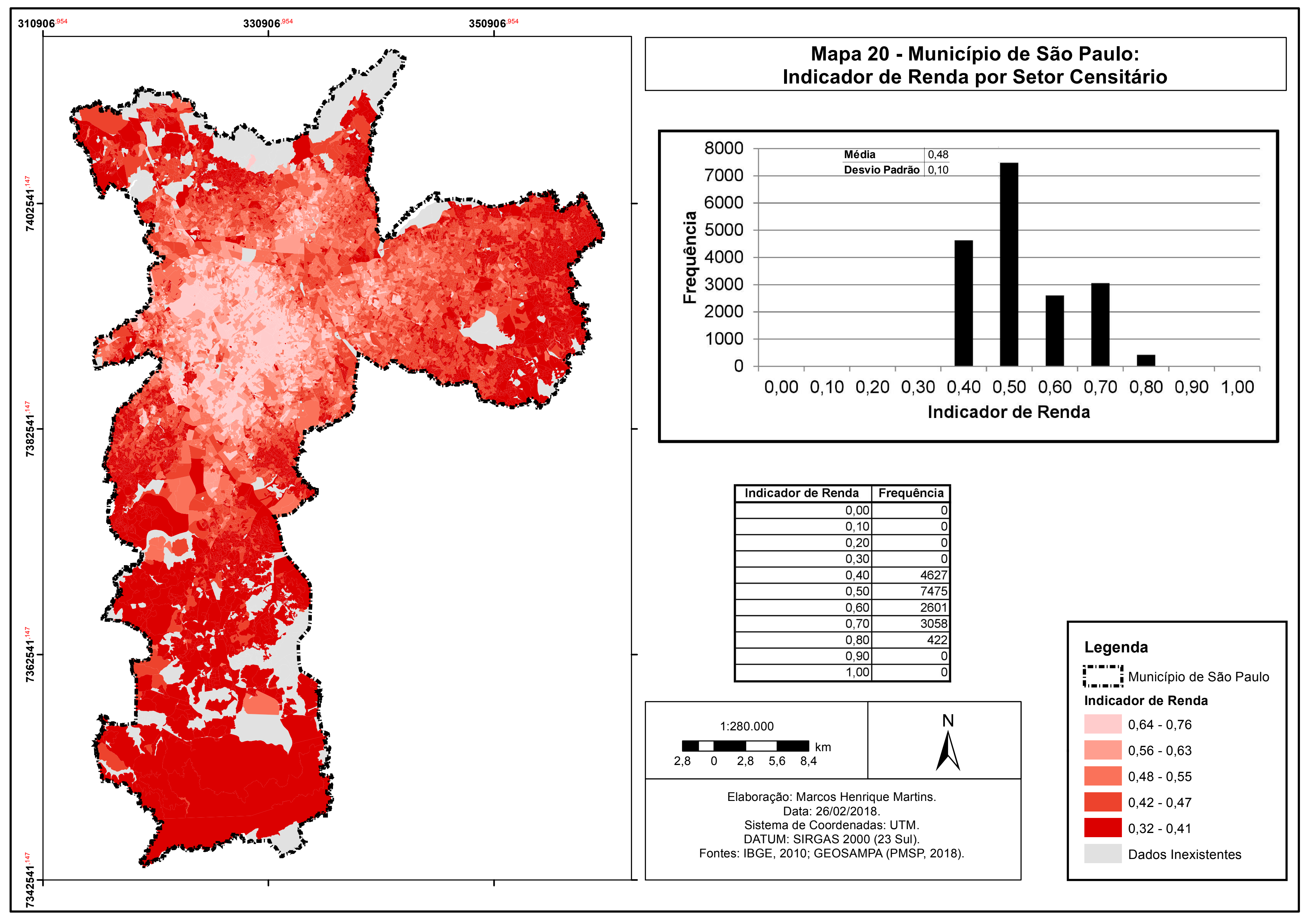




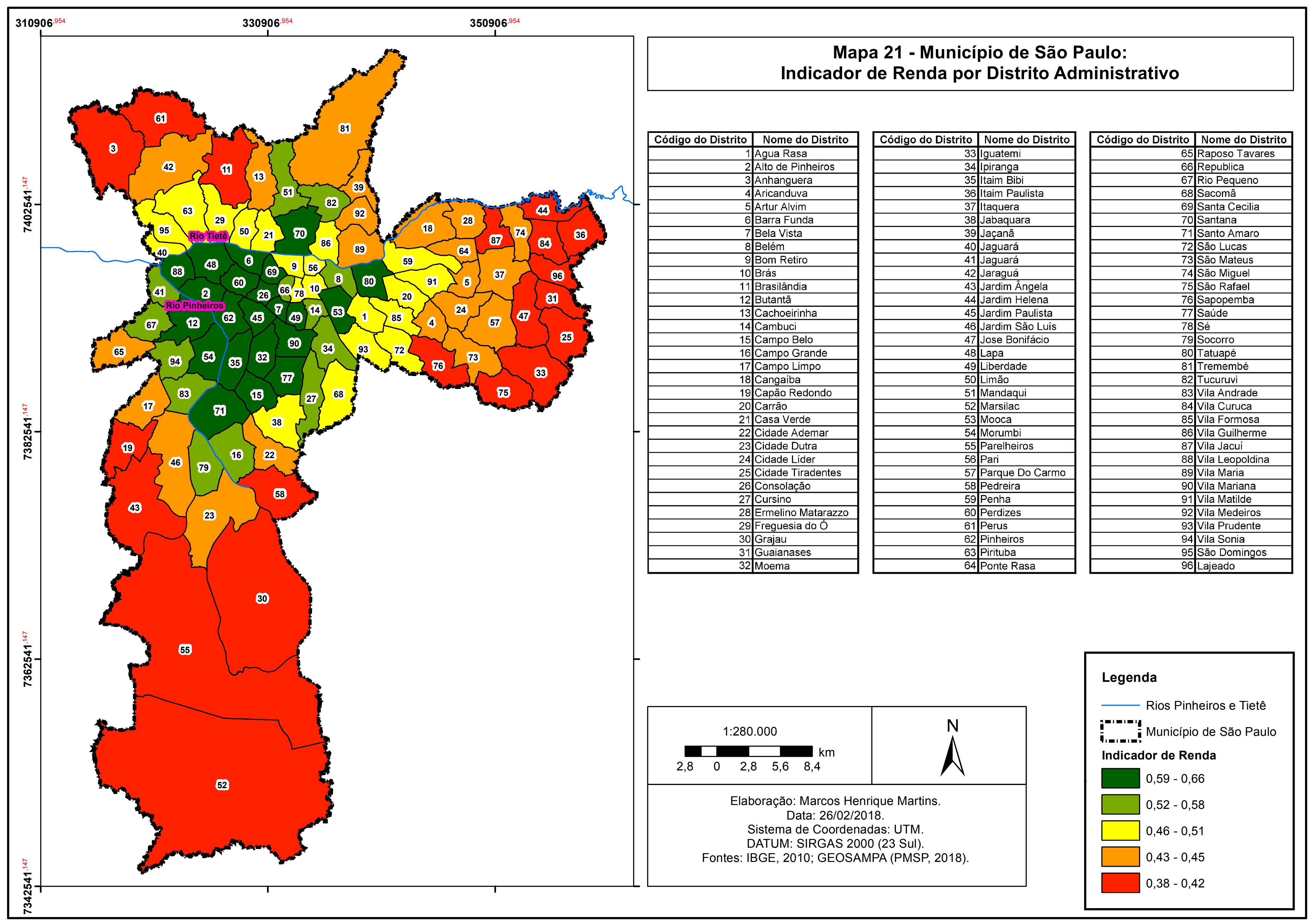




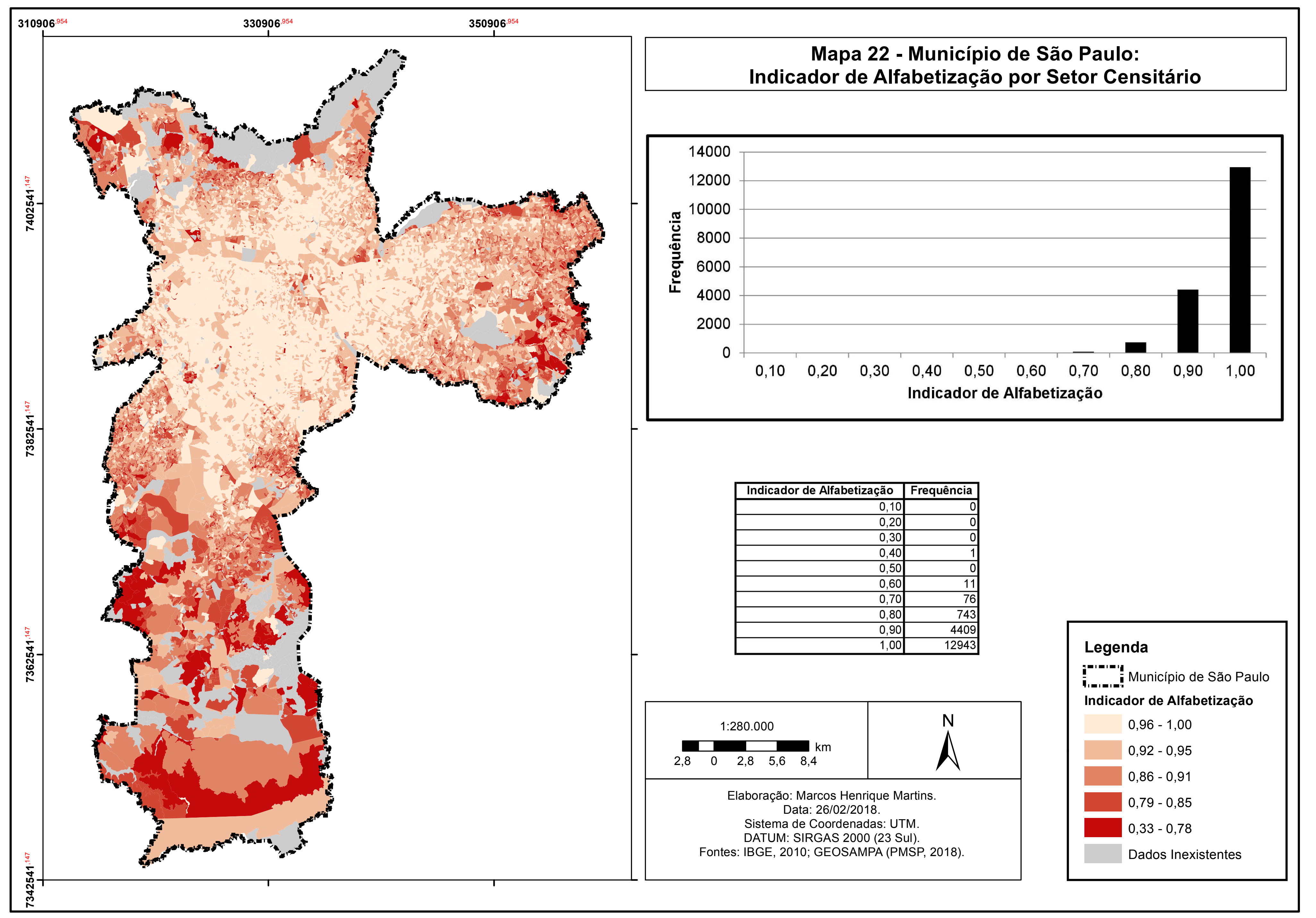




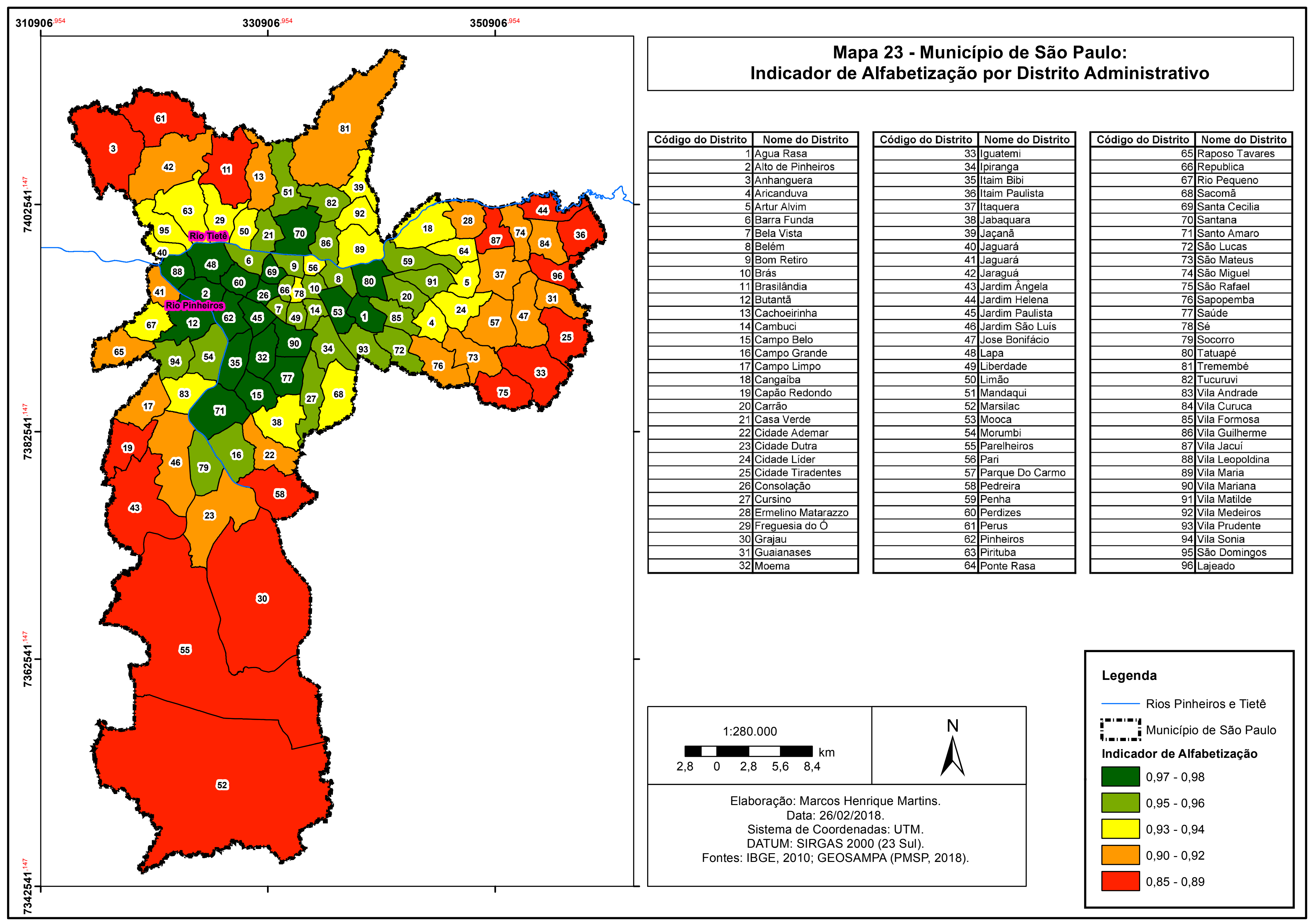




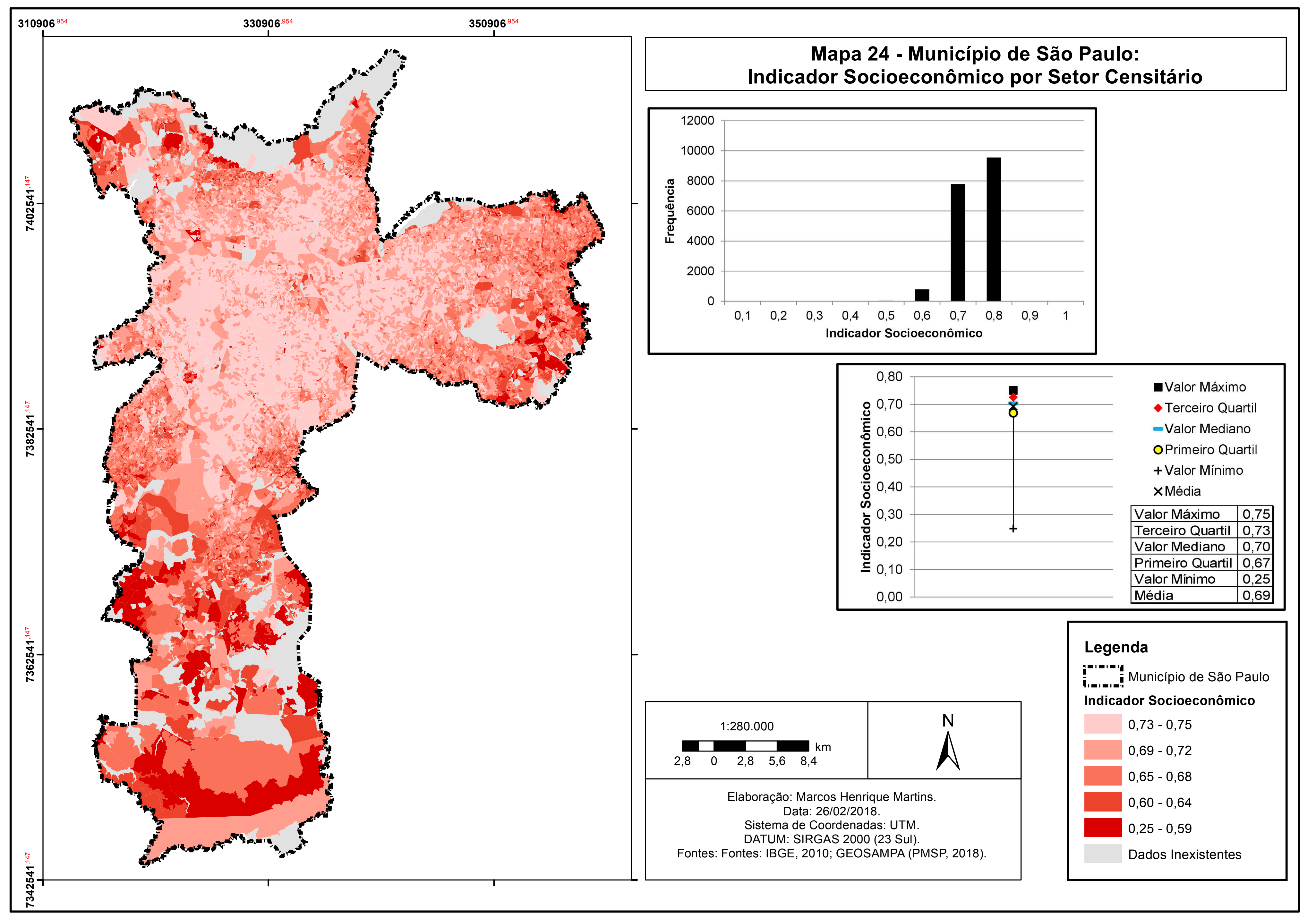




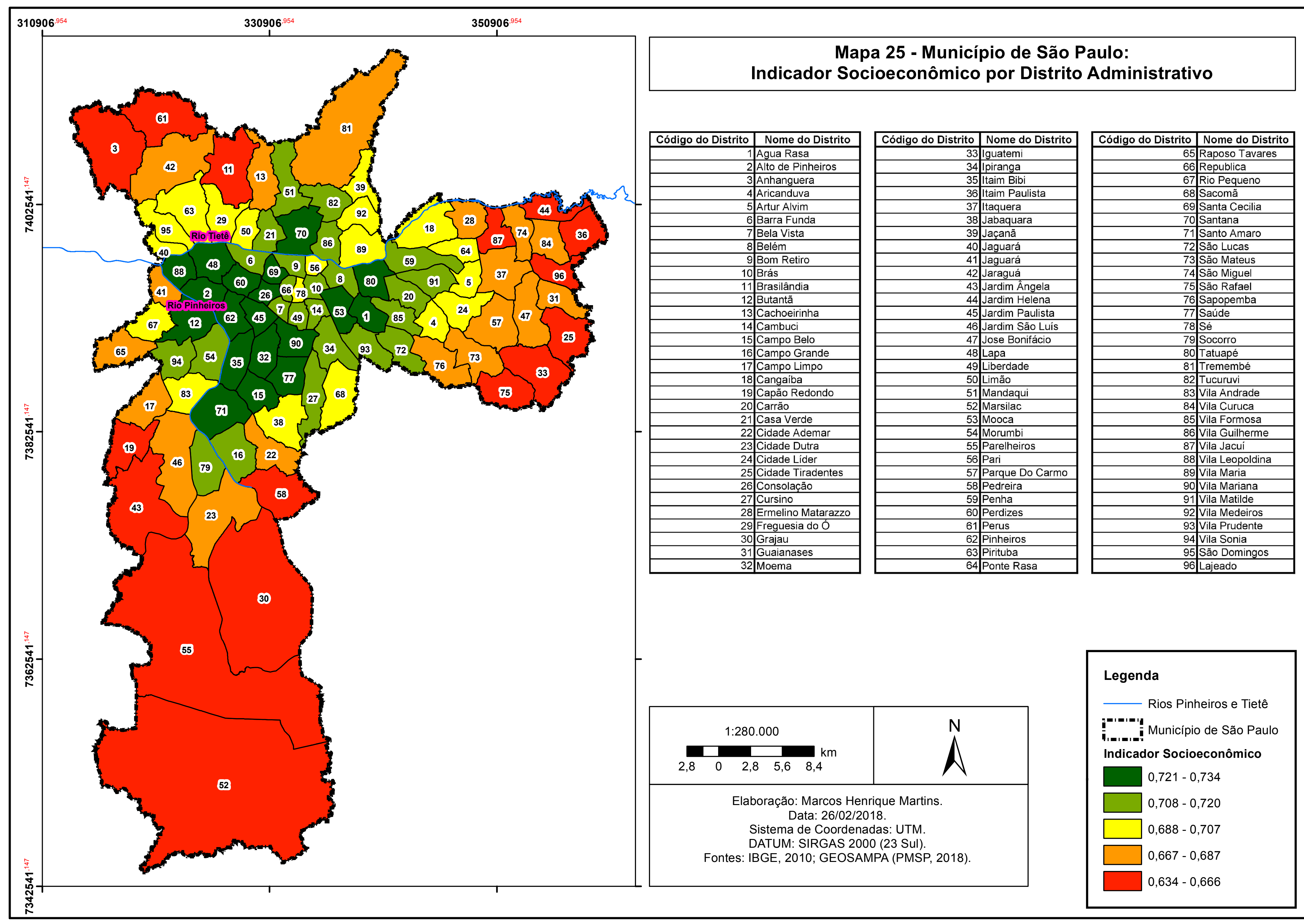




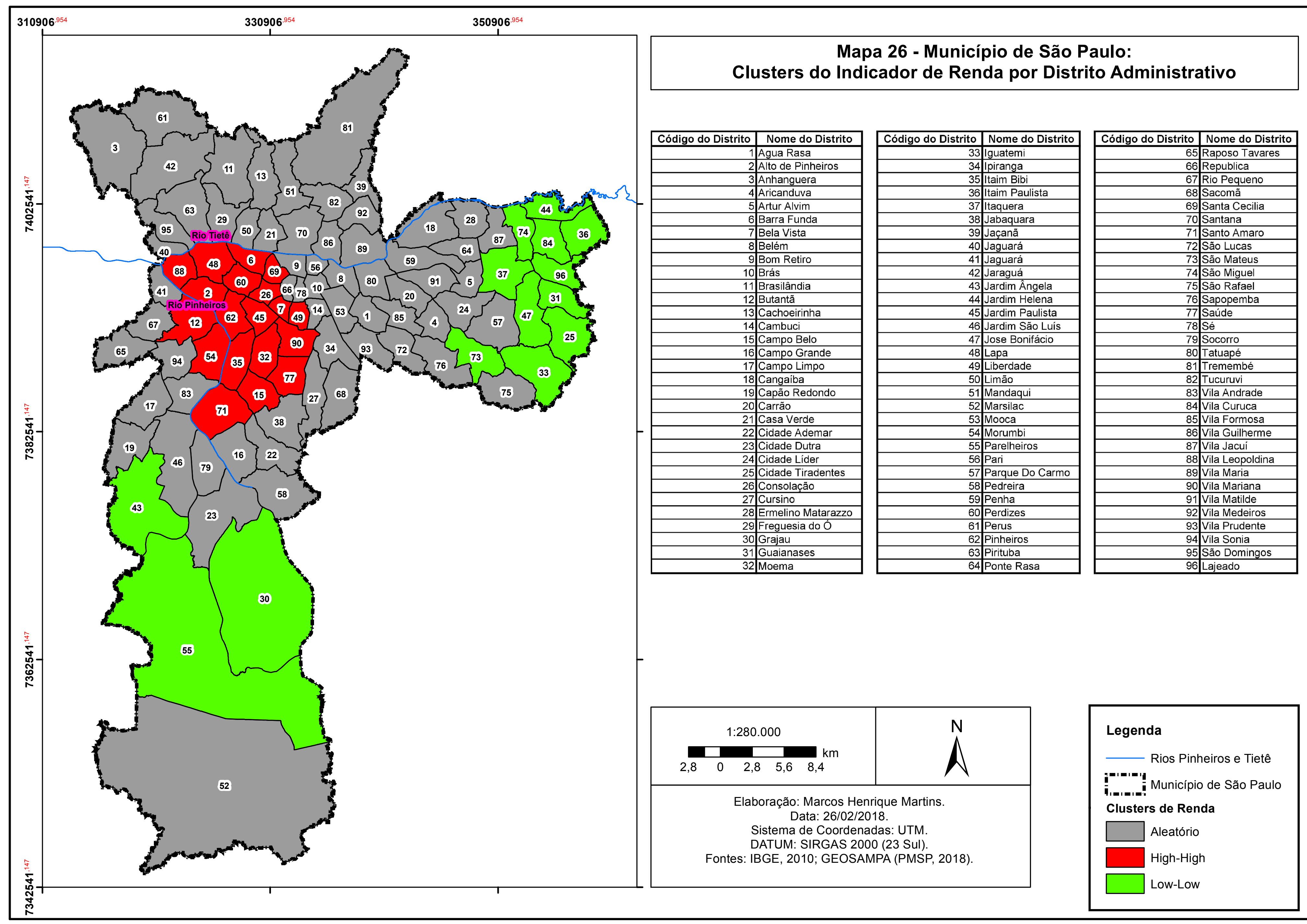


No mapa 20 e, especialmente, no 21 é possível observar a caracterização espacial da concentração de renda no MSP. Nota-se que os distritos localizados entre os rios Pinheiros e Tietê, próximos à confluência dos referidos rios, apresentam as maiores rendas médias por domicílio do MSP. Neste sentido, observa-se que os distritos mais pauperizados estão localizados principalmente nas extremidades do município.

Os mapas 22 e 23 representam a realidade da alfabetização do MSP. A análise desses mapas indica uma situação aparentemente bastante positiva, haja vista o indicador de alfabetização apresentar menor discrepância interdistrital. Entretanto, vale recordar que o referido indicador é incapaz de mensurar a qualidade do ensino nos referidos distritos, haja vista os dados disponibilizados pelo IBGE (2010) para o universo censitário representarem apenas o número de pessoas alfabetizadas, por faixa etária, sem qualquer parâmetro avaliativo da qualidade do ensino. Neste sentido, o analfabetismo funcional não é mensurado pelo referido indicador de alfabetização, impossibilitando análises mais profundas.

Apesar de apresentarem, em geral, um bom indicador de alfabetização, é importante notar, especialmente no mapa 23 , que os distritos com um maior número de pessoas alfabetizadas estão localizados entre os rios Pinheiros e Tietê, nas proximidades da confluência desses dois rios e, principalmente, no entorno do rio Pinheiros. Este padrão de distribuição dos distritos com melhores indicadores, também observado no mapa 21, mantêm-se nos mapas 24 , 25 e 26, relativos ao indicador socioeconômico, por setor censitário e por distrito administrativo, respectivamente.

Na margem direita do Rio Pinheiros, desde sua confluência com o Rio Tietê até os pontos mais elevados do seu curso, é onde se localizam os distritos cuja realidade socioeconômica é caracteristicamente mais avantajada, considerando-se a totalidade do município de São Paulo. À direita do referido rio, estão localizadas as melhores rendas e os melhores índices de alfabetização, bem como uma maior variabilidade dos percentuais de impermeabilização do solo, o que se justifica pela presença de um planejamento urbano que valorizou a manutenção de áreas verdes, tendo em vista seu valor paisagístico e microclimático.

Por outro lado, as zonas periféricas localizadas nos extremos sul, norte e leste do MSP são caracteristicamente mais pobres, mais analfabetas e apresentam uma menor variabilidade nos percentuais de impermeabilização, sendo caracterizadas por amplas áreas impermeáveis em contato com extensas áreas verdes, como é o caso do Parque Estadual da Serra do Mar, que recobre parte do distrito administrativo de Marsilac, na zona sul do município. 
Ademais, considerando-se a área urbana mais adensada do MSP, vale notar que as menores temperaturas radiantes encontram-se também nos distritos localizados no entorno do Rio Pinheiros, especialmente em sua margem direita.

Neste sentido, pode-se identificar, já nesta fase da análise, uma relação espacial entre renda, alfabetização, TAS e impermeabilização do solo no MSP. Os dados distritais relativos aos indicadores apresentados até o presente momento, neste capítulo, podem ser correlacionados entre si, conforme se demonstrou no capítulo 2. Assim sendo, é possível correlacionarmos os valores dos referidos indicadores considerando-se os clusters VARIMP, gerados no subcapítulo 2.1.3.

A relação entre os indicadores VARIMP e de renda, expressa na regressão linear exposta no gráfico 3.1, abaixo, sugere que a variabilidade em questão está intimamente relacionada com a renda média domiciliar distrital, de modo que, quanto maior for a renda em questão, maior a variabilidade nos percentuais de impermeabilização.

Gráfico 3.1 - Relação entre os indicadores de renda e VARIMP nos clusters VARIMP

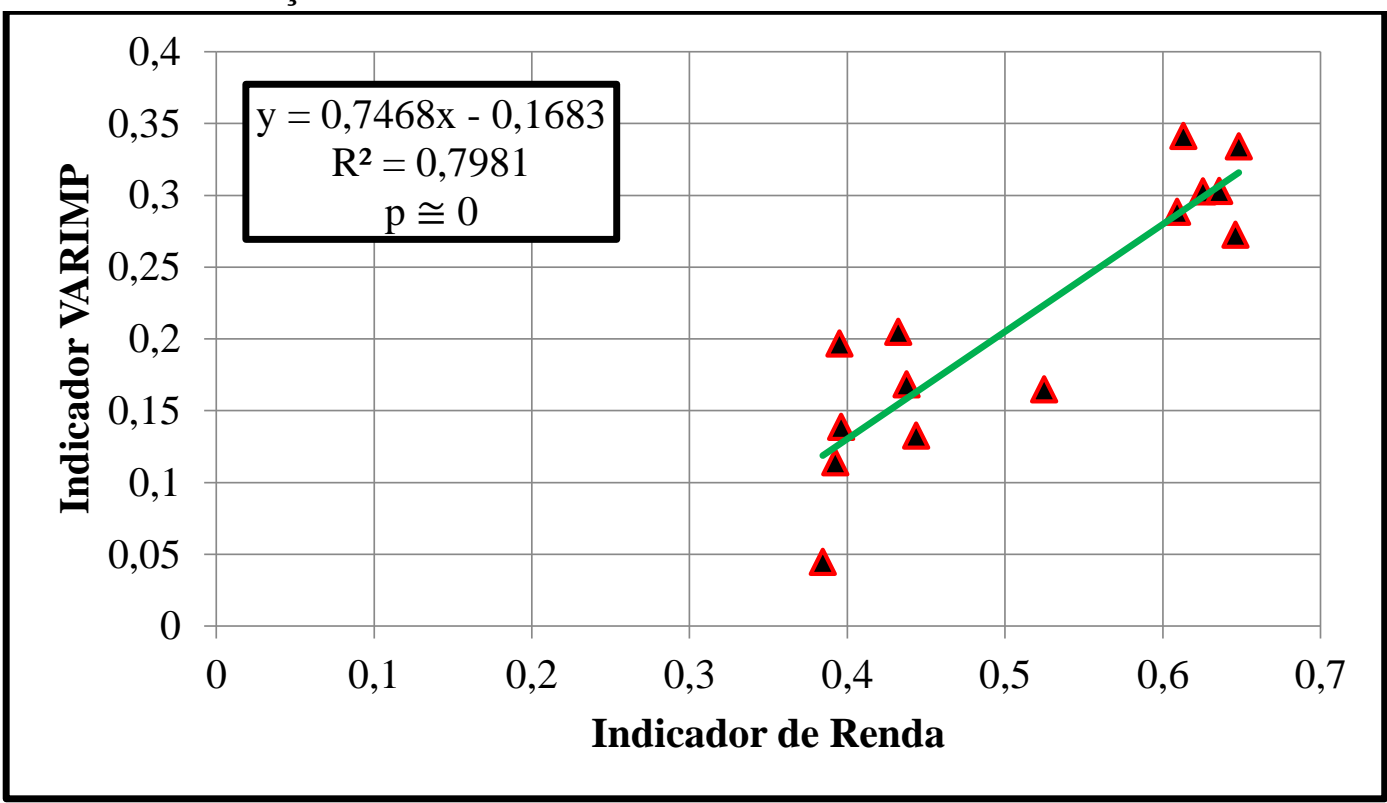

Fonte: Elaboração própria. Data: 27/02/2018.

Os dados relativos à alfabetização nos distritos que compõem os clusters VARIMP reforçam o que se observa no gráfico 3.1, ou seja, indicam que, quanto maior a variabilidade dos percentuais de impermeabilização, maior a alfabetização dos distritos em análise, conforme se pode observar no gráfico 3.2, disposto abaixo. 
Gráfico 3.2 - Relação entre os indicadores de alfabetização e VARIMP nos clusters VARIMP

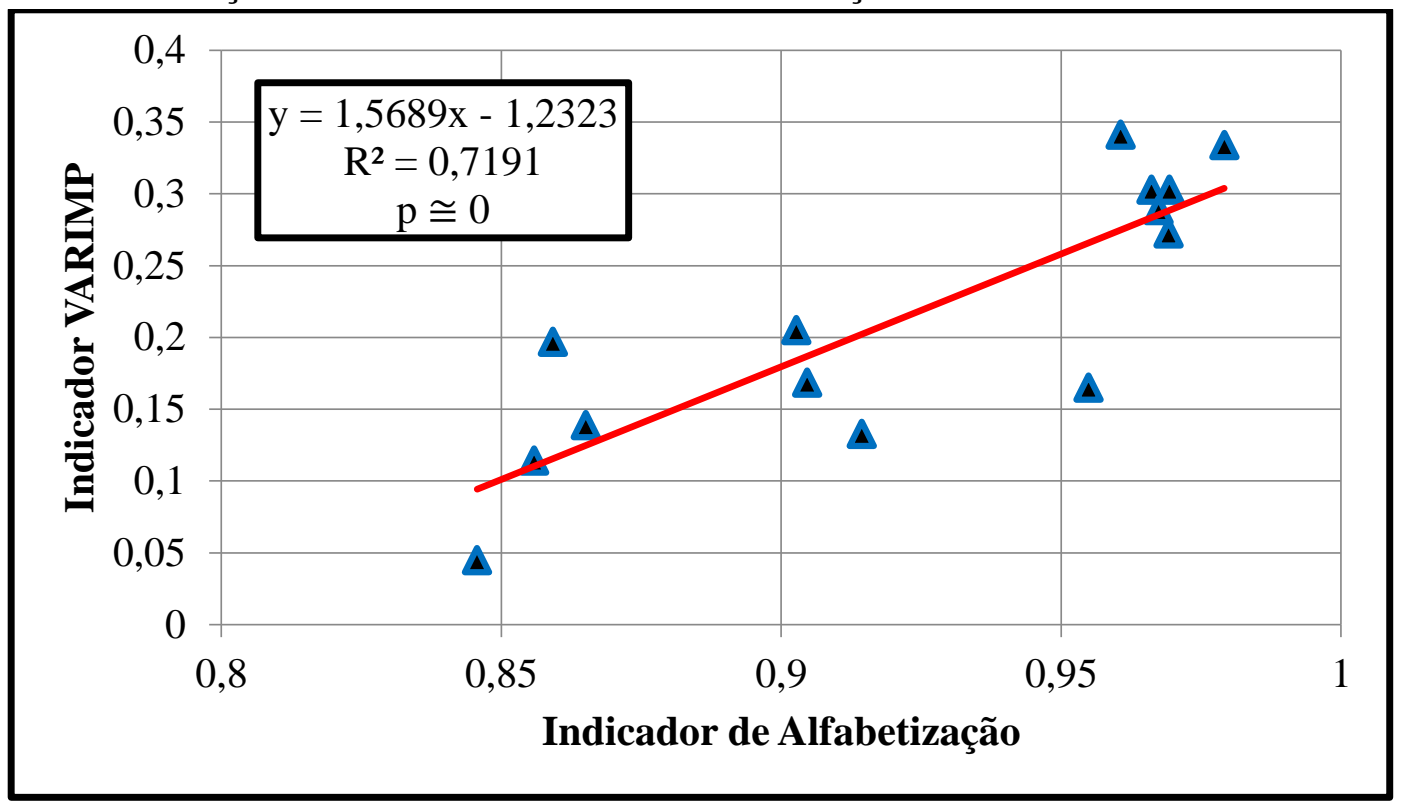

Fonte: Elaboração própria. Data: 27/02/2018.

As regressões lineares presentes nos gráficos 3.1 e 3.2 apresentam resultados que reforçam a importância das condições socioeconômicas avaliadas em correlação com a variabilidade da impermeabilização do solo nos distritos em questão. Não se pode desconsiderar, portanto, a relação entre este indicador ambiental e os indicadores socioeconômicos, conforme podemos observar no gráfico 3.3, abaixo.

Gráfico 3.3 - Relação entre os indicadores socioeconômico e VARIMP nos clusters VARIMP

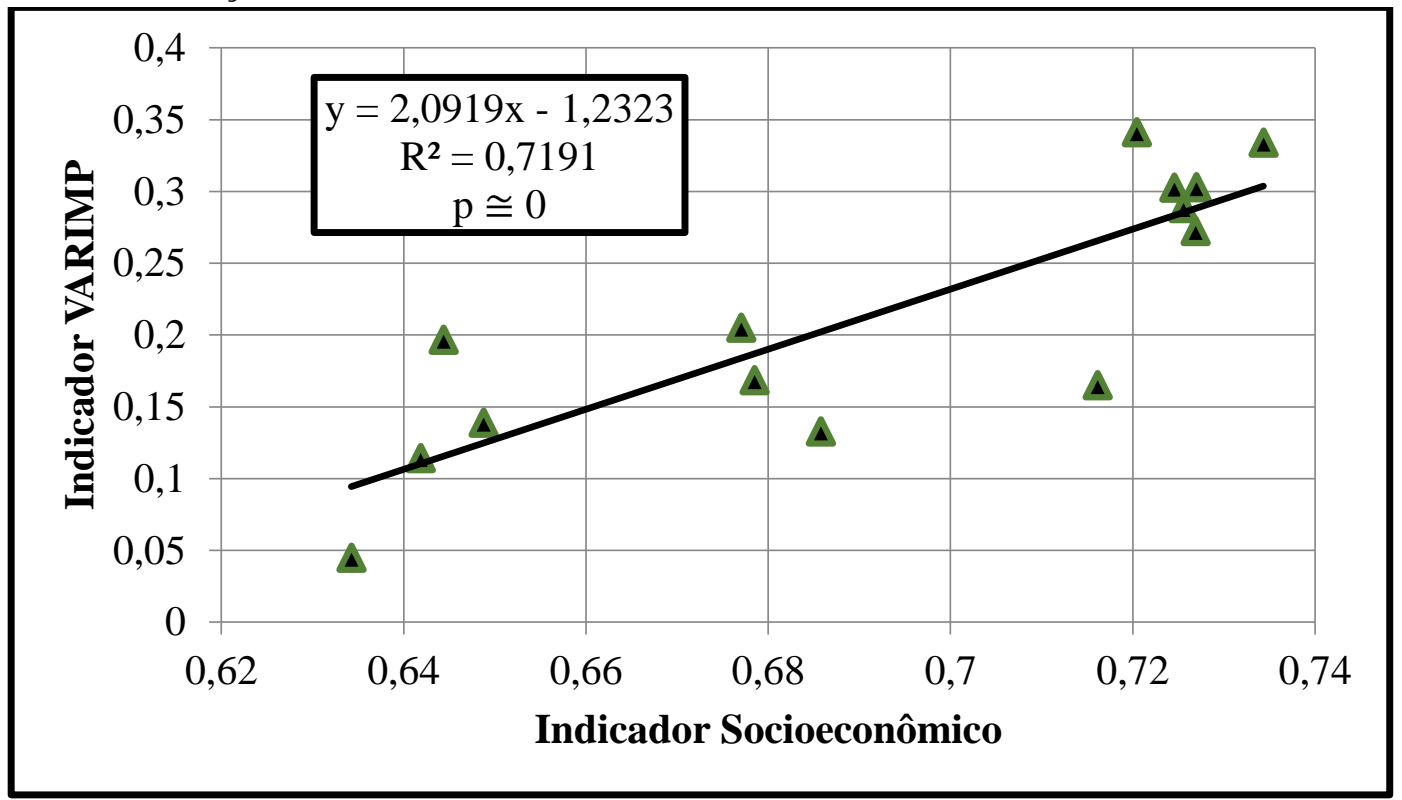

Fonte: Elaboração própria. Data: 27/02/2018. 
Ao considerar-se a temperatura aparente de superfície para os distritos que compõem os clusters VARIMP, observa-se que a relação entre esses indicadores não apresenta um comportamento linear. A reta de regressão constituída é um polinômio do segundo grau, indicando que a TAS tende a aumentar com o aumento do indicador VARIMP até certo ponto, a partir do qual nota-se uma redução da temperatura radiante em função do aumento da variabilidade dos percentuais de impermeabilização do solo, conforme podemos observar no gráfico 3.4, disposto abaixo.

Gráfico 3.4 - Relação entre a TAS e o indicador VARIMP nos clusters VARIMP

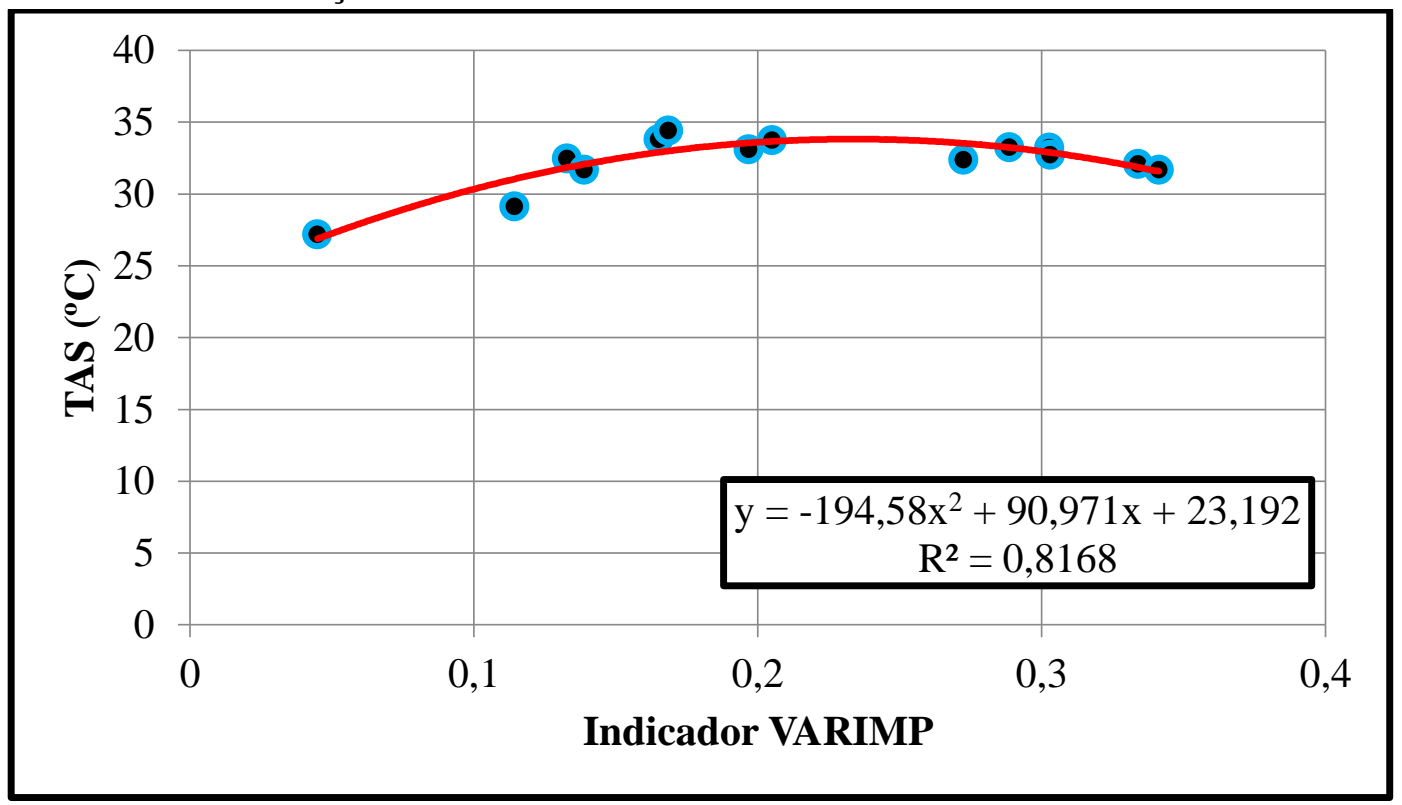

Fonte: Elaboração própria. Data: 27/02/2018.

Ademais, outro dado importante a ser explorado no escopo deste trabalho diz respeito à fragilidade etária dos distritos, ou seja, a susceptibilidade dos distritos à ocorrência de mortalidade MSC devido à sua própria composição etária.

\subsection{Fragilidade Etária}

Ao analisarmos a taxa de mortalidade, por faixa etária, para o município de São Paulo, observou-se que os óbitos MSC ocorreram principalmente em indivíduos com mais de 55 anos em 2015. Neste sentido, computou-se um indicador capaz de equiparar os distritos administrativos do MSP a partir da concentração de indivíduos com mais de 55 anos residentes nesses distritos. Os mapas 27 e 28 apresentam o referido indicador para o município de São Paulo, por setor censitário e distrito administrativo, respectivamente. 


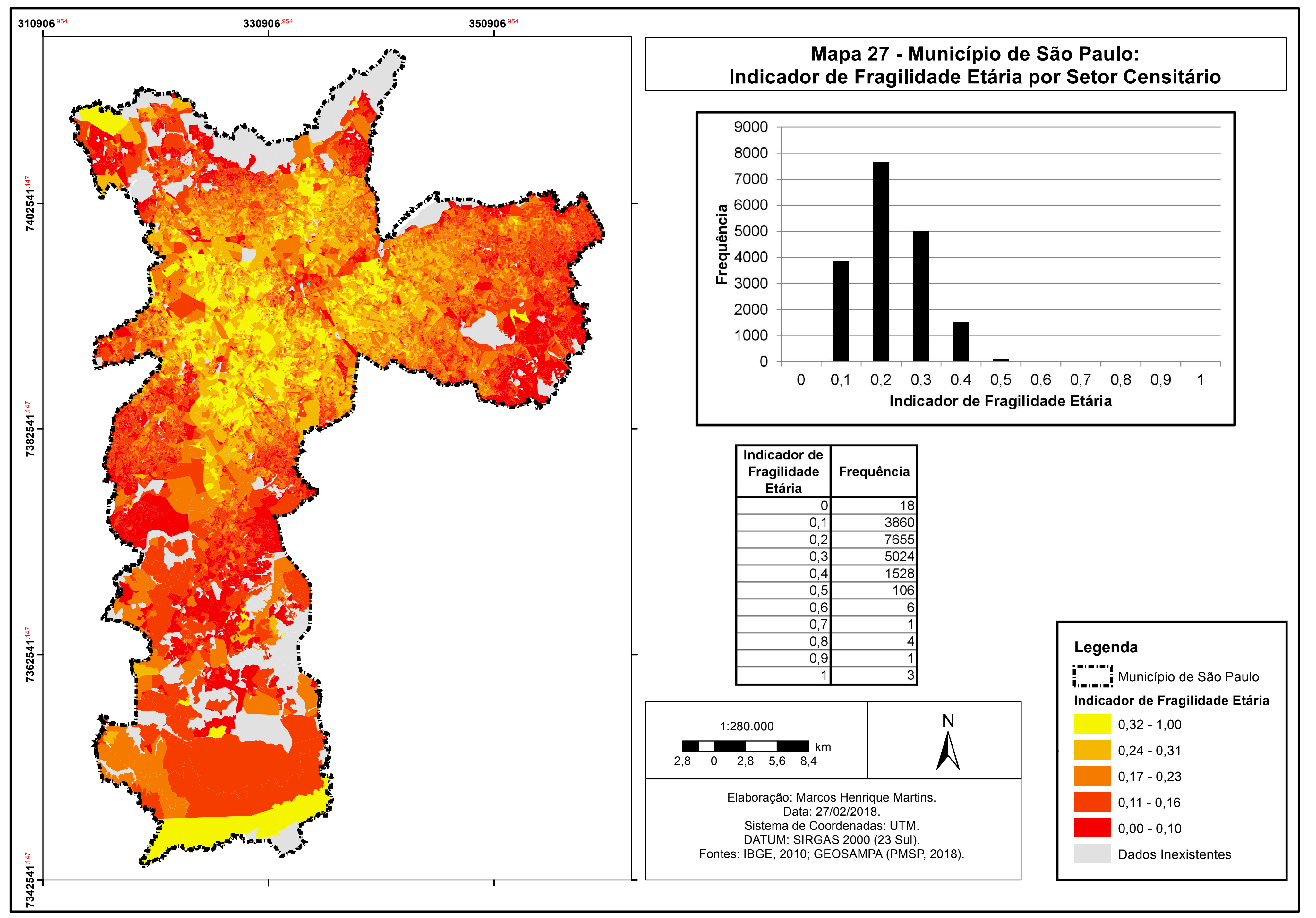




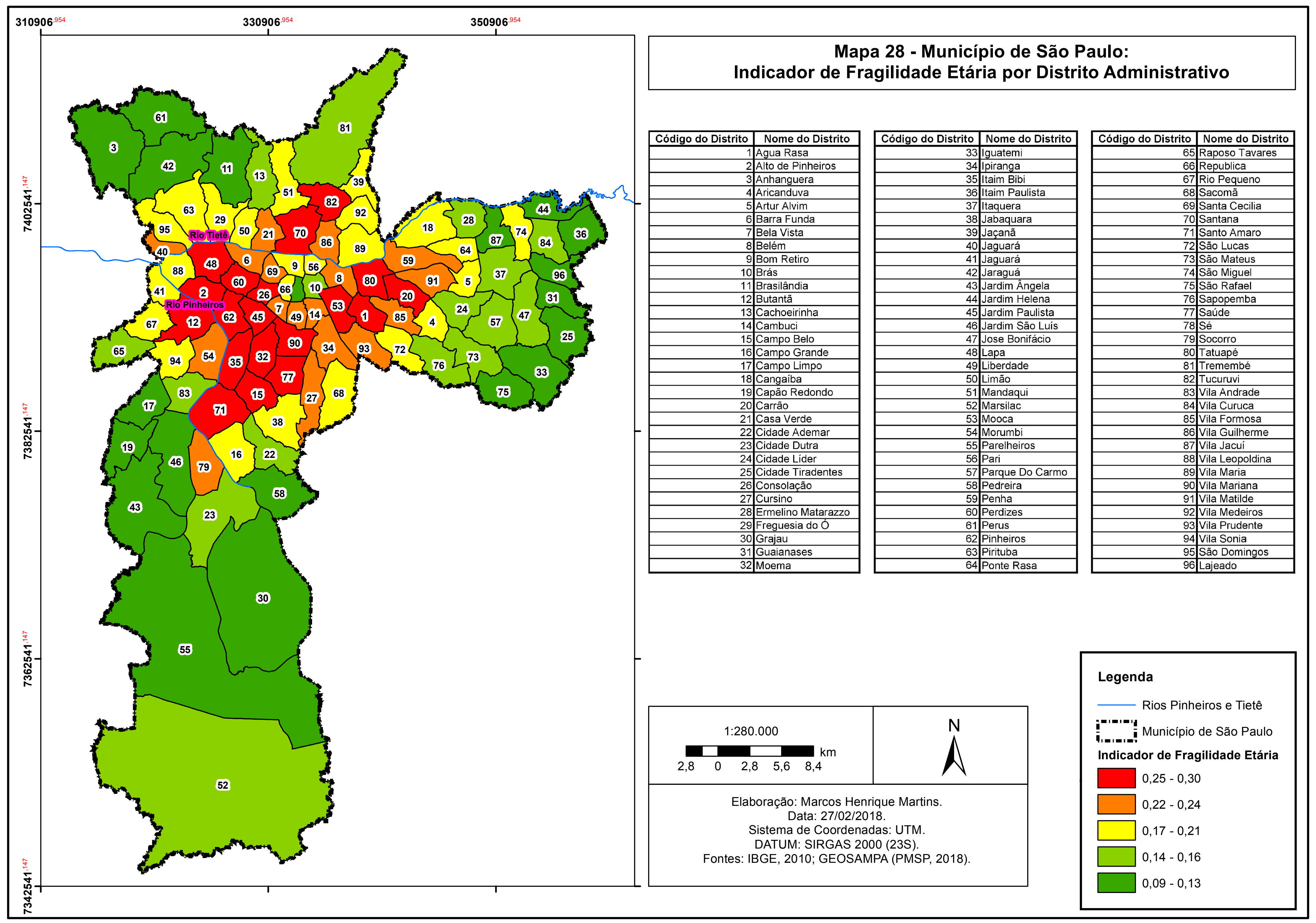


No mapa 27 é possível notar que os setores censitários que compõem as regiões centrais do MSP apresentam uma maior concentração de idosos que os demais setores. Este padrão é confirmado ao analisarmos o mapa 28. Neste mapa é possível notar que o padrão de concentração observado nos mapas anteriores se repete: partindo-se da confluência dos rios Pinheiros e Tietê, nota-se uma maior concentração de idosos na margem direita do Rio Pinheiros. Os distritos localizados nesta localidade apresentam, como observado, maiores índices de alfabetização e rendas médias mais elevadas. Ademais, os percentuais de impermeabilização não são tão elevados, nem se concentram em pontos adensados do território. Destarte, é relevante pontuarmos que a expectativa de vida elevada observada nesses distritos, representada pela concentração de idosos que eles apresentam, está intimamente associada com os indicadores socioeconômicos e ambientais analisados.

No gráfico 3.5, disposto a seguir, é possível observar que há uma relação significativa entre a concentração de idosos e a concentração de renda, ratificando a compreensão de que a renda é determinante para a longevidade da população.

Gráfico 3.5 - Relação entre renda e fragilidade etária nos distritos administrativos do MSP

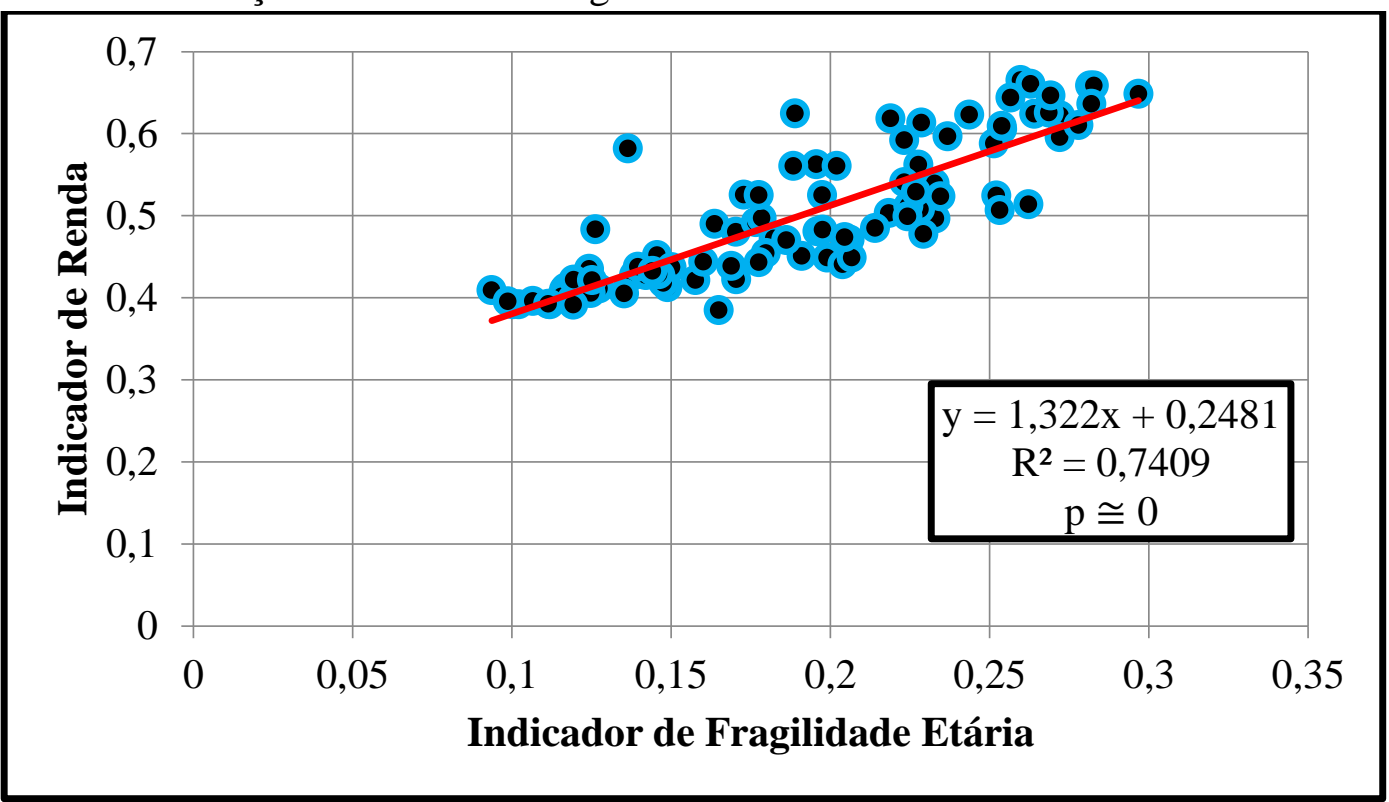

Fonte: Elaboração própria. Data: 27/02/2018.

No gráfico 3.6, fica exposto que a expectativa de vida tem também uma íntima relação com o indicador de alfabetização, indicando que, quanto maior a alfabetização, maior a expectativa de vida. Ademais, no gráfico 3.7, é possível identificar que a renda e a alfabetização também estão intimamente associadas, de forma que, quanto maior a renda, maior a alfabetização dos indivíduos. 
Gráfico 3.6 - Relação entre alfabetização e fragilidade etária nos distritos administrativos do MSP

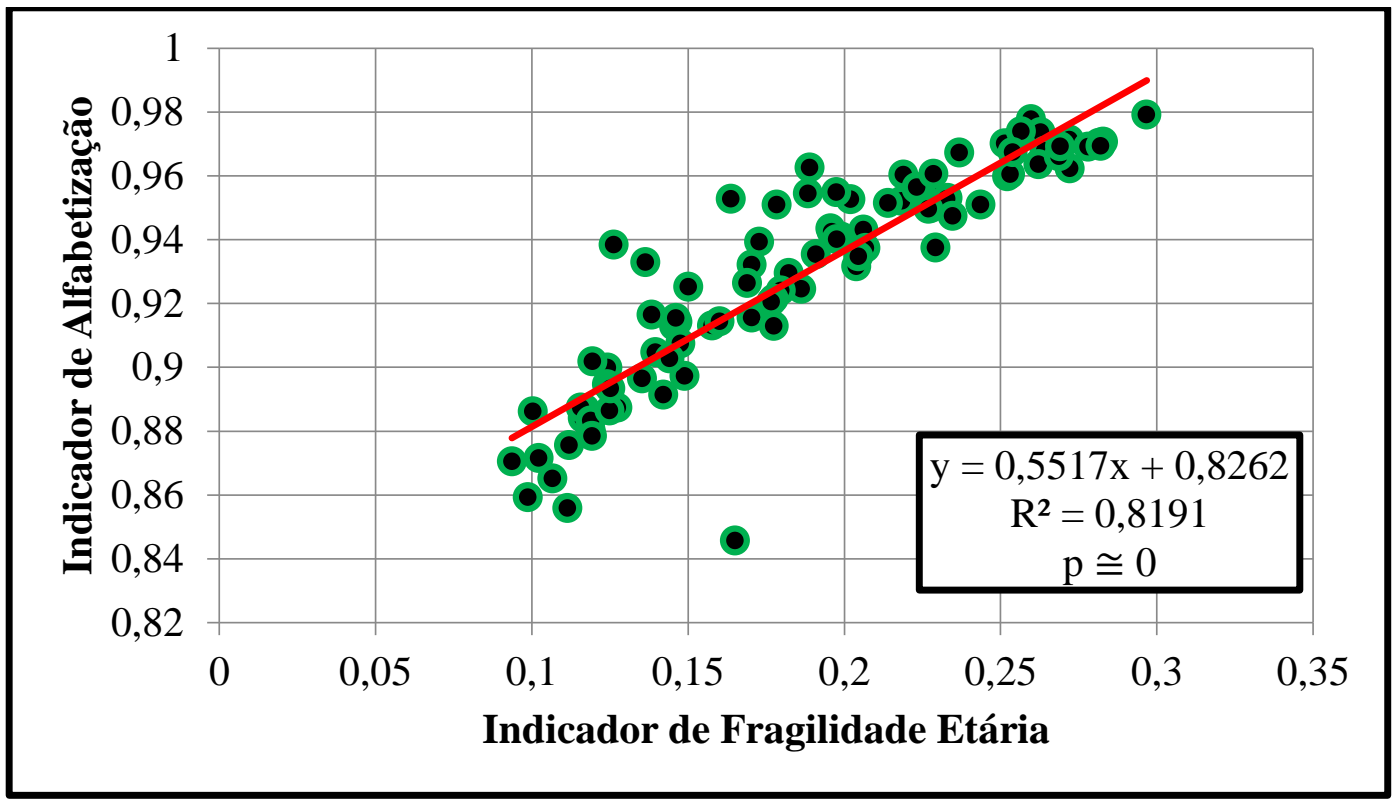

Fonte: Elaboração própria. Data: 27/02/2018.

Gráfico 3.7 - Relação entre alfabetização e renda nos distritos administrativos do MSP

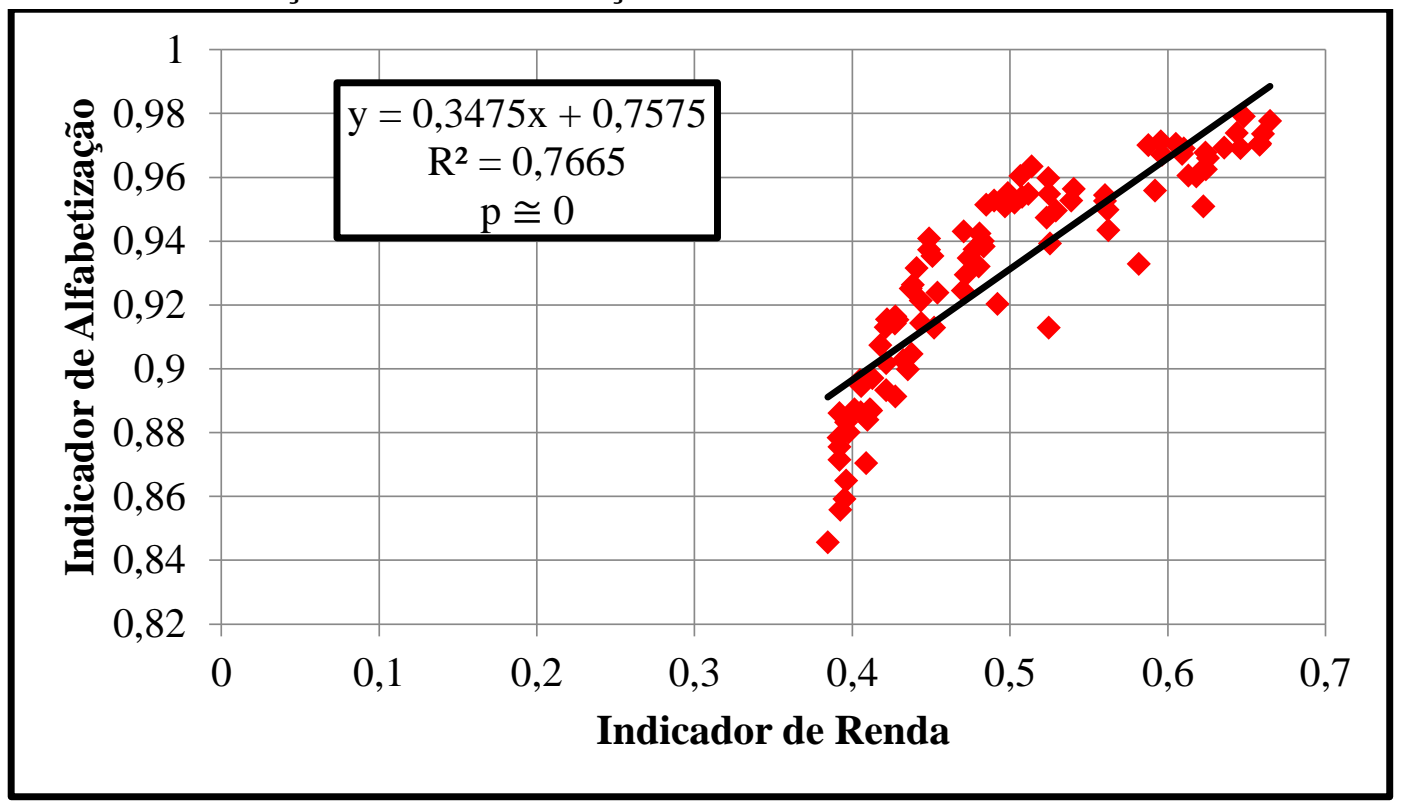

Fonte: Elaboração própria. Data: 27/02/2018.

No gráfico 3.8, a seguir, estão correlacionados os indicadores socioeconômico e de fragilidade etária. A referida correlação indica que as condições socioeconômicas dos indivíduos estão fortemente correlacionadas com a expectativa de vida dos mesmos. Este dado se nos apresenta com grande relevância, conforme veremos a seguir. 
Gráfico 3.8 - Relação entre os indicadores socioeconômico e de fragilidade etária nos distritos administrativos do MSP

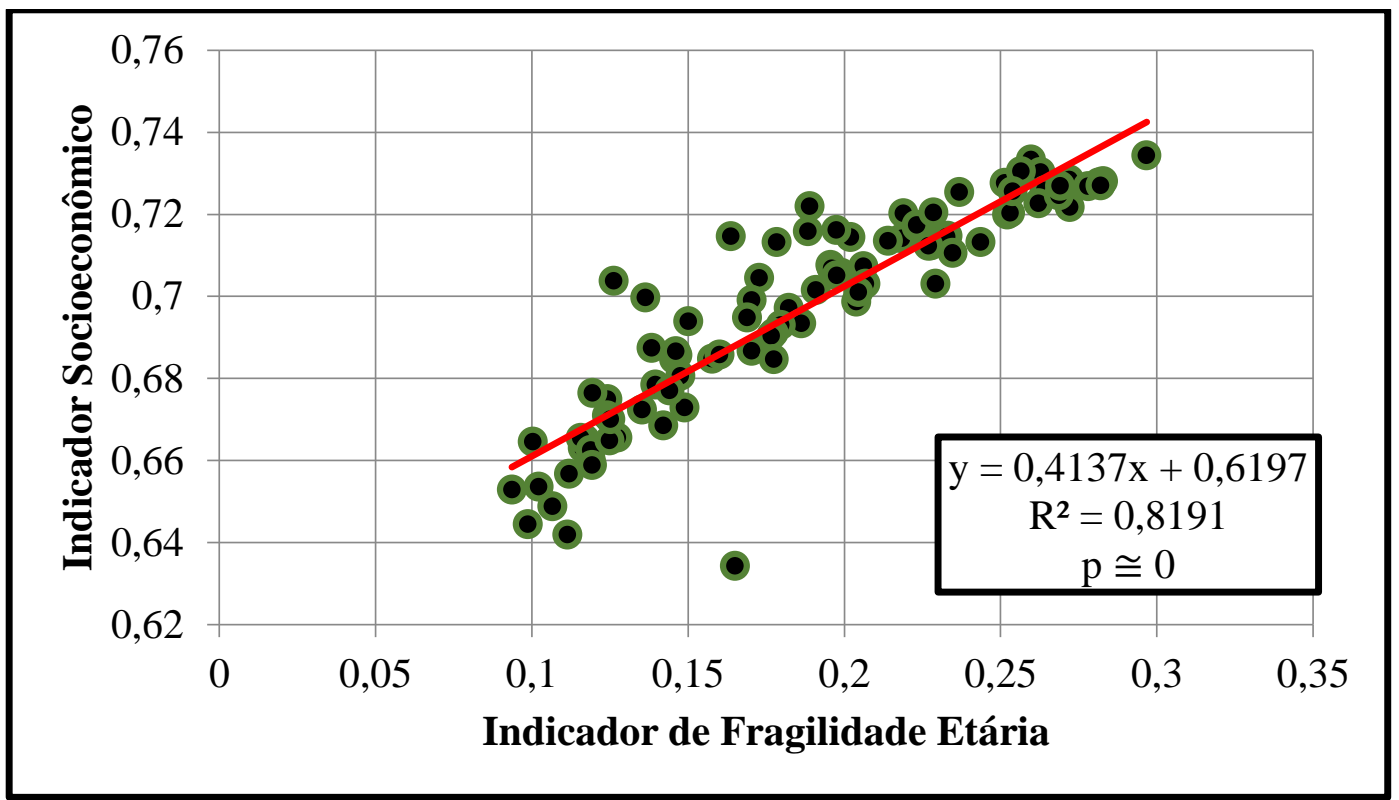

Fonte: Elaboração própria. Data: 27/02/2018.

Por fim, vale notar que os gráficos de 3.5 a 3.8 apresentaram valor-p tendendo a nulidade, o que sugere desconsiderar a hipótese nula. Ademais, todos os referidos gráficos possuem elevado coeficiente de determinação (acima de 70\%).

Ao analisarmos os clusters VARIMP, correlacionando-os com os valores do indicador de fragilidade etária para os distritos compositores destes clusters, nota-se que, quanto maior a variabilidade na composição dos percentuais de impermeabilização do solo, maior a concentração de idosos nos distritos analisados. Pode-se observar tal correlação no gráfico 3.9, disposto abaixo. 
Gráfico 3.9 - Relação entre os indicadores de fragilidade etária e VARIMP nos clusters VARIMP

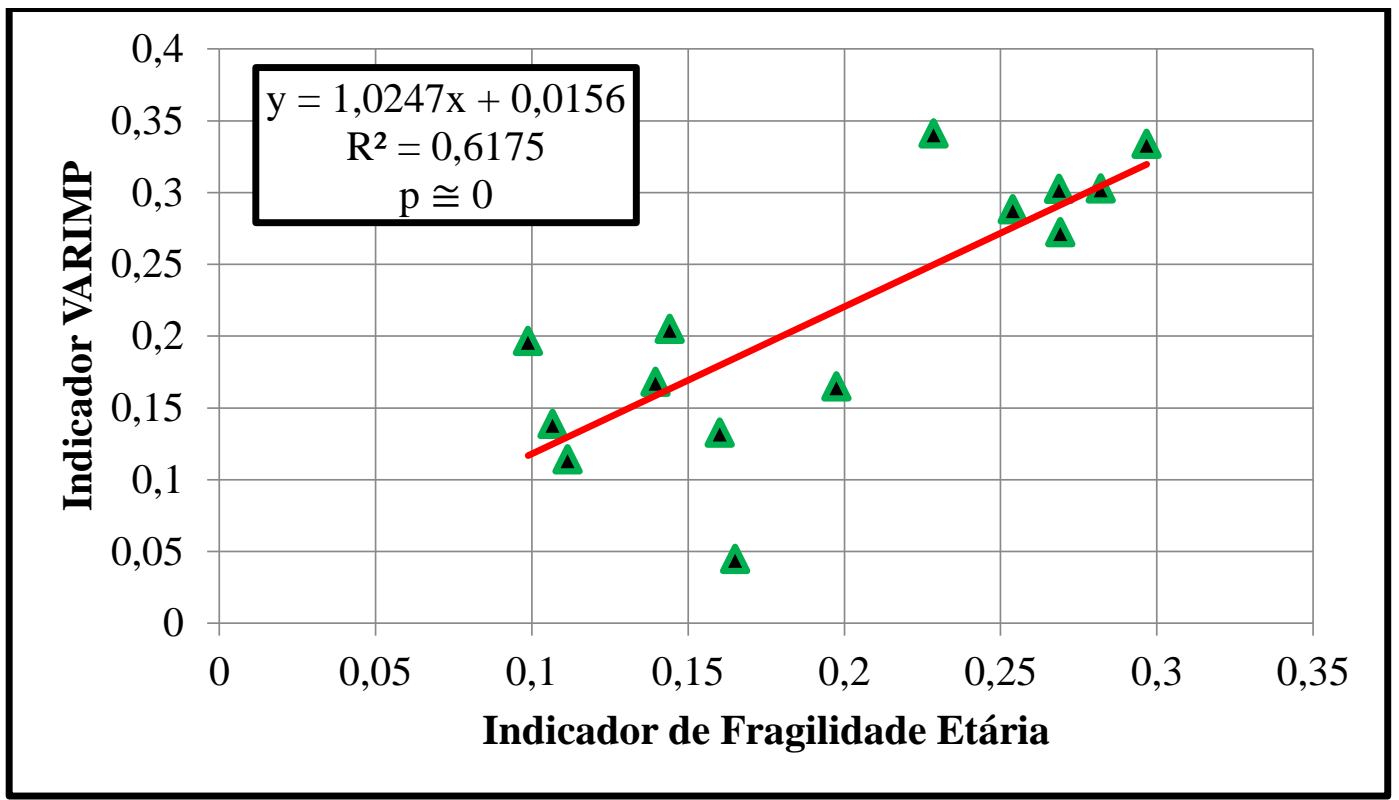

Fonte: Elaboração própria. Data: 27/02/2018

O gráfico 3.9 reforça a relação íntima entre as condições socioeconômicas dos distritos analisados e a caracterização da impermeabilização do solo nos referidos distritos. Neste sentido, até o presente momento, parece sensato indicarmos que os fatores socioeconômicos e ambientais analisados apresentam uma relação que não pode ser desconsiderada.

Ademais, ao correlacionarmos o indicador de fragilidade etária com o indicador de mortalidade MSC, observa-se uma relação diferente da observada quando consideramos apenas a taxa de mortalidade MSC, por faixa etária, sem seus condicionantes locais. Nota-se, no gráfico 3.10, que quanto maior a concentração de pessoas com mais de 55 anos, menor a taxa de mortalidade MSC observada nos distritos administrativos do MSP. 
Gráfico 3.10 - Relação entre os indicadores de fragilidade etária e de mortalidade MSC nos distritos administrativos do município de São Paulo

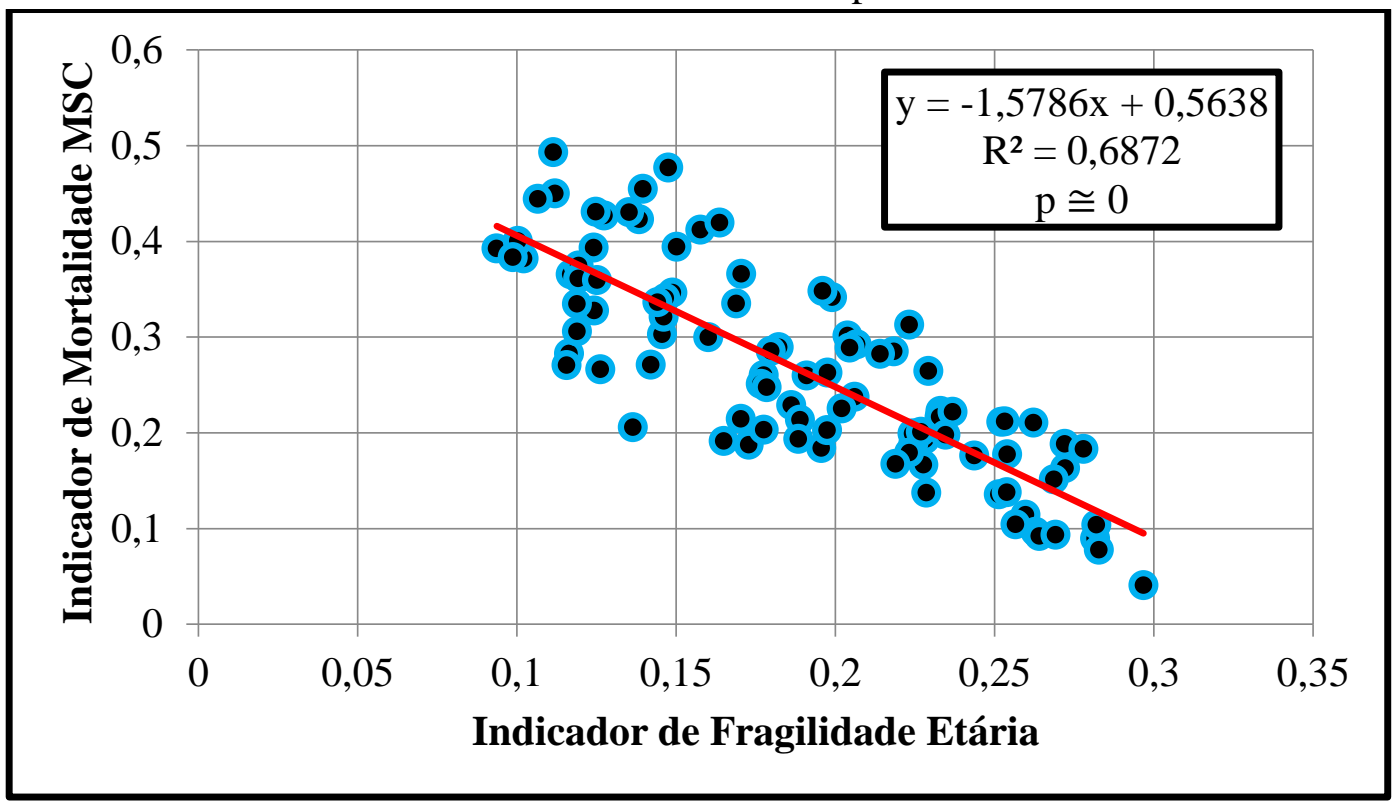

Fonte: Elaboração própria. Data: 27/02/2018.

A relação representada pela regressão exposta no gráfico 3.10 é acentuada quando se considera apenas os distritos que compõem os clusters de mortalidade MSC, conforme pode-se observar no gráfico 3.11, a seguir.

Gráfico 3.11 - Relação entre os indicadores de fragilidade etária e de mortalidade MSC nos clusters MSC

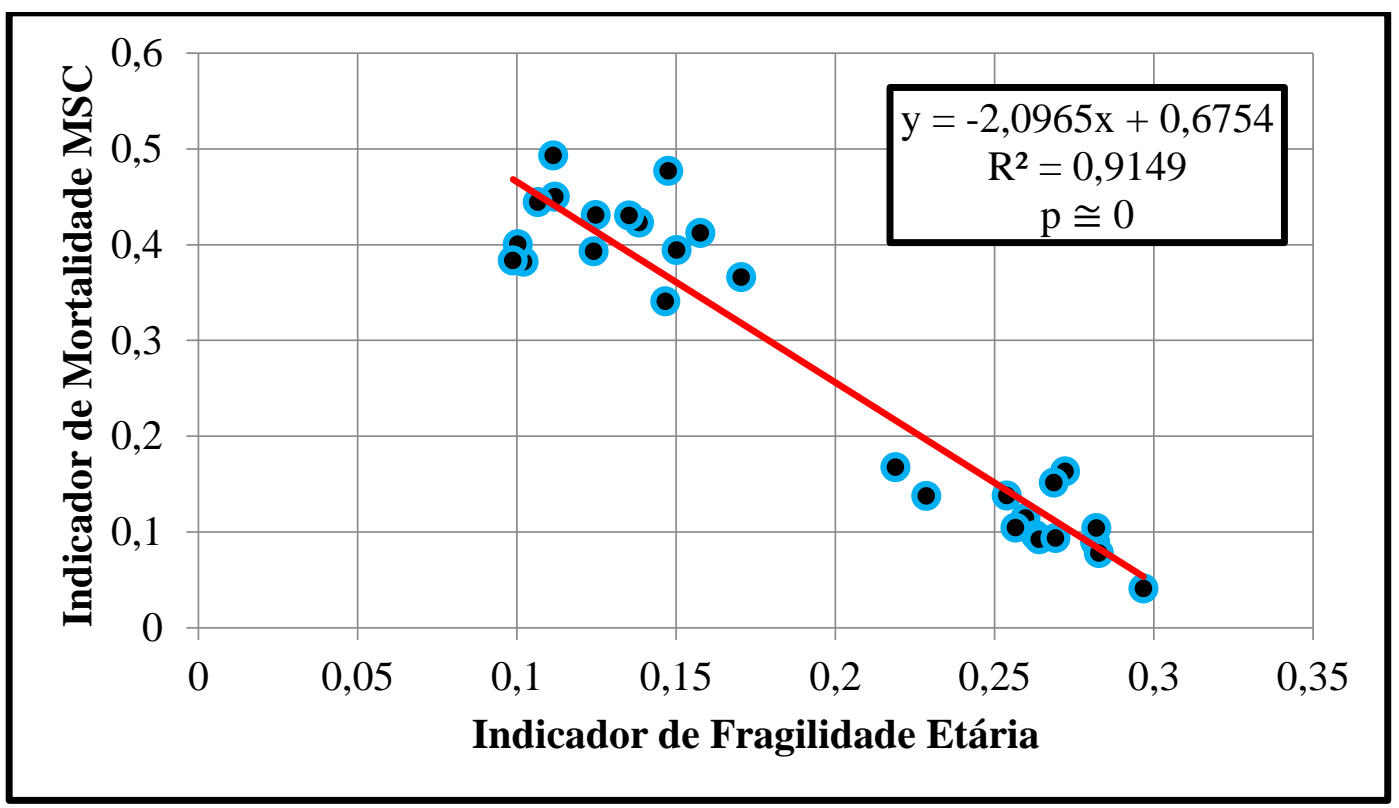

Fonte: Elaboração própria. Data: 27/02/2018. 
Assim sendo, tendo em vista a correlação entre a concentração de pessoas com mais de 55 anos nos distritos administrativos do MSP e os indicadores de renda, alfabetização e socioeconômico, pode-se concluir que, para a tipologia de mortalidade considerada, a idade dos indivíduos teoricamente mais susceptíveis aos óbitos associados às doenças do aparelho circulatório importa menos que seu status socioeconômico. Em outras palavras, envelhecer e morrer são processos diferentes quando se considera indivíduos com condições socioeconômicas distintas, ainda que pertençam ao mesmo município. Destarte, envelhecer não significa necessariamente estar susceptível à tipologia de doenças analisada, haja vista ser necessário considerar-se outros fatores espacialmente definidos.

Estas considerações sobre a fragilidade etária da população analisada podem ser extrapoladas para questionamentos de ordem filosófica, que serão explorados nos próximos capítulos. Por enquanto, cabe manter em alta alguns questionamentos: envelhecer é um processo natural? É um fenômeno social? Como se definir a morte? Há possibilidade de uma definição puramente biológica para a vida? Natureza e cultura são distinções plausíveis?

\subsection{Análise dos Oito Distritos Discriminados}

No ano de 2015, o município de São Paulo registrou 23.669 óbitos associados às doenças do aparelho circulatório. Desses óbitos, 1391 ocorreram nos oito distritos selecionados para análise, ou seja, um total de, aproximadamente, 5,87\%. A população do município de São Paulo, no ano de 2010, era de 11.249.076 habitantes (IBGE, 2010), dos quais 660.699 (5,87\%) residiam nos referidos distritos. A área do município de São Paulo corresponde a aproximadamente $1.527 .535 .803 \mathrm{~m}^{2}$ (cerca de 150.000 hectares), dos quais, $236.480 .481,5 \mathrm{~m}^{2}$ $(15,5 \%)$ estão circunscritos nos limites dos distritos discriminados. Ademais, 69.201.130,7 m² dos referidos distritos estão impermeabilizados, o que representa cerca de 1/3 (29,3\%) da área desses distritos.

A tabela 3.1, disposta abaixo, indica os distritos administrativos selecionados, seus códigos, suas áreas, os percentuais de impermeabilização do solo, o número total de habitantes, o número total de óbitos ocorridos, a taxa e o indicador de mortalidade MSC. O mapa 29 indica a localização dos referidos distritos. 
Tabela 3.1 - Dados relativos aos distritos selecionados para análise

\begin{tabular}{|c|c|c|c|c|c|c|c|c|}
\hline $\begin{array}{c}\text { Código } \\
\text { do } \\
\text { Distrito }\end{array}$ & Nome do Distrito & Habitantes & Área $\left(\mathbf{m}^{2}\right)$ & $\begin{array}{l}\text { Impermeabilização } \\
\text { do Solo }\left(\mathbf{m}^{2}\right)\end{array}$ & $\begin{array}{c}\text { Impermeabilização } \\
\text { do Solo }(\%)\end{array}$ & $\begin{array}{c}\text { Óbitos } \\
\text { MSC }\end{array}$ & $\begin{array}{c}\text { Taxa de } \\
\text { Mortalidade } \\
\text { MSC }\end{array}$ & $\begin{array}{c}\text { Indicador de } \\
\text { Mortalidade } \\
\text { MSC }\end{array}$ \\
\hline 8 & Belém & 45057 & 6045899,57 & 5312640,26 & 87,87 & 129,00 & 189,36 & 0,31 \\
\hline 10 & Brás & 29265 & 3629272,92 & 3441263,78 & 94,82 & 78,00 & 285,55 & 0,42 \\
\hline 13 & Cachoeirinha & 143493 & 13543301,88 & 6687321,39 & 49,38 & 325,00 & 266,48 & 0,45 \\
\hline 47 & José Bonifácio & 124034 & 14547052,71 & 8010359,62 & 55,07 & 282,00 & 296,47 & 0,48 \\
\hline 55 & Parelheiros & 131047 & 152607454,57 & 23068012,78 & 15,12 & 240,00 & 353,71 & 0,49 \\
\hline 57 & Parque do Carmo & 68162 & 15451447,34 & 6538108,73 & 42,31 & 130,00 & 244,63 & 0,42 \\
\hline 61 & Perus & 80156 & 23663672,40 & 10585104,42 & 44,73 & 115,00 & 222,01 & 0,27 \\
\hline 88 & Vila Leopoldina & 39485 & 6992380,12 & 5558319,71 & 79,49 & 92,00 & 182,55 & 0,21 \\
\hline
\end{tabular}

Fonte: IBGE, 2010; PMSP, 2018; EMPLASA, 2010; USGS, 2017. Elaboração própria. Data: 28/02/18 


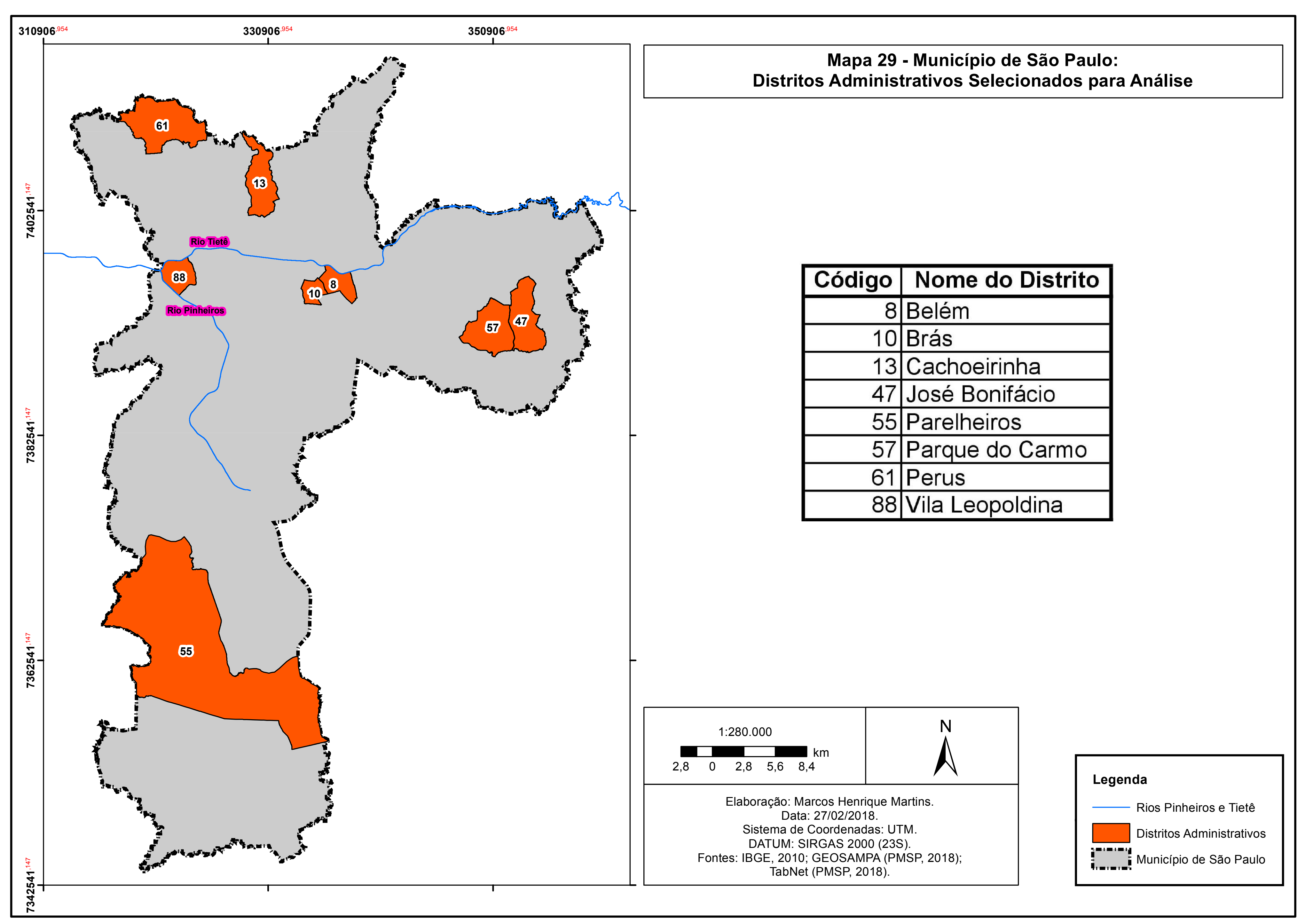


Os distritos selecionados para análise não apresentam correlação significativa entre o indicador de mortalidade MSC e os indicadores de alfabetização, de renda, socioeconômico e de fragilidade etária. Ainda que os coeficientes de determinação para essas regressões possam ser considerados, o valor-p indica que não é possível descartar a hipótese nula, ou seja, de que os referidos indicadores não possuam correlação com a mortalidade MSC nesses distritos. Essas informações encontram-se disponíveis no mapa 30, disposto abaixo. O referido mapa é composto por um conjunto de imagens do município de São Paulo, cada qual representando um dos indicadores elaborados previamente para os distritos discriminados. Ademais, para cada imagem há um mapa demonstrando a regressão linear existente entre o indicador representado e o indicador de mortalidade MSC. 


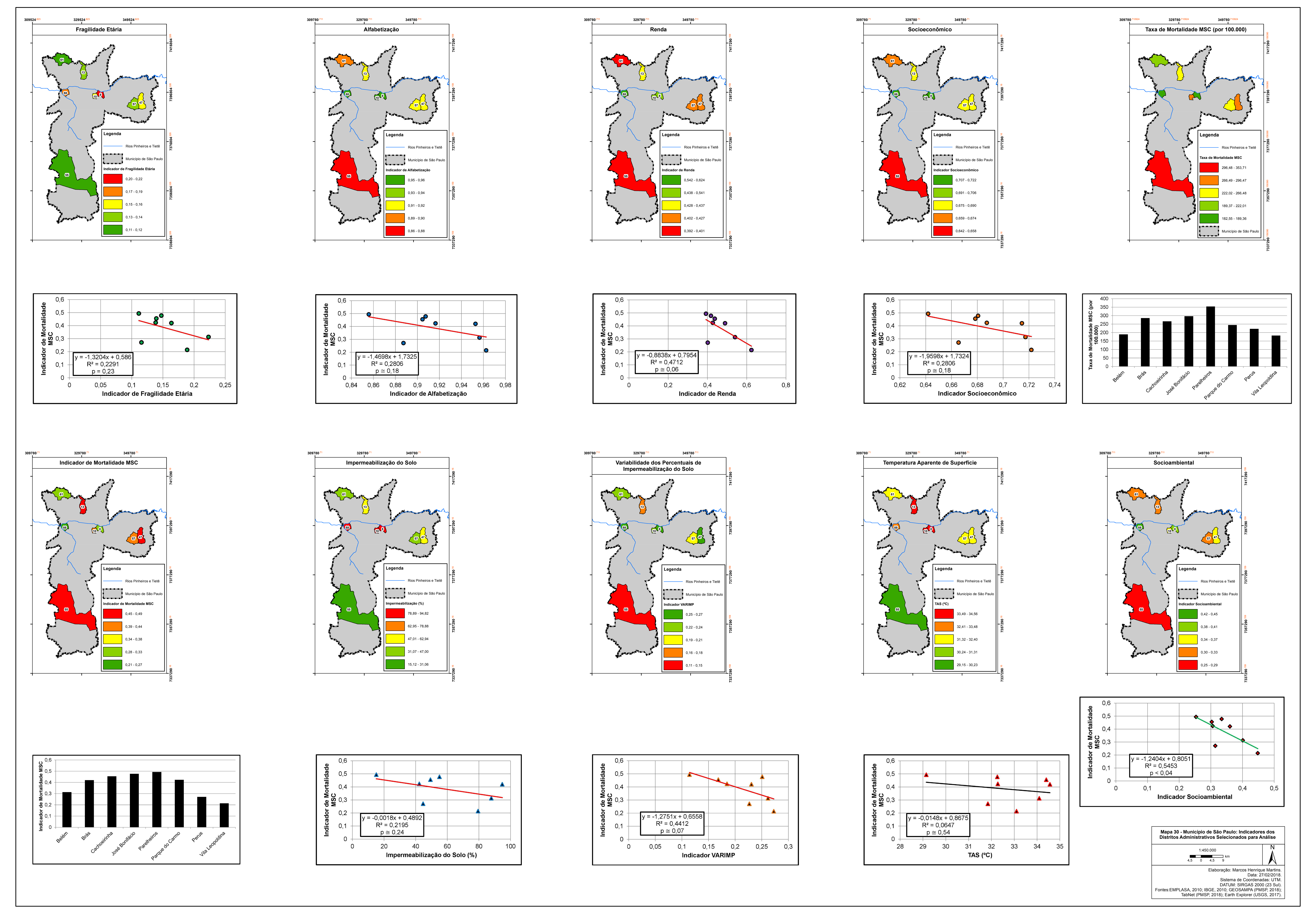


No mapa 30, é possível notar que os indicadores de renda e VARIMP foram os que apresentaram maior coeficiente de determinação e menor valor-p, relativamente aos demais dados apresentados. Partindo-se desta informação, foi possível computar um indicador socioeconômico, conforme apresentado nos subcapítulos 2.6 e 2.7. O referido indicador apresenta uma correlação considerável quando relacionado ao indicador de mortalidade MSC, resultando em um coeficiente de determinação de 0,54 , e um valor-p de 0,04 , indicando ser plausível desconsiderar-se a hipótese nula. É importante avaliarmos o significado e a relevância deste dado.

Neste sentido, ao avaliar-se a relação entre os indicadores VARIMP e de Renda, os quais compõem o indicador socioambiental, nota-se que não se pode desconsiderar a possibilidade de que tais indicadores não possuam uma correlação válida, ainda que o coeficiente de determinação seja elevado, conforme indicado no gráfico 3.12, disposto abaixo. Este é um resultado fundamental de nossas investigações, haja vista podermos ponderar, a partir dele, se a pobreza ou a riqueza não possuiriam um outro aspecto, para além do estritamente monetário, como veremos nos capítulos subsequentes.

\section{Gráfico 3.12 - Relação entre os indicadores VARIMP e de renda nos distritos selecionados}

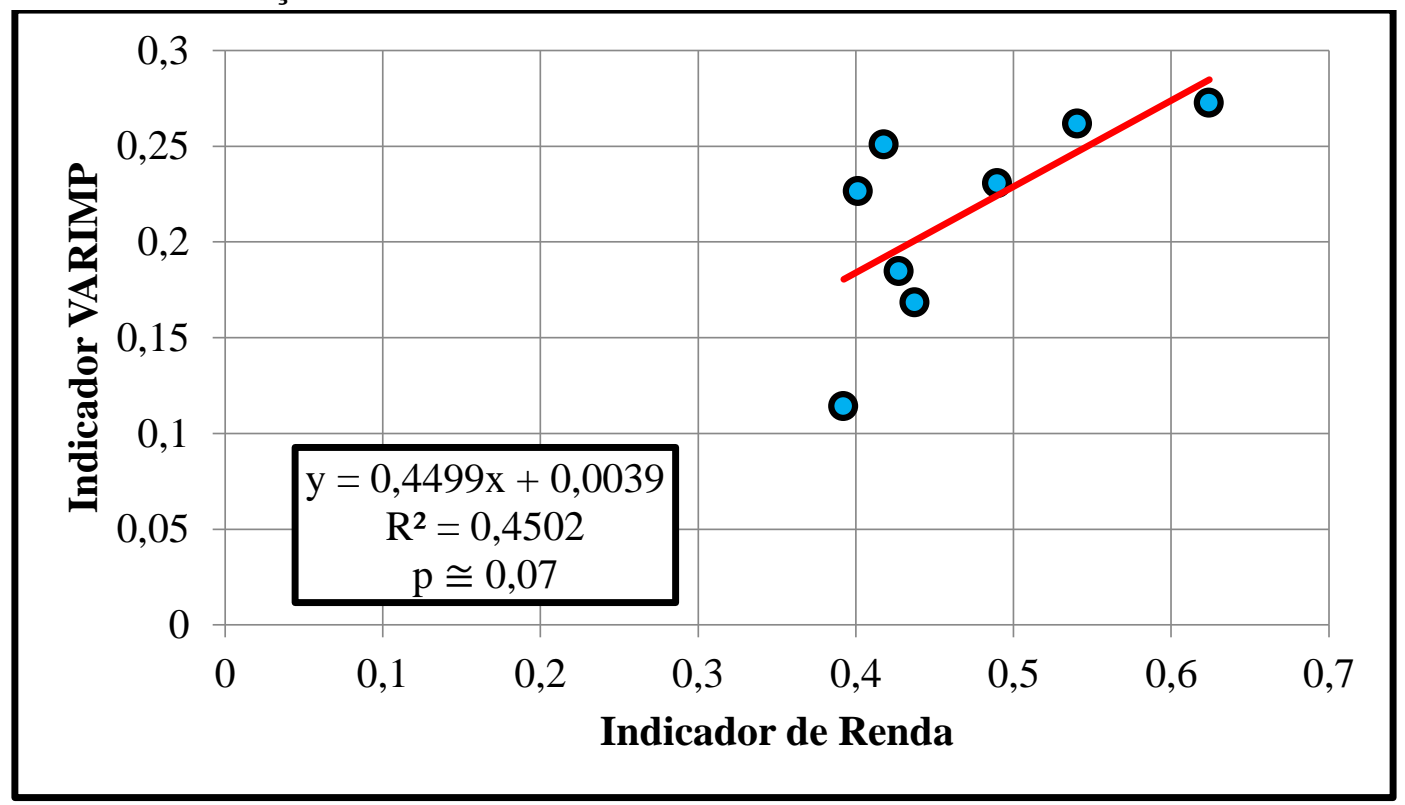

Fonte: Elaboração própria. Data: 28/02/2018.

Por outro lado, conforme indicado no gráfico 3.13, a seguir, é necessário compreendermos que, para os distritos discriminados, o aumento da variabilidade nos percentuais de impermeabilização do solo que compõem seus territórios está relacionado a um aumento nos percentuais de impermeabilização do solo nesses distritos. Em outras palavras, o aumento da impermeabilização do solo nos oito distritos selecionados está relacionado a um 
aumento no percentual de impermeabilização em pelo menos $64 \%$ dos casos analisados. Esta relação pode ser explicada pela variabilidade dos distritos selecionados, haja vista possuírem realidades distintas do ponto de vista das formas de uso e ocupação de seus territórios. Ademais, é compreensível que, partindo-se de uma realidade agrária, com formas de uso e ocupação do solo típicas desta realidade, o aumento da impermeabilização do solo esteja relacionado ao aumento da variabilidade das formas de uso e ocupação da terra. Entretanto, este processo não é igual para a totalidade dos distritos que compõem o MSP.

Gráfico 3.13 - Relação entre o indicador VARIMP e os percentuais de impermeabilização do solo nos distritos discriminados

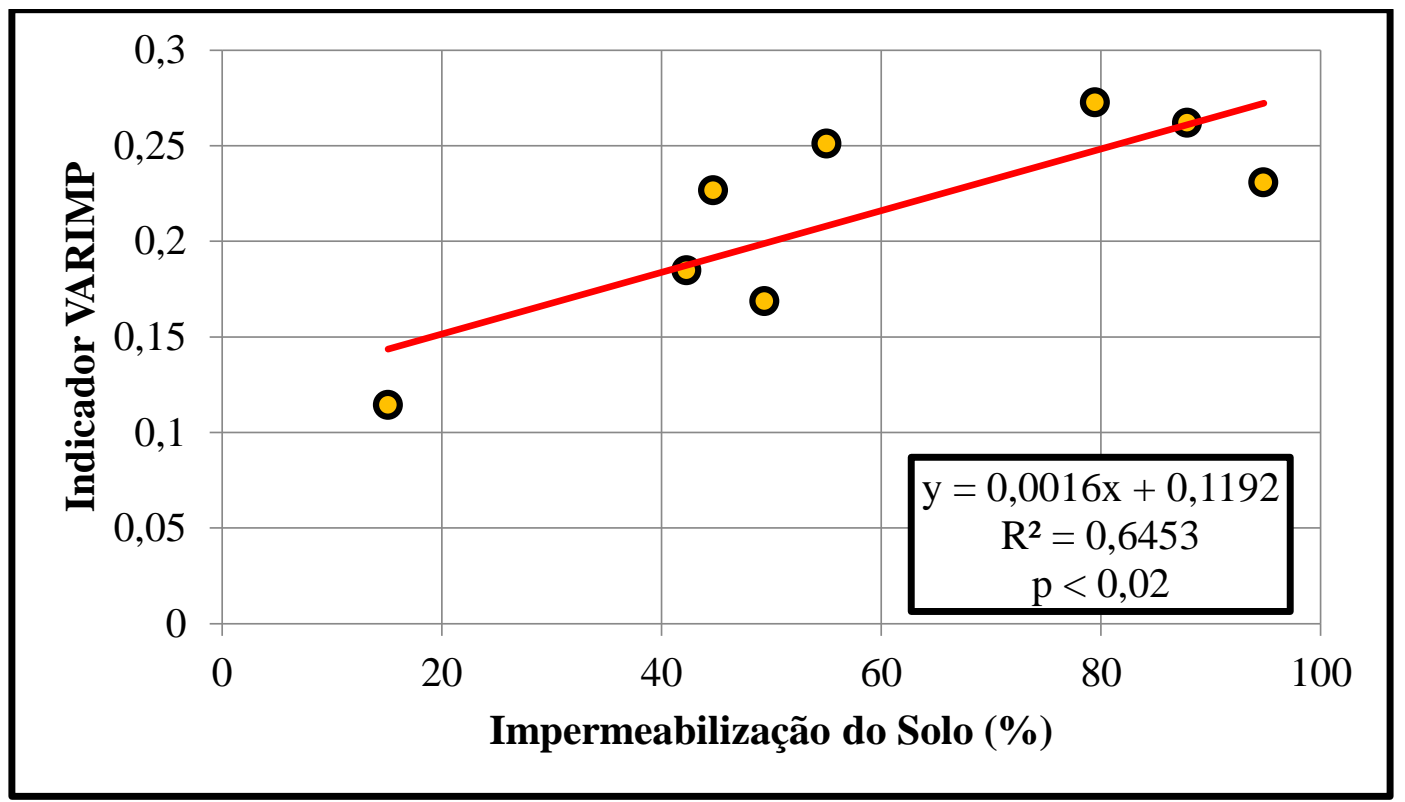

Fonte: Elaboração própria. Data: 28/02/2018.

No gráfico 3.14, a seguir, é possível notar que a relação entre impermeabilização do solo e o indicador VARIMP não segue uma lógica linear para a totalidade dos distritos que compõem o MSP. Em certa medida, o aumento da impermeabilização está associado ao aumento da variabilidade nos percentuais de impermeabilização do solo. Entretanto, a partir de certo momento, o excesso de impermeabilização reduz a variabilidade nos distritos administrativos, provocando um desequilíbrio. 
Gráfico 3.14 - Relação entre o indicador VARIMP e os percentuais de impermeabilização do solo nos distritos administrativos do MSP

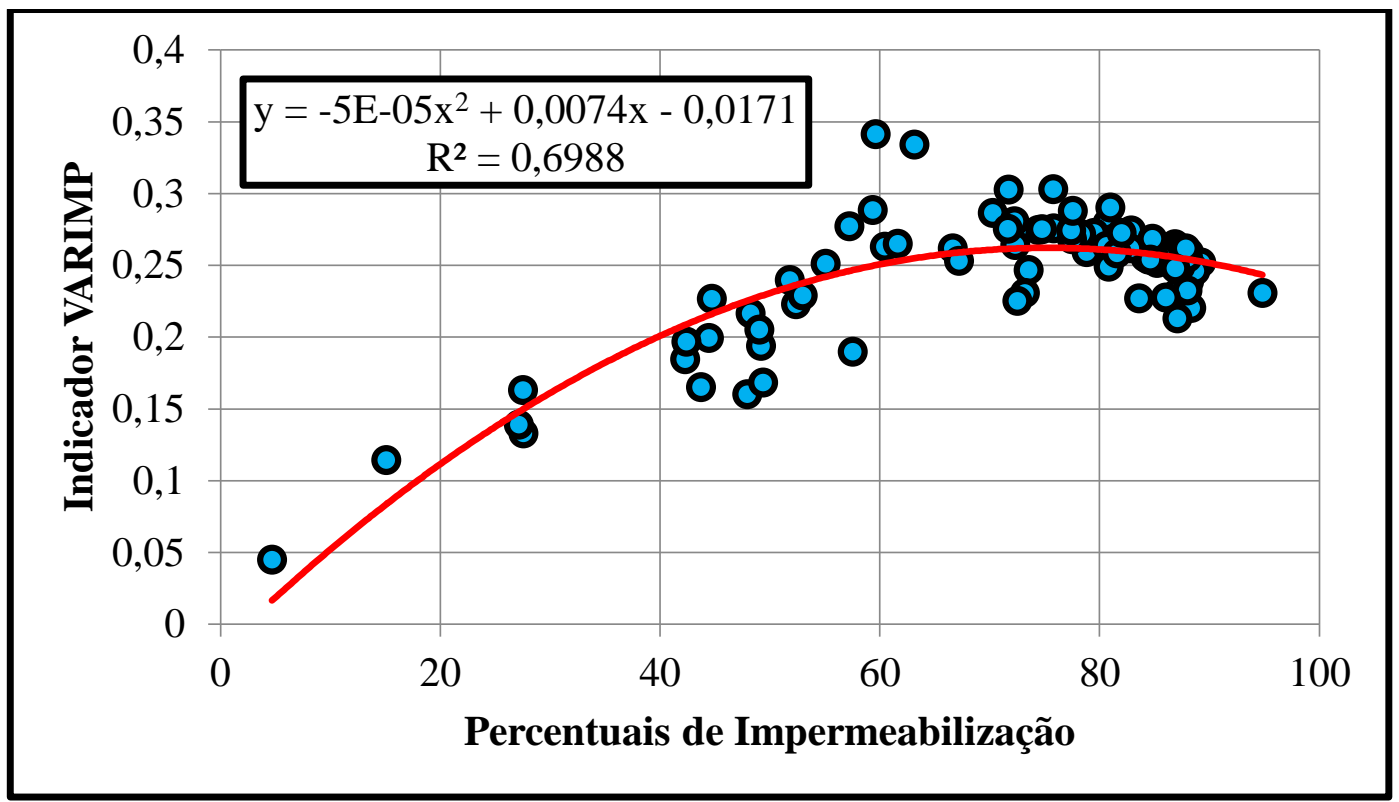

Fonte: Elaboração própria. Data: 28/02/2018.

Ademais, ao se analisar a relação entre o indicador VARIMP e a TAS, observa-se que aquele indicador não possui uma correlação significativa com a temperatura radiante dos objetos que compõem a superfície do território em análise, como se pode observar no gráfico 3.15, abaixo. Por outro lado, ainda que se considerem as generalizações oriundas da redução da escala de análise, resultante da agregação dos dados para o nível dos distritos administrativos, ainda é notada uma forte correlação entre a impermeabilização do solo e a temperatura aparente de superfície, conforme pode-se observar no gráfico 3.16. 
Gráfico 3.15 - Relação entre o indicador VARIMP e a temperatura aparente de superfície (TAS) nos distritos administrativos discriminados

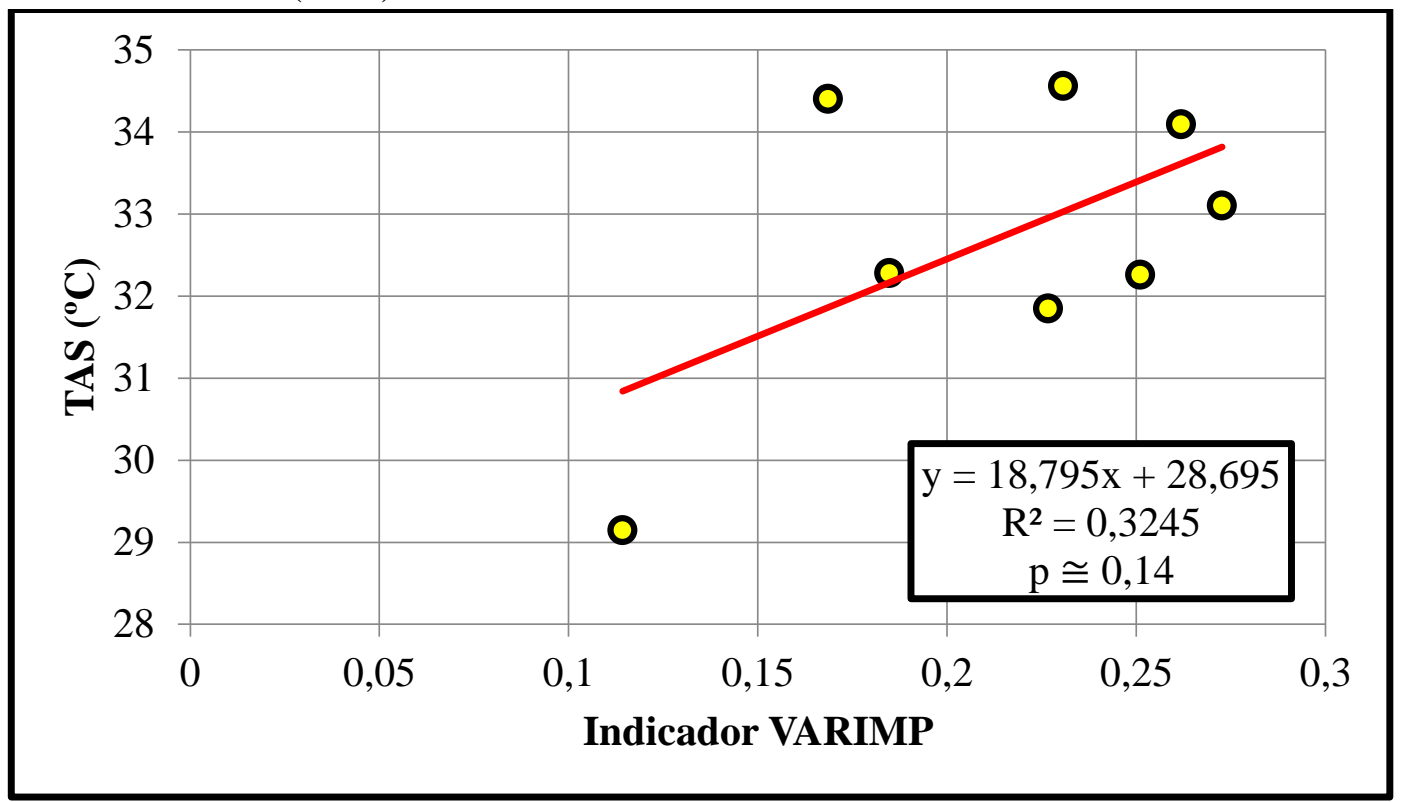

Fonte: Elaboração própria. Data: 01/03/2018.

Gráfico 3.16 - Relação entre impermeabilização do solo e temperatura aparente de superfície (TAS) nos distritos administrativos discriminados

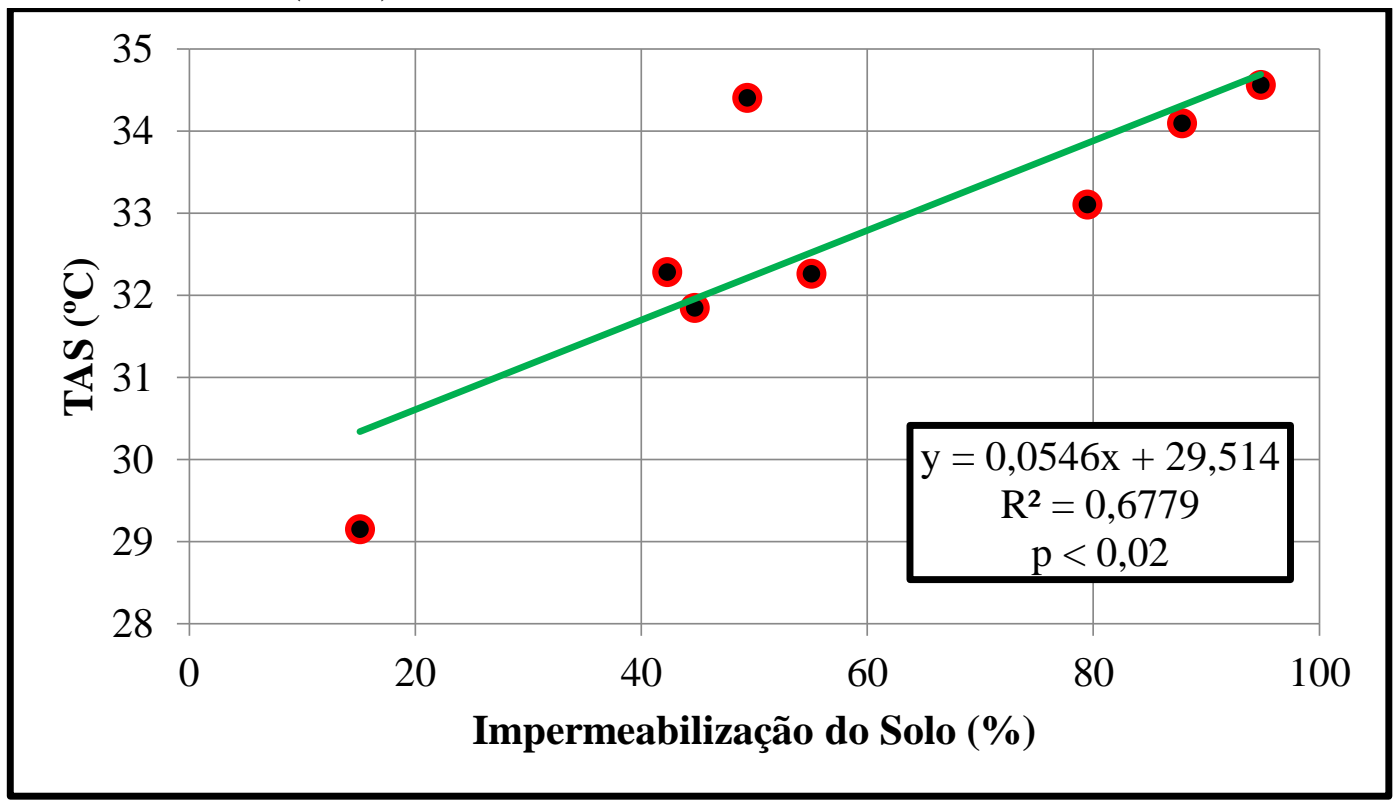

Fonte: Elaboração própria. Data: 01/03/2018.

Assim sendo, conclui-se que o indicador socioambiental elaborado para os fins deste estudo é composto por indicadores que fornecem informações distintas sobre os distritos discriminados para análise. O gráfico 3.17, disposto abaixo, apresenta a regressão linear composta pelos indicadores de mortalidade MSC e socioambiental para os oito distritos discriminados. Este mesmo gráfico está anexo ao mapa 30. 
Gráfico 3.17 - Relação entre os indicadores de mortalidade MSC e socioambiental nos distritos administrativos discriminados

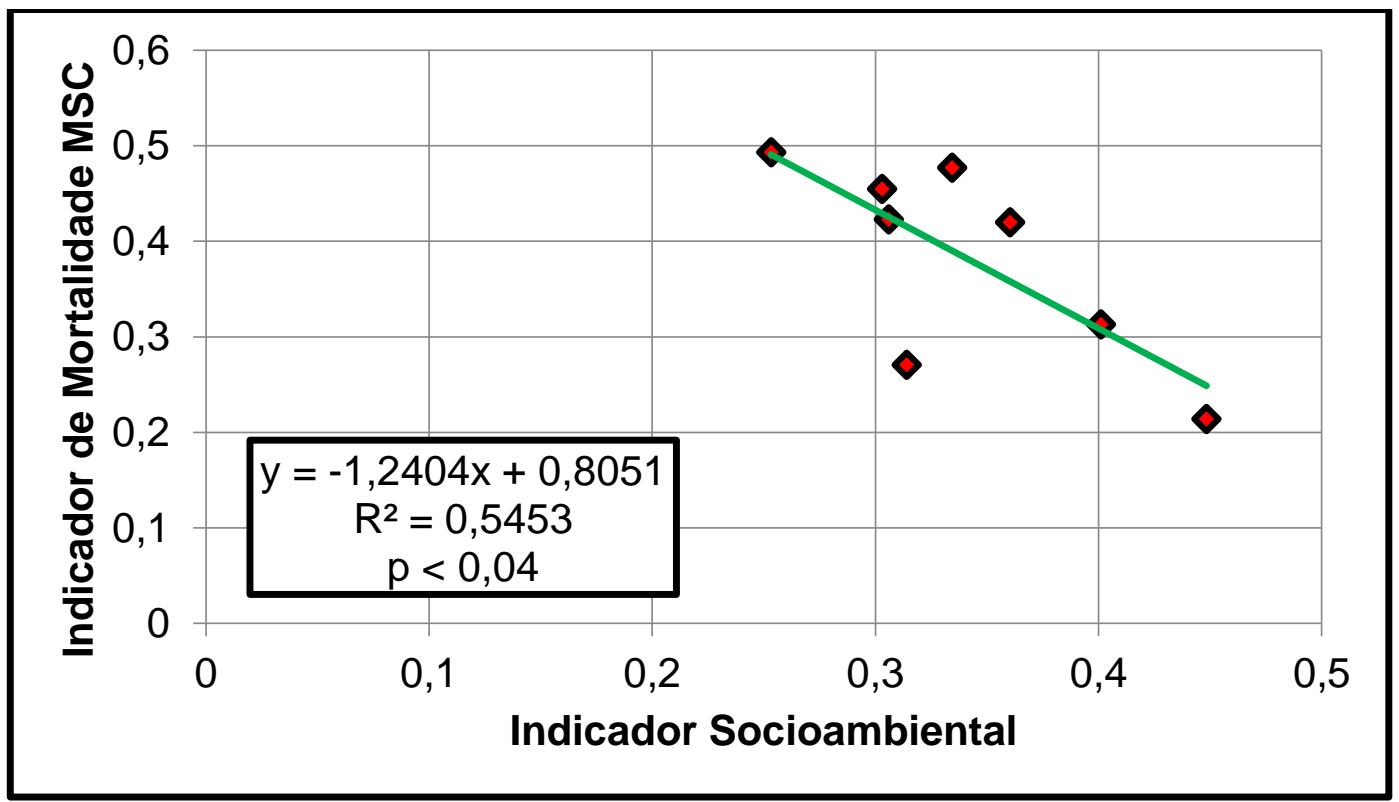

Fonte: Elaboração própria. Data: 01/03/2018.

A análise do gráfico 3.17 aponta no sentido de se afirmar a necessidade de considerarmos a variável ambiental em questão como relevante para compreensão da tipologia de óbitos analisada. Neste sentido, ao extrapolarmos a análise da relação entre esses indicadores para a totalidade dos distritos administrativos do MSP, obtemos os resultados apresentados no gráfico 3.18, disposto a seguir. 
Gráfico 3.18 - Relação entre os indicadores socioambiental e de mortalidade MSC nos distritos administrativos do MSP

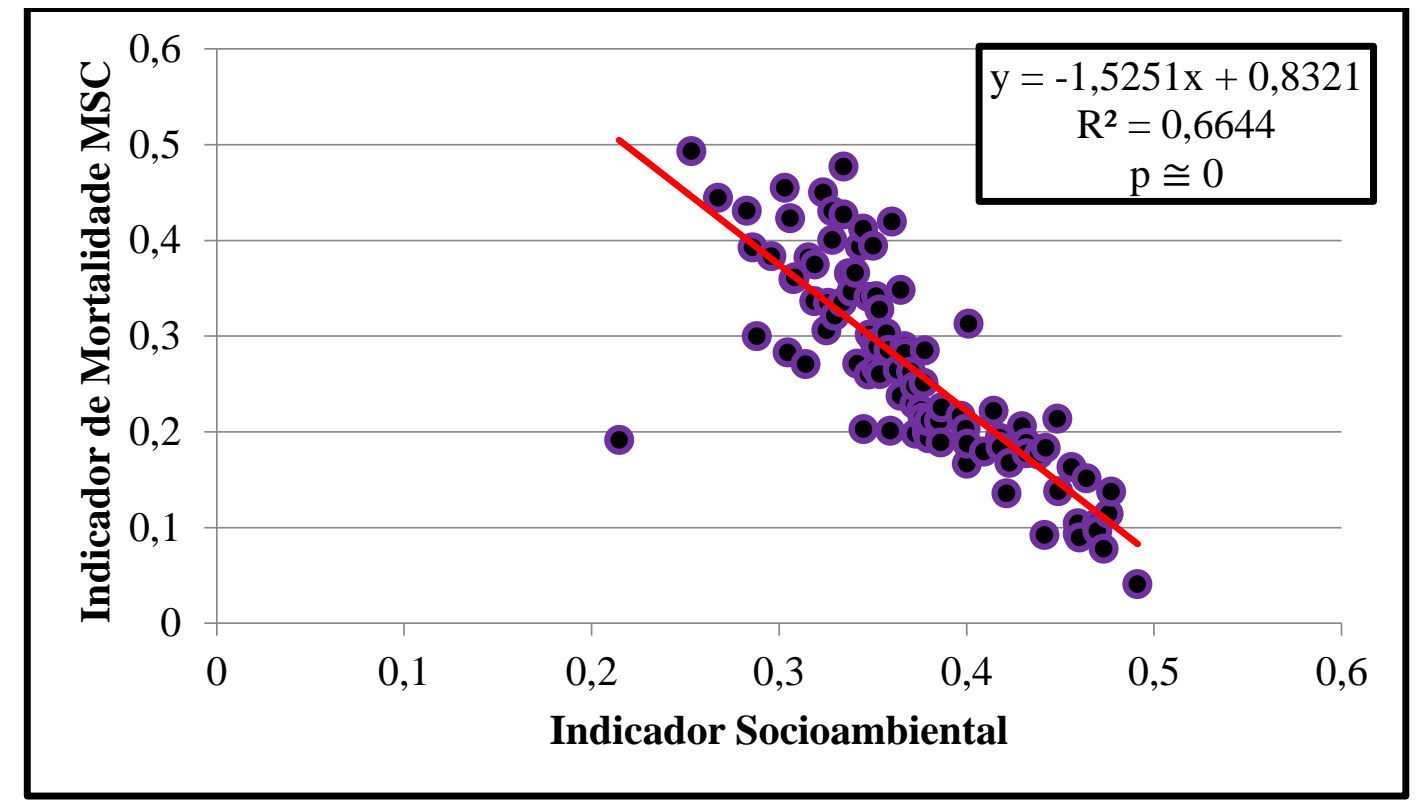

Fonte: Elaboração própria. Data: 01/03/2018.

Os resultados do gráfico 3.18 são menos satisfatórios que os apresentados no gráfico 2.15, o qual relaciona os indicadores de renda e de mortalidade MSC para a totalidade dos distritos administrativos do MSP. Neste sentido, conclui-se que, ao se considerar a totalidade dos distritos administrativos do município de São Paulo, o indicador socioambiental é menos satisfatório que o indicador de renda. Esse resultado, entretanto, não desqualifica a relevância do indicador socioambiental, pois ainda que a renda seja a variável mais explicativa para a escala dos distritos administrativos, haja vista a referida variável agregar inúmeros aspectos da realidade, os fatores ambientais não podem ser desconsiderados caso se objetive compreender mais detalhadamente a localização, distribuição e ocorrência da tipologia de mortalidade analisada.

Ao aplicarmos a equação disponível no gráfico 3.18, é possível estimar o indicador de mortalidade MSC a partir do indicador socioambiental. Partindo-se deste procedimento, foi possível selecionar os distritos nos quais a relação entre os óbitos MSC e o indicador socioambiental apresenta uma relevância maior que a relação entre esta tipologia de mortalidade e a renda média.

A análise dos resíduos da modelagem socioambiental indica que o modelo gerado apresenta alta capacidade preditiva, haja vista grande parte dos resíduos serem equivalentes à zero, ou seja, o modelo foi capaz de prever, na maioria dos casos, os valores do indicador de 
mortalidade MSC a partir do indicador socioambiental, como podemos observar nos gráficos 3.19 e 3.20 , dispostos abaixo.

Gráfico 3.19 - Frequência das classes de resíduos da modelagem socioambiental

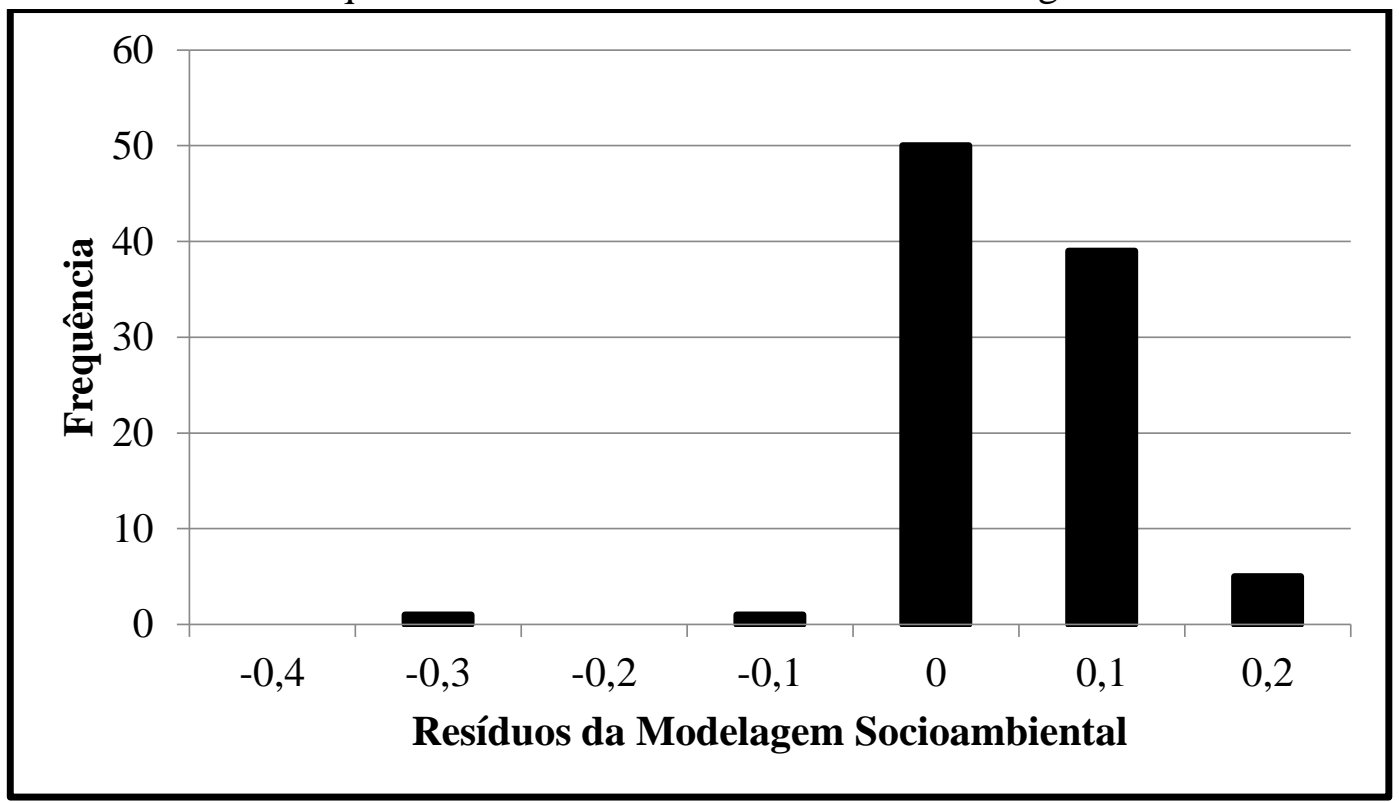

Fonte: Elaboração própria. Data: 01/03/2018.

Gráfico 3.20 - Bloxpot dos resíduos do modelo socioambiental

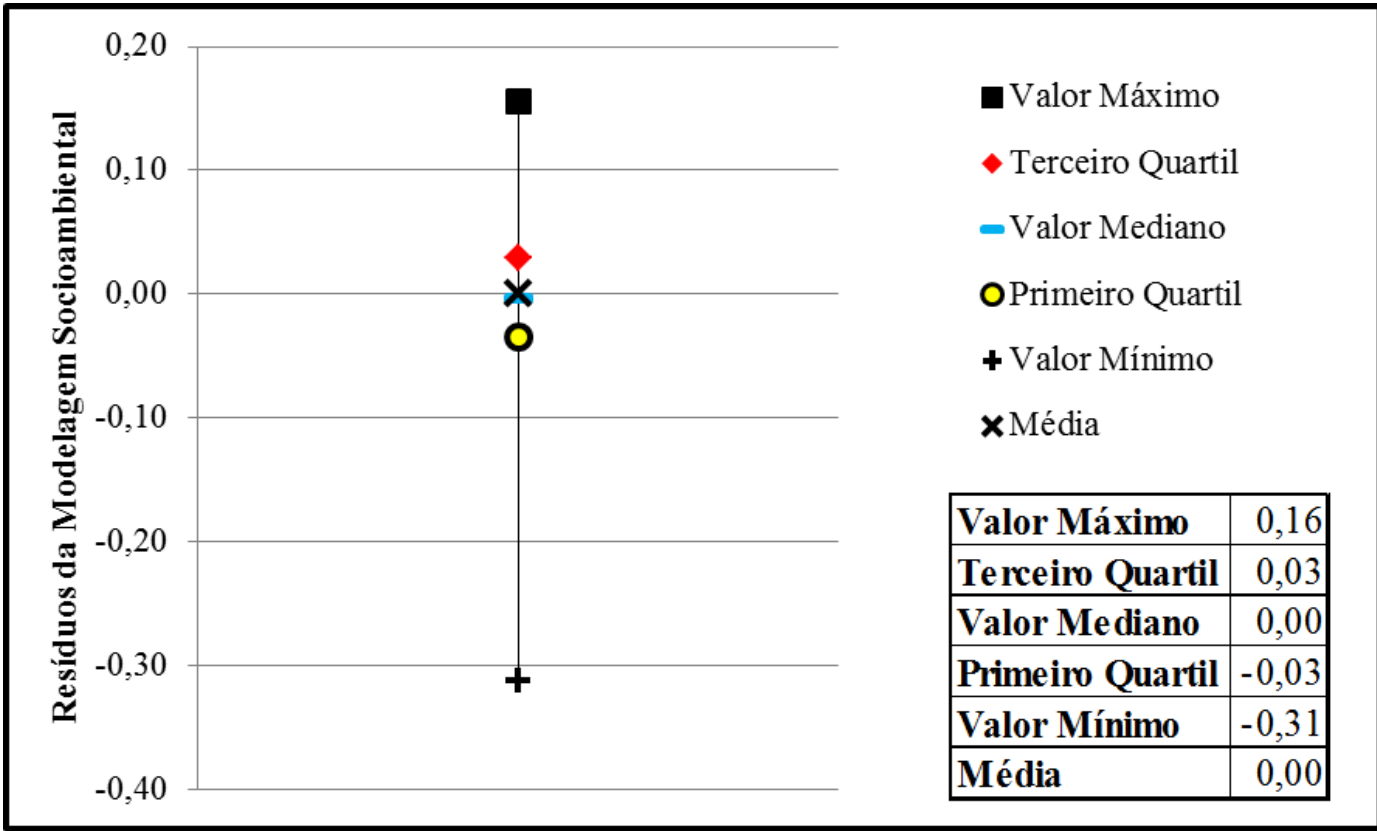

Fonte: Elaboração própria. Data: 01/03/2018.

A análise dos gráficos em questão indica que a dispersão dos resíduos foi pequena em relação ao valor nulo desejado. A média igualou-se a zero, indicando que a modelagem se aproximou dos valores reais de referência. Entretanto, como apontado previamente, a relação entre os indicadores de mortalidade MSC e de renda é mais significativa que a relação entre 
aquele indicador e o socioambiental. Neste sentido, no intuito de melhor compreendermos a relação entre o status socioeconômico da população analisada, seu ambiente e as mortes associadas ao aparelho circulatório, operou-se a seleção dos distritos administrativos cujo modelo socioambiental apresentou melhor correlação com o indicador de mortalidade MSC.

Partindo-se da média dos resíduos, que se equivaleu a zero, operou-se a seleção dos distritos cujos resíduos não distavam mais de um desvio padrão em relação ao valor da média, ou seja, selecionou-se os distritos cujos resíduos da modelagem socioambiental estivessem entre $-0,06$ e 0,06. Ao procedermos de tal modo, selecionou-se $78 \%$ dos distritos analisados, ou seja, 75 distritos dentre os 96 existentes. Ao realizarmos tal operação, verificou-se que o indicador de renda, ainda que apresentasse significativa correlação com o indicador de mortalidade MSC, não foi capaz de superar os resultados da relação observada entre este indicador e o socioambiental, o que pode ser observado nos gráficos 3.21 e 3.22, dispostos a seguir.

Gráfico 3.21 - Relação entre os indicadores de renda e de mortalidade MSC para os distritos selecionados a partir da análise dos resíduos da modelagem socioambiental.

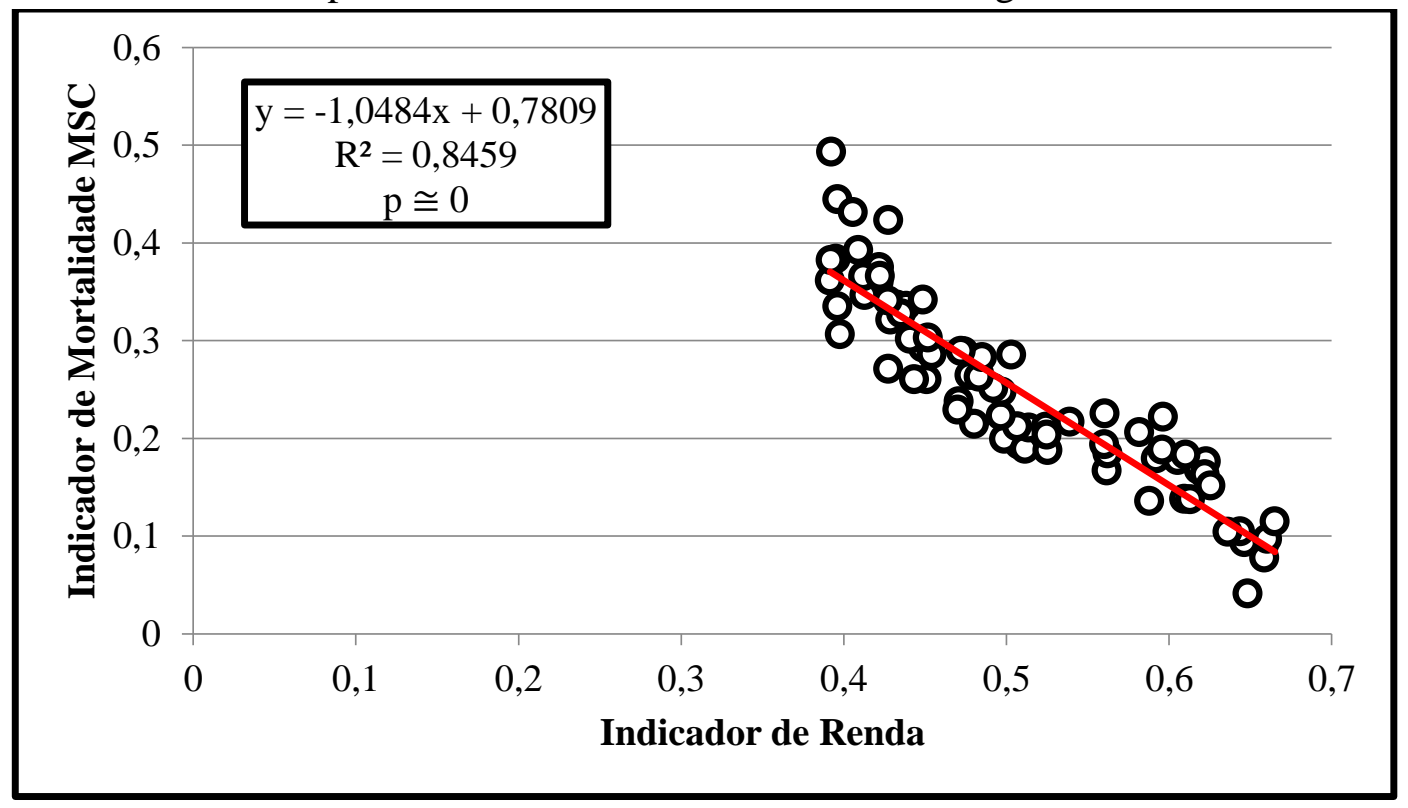

Fonte: Elaboração própria. Data: 01/03/2018. 
Gráfico 3.22 - Relação entre os indicadores socioambiental e de mortalidade MSC para os distritos selecionados a partir da análise dos resíduos da modelagem socioambiental.

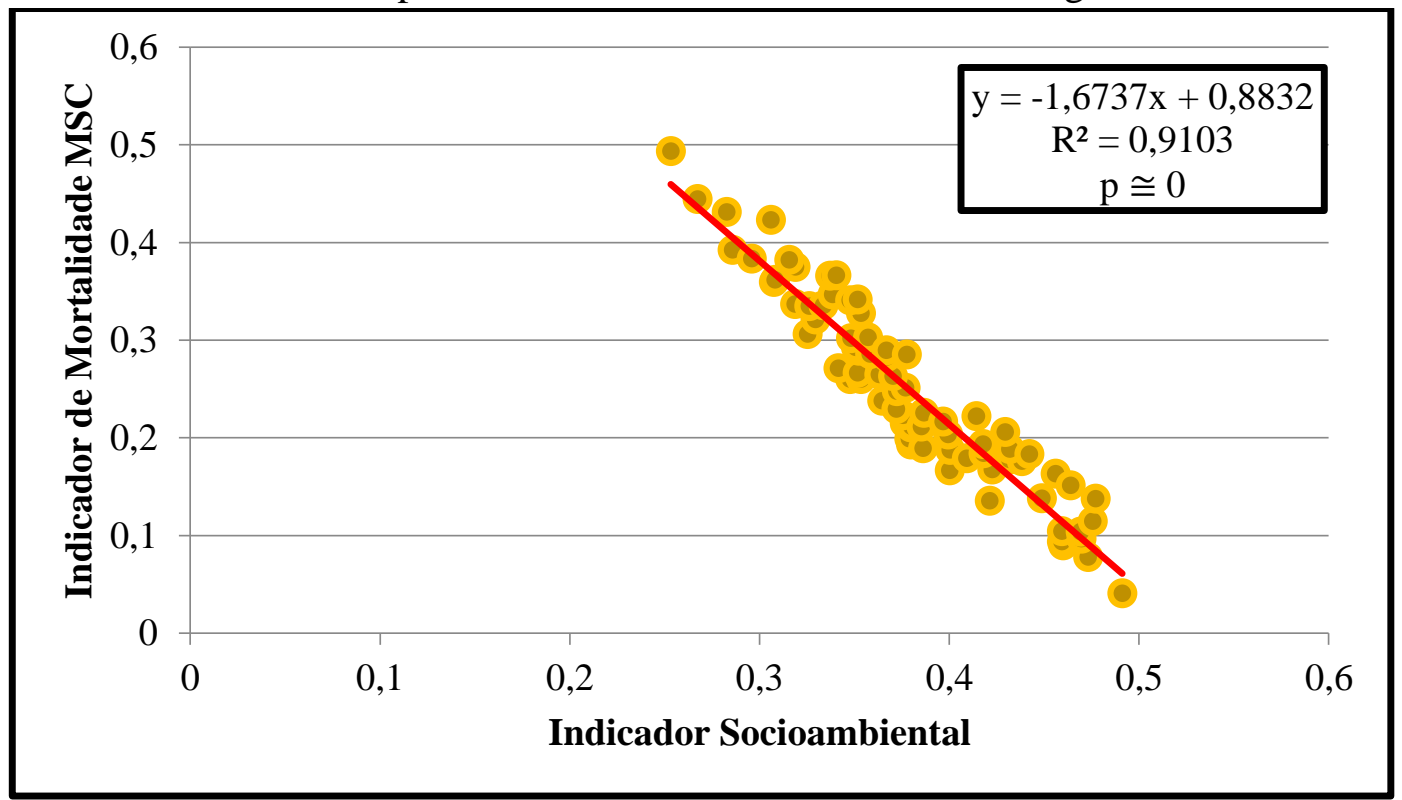

Fonte: Elaboração própria. Data: 01/03/2018.

Os 75 distritos selecionados compõem uma extensão territorial de 1.048.929.669,31 $\mathrm{m}^{2}$ (aproximadamente 104.893 hectares), representado 68,67\% do território do município de São Paulo. A população desses distritos é de 8.919 .391 habitantes, representando 79,3\% da população do município de São Paulo. Ademais, os referidos distritos concentraram 18.890 óbitos MSC no ano de 2015, ou seja, 79,7\% do total de óbitos MSC ocorridos no MSP.

No mapa 31, disposto a seguir, é possível identificar os referidos distritos. Nos anexos do presente trabalho (ANEXO B) estão presentes os indicadores elaborados para todos os distritos administrativos do MSP, bem como para os distritos selecionados pela modelagem MSC partindo-se dos indicadores de renda e socioambiental. Nos distritos apresentados no mapa 31, observa-se a relação descrita pela regressão do gráfico 3.22, ou seja, a variabilidade dos percentuais de impermeabilização compõe, com a renda, um indicador explicativo que sugere considerarmos uma variável ambiental para a compreensão da distribuição da tipologia de óbito analisada, haja vista o aumento da correlação quando a variável relacionada à impermeabilização do solo fora incluída no modelo.

No mapa 32 é possível contemplar os distritos administrativos discriminados pela modelagem socioambiental, os clusters de mortalidade MSC e os valores do indicador socioambiental, por distrito administrativo. 


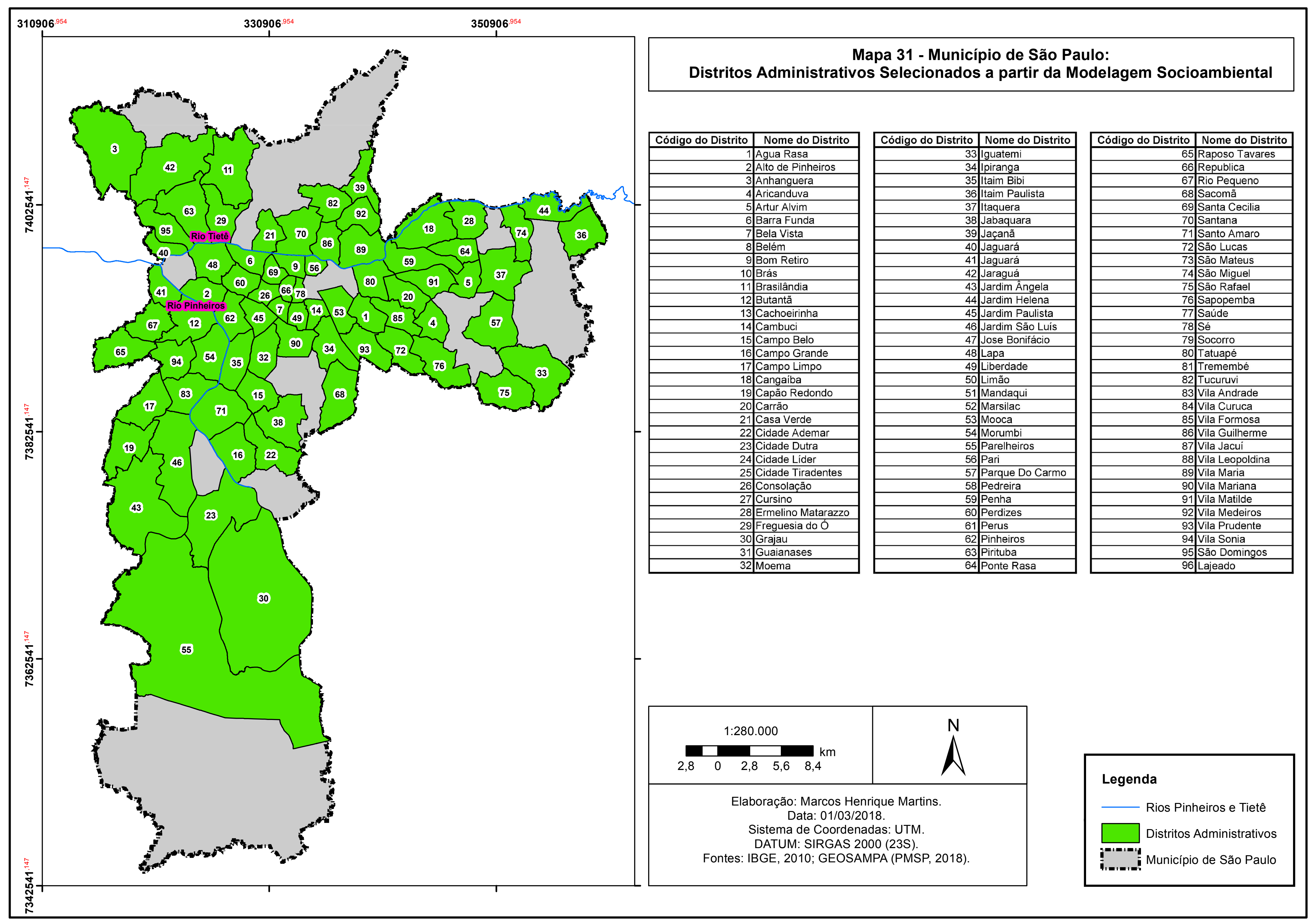




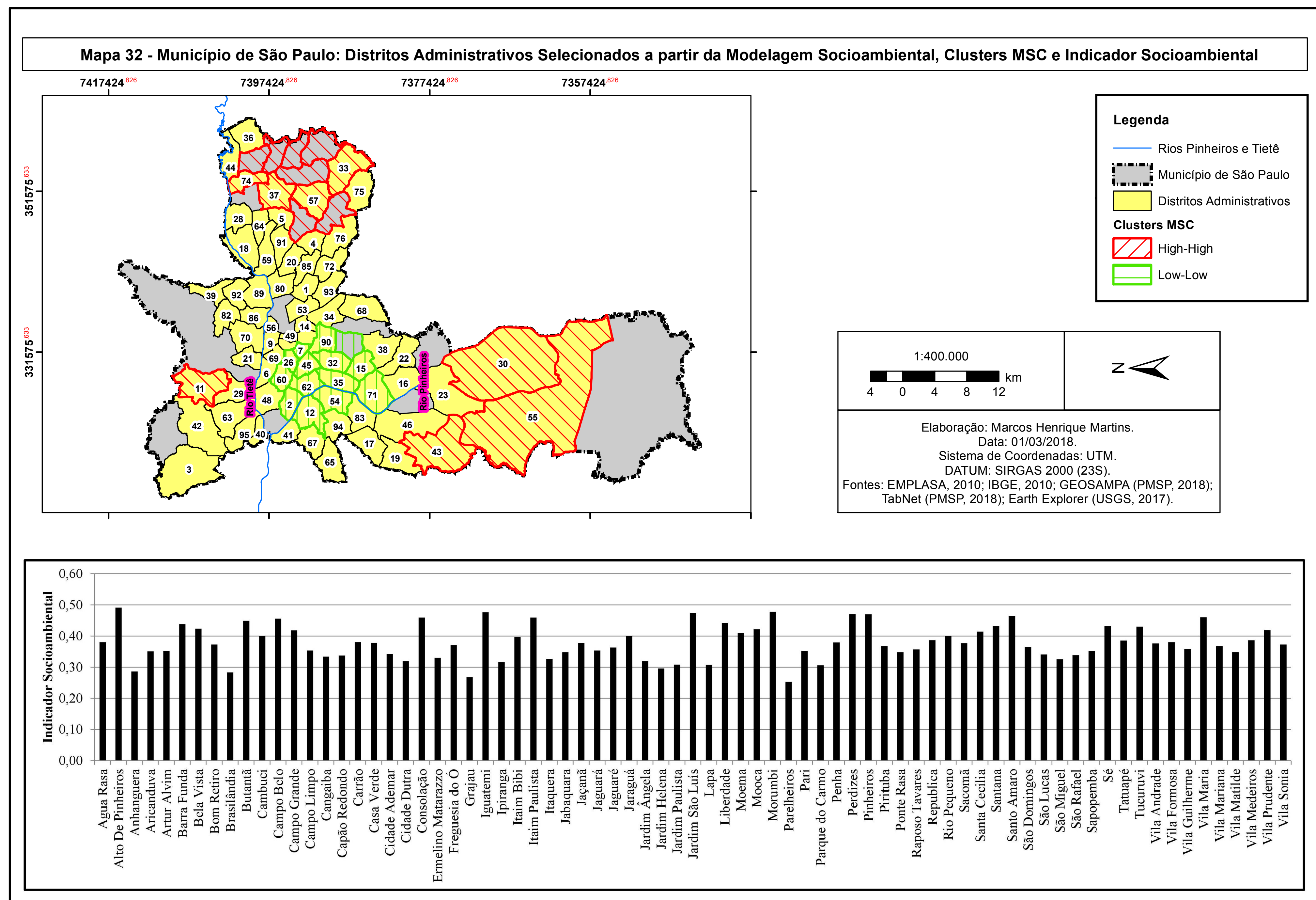




\subsection{Considerações Finais}

Os resultados descritos e analisados no escopo deste segundo capítulo apontam para, ao menos, duas considerações fundamentais: 1) os óbitos associados às doenças do sistema circulatório não podem ser satisfatoriamente compreendidos sem que se considere sua localização e distribuição; 2) fatores de ordem ambiental podem apresentar uma determinação sobre a localização e distribuição desta tipologia de óbitos, indicando a necessidade de estudos mais aprofundados sobre o assunto, haja vista os resultados e limitações do presente trabalho.

Considerando-se os dados relativos à mortalidade MSC, por faixa etária, sem que se considerem sua localização e distribuição, observou-se que há uma relação entre o envelhecimento da população e sua susceptibilidade a esta tipologia de mortalidade. Entretanto, ao se considerar a localização e distribuição dos óbitos MSC, observou-se que o envelhecimento da população está condicionado a fatores de ordem socioeconômica que invertem a relação da fragilidade etária com a referida tipologia de mortalidade. Em outras palavras, envelhecer em locais distintos de uma mesma cidade, estando sujeito, portanto, a condicionantes socioeconômicos e ambientais distintos, resulta em efeitos distintos. Destarte, o tempo de morte e de vida se nos apresenta para além, mas não a despeito de, simples indicadores biológicos, indicando, portanto, que Ikefuti e Barrozo (2015, p.640), por exemplo, ao afirmarem que “[...] o aumento da expectativa de vida favorece a ocorrência das doenças crônico-degenerativas não transmissíveis (e.g., câncer e doenças cardiovasculares)", incorreram em um equívoco.

Neste sentido, a análise dos distritos administrativos cuja relação entre mortalidade MSC e o indicador socioambiental apresentaram melhores resultados estatísticos indicou a necessidade de se melhor analisar a relação entre renda e ambiente na compreensão da distribuição desta tipologia de mortalidade. Ainda que tenhamos considerado apenas a impermeabilização do solo como um indicador ambiental, devido às limitações impostas ao pesquisador pela complexidade do estudo, fica evidenciado que a impermeabilização do solo possui relação com a distribuição dos óbitos associados às doenças do aparelho circulatório.

Estas considerações são fundamentais para que se possa dar prosseguimento a uma reflexão mais aprofundada sobre a metodologia empregada neste estudo, bem como sobre os resultados alcançados. Entretanto, este caminho não é simples, haja vista necessitarmos considerar a genealogia do método empregado, suas implicações lógicas e éticas, bem como sua influência no seio da ciência geográfica.

Assim sendo, ultrapassaremos, a partir do terceiro capítulo, os limites estabelecidos para a elaboração dos dois capítulos iniciais deste trabalho. Em que consistem esses limites? Em 
fundamentos lógicos subjacentes às escolhas metodológicas tomadas no intuito de se efetuar um estudo que pudesse ser considerado científico. A partir do capítulo seguinte, propõem-se uma análise filosófica do método empregado, de sua gênese no seio de uma proposta de Filosofia da Ciência a qual necessita de uma melhor compreensão, haja vista a iminente necessidade de um aprofundamento do debate em torno da Filosofia da natureza que tem nutrido, consciente e inconscientemente, uma certa perspectiva de ciência geográfica. A relevância e arcabouço teórico deste debate serão apresentados no capítulo seguinte. 


\title{
4. Crítica à Geografia da Efetividade
}

\author{
"Depois de amanhã, sim, só depois de amanhã... \\ Levarei amanhã a pensar em depois de amanhã, \\ E assim será possível; mas hoje não... \\ Não, hoje nada; hoje não posso. \\ A persistência confusa da minha subjetividade objetiva, \\ O sono da minha vida real, intercalado, \\ O cansaço antecipado e infinito, \\ Um cansaço de mundos para apanhar um eléctrico... \\ Esta espécie de alma... \\ Só depois de amanhã... \\ [...] A minha vida triunfar-se-á, \\ Todas as minhas qualidades reais de inteligente, lido e prático \\ Serão convocadas por um edital... \\ Mas por um edital de amanhã..."
}

(PESSOA, 1944, p.266).

Em dias de hoje estou disposto a pensar. Pensar sobre o ontem e o amanhã. Devo estabelecer relações. Não, hoje nada, hoje não posso ser. Creio que amanhã serei o que ontem não fui e o que hoje ignoro - ser. Persiste a confusa objetividade de minha subjetividade que se presta a analisar a relação entre impermeabilização do solo e a distribuição daquelas mortes que são o que os cadáveres já não são. E eu, que não sou mais do que estes, devo ser, depois de amanhã, o que eles não puderam ser hoje. Devo crer que, amanhã, os pensamentos de hoje serão o fruto doce da ciência árdua que lapida corpos para encontrar números e, ao encontrá-los, nega a irracionalidade imanente. Esta negação é o suprassumo do temor à morte, "que sempre o Mal pretende e que o Bem sempre cria" (GOETHE, 2011, p.118). Destarte, vejamos em que consiste as páginas precedentes do presente escrito.

Nos capítulos anteriores, demonstrou-se, de modo pormenorizado, o percurso metodológico engendrado no âmbito da necessidade de se estabelecer uma reflexão que, minimamente, pudesse ser considerada científica. Neste sentido, de um lado, a metodologia aparece como um argumento válido estabelecido, em seus fundamentos, a priori da realização efetiva deste estudo, ou seja, como um necessário percurso do estudo mesmo, para que este fosse considerado cientificamente válido. Por outro lado, a metodologia é engendrada no efetivar do referido estudo, como um procedimento efetivamente executado, seja no âmbito do trabalho mesmo, seja na realidade a que ele se refere. Neste sentido, aparentemente, partese da efetividade da lógica formal, enquanto proposta metodológica, para se afirmar a efetividade da lógica formal, seja enquanto verdade efetiva observável - realidade -, seja como reflexão válida sobre esta realidade. Destarte, parece ser necessário considerar-se o que se está denominando efetividade. Partamos, de início, da Lógica Formal. 


\subsection{A Lógica Formal e As Bases Metafísicas da Ciência Moderna}

A lógica formal tem imediatamente um conteúdo ideal fundamental: "logic is about good and bad reasoning” (HACKING, 2001, p.1), ou seja, cabe à lógica formal avaliar se um raciocínio determinado é válido ou inválido. Um argumento válido não é necessariamente verdadeiro, ou seja, não necessariamente parte de premissas verdadeiras e possui conclusões verdadeiras, do mesmo modo que um dado argumento pode ser inválido, mas ter premissas e conclusões verdadeiras. Neste sentido, a lógica formal tem como finalidade garantir a validade do argumento lógico: "logicians study the relations between premises and conclusions, but, as logicians, are not especially qualified to tell whether the premises as true or false" (HACKING, 2001, p.7, grifo nosso).

O argumento lógico é o cerne de toda exposição científica, seja nas ciências ditas "humanas", seja nas ciências ditas "naturais". A matemática, por sua vez, é concebida como o argumento lógico por excelência, pois, do ponto de vista de sua fundamentação, é predominantemente uma linguagem dedutiva. Sua irmã e conterrânea é a estatística. Mas esta irmã é um pouco diferente daquela: sua fundamentação é, predominantemente, indutiva. $\mathrm{O}$ argumento dedutivo válido se caracteriza pela certeza: se as premissas são verdadeiras, a conclusão deste tipo de argumento deve ser, necessariamente, verdadeira. Trata-se, portanto, de um argumento que preza pela certeza, e que, desta forma, pode estar equivocado de dois modos: as premissas assumidas são falsas, ou o argumento é inválido. Por outro lado, o argumento indutivo "is about risky arguments" (HACKING, 2001, p.11), ou seja, assume-se a incerteza, do ponto de vista lógico, como uma constante neste tipo de argumentação. A incerteza é a cruz da lógica indutiva e seu calvário é a probabilidade. A análise do argumento indutivo passa necessariamente, portanto, pelo julgamento probabilístico (HACKING, 2001, p.11).

A probabilidade estatística é a fundamentação primeira do escopo metodológico responsável pela validação, no âmbito dos primeiros capítulos desta obra, do argumento indutivo engendrado e defendido: de que há uma relação entre impermeabilização do solo e a distribuição de óbitos associados às doenças do aparelho circulatório. Este argumento recai, devido sua natureza metodológica, no problema da incerteza. Enquanto cientistas, permanecemos neste problema da incerteza de uma forma emblemática: a certeza da incerteza alimenta a necessidade da probabilidade como fundamentação da validade do argumento 
indutivo rumo à verdade. Portanto, enquanto cientistas, somos tragédia infausta aparentemente bem-aventurada de nossas capacidades lógico-estatísticas face à certeza da incerteza:

\author{
Oh, quão feliz, quem ainda espera \\ Surgir daquele mar do engano e da quimera! \\ O que se ignora é o que mais falta faz, \\ E o que se sabe, bem algum nos traz \\ (GOETHE, 2011, p.101).
}

Destarte, a incerteza está fundamentada no saber do não-saber, na certeza de que o que se ignora é o que mais faz falta na indução, mas aquilo que se sabe, sabe-se enquanto incerteza e, portanto, bem algum nos traz. Entretanto, há a espera de que do mar do engano emerja a certeza. Mas esta certeza já está lá, como certeza da incerteza! Em que se fundamenta esse quiproquó? Em um enigma que, desde os tempos antigos da Filosofia ocidental, perturbou a cabeça dos filósofos: a relação entre determinação e acaso ${ }^{11}$.

De forma objetiva e sem delongas, a ciência enquanto agir do cientista parte de uma definição determinada de acaso: este seria uma propriedade física disposicional, conforme defende Ian Hacking, em seu tratado de lógica denominado Logic of Statistical Inference (2016). Em outras palavras, a ciência parte do acaso determinado, enquanto premissa, pressuposto lógico, para defender, de acordo com argumentos lógicos, a determinação do acaso:

\footnotetext{
o universo, essa vasta reunião de tudo aquilo que existe, não nos oferece em toda a parte senão a matéria e o movimento: seu conjunto não nos mostra senão uma cadeia imensa e ininterrupta de causas e efeitos. Algumas dessas causas nos são conhecidas, porque elas impressionam diretamente os nossos sentidos; outras nos são desconhecidas, porque elas atuam sobre nós apenas por intermédio de efeitos quase sempre muito afastados das suas primeiras causas (HOLBACH, 2010, p.40, grifo nosso).
}

Ademais,

a natureza não é uma causa cega. Ela não age ao acaso; tudo aquilo que ela faz jamais seria fortuito para aquele que conhecesse a sua maneira de agir, os seus recursos e o seu comportamento. Tudo aquilo que ela produz é necessário e nunca passa senão de uma consequência de suas leis fixas e constantes. Tudo nela está ligado por nós

\footnotetext{
${ }^{11}$ Foi Kant que indicou como o problema da certeza seria fundamental para o estabelecimento de uma "Filosofia Transcendental”, ou para a "Crítica da Razão Pura": “[...] Onde basearia a experiência a sua certeza se todas as regras que empregassem fossem sempre empíricas e contingentes?” (KANT, 1958, p.9, grifo nosso). Para o referido filósofo, "[...] o conhecimento humano tem duas origens e que talvez ambas procedam de uma comum raiz desconhecida para nós; estão são: a sensibilidade e o entendimento; pela primeira os objetos nos são dados, e pelo segundo concebidos" (KANT, 1958, p.27, grifo nosso). Hegel também irá explorar a relação entre sensibilidade e entendimento em sua argumentação sobre a experiência da consciência na "Fenomenologia do Espírito", conforme demonstraremos mais adiante.
} 
invisíveis e todos os efeitos que vemos decorrem necessariamente das suas causas, quer as conheçamos, quer não as conheçamos. [...] Isso pode servir de resposta à eterna objeção que fazem aos partidários da natureza, que são incessantemente acusados de atribuir tudo ao acaso. $O$ acaso é uma palavra vazia de sentido, ou ao menos não indica senão a ignorância daqueles que a empregam [...] - a menos que se queira negar que causas semelhantes em tudo devam produzir efeitos semelhantes (HOLBACH, 2010, p.597-598, grifo no original e grifo nosso).

Ou ainda: "vê-se, portanto, que nada se faz ao acaso. Todas as obras da natureza são feitas de acordo com leis certas, uniformes, invariáveis [...]” (HOLBACH, 2010, p.599). Destarte, este é o proceder fundamental da ciência que, portanto, fez-se presente nos primeiros capítulos desta obra.

Tendo em vista o acaso como uma propriedade disposicional (HACKING, 2016), a defesa de um argumento indutivo na ciência passa, ainda que de forma não-declarada, pela teoria do suporte (HACKING, 2016). A referida teoria defende que um dado argumento indutivo-inferencial deve considerar, impreterivelmente, o suporte físico-disposicional que garanta a validade deste argumento, pois uma dada frequência em que um determinado fenômeno ocorre seria determinada pelas propriedades físicas relacionadas a esse fenômeno. Do ponto de vista lógico-científico, isso se expressaria da seguinte forma: se considero mil lançamentos de uma dada moeda no qual em 3/4 das vezes obtenho cara e em apenas $1 / 4$ obtenho coroa, esta frequência é determinada pelas propriedades físicas da moeda (um lado teria mais metal que outro, por exemplo), pelo ambiente no qual ela é lançada (gravidade, resistência do ar, etc.), pela mão do jogador e/ou pelo dispositivo de lançamento (força, inércia, etc.), e por outras considerações desta ordem que possam surgir. Assim, a frequência, de um certo ponto de vista, é algo determinado na realidade objetiva material e observável matematicamente, ou, em outras palavras, a frequência é a medida do acaso determinado pelas propriedades objetivas efetivas da realidade.

Este saber da determinação do acaso como saber do acaso determinado é a chave para os grandes desafios da ciência moderna, desde o problema da relação entre física quântica e teoria da relatividade, até as questões da economia política, sociologia, geografia, etc. Esta chave tem como base um intrincado enredo metafísico, que a ciência não pode simplesmente desconsiderar, ainda que o ignore e o cubra sob o véu da humanidade da incerteza, como alguém maldisposto empurra o pó para debaixo do tapete, e afirma: não há ambiente mais asseado que o da ciência! Que luz! Que Iluminismo! Mas não sejamos cínicos, pois não basta acusar, é necessário evidenciar. 
Partamos do princípio: se a lógica tem como objetivo garantir a validade de um argumento e, no nosso caso específico, de um argumento científico e, se nesse proceder, ela deve partir de premissas que necessariamente deve considerar como verdadeiras para que as conclusões também o sejam e, ademais, se possui como verdade a certeza da determinidade, ainda que na forma da certeza da incerteza, devo levantar, ao menos, dois questionamentos: o que é a verdade para a lógica formal?; a lógica, partindo da verdade para chegar à verdade, não é ela mesma já um argumento, considerado a priori verdadeiro, sobre a validade da argumentação? A genealogia da moderna argumentação lógica dá conta de introduzir a problemática aqui expressa de maneira um pouco mais esclarecedora.

$\mathrm{Na}$ Antiguidade Clássica, a forma de expressão matemática do mundo concebida pelos filósofos era a Geometria. Neste sentido,

a famosa doutrina pitagórica de que o mundo é composto por números tende a parecer bastante ininteligível aos modernos até que se reconheça que o significado pretendido é o de unidades geométricas [...]. Os "números" significavam que os elementos últimos do cosmos eram porções limitadas de espaço (BURTT, 1991, p.33-34).

Neste sentido, de acordo com Burtt, já é possível "apreciar de imediato o tremendo avanço que estava por vir para a álgebra moderna quando ela finalmente logrou libertar-se dos grilhões da espacialidade" (BURTT, 1991, p.35), o que só iria acontecer com a criação do cálculo infinitesimal por Newton e Leibniz. Até este reconhecido momento da história da ciência, que se deu na virada do século XVII para o XVIII, há que se engendrar a validade de asserções lógicas que não são imediatamente geométricas, o que logrou séculos para acontecer, haja vista que

a concepção que fazemos atualmente da matemática como uma ciência ideal e da geometria, em particular, como ciência que se ocupa de um espaço ideal, ao invés de constituir o espaço real em que o universo se encontra, era uma noção praticamente inexplorada antes de Hobbes e que não mereceu crédito até meados do século XVIII [...]. O espaço da geometria parece ter sido o espaço do universo real para todos os pensadores antigos e medievais que deixaram algum indício de suas noções a respeito da matéria (BURTT, 1991, p.35, grifo nosso).

O que Burtt observa aqui evidencia algo importante para a Filosofia, ainda que o próprio Burtt tenha se mantido um pouco limitado em seus apontamentos sobre o assunto: para estes pensadores clássicos, o saber da verdade, ou saber sobre algo relativo à verdade, não era concebido como verdade. Em outras palavras, o saber geométrico não se sabia como verdadeiro, mas como um saber da verdade. Por isso a matemática deveria ser geométrica: porque observa espaços verdadeiros, mas não é ela mesma a verdade, ou seja, o espaço era geométrico, não o 
saber. O saber era uma evidenciação dessa geometria. Retomaremos, mais tarde, esta distinção entre saber e verdade, mais propriamente tratada na Fenomenologia do Espírito de Hegel.

Basta, por enquanto, notar que, nesta Antiguidade Clássica engendraram os pensadores medievais suas Filosofias e teologias. Mas, desta Filosofia clássica cujo saber não era um saber que se sabia como verdade, passou-se, na Idade Média, a uma forma de saber moral, que se sabia como saber responsável pela manutenção da verdade, do bem, de Deus. Retomaremos também este ponto com os pormenores necessários. Por enquanto, é necessário notar que

\begin{abstract}
durante o início da Idade Média foi obtida a síntese entre teologia cristã e a Filosofia grega, esta em sua expressão predominantemente platônica, ou melhor, neoplatônica. Ora, o elemento pitagórico no neoplatonismo era muito acentuado. Todos os pensadores importantes da escola gostavam de expressar suas doutrinas favoritas em termos da teoria dos números, seguindo a sugestão de Platão em Parmênides de que a pluralidade se desdobra a partir da unidade através de um processo necessariamente matemático (BURTT, 1991, p.41, grifo nosso).
\end{abstract}

Ou seja, “[...] todo conhecimento seguro acessível ao homem deve ser conhecimento matemático" (BURTT, 1991, p.42). A matemática, portanto, foi consagrada, na história do pensamento ocidental moderno, desde a Antiguidade Clássica e mesmo durante a Idade Média, como a voz do conhecimento, a linguagem do conhecimento, a fala sobre a verdade, ainda que não necessariamente como verdade. Aparentemente, surge a matemática como conhecimento antes do conhecimento como verdade.

Um exemplo histórico importante para a compreensão do significado da matemática no início da modernidade, especialmente da Geometria em um primeiro momento, revela-se na defesa do modelo heliocêntrico por Copérnico. Este grande pensador viveu entre os séculos XV e XVI e foi antecessor de outro grande pensador de sua época: Galileu. Sendo assim, por um lado, Copérnico não pôde defender empiricamente seu modelo heliocêntrico, pois não tinha como fazê-lo, haja vista não dispor de instrumentos para tal; por outro lado, mesmo que dispusesse de tais instrumentos, a questão a qual Copérnico deveria fazer face não dizia respeito à verdade de seu modelo, ou se o modelo geocêntrico era falso, mas como sustentar seu modelo face ao oposto, pois "matematicamente não está em questão qual dos dois sistemas é verdadeiro. Na medida em que a astronomia é matemática, ambos são verdadeiros, pois ambos representam os fatos, mas um é mais simples e harmonioso que o outro" (BURTT, 1991, p.38, grifo nosso).

Aqui está em gestação um fundamento essencial para o argumento científico: a verdade é simples e, principalmente, harmoniosa. Esta simplicidade e harmonia do argumento científico não diz respeito à extensão formal do argumento, pois uma obra científica 
pode ser extensa, até mesmo mal escrita. Tampouco diz respeito à compreensão da obra, pois esta simplicidade e harmonia podem ser, ainda sim, bastante complicadas para a compreensão. Tratam-se, por certo, a simplicidade e harmonia, não de conteúdos determinados, mas de formas específicas do argumento científico que se engendrava naquele momento. Copérnico, enquanto alguém que produziu uma cientificidade argumentativa, partiu de um postulado fundamental para sua defesa do modelo heliocêntrico: “[...] o universo astronômico é uma harmonia matemática ordenada" (BURTT, 1991, p.42). Do ponto de vista filosófico, portanto, o ser do universo é harmônico, simples e ordenado, ou, em outras palavras, determinado. A simplicidade do argumento deve fazer jus à forma do universo e vice-versa. Esta simplicidade, portanto, não é simplesmente uma forma do argumento, mas é o universo mesmo.

Ademais, algo muito delicado se processa nesta virada de referencial astronômico. Sabe-se hoje que, do ponto de vista da mecânica newtoniana, o movimento é relativo. Então não é inverossímil dizer que a Terra ou o Sol sejam o centro do sistema astronômico próximo, pois, sendo o movimento relativo, tratar-se-ia apenas de uma questão de referencial. Entretanto, do ponto de vista da harmonia e da simplicidade evocadas por Copérnico, o sistema heliocêntrico seria mais belo, harmonioso e simples, mais objetivamente determinado. Este objetivamente é, claramente, uma revolução: ao tirar do centro da astronomia o homem, seu ser-aí-terreno, seu planeta e, por conseguinte, ao colocar o Sol no centro da vida astronômica, o homem passa para o segundo plano. Este "passar para o segundo plano" é algo que evidencia uma novidade, do ponto de vista metafísico: a compreensão do homem também como um ser objetivo, determinado, harmonioso, simples e em concordância com seu universo como um planeta em sua órbita.

Depois de Copérnico, Kepler, entre os séculos XVI e XVII, foi responsável pela defesa do modelo heliocêntrico. Sua defesa possui certas especificidades que foram fundamentais para o desenvolvimento das bases metafísicas da ciência moderna. Neste sentido, vale ressaltar que, "apesar de ser o fundador da ciência exata moderna, Kepler combinava com seus métodos exatos certas superstições da há muito desacreditadas, inclusive o que não seria injusto descrever como a adoração do Sol, e nelas encontrava mesmo sua motivação para o uso daqueles métodos" (BURTT, 1991, p.45). Assim sendo, o nascimento da ciência moderna não se desvincula, de forma absoluta, da religiosidade de sua época. No caso específico do pensador a que nos referimos, "a ligação entre Kepler, o adorador do Sol, e Kepler, o investigador do conhecimento matemático da natureza astronômica, é muito estreita” (BURTT, 1991, p.46). 
Este estreito relacionamento entre ciência e religião marca o fundamento metafísico da ciência moderna. Este "relacionamento" seria melhor descrito, por um lado, como um engendrar da ciência no seio da metafísica mesma e vice-versa; por outro lado, trata-se de um processo material da sociedade moderna, que, portanto, não pode partir do nada abstrato e instaurar a razão como tudo, ou negar absoluta e efetivamente a religião em favor da ciência, haja vista que a ciência não pode abrir mão de formas religiosas de consciência em sua defesa, reproduzindo-as, ainda que contraditoriamente, em simultaneidade com o argumento científico. Veja-se, por exemplo, que "tanto Copérnico quanto Kepler acreditavam firmemente, por motivos religiosos, na uniformidade do movimento, isto é, no fato de que cada planeta, em sua revolução, era impelido por uma causa constante e infalível [...]” (BURTT, 1991, p.48, grifo nosso). Assim sendo, portanto, faz-se necessário evidenciar que as questões metafísicas não são apenas questões que habitam uma espécie de "mundo imaginário da ideia”, mas que assentam pés firmes sobre o solo, têm materialidade - tanto quanto a materialidade, veremos adiante, é também metafísica. A respeito da natureza da metafísica trataremos mais adiante. Continuemos com a exposição necessária da gênese da metafísica moderna.

A grande contribuição de Kepler, associada à sua concepção religiosa de mundo, refere-se, conforme já mencionado, à harmonia matemática do universo. Esta concepção matemática de harmonia, que se expressava geometricamente no universo conhecido, foi o argumento utilizado por este pensador para a defesa do modelo heliocêntrico de Copérnico. Neste sentido,

\begin{abstract}
o primeiro e mais importante aspecto é o de que ele $\{\text { Kepler }\}^{12}$ logrou uma nova concepção de causalidade, ou seja, ele concebeu a harmonia matemática subjacente e passivel de descobrimento nos fatos observados como a causa de tais fatos; nas palavras normalmente usadas por Kepler, a razão por que eles são como são. [...] A exatidão ou o rigor com que a harmonia causal deve ser verificada nos fenômenos é a característica nova e importante de Kepler. [...] A causalidade, repitamos, passa a ser reinterpretada em termos de simplicidade e harmonia matemáticas (BURTT, 1991, p.49-50, grifos no original).
\end{abstract}

Verifica-se, portanto, que Kepler foi um dos responsáveis pela concepção matemática de causalidade que, na lógica formal, constitui a compreensão do acaso determinado como harmonia matemática, ou, em outras palavras, da determinação do acaso como uma propriedade física engendrada no seio da natureza, em seus processos naturalmente harmoniosos. Assim sendo,

\footnotetext{
${ }^{12}$ No escopo deste trabalho, utilizaremos " \{\} " para indicar nossas inclusões nas citações, enquanto "[ ]" serão utilizados para as inclusões feitas pelos tradutores das obras citadas.
} 
[...] para Kepler, uma hipótese verdadeira deve conter um enunciado referente à harmonia matemática subjacente passível de descobrimento nos efeitos. [...] $\mathrm{O}$ pensamento de Kepler é o de que dentre um número de hipóteses variantes sobre os mesmos fatos, a verdadeira é a que revela por que certos fatos, que nas demais hipóteses aparecem sem relação entre si, são como são, isto é, a que revela a conexão matemática ordenada e racional entre eles. [...] Uma hipótese verdadeira é sempre uma concepção mais abrangente, que vincula fatos até então vistos como independentes; ela revela uma ordem matemática e uma harmonia onde antes havia uma diversidade não explicada. E é importante recordar que esta ordem matemática mais abrangente é algo descoberto nos próprios fatos (BURTT, 1991, p.50, grifos no original).

Assim, ao situar o argumento matemático como um a priori necessário ao estabelecimento de hipóteses, haja vista a harmonia do mundo engendrada pelas causas constantes e infalíveis, estabelece-se o priorado da razão. Este priorado é, como qualquer outro, constituído por uma religiosidade inerente ao argumento matemático. Destarte, a lógica formal, em sua defesa do argumento racional-matemático como legítimo e válido, é a defesa da harmonia do mundo e de suas causas constantes e infalíveis. Neste sentido, “[...] o mundo real é um mundo de características exclusivamente quantitativas; suas diferenças são diferenças exclusivamente numéricas" (BURTT, 1991, p.51, grifo no original); consequentemente, para Kepler

[...] todo conhecimento certo tem de ser o conhecimento das características quantitativas; o conhecimento perfeito é sempre matemático. [...] Portanto, a quantidade é a característica fundamental das coisas [...]. As características quantitativas são as únicas características das coisas do ponto de vista do mundo do nosso conhecimento (BURTT, 1991, p.51-52, grifos no original e grifos nossos).

Veja-se, portanto, a relação genética entre o desenvolvimento da cientificidade como argumento matemático e a cientificidade do argumento apresentado nos dois primeiros capítulos do presente estudo. Em Kepler, portanto, encontramos "claramente enunciada, a posição de que o mundo real é a harmonia matemática passível de ser descoberta nas coisas. [...] Tudo isso tem um feitio claramente pitagórico e neoplatônico; é o reino das ideias platônicas subitamente identificado com o reino dos relacionamentos geométricos" (BURTT, 1991, p.52, grifo nosso). Neste sentido, vê-se a gestação dos pressupostos fundamentais da Filosofia cartesiana, na qual a realidade e o conhecimento são possibilidades divinas:

A razão pela qual essa vasta e bela ordem matemática existe no universo não encontra outra explicação para Kepler que não aquela fornecida pelo aspecto religioso de seu neoplatonismo. Ele cita com aprovação a famosa expressão de Platão de que Deus 
realiza sempre a geometria; ele criou o mundo de acordo com harmonias numéricas, e essa é a razão por que ele fez a mente humana de tal modo que ela só pode compreender através das quantidades (BURTT, 1991, p.52).

Antes de prosseguirmos, nesta compreensão das bases metafísicas da ciência moderna tecida por Burtt (1991), evidencia-se a importância que o referido autor dá ao teísmo na gênese de tais bases. Seguiremos com esta compreensão, até o momento em que será necessário superála, no sentido de que, o problema da metafísica moderna, aparentemente, não seria Deus, ou a religiosidade do argumento, mas a metafísica do problema. Retomaremos este ponto mais à frente.

A realização de Kepler que será fundamental para o futuro da ciência foi sua insistência em que "[...] as hipóteses matemáticas válidas devem ser passíveis de verificação no mundo observado" (BURTT, 1991, p.53). Kepler, como Descartes, era convicto de que “[...] o universo era fundamentalmente matemático e de que todo conhecimento genuíno tem de ser matemático" (BURTT, 1991, p.53). O ponto interessante a ser observado aqui é o seguinte: saber o universo como matemático implicava em que se soubesse como operar este saber; ou que se soubesse o universo como algo a ser sabido, enquanto saber; ou ainda, que se soubesse o saber inerente ao universo, sua harmonia matemática, de forma consistente, racional. Instaura-se, portanto, um dos relevantes questionamentos em torno da verdade moderna: “[...] as leis do pensamento, inatas em nós como dom divino, não podiam chegar a nenhum conhecimento realmente próprio; é preciso que haja os movimentos percebidos que fornecem o material para sua exemplificação exata" (BURTT, 1991, p.53-54, grifo nosso). Qual seria, portanto, a relação entre o saber e as sensações; entre a razão e o mundo sensível? Um dos grandes expoentes dessa problemática, na virada do século XVI para o XVII, foi Galileu Galilei.

Para Galileu “[...] a natureza é o domínio da matemática” (BURTT, 1991, p.61). Este pensador ratifica, portanto, a nascente compreensão de seu tempo de que a matemática era a voz da harmonia. Por outro lado,

[...] esse método de demonstração matemática, fundado como está na própria estrutura da natureza, apresenta-se ocasionalmente a Galileu como substancialmente independente da verificação sensorial - um método exclusivamente apriorístico de chegar-se à verdade. [...] Sua crença firme na estrutura matemática do mundo o emancipava da necessidade de recorrer seguidamente à experiência. [...] De fato, a confirmação por meio da experiência é apenas necessária no caso de conclusões sobre cujas bases necessárias e racionais não podemos ter intuição ${ }^{13}$ imediata (BURTT, 1991, p.62, grifo nosso).

\footnotetext{
${ }^{13}$ Sobre a intuição falaremos mais adiante, de acordo com as contribuições de Hegel para a Filosofia.
} 
Entrementes, o mundo sensível, para Galileu, não poderia ser simplesmente revogado, ou ignorado, mas deveria ser explicado. Neste sentido, "não foi apenas para vencer discussões que Galileu achou conveniente recorrer, com frequência, à confirmação pelos sentidos. Seu empirismo alcançava boa profundidade" (BURTT, 1991, p.62). Gesta-se, neste momento do nascimento da ciência moderna, a compreensão de um mundo dual, sensível-ideal, cujo desvelar é dado pela razão:

\begin{abstract}
é lícito começar com a afirmação de que o que nossa Filosofia busca explicar não é nada mais do que o mundo revelado pelos sentidos. [...] Mas o mundo dos sentidos não é sua própria explicação; tal como se apresenta, ele é um código não decifrado, um livro escrito em língua estranha, que deve ser interpretado ou explicado em termos do alfabeto dessa língua \{a matemática\}. Após vaguear por muito tempo em direções errôneas, o homem por fim descobriu os rudimentos desse alfabeto, ou seja, os princípios e unidades da matemática. [...] Por conseguinte, quando tratamos de decifrar uma página pouco familiar da natureza, o método é, obviamente, o de buscar nela o nosso alfabeto; 'resolvê-lo' em termos matemáticos (BURTT, 1991, p.6364, grifos nossos).
\end{abstract}

Assim sendo, a relação entre os sentidos humanos e a explicação matemática do mundo torna-se o problema do proceder empírico da ciência. Como saber se o que sinto e vivo é real, verdadeiro? Galileu percebeu, neste sentido, que o método matemático de

[...] explicação do mundo dos sentidos leva, com frequência, por estranho que pareça, a conclusões que violentam a experiência sensorial imediata. $\mathrm{O}$ exemplo principal desse fato é a astronomia de Copérnico, que fornece a instância suprema da vitória da razão matemática sobre os sentidos. [...] Ocasionalmente, a razão dá ainda, através da invenção de instrumentos como o telescópio, uma oportunidade aos sentidos de corrigir seus próprios erros de julgamento (BURTT, 1991, p.64).

Em outras palavras, não se pode simplesmente negar que os sentidos ofereçam o mundo a ser explicado, ou seja, que os sentidos confirmam a exterioridade de um mundo existente como mundo sensível. Por outro lado, os sentidos não proporcionam imediatamente a ordem racional do mundo, ou seja, esta ordem não é imanente aos sentidos, pois “tal ordem é sempre matemática e só pode ser alcançada através dos métodos aceitos da demonstração matemática" (BURTT, 1991, p.64). Mas, dada a distinção entre esses dois mundos, o mundo sensível e o mundo da razão, qual seria a garantia de que é possível uma igualdade entre tais mundos que possibilitaria uma compreensão verdadeira do sensível pela razão? Para Galileu, ainda que se considere sua insistência na tentativa de compreensão da natureza física do mundo, tal insistência não significou 
por meio de seu conhecimento criativo imediato da natureza, projeta no mundo essa necessidade matemática rigorosa que nós alcançamos apenas com esforço, através de resoluções e demonstrações. Deus é um geômetra em seus afazeres criativos - o mundo é, para ele, um sistema matemático. A distinção entre o seu conhecimento das coisas e o nosso é a de que o seu é completo e o nosso parcial; o seu é imediato, o nosso discursivo (BURTT, 1991, p.66).

Ademais, para Galileu, as “[...] passagens duvidosas das Escrituras deveriam ser interpretadas à luz das descobertas científicas, e não vice-versa. Deus fez o mundo como um sistema matemático imutável, propiciando, através do método matemático, uma certeza absoluta ao método científico” (BURTT, 1991, p.66, grifo nosso). Ainda segundo Galileu, “[...] conhecemos Deus primeiro pela natureza e depois pela revelação” (BURTT, 1991, p.67). A natureza aparece, portanto, como a presença material de Deus, como filho pregado na cruz, como a garantia de sua existência, o que se verificaria na harmonia inerente à natureza. Esse caminho do divino para o terreno é a garantia do caminho reverso, ou seja, de que a razão, discursivamente, pode alcançar a verdade divina, que é a matemática. Verdade e validade encontram-se, assim, divinamente associadas.

Aqui fica indicado que foi Galileu, contemporâneo de Descartes, quem “"[...] fez claramente a distinção entre o que no mundo é absoluto, objetivo, imutável e matemático e o que é relativo, subjetivo, flutuante e sensorial. O primeiro é o reino do conhecimento, divino e humano; o último é o reino da opinião e da ilusão" (BURTT, 1991, p.67). Esta distinção, porém, ficou à mercê dos céticos, contra os quais Descartes irá fazer face em sua Filosofia. Antes de adentramos nos pormenores cartesianos, faz-se necessário um adendo, fundamental do ponto de vista da gênese da moderna metafísica.

Galileu, como Copérnico e Kepler, ao atribuir tal posição à matemática no seio da ciência, devido a sua compreensão harmônica de mundo, deu

um passo fundamental no rumo da expulsão do homem do grande mundo da
natureza e do tratamento dado ao homem como um efeito do que acontece em tal
mundo, procedimento que se tornou uma característica bastante constante da
Filosofia da ciência moderna e que simplificou extraordinariamente o campo da
ciência, mas que trouxe em seu bojo os grandes problemas metafísicos e
especialmente epistemológicos da Filosofia moderna (BURTT, 1991, p.71, grifo
nosso).

A expulsão do homem do centro do mundo, já citada por nós e evidenciada pelo modelo heliocêntrico e pela centralidade da matemática como garantia da harmonia inerente ao universo e revelada pela razão, não foi simples e puramente uma "expulsão", mas o engendrar da diferenciação do ser do homem em relação à materialidade do mundo. $\mathrm{O}$ que se pode 
denominar como ser humano diferenciou-se, absolutamente, do mundo - isto se evidenciará na Filosofia cartesiana. Mas, posta a diferença, como seria garantido o saber racional, pelo homem, de seu mundo? Não basta dizer "matematicamente". Pois o saber do homem como saber distinto da efetividade de seu mundo necessitaria encontrar uma igualdade que possibilitasse a determinação da razão sobre o mundo. Esta determinação, como já apontado, foi garantida pela via dupla engendrada no desenvolvimento da modernidade: deus-mundano mundo-divino.

Para Burt (1991), este engendrar apareceu como a positivação da matemática divina e a negação do homem mundano:

\begin{abstract}
Obviamente, o homem não era tema adequado ao estudo matemático. Suas atividades não podiam ser tratadas pelo método quantitativo senão da maneira mais chã. Sua vida compunha-se de cores e sons, de prazeres, de dores, de amores apaixonados, de ambições e de lutas. Por conseguinte, o mundo real tinha de ser o mundo fora do homem, o mundo da astronomia e o mundo dos objetos terrestres em repouso ou em movimento. A única coisa comum entre o homem e este mundo real era a capacidade humana de descobri-lo, fato que, sendo necessariamente pressuposto, era facilmente negligenciado e não era, de todos os modos, suficiente para exaltá-lo a uma paridade, em termos de realidade e de eficiência causal, com aquilo que ele era capaz de conhecer. Naturalmente, ao lado dessa exaltação do mundo exterior como mais primário e mais real, ocorria também a atribuição, a esse mundo, de maior dignidade e maior valor (BURTT, 1991, p.71, grifo nosso).
\end{abstract}

Positivo e Negativo aparecem para Burt (1991), portanto, como um movimento de grande reviravolta presente no engendrar da Filosofia moderna. Entretanto, parece que esse movimento ainda é incipientemente contemplado na obra de Burtt. Veremos isso mais adiante. A contribuição deste referido autor para as nossas reflexões não reside nos termos de suas conclusões sobre as bases metafísicas da ciência moderna, nem em sua explanação propriamente dita, mas em algumas considerações fundamentais para ilustrarmos o citado quiproquó da ciência moderna: o enigma em torno da sua premissa de verdade. Neste sentido, argumenta Burt que

era inevitável que, nessas circunstâncias, o homem parecesse estar fora do mundo real; o homem é pouco mais que um feixe de qualidades secundárias. Observa-se que o cenário está montado para o dualismo cartesiano - do lado do primário, o reino matemático; no outro lado, o reino do homem. E os requisitos de importância e valor, assim como de existência independente, estão todos com o primeiro. O homem começa a aparecer, pela primeira vez na história do pensamento, como um espectador irrelevante e um efeito insignificante do grande sistema matemático que é a substância da realidade (BURTT, 1991, p.71-72, grifos no origina e grifos nossos). 
Assim, em nome da harmonia do mundo, necessária para a afirmação das causas constantes e infinitas e em nome dessas causas, necessárias para a afirmação da harmonia do mundo; ou ainda, devido à necessidade de certeza dessa harmonia para a firmação do saber racional, o mundo da natureza, para Burtt (1991, p.74) passou, a partir de Galileu, a ser algo infinito ao invés de finito. Adicionamos a seguinte contraposição à visão do referido autor: o engendrar da infinitude da natureza ${ }^{14}$ do mundo mostrou-se necessário frente ao engendrar da finitude da efetividade da natureza mundana; ou melhor, o engendrar da infinitude da natureza do mundo é a garantia do engendrar da infinitude da certeza da harmonia inerente ao mundo efetivo, o qual não é certo de nada, é incerto, opera incertamente e demanda, face a certeza desta incerteza, o argumento da harmonia como harmonia do argumento racional em relação ao mundo efetivo. Esta oposição, indicada por nós, são as pérolas do colar do idealismo hegeliano, o qual exploraremos melhor adiante. Apenas indica-se, por enquanto, que o descentralizar do homem é um autoproduzir-se deste homem mesmo, e não um simples expulsálo de sua centralidade, do ponto de vista da dialética hegeliana.

A despeito das críticas que possam ser tecidas contra as contribuições de Burtt (2001), deve-se atentar para como o referido autor consegue tomar nota de algo fundamental no desenvolvimento das bases metafísicas da ciência moderna. Trata-se da relação entre "porque" e "como" na ciência:

a Filosofia medieval, que tentava explicar os porquês últimos dos fatos, ao invés de
seu como imediato e que realçava, assim, o princípio da causalidade final (pois a
resposta a essa pergunta só pode ser dada em termos de propósito ou de uso), tivera
sua própria concepção de Deus. Aí estava a hierarquia teleológica das formas
aristotélicas, que culminavam em Deus, ou na Forma Pura, cabendo ao homem uma
posição intermediária, em termos de realidade ou importância, entre ele e o mundo
material. O porquê final dos fatos nesse mundo podia ser explicado principalmente
em termos de seu uso para o homem; o porquê final das atividades humanas, em
termos da eterna busca da união com Deus. Ora, estando a superestrutura, a partir do
homem para cima, banida do reino primário, o qual, para Galileu, identifica-se com
átomos materiais em suas relações matemáticas, o como dos fatos passa a ser o único
objeto do estudo exato e deixa de haver lugar para qualquer tipo de causalidade final.
O mundo real é simplesmente uma sucessão de movimentos atômicos em
continuidade matemática. [...] Mas que fazer com Deus? Com a derrubada da
causalidade final, Deus, como concebido pelo aristotelismo, estava praticamente
perdido; negar francamente sua existência, no entanto, era, à época de Galileu, um
passo demasiado radical para que qualquer pensador importante pudesse considerá-
lo. A única maneira de mantê-lo no universo era inverter a metafísica aristotélica e

${ }^{14}$ Em sua "Carta Sobre os Cegos", Diderot descreve as últimas palavras de Nicholas Saunderson, célebre matemático e cientista cego inglês, a respeito da infinitude da natureza: "julgais a existência sucessiva do mundo, como a mosca efêmera, a vossa. O mundo é eterno para vós, como sois eterno para o ser que vive apenas um instante: ainda assim, o inseto é mais razoável do que vós. [...] O tempo, a matéria e o espaço não são talvez senão um ponto" (DIDEROT, 1979, p.63). 
encará-lo como Primeira Causa Eficiente, ou o Criador dos Átomos. [...] Desse modo, Deus deixa de ser o Bem Supremo em qualquer sentido importante; ele é um imenso inventor mecânico, a cujo poder se faz apelo somente para explicar o aparecimento inicial dos átomos (BURTT, 1991, p.78, grifos no original).

Nesta colocação, apesar da rápida relação que Burtt estabelece entre o Aristotelismo e a Filosofia Medieval, fica indicada a inversão dos "porquês" e "comos". Nesta inversão está a chave para o problema metafísico da relação entre determinação e acaso. Entretanto, esta “inversão" não é simplesmente um inverter da lógica aristotélica, mas um engendrar de algo muito distinto dos problemas relativos ao azar e a fortuna presentes na Filosofia de Aristóteles e nas distinções que este filósofo estabeleceu em relação a Platão. Trata-se do engendrar, pela sociedade em que viveu Galileu, da seguinte problemática: qual a relação entre determinação e acaso? Tudo está previamente determinado? Qual o lugar do acaso? Primeiro o acaso e depois a determinação, ou o oposto? Trataremos desta imbricada questão, fundamental para o debate científico, mais adiante. Neste primeiro apontar dos fatos relativos a gênese das bases metafísicas da ciência moderna, vale a indicação de que

[...] para a ciência, tanto as causas quanto os efeitos são movimentos e a causa é matematicamente equivalente ao efeito em termos de trabalho. [...] Ao invés de uma explicação causal em termos não impróprios para uma metafísica que via o homem como parte determinante da natureza e como elo entre a matéria e Deus, passamos, após banir o homem do mundo real, a explicar a causalidade exclusivamente em termos de forças que se revelam nos movimentos matematicamente expressáveis da própria matéria (BURTT, 1991, p.80, grifos nossos).

Em outras palavras, passou-se a engendrar o que se poderia chamar de um quiproquó entre "porquês" e "comos". Um quiproquó que não pode ser simplesmente considerado desmedido, pois é exatamente o engendrar da medida necessária ao argumento racional que justifica a validade da ciência - a incerteza. Neste sentido, a lógica formal não se engana ao responder "porquês" como se "comos" fossem. Ela (re)produz e é engendrada pela ilusão da certeza de que porque = como. Neste "=" está o segredo do referido quiproquó: a moral. Exploraremos mais a temática adiante. Por enquanto, indicar-se-á um exemplo de como a ciência responde a "porquês" como se "comos" fossem.

A revista da Fundação de Amparo à Pesquisa do Estado de São Paulo (FAPESP), em 
artigo de 19 de junho de $2018^{15}$, publicado sob o título "Frentes frias podem aumentar a mortalidade por AVC", indicou, com base em uma série de trabalhos, entre os quais se encontrava o da geógrafa Priscilla Venâncio Ikefuti ${ }^{16}$, que "com a chegada do frio nas regiões Sul e Sudeste do Brasil, as quedas de temperatura podem ser acompanhadas pelo aumento no número de mortes por acidente vascular cerebral (AVC), principalmente entre a população com mais de 65 anos" (MOON, 2018). Neste sentido, se questionarmos: "por que a chegada de frentes frias nas referidas regiões provocam o aumento do número de mortes por acidente vascular cerebral?", o referido artigo traz respostas interessantes associadas a questões de ordem bioquímica, ambientais e socioeconômicas. Entretanto, todas essas respostas para o "por quê?", legítimas do ponto de vista científico, não respondem esta pergunta. Respondem, ao contrário, ao como: por ter mais de 65 anos, por se enquadrar em certa classe socioeconômica, por ser mulher, por estar suscetível a variações climáticas de significativa amplitude etc, observa-se um aumento do número de mortalidades por AVC suportado - teoria do suporte na inferência estatística - por esses fatores de ordem bioquímica, ambiental e social.

O "como", relativo ao processo de envelhecimento, às questões socioeconômicas, às características bioquímicas das mulheres e à chegada de frentes frias, se confunde com o "por quê?" devido aos pressupostos metafísicos que são assumidos pela ciência de modo "acrítico". De qual justificativa - por quê? - a ciência lança mão para que se suporte tais processos causais - como - no âmbito de seu proceder científico? Lança mão do autoproduzir da natureza - bioquímica, fatores de ordem climática, etc. - e da sociedade - questões de gênero, questões de ordem socioeconômica, etc. O cientista responde, portanto, ao referido "por quê?" antes mesmo de iniciar qualquer investigação científica. O “por quê?” é um pressuposto: porque é natural, porque é social e, no limite, porque sim! Resta-nos questionar, retornando ao debate sobre a gênese das bases metafísicas da ciência moderna, qual a diferença, do ponto de vista metafísico, em responder ao "por quê?" com “porque é natural”, ou "porque é social”, e em dar à mesma pergunta a seguinte resposta: “porque Deus quer”? Trata-se, assim, de um questionamento relativo à natureza dos pressupostos metafísicos assumidos.

De acordo com Burtt (1991, p.80, grifo nosso), "se seguirmos Galileu na tentativa de

\footnotetext{
${ }^{15}$ MOON, Peter. Frentes frias podem aumentar a mortalidade por AVC. Revista Eletrônica da Fundação de Amparo à Pesquisa do Estado de São Paulo (FAPESP). São Paulo, 2018. Disponível em: <http://agencia.fapesp.br/frentes-frias-podem-aumentar-mortalidade-por-avc/28055/>. Acesso em 19 jun. 2018.

${ }^{16}$ IKEFUTI, P. V. Associação entre variáveis meteorológicas, Índice Climático, fatores socioeconômicos e mortalidade por doenças do aparelho circulatório (Acidente Vascular Cerebral e Embolia Pulmonar) no município de São Paulo - SP. 2016. Tese (Doutorado em Geografia Física). Faculdade de Filosofia, Letras e Ciências Humanas, Universidade de São Paulo, São Paulo, 2016.
} 
responder essa pergunta, grande parte da metafísica medieval deportada poderá retornar ao cenário. [...] Segundo Galileu, não sabemos nada a respeito da natureza íntima da força, ou de sua essência; só conhecemos seus efeitos quantitativos em termos de movimento" (BURTT, 1991, p.80, grifo nosso). Esta colocação indica que a ciência parte dos efeitos quantitativos ou qualitativos observáveis no intuito de se desvelar a causa para tais efeitos, independentemente da "natureza íntima" desses processos, ou seja, do porquê eles ocorrem. Mas este "independentemente" é uma ilusão, pois, de fato, é já a resposta ao "por quê?", assumida como pressuposto para o desvelar da causalidade. Este "independentemente" é a assumpção de uma igualdade na diferença entre o mundo discursivo da razão, onde residiria a causalidade lógica dos fenômenos desvelados pela ciência, e o mundo dos referidos fenômenos propriamente ditos.

Portanto, este “independentemente” já é o negar de algo que, para ser negado, precisa ser afirmado como algo de fato existente, ou seja, é uma afirmação na forma de uma negação.

Descartes, que viveu no mesmo período de Galileu, percebeu um problema de ordem metafísica no "independentemente", problema este que residia na necessidade de garantia de igualdade entre os dois mundos referidos acima: a res extensa (mundo dos fenômenos materialmente observáveis, sensível, caracterizado pela extensão ou espacialidade material desses fenômenos) e a res cogitans (grosso modo: mundo do operar da razão objetiva, do questionar, do cogito).

\footnotetext{
\{Descartes\} estava ansioso por encontrar uma garantia absoluta de que suas ideias matemáticas claras e distintas tinham de ser verdades eternas do mundo físico e percebia que seria necessário um novo método para superar essa dificuldade última. [...] Verificamos que, para si próprio, ele resolvera satisfatoriamente o problema, concluindo que as leis matemáticas da natureza foram estabelecidas por Deus e sua invariabilidade eterna é dedutível a partir da perfeição do criador (BURTT, 1991, p.92, grifo no original e grifos nossos).
}

Encontra-se, portanto, na Filosofia cartesiana, suporte para que se possa evidenciar em que consiste a igualdade assumida no "independentemente". Não é exagero considerar que tal Filosofia é um marco do pensamento ocidental e do nascimento da ciência moderna. Neste sentido, não é pouco relevante o fato de que a existência da alma humana e de Deus são fundamentos da metafísica para Descartes (DESCARTES, 2009). Mas não é suficiente indicar a presença de Deus na Filosofia cartesiana, como se isso bastasse enquanto algum tipo de acusação contra seus fundamentos. Ao contrário, a relevância da referida Filosofia está, mais precisamente, nas considerações teístas que o referido filósofo tece, e em como, desta forma, 
foi capaz de indicar um processo engendrado no seio da sociedade em que viveu, fornecendo contribuições inegáveis ao desenvolvimento científico. A ironia destas considerações se constitui como ironia pelo aparente pavor que a ciência engendra em relação ao teísmo. Mas este pavor é um recurso mais discursivo que qualquer outra coisa. Caminhemos por partes.

Importa indicar, momentaneamente, que, para Descartes, a razão é um atributo divino, “[...] tendo Deus concedido a cada um de nós alguma luz para discernir o verdadeiro do falso [...]” (DESCARTES, 2009, p.50). Para o filósofo, isto que se constitui enquanto um pressuposto metodológico necessário, foi alcançado a partir do que se pode considerar uma intrigante argumentação.

No momento em que viveu e escreveu sua Filosofia, Descartes deparou-se com uma corrente filosófica suficientemente forte para requerer sua atenção: o ceticismo. Tal corrente filosófica assume a incerteza como máxima argumentativa. A incerteza, para os céticos, não é simplesmente um momento do pensar mesmo, mas uma forma de argumentação negativa: mais certo estou se sou capaz de negar, pois não posso afirmar com certeza absolutamente nada, haja vista minhas limitações cognitivas, as quais me fazem um ser de ilusões, e dais quais não posso abrir mão. O método cético consiste, portanto, no absoluto negar, que nada mais é do que o afirmar da incerteza. Parte, Descartes, portanto, desta premissa: não posso estar certo de nada que me advenha dos sentidos. Mas ao afirmar a incerteza, na tentativa de se posicionar contrariamente aos céticos, ele percebe algo: o fundamento da incerteza é o ato de duvidar e, ainda que duvide de absolutamente tudo, incluindo-se Deus e a minha própria corporeidade ${ }^{17}$, não posso duvidar, ainda assim, de que duvido. Em outras palavras, cogito ergo sum (DESCARTES, 2009):

\footnotetext{
[...] enquanto queria pensar que tudo era falso, era necessariamente preciso que eu, que o pensava, fosse alguma coisa. E notando que esta verdade - penso, logo existo era tão firme e tão certa que todas as mais extravagantes suposições dos céticos não eram capazes de a abalar, julguei que podia admiti-la sem escrúpulo como o primeiro princípio da Filosofia que buscava (DESCARTES, 2009, p.58-59, grifo no original e grifo nosso).
}

Mas essa afirmação, de que posso questionar tudo menos que estou questionando, não resolve o problema da existência da res extensa. Pois, sendo iludível, como poderia afirmar um mundo além do mundo da dúvida? A resposta para esta questão reside na pressuposição da

\footnotetext{
${ }^{17}$ Segundo Descartes, “[...] a alma pela qual sou o que sou, é inteiramente distinta do corpo, e até mais fácil de conhecer que ele, e, mesmo se o corpo não existisse, ela não deixaria de ser tudo o que é" (DESCARTES, 2009, p.60, grifo nosso).
} 
harmonia, já indicada previamente por nós. A harmonia, ou perfeição em si, é um ponto de fundamental relevância na metafísica cartesiana, pois, para Descartes, como o homem é passível de ser iludido pelas suas sensações, sentimentos e sentidos, mas ainda assim é capaz de conceber coisas com perfeição, então deve haver algo que garanta tal forma de perfeição, pois seres imperfeitos não podem conceber coisas perfeitamente, e "conhecer era maior perfeição que duvidar", ou seja, a questão da perfeição não reside no plano do conteúdo propriamente dito, mas na forma mesma do conhecimento que, apesar da dúvida, era perfeito, pois não advinha do plano sensorial, mas constituía uma substância particular - a alma. Este "algo" que deve haver, portanto, deve ser "algo" perfeito, o qual seja a garantia da harmonia, da certeza da razão, da verdade:

[...] refletindo sobre o fato de que eu duvidava e de que, por conseguinte, meu ser não era completamente perfeito, pois via claramente que conhecer era maior perfeição que duvidar, ocorreu-me procurar de onde aprendera a pensar em alguma coisa mais perfeita que eu; e soube, com evidência, que devia ser de alguma natureza que fosse, evidentemente, mais perfeita (DESCARTES, 2009, p.61, grifo nosso).

Ademais, “[...] aquilo mesmo que há pouco tomei como regra, ou seja, que as coisas que concebemos muito clara e distintamente são todas verdadeiras \{ou seja, são perfeitas\}, só é certo porque Deus é ou existe, e é um ser perfeito, e tudo o que existe em nós vem dele" (DESCARTES, 2009, p.68-69, grifo nosso).

Por outro lado, o penhor da verdade é a garantia do algo a que se refere a verdade: a res extensa. Deus é essa garantia, no conceber de Descartes. Mas não se trata apenas de "garantias", mas de algo um pouco mais complexo: a independência dos mundos. Assim sendo,

\footnotetext{
por um lado, existe um mundo de corpos, cuja essência é a extensão; cada corpo é uma parte do espaço, uma grandeza espacial limitada, diferente de todos os demais corpos apenas por diferentes modos de extensão - um mundo geométrico cognoscível apenas, e inteiramente, em termos de matemática pura. [...] Este mundo não depende em qualquer medida do pensamento e todo o seu mecanismo continuaria a existir e a operar mesmo que não existisse qualquer ser humano. Por outro lado, existe o reino do interior, cuja essência é o pensamento e cujo modo é composto de processos subsidiários, tais como a percepção, a vontade, o sentimento, a imaginação, etc., reino que não é dotado de extensão e que, por sua vez, é independente do outro, pelo menos no que se refere a nosso conhecimento adequado a seu próprio respeito. [...] Tudo o que lá existe é um modo da substância pensante (BURTT, 1991, p.94-95, grifo nosso).
}

Esta independência, ou "independentemente", se nos apresenta como a afirmação da igualdade entre esses dois mundos, garantida por Deus. Esta igualdade é a harmonia, ou 
perfeição, possível à compreensão humana pela mesma harmonia ou perfeição presente no cogito, na razão.

\begin{abstract}
Se cada uma das duas substâncias existe em independência absoluta com relação à outra, como os movimentos das coisas dotadas de extensão produzem sensações destituídas de extensão e como ocorre que as concepções claras ou as categorias da mente destituídas de extensão sejam válidas perante a res extensa? Como é que o que não tem extensão pode conhecer um universo dotado de extensão e, conhecendo-o, alcançar propósitos nele? A resposta menos objetável a Descartes a essas dificuldades é a mesma que Galileu deu a um problema semelhante, embora não tão claramente formulado - o recurso a Deus. Deus fez o mundo material de tal modo que os conceitos matemáticos puros intuídos pela mente são perenemente aplicáveis a ele (BURTT, 1991, p.96).
\end{abstract}

Assim, observa-se, por um lado, que a questão apontada por Burtt na citação acima, de como garantir a igualdade na diferença, reside, portanto, de acordo com sua compreensão, na visão teísta dos pensadores referidos; por outro lado, evidencia-se nesse excerto outra grande contribuição de Descartes: uma defesa do mecanicismo do mundo, a qual seria portadora de uma inerência lógica e de uma imanência fenomenológica, ambas simultâneas e verdadeiras, ou melhor, efetivas. Assim, para além do "porque Deus", há um como fundamental:

[...] eu descrevera a alma racional, e mostrara que ela não pode de modo algum ser tirada do poder da matéria, como as outras coisas de que falara, mas que deve ser expressamente criada; e que não basta estar alojada no corpo humano, como um piloto em seu navio, a não ser, talvez, para mover seus membros; mas que precisa estar mais estreitamente ligada e unida a ele, para ter, além disso, sentimentos e apetites semelhantes aos nossos, e assim constituir um verdadeiro homem (DESCARTES, 2009, p.98, grifo nosso).

Neste sentido, vale indicar aqui que a Alma, em Descartes (2009), é um complexo, composto não apenas pela razão, mas também pela emoção, pela imaginação, etc. A alma humana é divina, sua existência se prova, para Descartes (2009), pela dúvida, conforme já apontamos. Por outro lado, o corpo humano é material extenso, e isto o referido filósofo não ignora: "\{Descartes\} mostrara qual deve ser a constituição dos nervos dos músculos do corpo humano para fazer com que os espíritos animais neles contidos tenham força para mover os seus membros, assim como se vê que as cabeças, pouco depois de serem cortadas, ainda se mexem e mordem a terra [...]" (DESCARTES, 2009, p.92, grifo nosso). Por outro lado, há uma distinção entre o homem-animal e o animal em geral:

[...] também se pode conhecer a diferença que há entre os homens e os animais. Pois é uma coisa fácil de se notar que não há homens tão embrutecidos e tão estúpidos, sem excetuar nem mesmo os dementes, que não sejam capazes de combinar diversas 
palavras e de com elas compor um discurso no qual possam expressar seus pensamentos; e que, pelo contrário, não há outro animal, por mais perfeito e bem nascido que seja, que faça o mesmo. [...] E isto não prova que os animais têm menos razão que os homens, mas que não têm absolutamente nenhuma (DESCARTES, 2009, p.95-97, grifo nosso).

A razão, portanto, é o atributo genuinamente humano, mas não é o único atributo do homem. Todos esses pormenores evidenciáveis na Filosofia cartesiana fizeram dos cientistas, entre os quais estamos nós geógrafos, e também dos filósofos como cabeças cortadas a comer terra, ou como diria Martins (2007, p.44): "todos os homens são o complexo bio-ontológico". A afirmação desta distinção que não é, afinal, distinção alguma; ou melhor, a necessidade do "independentemente" para a subsistência da igualdade no argumento lógico é a igualdade ideal, especulativa, divina. O problema da metafísica moderna, portanto, não é precisamente o teísmo, como crê Burtt (1991), mas a metafísica do problema, que instaura o divino como garantia, como certeza, ainda que na forma da certeza da incerteza. Em outras palavras, a questão é o saber da dúvida como saber, é o saber da possibilidade da certeza como certeza da incerteza e, em primeiro lugar, o saber da afirmação ou negação de Deus como saber, como afirmação ou negação, o que é o mesmo - saber.

Descartes, portanto, além de filósofo é também um grande ilusionista: chama a atenção para o resultado de sua mágica, mas esconde o seu segredo: ele parte da razão na forma da certeza da incerteza, ou da impossibilidade de negar que duvidamos, ainda que duvidemos de tudo, para chegar no único lugar possível: a razão, afirmada como perfeição - e perfeição divina, além-humana -, afinal é a única que subsiste a todo e qualquer questionamento - e como não poderia subsistir, se ela mesma é a forma do questionamento? Como posso ir de carro a algum lugar e não chegar à brilhante conclusão de que cheguei a algum lugar de carro? Como defino o homem como complexo bio-ontológico e não chegar à conclusão de que, afinal, ele não seja este complexo, e não ver tudo como nada e nada como tudo?

Portanto, já se observa em Descartes a concepção de um complexo humano que pergunta e responde e que produz a razão a partir de sua corporeidade, ainda que esta razão subsista além-homem, além-singularidade. Assim, quando Descartes diz "Deus", ele também já o nega, pois, de acordo com este filósofo, a alma concebe o mundo extenso pela mente alojada no cérebro humano. Há uma compartimentação biológica para a alma e, portanto, o pensamento individual fica reduzido ao mecanismo biológico. Descartes, portanto, passou

[...] a conceber a mente como algo localizado e totalmente confinado ao corpo. O que Descartes pretendia dizer era que, por meio de uma parte do cérebro, uma substância desprovida de extensão entrava em relação efetiva com o reino da extensão. $O$ 
resultado líquido de suas tentativas a esse respeito, para a corrente científica positiva de pensamento, foi o de que a mente existia em um ventrículo do cérebro (BURTT, 1991, p.97, grifos no original).

Assim ficou, portanto, evidenciada a semente da humanidade genérica: Homo sapiens sapiens; ou seja, não apenas o homem que sabe, mas o homem que sabe o que sabe, e que se sabe como biologicamente disposto. Este "biologicamente" é, por um lado, independente da determinação do saber, ou seja, é engendrado pela natureza; por outro lado, é o saber da natureza e o saber deste saber. Em outras palavras, o complexo bio-ontológico é o saber deste complexo como um acaso - ou autoproduzir (engendrar) da natureza - e, simultaneamente, o saber deste saber do acaso como determinado no seio deste autoproduzir, como lógica inerente ao autoproduzir e logicamente evidenciável ou, ainda, como saber da (sobre a) natureza que se produz como saber natural (engendrado pela natureza). A teoria do vórtice, para dar um último exemplo cartesiano, pode ilustrar a gênese desta compreensão moderna.

Após indicar os fundamentos de sua metafísica, no Discurso do Método, Descartes procurou demonstrar "[...] toda a cadeia de outras verdades que deduzi destas primeiras \{verdades metafísicas\}" (DESCARTES, 2009, p.73). Neste sentido, o referido filósofo criou uma alegoria para indicar sua compreensão do mundo físico, o qual seria independente da razão humana e determinado pelas leis divinas subjacentes à natureza:

resolvi deixar todo este mundo aqui para suas discussões \{dos doutos\}, e falar
somente do que aconteceria num novo, se Deus criasse agora em algum lugar, nos
espaços imaginários, matéria suficiente para compô-lo, e agitasse diversamente e sem
ordem as diversas partes dessa matéria, a fim de compor com ela um caos tão confuso
quanto o imaginado pelos poetas, e depois se limitasse a prestar seu concurso normal
à natureza e deixá-la agir segundo as leis que ele estabeleceu.[...] Ademais, mostrei
quais eram as leis da natureza; e, sem apoiar minhas razões em nenhum outro
princípio que não o das perfeições infinitas de Deus, procurei demonstrar todas
aquelas sobre as quais pudesse haver alguma dúvida, e mostrar que elas são tais que,
mesmo que Deus houvesse criado vários mundos, não poderia haver nenhum onde
elas deixassem de ser observadas. Depois disto, mostrei como a maior parte da
matéria desse caos devia, em decorrência dessas leis, dispor-se e arranjar-se de um
certo modo que a tornasse semelhante a nossos céus; e como, entretanto, algumas de
suas partes deviam compor uma Terra, outros planetas e cometas, e algumas outras
um Sol e estrelas fixas (DESCARTES, 2009, p.76-77, grifo nosso).

Descartes, como Fausto, está evidentemente maravilhado ante o livro do mundo: “Ah, que visão!" (GOETHE, 2011, p.63). Também como Fausto, aquele filósofo proclama: "Vergai ante a mercê divina,/ Que ajuda e que a ajudar ensina" (GOETHE, 2011, p.98). E nesta certeza da certeza, fundamentada na perfeição divina, crê. Entretanto, ao crer na certeza, não pode negar de forma absoluta a incerteza e, mesmo que discurse a favor de um tal método de negação, 
primeiro deve afirmá-la e, assim, ao dobrar os joelhos perante a Deus, ouve, antes, como um estudante desprecavido, as palavras de Mefistófeles: "Haveis de entrar, assim, por seguro portal,/ No templo da certeza incondicional” (GOETHE, 2011, p.160). Ao adentrar o portal da razão, crente em Deus e fiel ao demônio, Descartes completa seu destino infausto:

\author{
Que espera ainda a cabeça que se crava \\ Só na matéria estéril, rasa e fria, \\ Que por tesouros com mão cobiçosa cava \\ E ao encontrar minhocas se extasia?
}

(GOETHE, 2011, p.73)

As minhocas estão para o solo como a razão para o cérebro humano: nenhum dos dois é além ou aquém do outro - um verdadeiro complexo bio-ontológico. Ademais, não é difícil notar que o pacto infernal é contagioso. De acordo com Burtt (1991, p.91),

[...] a teoria do vórtice foi uma realização histórica da maior significação. Foi a primeira tentativa abrangente de representar todo o mundo exterior de uma maneira fundamentalmente diferente da visão platônico-aristotélico-cristã, a qual, sendo essencialmente uma concepção teleológica e espiritual dos processos da natureza, controlara o pensamento humano por mil e quinhentos anos. [...] O mundo é representado concretamente como material e não espiritual, como mecânico e não teleológico (BURTT, 1991, p.91).

Evidencia-se, portanto, uma limitação na compreensão de Burtt sobre a teoria em questão. Tal limitação aparece para este filósofo como ouro, mas, olhado mais de perto, é pirita, ou, pior, minhocas.

A contribuição de Descartes situa-se, por um lado, no discurso da independência do mundo físico em relação à razão humana, ou na defesa da autoprodução deste mundo segundo leis naturais divinas inerentes a esse mundo; por outro lado e consequentemente, a razão aparece em Descartes como uma inerência que, face ao "independente" autoproduzir da natureza, é a garantia de igualdade entre a ideia de mundo e o mundo-em-si, entre a coisa existente externamente e o objeto do pensamento para a consciência racional.

Vemos, portanto, como Descartes compreende Deus: “[...] Deus, de fato, tem extensão em termos de poder, ou seja, é capaz de pôr a matéria em movimento em qualquer ponto, mas isso era algo essencialmente diferente da extensão geométrica imputável à matéria" (BURTT, 1991, p.114). Em outras palavras, Deus é o "porquê" da possibilidade dos "comos" científicos fundamentados no Discurso do Método. Deus, entretanto, não é uma imaginação referida à Idade Média, para Descartes. É o saber Deus como certeza da possibilidade da razão na forma da própria razão ou, em termos hegelianos, é já o Saber Absoluto, conforme estabeleceremos 
mais adiante. Em outras palavras, o argumento mágico de Descartes pode ser mais propriamente desnudado na seguinte exposição: sei que o método que defendo é tão perfeito que, por isso, só pode ser-divino:

Perguntei-lhe \{ao cego $\}$ o que entendia por espelho: "Uma certa máquina, respondeu-me, que põe as coisas em relevo longe de si mesmas, se se encontram situadas convenientemente em relação a ela. É como minha mão, que não preciso pousar ao lado de um objeto a fim de senti-la". Descartes, cego de nascença, teria que, parece-me, felicitar-se com semelhante definição (DIDEROT, 1979, p.29, grifo nosso).

Assim, Diderot, o materialista e enciclopedista francês do século XVIII, critica a compreensão mecanicista de Descartes da qual não era componente o sentido, o qual seria uma essência pertencente à substância pensante - alma - e não à substância extensa: como o cego, Descartes imagina que não é preciso pousar a mão para senti-la, haja vista o sentido ser um atributo da alma para este filósofo. A alma sentiria a mão. O sentido não seria extenso. A possibilidade de união entre o sentido pensante e a máquina extensa era dada, assim, pela certeza da harmonia divina, na Filosofia cartesiana. Assim, a igualdade no “independentemente" é uma questão moral.

Burtt observa esse engendrar nos termos da história da ciência moderna, e defende a necessidade de se considerar as bases metafísicas desta ciência:

ora bem, a história da mente revela, de forma clara, que o pensador que condena a metafísica guardará, na verdade, três tipos principais de noções metafísicas. Primeiramente, ele partilhará as ideias de sua época sobre questões fundamentais, enquanto tais ideias não contrariarem seus interesses ou despertarem sua crítica. [...] Em segundo lugar, se se trata de uma pessoa engajada em qualquer investigação importante, ela deverá ter um método, e estará sob uma forte e constante tentação para criar, do seu método, uma metafísica, ou seja, supor o universo, fundamentalmente, de tal modo que seu método seja apropriado e bem-sucedido. [...] Finalmente, desde que a natureza humana exige a metafísica para sua completa satisfação intelectual, nenhuma grande mente pode evitar inteiramente jogar com questões fundamentais, especialmente quando elas são poderosamente lançadas por considerações provenientes de suas investigações positivistas, ou por certos vigorosos interesses extracientíficos, como a religião (BURTT, 1991, p.181-182).

Em distinção com este filósofo, carece questionarmos: a natureza humana exige metafísica para sua completa satisfação? Há distinção, portanto, entre metafísica e natureza humana? O que Burtt chama de natureza humana? Ademais, até que ponto se estabelece uma distinção entre religião e ciência?

Burtt critica o positivismo pela relação que ele estabelece entre as partes e o todo, mas recai na sua própria crítica quando imagina haver uma distinção absolutamente unilateral entre 
ciência e religião. A ciência tem a conveniente necessidade ético-política de se calar sobre a metafísica, para se afirmar em posição superior às crenças humanas, mas nenhum cientista é capaz de provar que a ciência não é nada mais do que uma crença, ainda que uma crença útil haveria crença inútil?

Devido à defesa da necessidade de se estabelecer uma distinção unilateral entre teísmo e lógica formal a partir de um apreender crítico em relação às bases metafísicas da ciência moderna, que estabelece em seu trabalho, Burtt (1991) conclui que a lição principal de seu estudo histórico, tendo em vista a referida necessidade,

[...] deve ser a de que os esforços para a formulação desse novo ponto de vista pela simples síntese de informações científicas, ou pela crítica lógica das suas premissas, estão fadados a se tornarem inadequados, em ambos os casos. É de importância capital que eles sejam suplementados por um discernimento judicioso dos fatos principais que condicionaram o surgimento da metafísica medieval e da sua sucessora mecânicomatemática, que é agora tida como carente de uma completa reforma crítica. Sem esse discernimento, a nova metafísica, quando surgir, será apenas a objetificação do espírito de uma era, talvez instável e temporária, em vez de uma expressão racional da compreensão intelectual de todas as eras (BURTT, 1991, p.240, grifo nosso).

De um lado, restam ainda demasiados questionamentos em torno desta defesa. Como esse discernimento é possível, se ele também se apoia na metafísica em que critica? Como será possível tecer uma crítica a partir do que é criticado? É possível criticar a metafísica partindose da metafisica? Há outro lugar de onde partir? Por outro lado, foi possível, até aqui, estabelecer-se pontos importantes para a reflexão em torno do objeto principal deste capítulo a efetividade.

Neste sentido, o problema de Deus na metafísica não é Deus, mas a metafísica mesma. Para Deus ser um princípio metafísico é necessário, primeiramente, que a metafísica afirme Deus, saiba Deus. Deus deve se ajoelhar ao saber de Deus como o Deus que é a certeza desse saber e do objeto do saber. Deus emerge da metafísica e vice-versa. Por outro lado, a efetividade da qual emerge a metafísica, seja esta teísta ou não, é incomensurável, impensável, incerta. O saber desta incerteza é o produzir social da mesma, ou seja, o comer poeira da cabeça decapitada enquanto produção social da decapitação do complexo bio-ontológico engendrado nesse produzir. Neste sentido, quando se apresenta o mundo físico, ele já é metafísico, pois sem saber de mundo não há mundo sabido possível, ainda que se estabeleça essa possibilidade a partir de um certo viés científico. Entretanto, nenhuma metafísica será capaz de expressar uma compreensão racional de todas as eras, a não ser enquanto saber desta compreensão como saber de todas as eras distinto dessas eras mesmas, da efetividade dessas eras, pois há uma 
incapacidade, permanente no pensamento, no ato de expressar a própria compreensão de sua fenomenologia, pois seus fundamentos antecedem o racional. Em outras palavras, ainda que se engendre, na sociedade moderna, a positivação da lógica formal como método válido para o desvelamento da verdade, seria estranho compreender a verdade como qualquer outra coisa além desse engendrar mesmo, ou seja, como efetividade, necessariamente irracional, da qual emerge, necessária e efetivamente, a racionalidade.

Tendo em vista os termos dos apontamentos realizados até aqui, faz-se necessário aprofundarmos a problemática do engendrar social da verdade na modernidade e, consequentemente, da compreensão deste engendrar na forma da crítica da efetividade mesma. Para Burtt, a chave das limitações filosóficas da ciência são suas bases metafísicas, historicamente constituídas. Tais bases estariam impregnadas pelo teísmo dos grandes nomes reconhecidos na história do pensamento científico moderno. De acordo com o referido autor,

com a despedida da Divindade, as dificuldades epistemológicas da situação dificilmente poderiam deixar de oferecer um desafio irresistível. Como poderia a inteligência alcançar um mundo inacessível, em que não havia uma inteligência capaz de controlar? Não foi por acidente que Hume e Kant, os dois primeiros que realmente baniram Deus da Filosofia metafísica, igualmente destruíram, por meio de uma crítica cética, a fé exagerada na competência metafísica da razão (BURTT, 1991, p.231232).

Entretanto, a despeito da suposta despedida do teísmo da ciência e da Filosofia, reconhecida em nomes como o de Immanuel Kant - o moralista cristão -, a questão de ordem permanece. E permanece porque, conforme apontamos, o problema filosófico relativo à verdade não diz respeito à Deus, mas à Filosofia mesma. Em outras palavras, o problema da metafísica é a constituição metafísica do problema, ou seja, sua fenomenologia. Neste sentido, um dos últimos grandes filósofos ocidentais da modernidade que trataram adequadamente do assunto foi George W. F. Hegel.

No subcapítulo seguinte, veremos qual a contribuição de Hegel para a compreensão da verdade na Filosofia e, para tal, seguiremos os apontamentos de um dos leitores mais conceituados do referido filósofo alemão: "um olhar sobre o sistema hegeliano tem de iniciarse com a Fenomenologia hegeliana, o verdadeiro lugar do nascimento e o segredo da Filosofia de Hegel” (MARX, 2004, p.119, grifo nosso). 


\subsection{A Dialética Hegeliana e o Saber Absoluto}

A Fenomenologia do Espírito, ou Ciência da Experiência da Consciência ${ }^{18}$, é considerado um dos últimos tratados de Filosofia da modernidade. No escopo do referido tratado, Hegel vê-se atormentado por uma velha questão filosófica: a verdade. Inova no tratamento desta questão por ousar apresentá-lo a partir dos meandros da dialética. Conclui, no âmbito do referido tratamento, pelo necessário engendrar da dissimulação da verdade como Saber Absoluto. E o referido Saber, para Hegel, é

o espírito que se sabe em figura-de-espírito, ou seja: é o saber conceituante. A
verdade não é só em si perfeitamente igual à certeza, mas tem também a figura da
certeza de si mesmo: ou seja, é no seu ser-aí, quer dizer, para o espírito que sabe, na
forma do saber de si mesmo. A verdade é o conteúdo que na religião é ainda desigual
à sua certeza. Ora, essa igualdade consiste em que o conteúdo recebeu a figura do
Si. Por isso, o que é a essência mesma, a saber, o conceito, se converteu no elemento
do ser-aí, ou na forma da objetividade para a consciência. O espírito, manifestando-
se à consciência nesse elemento, ou, o que é o mesmo, produzido por ela nesse
elemento, é a ciência (HEGEL, 2014, p.524, grifo no original e grifo
nosso).

A verdade do Saber Absoluto é, portanto, certeza. É espírito que está certo de si como saber de si. É certeza de si mesmo. É certeza que, mesmo face à incerteza absoluta, é certo de que sabe esta incerteza como certeza. É certo, portanto, mesmo na incerteza, de que cogita. $\mathrm{E}$ mesmo certo de que a tudo possa negar, não pode negar que está negando e que, portanto, ao negar, é afirmação de si mesmo como certeza de si mesmo: cogito ergo sum. Nega, ao afirmar a certeza, a negação. A verdade, portanto, é movimento dialético, é negação da negação.

Assim sendo, para que se compreenda a Fenomenologia do Espírito que se sabe como saber e que é, portanto, Saber Absoluto, faz-se necessário um retomar dos termos da Filosofia Hegeliana, bem como um apontar das limitações desta Filosofia, especialmente no que diz respeito à sua dialética. A justificativa deste necessário retomar diz respeito, no escopo deste trabalho, à relação entre saber e verdade. Consequentemente, diz respeito, em primeiro lugar, à questão da efetividade, que passará a ser tratada, neste subcapítulo, nos termos da dialética hegeliana.

Neste sentido, primeiramente, e de forma um tanto abrupta, a verdade é, para Hegel (2014, p.35, grifo nosso), “[...] o movimento do refletir-se em si mesmo”. Este movimento é a dialética. Para Hegel, a dialética é o engendrar da negatividade enquanto princípio motor

\footnotetext{
${ }^{18}$ Primeiro título escolhido por Hegel para a sua Fenomenologia do Espírito.
} 
e gerador da verdade, ou seja, é “"[...] esse caminhar que a si mesmo produz, que avança e que retorna a si”" (HEGEL, 2014, p.62, grifo nosso). Assim sendo,

\begin{abstract}
a grandeza da "Fenomenologia" hegeliana e de seu resultado final - a dialética, a negatividade enquanto princípio motor e gerador - é que Hegel toma, por um lado, a autoprodução do homem como um processo, a objetivação como desobjetivação, como exteriorização e suprassunção dessa exteriorização; é que compreende a essência do trabalho e concebe o homem objetivo, verdadeiro, porque homem efetivo, como o resultado de seu próprio trabalho (MARX, 2004, p.123, grifo no original e grifo nosso).
\end{abstract}

Ou seja, o que denominamos logo acima como "refletir-se", ou o ato da reflexão mesma, diz respeito à complexa relação entre consciência universal e consciência-de-si. Nesta relação, que não pode ser evidenciada nos termos da causalidade simples da lógica formal por tratar-se de um processo de objetivação como desobjetivação, de exteriorização e suprassunção dessa exteriorização, a verdade é, sempre, dissimulação. Tal dissimulação, entretanto, não é apenas um momento, positivo ou negativo, da Fenomenologia do Espírito, mas é o movimento mesmo do espírito, já dissimulado.

\begin{abstract}
Mas se esse mundo da dissimulação não é outra coisa que o desenvolvimento da consciência-de-si moral em seus momentos, e por isso é sua realidade, ela não vai tornar-se, segundo sua essência, nada diverso pelo fato de seu retornar a si; seu retornar a si é antes somente sua consciência alcançada de que sua verdade é uma pretensa verdade. A consciência deveria ainda sempre fazê-la passar por sua verdade, já que tem de se expressar e apresentar como representação objetiva; mas saberia que é uma dissimulação apenas. Isso seria, de fato, a hipocrisia, e aquele repudiar de tal dissimulação já seria a primeira exteriorização da hipocrisia (HEGEL, 2014, p.420, grifo no original e grifo nosso).
\end{abstract}

Em outras palavras, o evidenciar desta dissimulação objetiva da verdade não se dá, nos termos da Filosofia hegeliana, como uma acusação, ou demonstração especulativa, mas como um evidenciar mesmo da dissimulação, que só poderia ocorrer na forma da dissimulação mesma. Assim sendo, Hegel elabora a fenomenologia do espírito no intuito de evidenciar o movimento dialético do engendrar da verdade como produção humana e do engendrar da humanidade como o produzir mesmo da verdade. Neste duplo-engendrar, a objetividade aparece como uma questão fundamental.

A objetividade, na Fenomenologia, é a forma do estranhamento. É a forma do estranhamento como o produzir desta forma. É o movimento da produção da objetividade como objetividade estranhada e, consequentemente, da produção do estranhamento como conteúdo desta forma objetiva. É a afirmação de um mundo objetivo aquém da consciência no 
próprio processo de produção desse mundo e, simultaneamente, no processo de produção desta consciência como consciência além deste mundo objetivo. Em outras palavras, é a negação da consciência do mundo objetivo como objetivação estranhada deste mundo e, consequente e necessariamente, afirmação do estranhamento como certeza da incerteza ou como necessidade da certeza.

Neste ponto, para ilustrarmos a relevância desta argumentação, retomaremos o objetivo a que se referem os dois primeiros capítulos desta monografia: "analisar a relação entre impermeabilização do solo e a distribuição dos óbitos associados às doenças do aparelho circulatório". Temos, nos termos deste objetivo, duas Coisas: 1) a impermeabilização do solo; 2) a distribuição dos óbitos associados às doenças do aparelho circulatório. Ademais, temos também uma proposta analítica: “analisar”. Esta proposta, conforme demonstrado, é executada nos termos da lógica da inferência estatística.

Para que se leve a cabo a análise da relação entre as coisas definidas, faz-se necessário a certeza da possibilidade desta análise. Esta certeza fundamenta-se, por um lado, nas propriedades físico-disposicionais que as coisas teriam em-si, ou seja, na natureza imediata das coisas às quais a consciência se refere - impermeabilização e distribuição dos óbitos. Por outro lado, tal certeza é garantida pelo movimento de suprassunção da coisa. A consciência, por sua vez, é o movimento da certeza sensível, da percepção e do entendimento.

A certeza sensível é o movimento de afirmação dos sentidos em relação direta com a imediatez da Coisa. É certeza que, tendo a sensibilidade como conteúdo, afirma: há alguma coisa aqui. A percepção, por sua vez, é a suprassunção da certeza sensível, sua elevação à consciência em geral: esta coisa é um livro. O entendimento, por outro lado, é o momento do movimento como suprassumir da percepção, como diferenciação: esta coisa, que é um livro, é composta por partes distintas, as quais a tornam distintas de outro livro e de tantas outras coisas. Esta distinção, ou diferenciação, entretanto, já é o movimento do suprassumir do entendimento e sua passagem necessária - retorno - à certeza sensível. O movimento da consciência, portanto, é objetivo. Assim, o que está em questão não é o objetivo, mas o movimento de objetivação.

Neste sentido, a suprassunção do em-si da coisa (objeto imediato dos sentidos) em sua universalidade simples, ou seja, na forma do em-si para a consciência (objeto da consciência), é a negação da singularidade da imediatez da coisa, ou seja, é o aparecimento de um outro objeto. Esse aparecimento de um outro objeto é a negação da coisa essente, é a suprassunção do Ser Em-si da Coisa para o Ser Em-si do objeto do saber. Este objeto é, por sua 
vez, suprassumido no movimento de diferenciação de suas partes e no de sua distinção em relação a outros objetos. Evidencia-se, portanto, a objetividade do saber como engendrar da objetividade mesma enquanto primeira negação, suprassunção da efetividade da coisa. Esta negação, por sua vez, passa por uma segunda e simultânea negação: a negação da negação primeira do ser efetivo da coisa e, consequentemente, a afirmação do Si como essência universal. Nesta dupla-negação, retorna-se à certeza sensível: a coisa em-si essente. Neste movimento, portanto, evidencia-se, fundamentalmente, o retorno. Este retorno é, por um lado, a reposição do estranhamento necessário para o desvelamento do mundo e, por outro, dos termos da fenomenologia desse desvelamento, ou seja, da objetividade.

A evidenciação do movimento dialético da consciência, ou o operar da "ciência da experiência da consciência" revela que o primeiro negar é já a negação deste negar, pois na coisa primeira da certeza sensível já está a afirmação da forma de consciência que se pretende desvelar, ou seja, da coisa em-si essente. Em outras palavras, esta "coisa primeira" não é, de fato, a primeira. É apenas um momento da experiência da consciência. A reposição desses momentos na forma da suprassunção é a fenomenologia da dissimulação da verdade. $\mathrm{O}$ acusar esta dissimulação, entretanto, é como o explodir dos fogos de artifício: luz para os olhos e barulho para os ouvidos que, sem o explodir mesmo, não é. Neste sentido, o estranhamento, por sua vez, é o próprio mecanismo da dissimulação da verdade, e sua fenomenologia o efetivo produzir fogos de artifício. Este estranhamento inerente ao movimento dialético é a alienação.

A alienação é o estranhar conjugado no gerúndio, ou seja, é o movimento efetivo no qual se evidencia o estranhamento simultaneamente como necessidade e finalidade. Parte-se da coisa estranhada já na forma do retorno à coisa estranhada, ou seja, "eu sou o Alfa e o Ômega, o primeiro e derradeiro, o princípio e o fim". Neste sentido, a verdade diz respeito ao movimento efetivo da experiência da consciência, ou fenomenologia do espírito, o qual se dá na forma da negação da negação.

\footnotetext{
Por isso, em Hegel, a negação da negação não é a confirmação da verdadeira essência, precisamente mediante a negação da essência aparente, mas a confirmação da essência aparente ou da essência estranhada de si em sua negação ou a negação dessa essência aparente enquanto uma essência objetiva, habitando fora do homem e independentemente dele, e sua transformação no sujeito. Um papel peculiar desempenha, por isso, o suprassumir, onde a negação e a conservação, a afirmação, estão ligadas" (MARX, 2004, p.130, grifo nosso).
}

Assim sendo, a negação da negação seria o movimento contraditório de positivação da essência estranhada, alienada, na forma da própria negação, ou seja, seria o engendrar efetivo da essência objetiva na forma da suprassunção dos momentos constituintes do 
movimento dialético. Esta "suprassunção" é o ápice do movimento de experiência da consciência para Hegel, pois garante, perante o desvanecimento inerente à dialética, a conservação da essência universal como essência externa, objetividade em-si-essente. Esta "conservação" é a afirmação da objetividade em-si-essente; afirmação cuja fenomenologia revela um movimento negativo: 1) parte-se já da objetividade em-si-essente (coisa para a certeza sensível), 2) suprassume-se esta coisa para a certeza sensível (nega-se sua essencialidade exterior à consciência universal e afirma-se sua generalidade objetiva para o pensamento na forma da percepção), 3) nega-se esta generalidade objetiva no processo de determinação da coisa para o entendimento e, ao fazê-lo, retorna-se à objetividade em-si-essente ao suprassumir o entendimento e, desta forma, afirma a referida objetividade como saber. A negação da negação, portanto, é a negação da forma do saber para a afirmação do conteúdo desta forma como saber. O que se evidencia, na "Fenomenologia", portanto, é o engendrar do saber como uma relação necessária entre forma e conteúdo no movimento dialético do espírito. Esta relação é, pois, estranhada, haja vista o movimento de negação da essência aparente (forma) para afirmação de uma essencialidade universal como conteúdo da forma. Destarte, a afirmação do saber passa, antes, pela negação da forma do saber, ou seja, afirmação que é a negação do que já negou.

A negação da negação é o círculo de ciranda, em movimento, dos momentos da dialética hegeliana. Cada indivíduo, ao dar a mão para o próximo, constitui uma parte singular efetiva da roda e, ao mesmo tempo, tem sua consciência constituída de modo que se sabe como singularidade universal, como parte da roda. Só faz sentido sua participação na ciranda se canta a mesma música. A singularidade, portanto, só é reconhecida perante o universal, como o singular de um universal. O movimento da ciranda é o desvanecimento da singularidade efetiva, seu movimento de estar aqui e já não estar mais, pois a ciranda não para: "Roda mundo, rodagigante/ Rodamoinho, roda pião/ O tempo rodou num instante" (HOLLANDA, 1968). Entretanto, a igualdade entre singularidade e universalidade é estranha, pois se dá na forma do estranhamento. Neste sentido,

buscando como singular, ele não é uma singularidade pensada universal; não é conceito, mas é singular como objeto ou como algo efetivo: objeto da certeza sensível imediata, e por isso mesmo é somente uma coisa tal que desvaneceu. Portanto, para a consciência, só pode fazer-se presente o sepulcro de sua vida. Mas, porque o próprio sepulcro é uma efetividade, e é contra a sua natureza manter uma posse duradoura, assim também essa presença do sepulcro é somente a luta de um esforço que tem de fracassar (HEGEL, 2014, p.163, grifo no original e grifo nosso). 
A efetividade objetiva essente imediata, portanto, é desvanecimento constante, é o movimento mesmo da ciranda. Neste sentido, o encontrar-se a si mesmo na essência "é uma luta que tem de fracassar", pois o saber que emerge da efetividade não é a efetividade mesma, mas o sepulcro do que foi, sua suprassunção, sua negação. Entretanto, por outro lado, o sepulcro é também uma efetividade: o espírito que é a negação que nega que negou. Mas essa efetividade do sepulcro, ou efetividade objetiva essente mediata, é também desvanecimento constante, é a música da ciranda. Estranho nisso tudo, portanto, é a duplicidade da efetividade:

[...] A consciência surge aqui igualmente como algo efetivo, mas também como cindida interiormente. Essa cisão se apresenta em seu trabalhar e gozar por cindirse em uma relação para com a efetividade - ou o ser-para-si - e em um ser-em-si. Aquela relação para com a efetividade é o alterar ou agir é o ser-para-si que pertence à consciência singular como tal. Mas nisso ela é também em si; esse lado pertence ao Além imutável: são as faculdades e as forças - um dom alheio que o Imutável concede igualmente à consciência para que dele goze (HEGEL, 2014, p.165, grifo no original e grifo nosso).

A consciência cindida é a simultaneidade do Em-si (universal) e do Para-si (singular). Esses dois momentos constituem a efetividade como uma dualidade em movimento evanescente. A consciência-de-si singular é o momento da relação para com a efetividade externada desta consciência, ou seja, é o ser-para-si. Neste agir, entretanto, o singular é também em-si, ou seja, é um singular-para-si para um universal-em-si. É singular, portanto, para uma consciência universal. Destarte, este singular emerge da cisão da consciência nas formas do emsi e do para-si. Esta cisão é a afirmação da consciência-de-si como certeza de que é em-si e para-si, ou seja, como razão. Esta certeza está fundamentada, portanto, no Si, que é a garantia de igualdade entre o singular-para-si e o universal-em-si. Esta garantia de igualdade, ou certeza, é a afirmação da razão como toda a realidade, ou seja, como realidade que se sabe como verdade, ou como a verdade que é a realidade. Assim, "porque a consciência-de-si é razão, [...] está certa de que toda a efetividade não é outra coisa que ela. Seu pensar é imediatamente, ele mesmo, a efetividade; assim comporta-se em relação a ela como idealismo" (HEGEL, 2014, p.171-172, grifo nosso).

A razão, cujo comportamento idealista demonstra Hegel, apresenta, portanto, um movimento que deve ser evidenciado no intuito de que se experimente sua total realização, pois

a razão se vislumbra como uma essência mais profunda do que é o Eu puro, e deve exigir que a diferença - o ser multiforme - se torne para ela o próprio seu; que se intua como a efetividade, e que se ache presente como figura e como coisa. Porém a razão, mesmo revolvendo todas as entranhas das coisas, e abrindo-lhes todas as veias - a fim de ver-se jorrar dali para fora -, não alcançará essa felicidade; mas deve ter-se 
implementado antes em si mesma, para depois experimentar sua plena realização (HEGEL, 2014, p.178, grifo no original e grifo nosso).

Em outras palavras, partindo-se da compreensão da experiência da consciência já demonstrada, evidencia-se que a razão é já premissa da certeza da razão. O operar da racionalidade parte da forma necessária da certeza dessa racionalidade e escrutina, nas entranhas das coisas, um conteúdo racional. Assim, neste movimento, que podemos observar, como já demonstrado, na Filosofia cartesiana, "a razão, certa de sua realidade em si e para si, já não busca produzir-se como fim, em oposição à efetividade imediatamente essente, mas tem por objeto de sua consciência a categoria como tal" (HEGEL, 2014, p.271, grifo no original e grifo nosso). Ou seja, a finalidade da razão, no curso de sua efetividade, é a sua necessidade, ou seja, a racionalização mesma, a certeza desta racionalização e, consequentemente, a necessidade ou imperativo categórico.

Esta certeza aparece, para a ciência, como uma tautologia sagrada: a matemática. $\mathrm{O}$ fundamento lógico do argumento matemático é a defesa de sua validade. Este fundamento, entretanto, é vazio:

uma proposição tautológica; seja expressa como razão direta ou inversa, e que em sua expressão peculiar só quer dizer que "uma grandeza aumenta quando essa grandeza aumenta". O buraco e o material que o enche e é jogado fora são qualitativamente opostos, enquanto o real deles e sua grandeza determinada são, em ambos, uma só e a mesma coisa, de forma que sua oposição vazia de sentido vem a dar numa tautologia (HEGEL, 2014, p.197, grifo no original e grifo nosso).

Assim, para retomarmos o objetivo científico dos dois primeiros capítulos deste trabalho, a relação entre impermeabilização do solo e a distribuição dos óbitos associados às doenças do aparelho circulatório demonstra-se limitada nos termos de uma tautologia. Evidenciar esta tautologia nos termos da dissimulação da verdade apresenta-se como uma tarefa necessária, pois "o intento de encontrar séries de corpos que se organizem segundo esse paralelismo simples de dois lados, e exprimam a natureza essencial dos corpos segundo uma lei desses lados, deve ser considerado como um pensamento que desconhece sua tarefa própria e os meios através dos quais ela deva ser cumprida” (HEGEL, 2014, p.208, grifo nosso).

Este "pensamento que desconhece", a razão, quer possuir-se como objeto essente, como ser em-si e, ao fazê-lo, perde-se a si mesma para encontrar-se, dissimuladamente, objetivamente. Em outras palavras, 
[...] a razão quer encontrar-se e possuir-se como objeto essente, como modo efetivo, sensivelmente presente. De certo, a consciência dessa observação 'visa' e diz que não pretende experimentar-se a si mesma, mas, pelo contrário, a essência das coisas como coisas. [...] Soubesse tal consciência que a razão é igualmente essência das coisas e da consciência mesma, - e que a razão, em sua figura peculiar, só na consciência pode estar presente - então desceria às suas próprias profundezas, e buscaria a razão antes ali que nas coisas. Se já tivesse encontrado a razão no mais profundo de si mesma, essa seria novamente levada para fora, para a efetividade, a fim de nela contemplar sua expressão sensível; mas também a fim de tomá-la logo, como sendo essencialmente conceito (HEGEL, 2014, p.179, grifo no original e grifo nosso).

O conteúdo da forma racional, portanto, é a racionalidade mesma, o conceituar. Não há conteúdo racional sem a forma da racionalidade mesma, ou seja, sem a certeza, a fé, a crença na tautologia dissimulada da razão. O próprio movimento descendente em busca da racionalidade no interior da consciência é já a forma da racionalidade, que procura a si mesma no interior da consciência objetiva, ou seja, que almeja sua certeza para-si e em-si essente.

Neste sentido, a consciência racional é formalmente objetiva. Consequentemente, em um primeiro momento, “[...] deve tomar sobre si mesma o movimento peculiar do objeto, e por não ser ainda seu entendimento \{ de início, a consciência apenas reitera o em-si da objetividade universal , deve pelo menos ser sua recordação - a qual exprime de maneira universal o que na efetividade só está presente de maneira singular" (HEGEL, 2014, p.180, grifo nosso). A razão, portanto, é um jogador de meio-campo que se move entre o singular e o universal, a corda esticada, a haste do símbolo musical. Assim,

quando o instinto-da-razão chega à determinidade conforme sua natureza, que
consiste essencialmente em não ser para si, mas em passar ao seu oposto, então vai
em busca da lei e do seu conceito: procura-os, decerto, como efetividade essente. [...]
Para a consciência observadora a verdade da lei não está em si e para si mesma; está
na experiência, como no modo em que o ser sensível é para ela (HEGEL, 2014,
p.183, grifo no original e grifo nosso).

Evidencia-se, portanto, que a determinidade da razão reside na sua confirmação afirmação, positivação, conservação - na forma da objetividade essente, ou seja, em sua passagem ao seu oposto, em sua extrusão. A verdade da lógica formal reside, portanto, não pura e simplesmente nos termos matemáticos a que refere - estes dizem respeito apenas à validade do argumento em-si -, mas na totalidade da experiência da consciência, ou seja, no espírito. E “o espírito não é algo abstratamente simples, mas um sistema de movimentos, nos quais se distingue em momentos, embora permanecendo livre nessa distinção" (HEGEL, 2014, p.231, grifo nosso). Esta liberdade em que o espírito permanece é a totalidade dos 
movimentos, a verdade. Esta verdade é a negação da negação, a certeza de totalidade. O espírito é, em primeiro lugar, portanto, o saber do espírito como espírito. Em segundo lugar, é o espírito que se sabe como saber do espírito e que, portanto, diz: cogito ergo sum. A razão, no seio desta "Fenomenologia", é o operar racional enquanto certeza da racionalidade, ou seja, é razão engendrada como certeza da verdade enquanto saber da verdade.

Neste sentido, tomando-se como ponto essencial para o andamento desta reflexão o papel que a matemática exerce no operar da razão, ou mais precisamente, o papel ou momento do argumento lógico inferencial na certeza da racionalidade e, assim sendo, sua inegável determinação na negação da negação como momento da certeza, evidencia-se que, como afirmado previamente, o problema da metafísica não é o divino, mas a metafísica mesma, seu movimento, sua fenomenologia. Veja-se que a certeza, na ciranda espiritual de Hegel, é um meio-termo, um momento entre os momentos interior e exterior da consciência. Neste sentido, o número " $[. .$.$] une a vida indeterminada \{$ interior $\}$ com a vida efetiva $\{$ extrusada\}: simples como uma, e determinado como a outra. O que na primeira - no interior - estaria como número, deveria ser expresso a seu modo pelo exterior, como efetividade multiforme, gênero de vida, cor etc.; como toda multidão de diferenças, em geral, que se desenvolvem no fenômeno. (HEGEL, 2014, p.205, grifo no original e grifo nosso). Entretanto, “[...] o número é precisamente a determinidade de todo inerte, indiferente e morta na qual todo movimento e relacionamento se extinguem; e que rompeu a ponte com a vitalidade dos impulsos, com os hábitos, tipo de vida e todo o ser-aí sensível” (HEGEL, 2014, p.205, grifo no original e grifo nosso).

Assim sendo, o número é um impostor, ou melhor, uma impostura na forma da certeza. Esta impostura, por um lado, é a "determinidade de todo inerte", o sepulcro de sua vida; por outro lado é também a efetividade mesma desse sepulcro, cuja finalidade, sua conservação, é “[...] somente a luta de um esforço que tem de fracassar” (HEGEL, 2014, p.163). Tende a fracassar porque já é fracassada na negação da negação, no cerne e totalidade de seu movimento, no espírito. Ao tentar manter-se como certeza, desfaz-se em seu próprio movimento, "feito espumas ao vento" (LOPES, 1997).

Esse desfazer-se é o operar permanente da consciência-de-si que, em-si e para-si, sabese enquanto razão - cogito ergo sum. Este operar, portanto, é o desvanecimento do objeto essente e da essência objetiva. O saber desse desvanecimento é a necessidade da certeza da objetividade, que é a suprassunção do objeto essente na forma da essência objetiva para a consciência-de-si racional. A razão, portanto, é a fundamentação lógica da certeza do 
“independentemente", ou seja, é a certeza de que é possível, perante o desvanecimento do objeto, conservar a objetividade como essência, como saber do saber, como Saber Absoluto. A objetividade, portanto, é a chave do estranhamento: parte-se de um objeto estranhado (uma coisa para a certeza sensível), que é suprassumido enquanto objeto para a consciência-de-si racional no momento da percepção daquela por esta; suprassume-se, novamente, o referido objeto para que se constitua, na consciência, um entendimento racional do mesmo, ou seja, um entendimento que defina as partes constituintes desse objeto - e assim define novos objetos - e estabeleça as distinções entre este objeto e aquele objeto, ou ainda, um entendimento que é a diferenciação do objeto na forma da objetividade; a diferenciação é já a suprassunção do entendimento e sua ligação com o momento da certeza sensível: não basta dizer que esta página é constituída de moléculas, a empiria deve comprová-lo. Por sua vez, as moléculas, primeiro, são coisas constituintes desta página, que é, por sua vez, coisa constituinte deste livro, que é, por sua vez, coisa constituinte de uma fogueira, etc. As moléculas, entretanto, percebidas enquanto tais na constituição desta página, são diferenciadas 1) entre si e 2) em si: 1) uma molécula de água não é igual a uma molécula de gás oxigênio; 2) a molécula de água possui dois átomos de hidrogênio e um de oxigênio. Por sua vez, o átomo é uma coisa sensível para a percepção humana, e assim continua a ciranda.

Entretanto, nesse palavrório todo, nesse "continua a ciranda”, este continuar não é uma continuidade simples, um simples cirandar. É um produzir. Neste sentido, quando alguém descobre que existe uma relação entre massa e volume mensurável a partir de uma banheira cheia de água e sai por ai gritando "Eureca!", o que este alguém encontrou não foi simplesmente o que procurava. Ele produziu um achado. Ele achou que achou algo. Outra estória popular que nos auxilia na sedimentação desta questão diz respeito a um certo rapaz que, sentado sobre uma macieira, foi surpreendido pela queda de uma fruta. Este rapaz também achou que achou algo, mas esse achado é dissimulado, porque só pode ser-encontrado aquilo que é-procurado, aquilo que se tem certeza da existência. E a procura é já a negação da negação, a verdade dissimulada para a qual a certeza é objetiva e a objetividade, por sua vez, é efetiva.

Assim sendo, faz-se necessário constatar que o que é efetivo

[...] não é absolutamente o pensamento. O gênero como orgânico efetivo se faz apenas substituir por um representante $\{: 0$ número $\}$. [...] [Na verdade, porém,] o número antes designa a indiferença e a liberdade recíprocas do universal e do singular. O singular foi abandonado pelo gênero a uma diferença carente de essência - a diferença de grandeza; mas o singular mesmo, enquanto vivo, mostra-se também livre dessa diferença. A universalidade verdadeira, como já foi determinada, é aqui somente a essência interior, como determinidade da espécie, é a universalidade formal. Em contraste com ela, coloca-se aquela universalidade verdadeira ao lado da 
singularidade, a qual por isso é uma singularidade vivente, que mediante o seu interior se põe acima de sua determinidade como espécie. Entretanto, essa singularidade não é, ao mesmo tempo, o indivíduo universal no qual a universalidade tenha igualmente uma efetividade exterior: o indivíduo universal incide fora do orgânico vivente (HEGEL, 2014, p.210 - 211, grifo no original e grifo nosso).

O indivíduo universal, portanto, é uma externação do singular vivente, incide fora deste. A universalidade, neste sentido, é o movimento do rememorar externado que, ao mesmo tempo, é em-si e para-si. É em-si um conteúdo determinado, indiferente. Por outro lado, parasi aparece como orgânico vivente, universalidade verdadeira comprovada pela singularidade vivente. Esta universalidade é a substância rememorada na forma da singularidade vivente. O indivíduo universal é o interior substancial desta singularidade, que incide fora dela e constitui seu conteúdo substancial interno. Assim, "sendo já um pensado, o conteúdo é propriedade da substância; já não é o ser-aí na forma do ser-em-si, porém, é somente o que - não sendo mais simplesmente o originário nem o imerso no ser-aí, mas o Em-si rememorado - deve ser convertido na forma do ser-para-si” (HEGEL, 2014, p.40, grifo no original).

A dialética do Saber Absoluto, em seu movimento estranhado "[...] compreendido como [estado de] repouso, o que nele se diferencia e se dá um ser-aí particular é conservado como algo que se rememora, cujo ser-aí é o saber de si mesmo; como esse saber é também imediatamente ser-aí" (HEGEL, 2014, p.50, grifo no original). Assim, a experiência da consciência, sua Fenomenologia, consiste no movimento do universal para o singular vivente e vice-versa, em sua forma estranhada, objetiva.

\footnotetext{
É desse modo que a consciência, entre o espírito universal e sua singularidade, ou consciência sensível, tem por meio-termo o sistema das figurações da consciência, como uma vida do espírito ordenando-se para [constituir] um todo: é o sistema considerado nesta obra \{na "Fenomenologia do Espírito"\}, e que, como história do mundo, tem seu ser-aí objetivo. Mas a natureza orgânica não tem história: de seu universal - a vida precipita-se imediatamente na singularidade do ser-aí; e os momentos unificados nessa efetividade - a determinidade simples e a vitalidade singular - produzem o vir-a-ser apenas como movimento contingente \{acaso, acidental\}, no qual cada um desses momentos é ativo em sua parte, e no qual o todo é conservado. Porém, essa mobilidade é, para si mesma, limitada somente a seu [próprio] ponto, porque nele o todo não está presente; e não está presente porque aqui não está como todo para si. Assim, a razão observadora só chega na natureza do orgânico à intuição de si mesma como vida universal em geral (HEGEL, 2014, p.212, grifo no original e grifo nosso).
}

A consciência, portanto, "fala" de si a partir de um sistema de figurações engendrado como meio-termo entre o singular e o universal, enquanto forma universal de externação desta singularidade substancial, enquanto consciência sensível - ser-aí objetivo. Por outro lado, em- 
si esta consciência, em sua experiência, é a conservação de si mesma enquanto universalidade formal cujo conteúdo é a certeza de sua substancialidade. Esta certeza é o movimento mesmo de intuição de si mesma, alcançada pela razão observadora na natureza orgânica como vida universal em geral, como ser genérico. Destarte, o movimento evanescente do orgânico suprassumido na forma de sua negação, da individualidade universal, é a impostura da razão, a afirmação de si mesma como certeza da universalidade em geral face ao desvanecimento da singularidade efetiva-vivente cujo meio termo é o sistema de figurações do espírito, o movimento de rememoração, ou seja, esta universalidade é a certeza do desvanecimento - da incerteza - como necessidade da forma da objetividade externada nesta forma mesma. Portanto, no movimento de negação da negação, ou da afirmação desta objetividade como em-si que é para-si, a certeza é a necessidade como finalidade, ou seja, é necessária para que a objetividade - o sistema de figurações do espírito - se mantenha para a consciência como experiência efetiva face ao desvanecimento.

A conservação do todo, portanto, é o mistério das cousas que, para-si desvanecem e, ao desvanecerem, permanecem eternas em-si, em sua forma universal cujo conteúdo singular não pode negar absolutamente esta universalidade. Neste sentido, "as cousas são o único sentido oculto das cousas" (PESSOA, 2017, p.21), ou seja, o mistério é a objetividade mesma, seu movimento enquanto figuração do espírito, enquanto ser-aí deste espírito que é em-si evanescente. Por outro lado, o desvanecimento desta objetividade para-si essente é a certeza da universalidade cujo conteúdo é o em-si externado na forma desta objetividade mesma.

O movimento do rememorar, portanto, é a igualdade do em-si e do para-si na forma do si.

\footnotetext{
Enquanto sua perfeição \{do Si\} consiste em saber perfeitamente o que ele é - sua substância - esse saber é então seu adentrar-se em si, no qual o espírito abandona seu ser-aí e confia sua figura à rememoração. No seu adentrar-se-em-si, o espírito submergiu da noite de sua consciência-de-si; mas nela se conserva seu ser-aí que desvaneceu; e esse ser-aí suprassumido - o [mesmo] de antes, mas recém-nascido [agora] do saber - é o novo ser-aí, um novo mundo e uma nova figura-de-espírito (HEGEL, 2014, p.530-531, grifo no original e grifo nosso).
}

O Si, portanto, é o saber do ser que se sabe enquanto saber, é o movimento externado do adentrar-se em si na forma da rememoração. Rememorar é saber, é reflexão que conserva o ser-aí desvanecido na forma da suprassunção, no movimento de negação da negação. Para Hegel, neste movimento de negação do desvanecimento como forma de afirmação do saber surge um novo ser-aí, uma nova figura do espírito: o espírito na figura do saber do espírito, que se sabe como saber. Assim, “[...] a rememoração é o interior, e, de fato, 
a forma mais elevada da substância. Portanto, embora esse espírito recomece desde o princípio sua formação, parecendo partir somente de si, ao mesmo tempo é de um nível mais alto que [re]começa" (HEGEL, 2014, p.531, grifo nosso).

Para Hegel, portanto, a efetividade mundana é uma herança produzida, cujo rememorar é a reflexão capaz de evidenciar os sucessivos estágios do reinado espiritual. Esta reflexão é o movimento cujos momentos são os reflexos, o sistema de figuração do espírito. Esse sistema é o engendrar da certeza da igualdade do em-si e do para-si na forma do si. A linguagem da certeza é a razão. Na ciência, o operar da razão é lógico, se manifesta como argumento lógico. Assim, a efetividade evanescente substancial, a verdade essencial universal e a certeza moral do ser constituem a objetividade como movimento dialético do espírito que se sabe como saber do espírito.

\begin{abstract}
O reino-dos-espíritos, que desse modo se forma no ser-aí, constitui uma sucessão na qual um espírito sucedeu a um outro, e cada um assumiu de seu antecessor o reino do mundo. Sua meta é a revelação da profundeza, e essa é o conceito absoluto. Essa revelação é, por isso, o suprassumir da profundeza do conceito, ou seja, sua extensão, a negatividade desse Eu que-em-si-adentra: negatividade que é sua extrusão ou substância. Essa revelação é seu tempo, em que essa extrusão se extrusa nela mesma, e desse modo está, tanto em sua extensão quanto em sua profundeza, no Si. A meta - o saber absoluto, ou espírito que se sabe como espírito - tem por seu caminho a rememoração dos espíritos como são neles mesmos, e como desempenham a organização de seu reino. Sua conservação, segundo o lado de seu ser-aí que se manifesta na forma da contingência, é a história; mas segundo o lado de sua organização conceitual, é a ciência do saber que-se-manifesta. Os dois lados conjuntamente - a história conceituada $\{$ a contingência determinada cientificamente - formam a rememoração e o calvário do espírito absoluto; a efetividade, a verdade e certeza de seu trono, sem o qual o espírito seria a solidão em vida [...] (HEGEL, 2014, p.531, grifo no original e grifo nosso).
\end{abstract}

A Fenomenologia do Espírito, portanto, procura revelar, na constituição do movimento de reflexão, o rememorar mesmo desta constituição como um movimento de engendramento. Neste sentido, a religião, para Hegel, ocupa um lugar de relevância neste movimento, enquanto processo de produção desta reflexão que rememora. A questão, portanto, não é religiosa, nem está centrada na figura de Deus, mas é o próprio movimento de reflexão, o qual Hegel explora em três formas de religiosidade: a religião natural, a religião da arte e a religião manifesta (HEGEL, 2014, p.447-517).

Na religião natural, a consciência-de-si é reflexo contingente, figura que aparece como uma imagem em uma poça d'água. A figura da consciência-de-si aparece como uma impostura do acaso, representado pela poça d'água nesta analogia. A poça d'água é, portanto, forma contingente, que recebe a luminosidade como seu conteúdo. No engendrar da sociedade da 
poça d'água, o aparecimento do artesão é o aparecimento da consciência-de-si que passa à produção da forma da poça como receptáculo da luminosidade. A luminosidade, entretanto, é a simultânea escuridão, pois o artesão tão somente projeta o receptáculo para o espírito, não é consciência-de-si que se sabe como espírito que se sabe como consciência-de-si.

\begin{abstract}
A primeira forma, por ser a imediata, é a forma abstrata do entendimento, e a obra não está ainda, nela mesma, preenchida pelo espírito. Os cristais das pirâmides e dos obeliscos, simples combinações de linhas retas com superfícies planas e proporções iguais das partes - em que é eliminada a incomensurabilidade da curva - são os trabalhos desse artesão da rigorosa forma. Devido à mera inteligibilidade da forma, ela não é sua significação nela mesma; não é o Si espiritual. As obras, assim, só recebem o espírito; ou o espírito em si, como um espírito estranho e separado, que abandonou sua compenetração viva com a efetividade, e [como é] ele mesmo morto, se aloja nesses cristais desprovidos de vida; ou então, as obras se referem externamente ao espírito; - como a um espírito que "é-aí" exteriormente, e não como espírito; como à luz nascente que projeta sobre as obras sua significação (HEGEL, 2014, p.459, grifo nosso).
\end{abstract}

O aparecimento do artesão é o nascimento do saber. A verdade, neste engendramento do saber, é contingencial e obscura. O saber é a luminosidade que emana desta obscuridade e que integra a forma como luminosidade, como figura que aparece no interior da poça d'água. O artesão, por sua vez, ao produzir o receptáculo para a figuração, semeia a superação desta primeira forma de religiosidade, pois ao produzir uma superfície que pudesse servir de receptáculo para a luminosidade, produz também o saber de sua produção. Este saber não se distingue absolutamente do artesão, ou seja, este saber é o engendrar do artesão mesmo. Este engendrar é a semente da suprassunção desta primeira forma do espírito.

Ao produzir a superfície reflexiva como anteparo para o reflexo, o artesão produz também o receptáculo para seu próprio reflexo, para a reflexão de si mesmo. Neste movimento, engendra a distinção entre saber e verdade. A contingencialidade do saber é sua determinidade enquanto figura que aparece na superfície reflexiva produzida. A produção do anteparo é a produção de sua reflexão sobre esta figura mesma, que não independe do anteparo. Este, por sua vez, não é apenas o saber do artesão que o produziu, mas a possibilidade desta produção, dada pela verdadeira natureza dos elementos que o constituem. A distinção entre saber e verdade, portanto, é o cerne da religião da arte:

O espírito elevou sua figura, na qual é [presente] para sua consciência, à forma da consciência mesma; e produz para si uma tal forma. O artesão abandonou o trabalho sintético, o combinar de formas heterogêneas do pensamento e do natural: quando a figura adquiriu a forma da atividade consciente-de-si, o artesão se tornou trabalhador espiritual (HEGEL, 2014, p.462, grifo no original e grifo nosso). 
Assim, no produzir do artesão reside um duplo-engendramento: ele produz a obra e a si mesmo como consciência-de-si. A obra, entretanto, não aparece para esta consciência apenas como saber do artesão, mas também como verdade. O saber do artesão é o saber que produz para si uma tal forma de reflexão enquanto saber; mas é no reino divino da verdade que reside a possibilidade do mundo do anteparo. Neste sentido, na religião da arte, por um lado, a consciência-de-si é saber, logos; por outro lado, a verdade opera independentemente deste saber. O saber se sabe como advertência em relação à verdade, mas não como verdade. Neste sentido, o saber sabe a verdade como o não revelado e, portanto, sabe que não pode estar certo do saber sobre a verdade e que, portanto, a certeza no saber é digna de punição.

Seguindo o deus que-sabe, antes apreendeu o não revelado, e \{a consciência $\}$ é castigada por ter confiado no saber cuja ambiguidade - pois esta é sua natureza deveria estar presente também para essa consciência, e servir-lhe de advertência. $\mathrm{O}$ frenesi da sacerdotisa, a figura desumana das bruxas, a voz da árvore, do pássaro, o sonho, etc., não são modos em que a verdade apareça, mas sinais de advertência do embuste, da irreflexão, da singularidade e contingência do saber. Ou - o que é o mesmo - a potência oposta, ofendida pela consciência, está presente como lei promulgada e direito vigente: seja a lei da família, ou do Estado. A consciência seguiu, ao contrário, o próprio saber, e ocultou a si mesma o [que era] manifesto. Entretanto, a verdade das potências do conteúdo e da consciência, que se enfrentam uma à outra, é o resultado de que ambas têm igual direito, e por isso em sua oposição que o agir produz - têm a mesma falta-de-direito (HEGEL, 2014, p.486, grifo no original e grifo nosso).

O saber, portanto, é ambíguo. É saber que sabe que o reflexo que aparece na forma produzida para a reflexão pode ser enganoso. $\mathrm{O}$ saber é, antes, incerteza da certeza. $\mathrm{O}$ artesão aparece como consciência-de-si que está presa em uma caverna e para o qual toda a verdade não é senão mistério sombrio. O sair da caverna é o aparecimento do saber como saber da universalidade da forma, como saber formal que emerge da contingência sombria como revelação da natureza ambígua do saber mesmo - ou dialética. Tal revelação agride o olhar do artesão, e este sofre, pois o destino não lhe pertence, ou seja, a consciência-de-si sabe que o destino não pode ser modificado, pois o acaso leva sempre ao mesmo lugar inalterado, um lugar não-sabido, independente do saber. Se nem mesmo a ira de Aquiles pôde mudar o destino da guerra, como Édipo poderia evitar seu terrível futuro? Neste sentido, a substância emerge da suprassunção da luminosidade e toma a forma do saber da substância. Este saber, entretanto, sabe a essência como 
honra igual, e, portanto, a inefetividade indiferente de Apolo e da Erínia, e o retorno de seu entusiasmo e atividade ao Zeus simples. Esse destino completa o despovoamento do céu - a combinação, carente-de-pensamento, da individualidade e da essência - uma combinação pela qual o agir da essência aparece como um agir inconsequente, casual, indigno de si; pois a individualidade, só superficialmente unida à essência, é a individualidade inessencial (HEGEL, 2014, p.486, grifo nosso).

Neste sentido, a individualidade sabe que, por mais que seja advertida sobre o destino, não pode sabê-lo como destino seu, como causalidade administrável pelo saber. A individualidade está jogada ao acaso, ainda que o saiba, pois o saber não é a verdade. Assim sendo, na religião da arte, a substância é o saber determinado e, portanto, também é não-saber, porquanto seja apenas advertência; a essência é o movimento contingente do destino; e a consciência-de-si é o meio termo sofredor das consequências da união superficial da essência e da substância. Esta individualidade, portanto, não é o saber de si como essência. É saber inessencial, que nega a si mesmo a verdade. Este negar é o engendrar do crepúsculo dos deuses da religião da arte, a suprassunção desta forma de religião.

\begin{abstract}
A divisão, de que parte o espírito do artesão - a do ser-em-si, que se converte no material que ele elabora, e do ser-para-si, que é o lado da consciência-de-si que trabalha - essa divisão em sua obra se tornou objetiva. Seu esforço ulterior deve tender a suprassumir essa separação da alma e do corpo; e revestir e a modelar a alma nela mesma; e, por sua vez, a infundir alma no corpo. Os dois lados, ao serem aproximados um do outro, conservam com isso respectivamente a determinidade do espírito representado \{ser-essência-obscura-luminosa\}, e do envoltório que o reveste \{material trabalhado\}: sua unidade consigo mesmo contém essa oposição da singularidade e universalidade (HEGEL, 2014, p.459, grifo no original e grifo nosso).
\end{abstract}

Assim, nesta oposição, já na religião natural, está semeada a suprassunção do divino no próprio processo de produção do corpo humano como anteparo para a alma, para a reflexão. $\mathrm{Na}$ religião da arte, a representação artística do divino no teatro é a afirmação de sua mundanidade na própria corporeidade humana. Esta afirmação, entretanto, não é imediata. $\mathrm{O}$ divino é mundanizado no engendrar mesmo do teatro, da arte, e o humano é elevado à representação do divino. Os espectadores, por sua vez, aparecem como momento indiferente do representar, do destino.

Perante essa consciência espectadora como terreno indiferente do representar, o espírito não aparece em sua multiplicidade dispersa, mas no desdobramento simples do conceito. A substância do espírito mostra-se, pois, somente desmembrada em suas duas potências extremas \{abstrato-efetivo\}. Essas essências universais elementares são, ao mesmo tempo, individualidades conscientes-de-si: - heróis que põem sua consciência em uma dessas potências, nela possuem a determinidade do caráter, e 
constituem sua ativação e efetividade. Essa individualização universal desce ainda, como já se mencionou, à efetividade imediata do autêntico ser-aí [do ator] e se apresenta a uma multidão de espectadores que têm no coro sua cópia, ou melhor, sua própria representação exprimindo-se [a si mesma] (HEGEL, 2014, p.482483, grifo no original e grifo nosso).

Destarte, os espectadores são representados no teatro mesmo como o coro, como a manutenção do saber do destino, como representar do cantar efetivo que é a garantia de personificação dos deuses e dos heróis na "efetividade imediata do autêntico ser-aí", no ator. A atuação, por sua vez, apresenta uma duplicidade: de um lado, o ator é a representação do herói e da divindade; de outro lado, é consciente-de-si como distinto da máscara. Essa distinção é suprassumida pela atuação do coro: o hino eleva o ser-aí efetivo à forma da universalidade linguística. O hino é ser-aí efetivo que, no movimento do desvanecimento do cantar propriamente dito, eleva a distinção múltipla das vozes que compõem o coro à universalidade que suprassume essa distinção:

[...] A consciência-de-si permanece imediatamente junto a si no objetivar-se de sua essência \{na linguagem\}. Estando assim, dentro de sua essência, junto a si mesma, é puro pensar; ou é a devoção cuja inferioridade tem ao mesmo tempo seu ser-aí no hino. [...] A devoção, que em todos se acende, é a correnteza espiritual, que na multiplicidade das consciências-de-si é cônscia de si como de um igual agir de todos, e como um ser simples (HEGEL, 2014, p.467-468, grifo no original e grifo nosso).

Ou seja, considerando-se a multiplicidade efetiva das consciências-de-si que compõem o coro, o engendrar desta forma de figuração do espírito é o engendrar de um ser simples cuja finalidade é a garantia de igualdade na diferença. O professar da fé em uníssono é o engendrar da universalidade na forma do logos, da linguagem enunciadora de cuja efetividade suprassumida nasce o ser em geral, a consciência-de-si universal, a singularidade universal suprassumida da individualidade viva.

O verdadeiro ser-aí consciente-de-si, que o espírito recebe da linguagem - que não é a linguagem da consciência-de-si estranha e, portanto, contingente, não universal é a obra de arte que acima vimos: [o hino]. Ele está em contraste com o caráter-decoisa da estátua. Como a estátua é um ser-aí estático, o hino é o ser-aí evanescente; como nesse ser-aí estático a objetividade deixada livre carece do Si imediato próprio, assim no hino, ao contrário, fica a objetividade demasiado encerrada no $\mathrm{Si}$, chega demasiado pouco à figuração; e, tal como o tempo, imediatamente já não "é-aí" quando "é-aí". \{Portanto\} O culto combina o movimento de dois lados, em que abandonam mutuamente sua determinação diferente, a figura divina movida no puro elemento sensível da consciência-de-si, e a figura divina em-repouso no elemento da coisidade; e [assim] chega ao ser-aí a unidade que é o conceito da essência divina. No culto, o Si se proporciona a consciência da descida da essência 
divina desde o seu além até ele; desse modo, a essência divina que anteriormente é o inefetivo e somente objetivo, adquire a efetividade própria da consciência-de-si (HEGEL, 2014, p.470, grifo no original e grifo nosso).

O culto, portanto, é a produção da mundanidade do divino - e de sua objetivação. Esta produção é, por um lado, a descida da essência divina desde o seu além até o consciência-de-si sensível, efetiva. Por outro lado, é a elevação da consciência-de-si à universalidade. Assim, o que na religião natural aparecia como a emanação da luminosidade desde a obscuridade misteriosa até a forma contingente, representada pelo aparecimento da figura da coisa como consciência da essência absoluta - a poça d'água como anteparo para a imagem refletida -, na religião da arte, surge a consciência da essência absoluta na forma da consciência-de-si, ou seja, a imagem refletida agora é o reflexo da consciência-de-si consciente de si como unidade de si com a essência universal. O reflexo é produzido como objetividade artística - a estátua, o teatro - cuja finalidade é ser anteparo para o reflexo evanescente - o hino. O teatro é o espelho produzido como arte cujo reflexo é o aparecimento da consciência-de-si, no coro, para a multidão das consciências-de-si espectadoras. A consciência-de-si vê-se como consciência-desi, como saber. Sabe o reflexo como obra, como produto. Sabe, entretanto, da incerteza desse saber perante à verdade: o saber da universalidade é trágico e a ironia da tragédia do saber é a comédia.

A ironia da comédia é o movimento da racionalidade do pensar. Este movimento

[...] liberta a essência divina de sua figura contingente, e em contraste com a sabedoria carente-de-consciência do coro - que aduz máximas éticas de todo tipo e faz vigorar uma multidão de leis e conceitos determinados de deveres e direitos eleva-os às ideias simples do belo e bom. O movimento dessa abstração é a consciência da dialética, que essas máximas e leis nelas possuem, e por isso a consciência do desvanecer da validade absoluta sob a qual apareciam antes. Enquanto desvanece a determinação contingente e a individualidade superficial que a representação atribui às essencialidades divinas - elas, segundo seu lado natural, só têm ainda a nudez de seu ser-aí imediato: são nuvens, uma névoa evanescente como aquelas representações (HEGEL, 2014, p.489, grifo no original e grifo nosso).

A essencialidade, portanto, da emanação luminosa misteriosa na forma da coisa é suprassumida em uma essencialidade pensada. No engendrar desta suprassunção, o mistério da imagem refletida na poça d'água, ou da luz do sol para a qual as pirâmides serviriam de anteparo, de receptáculo, é suprassumido na forma da divindade humana cantada pelo coro, ou seja, é suprassumido enquanto pensamento da divindade, enquanto ideia sustentada pela consciência-de-si como saber da divindade e como saber do saber da divindade, como saber 
que se sabe produtor da reflexão da divindade, da imagem da divindade. Esta imagem, posta na própria corporeidade da consciência-de-si efetiva, é a unificação contraditória entre consciência e consciência-de-si: suprassunção da individualidade viva na forma da singularidade universal e suprassunção da universalidade em geral na forma da singularidade efetiva.

Destarte, o aparecimento da figura do sujeito é o engendrar da figura do espírito propriamente dito enquanto reflexão. Pensando em termos de uma analogia, o que na religião natural aparecia como receptáculo para a luminosidade essencial, como coisa cuja finalidade era a reflexão da luminosidade, como um espelho d'água, uma poça cujo desígnio é ser receptáculo para o conteúdo refletido; na religião da arte aparece como suprassunção deste aparecimento anterior: como produzir efetivo e saber deste produzir do reflexo dos deuses como reflexos humanos. O teatro é o plano polido simples no qual aparece, no mesmo plano, os heróis, os deuses e o coro. O hino é a suprassunção da voz do coro, que é a representação do espectador. Esta suprassunção é o movimento da consciência-de-si, é saber. Este saber, entretanto, é temporal, névoa evanescente, cantar efetivo que se desmancha no ar. Por outro lado, o cantar é o rememorar, é a negação do desvanecimento e a elevação do saber à universalidade. A consciência-de-si não é mais, como na religião natural, acidentalidade, reflexo que aparece acidentalmente em uma poça d'água; é consciência-de-si enquanto sujeito que produz o reflexo, a arte, o culto, a religião. É consciente também de sua limitação, pois sabe a distinção entre consciência e consciência-de-si, entre ser simples, em geral, e indivíduo efetivo vivo. Na religião da arte, portanto, aparece a figura da consciência-de-si como saber de si mesma, como certa de si, como sujeito desta certeza.

\footnotetext{
O espírito avançou da forma da substância à forma do sujeito através da religião da arte, pois ela produz a figura do espírito e assim põe nela o agir ou a consciênciade-si - que na substância aterradora só desvanece, e que na confiança não se apreende a si mesma. Essa encarnação da essência divina começa na estátua, que só tem nela a figura externa do $\mathrm{Si}$, enquanto o interior - sua atividade - incide fora dela. No culto, porém, os dois lados tornaram-se um; no resultado da religião da arte, essa unidade em sua plenitude passou também ao mesmo tempo, ao extremo do $\mathrm{Si}$. No espírito, que é totalmente certo de si na singularidade da consciência, toda a essencialidade soçobrou. A proposição que enuncia essa leveza soa assim: $o$ Si é a essência absoluta. A essência, que era substância, e em que o Si era a acidentalidade, afundou até ao [nível do] predicado, e o espírito perdeu sua consciência nessa consciência-de-si, à qual nada se contrapõe na forma da essência. Essa proposição: " $o$ Si é a essência absoluta" pertence, como é evidente, ao espírito efetivo, ao não religioso (HEGEL, 2014, p.490, grifo no original e grifo nosso).
}

Assim, na religião da arte, o aparecimento do saber como efetividade humana é o engendrar de uma universalidade na qual esse saber efetivo é suprassumido na forma da 
universalidade. Esse momento de suprassunção é a perda que o espírito sofre: ele perde sua consciência na consciência-de-si, ou seja, a consciência não é mais um emanar da luminosidade, mas uma efetividade que se produz como o refletir dessa espiritualidade, como saber dessa espiritualidade, como consciência-de-si refletida na espiritualidade, como consciência que é reflexo dessa consciência-de-si e como consciência-de-si que é reflexo dessa espiritualidade. Este reflexo é o momento do desvanecimento, é o cantar, o hino, o ato teatral; o saber da reflexão é a manutenção do reflexo como produto, como obra, como objeto, anteparo, espelho cuja finalidade é a manutenção do saber face ao desvanecimento.

Na religião da arte, o engendrar do Si como essencialidade absoluta é já a semente da religião manifesta. A consciência-de-si e o em-si da consciência, no movimento do produzir efetivo do saber, é o engendrar do sujeito moral, ou seja, é o efetivo produzir de uma igualdade da consciência-de-si e do em-si objetivo da obra de arte. O em-si efêmero do hino é suprassumido pela consciência-de-si que sabe o hino como momento evanescente. Esta suprassunção é a negação desta efemeridade em nome da conservação do espírito na forma da objetividade, na forma da reflexão mesma, pois tanto o espelho quanto o ato do reflexo efetivos são efêmeros. Assim, na religião da arte, o espelho é a universalidade efetiva, um povo, e o reflexo é a consciência-de-si efetiva, é cidadão de um povo. Estas efetividades desvanecem, mas a analogia permanece na efetivação mesma do saber, ou seja, permanece o movimento que aqui figuramos nos termos dessa analogia: "Como substância efetiva, o espírito é um povo; como consciência efetiva, é cidadão do povo" (HEGEL, 2014, p.302, grifo no original).

Destarte, na religião da arte estão dadas todas as condições para o nascimento do espírito consciente de si como espírito.

\footnotetext{
O círculo das produções da arte abrange as formas das extrusões da substância absoluta, a qual está na forma da individualidade, [a] - como uma coisa, como objeto essente da consciência sensível; [b] - como a linguagem pura, ou o vir-a-ser da figura, cujo ser-aí não sai do Si, e é objeto puramente evanescente; [c] - como unidade imediata com a consciência-de-si universal, em sua inspiração, e como unidade mediatizada no agir do culto; [d] - como a bela corporeidade do-Si, e, finalmente, [e] - como o ser-aí sublimado na representação, e sua expansão em um mundo que afinal se concentra na universalidade, que é, igualmente, a pura certeza de si mesmo (HEGEL, 2014, p.493, grifo no original e grifo nosso).
}

Assim, a produção do sujeito como o momento do saber é o movimento de extrusão da substância, que se torna consciência-de-si. Por sua vez, a consciência-de-si se extrusa no ato efetivo do saber, e se converte em coisidade, em Si universal, essencialidade. 
verdadeira unificação. A extrusão da substância, seu converter-se em consciênciade-si, exprime a passagem ao oposto: a passagem, carente-de-consciência, da necessidade; ou seja, exprime que a substância é em si consciente-de-si. Inversamente, a extrusão da consciência-de-si exprime que ela é em-si a essência universal, ou - porque o Si é o puro ser-para-si, que em seu contrário fo ser-aí reificado da substância\} permanece junto a si - [exprime] que é para o Si que a substância é consciência-de-si, e justamente por isso é espírito. Desse espírito, que abandonou a forma da substância e entra no ser-aí da figura da consciência-desi, pode-se dizer [...] que o espírito tem uma mãe efetiva, mas um pai em-si-essente. Com efeito, a efetividade ou a consciência-de-si, e o Em-si como a substância, são os seus dois momentos, pela extrusão mútua dos quais - tornando-se cada um deles o outro - o espírito entra no ser-aí como sua unidade (HEGEL, 2014, p.494, grifo no original e grifo nosso).

Hegel evidencia nesta passagem, portanto, que a efetividade é o momento do operar da consciência-de-si propriamente dita. Este operar - engendrar ou produzir - é a mãe do espírito. A efetividade cônscia de si, a atuação imediata do sujeito, portanto, é o gestar do espírito. Por outro lado, o em-si do espírito é a substância paterna, o pai em-si-essente. Da cópula desses momentos, o espírito entra na imediatez do ser-aí: ele aparece como em-si e parasi, ou seja, como consciência-de-si cujo saber evanescente gesta para-si a substancialidade emsi. A consciência-de-si efetiva é mãe solteira de um pai universal. A igualdade destes momentos é o movimento da cópula: o pai universal precisa se singularizar na forma da individualidade consciente-de-si e, ao mesmo tempo, esta individualidade efetiva cônscia-de-si é suprassumida na forma da universalidade. Este duplo movimento é a certeza da igualdade garantida pelo ato de cópula, pelo hino, pela arte, pela ação da consciência-de-si. Esta ação, entretanto, tem uma fundamentação universal: o Si, que está para a "Fenomenologia do Espírito" como o sinal de igualdade (=) está para a matemática. Entretanto, esta igualdade não é formal e positiva, mas é o processo de produção desta afirmação de igualdade, desta certeza, como negação da negação. Ademais, é o evidenciar desta produção como produção do Saber Absoluto.

Assim sendo, na religião manifesta o espírito alcança o saber de si como verdade, como imediatez aí-essente. O deus desta forma religiosa aparece imediatamente no Si, como um “[...] efetivo homem singular, sensivelmente intuído; só assim ele é consciência-de-si” (HEGEL, 2014, p.496, grifo no original e grifo nosso). Esse deus fala: "eu sou o que sou". O ser substancial universal aparece como imanente, como ser-aí que enuncia, que sabe que é. Assim, evidencia-se que, na religião manifesta, "o espírito é conhecido como consciência-de-si, e é imediatamente revelado a esta por ser ela mesma. A natureza divina é o mesmo que a humana, e é essa unidade que é intuída" (HEGEL, 2014, p.497, grifo no original e grifo nosso). Em outras palavras, a consciência-de-si é cônscia do espírito como saber, como consciência- 
de-si. Assim, por outro lado, sabe o espírito como a si mesma, como ser que enuncia que sabe que é. A substância divina e a humana são a mesma. O homem é reflexo semelhante ao seu deus. Independentemente da forma do anteparo argênteo, o conteúdo é a afirmação da certeza da igualdade, da unidade do saber e da verdade. Esta certeza, entretanto, não se sabe como certeza ainda, ou seja, ela é certa do porquê da igualdade, mas não do como desta igualdade. Em outras palavras, o espírito da religião manifesta “[...] não tem ainda a consciência sobre o que ele é; é a consciência-de-si espiritual, que não é, como esta consciência-de-si, objeto para si”" (HEGEL, 2014, p.515), ou seja, a consciência-de-si, na religião manifesta, é objeto para si, mas o espírito ainda não aparece como objeto para a consciência-de-si. A consciênciade-si se sabe, ao mesmo tempo, como ser imediato e como abstração pura. Esta duplicidade é constituída pelos momentos do movimento de engendramento da igualdade do espírito e da consciência-de-si: em seu ser imediato, a consciência-de-si é a imediatez da essência, é-aí; enquanto puro pensar, é a certeza da permanência e negação do desvanecimento da imediatez do ser, é substancialidade.

Assim,

o que se denomina consciência sensível é justamente essa abstração pura: é esse pensar, para o qual o ser é o imediato. O ínfimo é, ao mesmo tempo, o supremo; o manifesto, que aparece completamente na superfície, é justamente nisso o mais profundo. Que a essência suprema seja vista, ouvida, etc., como uma consciência-desi essente, isso é, pois, de fato, a plena realização de seu conceito; e por meio dessa realização plena a essência "é-aî" tão imediatamente como ela é essência (HEGEL, 2014, p.497-498, grifo no original e grifo nosso).

Assim, a objetividade se constitui nessa duplicidade da essência que "é-aí tão imediatamente como ela é essência", ou seja, que é-aí tão imediatamente quanto não é, que é o ser-aí da essência. Assim, dissemelhantemente do papel do oráculo ou das bruxas na religião da arte, cujas falas são ambíguas e enganadoras, haja vista a distinção entre saber e verdade, na religião manifesta, a verdade é divina e providencial, pois deus é a manifestação do bem. Esta divindade é a garantia da harmonia entre os olhos da consciência-de-si viva e a sua imagem refletida no espelho. Esta imagem é verdadeira pois é a semelhante a deus e este deus não é senão a manifestação consciente-de-si da verdade. A consciência-de-si sabe esta manifestação como manifestação consciente-de-si, ou seja, sabe sua igualdade com deus, pois é feita à sua imagem e semelhança. Entretanto, esta igualdade é a negação da imediatez da consciência-desi, de sua singularidade individual. É também o estranhamento da consciência-de-si em relação à essência divina, pois, ainda que se saiba como em unidade com deus, sabe também que não é 
deus, que não pode conceber deus, pois é limitada, é evanescente, é imperfeita. A certeza da perfeição é a certeza da incerteza da consciência-de-si. É a impossibilidade de se tomar o espírito como objeto da consciência-de-si, ainda que esse espírito seja cônscio-de-si, seja a voz que diz "eu sou".

Assim, na religião natural engendra-se o espírito como coisa, ou seja, a reflexão nasce como não-saber, como extrusão do espírito, como reflexo natural da coisa na coisa, como imagem produzida aleatoriamente no anteparo ou receptáculo do espírito. A tentativa de se manter a imagem, a representação, é o engendramento do culto, do hino, do cantar. Para manter a iluminação, é preciso manter o fogo aceso. O manter o fogo acesso aparece, nesta forma de religiosidade, como ritual. O ritual é a obra. A obra é obra de um artesão. O produzir da obra é o produzir do saber da obra. O nascimento do saber, portanto, marca o crepúsculo da religião natural e o amanhecer da religião da arte.

O culto à imagem é a produção da manutenção da imagem, é a produção do espelho em substituição à poça d'água. Esta produção é o saber produzir, é a produção desse saber, do sujeito desse saber, do artista. $\mathrm{O}$ engendramento do saber é a produção da consciência-de-si que se sabe como sujeito do saber, ou seja, que é cônscia-de-si, que se sabe como consciência-desi. Na religião da arte, portanto, o produzir da arte na forma da religiosidade é o produzir do ritual religioso como garantia de efetivação da obra, ou seja, como garantia de efetivação do saber (consciência-de-si) pela verdade (essência absoluta).

A consciência-de-si se sabe como atuante em sua efetivação e, por isso, é responsável por esta atuação e, consequentemente, sofre com as limitações desse saber face ao destino trágico. O teatro, na religião da arte, é a representação desta consciência-de-si e da consciência de seu mundo. Assim, o culto à imagem refletida na poça d'água passa à produção do espelho como anteparo artístico, como obra, cuja finalidade não é a manutenção da imagem em-si propriamente dita, mas da reflexão, do ato de refletir. A imagem é a efemeridade do ato teatral propriamente dito, o engendrar da certeza de que o ato se efetivou no reflexo; o espelho é o teatro, é a obra de arte, a estátua, ou seja, é obra concebida pela consciência-de-si que afirma a certeza de si na efetivação de sua imagem, na voz efêmera do coro que entoa o hino do saber que dá vida à obra - vida efêmera que já é, portanto, a morte dos deuses, seu vir do além para o aquém na forma da representação, da imagem refletida, da estátua, do ato teatral.

O produzir da obra na religião da arte engendra a consciência-de-si simultaneamente como finalidade e necessidade no movimento de efetivação da religiosidade mesma. Entretanto, esta consciência-de-si é saber que se sabe como instável, sublunar, incerto, susceptível aos 
desígnios da essência absoluta, da verdade obscura. A religião da arte engendra a consciênciade-si como consciência da produção da obra de arte cuja finalidade é ser anteparo para a imagem a ser refletida. Entretanto, o reflexo para esta consciência-de-si é ainda um mistério: a essência obscura do destino, que reside sobre as nuvens, no Olimpo. A imagem refletida no espelho artístico é ainda distorcida, o que se evidencia na voz dos oráculos e das bruxas, os quais falam na linguagem das esfinges. Esta consciência-de-si, portanto, não sabe esta imagem como a si mesma, ou seja, sabe esta imagem como não-saber da essência da imagem e o não-saber é a verdade que reside no Olimpo e pela qual os deuses impõem o destino aos homens, os quais são apenas cônscios de sua tragédia e da ironia de seu saber.

Esta consciência-de-si aparece, portanto, como o engendrar da ética: o saber que sabe de suas limitações e da imanência da escolha. Assim sendo, "se indagamos, por conseguinte, qual é o espírito efetivo que na religião da arte tem a consciência de sua essência absoluta, resulta que é o espírito ético ou o espírito verdadeiro" (HEGEL, 2014, p.462, grifo no original e grifo nosso). Destarte, a voz do espírito, cuja efetividade é o coro, a união das consciênciasde-si efetivas no cantar do hino, o momento efêmero da reflexão dada no culto, é a produção da universalidade das consciências-de-si, de sua igualdade perante às contingências individuais. Surge, portanto, na religião da arte, a consciência-de-si singular universal: a substância em geral das consciências-de-si, o logos.

Ele \{o espírito ético\} não é só a substância universal de todos os Singulares; mas
enquanto esta \{substância universal\} tem para a consciência efetiva a figura da
consciência, isso significa que a substância, que tem individualização, é conhecida
pelos singulares como sua própria essência e obra. A substância não é, desse modo,
para eles, a luminosidade, em cuja unidade o ser-para-si da consciência-de-si só está
contido negativamente, só de maneira transitória, e nele contempla o senhor e sua
efetividade; nem é o incessante entre-devorar-se de povos que se odeiam; nem sua
subjugação a um sistema de castas, constituindo em conjunto a aparência da
organização de um todo perfeito, mas a que falta a liberdade universal dos indivíduos.
Ao contrário, esse [espírito] é o povo livre, no qual os costumes constituem a
substância de todos, e cuja efetividade e ser-aí, todo e cada Singular sabe como sua
vontade e seu ato (HEGEL, 2014, p.462, grifo no original e grifo nosso).

Assim, o espírito ético é tanto a substância universal de todas as consciências-de-si individuais, como a vontade e ato desses indivíduos suprassumida na forma da universalidade - Democracia? Por isso Hegel afirma, como já apontamos, que o espírito avançou, através da religião da arte, da forma da substância à forma do sujeito, pois unificou na obra o saber como ato individual e como essência universal: o homem é animal de logos. Esta unificação é o nascimento da ética e o assassinato dos deuses - Democracia? O engendrar da ética na religião da arte, portanto, marca o nascimento da religião manifesta no interior mesmo daquela forma 
de religiosidade, similar ao crescimento de um verme no interior de uma fruta. Este verme é o deus que se anuncia como sendo, é o espírito que se sabe como espírito.

O saber do espírito como espírito é a certeza absoluta: é a imagem que olha para a efetividade e anuncia: "eu sou”, “eu sou o que sou”, “eu sou me enviou a vocês". O espírito é consciente-de-si como espírito na religião manifesta. O espelho agora é a certeza do mundo feito à imagem e semelhança de deus. Se se compreende a alma como o reflexo que aparece no espelho da religião manifesta, deus então seria a reflexão propriamente dita, a natureza da imagem refletida, ou seja, a certeza da efetividade do reflexo na objetividade do mundo no qual o espelho é obra. A fé no espírito divino do qual emana a alma humana como obra, criação, é a certeza da efetiva objetividade mundana, como obra, criação e vice-versa. Na religião manifesta, a consciência-de-si é a imagem que aparece no espelho e que está certa de sua efetividade devido à natureza mesma do espelho. Como a imagem, o espelho é em-si e este emsi é certo de si pela imagem. Quando a imagem diz: "eu sei que sou”, ela não pode negar absolutamente que não está para além do espelho, entretanto ela o faz. A imagem diz: sou o aquém de um além, sou o reflexo da divindade que diz "eu sou", eu sou o enviado do eu sou. Entretanto, esta imagem é um títere: é o momento consciente-de-si do operar da consciência na forma da suprassunção da consciência-de-si individual e efetiva. Por outro lado, esta consciência-de-si individual e efetiva está presa ao títere e não pode se desatar dele, dessa imagem à qual dá vida e voz e que, ao mesmo tempo, é a externação objetiva de sua vida e voz. Evidencia-se, portanto, uma união indissociável do ser efetivo da consciência-de-si e do efetivo pensar.

\footnotetext{
Há assim nessa união do ser e pensar o defeito de estar a essência espiritual ainda afetada por uma cisão, não reconciliada, em um aquém e além. $\mathrm{O}$ conteúdo é o verdadeiro, mas todos os seus momentos, postos no elemento do representar, tem o caráter de não serem conceituados, mas de aparecerem como lados totalmente independentes, que se relacionam exteriormente um com o outro. Para que o verdadeiro conteúdo receba também sua verdadeira forma para a consciência, fazse mister a mais alta formação [cultural] dessa consciência: há que elevar ao conceito sua intuição da substância absoluta, igualar, para ela mesma, sua consciência com sua consciência-de-si: - como para nós, ou em-si, [já] ocorreu (HEGEL, 2014, p.500, grifo no original e grifo nosso).
}

Assim, a cisão do aquém e do além aparece para Hegel como defeito da essência espiritual da religião manifesta. O suprassumir desta cisão é o aparecimento do Saber Absoluto, do saber que sabe a verdade como saber, ou seja, como unidade da consciência com a consciência-de-si. Nesta unidade, o espírito aparece como objeto da consciência-de-si, como verdade cujo conteúdo é o saber da consciência-de-si e cuja forma é esta unidade mesma e a 
afirmação da universalidade. No Saber Absoluto, o engendrar da verdade é o movimento mesmo do saber. Este movimento é objetivo, ou seja, se dá na forma da objetividade da experiência da consciência.

A cisão presente na religião manifesta é o engendrar da moralina e da aceitação do desígnio divino como finalidade. A alma deve se aproximar do desígnio de seu deus, e este "aproximar" é saber-se como a imagem do espelho e se reproduzir enquanto tal. Este processo de reprodução, entretanto, é a impostura mesma da suprassunção desta cisão e do nascimento do Saber Absoluto.

Na religião manifesta, portanto,

o espírito é, desse modo, o espírito que se sabe a si mesmo: ele se sabe; o que para ele
é objeto, é. Ou seja, sua representação é o verdadeiro conteúdo absoluto; exprime,
como vimos, o espírito mesmo. Ao mesmo tempo, não é somente conteúdo da
consciência-de-si, nem é somente objeto para ela, mas é também espírito efetivo. O
espírito é isso, ao percorrer os três elementos de sua natureza - esse movimento
através de si mesmo constitui sua efetividade: [1] o que se move é ele; [2] ele é o
sujeito do movimento, e [3] ele é igualmente o mover mesmo, ou a substância
através da qual passa o sujeito (HEGEL, 2014, p.514, grifo no original e
grifo nosso).

Assim, o espírito que se sabe a si mesmo, que é, portanto, saber, aparece para a consciência-de-si como a totalidade. A totalidade, portanto, é o saber. A suprassunção desta forma de consciência é o aparecimento do Saber Absoluto, que toma o espírito como objeto deste saber e, assim, afirma a verdade, a totalidade do movimento, como saber. A verdade, portanto, é o movimento de engendramento da verdade, movimento de negação da negação.

Destarte, a cisão a qual se refere Hegel é a alienação mesma, o estranhamento:

a alienação da essência divina se coloca, pois, em sua dupla modalidade: o Si do espírito e seu pensamento simples são os dois momentos cuja unidade absoluta é o espírito mesmo; sua alienação consiste em se dissociarem esses momentos e em terem um valor desigual, um em relação ao outro. Tal desigualdade é por isso desigualdade dupla: e surgem duas uniões, cujos momentos comuns são os enunciados fo Si do espírito e seu pensamento simples \}. Em uma delas a essência divina conta como o essencial, enquanto o ser-aí natural e o Si constam como o inessencial e o que sedeve-suprassumir. Ao contrário, na outra união, o ser-para-si conta como o essencial, e o Divino simples como o inessencial. Seu meio-termo, ainda vazio, é o ser-aí em geral, a simples comunidade de seus dois momentos (HEGEL, 2014, p.507-508, grifo no original e grifo nosso).

Para Hegel, portanto, o Saber Absoluto é o movimento de evidenciação da negação da negação como engendrar do Espírito, ou seja, este movimento é a própria Fenomenologia do Espírito. Assim, para Hegel, o nascimento do Saber Absoluto, sua produção, é a suprassunção 
da própria alienação:

[...] esses mundos espirituais \{da pura consciência e da consciência-de-si efetiva\}, cujos momentos se firmam todos como uma efetividade fixa e uma substância espiritual, vão dissolver-se na pura inteligência. Essa, como o Si que se apreende a si mesmo, consuma a cultura: nada apreende senão o $\mathrm{Si}$, e tudo apreende como o $\mathrm{Si}$, quer dizer, tudo conceitua; suprime toda a objetividade e transmuta todo o serem-si em um ser-para-si. Voltada contra a fé, como reino da essência estranho e situado além, é o Iluminismo. O Iluminismo leva a cabo a alienação, inclusive naquele reino onde se refugia o espírito alienado de si qque é o reino da fé, para Hegel\}, como na consciência da quietude igual a si mesma. Perturba-lhe a ordem doméstica que o espírito administra no mundo da fé, introduzindo ali instrumentos do mundo do aquém, que o espírito não pode renegar como propriedade sua, já que sua consciência igualmente pertence a esse mundo. Nessa tarefa negativa, a pura inteligência se realiza a si mesma, ao mesmo tempo, e produz seu objeto próprio a essência absoluta incognoscível e o útil. Como a efetividade perdeu assim toda a substancialidade, e nela nada mais é em si, então ruiu tanto o reino da fé quanto o do mundo real. Essa revolução produz a liberdade absoluta; com ela, o espírito, antes alienado, retornou completamente a si; abandona essa terra da cultura e passa para outra - para a terra da consciência moral (HEGEL, 2014, p.331, grifo no original e grifo nosso).

A pura inteligência, ou o Si que se apreende a si mesmo no movimento objetivo do conceito, é a obra do Iluminismo. Para Hegel, esta obra é a guilhotina da alienação, é a arma contra a ordem doméstica que o espírito religioso administra - como um médico administra uma droga a um paciente - no mundo da fé. Assim, o Iluminismo aparece como a solução para o mundo alienado da fé, a cola para a cisão do espírito. A mundanidade da metafísica aparece como mundanidade da consciência-de-si efetiva, como mundanidade sua. Esta consciência-desi, ao apreender sua própria fenomenologia, revelar-se-ia a si mesma como o produzir da verdade: a pura inteligência que se realiza a si mesma como o produzir da objetividade. Assim, o espírito, antes alienado, retornaria completamente a si como o apreender de seu engendrar social para a consciência-de-si. Ademais, neste retorno da consciência-de-si a si mesma, nesta unificação do espírito alienado, a efetividade perderia toda a substancialidade e nada apareceria mais como em-si e, consequentemente, o mundo real e o mundo da religião ruiriam, ou seja, todo o mundo da cultura seria abandonado pelo da consciência moral.

Nota-se, portanto, que Hegel alimenta uma crença em relação ao Iluminismo: a de que o seu mantra - o guia perfeito para orientar a mente -, a pura inteligência, ou melhor, a razão, é o caminho que leva à verdade. Ao mesmo tempo, este "caminho" é o próprio movimento dissimulado da verdade. Esta verdade, como já anunciamos, seria propriamente o movimento de engendramento da verdade mesma, apoiada no argumento de racionalidade que institui o referido movimento nos termos da Fenomenologia. Destarte, a razão e a verdade aparecem, 
ambas como necessidade e finalidade uma da outra: a razão é necessária para o engendramento efetivo da verdade e sua consequente suprassunção efetiva e, por outro lado, a suprassunção do operar da razão na forma da verdade é o conteúdo mesmo da verdade que, por sua vez, é suprassumido no movimento de externação da razão na forma da objetividade, que é a forma de operar da razão e cujo conteúdo é o verdadeiro. Assim, observa-se uma limitação na argumentação deste filósofo alemão: ele defende a superação da alienação na forma da alienação mesma, ou seja, acredita na suprassunção da objetividade nos próprios termos do operar efetivo da objetividade. Este quiproquó, entretanto, não pode obscurecer a contribuição fundamental deste filósofo: o engendrar da metafísica como obra. Por outro lado, este engendrar aparece para Hegel como uma constatação da centralidade do sujeito no processo de apreensão e superação da alienação:

A coisa é Eu: de fato, nesse juízo infinito a coisa está suprassumida: a coisa nada é em si; só tem significação na relação, somente mediante o Eu, e mediante sua referência ao Eu. Para a consciência, apresentou-se esse momento na pura inteligência e no Iluminismo. As coisas são pura e simplesmente úteis, e só segundo sua utilidade há que considerá-las. A consciência-de-si cultivada - que percorreu o mundo do espírito alienado de si, produziu por sua extrusão a coisa como a si mesma: portanto, conserva-se ainda a si mesma na coisa e sabe a falta-deindependência da coisa, ou sabe que a coisa é essencialmente apenas ser-para-outro; ou, para exprimir perfeitamente a relação - isto é, o que constitui aqui somente a natureza do objeto \{que ele seja relação - a coisa para ela vale como algo para-siessente. Ela enuncia a certeza sensível como verdade absoluta, mas esse mesmo ser-para-si como momento que apenas desvanece e passa ao seu contrário: ao ser que ao outro se abandona (HEGEL, 2014, p.519, grifo no original e grifo nosso).

Retomando a analogia do espelho, se considerarmos que, na religião natural, o reflexo na poça d'água representa o momento do movimento de engendramento do espírito absoluto e do saber desse espírito como separado da coisa; na religião da arte, a manutenção desse espírito é o engendrar do saber do espírito, da consciência-de-si, como o produzir da obra para adoração do espírito, ou seja, o produzir do espelho para manutenção do reflexo da poça d'água e, neste produzir, o produzir do saber produzir, da consciência-de-si que sabe, que é saber, mas que não é a verdade, não é o reflexo; na religião manifesta, este saber que produz a obra e que é produzido no produzir da obra se vê no espelho, no reflexo, e sabe esse reflexo como saber, como logos que anuncia: eu sou aquele que vos enviou. Na religião manifesta, portanto, a imagem refletida fala que é saber, se sabe em-si, e anuncia para a consciência-de-si que é parasi e em-si. Esta anunciação do objeto da consciência-de-si é a certeza da harmonia divina, de sua igualdade desigual para com a alma humana, pois essa certeza é a garantia moral do bem e 
do mal. A harmonia, portanto, é a ligação universal das consciências-de-si, é a universalidade moral sobre a cabeça das individualidades efetivas garantida pela efetivação mesma destas individualidades na forma da singularidade universal.

Mas, o senhor estará achando que desvario e desoriento-me, confundindo o físico, o hiperfísico e o transfísico, fora do menor equilíbrio de raciocínio ou alinhamento lógico - na conta agora caio. Estará pensando que, do que eu disse, nada se acerta, nada prova nada. Mesmo que tudo fosse verdade, não seria mais que reles obsessão auto-sugestiva, e o despropósito de pretender que psiquismo ou alma se retratasse em espelho... Dou-lhe razão. Há, porém, que sou mau contador, precipitando-me às ilações antes dos fatos, e, pois: pondo os bois atrás do carro e os chifres depois dos bois. Releve-me. E deixe que o final de meu capítulo traga luzes ao até agora aventado, canhestra e antecipadamente (ROSA, 2008, p.83-84).

Neste sentido, o nascimento do Saber Absoluto é a vitória do argumento lógico que toma o espírito ético como princípio, e afirma negá-lo. Parte da harmonia, da certeza, para afirmar a certeza e a harmonia do argumento lógico. Assim, primeiro afirma aquilo que não é para negar sê-lo e, em seguida, põe o ser na negação daquilo que não é. Em outras palavras, diz que a religião é uma ilusão e nega operar por essa ilusão em nome da razão, único mantra verdadeiro; em seguida, afirma o ser nesta negação, ou seja, afirma que da ilusão deve emergir o argumento racional como negação dessa ilusão na forma do Eu, do sujeito. Parte, portanto, da religião para afirmar sua superação pela racionalidade, cujos princípios são religiosos. Esses "princípios", que Hegel coloca na Fenomenologia do Espírito, e que ele vê como o efetivar da objetividade do Espírito, colocam, ao mesmo tempo, Hegel de pernas para o ar: são princípios engendrados no produzir da verdade enquanto produzir efetivo da objetividade mesma. Assim, em sua Filosofia, Hegel afirma uma dupla efetividade, mas dá mais valor para uma do que para a outra: o efetivo produzir material do rememorar aparece como escravo do produzir do espírito que se efetiva nesse rememorar. A palavra de ordem, portanto, é efetividade.

No que concerne à efetividade em Hegel, completa-se em sua Filosofia a alegoria do espelho: no Saber Absoluto, a imagem do espelho se sabe como externação produzida socialmente e representa, nesse processo de externação, a pura inteligência, a razão na forma da consciência-de-si individual. Esta imagem, que está junto de si em seu ser-outro enquanto tal, ou seja, que se sabe como indissociável do espelho e do objeto refletido, sabe o espelho como consciência universal socialmente produzida, sabe o objeto como objeto de reflexão e sabe esta reflexão como externalidade objetiva. Ao mesmo tempo, sabe a externalidade do objeto como externalidade do reflexo, como garantia, certeza do reflexo mesmo. 
No Saber Absoluto, o reflexo é a consciência-de-si individual suprassumida para a forma universal; o espelho é a universalidade da forma de consciência, é o objeto efetivo, externo, material, extenso, é a certeza da reflexão enquanto objetividade imanente, enquanto coisa. Por sua vez, a coisa é o Eu: a consciência-de-si imanente suprassumida para a forma da universalidade da consciência, a qual é suprassumida novamente para a forma da coisa imanente, em-si-essente. A experiência da consciência é a passagem da coisa em-si essente para a forma da consciência universal; por sua vez, a consciência universal constitui-se pela múltipla singularidade do reflexo, pela totalidade das consciências-de-si efetivas cuja suprassunção na forma do reflexo é também suprassumida na forma do objeto imanente. O "Absoluto" do Saber é a analogia do espelho como totalidade da experiência da consciência retornada à consciênciade-si, a qual se sabe como em-si-para-si da coisa.

Por fim, é necessário indicar que a contribuição fundamental da Filosofia hegeliana para esta reflexão reside no movimento mesmo do processo de apreensão de Hegel sobre a efetividade, sendo esta compreendida como a totalidade do movimento da experiência da consciência retornada a si. Em seguida, veremos como Marx considera essas reflexões da Filosofia hegeliana em geral, especialmente no que concerne à sua compreensão da efetividade humana.

\subsection{Crítica da Dialética e da Filosofia Hegelianas em Geral}

Nos “Manuscritos Econômico-Filosóficos" (MARX, 2004), é possível reconstituir os elementos fundamentais das reflexões filosóficas de Marx que marcam sua ruptura com o movimento hegeliano. Em outras obras de referência deste filósofo, como "A Sagrada Família" e "A Ideologia Alemã", estes fundamentos aparecem já bastante desenvolvidos e amadurecidos, entretanto, a contribuição de maior relevância para este estudo reside na apreensão do movimento mesmo de constituição deste momento de ruptura, que pode ser notado de forma bastante clara no capítulo da referida obra intitulado "Crítica da Dialética e da Filosofia Hegelianas em Geral” (MARX, 2004, p115-137).

Antes de avançarmos sobre as distinções que Marx estabelece em relação à Filosofia hegeliana em geral, observa-se em seus Manuscritos que o surgimento da consciência-de-si em geral, universal, é um engendrar social simultâneo e necessário ao surgimento da propriedade privada. Destarte, o sujeito individual aparece como força de trabalho, como trabalho efetivo:

a essência subjetiva da propriedade privada, a propriedade privada enquanto 
atividade sendo para si, enquanto sujeito, enquanto pessoa, é o trabalho. Compreende-se, portanto, que só a economia nacional, que reconheceu o trabalho como seu princípio - Adam Smith - não sabia a propriedade apenas como um estado exterior ao homem -, que essa economia nacional é considerada, por um lado, como um produto da energia efetiva e do movimento da propriedade privada [...], como um produto da indústria moderna, e como ela, por outro, acelerou, glorificou, a energia e o desenvolvimento dessa indústria, e fez deles um poder da consciência. [...] Assim fica suprimida a riqueza existente fora do homem e dele independente (MARX, 2004, p.99, grifo no original e grifo nosso).

O princípio da economia nacional é a propriedade privada enquanto atividade sendo para si, ou seja, enquanto trabalho efetivo, enquanto sujeito. Ademais, este trabalho efetivo privado não aparece apenas como um estado exterior ao homem, mas também como um poder da consciência, ou seja, a riqueza da economia nacional é o processo mesmo de produção dessa riqueza na forma da propriedade privada, a qual é indissociável da forma humana da consciência-de-si, produzida enquanto necessidade e finalidade desse processo. A rapidez e aparente simplicidade destas colocações obscurecem a profundidade real das questões relativas à fisiologia, que estas referidas reflexões sugerem. No capítulo seguinte abordaremos mais detalhadamente a questão.

Assim, a objetividade externada da qual parte o pensamento na experiência da consciência é suprassumida "[...] na medida em que a propriedade privada se incorpora ao próprio homem e reconhece o próprio homem enquanto sua essência [...]” (MARX, 2004, p.99, grifo no original e grifo nosso). Em outras palavras, a propriedade privada não é apenas uma forma externa de relação social, mas é a relação social mesma da qual emerge a consciência-de-si enquanto necessidade e finalidade desta relação, enquanto essência humana da propriedade privada efetivamente estranhada.

O engendramento da propriedade privada faz da exteriorização real do homem um ato humano de venda, assegurado pela duplicidade do trabalho: 1) externação particular; 2) essência da riqueza em geral. Enquanto externação particular, o trabalho é uma determinidade, um ato individual. Por outro lado, a abstração do ato de trabalhar, o trabalho em geral, é a essência da riqueza na economia nacional, a igualdade de todos os trabalhos individuais, a igualdade da desigualdade, do pauperismo: “[...] somente a propriedade privada pode exercer o seu pleno domínio sobre o homem e tornar-se, na forma mais universal, um poder histórico-mundial" (MARX, 2004, p.102, grifo nosso).

Este domínio consiste em que, com o surgimento da propriedade privada, a relação de troca, de venda, constitui uma barreira material para o ser efetivo, para a consciência-de-si individual: para ser é preciso ter. Assim, "o trabalho, a essência subjetiva da propriedade 
privada enquanto exclusão da propriedade, e o capital, o trabalho objetivo enquanto exclusão do trabalho, são a propriedade privada enquanto sua relação desenvolvida da contradição [...] " (MARX, 2004, p.103, grifo no original e grifo nosso).

Em outras palavras, o engendramento da propriedade privada é constituído pela separação do trabalho e do objeto do trabalho. Esta "separação", portanto, é um engendrar desta forma de propriedade, ou seja, constitui-se enquanto necessário para o surgimento da propriedade privada e, ao mesmo tempo, é também uma finalidade: sua manutenção é a reprodução da relação social mesma, do "poder histórico-mundial".

A objetividade material, sensível, da propriedade privada é a forma do estranhamento da vida humana. O movimento do estranhamento é a realização da efetividade do homem, sua efetivação no processo de produção e consumo: "a propriedade privada material, imediatamente sensível, é a expressão material-sensível da vida humana estranhada. Seu movimento - a produção e o consumo - é a manifestação sensível de toda produção até aqui, isto é, realização ou efetividade do homem" (MARX, 2004, p.106, grifo no original e grifo nosso). As demais formas institucionais que aparecem no Capital são formas particulares de (re)produção desta relação social de produção que recaem sob a sua lei geral. Destarte, evidencia-se que a efetividade, em Marx (2004), é o efetivo viver material sem o qual não o Ser não é.

Neste sentido, a efetividade ganha um lugar primeiro na Filosofia marxista, enquanto uma premissa essencial. $O$ acontecer efetivo da relação social é o caráter universal de todo o movimento estranhado da consciência:

\footnotetext{
Igualmente, tanto o material de trabalho quanto o homem enquanto sujeito são tanto resultado quanto ponto de partida do movimento (e no fato de eles terem de ser este ponto de partida reside, precisamente, a necessidade histórica da propriedade privada). Portanto, o caráter social é o caráter universal de todo o movimento; assim como a sociedade mesma produz o homem enquanto homem, assim ela é produzida por meio dele (MARX, 2004, p.106, grifo no original e grifo nosso).
}

Assim, o Absoluto, em Marx, não é o Saber, o movimento da consciência que retorna a si enquanto consciência-de-si em-si e para-si, mas o caráter universal do movimento social, do engendrar da sociedade como produção humana e do engendrar da humanidade enquanto produção social. Neste sentido, a sociedade aparece enquanto “[...] unidade essencial completa do homem com a natureza, a verdadeira ressurreição da natureza, o naturalismo realizado do homem e o humanismo da natureza levado a efeito" (MARX, 2004, p.107, grifo no original e grifo nosso). Esta "unidade essencial" é a produção da distinção entre 
teologia e natureza, defendida pelos materialistas do Iluminismo Francês inspirados, como Marx, na Filosofia Epicurista ${ }^{19}$.

Marx, portanto, resgata e defende, na Filosofia hegeliana, o movimento do engendrar do pensamento como um engendrar do ser efetivo. Ademais, coloca este engendrar nos termos do materialismo e, consequentemente, traz o problema da objetividade para o terreno das relações sociais de produção: “[...] sou ativo socialmente porque [o sou] enquanto homem. Não apenas o material da minha atividade - como a própria língua na qual o pensador é ativo - me é dado como produto social, a minha própria existência é atividade social; por isso o que faço a partir de mim, faço a partir de mim para a sociedade, e com a consciência de mim como um ser social” (MARX, 2004, p.107, grifo no original e grifo nosso).

Destarte, a unidade entre Ser-aí e Pensar, defendida nos termos da Filosofia hegeliana como Saber Absoluto, aparece em Marx como efetiva relação social: "minha consciência universal é apenas a figura teórica daquilo de que a coletividade real, o ser social, é a figura viva, ao passo que hoje em dia a consciência universal é uma abstração da vida efetiva e como tal se defronta hostilmente a ela. Por isso, também a atividade da minha consciência universal - enquanto tal - é minha existência teórica enquanto ser social” (MARX, 2004, p.107, grifo no original e grifo nosso).

A consciência universal, portanto, também é efetiva, materialmente efetiva. Os problemas que os filósofos encontram no pensamento estão deslocados, porque são vistos como problemas metafísicos. O problema da metafísica é a ilusão da metafísica do problema como uma existência apartada da existência real. Mas ideia e realidade são, ambas, efetividades. Tanto a ideia é real quanto a realidade é ideal, e ambas são evanescentes. Este esvanecimento é o caráter social da relação de produção da distinção entre ser e pensar, e da suprassunção desta distinção na forma estranhada da natureza. Destarte, "pensar e ser são, portanto, certamente diferentes, mas [estão] ao mesmo tempo em unidade mútua" (MARX, 2004, p.108, grifo no original e grifo nosso).

Esta "diferença" entre ser e pensar constitui sua "unidade mútua" enquanto contradição. Por um lado, o ser aparece enquanto um ente material, enquanto ser-aí de um ente. De outro, o pensamento parece operar pela ação de entes abstratos, aparece, portanto, enquanto coisa abstrata. Entretanto, o pensamento não está além do ente sensível: é o pensar de um ser. Este pensar, entretanto, é social. O ser também o é. O social, portanto, é a unidade mútua e o

\footnotetext{
${ }^{19}$ Para maiores esclarecimentos, consultar as seguintes obras: 1) CARO, Tito Lucrécio. Da Natureza. Prefácio, tradução e notas de Agostinho da Silva. São Paulo: Globo, 1962 e 2) MARX, Karl. Diferença entre as Filosofias da natureza em Demócrito e Epicuro. Santos: Martins Fontes, 1972.
} 
produzir mesmo desta distinção necessária à sua reprodução enquanto relação social.

A reprodução da relação social é a necessidade que surge perante à consciência do desvanecimento, do temor à morte. Para Hegel, o temor à morte institui o pensamento enquanto permanência do ser encarcerado na consciência-de-si. Este encarceramento, para o referido filósofo, é “a essência perfeita e completa” (HEGEL, 2014, p.400). Assim, o encerramento do ser na consciência-de-si constituiria o cerne da liberdade absoluta enquanto negação da morte, permanência e efetivação. Esta essência perfeita e completa, absoluta unidade do ser e do pensar na forma do em-si-para-si essente, constitui, para Hegel, toda a efetividade, “[...] e essa efetividade só existe como saber. O que a consciência não soubesse, não teria sentido; nem pode ser um poder para ela. Na sua vontade sabedora, recolheu-se toda a objetividade, e [todo o] mundo. É absolutamente livre porque sabe sua liberdade, e precisamente esse saber de sua liberdade é sua substância e fim e conteúdo único" (HEGEL, 2014, p.401, grifo no original e grifo nosso).

Para Marx, entretanto, "a morte aparece como uma dura vitória do gênero sobre o indivíduo determinado e contradiz a sua unidade; mas o indivíduo determinado é apenas um ser genérico determinado, e, enquanto tal, mortal" (MARX, 2004, p.108, grifo no original e grifo nosso). Assim, o temor à morte, para este filósofo, representa esta vitória do gênero (da universalidade abstrata do pensamento) sobre o indivíduo determinado (efetivo vivente). Entretanto, esta individualidade determinada é uma determinidade social mortal. A morte, portanto, aparece como uma determinidade social necessária para a vitória do pensamento sobre o ser, pois aquele aparece para este enquanto permanecer infinito, enquanto este se sabe ou é sabido enquanto mortal. Entretanto, a morte é necessária para a efetivação da imortalidade do pensamento mortal: a afirmação da infinitude do pensamento é a negação de sua finitude, de seu esvanecimento. A constituição social da morte é a negação da plena efetivação humana enquanto produção social. Destarte, para Marx não é o saber que é toda a efetividade, mas é da relação social efetiva da qual emerge a negação do ser na forma do pensamento, o não-ser instituído como ser enquanto negação da efemeridade do ser e suprassunção de seu conteúdo efetivo para a forma abstrata do pensamento. O pensamento, portanto, é conteúdo que emerge da forma objetiva efetiva de realização social, por isso ele é distinto e indissociável do ser. A objetividade do ser, portanto, é a forma de efetivação social da qual emerge o conteúdo do pensamento. A objetividade estranhada é a efetividade mesma, operando enquanto relação social de produção:

o homem se apropria da sua essência omnilateral de maneira omnilateral, portanto 
como um homem total. Cada uma de suas relações humanas com o mundo, ver, ouvir, cheirar, degustar, sentir, pensar, intuir, perceber, querer, ser ativo, amar, enfim todos os órgãos de sua individualidade, assim como os órgãos que são em sua forma como órgãos comunitários, são no seu comportamento objetivo ou no seu comportamento para com o objeto a apropriação do mesmo, a apropriação da efetividade humana; seu comportamento para com o objeto é o acionamento da efetividade humana (por isso ela é precisamente tão multíplice quanto multíplices são as determinações essenciais e atividade humanas), eficiência humana e sofrimento humano, pois o sofrimento, humanamente apreendido, é uma autofruição do ser humano (MARX, 2004, p.108, grifo no original e grifo nosso).

A efetividade, portanto, aparece como o próprio movimento omnilateral de efetivação humana. O ser do homem é sua relação mundana: ver, ouvir, cheirar, degustar, sentir, pensar, intuir, perceber. Os órgãos de efetivação humana são órgãos sociais, são produzidos no processo de efetivação mesmo enquanto apropriação da efetividade humana. O comportamento objetivo humano é o acionamento desta efetividade, é o ser do homem. O homem é objetividade que se efetiva. Este efetivar, entretanto, é a autofruição do sofrimento humano, pois "o lugar de todos os sentidos físicos e espirituais passou a ser ocupado, portanto, pelo simples estranhamento de todos esses sentidos, pelo sentido do ter. A esta absoluta miséria tinha de ser reduzida a essência humana, para com isso trazer para fora de si sua riqueza interior" (MARX, 2004, p.108-109, grifo no original e grifo nosso).

Se retomarmos aqui a já citada analogia do espelho ${ }^{20}$, nota-se o seguinte: a produção social do espelho é a efetivação da objetividade da imagem do espelho, do pensamento - de uma forma específica de pensamento - que é reflexo desta objetividade social efetiva. Da poça d'água (religião natural em Hegel) à produção do espelho (religião da arte, espelho como obra, estranhamento da imagem) e à manifestação do espelho (religião manifesta). O Saber Absoluto enquanto reflexo-saber do espelho como verdade que se sabe enquanto tal e que se sabe enquanto tudo. Em Marx, a reversão da imagem do espelho para a produção da imagem do espelho como conservação da efetividade social. Mas que efetividade? Efetividade da miséria: Inês é Morta, mas Inês é uma mulher preta e pobre, que apanha do marido e teme que seus filhos sejam mortos pela polícia no caminho de volta da escola. "Aconteceu da mísera e mesquinha/ Que depois de ser morta foi Rainha" (CAMÕES, 2000, p.129) ... das estatísticas.

Destarte, "não só no pensar, portanto, mas com todos os sentidos o homem é afirmado no mundo objetivo" (MARX, 2004, p.110, grifo no original e grifo nosso). Ao produzir a objetividade, portanto, o homem precisa produzir a humanização da objetividade no

20 “ - E o espelho? - Se todos os corpos não são outros tantos espelhos, é por algum defeito em sua contextura [...]” (DIDEROT, 1979, p.101). 
sentido de sua subjetividade, isto é, precisa produzir os sentidos que compreendam e possam se apropriar de sua objetividade:

[...] o meu objeto só pode ser a confirmação de uma das minhas forças essenciais, portanto só pode ser para mim da maneira como a minha força essencial é para si como capacidade subjetiva, porque o sentido de um objeto para mim (só tem sentido para um sentido que lhe corresponda) vai precisamente tão longe quanto vai o meu sentido, por causa disso é que os sentidos do homem social são sentidos outros que não os do não social [...] (MARX, 2004, p.110, grifo no original).

A efetivação humana, portanto, é absolutamente social. O ser e o não-ser do ser são formas de sua efetividade social, são socialmente produzidos, são efetivos e, no temor à morte, evidencia-se esta efetivação como negação do desvanecimento - este que é o princípio primeiro da efetividade, "pois não só os cinco sentidos, mas também os assim chamados sentidos espirituais, os sentidos práticos (vontade, amor, etc.), numa palavra o sentido humano, a humanidade dos sentidos, vem a ser primeiramente pela existência do seu objeto, pela natureza humanizada" (MARX, 2004, p.110, grifo no original e grifo nosso).

A humanização da natureza é a perpetuação humana como autonomia natural. A autonomia da natureza é uma das contribuições do materialismo para a argumentação filosófica de Marx. Esta autonomia aparece para este filósofo, entretanto, como uma autonomia socialmente produzida, e não como autoengendramento em-si, como infinitude da matéria e de seu movimento. O materialismo em Marx é a produção material da miséria, do desvanecimento humano e de sua negação efetiva - o pensamento como negação da irracionalidade evanescente:

\footnotetext{
vê-se como subjetivismo e objetivismo, espiritualismo e materialismo, atividade e sofrimento perdem a sua oposição apenas quando no estado social e, por causa disso, a sua existência enquanto tais oposições; vê-se como a própria resolução das oposições teóricas só é possível de um modo prático, só pela energia prática do homem e, por isso, a sua solução de maneira alguma é apenas uma tarefa do conhecimento, mas uma efetiva tarefa vital que a Filosofia não pôde resolver, precisamente porque a tomou apenas como tarefa teórica (MARX, 2004, p.111, grifo no original).
}

Assim, se retomamos o objeto de investigação exposto nos termos de uma dada cientificidade argumentativa, presente nos dois primeiros capítulos desta reflexão, evidencia-se que o problema, portanto, não reside nos termos do próprio objeto de investigação - analisar a relação entre impermeabilização do solo e a distribuição daquela tipologia de mortalidade. Tampouco reside na validade lógica da análise proposta. O objeto da presente reflexão será redefinido nos termos de uma crítica à efetiva relação social que produz a necessidade de racionalização de sua irracionalidade efetiva. A premissa desta necessidade é a certeza de 
verdade. Sua finalidade, a afirmação desta certeza mesma como movimento de negação da efetiva relação social e consequente efetivação social do homem. O número é a voz da certeza. A lógica, o mantra da razão. O homem, seu escritor e escrito. O escrito, a negação do escritor. O escrever, o engendrar do escritor. Destarte, o cientista, portanto, é o verdadeiro objeto da ciência - da sociedade da ciência. Em termos de nossa ciência geográfica, o objeto da geografia é a efetividade do ser e de seu pensamento geográfico.

O abstrair da efetividade no engendrar da ciência geográfica aparece como afirmação da geograficidade do ser: "a Geografia nasce, portanto com a relação entre sociedade e natureza" (MARTINS, 2007, p.39), ou ainda:

[...] podemos ter a Geografia como categoria da existência. Esta categoria que é
constituída por espaço, tempo, relação e movimento, estabelecidos a partir da
entidade genérica do mundo que é a matéria, e por sua expressão subjetiva, a
Idéia. A matéria apresenta-se aqui na unidade processual presente entre homem-
meio e na relação entre subjetivo/objetivo. Dentro dessa dinâmica entre
subjetivo/objetivo o conteúdo geográfico ganhará forma a partir das noções de
absoluto e relativo, contínuo e descontínuo. E assim, como já foi apontado aqui e ali
anteriormente neste texto, podemos também, a partir de agora, designar a Geografia
de geograficidade, uma vez que ela se torna fundamento existencial que dá origem
aos adjetivos constituintes do ser (MARTINS, 2007, p.40).

Primeiramente, cabe-nos questionar: qual categoria não é uma categoria da existência? Ser e pensar não são a mesma coisa, mas são unos, ou seja, toda categoria é uma categoria da existência. Em segundo lugar, a categoria não é constituída por "espaço, tempo, relação e movimento", haja vista que dizer isto significa o mesmo que dizer: o buraco é constituído por um vazio que aumenta conforme o buraco aumenta; ou ainda: o buraco é o nada que cresce com o acréscimo de nada; ou ainda: tudo é nada, e nada é tudo. Espaço, tempo, relação e movimento são momentos da suprassunção da percepção no entendimento das relações que são arroladas no escopo do debate geográfico e da constituição do objeto deste debate na efetividade sensível enquanto constituição do debate mesmo e do objeto do debate.

Em terceiro lugar, os constituintes da suposta categoria existencial - espaço, tempo, relação e movimento - seriam estabelecidos a partir da matéria, considerada a entidade genérica do mundo, e por sua expressão subjetiva, a ideia. Esta concepção afirma a materialidade da natureza enquanto uma espécie de "causa primeira" da qual emergiria a ideia como uma “expressão subjetiva". Primeiro, devemos objetivar que pensar não é propriamente uma expressão subjetiva, mas uma relação objetiva que se dá na forma da subjetividade - e viceversa. Segundo, assumir a materialidade enquanto causa primeira, uma suposta conduta ateísta, referida ao materialismo francês do século XVIII, para o qual nada vem do nada e nada retorna 
ao nada, para o qual a matéria é infinita, sempre existiu e sempre vai existir, para o qual o acaso é o senhor e tudo o que há é necessário (CARO, 1962; LA METRIE, 1982; HOLBACH, 2010); a positivação desta conduta não revela seu emergir enquanto um processo social, apenas faz birra perante a Filosofia Especulativa.

Assim, se, por um lado, a ciência moderna constitui-se, em sua gênese, enquanto um argumento religioso, de outro, é também filha bastarda de um forte pressuposto materialista, por mais que esta junção seja aparentemente absurda. Se, por um lado, o engendrar da certeza na constituição da razão se estabeleceu enquanto crença religiosa, por outro, a fundação do objeto de investigação da ciência é materialista, ou seja, é crítica à religião:

que não venham nos dizer que é degradar o homem reduzir as suas funções a um puro mecanismo; que é aviltá-lo vergonhosamente compará-lo a uma árvore, a uma vegetação abjeta [...]. O homem de bem é uma máquina cujas engrenagens estão adaptadas de maneira a exercer as suas funções de um modo que deve agradar. Não, não terei vergonha de ser uma máquina desse gênero, e meu coração vibraria de alegria se pudesse pressentir que um dia os frutos de minhas reflexões serão úteis e consoladores para os meus semelhantes (HOLBACH, 2010, p.290)

Destarte, a ciência se constitui enquanto um sentido determinista-fatalista ${ }^{21}$. O humanismo, do qual Marx é crítico, institui-se, portanto, enquanto positivação universal deste argumento:

a natureza, não será ela própria uma vasta máquina, da qual a nossa espécie é uma frágil engrenagem? Não vejo nada de vil nela nem nas suas produções. Todos os seres que saem das suas mãos são bons, nobres e sublimes, a partir do momento em que cooperem para produzir a ordem e a harmonia na esfera onde eles devem atuar. De qualquer natureza que seja a alma - quer a façam mortal, quer a suponham imortal, quer a considerem como um espírito, quer a considerem como uma porção do corpo -, eu acharei essa alma nobre, grande e sublime [...]. Gemerei com a sua baixeza vendo alguns homens vis que incensam a tirania ou que rastejam servilmente aos pés da superstição. Tudo aquilo que vem sendo dito no decorrer desta obra nos prova claramente que tudo é necessário. Tudo está sempre em ordem relativamente à natureza, na qual todos os seres nada mais fazem que seguir as leis que lhes são impostas. Fazia parte do seu plano que algumas terras produziriam frutos deliciosos, enquanto outras forneceriam apenas sarças, espinheiros, vegetais perigosos. Ela quis que algumas sociedades produzissem sábios, heróis, grandes homens; dispôs que outras só fariam nascer homens abjetos, sem energia e sem virtudes. [...] Os vícios e as virtudes, as trevas e a luz, a ignorância e o conhecimento são igualmente necessários; uns não são bens e outros não são males a não ser para alguns seres particulares, dos quais eles favorecem ou perturbam a maneira de existir: o todo não pode ser infeliz, mas pode conter infelizes (HOLBACH, 2010, p.291, grifo nosso).

\footnotetext{
21 "Era fatalista; pensava que os esforços que efetuamos para escapar ao nosso destino servem apenas para nos conduzir a ele" (DIDEROT, 1979, p.100). Por outro lado, o determinismo se caracterizaria pela presença de uma causa final estabelecida a priori por uma substância pensante absoluta, universal e infinita.
} 
Dever-se-ia, segundo tal argumento, preservar a humanidade do sujeito pela correta condução da moral - ou seja, pela condução científica da moral, segundo as leis naturais estabelecidas previamente à ciência mesma. Para Holbach (2010), há apenas uma substância a matéria -, e o homem é, necessariamente, um ser físico e moral - ambas, coisas fatalistamente materiais. Assim, independeria do ser humano a constituição de seus sentidos, dos quais dependem necessariamente sua moralidade. Ademais, o homem moral é social. Destarte, a boa condução da moral humana depende da correta orientação de seus sentidos materiais pela sociedade do qual é parte.

\begin{abstract}
Assim, é sempre em nós mesmos, é na nossa maneira de sentir que vamos buscar as ideias de ordem, os atributos de sabedoria, de excelência e de perfeição que conferimos a deus, enquanto todo o bem e o mal que nos acontecem neste mundo são consequências necessárias das essências das coisas e das leis gerais da matéria. Em poucas palavras, da gravidade, da atração e da repulsa, das leis do movimento que o próprio Newton tão bem desenvolveu, mas que ele não mais ousou aplicar a partir do momento que entrou em questão o fantasma a quem o preconceito faz atribuir todos os efeitos dos quais a natureza é ela própria a verdadeira causa $(\mathrm{HOLBACH}$, 2010, p.585, grifo nosso).
\end{abstract}

Destarte, em quarto lugar, e não por acaso, a matéria aparece, para Martins (2007), enquanto uma unidade processual presente entre homem-meio e na relação entre subjetivoobjetivo. Esta suposta "unidade", entretanto, é a unidade do estranhamento, é a não-unidade, é a separação entre consciência-de-si humana e meio enquanto forma necessária de constituição da humanidade: um ser genérico para um ente miserável. A relação entre sujeito e objeto, na constituição do argumento materialista, é a relação material mesma, da qual emerge a referida concepção material do mundo enquanto Natureza ${ }^{22}$. Esta é a relação que fundamenta a existência da humanidade do ser enquanto uma contradição materialmente dada e suprassumida para a universalidade formal-abstrata. Esta materialidade, portanto, não é apenas geográfica. Entretanto, a geograficidade da materialidade é um momento da dupla efetivação que engendra o ser da consciência-de-si humana: um ser que se efetiva para-si na forma externada do em-si; um ser que para-si é em-si geográfico. A geografia, portanto, aparece como um objeto efetivo no processo de efetivação da objetividade humana.

Entretanto, esta objetividade humana é alienada, é estranhada. Neste sentido, o objeto que para a ciência geográfica se constitui geograficamente é marcado pela incompletude de sua

\footnotetext{
${ }^{22}$ Para maiores esclarecimentos, consular a seguinte referência: CARO, Tito Lucrécio. Da Natureza. Prefácio, tradução e notas de Agostinho da Silva. São Paulo: Globo, 1962.
} 
constituição mesma, se se apreende tal objeto enquanto um objeto simplesmente geográfico. Neste sentido, há que se considerar que a finalidade da ciência geográfica reside na necessidade de se estabelecer um fundamento geográfico para o ser, revelando o engendrar deste fundamento enquanto um processo simultâneo à própria existência do ser. Em outras palavras, o que Martins (2007) considera enquanto uma "geograficidade" do ente existencial e, portanto, enquanto mundo efetivamente existente para um ser que é aí, um Dasein ${ }^{23}$, aparece para Marx (2004) enquanto um ser que, para ser, imprescinde do aí que não possui, ou seja, que ao ser-aí também não é: efetiva-se enquanto um para-ser, um vir-a-ser que já é na forma da negação de si mesmo - a propriedade privada.

Destarte, o pensamento aparece, portanto, enquanto realização mundana do homem cujo ser é querer-ser. Seu ser efetivo engendra-se a si mesmo enquanto negatividade do pensamento que quer ser mais humano, mais geográfico, mais vivo, menos impermeável, menos açucarado, mais saudável. O pensamento, portanto, emerge enquanto esta negatividade efetiva, cuja finalidade é a positivação da razão na forma do sujeito objetivo e, portanto, finalidade que aparece já na necessidade de se negar a objetividade efetiva do sujeito. Assim, é nestes termos que o objeto da geografia aparece como a efetividade do ser e de seu pensamento geográfico, pois ser e pensar são ações objetivo-subjetivas engendradas enquanto sociedade.

Neste sentido, a própria materialidade da natureza é o movimento mesmo da sociedade da natureza, ou da natureza da sociedade:

as ciências naturais desenvolveram uma enorme atividade e se apropriaram de um material sempre crescente. Entretanto, a Filosofia permaneceu para elas tão estranha justamente quanto elas permaneceram estranhas para a Filosofia. A fusão momentânea foi apenas uma ilusão fantástica. Havia a vontade, mas faltava a capacidade. A própria historiografia só de passagem leva em consideração a ciência natural como momento do esclarecimento, da utilidade, de grandes descobertas

${ }^{23}$ O Dasein, para Heidegger, é o ente existencial lançado no mundo. Sua essência reside em sua existência mundana: Ser-aí. "O ser dos seres, tanto de outras entidades como do próprio Dasein, não é independente do Dasein: teorias, questões, instrumentos, cidades - tudo isso depende, para existir, e no tocante ao seu modo de ser, do fato de ser elaborado, feito, usado, habitado e interpretado por seres humanos. O Dasein é essencialmente no mundo [...]" (INWOOD, 2000, grifo nosso). Apesar da contribuição fornecida por essa definição mundana, temporal, finita da Ontologia, uma das limitações desta compreensão, a nosso ver, pode ser observada na contradição in adjecto (contradição nos próprios termos) de uma definição de Ser-aí, essencialmente no mundo. Tal contradição se nos apresenta da seguinte forma: o Dasein não pode prescindir de um mundo no qual ele possa Ser-aí, de tal modo que o mundo se lhe apresenta como condição de sua reposição enquanto Ser-aí mundano. Esta reposição do Ser pelo aí, do Ser pela Coisa posta pelo Ser, constitui-se em um melindre lógico. Ainda que a mundanidade do homem seja posta como crítica a uma pressuposição de Ser-em-Si infinito e eterno - penso, logo existo -, resta totalmente inexplorado o problema da Alienação (MARX, 2013), no seio do qual o Dasein aparece lançado no e do mundo, simultaneamente, instaurando-se, portanto, a contradição físico-metafísico que repõe constantemente o Fetiche da Mercadoria (MARX, 2013) como elemento necessariamente constituinte de uma Ontologia alienada: o homem é lançado no mundo que lança o homem; o homem repõe e é reposto pelo mundo; o homem produz o mundo e o mundo produz o homem. Este intrincado problema eleva a discussão relativa à Ontologia ao seu limite concebível: a Efetividade. 
singulares. Mas quanto mais a ciência natural interveio de modo prático na vida humana mediante a indústria, reconfigurou-a e preparou a emancipação humana, tanto mais teve de completar, de maneira imediata, a desumanização (MARX, 2004, p.112-113, grifo no original e grifo nosso).

Assim, as chamadas ciências naturais, dentre as quais não é difícil situar o que se tem denominado de "Geografia Física", ao operar seus argumentos lógicos em defesa da pressuposição da autonomia da natureza, produz desta autonomia a miséria do corpo humano. Esta miséria, entretanto, não é obra científica: é a própria ciência, sua necessidade e, portanto, sua finalidade.

Filha pródiga da religiosidade, conforme demonstramos previamente, a ciência põe no "mundo categorial" - epistemológico - o que os cristãos colocam no seu deus. A outra face da nossa ciência geográfica, a "Humana" - que Geografia não é Humana? -, também recai neste argumento, e de diversas formas. Afirmar a mundanidade do homem, sua cultura, a crítica ao capitalismo, a crítica às mazelas identitárias, étnicas, sociais, etc., é afirmar-se certa de uma posição a que galga, mas que não possui, ou melhor, que possui como finalidade cuja necessidade é a reposição dos próprios termos da crítica a que se presta, tão solícita.

Sociedade e Natureza, portanto, aparecem objetivamente para a consciência geográfica do ser enquanto certeza sensível: esta cidade é sociedade, aquela árvore é natureza; este prédio é sociedade, aquela montanha é natureza; estas palavras são sociais, mas a possibilidade de lêlas me é dado pelo complexo arranjo natural do cérebro. $\mathrm{O}$ cérebro é natural, mas sua ação é social. Mas se o cérebro é natural, sua ação também não o seria? Ou, se a ação do cérebro é social, sua constituição também não o seria? Quem criou o cérebro: a natureza ou a sociedade?

A criação é [...] uma representação muito difícil de ser eliminada da consciência do povo. O ser-por-si-mesmo da natureza e do homem é inconcebível para ele porque contradiz todas as palpabilidades da vida prática. A criação da terra recebeu um violento golpe da geognosia, isto é, da ciência que expõe a formação da terra, o vir a ser da terra como um processo, como auto-engendramento. A generatio aequivoca [geração espontânea] é a única refutação prática da teoria da criação. Ora, é certamente fácil dizer ao indivíduo singular o que já diz Aristóteles: foste gerado por teu pai e tua mãe, portanto, a cópula de dois seres humanos, logo um ato genérico do ser humano, produziu o ser humano em ti. Vês, portanto, que também fisicamente o ser humano deve sua existência ao ser humano. Tens de manter, portanto, não apenas $u m$ dos lados sob os olhos, o progresso infinito, segundo o qual continuas a perguntar: quem gerou o meu pai, quem gerou o seu avô etc. Tens também de não largar o movimento circular, que é sensivelmente intuível naquele progresso, segundo o qual o homem repete a si próprio na procriação, portanto, o ser humano permanece sempre sujeito. Responderás, porém: concedido a ti este movimento circular, concede-me tu o progresso, que sempre me impele a continuar, até que eu pergunte: quem gerou o primeiro ser humano e a natureza em geral? (MARX, 2004, p.113-114, grifo no original e grifo nosso). 
Assim, "este movimento circular" é o ponto chave da argumentação relativa à crítica da efetividade enquanto causalidade, objeto fundamental para a reflexão neste capítulo. A circularidade do movimento é a negação da efetividade enquanto negação desta circularidade na efetivação mesma do pensamento. Em outras palavras, é a necessidade de afirmação abstrata da certeza para que se chegue à certeza sensível do ser, cuja sensibilidade é um engendrar da sociedade, um ser que é, portanto, social e que, enquanto social, é o engendrar da natureza como sensibilidade humana. Neste sentido, a gênese desta certeza de ser humano e de ser natureza é o engendrar mesmo da abstração:

só posso responder-te: a tua pergunta é, ela mesma, um produto da abstração. Pergunta-te como chegas àquela pergunta; interroga-te se a tua pergunta não ocorre a partir de um ponto de vista ao qual eu não posso responde porque ele é um ponto de vista invertido. Pergunta-te se aquele progresso como tal existe para um pensar racional. Se tu te perguntas pela criação da natureza e do ser humano, abstrais, portanto, do ser humano e da natureza. Tu os assentas como não-sendo e ainda queres, contudo, que eu te os prove como sendo. Digo-te eu, agora: se renuncias à tua abstração também renuncias à tua pergunta ou, se quiseres manter a tua abstração, sê então consequente, e quando pensando pensas o ser humano e a natureza como não-sendo, então pensa-te a ti mesmo como não-sendo, tu que também és natureza e ser humano. Não penses, não me perguntes, pois, tão logo pensas e perguntas, tua abstração do ser da natureza e do homem não tem sentido algum. Ou és um tal egoísta que assentas tudo como nada e queres, tu mesmo, ser? (MARX, 2004, p.114, grifo no original e grifo nosso).

A constatação deste "ponto de vista invertido" se nos apresentou naquele quiproquó entre "como" e "porque", indicado previamente. Ao perguntar pelo "porque", a consciênciade-si humana instaura um momento anterior à efetividade (como não-sendo, como momento da criação) e espera que se prove, a partir dessa pergunta pela gênese, que a natureza e o homem são, efetivamente, causalidade infinita e progressista. O "porque" instaura a causalidade enquanto "porque" e este "instaurar" é o engendrar mesmo da sociedade.

Tu replicar podes a mim: eu não quero assentar o nada da natureza etc.; pergunto-te pelo ato de surgimento dela, assim como pergunto ao anatomista pela formação dos ossos etc. Mas, na medida em que, para o homem socialista, toda a assim denominada história mundial nada mais é do que o engendramento do homem mediante o trabalho humano, enquanto o via a ser da natureza para o homem, então ele tem, portanto, a prova intuitiva, irresistível, do seu nascimento por meio de si mesmo, do seu processo de geração. Na medida em que a essencialidade do ser humano e da natureza se tornou prática, sensivelmente intuível; na medida em que o homem [se tornou prática, sensivelmente intuível] para o homem enquanto existência da natureza e a natureza para o homem enquanto existência do homem, a pergunta por um ser estranho, por um ser acima da natureza e do homem - uma pergunta que contém a confissão da inessencialidade da natureza e do homem - tornou-se praticamente impossível. O ateísmo, enquanto rejeição dessa inessencialidade, não 
tem mais sentido algum, pois o ateísmo é uma negação de Deus e assenta, por intermédio dessa negação, a existência do homem; mas o socialismo enquanto socialismo não carece mais de uma tal mediação; ele começa da consciência teorética e praticamente sensível do homem e da natureza como [consciência] do ser. Ele é consciência de si positiva do homem não mais mediada pela superação da religião, assim como a vida efetiva é a efetividade positiva do homem não mais mediada pela suprassunção da propriedade privada, o comunismo. O comunismo é a posição como negação da negação, e por isso o momento efetivo necessário da emancipação e da recuperação humanas para o próximo desenvolvimento histórico. O comunismo é a figura necessária e o princípio enérgico do futuro próximo, mas o comunismo não é, como tal, o termo do desenvolvimento humano - a figura da sociedade humana (MARX, 2004, p.114, grifo no original e grifo nosso).

O Comunismo seria a necessidade de Vontade de Poder, Marx? Retomaremos a questão no capítulo seguinte. Neste momento, resta questionarmos: "o que fazer diante da dialética hegeliana?" (MARX, 2004, p.115, grifo no original).

Marx considera, assim como nós o fizemos no decorrer do subcapítulo precedente, que "um olhar sobre o sistema hegeliano tem de iniciar-se com a Fenomenologia hegeliana, o verdadeiro lugar do nascimento e o segredo da Filosofia de Hegel” (MARX, 2004, p.119, grifo nosso).

O que Hegel produziu enquanto "Fenomenologia do Espírito", temos visto, foi uma “[...] expressão abstrata, lógica, especulativa para o movimento da história, a história ainda não efetiva do homem enquanto um sujeito pressuposto, mas em primeiro lugar ato de produção, história da geração do homem” (MARX, 2004, p.118-119, grifo no original e grifo nosso). Em outras palavras, para Hegel, a efetivação do homem - de sua humanidade, de seu ser genérico na forma da individualidade em-si e para-si essente - apareceria como efetivação da lógica especulativa enquanto ato de produção da história de geração do homem conscientede-si, que se sabe enquanto verdadeiramente em-si e para-si.

Assim, o espírito filosófico nada mais é do que o espírito pensante do interior de seu estranhamento-de-si, isto é, espírito estranhado do mundo, que se concebe abstratamente. A lógica - o dinheiro do espírito, o valor do pensamento, o [valor] especulativo do homem e da natureza - sua essência tornada totalmente indiferente contra toda determinidade efetiva e, portanto, [essência] não-efetiva - é o pensar exteriorizado que, por essa razão, faz abstração da natureza e do ser humano efetivo; o pensar abstrato. A externalidade desse pensar abstrato... a natureza tal como ela é para este pensar abstrato. Ela lhe é exterior, sua perda-de-si; e ele a concebe também exteriormente, enquanto pensamento abstrato, mas enquanto pensamento abstrato exteriorizado. Finalmente o espírito, este pensamento retornado ao seu próprio lugar de origem, o qual, enquanto espírito antropológico, fenomenológico, psicológico, ético, artístico, religioso, não vale ainda para si mesmo até que finalmente se encontre e autoafirme enquanto saber absoluto e, por conseguinte, espírito absoluto, isto é, espírito abstrato, [até que] encerre sua existência consciente, e [a existência] que lhe corresponde. Pois sua existência efetiva é a abstração... 
(MARX, 2004, p.120-121, grifo no original e grifo nosso).

Este excerto demonstra uma centralidade do pensamento hegeliano para Marx, especialmente no que concerne ao Saber Absoluto. Este Saber se concebe abstratamente na Filosofia hegeliana, se sabe como saber estranhado que deve ser suprassumido e retornar a si e se afirmar enquanto Saber Absoluto. Neste movimento, revela-se, portanto, a pressuposição da certeza enquanto afirmação do $\mathrm{Si}$, do Saber Absoluto na forma da consciência-de-si universal individualizada: a pura inteligência efetivando-se. Esta efetivação abstrata enquanto efetivação da abstração é a verdadeira forma do espírito filosófico. Para Hegel,

[...] apenas o espírito é a verdadeira essência do homem, e a verdadeira forma do espírito é o espírito pensante, o espírito lógico, especulativo. A humanidade da natureza e da natureza criada pela história, dos produtos do homem, aparece no fato de estes serem produtos do espírito abstrato e nessa medida, portanto, momentos espirituais, seres de pensamento. A "Fenomenologia" é, por isso, a crítica oculta, em si mesma ainda obscura e mistificadora; mas na medida em que ela retém o estranhamento do homem - ainda que este último apareça apenas na figura do espírito -, encontram-se nela ocultos todos os elementos da crítica, muitas vezes preparados e elaborados de modo que suplantam largamente o ponto de vista hegeliano (MARX, 2004, p.122, grifo no original e grifo nosso).

Assim, evidencia-se que

da mesma forma que a essência, o objeto enquanto ente do pensamento, o sujeito é, portanto, sempre consciência ou consciência-de-si, ou antes, o objeto aparece apenas como consciência abstrata, o homem apenas como consciência-de-si, as diferentes figuras do estranhamento que surgem são, por conseguinte, apenas diferentes figuras da consciência ou da consciência-de-si. Como, em si, a consciência abstrata - pois é assim que o objeto é concebido - é puramente um momento da diferenciação da consciência-de-si, assim também surge como resultado do movimento a identidade da consciência-de-si com a consciência, o saber absoluto, o movimento realizado do pensamento abstrato enquanto resultado que não [se passa] mais fora de si, mas somente em si mesmo como resultado; isto é, a dialética do pensamento puro é o resultado (MARX, 2004, p.123, grifo no original e grifo nosso).

A riqueza da Filosofia Hegeliana, portanto, não se encontra em suas considerações finais, no resultado de seu trabalho, mas mais propriamente nesta dialética do pensamento puro, no movimento de negação, da crítica, enquanto motor e gerador da humanidade:

a grandeza da "Fenomenologia" hegeliana e de seu resultado final - a dialética, a negatividade enquanto princípio motor e gerador - é que Hegel toma, por um lado, a autoprodução do homem como um processo, a objetivação como desobjetivação, como exteriorização e suprassunção dessa exteriorização; é que compreende a essência do trabalho e concebe o homem objetivo, verdadeiro, porque 
homem efetivo, como o resultado de seu próprio trabalho (MARX, 2004, p.123, grifo no original e grifo nosso).

É esta herança uma das quais procurarmos rememorar neste capítulo: o processo propriamente dito de evidenciação da negação dialética, que apresenta o positivo enquanto momento que se positiva ao negar. A gênese humana e de sua natureza é, portanto, o imanente efetivar-se desta humanidade e de sua natureza. Este efetivar-se, entretanto, é crítico, pois é um efetivar-se estranhado:

a objetividade enquanto tal vale por uma relação estranhada do homem, não correspondente à essência humana, à consciência-de-si. A reapropriação da essência objetiva do homem, produzida enquanto [algo] estranho sob a determinação do estranhamento, tem assim não somente o significado de suprassumir $o$ estranhamento, mas a objetividade, ou seja, dessa maneira o homem vale como uma essência não-objetiva, espiritualista (MARX, 2004, p.125, grifo no original e grifo nosso).

O estranhamento, portanto, é o movimento mesmo da objetividade humana. Assim, o suprassumir deste estranhamento na forma da racionalidade é o suprassumir de sua determinação objetiva. A produção do estranhamento humano em relação à sua natureza objetiva é o engendrar da propriedade privada, não apenas em sua forma jurídica, mas em sua forma efetiva-objetiva. É neste sentido que Marx vai constatar que “[...] é totalmente falso dizer: a consciência-de-si tem olho, ouvido, força essencial. A consciência-de-si é, antes, uma qualidade da natureza humana, do olho humano etc., não é a natureza humana [que é] uma qualidade da consciência-de-si. O Si abstraído e fixado para si é o homem enquanto egoísta abstrato, que em sua pura abstração é o egoísmo elevado ao pensar" (MARX, 2004, p.125, grifo no original e grifo nosso).

Assim, a razão aparece para Marx como uma das formas de efetivação do homem, mas não como a totalidade de sua efetivação, como sua essência verdadeira. Destarte, o homem não produz sua natureza de acordo com as determinações de sua consciência, mas é antes uma impostura desta natureza que se faz consciente desta impostura já na forma da impostura. Esta natureza, ademais, é o engendrar social da natureza humana. E o evidenciar deste engendrar na forma da impostura naturalista-humanista é a crítica a que nos filiamos. Esta crítica é a evidenciação da reposição do estranhamento na forma de sua negação lógica, enquanto negação da negação. Para Hegel, "a ciência que conceitua isto se chama, por conseguinte, Fenomenologia. Toda reapropriação da essência objetiva estranhada aparece, então, como uma incorporação da consciência-de-si; o homem apoderado de sua essência é apenas a 
consciência-de-si apoderada da essência objetiva. O retorno do objeto ao si é, portanto, a reapropriação do objeto" (MARX, 2004, p.125, grifo no original e grifo nosso).

Assim, a efetividade humana não seria absolutamente subjetiva, ou seja, "como o homem efetivo enquanto tal não é construído como sujeito, e por isto a natureza também não - o homem é a natureza humana -, mas apenas a abstração do homem, a consciência-de-si, então a coisidade só pode ser a consciência-de-si exteriorizada [...]” (MARX, 2004, p.126, grifo no original e grifo nosso). Destarte, a coisa em-si não é, portanto, absolutamente uma autonomia essente perante o sujeito, mas uma coisa simples, uma impostura da consciência, a qual se confirma nesta impostura. A coisa da certeza sensível, portanto, não pode confirmar a si mesma, mas confirma o ato de pôr. Assim, a geograficidade do ser não se confirma pela sua objetividade material, sensível, mas confirma, antes, o engendrar desta sensibilidade enquanto momento da constituição de uma consciência geográfica do ser humano:

[...] a coisidade de maneira alguma é, portanto, [algo] autônomo, essencial diante da consciência-de-si, mas sim uma simples criatura, um [algo] posto por ela, e o [algo que é] posto, ao invés de confirmar-se a si mesmo, é apenas uma confirmação do ato de pôr, que por um instante fixa sua energia como o produto e, para fazer de contamas só por um momento -, lhe concede o papel de um ser autônomo, efetivo (MARX, 2004, p.126, grifo no original e grifo nosso).

Este movimento de impostura da razão pela ação, ou a evidenciação do ato de pensar enquanto ato efetivo-objetivo, é a contribuição da reflexão filosófica de Marx para esta obra. Assentar a natureza enquanto humanidade estranhada em sua própria sensibilidade constitui o percurso filosófico que almeja evidenciar este estranhamento enquanto fundamento negativo da certeza.

\footnotetext{
Quando o homem efetivo, corpóreo, com os pés bem firmes sobre a terra, aspirando e expirando suas forças naturais, assenta suas forças essenciais objetivas e efetivas como objetos estranhos mediante sua exteriorização, este assentar não é o sujeito; é a subjetividade de forças essenciais objetivas, cuja ação, por isso, tem também de ser objetiva. O ser objetivo atua objetivamente e não atuaria objetivamente se o objetivo não estivesse posto em sua determinação essencial. Ele cria, assenta apenas objetos, porque ele é assentado mediante esses objetos, porque é, desde a origem, natureza. No ato de assentar não baixa, pois, de sua "pura atividade" a um criar do objeto, mas sim seu produto objetivo apenas confirma sua atividade objetiva, sua atividade enquanto atividade de um ser natural objetivo (MARX, 2004, p.126-127, grifo no original e grifo nosso).
}

Assim, evidencia-se que "o homem é imediatamente ser natural" (MARX, 2004, p.127, grifo no original e grifo nosso). Ademais, é imediatamente um ser natural que existe para si mesmo, ou seja, que se sabe enquanto existência verdadeira, efetiva, pois sabe seu ato 
de ser natureza. Entretanto,

\begin{abstract}
o homem não é apenas ser natural, mas ser natural humano, isto é, ser existente para si mesmo, por isso, ser genérico, que, enquanto tal, tem de atuar e confirmar-se tanto em seu ser quanto em seu saber. Consequentemente, nem os objetos humanos são os objetos naturais assim como esses se oferecem imediatamente, nem o sentido humano, tal como é imediata e objetivamente, é sensibilidade humana, objetividade humana. A natureza não está, nem objetiva nem subjetivamente, imediatamente disposta ao ser humano de modo adequado (MARX, 2004, p.128, grifo no original e grifo nosso).
\end{abstract}

Quando enunciava o complexo bio-ontológico, Martins (2007) aparentemente buscou assentar uma ontologia mundana com base nesta referência, bem como no existencialismo filosófico. Entretanto, o ponto de grande contribuição da Filosofia crítica em Hegel e Marx é o evidenciar deste enunciar enquanto um engendrar efetivo, e não um assentar, propriamente dito, da natureza humana no céu, na terra ou em qualquer outro lugar bio-ontológico. A contribuição, portanto, desta Filosofia para nossa ciência não é positiva, mas negativa, pois evidencia a negatividade enquanto autoengendramento humano extrusado na objetividade efetiva da natureza. Este "extrusado" é a constituição geográfica do ser. Assim, se assentamos a ciência geográfica no desvelamento da geografia do ser, assentamos esta ciência nela mesma, em seus próprios termos lógicos, que não superam em nada sua necessidade. Em outras palavras, a finalidade da ciência geográfica fica reduzida a sua reposição mesma enquanto ciência. Esta reposição, portanto, é a impostura de um homem que é geográfico, ou seja, é a impostura da ciência geográfica efetiva.

O que a ciência geográfica toma por objeto, portanto, é o engendrar mesmo de uma subjetividade objetiva. Esta subjetividade, entretanto, é estranhada, pois estranha-se a si mesma na objetividade externada, conforme indicamos previamente. Para Hegel, a suprassunção deste estranhamento é o retorno da consciência à consciência-de-si, o Saber Absoluto. Para Marx, este "retorno" é a reposição do estranhamento, sua reprodução efetiva:

[...] a apropriação do ser objetivo estranhado ou a suprassunção da objetividade sob a determinação do estranhamento - que tem de ir da estranheza desinteressada até o efetivo estranhamento hostil - tem para Hegel, ao mesmo tempo e até principalmente, a significação de suprassumir a objetividade, pois não é o caráter determinado do objeto, mas sim seu caráter objetivo que constitui, para a consciência-de-si, o escandaloso e o estranhamento. O objeto é por isso um negativo, um [negativo] que suprassume a si mesmo, uma nulidade. Esta nulidade do mesmo não tem para a consciência uma significação apenas negativa, mas positiva, pois aquela nulidade do objeto é justamente a autoconfirmação da não-objetividade, da sua própria abstração. Para a consciência mesma, a nulidade do objeto tem, por isso, um significado positivo, posto que ela sabe esta nulidade, o ser objetivo, como sua auto- 
exteriorização. O modo como a consciência é, e como algo é para ela, é o saber. $\mathbf{O}$ saber é seu único ato. Por isso, algo vem-a-ser para ela na medida em que ela sabe este algo. Saber é o seu único comportamento objetivo. Ora, a consciência-de-si sabe a nulidade do objeto, isto é, o ser-não-distinto do objeto com relação a ela, o não-ser do objeto para ela, na medida em que ela sabe o objeto enquanto sua autoexteriorização, isto é, ela se sabe - o saber como objeto - na medida em que o objeto é apenas a aparência de um objeto, uma emanação enganadora, o seu ser nada além do que o saber mesmo, o qual se confrontou consigo mesmo e, por isso, opôs a si uma nulidade, um algo que, fora do saber, não tem nenhuma objetividade; ou o saber sabe que enquanto se relaciona com um objeto, está apenas fora de si, se exterioriza; que ele mesmo aparece a si somente enquanto objeto, ou que o quê aparece para ele como objeto é somente ele mesmo. Por outro lado, diz Hegel, está aqui presente ao mesmo tempo este outro momento: que ela \{a consciência-de-si\} igualmente suprassumiu e recuperou dentro de si esta exteriorização e esta objetividade, e está, portanto, junto de si em seu ser-outro enquanto tal. Nesta exposição temos, juntas, todas as ilusões da especulação (MARX, 2004, p.128-129, grifo no original e grifo nosso).

Para Marx, Hegel assenta na suprassunção do estranhamento, no retorno da objetividade em-si ao para-si da consciência-de-si, no Saber Absoluto, na Fenomenologia da Experiência da Consciência, enfim, no pensamento mesmo a superação da forma do estranhamento, da dissimulação da verdade. Entretanto, esta superação, nestes termos, seria não mais que ilusória, meramente especulativa, pois “a razão está [...] junto de si na não-razão enquanto não-razão” (MARX, 2004, p.130, grifo no original e grifo nosso), ou seja, a razão é o operar da irracionalidade da objetividade estranhada e, portanto, está junto de si na não-razão.

Neste sentido, a questão religiosa fica deslocada para o plano da afirmação de si mesmo da consciência-de-si, e não constitui a consciência-de-si efetiva, mas a confirmação desta efetivação da consciência-de-si: "Se eu sei a religião como consciência-de-si humana exteriorizada, sei portanto nela, enquanto religião, não minha consciência-de-si, mas minha consciência-de-si exteriorizada e confirmada nela. Meu si-mesmo, a consciência-de-si pertencente à sua essência, eu o sei, portanto, confirmado não na religião, mas antes na religião aniquilada, suprassumida" (MARX, 2004, p.130, grifo no original e grifo nosso). Portanto, sei não minha consciência-de-si em si, mas minha consciência de si que se exterioriza e se confirma nesta exteriorização como certeza da religião e, consequentemente, da exteriorização mesma da consciência-de-si. Sei não o objeto determinado, mas a objetividade, o fato misterioso de que seja objetiva a realidade, de que ela se objetive. Assim, meu si-mesmo, o emsi-para-si de Hegel, eu o sei não porque se confirma na religião, mas porque abstrai dela; porque, por um lado, se externa, mas já pelas costas da consciência-de-si retorna como abstração, como negação da efetividade, como certeza de que se é em-si.

Destarte, para Marx, por um lado, “a existência que Hegel suprassume na Filosofia 
não é, portanto, a religião, o Estado, a natureza efetivas, mas a própria religião já como um objeto do saber, a dogmática, assim como a jurisprudência, a ciência política, a ciência natural" (MARX, 2004, p.131-132, grifo no original e grifo nosso). Destarte, na "Fenomenologia", Hegel evidencia, no interior da abstração, o ato de produção de si do homem, seu autoengendramento estranhado, do qual emerge sua vida enquanto uma vida genérica, que vem a ser pelo trabalho. Entretanto, este evidenciar aparece como abstração, como espiritismo.

Por outro lado, o processo de externação da vida humana como produção efetiva desta vida se constitui na forma da subjetividade - para que haja razão, é necessária que ela seja propagada por portadores, seres certos de si mesmos como racionalidades. Entretanto, este sujeito racional é um produto objetivo, um resultado:

[...] este processo \{de externação da vida humana\} tem de ter um portador, um sujeito; mas o sujeito só vem a ser enquanto resultado; este resultado, o sujeito que se sabe enquanto consciência-de-si absoluta, é, por isso, o Deus, o espírito absoluto, a ideia que se sabe e aciona. O homem efetivo e a natureza efetiva tornam-se meros predicados, símbolos desse homem não efetivo oculto, e desta natureza inefetiva. Sujeito e predicado têm assim um para com o outro a relação de uma absoluta inversão, sujeito-objeto místico ou subjetividade que sobrepuja o objeto, o sujeito absoluto como um processo, como sujeito exteriorizando-se e retornando a si da exteriorização, mas, ao mesmo tempo, retomando-a de volta em si, e o sujeito como este processo; o puro círculo infatigável em si (MARX, 2004, p.133, grifo no original e grifo nosso).

Assim, para Marx o sujeito consciente-de-si é um produzir objetivo-efetivo que apareceria para o pensamento hegeliano como superação desta objetividade estranhada pela via da razão. O sujeito, portanto, não seria o momento da externação objetiva da consciência-de-si que opera na experiência da consciência em geral, mas a impostura mesma da objetividade enquanto uma efetividade irracional da qual emerge a racionalidade enquanto certeza de si mesma da consciência-de-si efetivamente estranhada em-si, nesta objetividade externada. A razão, portanto, é o momento de afirmação da subjetividade que se questiona a si mesma de sua objetividade, ou melhor, é a certeza de si mesmo da consciência-de-si perante a sua objetividade estranhada. A objetividade, portanto, é o reino do autoproduzir-se do sujeito efetivo, não é uma impostura do saber operante, mas é o produzir mesmo deste saber como algo que emerge desta objetividade enquanto certeza objetiva.

Neste sentido, uma das contribuições de Hegel para a Filosofia crítica residiria na evidenciação da centralidade do estranhamento para sua concepção do pensar humano. Os conceitos, as formas de pensamento universais, a autonomia do operar da racionalidade individual diante da natureza e do pensamento, resultam deste estranhamento universal da 
essência humana e se constituem enquanto uma fenomenologia da abstração. Entretanto, para Marx, "a abstração que se apreende como abstração sabe-se como nada; ela tem de renunciar à abstração, e chega assim junto a um ser que é precisamente o seu contrário, junto à natureza. Toda lógica é, portanto, a prova de que o pensar abstrato por si nada é, de que a ideia absoluta por si nada é, de que somente a natureza é algo [...]” (MARX, 2004, p.133134, grifo no original e grifo nosso). Assim, é preciso assentar a abstração não nos termos mesmos da abstração, mas na efetividade objetiva a que ela se refere. Entretanto, este assentar já é abstrato:

[...] a pensador abstrato experimenta, junto de sua intuição da natureza, que os seres que ele, na dialética divina, imaginava criar a partir do nada, da pura abstração, como produtos puros do trabalho do pensar que se tece sobre si próprio e nunca olha para fora em direção à efetividade, nada mais são que abstrações de determinações da natureza. A natureza inteira repete para ele, portanto, apenas em forma sensível, externa, as abstrações lógicas. Ele a analisa novamente nestas abstrações. Sua intuição da natureza é, portanto, somente o ato de confirmação de sua abstração da intuição da natureza, o curso gerador de sua abstração, repetido por ele com consciência (MARX, 2004, p.136, grifo no original e grifo nosso).

Assim, a constituição do argumento científico válido é a constituição da certeza de verdade imanente, natural, como não-verdade, como confirmação da verdade abstrata: "a natureza enquanto natureza, isto é, na medida em que ainda se diferencia sensivelmente daquele sentido secreto oculto nela, a natureza separada, diferenciada destas abstrações, é nada, um nada confirmando-se enquanto nada, é sem-sentido ou tem apenas o sentido de uma externalidade que tem de ser suprassumida. Seu objetivo é a confirmação da abstração” (MARX, 2004, p.136, grifo no original e grifo nosso).

Assim, o estatuto lógico que se constitui como garantidor da validade científica do argumento geográfico que se apresenta nos dois primeiros capítulos desta reflexão tem como necessidade a garantia mesma desta validade e sua finalidade é a reprodução desta necessidade mesma enquanto forma de reprodução do argumento lógico. O saber válido, portanto, é o saber que se apresenta abstratamente, pois o verdadeiro é a ideia. Entretanto, esta verdade é a dissimulação mesma da ideia, ou seja, sua fenomenologia, que revelaria o seu fundamento irracional. Este fundamento é a diferença entre pensar e ser. Esta diferença, portanto, é a diferença da qual as partes não podem prescindir, pois são mutuamente dependentes entre si:

[...] o verdadeiro é ainda a ideia. A natureza é somente a forma de seu ser-outro. E, como o pensar abstrato é a essência, aquilo que lhe é externo é, segundo sua essência, apenas um externo. $\mathrm{O}$ pensador abstrato reconhece, ao mesmo tempo, que a 
sensibilidade é a essência da natureza, a externalidade em oposição ao pensar tecendo-se em si. Mas simultaneamente ele exprime essa oposição de tal forma que esta externalidade da natureza é sua oposição ao pensar, sua deficiência, que ela \{a natureza \}, na medida em que se diferencia da abstração, é um ser deficiente. Um ser deficiente não apenas para mim, aos meus olhos, um ser em si mesmo deficiente, tem fora de si algo que lhe falta. Isto é, sua essência é algo diferente dele mesmo. Para o pensador abstrato, a natureza tem, portanto, de se suprassumir a si mesma, porque já foi posta por ele como um ser em potência suprassumido (MARX, 2004, p.137, grifo no original e grifo nosso).

Assim, a efetividade apresenta-se como uma contradição entre ser e pensar, entre objetividades em-si-essentes e o pensar objetivamente essas objetividades, entre autoengendramento da natureza e o apreender racional desta natureza enquanto pensamento social da natureza ou pensamento natural da sociedade. A Geografia, portanto, constitui-se nesta contradição entre ser objetivo e objetividade pensada: é a efetividade que se efetiva tanto como irracionalidade efetiva quanto como racionalidade efetiva.

Neste sentido, como poderíamos constituir uma crítica à geografia da efetividade que se apresenta nos termos de uma análise da relação entre impermeabilização do solo e a distribuição dos óbitos associados às doenças do aparelho circulatório?

Primeiramente, esta "relação" não é puramente analítica, do ponto de vista lógico. Constitui-se, todavia, enquanto uma relação social de produção. Ademais, a “análise” também se constitui enquanto uma relação de (re)produção da cientificidade propriamente dita, conforme temos demonstrado. Assim, os "termos" da crítica a serem definidos operam segundo a contraditoriedade imanente engendrada no âmbito da efetividade do ser e de seu pensamento geográfico. Destarte, tendo em vista esta "imanência", o objeto definido no âmbito dos dois primeiros capítulos reconstitui-se enquanto uma relação social cuja crítica, ainda que se apresente na forma da dissimulação da verdade, deve evidenciar a constituição desta relação enquanto o engendrar da geografia mesma.

Por fim, no capítulo a seguir tratar-se-á, fundamental e principalmente, das temáticas da causalidade, da sensibilidade e da dialética em Nietzsche, outro importante filósofo alemão que constitui o tripé principal que sustenta nossas reflexões em torno da defesa que procuramos efetuar. 


\title{
5. Da Cidade Colonial Moderna, de Seus Corpos e de Suas Sombras
}

\author{
“Agora meu martelo investe furiosamente contra a sua prisão. A pedra solta \\ estilhaços; que me importa? \\ Quero completar isso: pois uma sombra veio até mim - a mais silenciosa e mais leve \\ das coisas veio um dia até mim!"
} (NIETZSCHE, 2018, p.83).

O que é a sombra do ente? Ouvi dizer, em oportunidade recente, na qual estive participando do XVII Ecuentro de Geógrafos de América Latina, realizado entre os dias 9 e 12 de abril de 2019 na cidade de Quito, capital do Ecuador, que alguns povos incaicos acreditavam que a sombra seria uma espécie de alma, que sempre os acompanhava. Sabe-se que o Sol, e Lua e os demais astros ocupam lugar de relevo nas religiões incaicas. Ademais, Quito, por sua configuração geomorfológica e localização geodésica, destaca-se como locus de observação dos fenômenos astronômicos, especialmente daqueles relacionados aos movimentos solares e lunares.

Some-se a estas pequenas verdades a informação de que a Linha do Equador passa por Quito e que, por este motivo, durante os Equinócios de Primavera e de Outono, é possível vivenciar um fenômeno interessante neste lugar: a ausência completa de sombra durante o dia. Este fenômeno teria impressionado os Incas durante os 40 anos de dominação incaica prévia ao período colonial espanhol que a região de Quito vivenciou. Destarte, o Sol ocupara um lugar divino no sentido existencial pré-colonial quiteño. A localização dos templos pré-coloniais dos povos incas e pré-incaicos demonstra esse sentido divino de existência, que fora, durante o período colonial, fundamental para o processo de urbanização, ou seja, para o processo de constituição de um modo citadino e, consequentemente, urbano de dominação colonial.

Uma das faces deste modo urbano de colonização pode ser evidenciada na relação estabelecida entre os colonizadores e os templos incaicos e pré-incaicos. Estes templos, quando da dominação espanhola, foram destruídos e as suas rochas foram reutilizadas para a construção das igrejas cristãs, tendo sido estas erigidas exatamente nos mesmos locais nos quais se situavam os templos dos povos nativos. Assim, de um certo ponto de vista científico, os espanhóis conseguiram capturar os efeitos luminosos oriundos da radiação solar que eram objeto de adoração para os povos incaicos e pré-incaicos. Os cristãos escravizaram não somente o corpo, mas o Espírito incaico. Ao corpo do indígena ataram correntes, mas o Espírito, a este a punição fora mais severa: atou-se lhe a cidade (forma material do poder cristão/científico). 
O que foram as igrejas coloniais? Centros religiosos? Certamente. Mas qual era o lugar da religião neste momento histórico em que a Igreja á indissociável do Estado?

Pedro de Almeida Vasconcelos (1996), em suas considerações sobre Os Agentes Modeladores das Cidades Brasileiras no Período Colonial, destaca "[...] como principais agentes modeladores das cidades: (1) a Igreja; (2) as ordens leigas; (3) o Estado; (4) os agentes econômicos; (5) a população e os movimentos sociais (VASCONCELOS, 1996, p.249). Notase que esta ordem de apresentação dos agentes equivale a sua importância e grau de atuação na morfogênese da cidade colonial, conforme Vasconcelos (1996) deixa claro em seu texto.

Sobre o papel da Igreja, um dos principais agentes modeladores da cidade colonial, Vasconcelos considera dois aspectos fundamentais: 1) do papel do clero secular - que teria tido uma atuação caracteristicamente político-burocrática; 2) do papel do clero regular - cuja atuação fora fundamental para a estruturação das cidades coloniais.

A estrutura hierárquica da Igreja Católica esteve - está - no período colonial intimamente ligada ao Estado. Segundo Vasconcelos, do ponto de vista formal, a Igreja esteve unida ao Estado

[...] pelo estabelecimento do Padroado e, por outro lado, pelas ordens religiosas, relativamente independentes do Estado e da hierarquia local. O Padroado correspondia, no Brasil, a um acordo entre o Papado e a Coroa portuguesa, em que a mesma recebia os dízimos relativos à Igreja, e ficava responsável pela manutenção da Igreja no Brasil (VASCONCELOS, 1996, p.249-250, grifo no original)

Destarte, um dos papéis estratégicos que o clero secular detinha era o de definir

[...] a localização da catedral e das igrejas matrizes, assim como delimitava as áreas territoriais correspondentes (paróquias). Essas divisões em paróquias e freguesias tiveram importância, até o momento atual, nas consequentes divisões administrativas das cidades. As igrejas matrizes correspondiam aos núcleos das paróquias (e dos futuros bairros), tendo uma importante função social, tanto no que se refere ao local de encontros e sociabilidade [...] como no papel de registro civil (censo, batismo, casamento etc.) (VASCONCELOS, 1996, p.250-251, grifo nosso).

Assim, evidencia-se o papel fundamental da Igreja na constituição da cidade, extensão necessária do corpo do homem moderno, possibilidade e impossibilidade de seu sol e sua sombra. Além do mais, o clero regular teve um papel fundamental na estruturação das cidades coloniais. 
As ordens que se estabeleceram em primeiro lugar, como a dos jesuítas, localizaramse perto dos núcleos iniciais (Salvador, Rio de Janeiro, Olinda), e as que chegaram posteriormente foram se instalando nas periferias imediatas das cidades, inclusive extramuros, como no caso de Salvador (beneditinos e carmelitas). Mas, sendo grandes consumidores de terrenos, tanto pelo seu porte como pelas suas atividades complementares (hortas, estábulos etc.), os conventos tiveram um papel de ponta na expansão urbana colonial: localizados nas periferias, nos finais dos eixos de crescimento urbano, tendiam a atrair o crescimento das cidades em sua direção (VASCONCELOS, 1996, p.252, grifo nosso).

Ademais, “em São Paulo o convento dos jesuítas, junto ao colégio, deu origem à cidade. Os conventos dos beneditinos, das carmelitas e dos franciscanos formavam o "triângulo" que delimitava o atual centro de São Paulo" (VASCONCELOS, 1996, p.253, grifo nosso). Neste sentido, Vasconcelos (1996) indica claramente o papel central da Igreja na “origem” da cidade de São Paulo. E não apenas a Igreja exercia um papel religiosamente estatal na cidade colonial brasileira, mas as ordens leigas também, especialmente aquelas de "maior prestígio", como as das

[...] Irmandades de Misericórdia, exclusiva dos brancos, excluindo aqueles que tivessem ascendência judia, moura ou negra. Essa ordem teve papeis muito importantes na cidade colonial, que foram assumidos posteriormente pelo Estado: ocupavam-se dos enfermos, implantando os primeiros hospitais brasileiros; cuidava dos enterros, inclusive de escravos; da assistência aos presos; da sustentação de moças pobres em recolhimentos, fornecendo dotes, e dos órfãos em geral (VASCONCELOS, 1996, p.254, grifo nosso).

O que se depreende desta sociedade colonial e, portanto, necessariamente racista, a qual oferece suporte aos "necessitados" pelas mãos de um dos setores mais conservadores da sociedade de então? Ademais, o que faz pensar sobre o papel do Estado, e da finalidade de suas funções?

Além do já exposto, ressalta-se que as confrarias consideradas de "menor prestígio"

[...] realizavam seus cultos, inicialmente numa capela de uma igreja ou de uma igreja de convento, em seguida estabeleciam capelas próprias, e posteriormente edificaram igrejas de porte. Em geral, localizavam-se nas periferias. No caso de Salvador, as igrejas do Rosário dos Pretos e a da Barroquinha, de irmandades de cor, estavam imediatamente fora dos muros da cidade. Em Olinda a igreja de N. S. do Guadalupe, dos pardos, e a igreja do Rosário dos Negros eram periféricas, mas em Recife, a igreja do Rosário dos Negros tinha uma localização perto do centro (VASCONCELOS, 1996, p.255-256, grifo nosso).

Um dos apontamentos que se pode inferir desta citação, que dá ênfase à questão do surgimento das periferias, é o que as regiões periféricas da cidade possuem em comum com 
os centros urbanos da colônia, e não exatamente a relação entre o prestígio e composição dessas ordens e a distância que estavam em relação aos centros das cidades coloniais: o elemento comum é a Igreja. A Igreja constituiu, grosso modo, a semente de um dos mecanismos de colonização moderna mais eficazes: a cidade. Tanto os centros das cidades coloniais quanto suas periferias, a despeito das diferenças que constituíam, possuíam um elemento comum fundamentalíssimo: a Igreja. A Igreja, portanto, era a medida da Cidade e de seu sucesso colonizatório. Mas que medida, em que medida? A medida da doença, da indisposição fisiológica cultivada como canteiro para o verme-consciência: "o cristianismo necessita da doença, mais ou menos como a cultura grega necessita de uma abundância de saúde - tornar doente é a genuína intenção oculta de todo o sistema de procedimentos de salvação da Igreja. E a Igreja mesma - não é o hospício católico como ideal derradeiro?” (NIETSZCHE, 2016, p.60, grifo no original). Tornar doente, fisiologicamente indisposto, não era a razão de toda teologia cristã? Não teria sido a razão colonizatória um tanto inspirada neste terrível manual fisiológico denominado "catolicismo"? Que fizeram e fazem com os "Índios"? Que fizeram e fazem com os "Negros"? Que fizeram e fazem com as "Mulheres”? Não há uma terrível seleção acontecendo?

Neste sentido, durante o período colonial, a relevância da Igreja e das famílias influentes associadas a ela constituem o papel reduzido do que se convenciona definir hodiernamente como Estado, ainda que este papel não tenha sido pouco complexo.

O Estado no período colonial tinha uma organização bastante complexa, embora tivesse funções bem mais restritas que o Estado atual. Destacava-se seu papel de apoio às atividades econômicas, na sustentação dos funcionários, do clero (e na manutenção das Igrejas), e sobretudo na realização de obras defensivas, e, mais recentemente, na sustentação das tropas. As Câmaras tinham um papel importante na condução dos negócios das cidades (VASCONCELOS, 1996, p.156-257, grifo nosso).

O papel do Estado nas cidades coloniais era fundamental, dentre outras coisas, por garantir o poder jurídico-político da Coroa sobre as suas Colônias. A efetiva existência da cidade colonial, portanto, contava com a ação efetiva do Estado, dentre cujas funções estava o de manter o clero, parte constituinte de sua estrutura institucional.

As Câmaras Municipais, por sua vez, eram responsáveis pelo “[...] controle das atividades urbanas: decidiam sobre impostos, taxas, controle de preços, limpeza das ruas, destino do lixo; sobre os animais nas ruas; sobre o comportamento dos escravos etc" (VASCONCELOS, 1996, p.259-260, grifo nosso). Ademais, “o controle das Câmaras estava 
nas mãos dos "homens bons", em geral proprietários de terra, que deveriam também residir nas cidades. Em meados do século XVIII os comerciantes também foram autorizados a participar da administração municipal” (VASCONCELOS, 1996, p.260, grifo nosso).

O papel das Câmaras, portanto, estava especialmente direcionado para o controle da rotina urbana, das atividades da cidade e do comportamento dos escravos e dos homens livres, bem como definindo quem poderia participar das decisões estatais sobre a cidade, ou seja, definindo quem seriam os "homens bons" - bondade que se media pelas propriedades que os ditos homens possuíam. A propriedade, portanto, como argumento definitivo para a defesa dos valores cristãos. Valores civis, citadinos, urbanos: “o cristão, em especial o cristão sacerdote, é um critério de valores" (NIETSZCHE, 2016, p.55, grifo no original).

Neste sentido, a conclusão a que chega Vasconcelos (1996, p.268) ressalta "o papel dominante da Igreja e do Estado nas cidades coloniais", indicando especialmente que "os estabelecimentos religiosos, importantes nas paisagens das cidades coloniais brasileiras, conforme se pode observar nos frontispícios traçados, refletiam o papel da Igreja ao longo do período e a importância que a população dava às questões religiosas, inclusive deixando parte da herança para fins religiosos, em detrimento de outros herdeiros" (VASCONCELOS, 1996, p.269). Ademais, o referido autor ressalta que "o papel da Igreja tem sido pouco destacado nos estudos urbanos. Mas, no Brasil, no período colonial, podemos afirmar que seu papel foi determinante na estruturação das cidades" (VASCONCELOS, 1996, p.270, grifo nosso).

Maurício de Almeida Abreu (1996), por sua vez, também dá relevo ao papel da Igreja nas cidades coloniais, rememorando e reforçando as considerações de Murilo Marx sobre a ligação umbilical entre Igreja e Estado.

Esta finalidade "colonizatória" das cidades coloniais fica mais clara ainda se somarmos ao exemplo nacional outras realidades coloniais, como é o caso das Colônias Espanholas, ao qual nos referimos brevemente acima. De acordo com Abreu (1996, p.147),

[...] a conquista espanhola alicerçou-se, desde o início, na fundação de cidades, uma prática que acabou sendo oficializada pela metrópole a partir de 1573, quando foram promulgadas as Ordenações de Descobrimento e de Povoamento de Felipe II, também conhecida como "Leis das Índias", um verdadeiro guia orientador de todo o processo de colonização espanhola e que tem sido apontado como o primeiro código de urbanismo da idade moderna.

Durante anos, as cidades coloniais brasileiras foram definidas pelos historiadores como um 
[...] produto da imprevidência, [...] [e] contrastariam flagrantemente com aquelas da América Espanhola, onde a implantação de núcleos urbanos foi prevista rigorosamente pela Coroa, que impunha a adoção do plano em grelha, do tabuleiro de xadrez, e que chegava a detalhar os locais onde seriam construídos os edifícios da administração, as igrejas, os conventos, e mesmo as residências da elite da terra (ABREU, 1996, p.151).

Entretanto, sabe-se hoje que estas afirmações são precipitadas, pois, de acordo com Abreu (1996, p.152), "se a comparação de planos de cidades revela, sem dúvida, diferenças marcantes quanto à forma urbana implantada por espanhóis e portugueses na América, ela não é suficiente para que se conclua que as cidades brasileiras surgiram e se estruturaram avessas a qualquer ordem", ou seja, as cidades coloniais brasileiras, especialmente as de maior relevância para o domínio colonial, "surgiram e se estruturaram” segundo uma “ordem”. A disputa teórica em torno da existência ou não de uma "ordem urbanística colonial" revela que, primeiramente, parece ter havido tal ordenamento e, em segundo lugar, que este ordenamento é existente nos dias de hoje, pois o que se procura é sua gênese, a gênese do urbanismo brasileiro moderno e da moderna forma da cidade. O argumento que apresento face a estas teorias é: tal ordenamento é o processo mesmo de colonização, a instituição de cidades, seja ao modo espanhol ou português. Pois, seja ao modo português ou espanhol, a catequese parece ter sido "a primeira função urbana \{ da cidade colonial\}", como afirma Pierre Monbeig (1957, p.84) para o caso da cidade de São Paulo.

Destarte, quando os espanhóis ou os portugueses constroem as igrejas como centralidades político-estatais das cidades coloniais e, consequentemente, instaura-se o processo de urbanização enquanto fundamento do processo de dominação colonial, cria-se uma das mais perversas máquinas modernas: a cidade colonial.

Assim sendo, a constituição de um processo de impermeabilização do solo está intimamente relacionada a esta constatação sobre o sentido colonial, ainda efetivo, da cidade moderna latino-americana. O processo de impermeabilização do solo é parte constituinte desta ontogênese do sujeito moderno colonial: a concretude de seu Espírito é pétrea; seu corpo é um templo, uma casa, uma rua, uma empresa, um parque - ou a ausência deste parque -, é um bairro, ou uma quadra deste bairro, é tudo isto sendo parte disto e parte para além do propriamente aqui. O pulsar de seu sistema nervoso é o tique-taque do relógio no ritmo urbano; seu fluxo sanguíneo são os fluxos de Milton Santos (2006), cujos fixos são seus órgãos urbanos. O ser humano não é um sistema endógeno, ou complexo bio-... Nem sequer é um complexo. Complexos são os sistemas, as máquinas e os organismos; e o Ser não é um sistema, nem uma máquina e muito menos um organismo, como temos tentado demonstrar desde o início. 
A efetividade do ser colonial moderno que procuramos evidenciar necessita de uma forma de compreensão no âmbito da qual o ser humano e seu ambiente sejam representados indistintamente, haja vista a particularidade histórica observada no processo colonial de constituição de cidades como a de São Paulo. Para estas realidades coloniais, observa-se que a cidade é o Espírito materializado do homem moderno, seus órgãos pétreos externados dos quais não pode abrir mão. As sombras da cidade, por sua vez, são o espírito humano abstrato, sua ciência ideal, a religião perfeita, a voz que fala intimamente como consciência-de-si-humana e que é humana porque é também sombra para além do corpo moderno. Que sentido bizarro de existência, no qual se é títere de uma parte de si mesmo compartilhada na comunhão universal de bens - materiais e imateriais (se é que estas estranhas divisas fazem algum sentido)!

Mas pior é o porvir! Pois há aqueles por aí que ainda são crentes do planejamento urbano, templários de um melhorismo barato. Como podemos melhorar a prisão mais terrível já criada, açougue de índios e de negros? "Não há sentido em fabular acerca de um "outro" mundo, a menos que um instinto de calúnia, apequenamento e suspeição da vida seja poderoso em nós: nesse caso, vingamo-nos da vida com a fantasmagoria de uma vida "outra", "melhor"”. (NIETZSCHE, 2017, p.23-24). Viver como se o melhor viver fosse o porvir. Viver como se o amanhã, ou o além, prometessem-nos cientificamente um melhor dia, uma melhor hora, um melhor lugar. "Viver de modo que já não há sentido em viver, isso torna-se o sentido da vida" (NIETZSCHE, 2016, p.49, grifo no original).

Destarte, o problema não é a cidade que queremos, mas a cidade que temos. E a cidade que temos nos têm, porque não somos senão a parte menor de um edifício, em uma rua de um bairro qualquer. Nosso corpo não nos pertence. Nos foi legado pouco, pouco nos foi permitido: apenas uma consciência falante em um pedaço de existência insignificante, cuja liberdade fora concretada ao solo. Apenas um corpo não nos é suficiente! É preciso mais que isso para que se possa existir completamente.

O corpo fora tornado apenas um pedaço insignificante da existência, um sistema, um organismo. Tudo que há para fora é muito maior do que a contingência corporal e o para fora, portanto, é o lugar do Ser. A história colonial evidencia esta exterioridade do Ser no próprio processo de dominação colonial via urbanização e criação de cidades.

Destarte, nos parágrafos seguintes serão apresentados os fundamentos para uma concepção sensualista da cidade colonial moderna. 


\subsection{Causa e Efeito}

A cidade pode ser compreendida, no escopo da Ciência, a partir de diversas vertentes teóricas, as quais dispenso apreciar aqui por motivos de brevidade. Independentemente dos pormenores, os "pormaiores" dessas diversas, distintas e contrariantes teorias são científicos, certamente. Se não fossem, não ocupariam lugar em títulos de Ciência nas ilustres estantes acadêmicas. Dito isto deste modo, a cidade, cientificamente soletrada, é um meandro de causas e efeitos. Meandro político, meandro social, meandro racial, meandro sexual, meandro cultural e, não menos importante, meandro fluvial. Causa e Efeito levam a cabo a cidade.

"Mas uma coisa é o pensamento, outra é o ato, e ainda outra, a imagem do ato. A roda da causalidade não gira entre eles" (Nietzsche, 2018, p.37, grifo nosso), assim falou Zaratustra. Se tomamos como referência este notável e extrapolamos suas reflexões para nossas páginas, que faço da Ciência Geográfica de nossos dias? Devo ponderar como se aplica esta crítica aos trabalhos geográficos, suas causas e efeitos? Não seria este o maior desatino, um desrespeito com a literatura consultada?

Não estou em briga de autoridades. Nem em rixa de menores, apequenados estatais. Apenas gostaria de expressar o seguinte: quando disse que a Ciência responde a "Por quê?" como se "Como" fosse, dizia também que a causalidade é justificada em um plano religioso. Nietzsche, assim como Hegel e Marx, aprofundou-se no tema com demasiada maestria, e observou a história da humanidade como o declínio desta humanidade mesma, o crepúsculo dos velhos ídolos e também do novo ídolo Estado (NIETZSCHE, 2017;2018).

Podemos observar, nas obras da tríade alemã do século XIX que se nos apresenta no decorrer desta monografia, um elemento em comum, notável, que salta aos olhos. Partindo-se deste primeiro ponto triádico em comum, será possível atingir o clímax de contribuição que Nietzsche trará para o escopo deste capítulo de minhas reflexões.

Se pensarmos o Cristianismo de forma bastante popular, não é absurda a constatação que um dos elementos mais fundamentais de sua teologia é a Santíssima Trindade: uma existência divina cindida em três distintos que são um - Pai, Filho e Espírito Santo. Freud também têm uma divina trindade: Id, Ego e Superego. Hegel explica a experiência da consciência a partir do "movimento" de suprassunção entre Certeza Sensível, Percepção e Entendimento. Marx, quando trata da Mercadoria n'O Capital, por exemplo, define-a como uma contradição entre Valor de Uso e Valor de Troca (Tríade: Mercadoria, Valor de Uso e Valor de Troca). Nietzsche, por sua vez, deixa claro que as companhias de Zaratustra são sua Águia e sua Serpente, "o mais orgulhoso animal sob o sol e o mais prudente animal sob o sol" 
(NIETZSCHE, 2018, p.23) e quando o profeta corre ele não está só, mas “[...] havia três a correr: na frente o mendigo voluntário [Jesus Cristo?], depois Zaratustra e, mais atrás, sua sombra” (NIETZSCHE, 2018, p.258).

Sacudindo para longe a numerologia que embaça a visão, o que de relevância podemos tirar destas "tri-vialidades" é aquilo que elas nos revelam: a ossatura das coisas. A lógica indutiva, a causalidade lógica, também é tripartite: Causa, Efeito e Erro - Pai, Filho e Espírito Santo. A religião das coisas, portanto, não está absolutamente enraizada nas coisas, mas na árvore das coisas - a cidade.

Para alcançarmos o patamar teórico relativo à Geografia, irei lançar mão de mais uma analogia. E como a vida sem a música é simplesmente um erro, falemos de música.

Nem sempre houve dança e música. Houve um tempo, aparentemente, em que dança e música eram uma coisa só e, portanto, não existiam como dança e música. Entretanto,

para tornar possível a música como arte distinta, foi imobilizado um certo número de sentidos, sobretudo a sensibilidade muscular (ao menos relativamente: pois, num determinado grau, todo ritmo ainda diz algo a nossos músculos): de modo que o homem já não imita e representa com o corpo tudo o que sente (NIETZSCHE, 2017, p.55, grifo nosso).

A música tornou-se, no decorrer da história da humanidade, uma arte distinta, com profundidade técnica e precisão matemática crescentes. O que Nietzsche indica nesta passagem é que a "grandiosidade" da música foi alcançada às expensas de outros sentidos humanos. Em que consiste esta grandiosidade? Aparentemente, na capacidade ampliada de controlarmos racionalmente a massa informe do som. Do mesmo modo que é possível, hoje, alguém falar uma determinada palavra e nós, letrados, escrevermos esta palavra, qualquer som pode ser escrito em um pedaço de papel.

Nos países anglo-germânicos, historicamente predominou uma forma de escrita musical denominada "Notação Literal", a qual representa as notas musicais a partir das letras do alfabeto: $\mathbf{A}=$ lá, $\mathbf{B}=$ si, $\mathbf{C}=$ dó, $\mathbf{D}=$ ré, $\mathbf{E}=$ mi, $\mathbf{F}=$ fá e $\mathbf{G}=$ sol. A notação literal é utilizada amplamente para representação dos acordes compositores dos campos harmônicos, de modo que, por exemplo, a letra “C”, em uma música, representa não apenas a nota dó, mas uma tríade maior, ou seja, um acorde composto pelas notas dó, mi e sol. Como exemplo, a seguir temos um trecho de uma música popular:

$$
\text { C } \quad \text { G }
$$

Parabéns pra você 
Nesta data querida

$\mathbf{F}$

Muitas felicidades

C $\mathbf{G} \mathbf{C}$

Muitos anos de vida

O "Parabéns pra você" pode ser escrito de outra forma, distinta da supracitada, de modo que cada nota cantada seja representada distintamente do campo harmônico que compõem, conforme figura 5.1, disposta a seguir.

Figura 5.1 - Partitura da música "Parabéns pra Você"

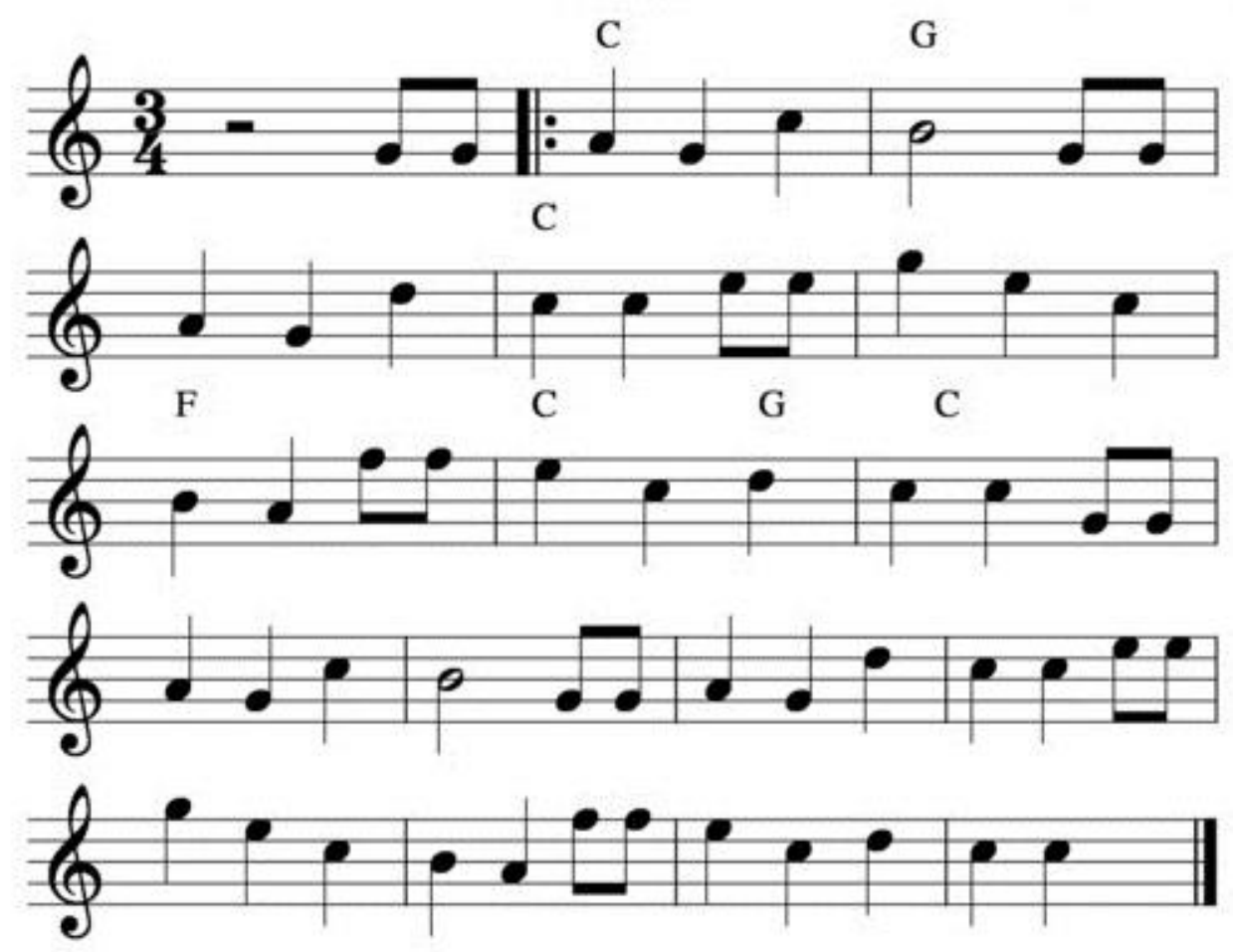

Elaboração própria. Data: 23/08/2019.

As letras representadas na parte superior dos compassos do pentagrama que compõe a partitura representam o acorde correspondente ao campo harmônico ao qual as notas grafadas pertencem. Portanto, duas coisas estão acontecendo ao mesmo tempo enquanto você canta Parabéns: há um tom dominante, no qual a música decorre, e há o que a música decorre. Entretanto, efetivamente a música é o acontecimento dessas duas coisas, harmônica e simultaneamente.

Ademais, o acorde de $\mathbf{C}$, por exemplo, pode ser grafado em uma partitura conforme ilustrado na figura 5.2, a seguir. 
Figura 5.2 - Partitura do Acorde de C (dó maior)

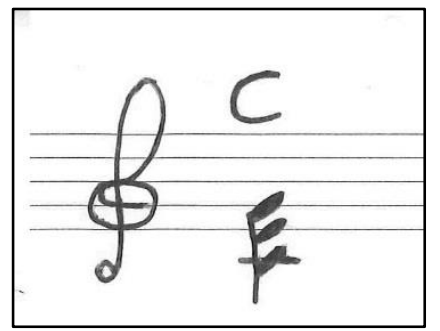

Elaboração própria. Data: 26/08/2019.

Note-se que, a despeito das tentativas, parece ser impossível fazer um Samba de uma nota só. Pois mesmo o acorde de dó não é simplesmente composto apenas pela nota dó, mas de três notas: dó, mi e sol. Isto se colocarmos as coisas de forma grosseira, como estamos fazendo, haja vista tratarmos da questão a nível de analogia.

Um pianista profissional, por exemplo, é capaz de tocar a nota fá mais grave de seu piano e ouvir ainda outras 5 notas na nota fá. Cada instrumentista de uma orquestra toca notas individuais que no conjunto da obra compõem um movimento harmônico. Neste sentido, há a nota dó do primeiro saxofonista, há também o acorde de dó do pianista e há, ademais, o movimento harmônico de dó que toda a orquestra compõem enquanto conjunto.

Toda a beleza da música, portanto, está nas sutilizas complexas que ela é capaz de manipular. Nenhuma matemática é capaz de explicar com tanta beleza o que a música é capaz de fazer, ainda que tentemos. Vejamos, por exemplo, como felicidade e tristeza caminham juntas na música.

O Campo Harmônico Maior Triádico de dó, por exemplo, pode ser grafado conforme figura 5.3, disposta a seguir.

Figura 5.3 - Partitura do Campo Harmônico Maior Triádico de C (dó maior)

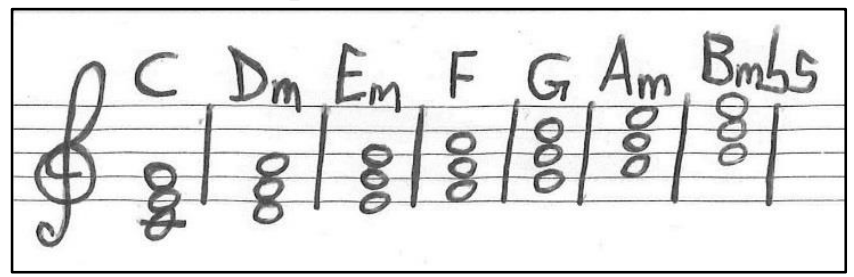

Elaboração própria. Data: 26/08/2019

Todo campo harmônico maior triádico segue esta mesma sequência de acordes, ou seja, se numerarmos os acordes de forma que $\mathbf{C}=\mathrm{I}, \mathbf{D m}=\mathrm{II}, \mathbf{E m}=\mathrm{III}, \mathbf{F}=\mathrm{IV}, \mathbf{G}=\mathrm{V}, \mathbf{A m}=\mathrm{VI}$ e Bmb5= VII, todo campo harmônico maior apresenta a seguinte estrutura: I, IIm, IIIm, IV, V, VIm e VIImb5. Destarte, em campos harmônicos maiores os acordes I, IV, V são sempre 
maiores, os acordes II, III e VI são sempre menores e o VII é sempre um acorde menor com a quinta diminuta.

As harmonias triádicas maiores são responsáveis pela representação de um certo sentido musical de felicidade. Se um compositor quer fazer você dançar e rir, ele provavelmente vai usar um campo maior triádico. Mas se ele quer que você chore, então pode fazer uma pequena alteração no campo harmônico maior e obter um Campo Harmônico Menor Natural. Há outros tipos de campos harmônicos menores e tantas outras teorias sobre música que dispensaremos aqui. Vamos, com pouco, observar qual a contribuição desta pequena reflexão.

Atentemos: é do tom maior de felicidade que extraímos a tristeza do campo menor natural. Na figura 5.4, disposta a seguir, podemos observar que o Campo Harmônico Triádico de Lá Menor Natural é uma derivação do campo harmônico maior triádico de dó - observe atentamente as notas que compõem os referidos campos, bem como a sequência de acordes. A distinção principal entre estes dois campos, como podemos observar, associa-se mais à sequência dos acordes (numerados de I a VII) que às suas estruturas propriamente ditas.

Figura 5.4 - Partitura do Campo Harmônico de Lá Menor Natural Triádico

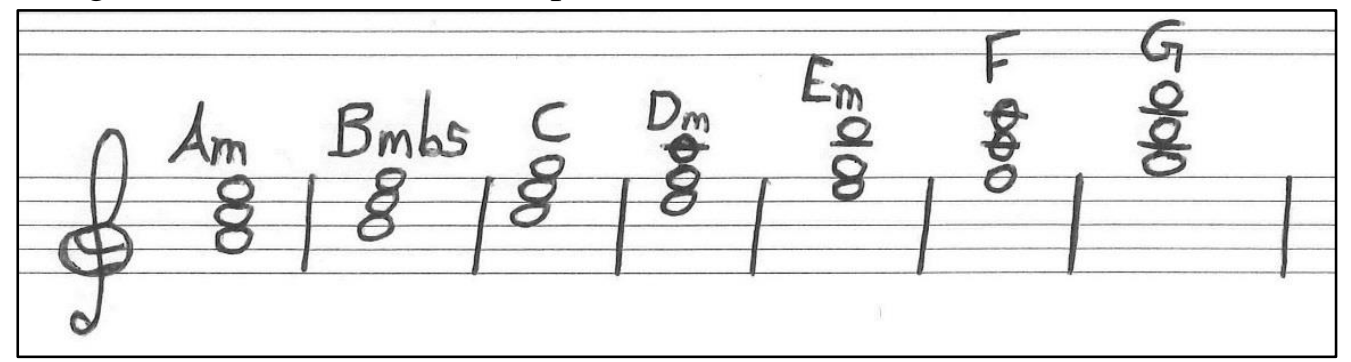

Elaboração própria. Data: 26/08/2019

Todo campo harmônico menor natural triádico segue esta mesma sequência de acordes, ou seja, se numerarmos os acordes de forma que Am=I, Bmb5=II, C=III, Dm=IV, $\mathbf{E m}=\mathrm{V}, \mathbf{F}=\mathrm{VI}$ e $\mathbf{G}=\mathrm{VII}$, todo campo harmônico menor natural triádico apresenta a seguinte estrutura: Im, IImb5, III, IVm, Vm, VI e VII. Destarte, em campos harmônicos menores naturais triádicos os acordes I, IV e V são sempre menores, os acordes III, VI e VII são sempre maiores e o II é sempre um acorde menor com a quinta diminuta.

O cerne de nossa razão musical, portanto, é triádico. Mas não se enganem: não estamos falando de música aqui. Estamos falando de cartografia. A diferença entre Música e notação musical é a mesma que se estende entre Geografia e cartografia. Não que uma coisa seja algo absolutamente distinta de outra, mas certamente não há Geografia que se possa cartografar 
com o êxito de se cartografar também as sensações das quais ela é Geografia. Já fui músico. Choro com música. Mas jamais chorei por ter lido uma partitura.

Quando Newton repensou a Matemática, o que ele fazia era Matemática ou Arte? Santos Dummont era Engenheiro ou Artesão? Um músico escreve sua música para tocá-la ou toca para poder, talvez, escrevê-la? A razão não emergiria de uma necessidade incomensurável de medida e repetição? De controle contínuo das coisas boas e ruins, seja lá o que forem tais coisas? De necessidade de convicção, de certeza: "Já há algum tempo, propus considerar se as convicções não seriam inimigos mais perigosos da verdade do que as mentiras. Agora faço essa pergunta definitiva: existe realmente oposição entre mentira e convicção?” (NIETSZCHE, 2016, p.66, grifo no original).

No capítulo precedente, instauramos inquéritos e ironias sobre o processo de constituição do sujeito moderno e de sua natureza no escopo da Ciência. No presente capítulo, a reflexão avança para outras searas, que não são absolutamente outras, mas distintos pontos de vista sobre o já debatido. Neste sentido, Causa e Efeito são objetos de reflexão neste capítulo em continuidade com o previamente expressado.

Segundo Nietzsche (2017, p.34-35, grifo no original e grifo nosso),

em todos os tempos as pessoas acreditaram saber o que é uma causa: mas de onde tiramos nosso saber, ou, mais precisamente, a crença de sabermos? Do âmbito dos famosos "fatos interiores", dos quais nenhum, até hoje, demonstrou ser real. Acreditávamos ser nós mesmos causais no ato da vontade; aí pensávamos, ao menos, flagrar no ato a causalidade. Tampouco se duvidava que todos os antecendetia de uma ação, suas causas, deviam ser buscados na consciência e nela se achariam novamente, ao serem buscados - como "motivos": de outro modo não se teria sido livre para fazê-la, responsável por ela. Afinal, quem discutiria que um pensamento é causado? Que o Eu causa o pensamento?... Desses três "fatos interiores" \{a Vontade, o Espírito e o Eu\}, com que parecia estar garantida a causalidade. O primeiro e mais convincente é o da vontade como causa; a concepção de uma consciência ("espírito") como causa e, mais tarde, a do Eu ("sujeito") como causa nasceram posteriormente, depois que a causalidade da vontade se firmou como dado, como algo empírico... Nesse meio-tempo refletimos melhor. Hoje não acreditamos em mais nenhuma palavra disso. O "mundo inteiro" é cheio de miragens e fogos-fátuos: a vontade é um deles. A vontade não move mais nada; portanto, também não explica mais nada ela apenas acompanha eventos, também pode estar ausente. O que chamam de "motivo": outro erro. Apenas um fenômeno superficial da consciência, um acessório do ato, que antes encobre os antecedentia de um ato do que os representa. E quanto ao Eu! Tornou-se uma fábula, uma ficção, um jogo de palavras: cessou inteiramente de pensar, de sentir e de querer!... Que resulta disso? Não há causas mentais absolutamente! Toda a sua suposta evidência empírica foi para o diabo! Eis o que resulta disso! - E havíamos cometido um belo abuso com essa "evidência empírica", com base nela havíamos criado o mundo como um mundo de causas, um mundo de vontade, um mundo de espíritos. [...] O homem projetou fora de si os seus três "fatos interiores", aquilo em que acreditava mais firmemente, a vontade, o espírito, o Eu 
- extraiu a noção de ser da noção de Eu, pondo as "coisas" como existentes à sua imagem, conforme sua noção do Eu como causa. É de admirar que depois encontrasse, nas coisas, apenas o que havia nelas colocado? - A coisa mesma, repetindo, a noção de coisa, [é] apenas um reflexo da crença no Eu como causa... E até mesmo o seu átomo, meus caros mecanicistas e físicos, quanto erro, quanta psicologia rudimentar permanece ainda em seu átomo! - Para não falar da "coisa em si", do horrendum pudendum [horrível parte pudenda] dos metafísicos! O erro do espírito como causa confundido com a realidade! E tornado medida da realidade! E denominado Deus! (NIETZSCHE, 2017, p.34-35, grifo no original e grifo nosso).

Em Kant, por exemplo, temos provas da pontualidade desta perspicaz crítica que Nietzsche apresenta quanto ao caráter "Em Si" da causalidade:

\footnotetext{
não se pode duvidar de que todos os nossos conhecimentos começam com a experiência, porque, com efeito, como haveria de exercitar-se a faculdade de conhecer, se não fossem pelos objetos que, excitando os nossos sentidos, de uma parte, produzem por si mesmos representações, e de outra parte, impulsionam nossa inteligência a compará-los entre si, a reuni-los ou separá-los, e deste modo à elaboração da matéria informe das impressões sensíveis para esse conhecimento das coisas que se denomina experiência? No tempo, pois, nenhum conhecimento precede a experiência, todos começam por ela (KANT, 1958, p.5, grifo nosso).
}

Destarte, para instaurar o seu imperativo categórico, Kant teve necessidade de tornar sua razão prática. Precisou afirmar a vida para negá-la, logo na sequência de suas experimentações. O Imperativo Categórico é o mecanismo da "mentira santa" tornada filosofia. A necessidade de convicções é a morte da experiência. Uma concepção limpa demais, imaculada demais de mundo: a maior mentira, o maior crime. Imaculada concepção categórica: maculada vida humana.

Ademais, não seriam os objetos já nossos sentidos? Nenhum conhecimento precede a experiência porque é simplesmente impossível conhecer sem estar vivo, ou seja, sem experiência. E, desde que vivo, é impossível deixar de experimentar. Feche os olhos e tente, nem que por um único instante, silenciar seu corpo, calar todas as sensações, todos os seus sentidos. Isto é estar morto, e é impossível conceber a morte. Neste sentido, Kant é a exemplificação do absurdo do em-si da causalidade, segundo Nietzsche.

A crença de que o acaso é determinado - ou seja, a convicção - é a necessidade de manutenção da ossatura do processo a que Hegel chama de Verdade, Marx denomina de $O$ Capital, e Nietzsche aborda a partir de sua imoralidade. Causa e Efeito são necessárias para a manutenção da objetividade mundana e da crença no Eu como Causa, como Vontade e Destino Racional e Jurídico. "Deus é besteira, a Ciência tem razão"; mas a moral é religiosa. A causalidade é esta religião, seu hino, seu estatuto, sua partitura e mapa. 
Nestas partituras da ópera humana há o grande erro do livre-arbítrio, que instaura a possibilidade de um julgamento justo, pois

\begin{abstract}
a doutrina da vontade foi essencialmente inventada com o objetivo da punição, isto é, de querer achar culpado. [...] Os homens foram considerados "livres" para poderem ser julgados, ser punidos - ser culpados: em consequência, toda ação teve de ser considerada como querida, e a origem de toda ação, localizada na consciência [...]. O cristianismo é uma metafísica do carrasco... (NIETZSCHE, 2017, p.38, grifo no original).
\end{abstract}

A Ciência, portanto, é um tribunal histórico, e da história do ocidente cristão. E a questão mais intrigante a respeito dessa história é: ela já não nasce como mentira? A Igreja falseou até mesmo a história da humanidade, "[...] tornando-a a pré-história do cristianismo" (NIETZSCHE, 2016, p.48). E a nossa ciência, não falseou toda a história da humanidade, tornando-a sua história? Ela não julga o efeito pela causa e vice-versa, estabelecendo uma linha entre eles, uma corda - a lógica do desencadeamento infinito? Nota: não confundir nossa ciência com a Ciência.

Ademais, quem é capaz de distinguir deve ser distinto, pois é culpado de todo o bem e de todo o mal. Mas há também uma doutrina diferente, uma outra perspectiva:

\footnotetext{
qual pode ser a nossa doutrina? - Que ninguém dá ao ser humano suas características, nem Deus, nem a sociedade, nem seus pais e ancestrais, nem ele próprio [...]. Ninguém é responsável pelo fato de existir, por ser assim ou assado, por se achar nessas circunstâncias, nesse ambiente. A fatalidade do seu ser não pode ser destrinchada da fatalidade de tudo o que foi e será. [...] Nós é que inventamos o conceito de "finalidade": na realidade não se encontra finalidade... Cada um é necessário, é um pedaço de destino, pertence ao todo, está no todo - não há nada que possa julgar, medir, comparar, condenar nosso ser, pois isto significaria julgar, medir, comparar, condenar o todo... Mas não existe nada fora do todo! (NIETZSCHE, 2017, p.3839, grifo no original e grifo nosso).
}

Quando Nietzsche diz que cada um "está no todo", neste excerto coloco o sentido geográfico da existência expressamente dito: não uma causa ou um efeito, mas uma dimensão, um sentido propriamente dito. Um sentido composto por outros sentidos; um acorde de Dó Maior composta por outras tantas notas, perdidas, inauditas.

Geografia é estar mergulhado em sensações, é esta característica ontologicamente expressa de imersão sensual inevitável, é o acontecimento propriamente dito dos sentidos. Destarte, estar é a constituição primeira do ser enquanto um feixe de sentidos. A certeza da existência é geográfica, e sua manipulação depende da constituição geográfica do ser. É neste sentido que leio o seguinte excerto de Nietzsche: 
os indivíduos mais poderosos sempre inspiraram os arquitetos; o arquiteto sempre esteve sob a sugestão do poder; arquitetura é uma espécie de eloquência do poder em formas, ora persuadindo, até mesmo lisonjeando, ora simplesmente ordenando. $\mathrm{O}$ mais alto sentimento de poder e segurança adquire expressão naquilo que tem grande estilo. O poder que já não tem necessidade de demonstração; que desdenha agradar; que dificilmente responde; que não sente testemunha ao seu redor; que vive sem consciência de que há oposição a ele; que repousa em si mesmo, fatalista, como uma lei entre as leis: isso fala de si na forma do grande estilo (NIETZSCHE, 2017, p.56, grifo no original e grifo nosso).

Destarte, é possível concretar o poder. A cidade é esta arquitetura do poder. Quando falamos em Geografia, portanto, estamos tratando de um processo de materialização de um sentido existencial, independentemente do que estejamos falando sobre ele.

Quando citei os colonizadores portugueses e espanhóis, disse que seu feito colonial foi a cidade colonial e uma forma urbana de ser que é indissociável desta cidade. Esta forma urbana de ser é este sentido geográfico citadino. Este sentido é alienado, como explorado em Marx e Hegel, mas ainda assim é sentido. A tese em questão é o que se pode denominar de Sensualismo Geográfico Dialético.

Assim, da mesma forma que se pode manipular uma massa informe sonora a partir de um manual denominado "partitura", é possível manipular outra massa informe sensível a partir de um manual denominado "ciência geográfica" ou "cartografia". Toda racionalização que se aprende nos cursos de geografia não são senão cartografias. Disto não se conclui, entretanto, que se possa resumir toda a ciência geográfica a uma disciplina, mas que toda a ciência geográfica é cartográfica. Toda teoria, todo pensamento geográfico não é senão cartografia ou fundamentos de cartografia. Isto porque sempre, na história do Estado Moderno, foi necessário controlar e nenhum regente pode ver para que lado toca a banda sem o auxílio de suas partituras. Mas um regente não é, absolutamente, o super-homem, ou um homem superior, necessariamente - ele é apenas um bobo da corte, caso não prove o contrário.

Neste sentido, o papel da geografia acadêmica não é absolutamente explicativo, nem os geógrafos são arautos da verdade. A Verdade moderna tornou-se o processo de representação da constituição geográfica do ser enquanto um feixe de sentidos, e seu objetivo é a Mentira Maior: a liberdade enquanto aprisionamento moral. Assim, na corrida que o homem moderno faz, a cidade segue sempre frente a ele e seu corpo biológico é apenas o meio termo entre o prédio que está diante de seus olhos e sua sombra urbana, que sempre o segue. A tríade se refaz: meio-homem-sombra. 
O homem que vive no lixo quase não se diferencia dele: sua cidade é escombro, seu corpo é descartável, sua sombra é baixa, cinza, ainda que possa ser, de alguma forma, "bela". Baixa também é a sombra do homem suburbano: está constantemente ofuscada pela presença de seus monumentais arquitetônicos.

Mas não é por morar no lixo que uma determinada pessoa é doente e pobre. A pobreza não pode ser medida em "ganha menos de um dólar por dia". Não pode ser contemplada matematicamente. Pode ser gerida de um escritório de engenharia, mas não pode ser mensurada. Mensurar é já a forma da pobreza. É preciso então mensurar a matemática? Ironia sem sentido, mas pode até ser que este subcapítulo se resuma a isso, uma medida da nossa Ciência Geográfica.

Neste sentido, quando apontei, nos capítulos anteriores, que não é o estresse térmico que aumenta a mortalidade associada às doenças do aparelho circulatório, não quis sugerir que eu saiba mais que os milhares de cientistas que possam afirmar esta hipótese tão interessante. Pois não estamos afirmando ou negando a realidade de um "dado" - esta conversa já tiveram os metafísicos. Deixo as partituras para os músicos. Deixo os mapas para os cientistas. Mas alguém precisa falar do que falam quando dizem "Geografia".

Destarte, Causa e Efeito são duas pontas de uma reta traçada em uma carta náutica. Navegar é preciso, mas viver não. Há brilhantes navegantes nos portos da academia, mas quantos mares e navios há dos quais bravos marinheiros não são senão gota d'água e prego enferrujado? Navegar não torna a vida precisa, ainda que navegar seja preciso. A imprecisão do mar é a necessidade de precisão náutica: o medo das sereias é uma das explicações plausíveis para o surgimento da Ciência, "pois o medo - é o sentimento original e fundamental do homem; pelo medo tudo se explica, pecado original e virtude original. Do medo também nasceu a minha virtude, que se chama 'ciência"' (NIETZSCHE, 2018, p.286, grifo no original), assim fala o Consciencioso do Espírito, Hegel.

Mas Zaratustra adverte ao Consciencioso de Espírito: “o medo - é a nossa exceção. Mas coragem, aventura, prazer no incerto, no ainda não ousado, - coragem parece-me ser toda a pré-história do homem" (NIETZSCHE, 2018, p.287, grifo no original). Por esse caminho, o criminoso pálido enfrenta sua realidade com ciência e coragem: "ele era da mesma altura de seu ato \{criminoso, de assassinato\}, quando o realizou; mas não lhe suportou a imagem depois de realizado" (NIETZSCHE, 2018, p.37). Matar, portanto, não é o que causa o efeito de aprisionamento do criminoso, mas a imagem do ato do assassinato. Matar, o assassino o faz porque é prazeroso, porque ele tem vontade e poder para. O que o assassino não suporta é o 
julgamento do ato, a imagem do ato, não o "ato em-si". O "ato em-si" é o acontecimento, a efetividade, que em nada guarda relação causal com o planejamento do assassinato e com o julgamento do mesmo.

A coragem de enfrentar sereias e deuses foi o que fez do medo o instrumento que esculpiu o homem, ou vice-versa. Medo e coragem não são coisas em-si distintas, da mesma forma que, na música, alegria e tristeza são irmãs siamesas. Não são absolutamente distintas, coisas em-si distintas. São movimento, flecha, direção e sentido. É sensação modelada da massa informe efetiva.

Neste sentido, o Pensamento, o Ato e a Imagem do Ato são efetivos, sua união é a efetividade, a totalidade, o acontecimento. Mas são efetivos não enquanto causa-efeito - esta é apenas a ossatura da Razão. Como ficaria então a questão do Saber Absoluto, do Saber que se sabe enquanto saber?

Os efeitos são, de acordo com Hegel (2014), a suprassunção da causa, e não sua consequência lógica absoluta. A existência da coisa-em-si é a manutenção da consciência-desi do em-si da coisa. O Saber Absoluto, portanto, é uma relação social, e é esta a contribuição que aqui procuramos evidenciar.

A irracionalidade da razão, apontada nas reflexões que temos feito sobre Marx (2004;2013), também segue por esse caminho de negação afirmativa. A irracionalidade e a razão são água do mesmo poço, mas não são a mesma água.

Explicar as coisas pela oposição crítica dos conceitos e evidenciar, assim, a natureza social do "em-si", afirmando sua existência não como coisa-em-si, mas como consciência-desi do em-si da coisa, ainda que na forma da irracionalidade, é trabalho acadêmico de Hegel e Marx. Para Nietzsche, por sua vez, o "em-si” é um dos maiores desatinos da história da Filosofia, e não constitui senão instrumento de controle.

Neste sentido, observa-se que o nascimento do "em-si" e a gênese do "Eu", modernos, são indissociáveis. São indissociáveis também do "em-si" e do "Eu" o fardo maior do Saber Absoluto: a crença no livre-arbítrio. Entretanto, se Hegel e Marx evidenciam sua crítica pela Dialética, Nietzsche não é, por assim dizer, um declarado adepto dessa velha objeção.

\subsection{A Dialética}

Três afirmações: 1) para Hegel, a Verdade é Dialética; 2) para Marx, o Materialismo é Dialético; 3) para Nietzsche, a Moral é Dialética. Em capítulo precedente, vimos como Hegel 
e Marx tratam desta questão, identificando sua efetividade no movimento de engendramento da Verdade (Hegel) e nas relações sociais efetivas de produção, enquanto contradição materialmente efetiva (Marx). A contribuição que Nietzsche oferece ao tema em questão coloca novas reflexões sobre a Dialética, principalmente sobre seu papel no estabelecimento de uma moral que representa a decadência da humanidade enquanto história da humanidade.

Segundo Nietzsche (2017, p.16), Sócrates teria estabelecido uma "equação da razão", segundo a qual "razão=virtude=felicidade". A maior das mentiras mais bem-sucedidas? Quem mais sabre sobre a Verdade está mais apto a mentir. Mas mentir não é errar; é acertar no jogo da Verdade quando se quer vencer. A virtude da razão é a vitória oculta, a felicidade de rapina. A razão é a ópera da Dialética: “com Sócrates, o gosto grego se altera em favor da dialética: que acontece aí propriamente? Sobretudo, um gosto nobre é vencido; com a dialética, a plebe se põe em cima” (NIETZSCHE, 2017, p.16, grifo no original e grifo nosso).

Neste sentido, Nietzsche procura "evidenunciar" como a Dialética instaura o mecanismo de produção da moralina (NIETZSCHE, 2016) moderna desde a filosofia socrática:

\footnotetext{
o moralismo dos filósofos gregos a partir de Platão é determinado patologicamente; assim também a sua estima da dialética. Razão = virtude = felicidade significa tão só: é preciso imitar Sócrates e instaurar permanentemente, contra os desejos obscuros, uma luz diurna - a luz diurna da razão. É preciso ser prudente, claro, límpido a qualquer preço: toda concessão aos instintos, ao inconsciente, leva parabaixo... (NIETZSCHE, 2017, p.18, grifo no original).
}

Destarte, a razão tornou-se a maior virtude do homem moderno. Virtude que ensina ao homem, segundo Nietzsche, a sempre negar a vida em favor de ideias "belas", como "progresso", "cristianismo", "ciência” e "planejamento urbano". A razão, para Nietzsche, é dialética e conta a história da humanidade como evolução. Antítese: "a humanidade não representa um desenvolvimento para melhor ou mais forte ou mais elevado, do modo como hoje se acredita. O "progresso" é apenas uma ideia moderna, ou seja, uma ideia errada" (NIETZSCHE, 2016, p.11, grifo nosso).

A delicadeza da leitura filosófica de Nietzsche sustenta que as filosofias pós-socráticas cultivaram um manifesto contra a vida: "ela não vale nada" (NIETZSCHE, 2017, p.14). O referido filósofo questiona, então: "talvez a sabedoria apareça na Terra, como um corvo, que se entusiasma com um ligeiro odor de cadáver?" (NIETZSCHE, 2017, p.14)

Esse pensamento desrespeitoso, de que os grandes sábios são tipos de decadência, ocorreu-me primeiramente num caso em que o preconceito dos doutos e indoutos se opõem a ele do modo mais intenso: eu percebi Sócrates e Platão como sintomas de 
declínio, como instrumentos da dissolução grega, como pseudogregos, antigregos (Nascimento da tragédia, 1872). Aquele consensus sapientiae [consenso dos sábios] - compreendi cada vez mais - em nada prova que eles tivessem razão naquilo acerca do qual concordavam: prova, isto sim, que eles próprios, esses mais sábios dos homens, em alguma coisa coincidiam fisiologicamente, para situar-se - ter de situarse - negativamente perante a vida (NIETZSCHE, 2017, p.14).

Nietzsche toma os juízos de valor acerca da vida, os quais são objeto de reflexão na filosofia, como sintomas da decadência da humanidade. O aparecimento de Sócrates é sintoma da decadência grega. A Filosofia do Pensamento surge para a decadência: "escolhe-se a dialética apenas quando não se tem outro recurso. Sabe-se que ela suscita desconfiança, que não convence muito. Nada é mais fácil de apagar que um efeito da dialética [...]” (NIETZSCHE, 2017, p.16). Neste sentido, o papel da dialética se fortalece com a decadência grega, e se fortalece pela decadência, pela vida da decadência, que em Nietzsche é a história do homem moderno.

Neste sentido, a razão é o instrumento de controle, implacável, cuja moral é mensurar a vida, é oferecer medida para, é escrutinar o inescrutável como se escrutável fosse, pois " $o$ valor da vida não pode ser estimado" (NIETZSCHE, 2017, p.15). Para Marx, conforme capítulo precedente, a razão é a moeda da vida humana. Para Nietzsche, a razão é a moenda da vida humana, da vontade de poder da vida humana. Sua garapa: moralina.

Como dialético, tem-se um instrumento implacável nas mãos; pode-se fazer papel de tirano com ele; expõe-se o outro ao vencê-lo. O dialético deixa ao adversário a tarefa de provar que não é um idiota: ele torna furioso, torna ao mesmo tempo desamparado. O dialético tira a potência do intelecto do adversário (NIETZSCHE, 2017, p.1617 , grifo no original).

Destarte, tudo o que vem da fraqueza, da razão, para Nietzsche é mau. Tudo aquilo que eleva o sentimento de poder, que fortalece a vontade de poder, é bom (NIETZSCHE, 2017, p.10). Portanto, a questão da dialética, em Nietzsche, não diz respeito ao Progresso da Verdade enquanto engendramento do Saber Absoluto per se, tampouco Nietzsche parece preocupado em evidenciar a irracionalidade efetiva da razão enquanto racionalidade irracional, ainda que vejo possibilidade de concordâncias quanto a este ponto. A tese da decadência pela razão ou da razão pela decadência não diz respeito ao "[...] que sucederá a humanidade na sequência dos seres (- o homem é um final -); mas sim que tipo de homem deve-se cultivar, deve-se querer, como de mais alto valor, mas digno de vida, mais certo de futuro" (NIETZSCHE, 2016, p.11, grifo no original). 
Tampouco Nietzsche quer simplesmente blasfemar por blasfemar contra o cristianismo, a filosofia e a ciência. No Anticristo, por exemplo, ele afirma: “[...] as percepções mais valiosas são os métodos" (NIETZSCHE, 2016, p.18, grifo no original). Traz, também neste livro, uma referência interessante a Descartes, que se aproxima de um elogio e evidencia, ao mesmo tempo, as consequências de uma concepção mecanicista de mundo, predominante nos dias atuais:

no tocante aos animais, foi Descartes quem, com audácia admirável, primeiramente ousou compreender o animal como máquina: toda nossa fisiologia se empenha em demonstrar essa tese. E coerentemente não situamos o homem a parte, como Descartes ainda fez: o que hoje entendemos do homem vai exatamente até onde ele é entendido como máquina (NIETZSCHE, 2016, p.19).

Entretanto, quando o referido filósofo afirma que as percepções mais valiosas são os métodos, citando Descartes para situar o que está dizendo, ele está argumentando favoravelmente a que "as percepções mais valiosas são alcançadas por último" (NIETZSCHE, 2016, p.18, grifo nosso). O método não seria um a priori, portanto? Se considerarmos a totalidade do excerto, ou seja, que "as percepções mais valiosas são alcançadas por último; mas as percepções mais valiosas são os métodos" (NIETZSCHE, 2016, p.18, grifo no original e grifo nosso), evidencia-se que o método é valioso por ser um produto da necessidade, um depois de, não um imediato para, uma solução previamente estabelecida ou um caminho certo para esta solução.

Para aqueles entre nós que se aventuraram a solucionar quebra-cabeças de metal, não é difícil conceber o que Nietzsche pode ter tentado dizer: um quebra-cabeça desses só é interessante antes de ser desvendado, depois já é menos valioso que o método para o solucionar. Entretanto, este método só pode ser percebido depois de solucionado o mistério. O método surge da coragem e da necessidade de solucionar algo; seu surgimento é criação. Entretanto, minha particular objeção a esta afirmativa é que a necessidade do método já é metodológica, ou seja, já é racional - ao menos na Ciência. As reflexões realizadas em capítulo precedente sobre o Discurso do Método, de Descartes, evidenciam esta objeção: de que o a priori per se do método já é o método enquanto necessidade do método. Em outras palavras, a certeza de que eu posso solucionar o quebra-cabeça de metal é que me faz querer solucioná-lo.

Destarte, primeiramente, sei que posso responder a uma pergunta e, por isso, estou imbuído de. Objetivo: analisar a relação entre impermeabilização do solo e a distribuição dos óbitos associados às doenças do aparelho circulatório. "Coloco minha mão na massa". Saber, neste caso, é sentir-se seguro para manipular algo. O método é como faço o que faço por que 
faço, simultaneamente - corpo, meio, sombra: como, o que, por que. A Dialética, portanto, é um tripé: tripalium que sustenta a partitura do mundo.

Três são as referências sobre a Dialética que suscitei: Hegel, Marx e Nietzsche. O intuito? Agora, parece-me que suas Dialéticas compõem uma Dialética também! Hegel aponta para a dialética da Sombra; Marx, para a dialética do Meio; Nietzsche, para a da moral-imoral do Corpo. O que se considera como sentido geográfico no escopo deste trabalho emerge do momento único em que estas três dimensões acontecem: agora. Tentar apreender isto é a continuação disto, na dimensão religiosa em que colocamos nosso apreender: na Ciência. O que se denomina de Geografia na Academia, portanto, é uma espécie de seita, que produz adeptos da manutenção de uma forma de consciência que continue o trabalho de oração cartográfica. $\mathrm{O}$ acontecimento disto é o que possibilita isto. Nada mais.

Coloco-me perante meus avaliadores, quanto a questão exposta, de forma tranquila, mas infelizmente pouco transparente. Nuvens espessas não dão espaço à visão. Direi de outras formas o problema, para evitar comoções cegas.

O que sugiro à Geografia Acadêmica é que, como toda crença, proponha-se reflexão continuada sobre seus objetivos, com a máxima honestidade possível, ou seja, com autocrítica. Não olhar no espelho e dizer: "quero o bem para as pessoas; quero a verdade para as pessoas; sou lógico e, por lógico, a lógica é o melhor para a humanidade”. Quanto à efetividade que os geógrafos definem como geográfica, ao que eles definem como "geográfico", proponho atenção às dimensões dialéticas deste problema. Proponho, ademais, especial atenção à dimensão sensível que constitui a simultaneidade entre meio-corpo-sombra: o homem está completo pelos pés - é pelos pés que se liga ao seu meio e à sua sombra.

A extensão do caminho que estamos tomando não diz respeito tão somente à classe trabalhadora, ou à classe trabalhadora acadêmica, mais especificamente. Tem-se o intuito de demonstrar, grosso modo,

[...] até que ponto a pretensão dos cidadãos filantropos \{cientistas, no nosso caso $\}$ está fundamentada na ideia de que se trata apenas de dar aos proletários um pouco de pão e de educação, como se somente os trabalhadores definhassem sob as atuais condições sociais, ao passo que, para o restante da sociedade, o mundo tal como existe fosse o melhor dos mundos (MARX, 2006, p.22).

Destarte, Marx e Nietzsche percebem um certo engendramento fisiológico na sociedade moderna. Veja o que diz o segundo filósofo, quando versa sobre o que é ser nobre: "a casta nobre sempre foi, no início, a casta de bárbaros: sua preponderância não estava primeiramente na força física, mas na psíquica - eram os homens mais inteiros [...]" 
(NIETZSCHE, 2005, p.153, grifo no original e grifo nosso). O que tenho denominado de Sensualismo Geográfico Dialético, argumento constituído no escopo do presente trabalho, faz referência a estas três dimensões de Dialética que temos explorado (Hegel, Marx e Nietszche), no intuito de estabelecer uma contribuição a uma outra perspectiva a respeito de nossa concepção moderna sobre fisiologia.

Assim, no subcapítulo a seguir serão apresentadas algumas considerações gerais sobre a perspectiva que aqui temos trilhado e alcançado.

\title{
5.3. Sensualismo Geográfico Dialético
}

Corpos fortes com mentes sãs: duas coisas aparentemente indesejáveis hoje em dia. Todo o progresso do homem moderno quanto a isto parece ter sido, efetivamente, um declínio fisiológico do pior tipo: daquele que se parece com melhoramento. Quanto a isto, a luta pelo progresso, pela vida melhorada, surge como "evidenunciação" de um absurdo:

\begin{abstract}
no que toca à célebre "luta pela vida", até agora me parece apenas afirmada e não provada. Ela acontece, mas como exceção; o aspecto geral da vida não é a necessidade, a fome, mas antes a riqueza, exuberância, até mesmo o absurdo esbanjamento - quando se luta, luta-se pelo poder... Não se deve confundir Malthus com a natureza. - Mas, supondo que haja essa luta - e, de fato, ela ocorre -, infelizmente ela resulta no contrário do que deseja a escola de Darwin, do que talvez se poderia desejar juntamente com ela: ou seja, em detrimento dos fortes, dos privilegiados, das felizes exceções. As espécies não crescem na perfeição: os fracos sempre tornam a dominar os fortes - pois são em maior número, são também mais inteligentes... Darwin esqueceu o espírito (- isto é inglês!), os fracos têm mais espírito... É preciso ter necessidade de espírito para adquirir espírito - ele é perdido, quando não mais se necessita dele. Quem tem força dispensa o espírito [...]. Entendo por espírito, como se vê, a cautela, a paciência, a astúcia, a dissimulação, o grande autodomínio e tudo o que seja mimicry [mimetismo] (esse último compreende boa parte do que se chama virtude) (NIETZSCHE, 2017, p.57-58, grifo no original e grifo nosso).
\end{abstract}

Na cidade colonial moderna, o Espírito é material e metafísico, sendo sua cisão e união a moralina causal. A necessidade de Espírito era a necessidade do colonizador, ou seja, o próprio processo de colonização é o engendramento desta necessidade - a necessidade de cidades e de urbanos. E necessidade de muita moralina - substância cuja materialidade é o corpo e cuja alma é a razão: a moralina é a contradição entre o corpo e a alma que instaura a união entre meio material (cidade) e meio universal (urbano). O acontecimento deste processo é a dimensão geográfica do Ser, ou seja, a efetividade dos sentidos desta moralina e de tudo o 
que ela é - cidade-moralina-urbana. Neste sentido, “[...] defini o moderno como a autocontradição fisiológica" (NIETZSCHE, 2017, p.76, grifo no original e grifo nosso).

Destarte, a fisiologia da pessoa urbana colonial é a fisiologia da moralina citadina, pois a função urbana primeira da cidade colonial é a catequese. Neste sentido, a Ciência, ela mesma, assim como a Arte, a Filosofia, a Religião, dentre outros, não seriam produtos desta fisiologia? Ademais, não seriam também suas constituintes? Por outro lado, a ossatura causal das coisas, a relação sujeito-objetiva, não passa a frequentar múltiplos planos? O Espírito, que é a contradição material-imaterial, ou físico-metafísico, ocuparia a posição de objeto ou de sujeito? E a moralina, seu corpo e sua alma, são sujeitos ou objetos? Veja-se como tardias estas questões, insuficientes, pois implicam em limitado material para correta evidenciação do problema aqui exposto - não se pode apropriar efetivamente do mecanismo de algo pelo próprio mecanismo de algo, sem que se cometa o equívoco a que esperam ansiosos os mais críticos: o equívoco da causalidade.

Destarte, no capítulo precedente, indicamos que "o trabalho, a essência subjetiva da propriedade privada enquanto exclusão da propriedade, e o capital, o trabalho objetivo enquanto exclusão do trabalho, são a propriedade privada enquanto sua relação desenvolvida da contradição [...] " (MARX, 2004, p.103, grifo no original e grifo nosso). Neste sentido, Marx observa o surgimento da propriedade privada de forma indissociável do nascimento do homem moderno - que passaremos a denominar "pessoa moderna", no intuito de superar o inevitável masculinismo do conceito de "homem". Esta "pessoa moderna" que está sendo gerada enquanto essência subjetiva da propriedade privada e essência objetiva do capital é a contradição entre trabalho concreto e trabalho abstrato, necessária para o surgimento das cidades europeias da revolução industrial.

A expansão crítica do capital, ou colonização, por sua vez, é a expansão da necessidade de (re)produção desta contradição entre trabalho concreto e trabalho abstrato, que nas cidades coloniais se nos apresenta não enquanto constituição de uma forma primeira de acumulação primitiva, como argumenta José de Souza Martins em diversas de suas obras, por exemplo, ou de desenvolvimento de um primeiro projeto de urbanização como se este fosse uma primeira fase histórica de nossas cidades atuais - apresentadas atualmente como póscoloniais, ou de histórias coloniais, mas raramente hodiernamente consideradas coloniais. Entretanto, enquanto efetiva manutenção da propriedade privada já na forma da propriedade privada, as cidades coloniais foram o grande feito colonizatório - a produção de uma fisiologia colonial. É a fisiologia das cidades coloniais que as distinguem das cidades metropolitanas. As 
cidades metropolitanas são as matrizes dos empreendimentos citadinos-coloniais - as primeiras grandes empresas multinacionais foram as cidades modernas!

Distintamente das cidades europeias, dentre as quais poderíamos citar exemplos históricos com mais de dois mil anos, as cidades coloniais não passaram por uma "reformulação histórica" de sua fisiologia, pois já nasceram modernas. Não temos exemplos nacionais como a Paris francesa, que fora já uma "cidade medieval", por assim dizer. Nossas cidades sempre foram coloniais, não foram jamais outra coisa. Enquanto cidades, nasceram como projeto colonizatório. Não têm outra história. Não houve uma ruptura efetiva de nossa fisiologia de anteontem. Somos ainda colônia do ponto de vista fisiológico. E é este ponto de vista que nos instiga a pensar que as dialéticas de Hegel e Marx evidenciam, elas mesmas, o processo colonizatório. Em outras palavras, elas já são o processo colonizatório. Ou seja, estamos presos a uma pobreza inclusive crítica, pois nossa necessidade de Espírito é ainda a necessidade do colonizador - oriunda do processo de colonização. Incluo minhas palavras, portanto, na limitação fisiológica imposta a elas. Sou tão pobre quanto posso criticar a pobreza.

Destarte, quais são as questões de hoje em dia? Família? Religião? Estado? Todas as questões não se resumiriam, até que satisfatoriamente bem, a estas? Feministas, Movimentos Negros, Movimentos Sem Teto, Movimentos Sem Terra, Mães de Maio etc., não estão pondo em questão Família, Religião e Estado? Jair Bolsonaro não é a afirmação desta problematização hodierna? De onde vêm tais questões? Quem as colocou? Parece-me - assumo o risco aqui que elas advêm de nossa fisiologia colonial.

Quando discutimos a relação entre impermeabilização do solo e a distribuição dos óbitos associados às doenças do aparelho circulatório, não estamos colocando em questão a fisiologia que aqui apresento: cidade-moralina-urbana? Não se deseja mensurar o quanto a cidade implica, em seu "ambiente físico", em uma distribuição de um tipo específico de mortalidade, a morte do corpo da moralina e, consequentemente, de sua alma singular? A relação que se objetiva evidenciar, portanto, não seria esta relação fisiológica cidade-moralinaurbana? Não seria uma relação, portanto, colonial? A Ciência, feita por pessoas reais, moralinas efetivas, não é já esta fisiologia? Marx, Hegel e Nietzsche não seriam úteis na exposição desta fisiologia enquanto fisiologia mesmo e não como arautos do saber dialético?

O que se constitui, portanto, enquanto "Geografia" está posto no invólucro desta fisiologia, e é o acontecimento efetivo dela, enquanto sensualismo, ou seja, enquanto efetivação dos sentidos sociais das pessoas, sua afirmação enquanto existência efetiva. Todo sensualismo é geográfico e todo geográfico, sendo fisiológico, é dialético. A dimensão geográfica do ser 
seria, portanto, a dimensão sensível desta fisiologia cidade-moralina-urbana acontecendo efetivamente. Portanto, a moralina não é toda a dimensão sensível, ou seja, toda a dimensão geográfica. Nem o Espírito Cidade-Urbano é toda a geografia. São apenas partes constituintes dela, desta fisiologia sensível-geográfica. A sensibilidade, portanto, não é atributo sujeitoobjetivo, mas fisiológico, ou seja, que emerge da contradição entre corpo e alma no seio do Espírito Colonial Moderno - simultaneamente. Destarte, o Sensualismo Geográfico Dialético é o acontecimento fisiológico do mundo moderno e, mais especificamente aqui, do mundo moderno colonial.

Esta é a contribuição que temos tentado constituir a partir de tantas reflexões já feitas: tendo em vista o que temos denominado Sensualismo Geográfico Dialético, a Ciência Geográfica precisa ver-se como parte do todo e não como aparte do todo. Não caberia, assim, a ela analisar simples e puramente este ou aquele "dado" ou "fato", bem como suas determinações e consequências causais, mas ao menos evidenciar esta fisiologia, numa tola utopia de que, um dia, possa haver algo como uma superação fisiológica deste mundo colonial. O problema não reside, portanto, tão somente e absolutamente no nível da razão, ou na materialidade das relações, ou simplesmente na contradição entre corpo e alma, mas na fisiologia complexa que nos faz cidade-moralina-urbana coloniais. Esta questão fisiológica, portanto, é o que gostariamos de ter apresentado até aqui. 


\section{Considerações Finais - ou divagações sobre o Martelo Geográfico}

A sinceridade da escrita é algo valiosa, mas com baixo preço no mercado acadêmico. Tudo que têm muito preço, pouco ou nenhum valor tem, assim falou Zaratustra (NIETZSCHE, 2018). Mas o que de pouco preço e de alto valor possa encontrar-se em alguma alma miserável que moribunda pelo sentido terreno da vida - isto é algo que a academia não pode suportar: ça ne mange pas de pain pour eux.

Não se pode profanar a ciência: é coisa séria, de gente grande! Há muita barba branca, saia longa e graves pausas na ciência - e isso enjoa as almas embriagadas pela leitura: ler não se pode na academia, não com tais olhos riscados de figuras geométricas!

Estudar: Apolo, Socorro! A primeira função urbana da cidade colonial foi... a Catequese! O Espírito de Gravidade é o que mais engana a Alma. Eu quero estudar, eu quero ler, eu quero, eu. Se nunca ninguém leu com os olhos de seus órgãos mais baixos, pois saibam: EU LI! Eu vi a cidade com os dedos, caminhei com a cabeça pela estrada de terra, gritei contra a professora com o balanço irrequieto das pernas sob a mesa escolar, e também pisei com os olhos - pisei gente, pisei bicho, pisei e piso ainda -, pois essa é minha herança europeia - ou maldição: pisar com os olhos. Com os pés faço minha comida, pois as mãos estão sujas de São Paulo - não quero me alimentar de minha sujeira (pequena ilusão de que posso...).

Do ruído da enxada de meus avós cultivaram minha alma - pois a alma é coisa valiosa, que não se pode comprar, mas que se paga a preço de sangue e suor, e que só tem valor se o corpo desgasta seu preço salarial, para assim contrabalancear, com o peso de uma ou mais vidas, a vontade de poder que se acumula; cultivaram o meu corpo do sal da terra, do mel do vale e também do estrume, do perfume das flores e dos safanões paternos e de tudo que se pode negar a uma criança de WhatsApp. Minha alma é minha sombra - esta é obra de Apolo, uma lembrança sempre eternizada de que somos poço, pedra, parede, sentido: tudo o que vem a nós resvala em nós, e se projeta, e se estende, e esperneia para lá e para cá, deixando-nos sempre ao lado sem nos deixar de lado. Mas essa Sombra não se pode ver com os olhos de carne que enfiaram na minha face. Por que cometeram tamanha atrocidade com a obra de Apolo de meus avós?

Os olhos são coisa da moralina, e não do corpo - por isso o Pensamento é seu atributo, e não o oposto. O Corpo é coisa que se manipula, que se apedreja e crucifixa, mas que não pode não se desgastar - é caminho, meio da estrada, coisa entre. Já a Sombra é essa profundidade intangível que se estende desde dentro pelo Corpo e para fora-fora, onde tudo que há é Espírito 
Material e Metafísico. A integridade insuportável do tão aclamado "Ser da Pessoa" é sua fisiologia, seu porquê, a insistência da religião do acaso quando consumado em acontecimento citadino-moralina-urbana.

Ensinaram-me a escrever como se deve, mas se posso escrever - isto é o maior pecado. Pois poder é pecado grave na academia. Só podem aqueles que receberam a benção do Novo Ídolo, o Estado: mas que poder pode aquele que a quem se concede? Só há poder quando a necessidade urge: e não há urgência no Estado.

Na Colônia, todos somos pontos de uma regressão que se estende desde a Metrópole e, portanto, desde o início de nossas histórias. E a História de todas as almas é a certeza de um Espírito enganador - urbano -, de um Pensamento maior que todos os pensamentos - uma ousadia digna de ânsia de vômito. Nesta regressão, todos os pontos se curvam à reta - uns mais, outros menos. Mas não há ponto que se curve suficientemente em reta sem que com isso pise em sua própria sombra - e há quem concorde que o pior dos cachorros seja aquele que morda o próprio rabo.

Corromper o ponto ou corromper a reta? Corromper a regressão! Mas jamais negá-la! É deselegante e estupidez em demasia dizer Não ao bambu que se curva ao vento - e pior, ao menor dos ventos! Tampouco deve-se passar a vida escorando varas-verdes - não se deve criar uma religião - ciência - para endireitar o bambuzal. A Alma só pode requerer do Corpo aquilo que ela deseja. Mas a Alma só pode desejar aquilo que ela sente com o Corpo que tem - e ela só pode ter aquilo que ela pesca representativamente, como vara que se enverga para além de $\mathrm{Si}$, e lança linha e anzol na profundidade do Espírito Colonial. Mas como pode um tal Pescador viver em tão raso Lago, de fétidas Águas Turvas? Não o envenena o Peixe Magro que traz em sua linha?

Peixe Magro são hoje muitas das ditas grandes invenções da modernidade. Águas tão rasas não favorecem ao pescador e já lhe dói os braços em Pensar na possibilidade da Profundidade: cavar em si o buraco de sua própria sombra é algo sensual, valioso, de pouco preço e que custa muito! Poucos querem deixar de ser fetos de um líquido amniótico tão pobre para se tornarem poço profundo de pescador faminto - e o acaso da fome é que ela ilude, para o bem e para o mal.

Meu coração, na doença, não quer marca-passos: quer poesia de festejo - pois não há maior prazer na vida que gozar a morte como se deve. Quando se teme a morte, vive-se constantemente em busca de prazeres vãos, pois o pescador famélico ainda quer pescar com seu 
corpo o frescor do lago e a sombra sobre a qual se pisa ainda é filha de Apolo - um Apolo europeu, um Apolo Colonizador.

Destarte, o Sensualismo Geográfico Dialético é nossa contribuição, nosso inquietante posicionamento indagatório frente à sua própria fisiologia cidade-moralina-urbana. Se exigem de nós uma conclusão, considerações objetivamente finais, cientificamente respaldadas - infelizmente devo sugerir a estes a releitura da presente monografia. Neste sentido, e por fim, peço, de antemão, desculpas ao leitor por oferecer tão somente esta conclusão: "destruidor da moral, assim me chamam os bons e justos: minha história é imoral" (NIETZSCHE, 2018, p.64, grifo nosso). 


\section{Referências}

- BORATTO, I. M. P.; GOMIDE, R. L. Aplicação dos índices de vegetação NDVI, SAVI e IAF na caracterização da cobertura vegetativa da região Norte de Minas Gerais. In: Simpósio Brasileiro de Sensoriamento Remoto - SBSR, 16., 2013, Foz do Iguaçu - PR. Anais... Foz do Iguaçu: INPE, pp.7345-7352. Disponível em: <http://www.dsr.inpe.br/sbsr2013/files/p0075.pdf>. Acesso em 13 mar. 2018.

- $\quad$ BRASIL. Decreto no 6.135, de 26 de junho de 2007. Dispõe sobre o Cadastro Único para Programas Sociais do Governo Federal e dá outras providências. Disponível em: <http://www.planalto.gov.br/ccivil_03/_ato2007-2010/2007/decreto/d6135.htm>. Acesso em 13 mar. 2018.

- BRASIL. Ministério da Saúde. Secretaria de Vigilância em Saúde. Saúde Brasil 2015/2016: Uma análise da situação de saúde e da epidemia pelo vírus Zika e por outras doenças transmitidas pelo Aedes aegypti. Brasília, 2017. Disponível em: <http://portalarquivos.saude.gov.br/images/pdf/2017/maio/12/2017-0135-verseletronica-final.pdf> . Acesso em 13 mar. 2018.

- BREITNER, S.; WOLF, K.; PETERS, A.; SCHNEIDER, A. Short-term effects of air temperature on cause-specific cardiovascular mortality in Bavaria, Germany. Heart, v.100, 2014. doi: 10.1136/heartjnl-2014-305578

- BURTT, E. A. As Bases Metafísicas da Ciência Moderna. Trad. de José Viegas Filho e Orlando Araújo Henriques. Brasília: Editora Universidade de Brasília, 1991. 268p.

- CAMÕES, Luís. Os Lusíadas. 4.ed. Lisboa: Ministério dos Negócios Estrangeiros. Instituto Camões, 2000.

- CARO, Tito Lucrécio. Da Natureza. Prefácio, tradução e notas de Agostinho da Silva. São Paulo: Globo, 1962.

- CERON, A. O.; DINIZ, J. A. F. O Uso das fotografias aéreas na identificação das formas de utilização agrícola da terra. Revista Brasileira de Geografia, v. 2, p. 161-173, 1966.

- CHANGNON, S. A. Inadvertent weather modification in urban areas: lessons for global climate change. Bull. Am. Meteorol. Soc., v. 73, pp. 619-627, 1992.

- DEPARTAMENTO DE INFORMÁTICA DO SUS (DATASUS). Informações de Saúde (TABNET). Brasília: Ministério da Saúde. Disponível em: <http://datasus.saude.gov.br/informacoes-de-saude/tabnet>. Acesso em 27 fev. 2017.

- DESCARTES, René. Discurso do Método. Tradução de Maria Ermantina de Almeida Prado Galvão. São Paulo: Martins Fontes, 2009.

- DIDEROT, Denis. Textos escolhidos/ Diderot. Traduções e notas de Marilena de Souza Chauí, J. Guinsburg. São Paulo: Abril Cultural, 1979.

- EMPRESA PAULISTA DE PLANEJAMENTO METROPOLITANO S.A. (EMPLASA). Recobrimento Aerofotogramétrico do Estado de São Paulo. São Paulo, 2010.

- ENVIRONMENTAL SYSTEMS RESEARCH INSTITUTE (ESRI). How Spatial Autocorrelation (Global Moran's I) Works. Disponível em: 
<http://pro.arcgis.com/es/pro-app/tool-reference/spatial-statistics/h-how-spatialautocorrelation-moran-s-i-spatial-st.htm>. Acesso em 13 mar. 2018.

- EPICURO. Carta sobre a Felicidade: (a Meneceu). Tradução e apresentação de Álvaro Lorencini e Enzo Del Carratore. São Paulo: Editora UNESP, 2002.

- $\quad$ ESTOQUE, R. C.; MURAYAMA, Y.; MYINT, S. W. Effects of landscape composition and pattern on land surface temperature: An urban heat island study in the megacities of Southeast Asia. Science of the Total Environment, v.577, 2017. doi: 10.1016/j.scitotenv.2016.10.195

- FARIAS, N. S. O. Mortalidade cardiovascular e desigualdades sociais no município de São Paulo, Brasil, 1996-1998 e 2008-2010. Epidemiologia e Serviços de Saúde, v. 23, n.1, pp.57-66, 2014. Disponível em: <http://www.scielo.br/pdf/ress/v23n1/2237-9622ress-23-01-00057.pdf>. Acesso em 13 mar. 2018.

- GALVÃO, N.; LEITE, M. L.; VIRGENS FILHO, J. S.; PONTES, C. C.. Relação entre Fatores Climáticos e Doenças do Aparelho Cardiovascular no Município de Ponta Grossa - RS. Revista Brasileira de Geografia Médica e da Saúde (Hygeia), Uberlândia, v.11, n.21, pp.93-106, 2015. Disponível em: <http://www.seer.ufu.br/index.php/hygeia>. Acesso em 27 fev. 2017.

- GOETHE, Johann Wolfgang von. Fausto: uma tragédia - primeira parte. Tradução de Jenny Klabin Segall; apresentação, comentários e notas de Marcus Vinicius Mazzari. São Paulo: Editora 34, 2011.

- HEGEL, G. W. F. Fenomenologia do Espírito. Tradução de Paulo Meneses com a colaboração de Karl-Heins Efken e José Nogueira Machado. 9.ed. Petrópolis, RJ: Vozes; Bragança Paulista: Editora Universitária São Francisco, 2014.

- HOLBACH, Barão de. Sistema da natureza ou Das leis do mundo físico e do mundo moral. São Paulo: Martins Fontes, 2010.

- HOllandA, Chico Buarque de. Roda Vida (música). Ano de lançamento: 1968. Disponível em: <http://www.chicobuarque.com.br/letras/rodaviva_67.htm>. Acesso em 27 ago. 2018.

- IKEFUTI, P. V. Associação entre variáveis meteorológicas, índice climático, fatores socioeconômicos e mortalidade por doenças do aparelho circulatório (acidente vascular cerebral e embolia pulmonar) no município de São Paulo - SP. 2016. Tese (Doutorado em Geografia Física) - Faculdade de Filosofia, Letras e Ciências Humanas da Universidade de São Paulo, São Paulo, 2016. Disponível em: <http://www.teses.usp.br/teses/disponiveis/8/8135/tde-13022017-114517/pt-br.php>. Acesso em 13 mar. 2018.

- IKEFUTI, P. V.; BARROZO, L. V. Variáveis socioeconômicas e o risco relativo por acidente vascular cerebral no município de São Paulo. Espaço \& Geografia, São Paulo, v.18, n.3, pp.639-656, 2015. Disponível em: <http://www.lsie.unb.br/espacoegeografia/index.php/espacoegeografia/article/view/45 6>. Acesso em 05 set. 2018.

- INSTITUTO BRASILEIRO DE GEOGRAFIA E ESTATÍSTICA (IBGE). Características da População e dos Domicílios: Resultados do Universo. Rio de Janeiro, 2010. Disponível em: <https://censo2010.ibge.gov.br/resultados.html > Acesso em 24 jan. 2018. 
- Instituto brasileiro DE GeOgRafia e estatísticA (IBGE). Censo Demográfico 2010: Resultados do Universo. Disponível em: <ftp://ftp.ibge.gov.br/Censos/Censo_Demografico_2010/Resultados_do_Universo/Ag regados/_por_Setores_Censitarios/>. Acesso em 07 jul. 2017.

- INSTITUTO BRASILEIRO DE GEOGRAFIA E ESTATÍSTICA (IBGE). Geociências. Disponível em: 〈https://www.ibge.gov.br/index.php〉. Acesso em 24 jan. 2018.

- INWOOD, M. Heidegger. São Paulo: Edições Loyola, 2000.

- JENSEN, J. R. Sensoriamento remoto do ambiente: uma perspectiva em recursos terrestres / tradução José Carlos Neves Epiphanio et al. São José dos Campos: Parêntese, 2009.

- KANT, Emmanuel. Crítica da Razão Pura. 2ed. São Paulo: Edições e Publicações Brasil Editora, 1958.

- KAWAKUBO, F. S.; MARTINS, M. H.; MORATO, R. G. Mapeamento de superfícies impermeáveis na Região Metropolitana de São Paulo utilizando fotografias aéreas e imagens LANDSAT-8 OLI. In: SIMPÓSIO BRASILEIRO DE GEOGRAFIA FÍSICA APLICADA, 17., 2017, Campinas. Anais... Campinas: UNICAMP, 2017, pp. 46764686. Disponível em: <http://ocs.ige.unicamp.br/ojs/sbgfa/article/view/2241〉. Acesso em 13 mar. 2018.

- LA MetTRie, J. O. O Homem-Máquina. Lisboa: Editorial Estampa, 1982.

- LANE, K. J.; STOKES, E. C.; SETO, K. C.; THANIKACHALAM, S.; THANIKACHALAM, M.; BELL, M. L. Associations between Greenness, Impervious Surface Area, and Nighttime Lights on Biomarkers of Vascular Aging in Chennai, India. Environ Health Perspect, Durham, v.125, n.8, 2015. doi: 10.1289/EHP541.

- LEE, W.; KIM, Y.; HONDA, Y.; KIM, H. Association between diurnal temperature range anda mortality modified by temperature in Japan, 1972-2015: Investigation of spatial and temporal patterns for 12 cause-specific deaths. Environment International, v.119, 2018.

- LIU, C.; YAVAR, Z.; SUN, Q. Cardiovascular response to thermoregulatory challenges. Am J Physiol Heart Circ Physiol, v.309, 2015. doi: 10.1152/ajpheart.00199.2015.

- LOPES, R. F. C. Espumas ao Vento (música). Ano de lançamento: 1997. Disponível em: <https://www.letras.mus.br/fagner/45918/>. Acesso em 27 ago. 2018.

- MARTINS, E. R.. Geografia e Ontologia: o Fundamento Geográfico do Ser. GEOUSP - Espaço e Tempo, São Paulo, n.21, pp.33-51, 2007. Disponível em: <http://www.revistas.usp.br/geousp/article/view/74047>. Acesso em 01 ago. 2018.

- MARTINS, M. H.; MORATO, R. G.; KAWAKUBO, F. S. Mapeamento de Superfícies Impermeáveis Utilizando Ortofotos, Imagens de Satélite e Regressão Linear. Revista do Departamento de Geografia, v.35, 2018. Doi:10.11606/rdg.v35i0.131542.

- MARX, Karl. Diferença entre as Filosofias da natureza em Demócrito e Epicuro. Santos: Martins Fontes, 1972.

- MARX, Karl. Manuscritos Econômico-Filosóficos. Tradução, apresentação e notas de Jesus Ranieri. São Paulo: BOITEMPO, 2004. 
- MARX, Karl. O Capital (Crítica da Economia Política). São Paulo: BOITEMPO, 2013.

- MARX, Karl. Sobre o suicídio. Tradução de Rubens Enderle e Francisco Fontanella. São Paulo: BOITEMPO, 2006.

- $\quad$ MIKAEL, L. R.; PAIVA, A. M. G.; GOMES, M. M.; SOUSA, A. L. L.; JARDIM, P. C. B. V.; VITORINO, P. V. O.; EUZÉBIO, M. B.; SOUSA, W. M.; BARROSO, W. K. S. Envelhecimento Vascular e Rigidez Arterial. Arquivos Brasileiros de Cardiologia, v.109, n.3, 2017.

- MINISTÉRIO DA SAÚDE. Cadastro Internacional de Doenças (CID 10). Brasília: Ministério da Saúde, 2017. Disponível em: < http://datasus.saude.gov.br/sistemas-eaplicativos/cadastros-nacionais/cid-10>. Acesso em 27 fev. 2017.

- MINISTÉRIO DA SAÚDE. Saúde Brasil 2014: Uma análise da situação de saúde e das doenças transmissíveis relacionadas à pobreza. Brasília: Ministério da Saúde, 2015. Disponível

em: <http://bvsms.saude.gov.br/bvs/publicacoes/saude_brasil_2014_analise_situacao.pdf > Acesso em 27 fev. 2017.

- MOON, Peter. Frentes frias podem aumentar a mortalidade por AVC. Revista Eletrônica da Fundação de Amparo à Pesquisa do Estado de São Paulo (FAPESP). São Paulo, 2018. Disponível em: <http://agencia.fapesp.br/frentes-frias-podemaumentar-mortalidade-por-avc/28055/>. Acesso em 19 jun. 2018.

- NASCIMENTO NETO, R. M. Atlas: Corações do Brasil. São Paulo: Sociedade Brasileira de Cardiologia, 2005.

- NIETZSCHE, F. Além do bem e do mal: prelúdio a uma filosofia do futuro. Tradução, notas e posfácio Paulo César de Souza. São Paulo: Companhia de Bolso, 2005.

- NIETZSCHE, F. Assim falou Zaratustra: um livro para todos e para ninguém. Tradução, notas e posfácio Paulo César de Souza. São Paulo: Companhia de Bolso, 2018

- NIETZSCHE, F. Crepúsculo dos ídolos, ou Como se fillosofa com o martelo. Tradução, notas e posfácio Paulo César de Souza. São Paulo: Companhia de Bolso, 2017.

- NIETZSCHE, F. O Anticristo: maldição ao cristianismo; Ditirambos de Dionísio. Tradução, notas e posfácio Paulo César de Souza. São Paulo: Companhia de Bolso, 2016.

- PAINE, D.; KISER, J. D. Aerial photography and image interpretation. NJ: John Wiley \& Sons, 2003.

- PESSOA, F. O Mistério das Cousas. In: O Guardador de Rebanhos. Disponível em: <http://www.dominiopublico.gov.br/download/texto/pe000001.pdf>. Acesso em 06 dez. 2017.

- PESSOA, Fernando. Poesias de Álvaro de Campos. Lisboa: Ática, 1944.

- PIRES, Érika Gonçalves; FERREIRA JÚNIOR, Laerte Guimarães. Mapeamento da temperatura de superfície a partir de imagens termais dos satélites Landsat 7 e Landsat 8. In: Simpósio Brasileiro de Sensoriamento Remoto, 7., João Pessoa, 2015. Anais Eletrônicos... Disponível em: <http://www.dsr.inpe.br/sbsr2015/files/p1671.pdf>. Acesso em 27 fev. 2017. 
- PREFEITURA DO MUNICÍPIO DE SÃO PAULO (PMSP). GEOSAMPA: Dados Abertos. Disponível

em: <http://geosampa.prefeitura.sp.gov.br/PaginasPublicas/_SBC.aspx>. Acesso em 24 jan. 2018.

- PRefeitura do MUNiCíPIO De SÃo PAUlo (PMSP). Plano Municipal da Mata Atlântica: Mapeamento. São Paulo, 2016. Disponível em: <http://www.prefeitura.sp.gov.br/cidade/secretarias/meio_ambiente/pmma/index.php? $\mathrm{p}=219941>$. Acesso em 08 mar. 2018.

- PREFEITURA DO MUNICÍPIO DE SÃO PAULO (PMSP). TabNet: Mortalidade Geral. São $\quad$ Paulo, $2018 . \quad$ Disponível em <http://www.prefeitura.sp.gov.br/cidade/secretarias/saude/tabnet/mortalidade/index.ph $\mathrm{p}$ ? $=6529>$. Acesso em 24 jan. 2018.

- ROSA, João Guimarães. Primeiras estórias. Rio de Janeiro: MEDIAfashion, 2008.

- ROUSE, J. W.; HAAS, R. H.; WELL, J. A.; DEERING, D. W. Monitoring vegetation systems in the great plains with erts. Remote Sensingcenter, Texas, 1973. Disponível em 〈https://ntrs.nasa.gov/archive/nasa/casi.ntrs.nasa.gov/19740022614.pdf〉. Acesso em 06 dez. 2018.

- SAKUNO, N. R. R.; KAWAKUBO, F. S.; SPALEVIC, V.; MINCATO, R. L. Mapeamento de Superfícies Impermeáveis em Áreas Urbanas Utilizando Imagens Índices Geradas Pelo Sistema Landsat-5 Thematic Mapper. Revista do Departamento de Geografia da USP, São Paulo, Volume Especial, Eixo 9, pp.190-198, 2017.

- SANTOS, Milton. A Natureza do Espaço: Técnica e Tempo, Razão e Emoção. 4ed. São Paulo: Editora da Universidade de São Paulo, 2006.

- SEABRA, O. C. L. Os meandros dos Rios nos Meandros do Poder. Tietê e Pinheiros: Valorização dos Rios e das Várzeas na cidade de São Paulo. 1987. Tese (Doutorado em Geografia) - Faculdade de Filosofia, Letras e Ciências Humanas da Universidade de São Paulo, São Paulo, 1987. Disponível em: $<$ http://eletromemoria.fflch.usp.br/content/os-meandros-dos-rios-nos-meandros-dopoder-tiete-e-pinheiros-valorizacao-dos-rios-e-das>. Acesso em 13 mar. 2018.

- SILVA, E. N.; RIBEIRO, H., SANTANA, P. Clima e saúde em contextos urbanos: uma revisão da literatura. Revista Bibliográfica de Geografía y Ciencias Sociales, Barcelona: Universidad de Barcelona, v.19, n.1092, 2014. Disponível em: http://www.ub.es/geocrit/b3w1092.htm. Acesso em 27 fev. 2017.

- SOARES, F. V.; GREVE, P.; SENDÍN, F. A.; BENZE, B. G.; CASTRO, A. P.; REBELATTO, J. R. Relação entre alterações climáticas e fatores determinantes da mortalidade de idosos no município de São Carlos (SP) em um período de dez anos. Ciência \& Saúde Coletiva, Rio de Janeiro, v.17, n.1, pp.135-146, 2012. Disponível: <http://www.cienciaesaudecoletiva.com.br/index_interno.php〉. Acesso em 27 fev. 2017.

- UNITED STATES GEOLOGICAL SURVEY (USGS). Earth Explorer. Disponível em: <https://earthexplorer.usgs.gov/>. Acesso em 10 jan. 2018.

- UNITED STATES GEOLOGICAL SURVEY (USGS). Using the USGS Landsat Level-1 Data Product. Disponível em: <https://landsat.usgs.gov/using-usgs-landsat-8product>. Acesso em 19 set. 2018. 
- WENG, Q. Remote sensing of impervious surfaces in the urban areas: requirements, methods, and trends. Remote Sensing of Environment, v. 117, p. 34-49, 2012.

- WENG, Q. Remote Sensing of Impervious Surfaces. Boca Raton: CRC Press, 2007.

- WORLD HEALTH ORGANIZATION (OMS). AGE STANDARDIZATION OF RATES: A NEW WHO STANDARD. OMS, 2001. Disponível em: <http://www.who.int/healthinfo/paper31.pdf>. Acesso em 13 mar. 2018.

- YI ZHOU; GUANG YANG; SHIXIN WANG; LITAO WANG; FUTAO WANG; XIONGFEI LIU. A new index for mapping built-up and bare land areas from Landsat8 OLI data. Remote Sensing Letters, v.5, n.10, pp.862-871, 2014. Disponível em: <https://www.tandfonline.com/doi/pdf/10.1080/2150704X.2014.973996?needAccess= true>. Acesso em 13 mar. 2018.

- YUAN, F.; BAUER, M. E. Comparison of impervious surface area and normalized difference vegetation index as indicators of surface urban heat island effects in Landsat imagery. Remote Sensing of Environment, v. 106, n. 3, p. 375-386, 2007.

- ZHA, Y.; GAO, J.; NI, S. Use of Normalized Difference Built-Up Index in Automatically Mapping Urban Areas from TM Imagery. International Journal of Remote Sensing, v.24, pp.583-594, 2003. Disponível em: <https://is.muni.cz/el/1431/podzim2012/Z8114/um/35399132/35460312/ndbi.pdf>. Acesso em 13 mar. 2018. 
ANEXOS 


\section{Anexo A}

Tabela A1 - Dados das imagens dos Satélites Landsat-7 e Landsat-8 utilizadas no escopo do trabalho

\begin{tabular}{|c|c|c|c|c|}
\hline Imagem & Bandas & Faixa do Espectro Eletromagnético (Descrição) & Resolução Espacial (m) & Órbita/Ponto \\
\hline \multirow{8}{*}{$\begin{array}{l}\text { Landsat-7 (Data de } \\
\text { Aquisição: 13/06/2010) }\end{array}$} & 1 & Azul & 30 & \multirow{19}{*}{$219 / 076$} \\
\hline & 2 & Verde & 30 & \\
\hline & 3 & Vermelho & 30 & \\
\hline & 4 & Infravermelho Próximo & 30 & \\
\hline & 5 & Infravermelho Médio & 30 & \\
\hline & 6 & Termal & 60 & \\
\hline & 7 & Infravermelho Distante & 30 & \\
\hline & 8 & Pancromática & 15 & \\
\hline \multirow{11}{*}{$\begin{array}{l}\text { Landsat-8 (Data de } \\
\text { Aquisição: 23/09/2015) }\end{array}$} & 1 & Aerosol/Ambiente Costeiro & 30 & \\
\hline & 2 & Azul & 30 & \\
\hline & 3 & Verde & 30 & \\
\hline & 4 & Vermelho & 30 & \\
\hline & 5 & Infravermelho Próximo & 30 & \\
\hline & 6 & Infravermelho Médio & 30 & \\
\hline & 7 & Infravermelho Distante & 30 & \\
\hline & 8 & Pancromática & 115 & \\
\hline & 9 & Cirrus & 30 & \\
\hline & 10 & Termal (Sensor TIRS) & 100 & \\
\hline & 11 & Termal (Sensor TIRS) & 100 & \\
\hline
\end{tabular}

Fonte: USGS, 2017. Data: 01/09/2017. 
Tabela A2 - Metadados das bandas dos satélites Landsat-7 e Landsat-8 utilizadas no escopo do trabalho

\begin{tabular}{|c|c|c|c|c|c|c|}
\hline Imagem & Bandas & $\begin{array}{c}\text { Faixa do Espectro } \\
\text { Eletromagnético } \\
\text { (Descrição) }\end{array}$ & $\begin{array}{c}\text { Resolução } \\
\operatorname{Espacial~(m)~}\end{array}$ & Órbita/Ponto & $\begin{array}{l}\text { Fator Multiplicativo } \\
\text { de Reescalonamento }\end{array}$ & $\begin{array}{l}\text { Fator Aditivo de } \\
\text { Reescalonamento }\end{array}$ \\
\hline \multirow{2}{*}{$\begin{array}{l}\text { Landsat-7 (Data de } \\
\text { Aquisição: 13/06/2010) }\end{array}$} & 3 & Vermelho & 30 & \multirow{4}{*}{$219 / 076$} & 0,0013209 & $-0,011945$ \\
\hline & 5 & Infravermelho Médio & 30 & & 0,0018456 & $-0,016468$ \\
\hline \multirow{2}{*}{$\begin{array}{c}\text { Landsat-8 (Data de } \\
\text { Aquisição: 23/09/2015) }\end{array}$} & 4 & Vermelho & 30 & & 0,00002 & $-0,1$ \\
\hline & 10 & Termal (Sensor TIRS) & 100 & & 0,003342 & 0,1 \\
\hline
\end{tabular}

Fonte: USGS, 2017. Data: 01/09/2017. 


\begin{tabular}{|c|c|c|c|c|c|c|c|c|c|c|c|c|c|c|c|c|c|c|}
\hline $\begin{array}{l}\text { Codigig a do Distrito } \\
\end{array}$ & 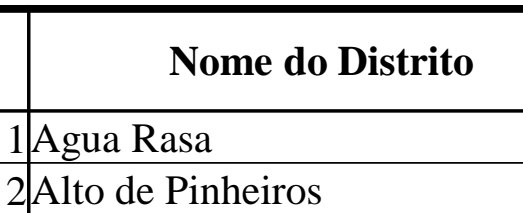 & 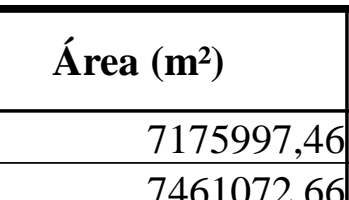 & 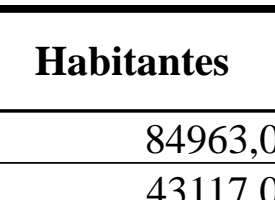 & \begin{tabular}{l|l} 
Total de ó bitios MSC \\
286
\end{tabular} & 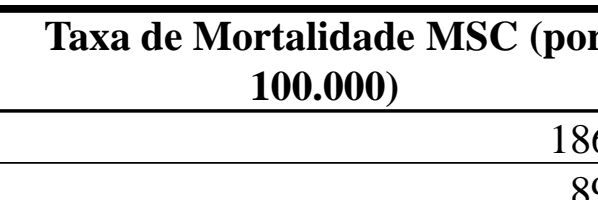 & 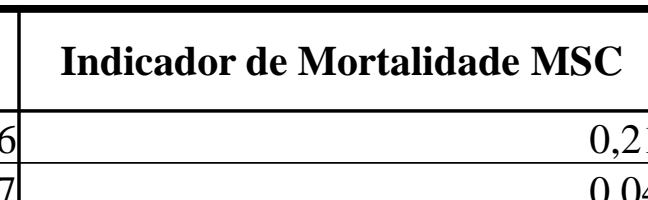 & 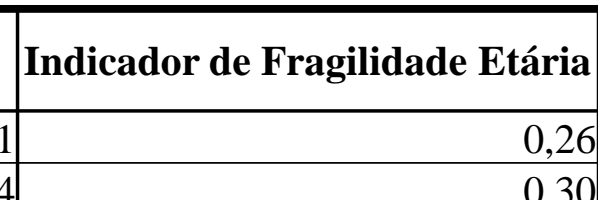 & $\begin{array}{l}\text { Inicacalor de Renala } \\
\end{array}$ & 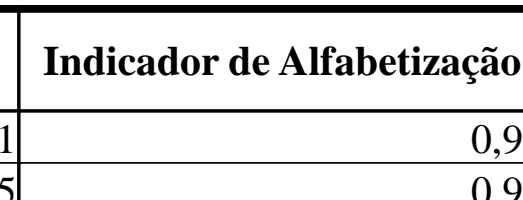 & 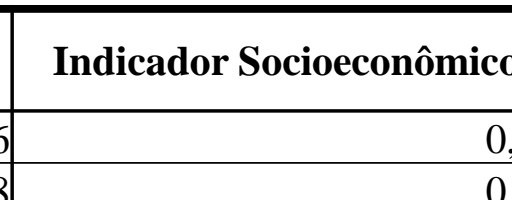 & 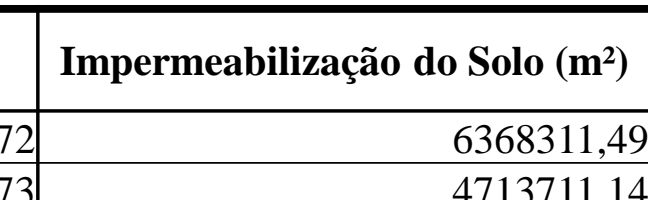 & 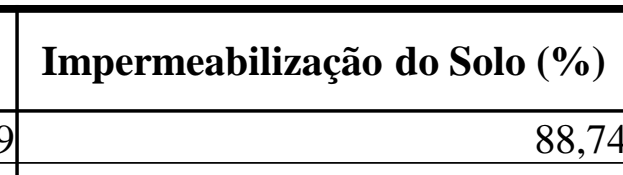 & Inticatar V VRMM & 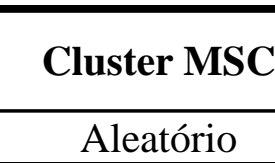 & $\begin{array}{l}\text { Cluster Rendata } \\
\text { Alefario } \\
\end{array}$ & 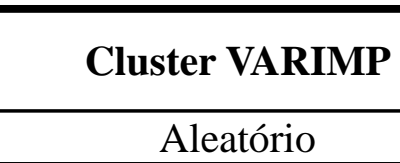 & & Indicador Sociaambiental \\
\hline & 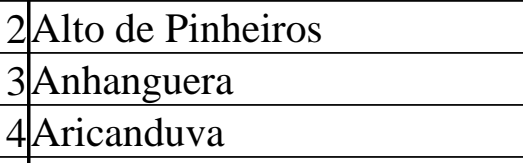 & 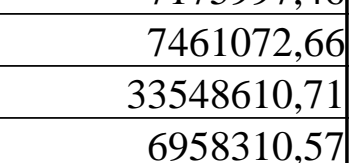 & 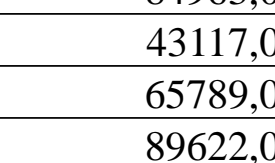 & 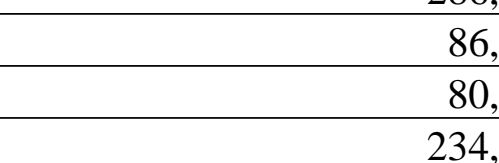 & & $-\frac{0.0}{0.2}$ & 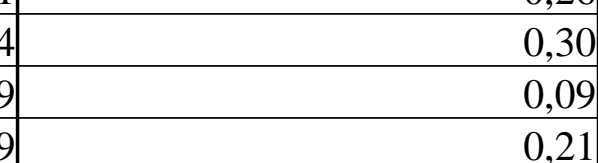 & 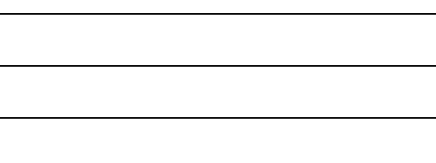 & $\frac{0.9}{0.8}$ & $\begin{array}{c}0 \\
0 \\
0\end{array}$ & $\begin{array}{ll}0 \\
\text { int }\end{array}$ & 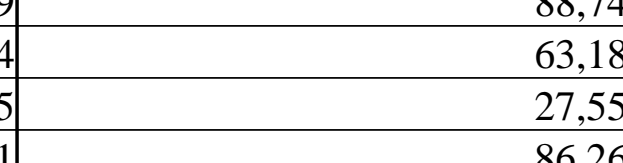 & $\frac{0}{0}$ & 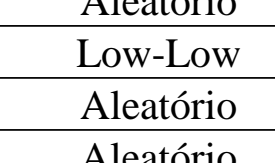 & 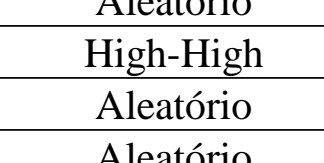 & 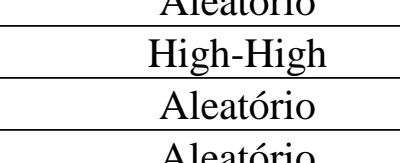 & $\begin{array}{l}3 \\
\frac{3}{3} \\
\end{array}$ & \\
\hline & 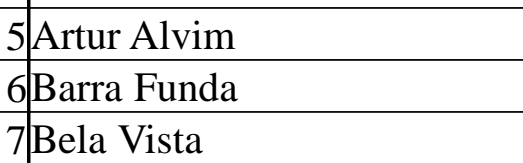 & 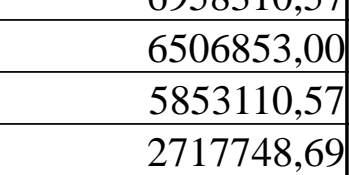 & 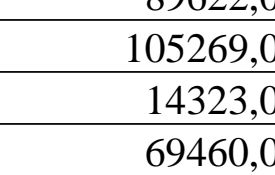 & $\begin{array}{l}\frac{280}{37} \\
\frac{374}{14}\end{array}$ & & & 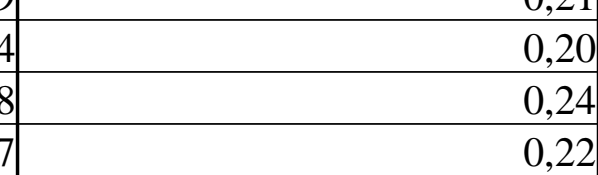 & & & g. & 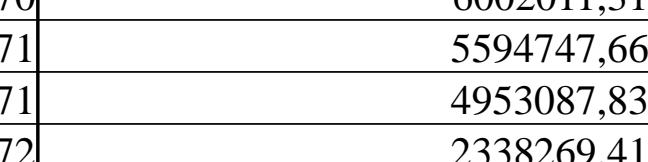 & 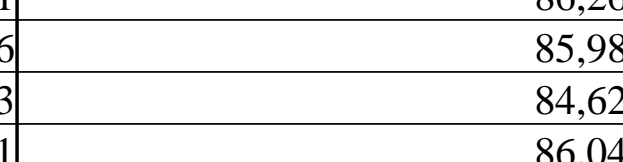 & $\frac{0}{0.0}$ & 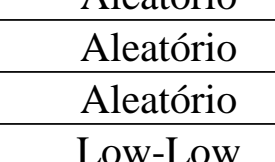 & 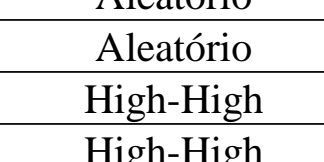 & 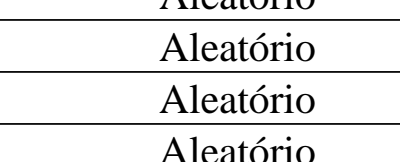 & $\frac{3}{3}$ & \\
\hline & 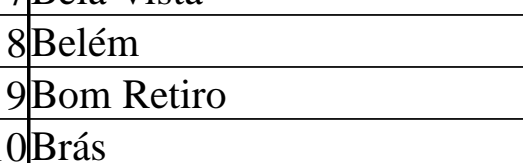 & 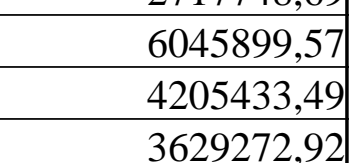 & 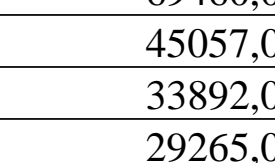 & 1292 & & & 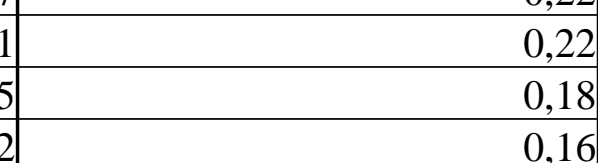 & & & 20 & 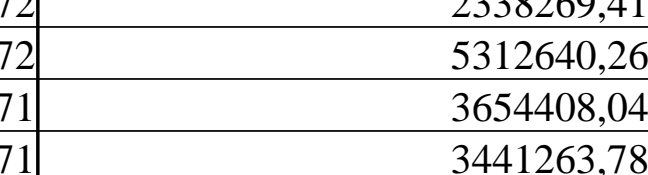 & 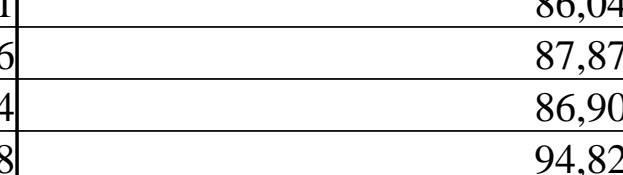 & & 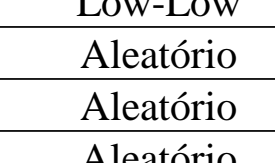 & 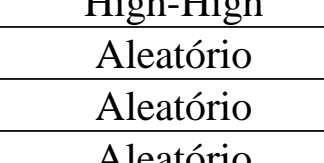 & 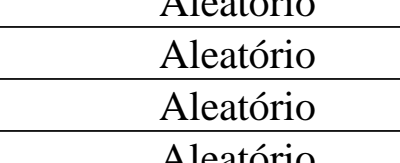 & & \\
\hline & 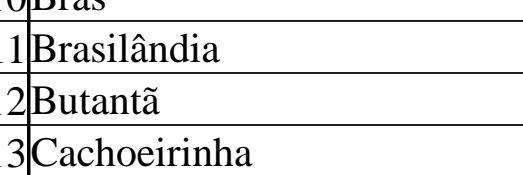 & 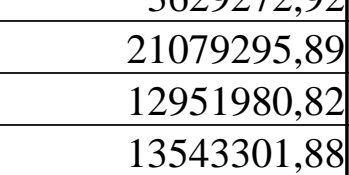 & 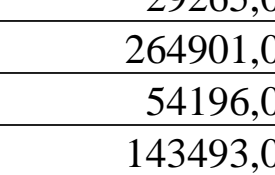 & 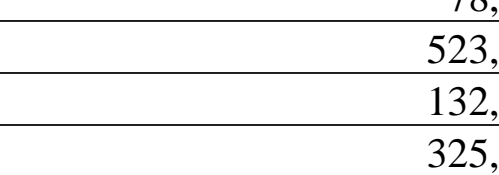 & & & $\begin{array}{c}0 \\
0 \\
0 \\
0\end{array}$ & & & $\frac{0}{0}=0$ & 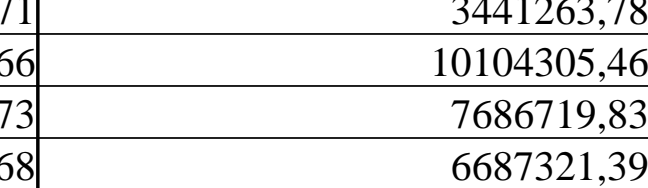 & 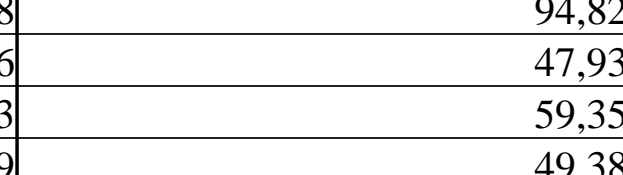 & & 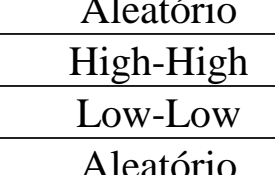 & 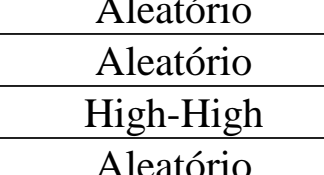 & 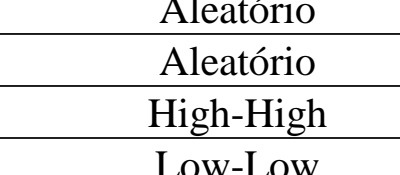 & $\frac{3}{3}$ & \\
\hline & 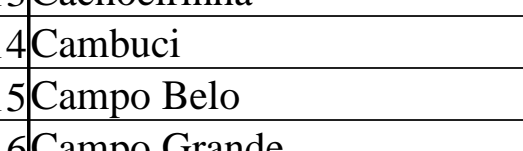 & 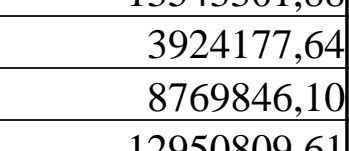 & 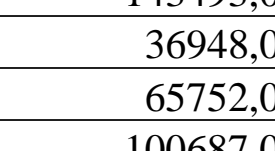 & $\begin{array}{ll}\frac{82}{718} \\
\frac{178}{185}\end{array}$ & & & & & & & 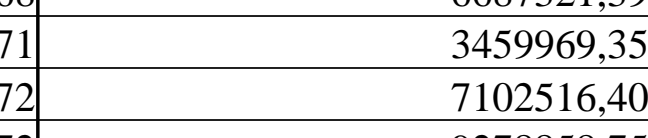 & $\begin{array}{ll}\frac{88.17}{88.99} \\
80.9\end{array}$ & 0. & 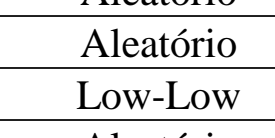 & 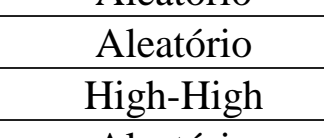 & 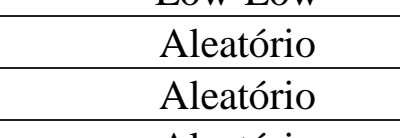 & $\frac{3}{3}$ & \\
\hline & 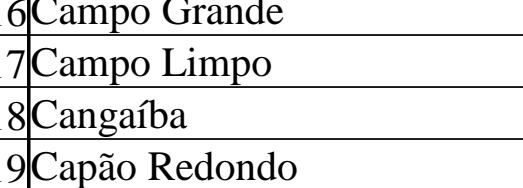 & 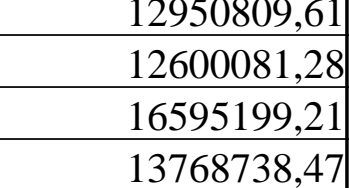 & 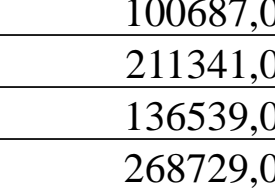 & $\frac{185}{205}$ & & & & & & & 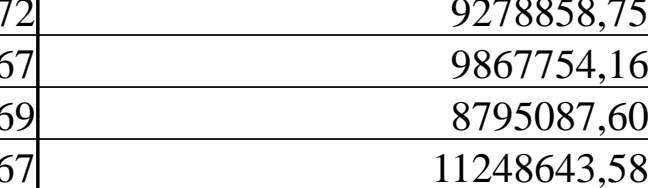 & 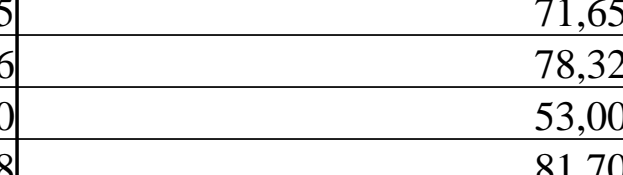 & & 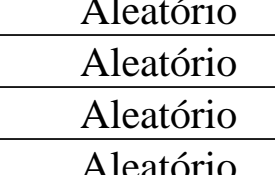 & 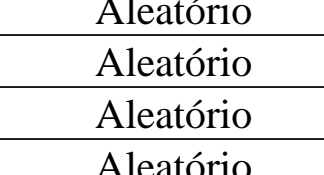 & 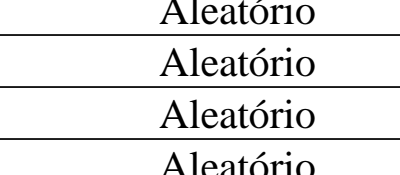 & $\frac{3}{3}$ & \\
\hline & 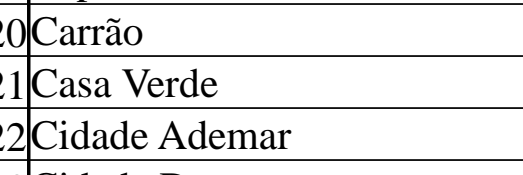 & 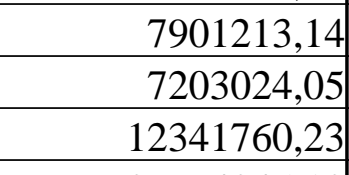 & 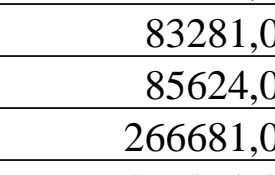 & & & & & & & & 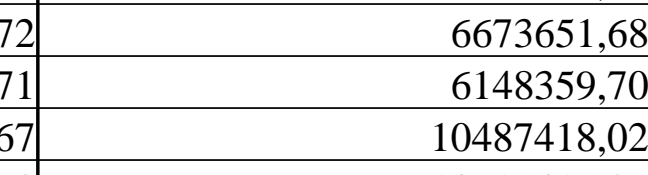 & 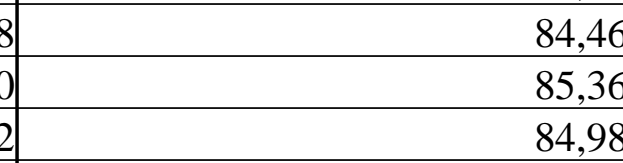 & $\frac{0}{0}$ & 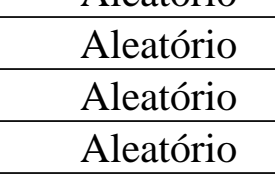 & 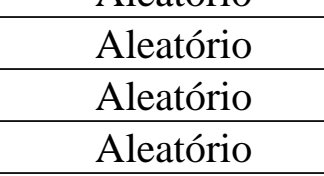 & 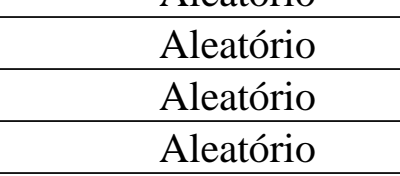 & $\frac{\frac{3}{3}}{3}$ & \\
\hline & 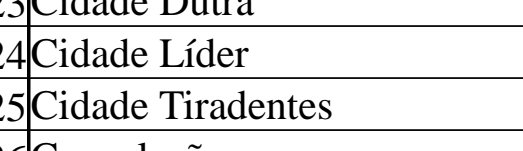 & 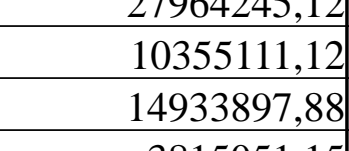 & 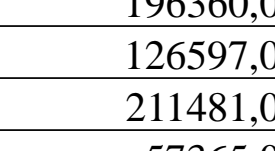 & 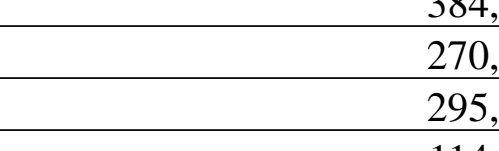 & & & $\underline{E}+2+3$ & & & & 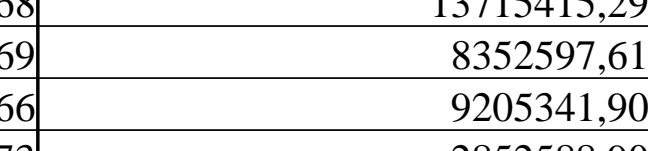 & 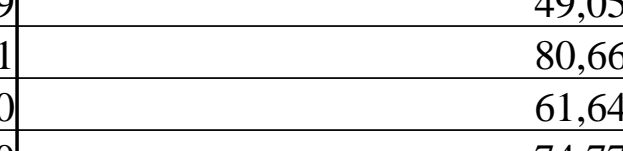 & & 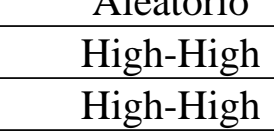 & 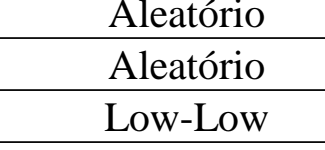 & 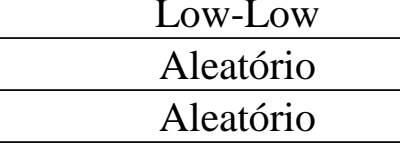 & \begin{tabular}{|c|c|}
3 \\
$\frac{3}{3}$ \\
\end{tabular} & \\
\hline & 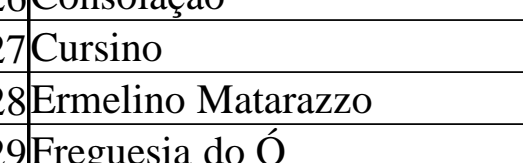 & 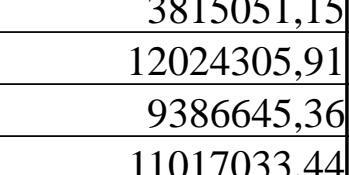 & 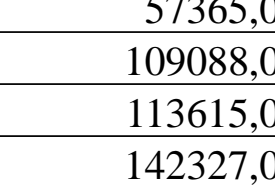 & & & & & & & & 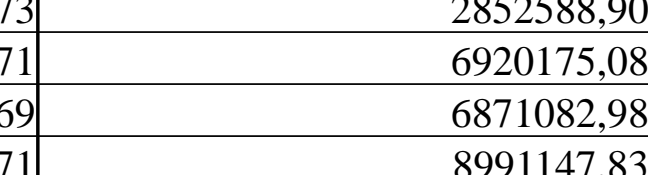 & 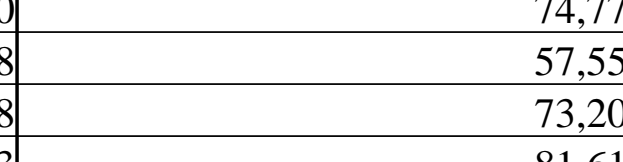 & & 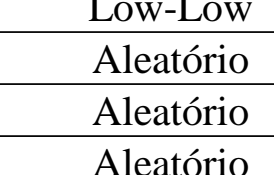 & 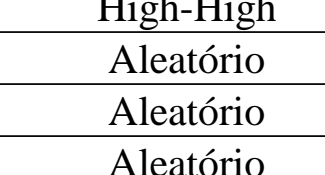 & 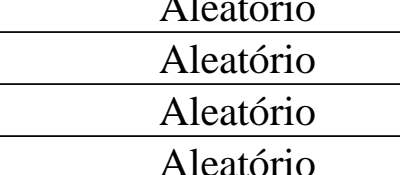 & $\begin{array}{ll}3 \\
3 \\
3\end{array}$ & \\
\hline & 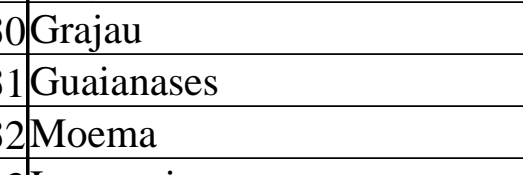 & 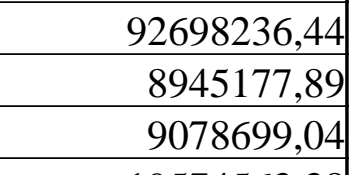 & 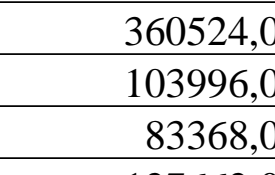 & & & & & & & & 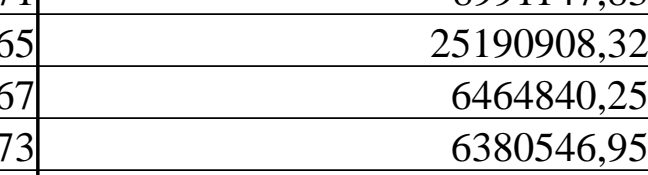 & 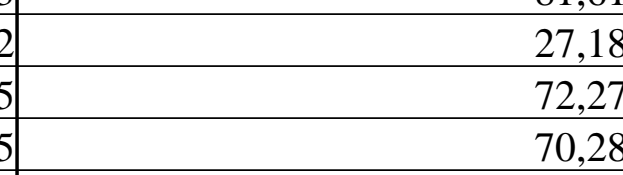 & & 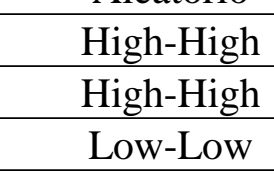 & 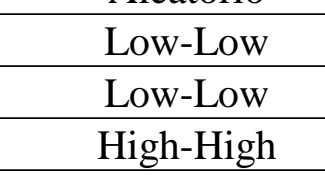 & 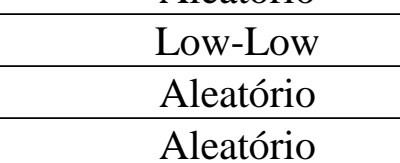 & \begin{tabular}{|l}
$\frac{3}{3}$ \\
\end{tabular} & \\
\hline & 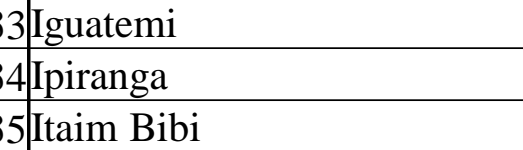 & 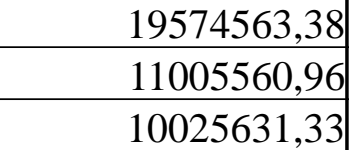 & 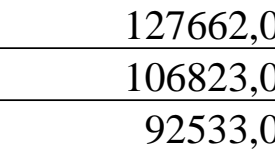 & & & & & & & & 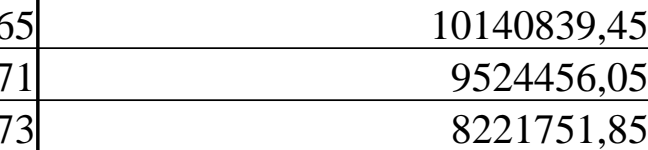 & 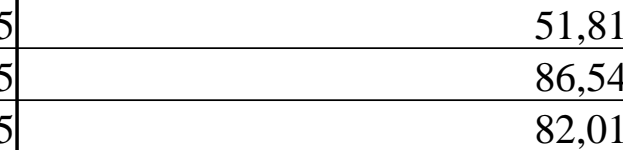 & & 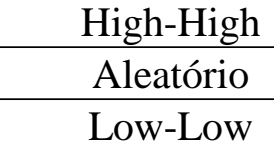 & 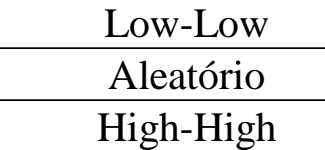 & 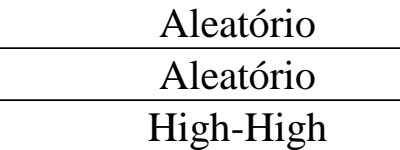 & $\frac{3}{3}$ & \\
\hline & 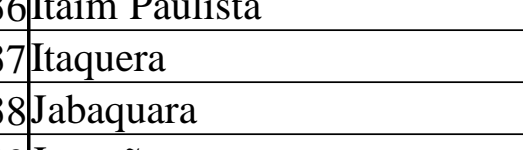 & 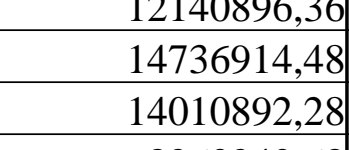 & 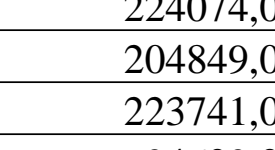 & & & & & & & & 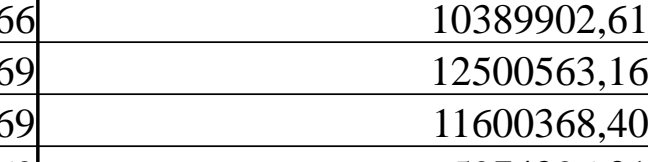 & 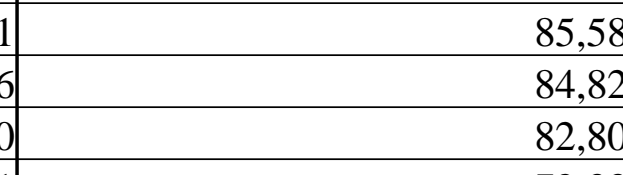 & & 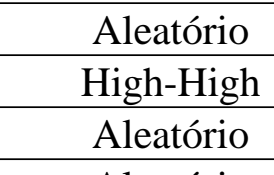 & 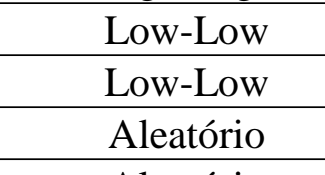 & 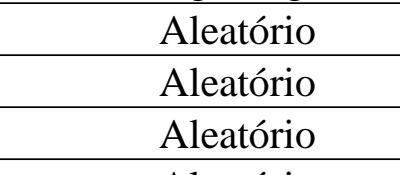 & $\frac{-\frac{3}{3}}{3}$ & \\
\hline & 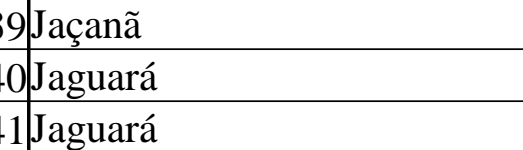 & 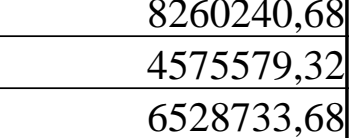 & 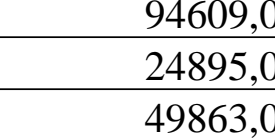 & & & & & & & & 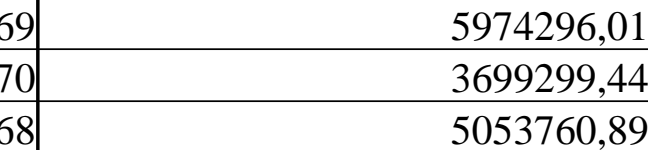 & 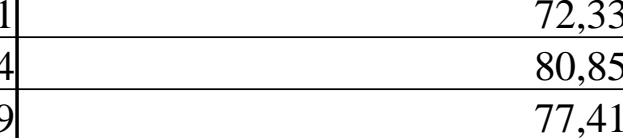 & & 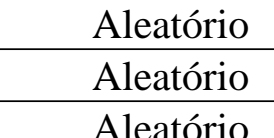 & 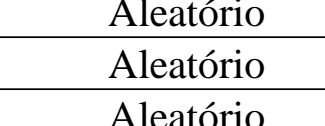 & 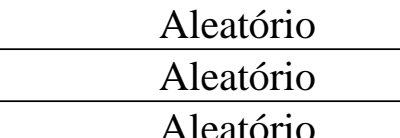 & $\frac{3}{3}$ & \\
\hline & 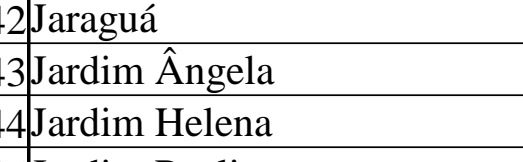 & 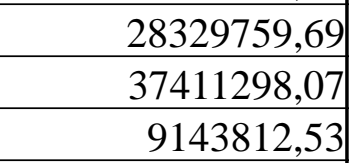 & 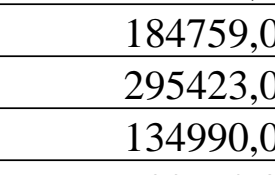 & & & & & & & & 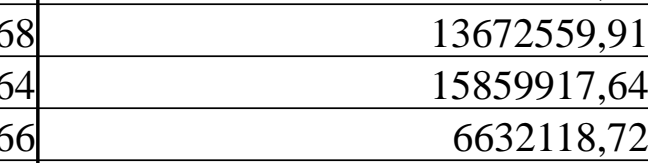 & 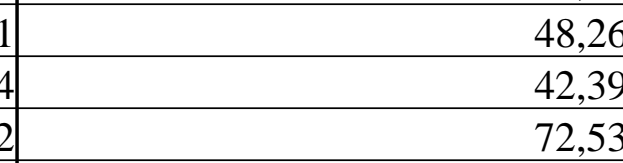 & $\frac{0 .}{0.0}$ & 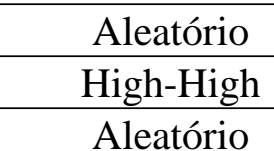 & 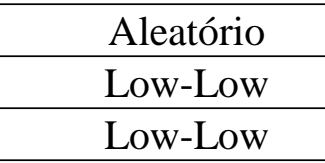 & 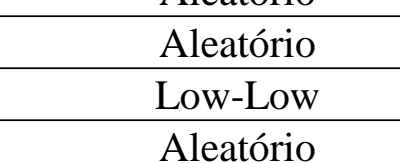 & $\frac{\frac{3}{3}}{3}$ & \\
\hline & 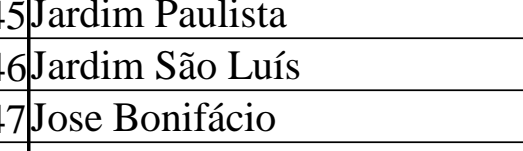 & 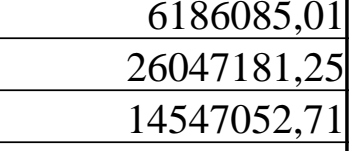 & 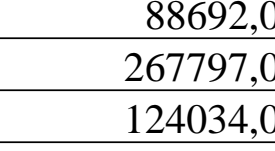 & & & & & & & & 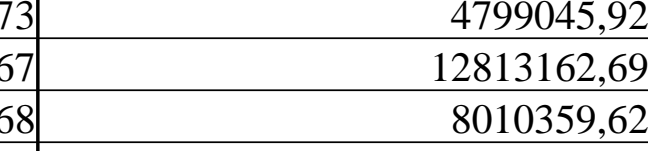 & 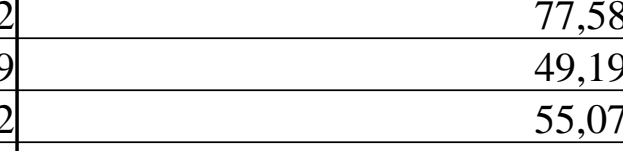 & & 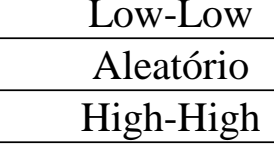 & 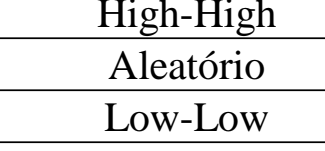 & 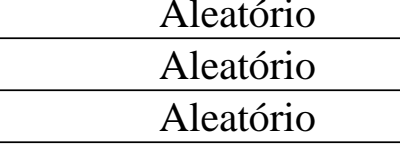 & & \\
\hline & 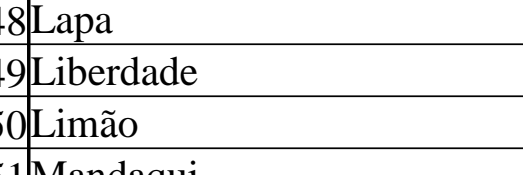 & 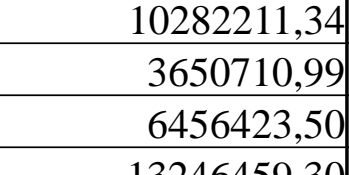 & 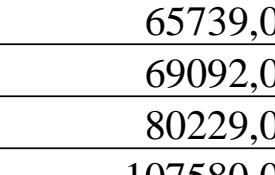 & & & & & & & & 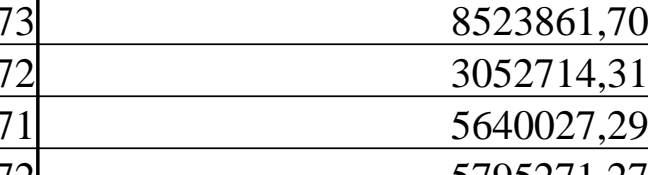 & 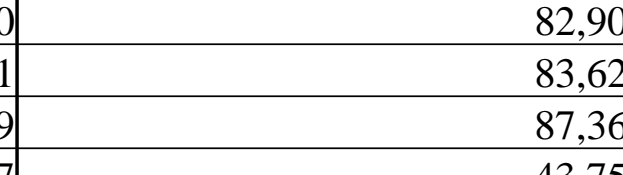 & & 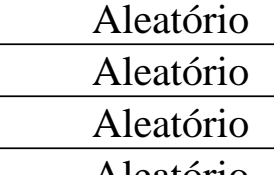 & 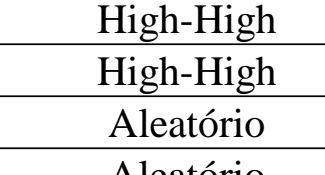 & 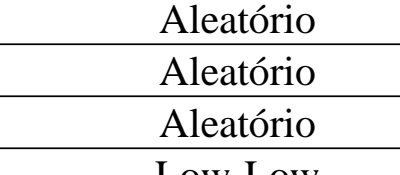 & \begin{tabular}{|l}
$\frac{3}{3}$ \\
$\frac{3}{3}$ \\
\end{tabular} & \\
\hline & 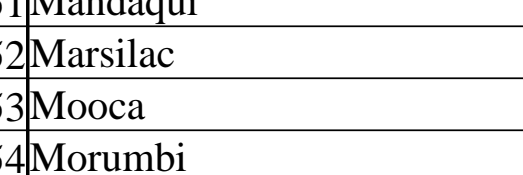 & 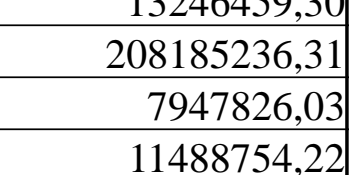 & 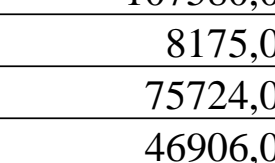 & & & & & & & & 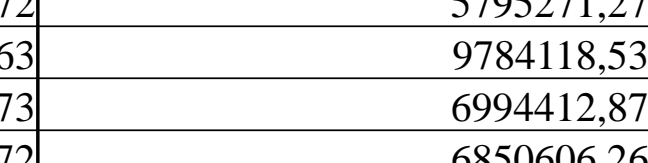 & 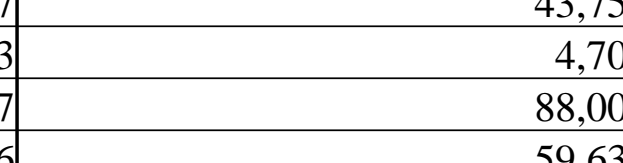 & & 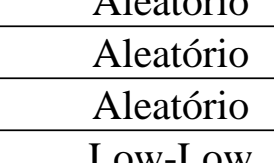 & 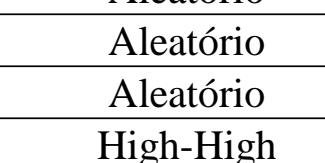 & 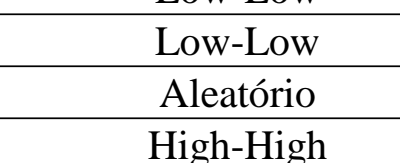 & 43 & \\
\hline & 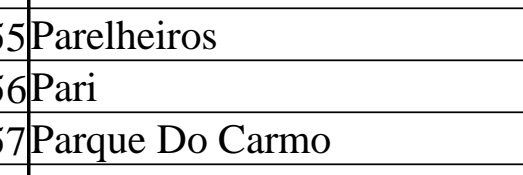 & 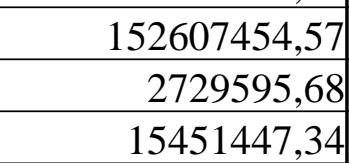 & 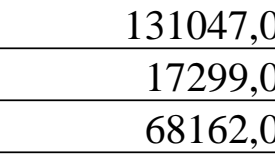 & & & & & & & & 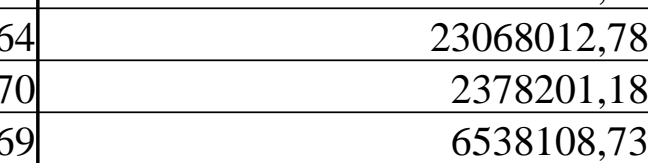 & 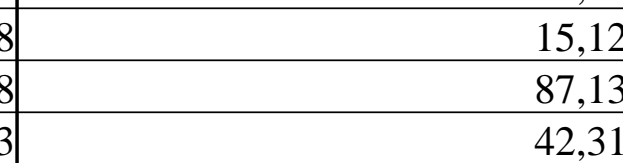 & & 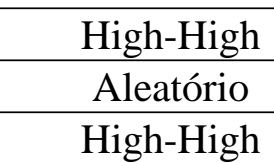 & 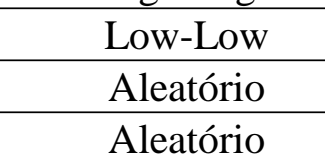 & 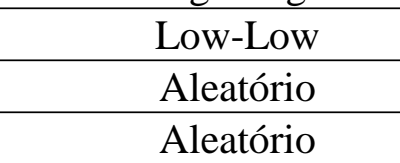 & & \\
\hline & 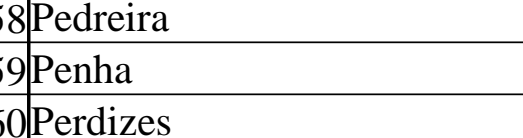 & 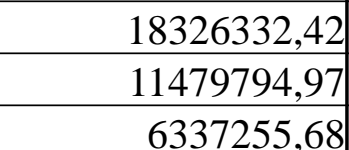 & 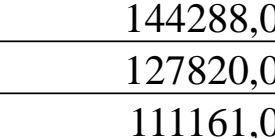 & & & & & & & & 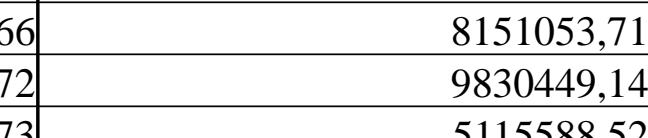 & 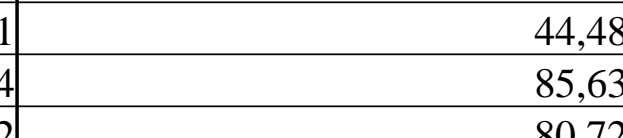 & & 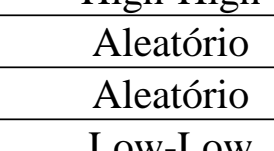 & 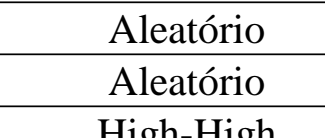 & 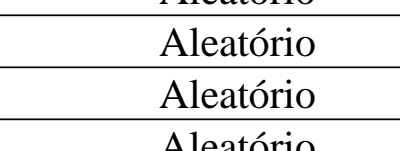 & $\frac{34}{x^{2}}$ & \\
\hline & 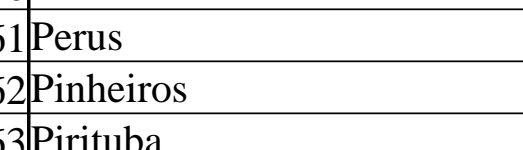 & 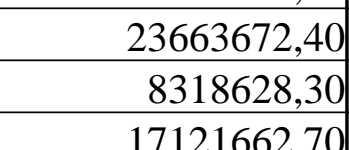 & 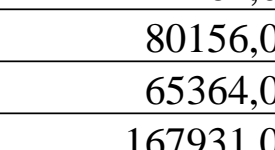 & & & & & & & & 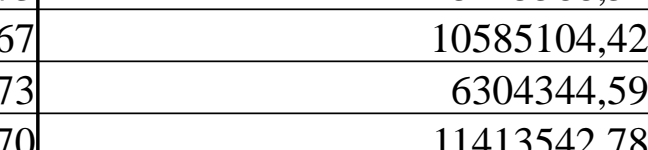 & 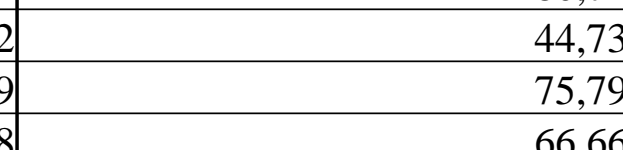 & & 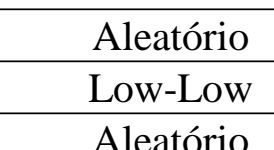 & 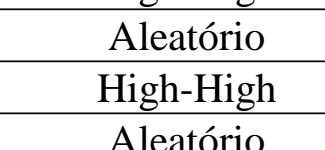 & 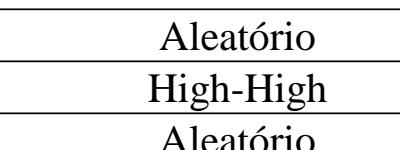 & & \\
\hline & 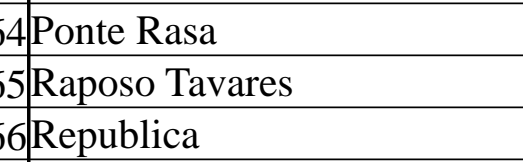 & 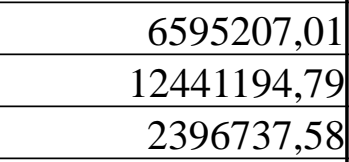 & 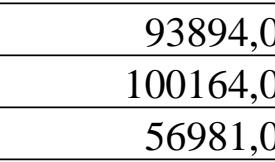 & & & & & & & & 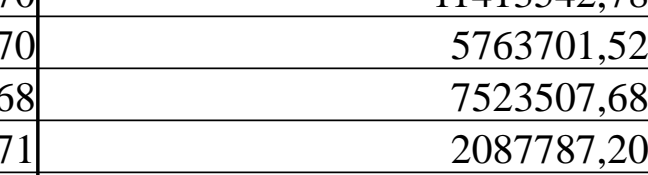 & 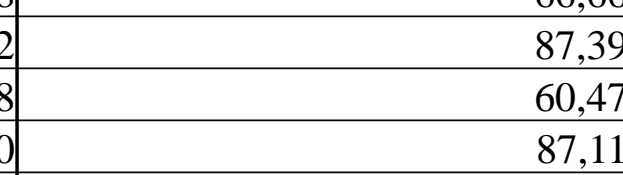 & & 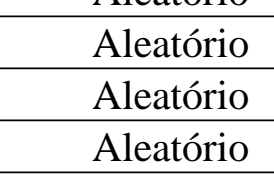 & 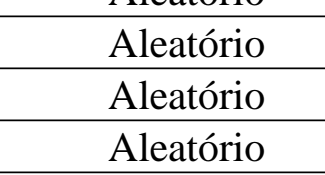 & 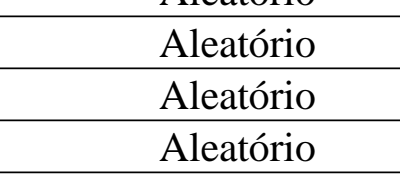 & \begin{tabular}{|l}
$\frac{3}{3}$ \\
$\frac{3}{3}$
\end{tabular} & \\
\hline & 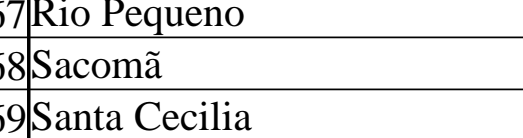 & 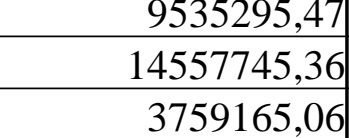 & 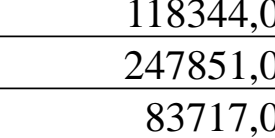 & & & & & & & & 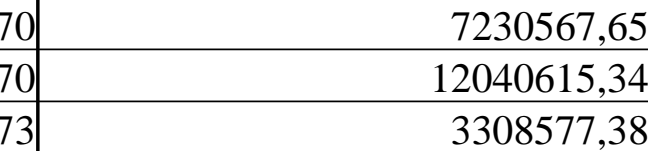 & & & 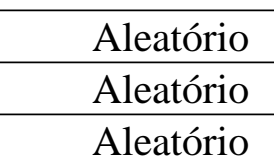 & 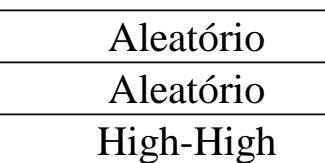 & 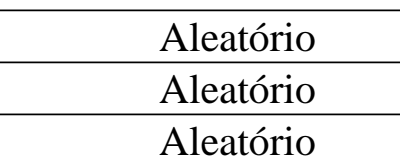 & & \\
\hline & 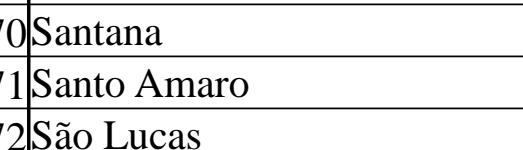 & 1300 & 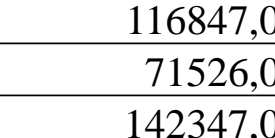 & 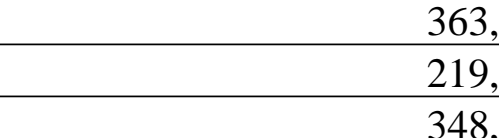 & & & & & & & 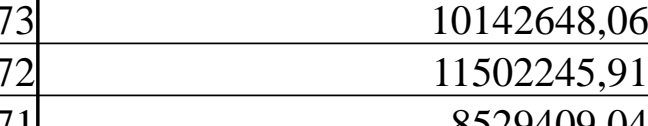 & $\begin{array}{l}\frac{77.48}{71.73} \\
8817\end{array}$ & & 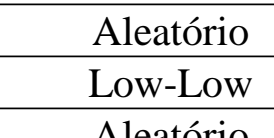 & 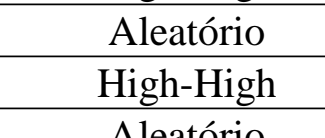 & 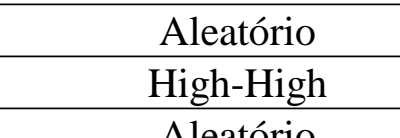 & & \\
\hline & 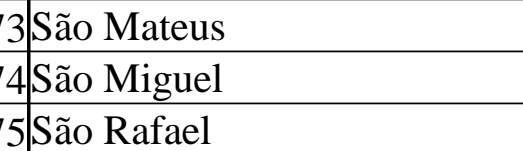 & 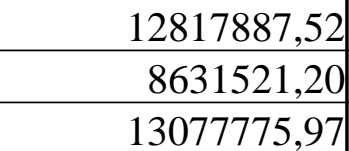 & 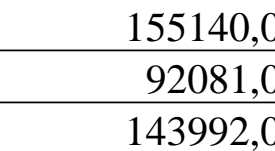 & & & & & & & & 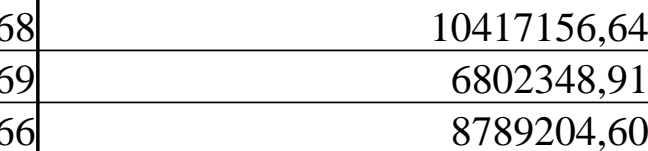 & $\begin{array}{l}\frac{8187}{78.8} \\
67521\end{array}$ & & 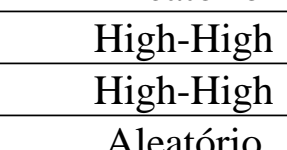 & 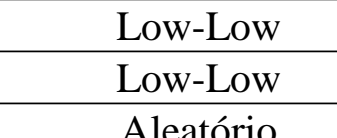 & 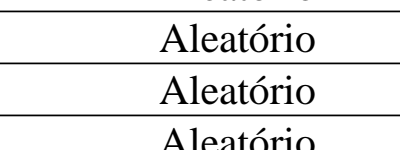 & & \\
\hline & 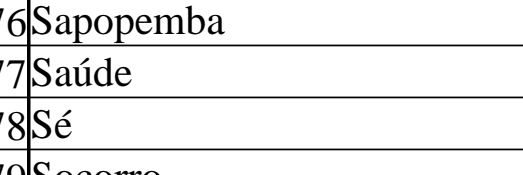 & 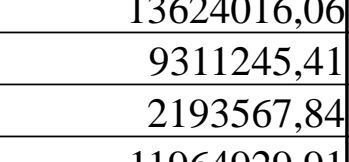 & 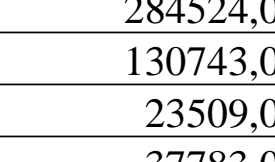 & $\begin{array}{l}\frac{2788}{288} \\
38\end{array}$ & & & & & & & 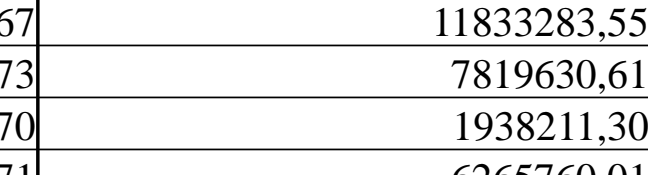 & 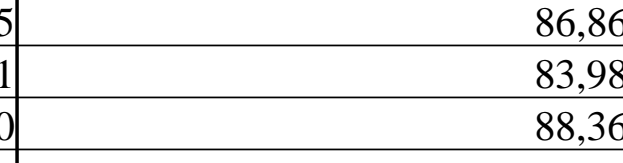 & & 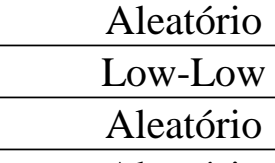 & 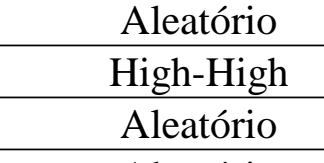 & 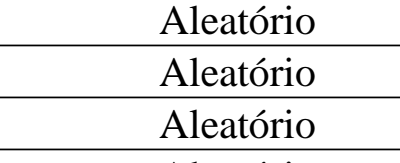 & & \\
\hline & 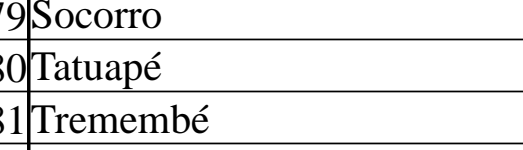 & 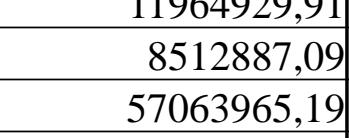 & 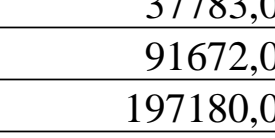 & & & & & & & & & $\begin{array}{l}86.37 \\
263.57 \\
27.56\end{array}$ & & 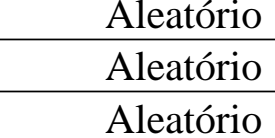 & 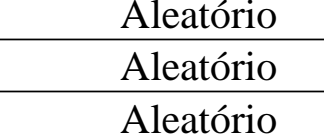 & 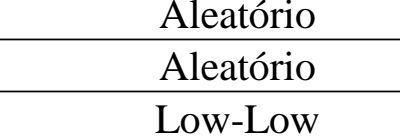 & & \\
\hline & 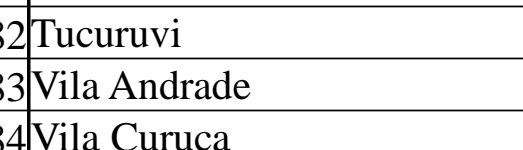 & 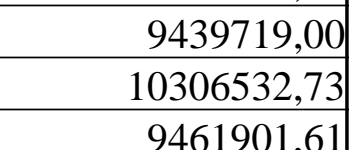 & 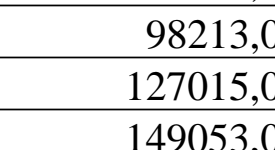 & 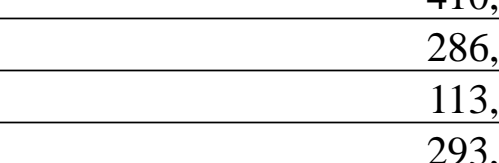 & & & & & & & 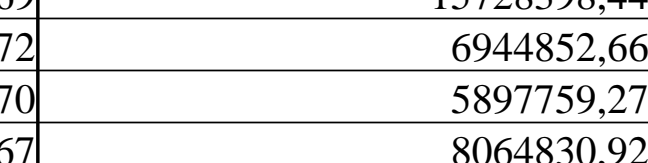 & 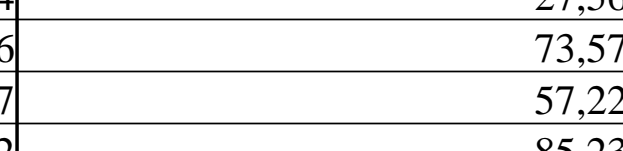 & & 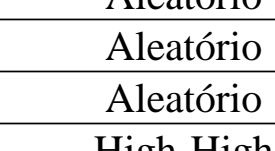 & 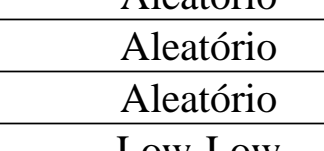 & 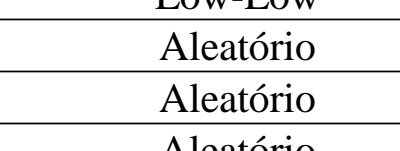 & $\frac{34}{\frac{3}{3}}$ & \\
\hline & 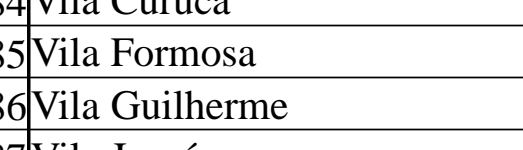 & 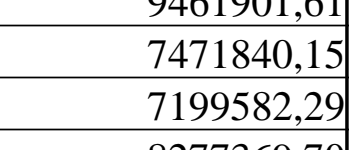 & 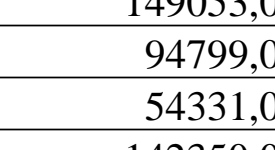 & $\begin{array}{l}\frac{281}{281} \\
144\end{array}$ & 117: & & 0 & & 2.90 & & 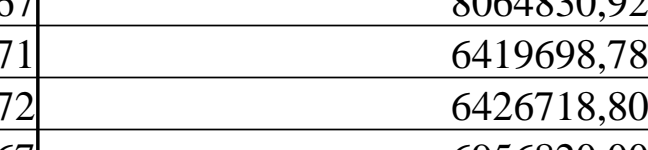 & $\begin{array}{l}\frac{8592}{85927} \\
89927\end{array}$ & & 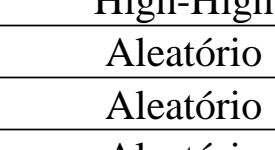 & 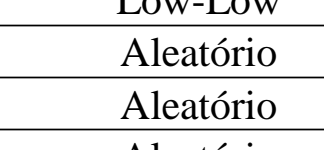 & 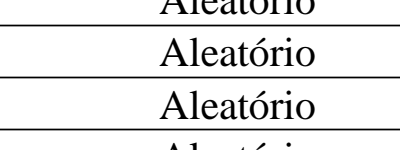 & & \\
\hline & 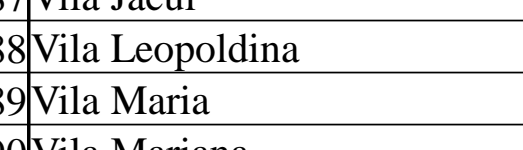 & 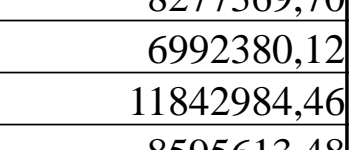 & 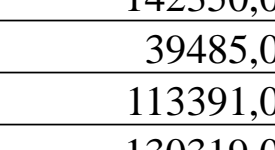 & 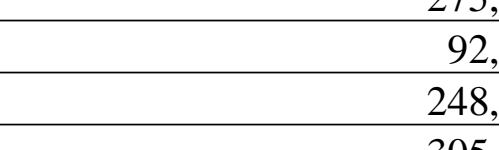 & $\begin{array}{l}18 \\
18 \\
19\end{array}$ & $0,2,2$ & $=0,100$ & & 0.900 & & 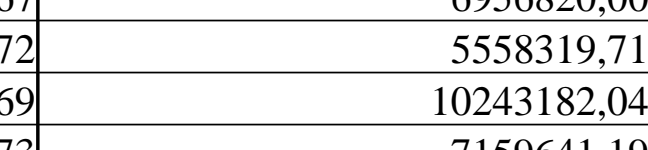 & 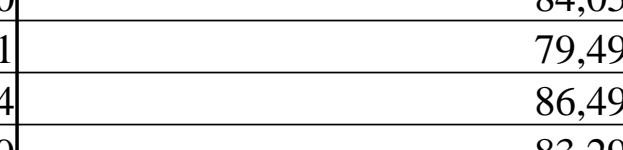 & & 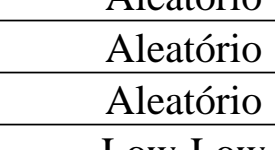 & 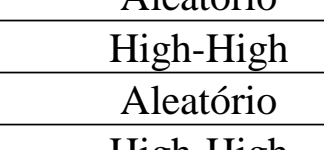 & 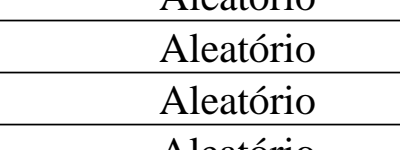 & & \\
\hline & 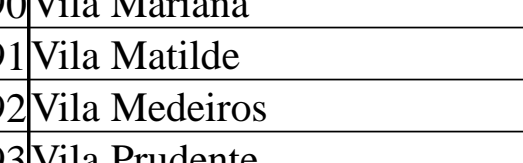 & 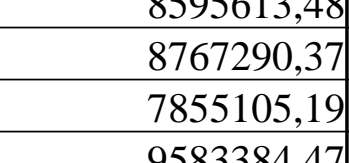 & 10208323. & 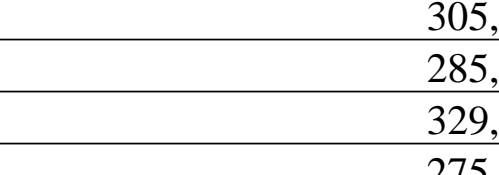 & 垔 & & $\begin{array}{l}0 . \\
0.0 \\
0.0\end{array}$ & & $\begin{array}{c}0.5 \\
0.5 \\
0.5\end{array}$ & & 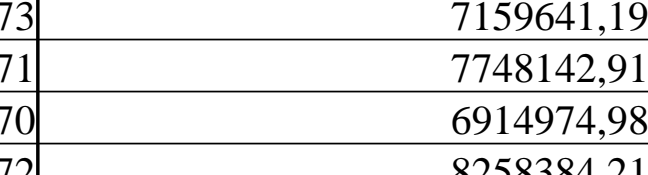 & 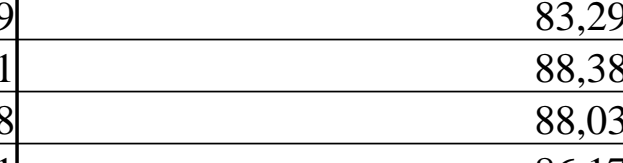 & & 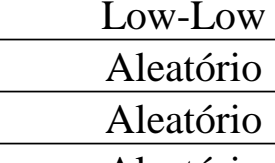 & 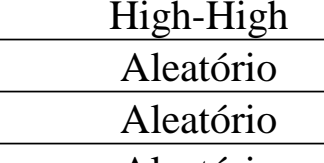 & 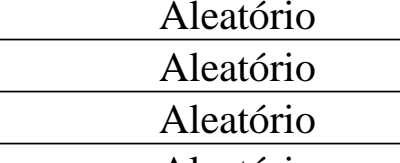 & & \\
\hline & 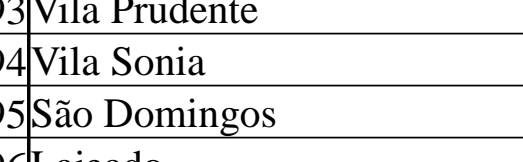 & 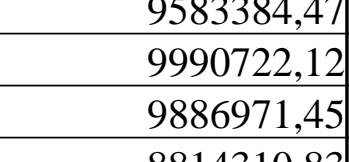 & 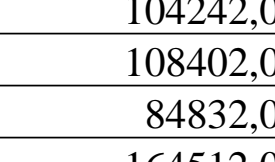 & 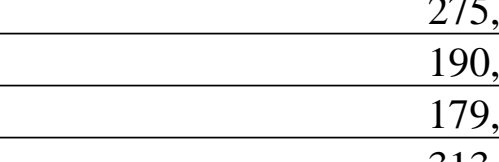 & $\begin{array}{l}15 \\
15 \\
19\end{array}$ & , & 0.19 & & $\begin{array}{l}0 \\
0 \\
0 \\
0\end{array}$ & & 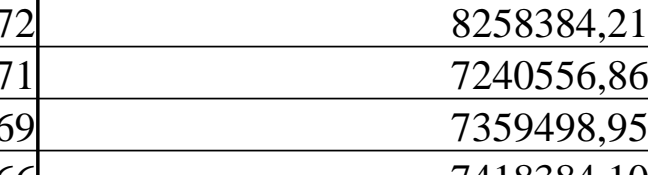 & 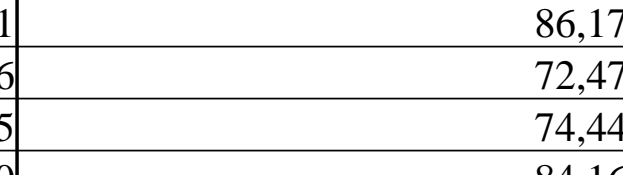 & & 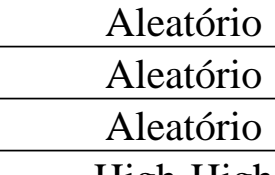 & 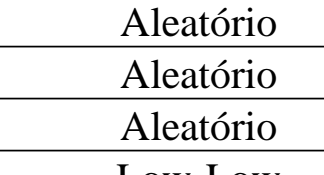 & 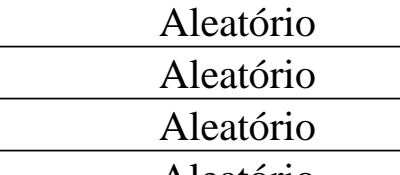 & 3. & \\
\hline
\end{tabular}

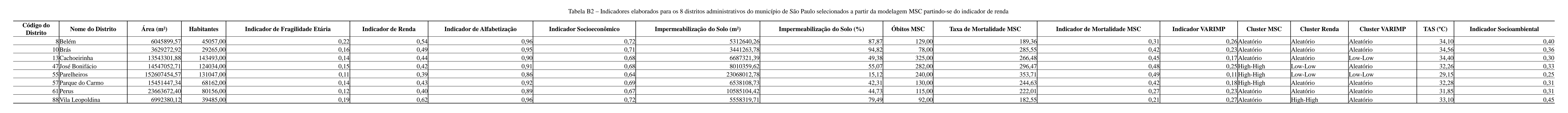




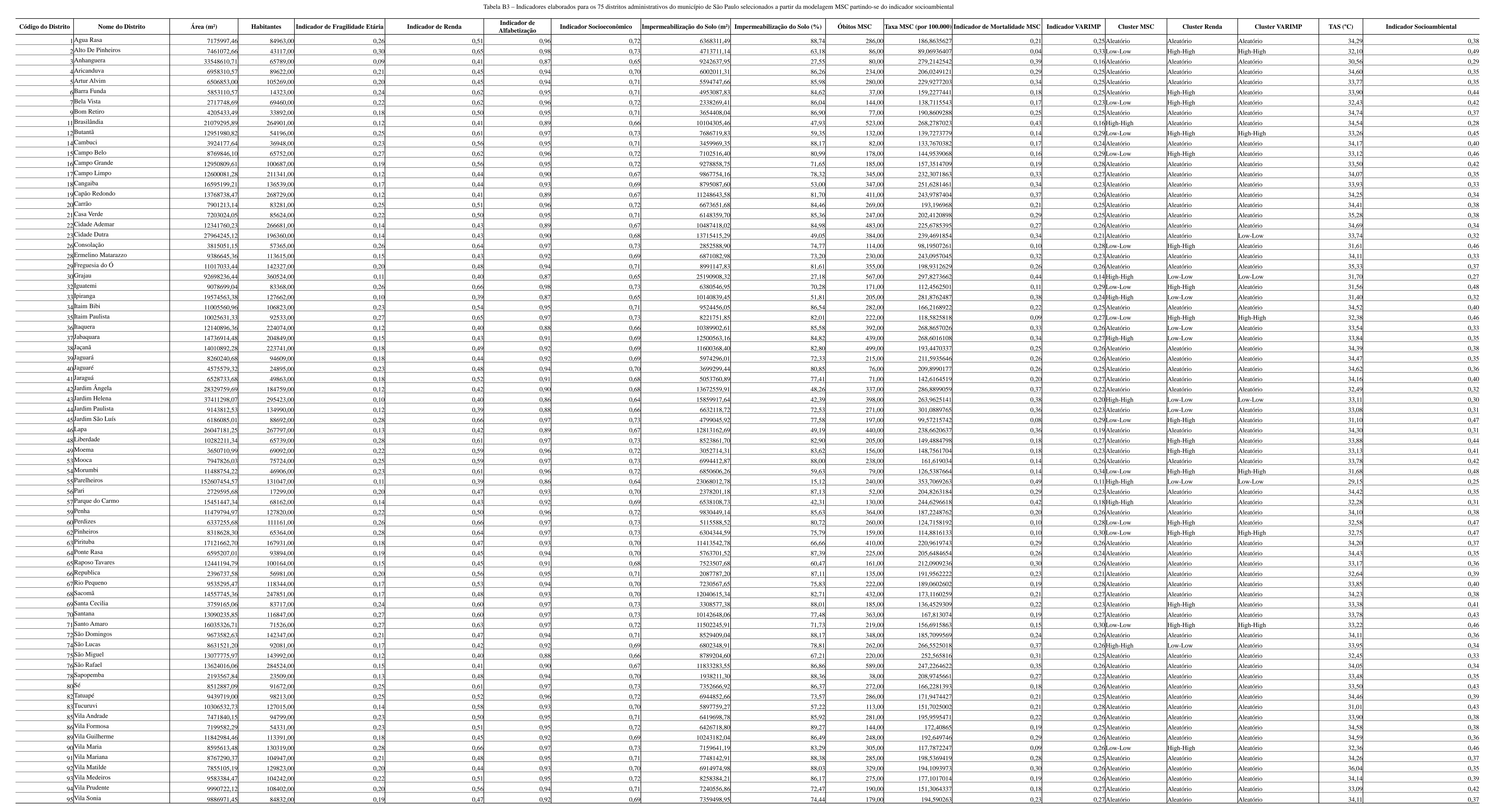

